STUDIA HISTORICA JYVÄSKYLÄENSIA 11

Kari Hokkanen

KRIEG UND FRIEDEN IN DER

POLITISCHEN TAGESLITERATUR

DEUTSCHLANDS ZWISCHEN

BASELER UND LUNÉVILLER FRIEDEN

(1795-1801)

JYVÄSKYLÄN YLIOPISTO, JYVÄSKYLÄ 1975 


\section{KRIEG UND FRIEDEN IN DER POLITISCHEN TAGESLITERATUR DEUTSCHLANDS ZWISCHEN BASELER UND LUNÉVILLER FRIEDEN \\ (1795-1801)}

von

KARI HOKKA NEN

wird mit Genehmigung der Humanistischen Fakultät der

Universität Jyväskylä am 24. April 1976 um 12 Uhr im Auditorium II 212 zur öffentlichen Verteidigung vorgelegt.

JYVÄSKYLÄ 1975

Jyväskylän Yliopisto 
KRIEG UND FRIEDEN IN DER

POLITISCHEN TAGESLITERATUR

DEUTSCHLANDS ZWISCHEN

BASELER UND LUNEVILLER FRIEDEN

(1795-1801) 
STUDIA HISTORICA JYVÄSKYLÄENSIA 11

Kari Hokkanen

KRIEG UND FRIEDEN IN DER

POLITISCHEN TAGESLITERATUR

DEUTSCHLANDS ZWISCHEN

BASELER UND LUNÉVILLER FRIEDEN

(1795-1801)

JYVÄSKYLÄN YLIOPISTO, JYVÄSKYLÄ 1975 
URN:ISBN:978-951-39-8479-3

ISBN 978-951-39-8479-3 (PDF)

ISSN 0081-6523

ISBN 951-677-559-4

Copyright (c) 1975 by

University of Jyväskylä

Vammalan Kirjapaino Oy Vammala 1975 


\section{VORWORT}

Die Anregung zu der vorliegenden Untersuchung erhielt ich eigentlich schon vor über zehn Jahren durch Frau Prof. Dr. Aira Kemiläinen mit dem Thema zu einem Seminarvortrag über die Einstellung Christoph Martin Wielands zur Französischen Revolution. In den folgenden Jahren weitete sich die Problemstellung so aus, daß die Deutschen im allgemeinen und ihr Verhältnis zu Krieg und Frieden während der Großen Revolution in Frankreich und in der Zeit der darauf folgenden Kriege im besonderen behandelt wurden.

$\mathrm{Zu}$ besonderem Dank bin ich Frau Prof. Dr. Aira Kemiläinen verpflichtet, unter deren unermüdlicher Anleitung die Arbeit entstand und der ich in den verschiedenen Entwicklungsphasen der Untersuchung wertvolle Hinweise und Unterstützung verdanke. Für weitreichende Ratschläge habe ich dem Korreferenten Herrn Prof. Dr. Matti Lauerma (Turku) der vorliegenden Dissertation und meiner Lizentiatenarbeit, Herrn Prof. Dr. Jaakko Suolahti (Helsinki) zu danken. Besonderen Dank möchte ich auch den Kollegen und dem Lehrkörper des Historischen Instituts der Universität Jyväskylä für Unterstützung und Kritik aussprechen; ich nenne vor allem Prof. Dr. Mauno Jokipii, Prof. Dr. Pekka Lappalainen, Prof. Dr. Erkki Lehtinen, Prof. Dr. Jorma Ahvenainen und Prof. Dr. Jorma Tiainen sowie das von Frau Prof. Dr. Aira Kemiläinen geleitete Lizentiatenseminar. Auch vom Seminar für Publizistik der Universität Göttingen (Prof. Dr. Wilmont Haacke) erhielt ich wertvolle Hinweise. Schließlich danke ich Herrn Dr. theol. Johannes Karawidopoulos (Thessaloniki) für die zahlreichen fruchtbaren Gespräche während meines Studienaufenthalts in Göttingen.

Für die Übersetzung der Untersuchung danke ich den Herren Richard Billhardt MA und Dr. Rolf Klemmt.

Für Hilfe und Unterstützung danke ich Bibliotheksangestellten in Göttingen, München, Wien, Zürich, Kopenhagen, Uppsala und London. Besonderen Dank schulde ich den Universitäts-Bibliotheken in Jyväskylä, Helsinki und Göttingen. 
Während meiner Arbeit habe ich von verschiedenen Institutionen finanzielle Unterstützung erfahren. Von entscheidender Bedeutung war ein Forschungsstipendium des Deutschen Akademischen Austauschdienstes im Studienjahr 1966/67, später erhielt ich Unterstützung durch die Botschaft der Bundesrepublik Deutschland in Helsinki. In meinem Heimatland schulde ich Dank: der Präsident Urho Kekkonen Stiftung, der Ellen und Artturi Nyyssönen Stiftung, der Emil Aaltonen Stiftung und der Finnischen Historisohen Gesellschaft. Schließlich hat die Universität Jyväskylä die Veröffentlichung der Arbeit durch Aufnahme in ihre Publikationen ermöglicht.

Zum Schluß danke ich meiner Familie, meiner Frau Mag. phil. Auli Hokkanen sowie meinen Töchtern Hanna und Elina für ihre Geduld während all dieser Jahre.

Korpilahti, im Dezember 1975

Kari Hokkanen 


\section{INHALT}

\section{AUSGANGSPUNKTE}

1. Aufgabenstellung der Untersuchung $\ldots \ldots \ldots \ldots \ldots \ldots \ldots \ldots \ldots \ldots$

2. Die politische Tagesliteratur 1795-1801 in Deutschland ........ 4

3. Das Heilige Römische Reich Deutscher Nation und die Französische Revolution ..................................... 16

4. Krieg und Frieden in der philosophischen Diskussion im Jahr-

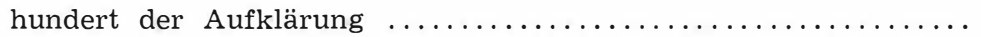

II. DAS FRIEDENSJAHR 1795: DER FRIEDE VON BASEL UND KANT'S »ZUM EWIGEN FRIEDEN»

1. Preußen schließt einen Sonderfrieden $\ldots \ldots \ldots \ldots \ldots \ldots \ldots \ldots \ldots . \ldots \ldots \ldots$

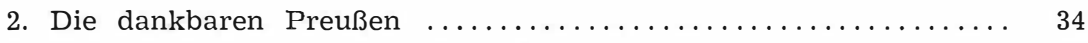

3. Zufriedenheit im $»$ dritten Deutschland» .................. 46

4. Enttäuschung und Zorn in Österreich und den »Reichsdeutschen» 67

5. Kant's »Zum ewigen Frieden» und sein Echo ............... 85

III. ERWARTUNG EINES ALLGEMEINEN FRIEDENS IN DEN JAHREN 1796-97

1. Die Kriegszüge der Franzosen 1796-97 ................ 95

2. Das leidende und resignierende Süddeutschland ............ 97

3. Kampf und Niederlage Österreichs und der »Reichsdeutschen» .. 106

4. $\gg$ Das glückliche Norddeutschland» .................... 123

IV. DIE WENDE VON 1797/98: DER STAATSSTREICH VOM 18. FRUCTIDOR, DER KONGRESS VON RASTATT UND DIE REVOLUTIONEN IN ITALIEN UND IN DER SCHWEIZ $\ldots \ldots \ldots \ldots \ldots \ldots \ldots \ldots \ldots . \ldots \ldots \ldots$

V. DIE MEHRHEIT IST FÜR KRIEG

1. Die letzten Siege des Reiches ....................... 147

2. »Herrmanns Enkel, der Kampf für Kaiser, Glaube und bürgerliche

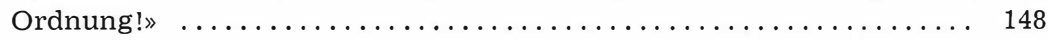

3. Die bedrohten Reichsstände stützen Österreich .............. 159

4. Die kriegerischen Friedensvertheidiger - kein Frieden ohne Revolu-

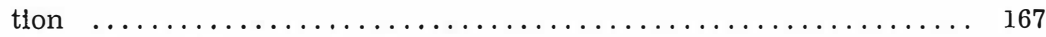

5. $\gg$ Das sich schämende Norddeutschland» $\ldots \ldots \ldots \ldots \ldots \ldots \ldots \ldots, 186$

6. Die abnehmenden Friedensstimmen ..................... 211 
VI. NIEDERLAGE UND UNTERGANG DES DEUTSCHEN REICHES

1. Rückkehr Napoleons und Niederlage der Koalition .......... 221

2. Der Kampf um Ehre und bessere Friedensbedingungen ........ 222

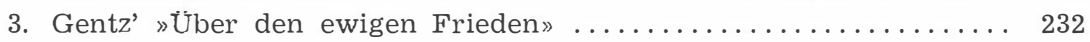

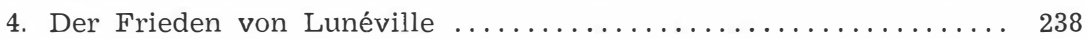

VII. QUANTITATIVE UNTERSCHUNG UND SCHLUSSFOLGERUNGEN

1. Schwankungen im Umfang der Zustimmung für Krieg oder Frieden 244

2. Regionale Unterschiede ......................... $24^{\prime}$ '

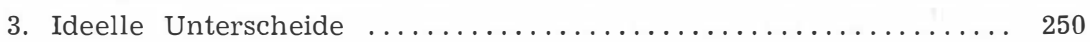

4. Idealismus oder Realpolitik? ...................... 253

QUELLEN UND DARSTELLUNGEN $\ldots \ldots \ldots \ldots \ldots \ldots \ldots \ldots \ldots \ldots \ldots \ldots, 258$

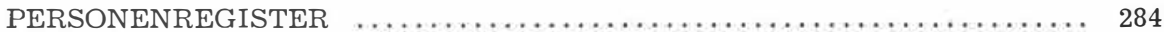




\section{AUSGANGSPUNKTE}

\section{Aufgabenstellung der Untersuchung}

Die vorliegende Untersuchung hat sich zur Aufgabe gestellt, die in der Zeit zwischen dem Baseler Frieden (1795) und dem Frieden von Lunéville (1801) geführte öffentliche Diskussion über Krieg und Frieden vorzutragen und $\mathrm{zu}$ analysieren. Bei der eindeutigen Begrenzung des Forschungsgegenstandes ergaben sich Schwierigkeiten. Einerseits hätte die Möglichkeit bestanden, in die Untersuchung nur die rein ideellen Stellungnahmen aufzunehmen, die Krieg und Frieden als philosophische Begriffe behandeln. Andererseits hätte sich der Aufgabenkreis der Untersuchung durch eine Behandlung der gesamten politischen Tagesliteratur erweitern lassen, die Krieg und Frieden als augenblickliches konkretes politisches Problem zum Gegenstand hatte. Es ist allerdings unmöglich, diese beiden "Phasen» der Diskussion von einander zu unterscheiden. Fast ausnahmslos wurde jede einzelne Aufforderung zum Frieden auch ideel begründet und andererseits nahmen auch die reinsten ideenphilosophischen Stellungnahmen zu der Frage nach Nutzen und Vorzug von Krieg oder Frieden fast immer Bezug auf die konkrete politische Situation.

Gegenstand dieser Untersuchung ist die in dem genannten Zeitraum zum Thema Krieg und Frieden in deutscher Sprache erschienene politische Tagesliteratur. Dabei sollen sowohl sich nur mit der Tagespolitik verbindende Stellungnahmen als auch die in der gleichen Zeit erschienenen ideellen Überlegungen zum Aufgabenkreis gehören. Infolge dieser Aufgabenstellung hat sich eine sehr umfangreiche Materialsammlung ergeben, was wiederum zu methodischen Schwierigkeiten und zu der Forderung nach einer auch quantitativen Darstellung geführt hat. Es ist besonders dann unmöglich, die Meinungen und Diskussionsbeiträge der in die Hunderte gehenden Diskussionsteilnehmer in "normaler» historisch-qualitativer Danstellungsweise zu behandeln, wenn die Arbeit einen angemessenen Umfang nicht überschreiten soll. Bei einer äußerst konzentrierten Darstellung würde seinerseits die Untersuchung leicht katalog- 
artig und trocken, das Bild von dieser farbigen Diskussion würde geradezu verfälscht.

Es wurde hier versucht, die erwähnten Schwierigkeiten zu verringern, indem die sich auf Krieg und Frieden beziehende Diskussion auf zwei Ebenen behandelt wurde. Es wurden die Stellungnahmen von einigen Dutzend besonders einflußreichen Persönlichkeiten verhältnismäßig gründlich untersucht. Da diese Personen bei ihren Stellungnahmen ausnahmslos auch auf dic während der theoretischen Friedensdiskussion deutlich gewordenen Begründungen Bezug nahmen, kommt so der ideengeschichtliche Aspekt der Untersuchung zu seinem Recht. Außerdem wurde versucht, den sichtbaren Hintergrund der Schniften der wichtigsten Persönlichkeiten zu verdeutlichen und die infrage kommenden Personen verhältnismäßig ausführlich als historische Persönlichkeiten durch die häufige Angabe von biographischen Daten, Entwicklungslinien in den Meinungen, der Einflüsse von den verschiedenen Seiten usw. darzustellen. Diese Personen, die in der Regel Schriftsteller, Wissenschaftler oder bedeutende Journalisten waren, wurden einmal so ausgewählt, daß unter ihnen typische Vertreter möglichst vieler verschiedener Meinungsrichtungen vertreten sind. Dabei sollen auch eventuelle Entwicklungslinien in ihrer Meinungsbildung sichtbar werden. Im Schlußteil der Untersuchung wird die politische Tagesliteratur als Ganzes mit dem Ziel untersucht, ein Resümee aus den Begründungen aller Personen, die an der Diskussion um Krieg oder Frieden teilgenommen hatten, zu ziehen.

Die Gliederung der Untersuchung ist in großen Zügen chronologisch in dem Sinne, daß die Diskussionen über Krieg und Frieden in den einzelnen Zeitabsohnitten nacheinander behandelt werden: der Friede von Basel, der Kriegszug vom Sommer 1796, der Friede von Campo Formio und der Staatsstreich am 18. Tag des Fructidor von 1797, der Beginn des Zweiten Koalitionskrieges und der Friede von Lunéville wurden als Wendepunkte in den Diskussionen angenommen. An dieser chronologischen Gliederung wurde jedoch nicht immer fesitgehalten. Die Unterkapitel beziehen sich größtenteils auf regional gebundene Standpunkte. Gerade die heimatstaatliche Herkunfit der Diskussionsteilmehmer beeinflußte deren Meinungen und besonders die Begründung ihrer Standpunkte. Weil auf den verschiedenen Seiten zu verschiedenen Zeiten Diskussionen und Debatten zu gewissen Sonderproblemen geführt wurden, mußte versucht werden, Diskussionen dieser Art als eine Einheit darzustellen.

Diese Arbeit hat sich vor allem die Aufgabe gestellt, eine Antwort auf die Frage nach dem Verhältnis der »allgemeinen Meinung» als 
Ganzes in der politischen Tagesliteratur zu einem Friedensschluß während der Zeit zwischen den Friedensschlüssen von Basel und Lunéville zu geben. Nach dem Friedensschluß von Basel war Deutschland in zwei Teile - sogar noch in fast zwei gleich große - geteilit, von denen der eine noch Krieg führte und der andere außerhalb des Kriegsgeschehen stand. Der Friede von Lunéville hatte dagegen Geltung für das ganze Reich und stellt so einen gewissen Endpunkt in der besonders regen Diskussion dar, die zu der Zeit des Baseler Friedens ihren Anfang genommen hatte. Außerdem wurden zusätzlich zur Erläuterung des erwähnten Gesamtbildes besonders die Begründungen untersucht, mit denen die Vorzüge von Krieg oder Frieden bewiesen werden sollten. Das Ende der zweiten Hälfte des 18. Jahrhunderts war eine Zeit, in der Aufklärung und Romantik, erwachender Nationalismus und Patriotismus, sowie Kosmopolitismus gegeneinander standen. Alle diese Ideen beeinflußten in ihrer Weise auch die Standpunkte in der Frage um einen Frieden. An zweiter Stelle un'tersucht diese Arbeit, welche Bedeutung den Wirkungen der ideellen Begründungen zukommen, vor allem derjenigen, die sich mit der Aufklärung und ihrem Humanismus, mit dem Patriotismus und der Religion verbinden und mit denen die Forderung nach Frieden unterstrichen wurde, und will außerdem die Bedeutung der Wirkung der realpolitischen und der militärischen Situation eines jeden Zeitabschnittes auf die jeweiligen Standpunkte bestimmen. Neben diesen Hauptproblem wir:d eine Reihe von Nebenfragen behandelt. So lassen sich mit der regionalen Uneinigkeit im Deutschen Reich die verschiedenen Standpunkte in den verschiedenen Territorien und Gebieten begründen. Besonders wurde versucht, die regionalen Unterschiede in den Meinungen zu gestimmen. Daran anschließend wird die Beziehung der tagespolitischen Schriften zu einigen ausländischen Staaten, vor allem zu England und Rußland, zu den im Reich durchgeführten Reformen und zu der Verfassungsreform, zur Säkularisierung der geistlichen Fürstentümer und zur Mediatisierung der kleineren weltlichen Territorien, zu den Emigranten usw. untersucht.

Eine Reihe von Unitersuchungen beziehen sioh auf die oben genannten Themen oder berühren sie. Von OTTO TSCHIRCH stammt die umfangreichste Gesamtdarstellung der Geschichte der politischen Tagesliteratur zur Jahrhundertwende von 1800: „Öffentliche Meinung in Preußen vom Baseler Frieden bis zum Zusammenbruoh des Staates (1795-1806)».1 Wie im Titel schon gesagt, bezieht sie sich größtenteils auf Preußen, sie

1 Tschirch, Otto, Öffentliche Meinung in Preußen vom Baseler Frieden bis zum Zusammenbruch des Staates (1795-1806) I-II, Weimar 1933-34. 
behandelt aber auch mehr oder weniger ausführlich die Literatur in den übrigen Teilen des Reiches. Abgesehen von ihren stark nationalen Tendenzen ist sie eine wertvolle Gesamtdarstellung, obgleich schwer zugängliches Quellenmaterial stellenweise nur lückenhaft verwendet wurde. Die vor kurzem erschienene Habilitation ${ }^{2}$ von JORMA TIAINEN über die im »dritten Deutschland» erschienene Literatur war in vieler Hinsicht eine wertvolle Hilfe. Die in der DDR von HEDWIG VOGT erschienene Untersuchung ${ }^{3}$ zur »Jakobinischen» Lileralur vertritt den marxistischen Standpunkt. Mit der in den kleineren Teilen des Reiches erschienenen politischen Tagesliteratur hat sich eine Reihe von Forschern beschäftigt. Die sich ebenfalls mit der »jakobinischen» Literatur beschäftigende Untersuchung ${ }^{4}$ von HEINRICH SCHEEL bezieht sich auf Süddeutschland, die von KYÖSTI JULKU auf die Rheinländer, ${ }^{5}$ außerdem wurden Untersuchungen zur politischen Tagesliteratur in einzelnen Territorien durchgeführt. 6 Natürlich gibt es auch eine Reihe von Untersuchungen, die sich teilweise auf die tagespolitische Literatur stützen, auch sie konnten hilfreich zu Rate gezogen werden.7 Dazu kommen noch Spezialuntersuchungen von einzelnen Wissenschaftlern oder Gruppen von Wissenschaftlern. ${ }^{8}$ Dagegen gibt es keine Untersuchung, die sich mit irgendeinem speziellen Thema für irgendeinen Zeitpunkt in der tagespolitischen Literatur beschäftigt. Für diese Untersuchung wurde das Thema Krieg und Frieden einmal wegen seiner Aktualität gewählt, und weil es die politische Tagesliteratur des zu untersuchenden Zeitabschnittes beherrscht.

\section{Die politische Tagesliteratur 1795-1801 in Deutschland}

Der Terminus wallgemeine Meinung», der in der Forschung oft gebraucht wird, ist nicht eindeutig $\mathrm{zu}$ bestimmen. Indem man diesen

2 Tiainen, Jorma, Napoleon und das Napoleonische Frankreich in der öffentlichen Diskussion des 'dritten Deutschland' 1797-1806, Diss. Jyväskylä 1971.

3 Vogt, Hedwig, Die deutsche jakobinische Literatur und Publizistik 17891800, Berlin 1955.

4 Scheel, Heinrich, Süddeutsche Jakobiner, Berlin 1962.

5 Julku, Kyösti, Die revolutionäre Bewegung im Rheinland am Ende des achtzehnten Jahrhunderts, II, Helsinki 1969.

6 z.B. Rieber, Horst, Liberaler Gedanke und französische Revolution im Spiegel der Publizistik der Reichsstädte Augsburg und Ulm, Diss. München 1969.

7 z.B. Kemiläinen, Aira, Auffassungen über die Sendung des deutschen Volkes um die Wende des 18. und 19. Jahrhunderts, Diss. Helsinki 1956.

8 Siehe später. Das Thema tangiert auch Czygam, Paul, Zur Geschichte der Tagesliteratur während der Freiheitskriege I-II, Leipzig 1910-11. 
Begniff durch »öffentliche Diskussion» ersetzte, gelangte man zu keiner besseren Definition, deshalb wurden im Laufe der Zeit eine große Zahl Begriffe gebildet, von denen keiner allgemeine Zustimmung gefunden hat. ${ }^{9}$ Die sich mit einer Begriffsbestimmung der Termini verbindenden Schwierigkeiten wurden in dieser Arbeit umgangen, indem der eindeutigere Begriff »politische Tagesliteratur» gebraucht wird.

Im Laufe der zweiten Hälfte des 18. Jahrhunderts ist eine starke Zunahme der öffentlichen Diskussion in deutscher Sprache zu beobachten. Deutlich wird dies vor allem an der starken Zunahme der Zeitschriften. So bilden auch die Zeitschriften den bedeutendsten Teil des Quellenmaterials dieser Arbeit. Offensichtlich hatten die Zeitschriften während der Französischen Revolution eine Bedeutung wie nie zuvor und wie sie sie nie wieder erreichen sollten. Der Grund dafür ist nicht nur in der Zunahme der öffentlichen Diskussion im allgemeinen sondern auch in der durch die Zensur verursachten schwachen Stellung der Tagespresse $\mathrm{zu}$ suchen.10 In dem behandelten Zeitraum erschienen mehrere hunderte Zeitschriften; allerdings sind für die politische Diskussion nur einige Dutzend von Bedeutung. ${ }^{11}$ In diesen Zeitschriften wurden häufig, je nach den Zensurbedingungen in den Erscheinungsgebieten, politische Fragen ausführlioh und mutig diskutiert. Die Bedeutung dieser Zeitschriften für diese Unitersuchung wird noch durch den Umstand verstärkt, daß sich die Meinungen und die Entwicklung in der politischen Einstellung der Herausgeber und der ständigen Mitarbeiter dieser Zeitschriften über einen längeren Zeitraum hin, in einigen Fällen für die ganzen sechs Jahre, untersuchen lassen. Als Unitersuchungsmaterial wurden 58 Zeitschriften verwendet, die für die politische Diskussion von größerer Bedeutung waren. Diese Zeitschriften unterscheiden sich in Umfang und Erscheinungsweise stark von einander. Die größeren sind Monatsschrifiten, von denen eine Nummer hunderte von Oktavseiten umfassen kann, dagegen erschienen die kleineren seltener und umfassen nur ungefähr zwanzig Seiten. Einige Zeitschriften erschienen in kürzeren Abständen, stellten aber dafür ihr Erscheinen bald wieder ein, andere wiederum erschienen über einen längeren Zeitraum hin, allerdings nur in unregelmäßigen Zeitabständen. Den Zeitschriften verwandt

9 Über die Definizierung z.B. Tiainen (1971) S. 9-17. Vgl. Haacke, Wilmont, Die politische Zeitschrift 1665-1965 I, Stuttgart, 1968, Einführung.

10 Salomon, Ludwig, Geschichte des deutschen Zeitungswesens II, Oldenburg-Leipzig 1902; Streisand, Joachim, Deutschland von 1789 bis 1815, Berlin 1961 , S. $76,93$.

11 Groth, Otto, Die Geschichte der deutschen Zeitungswissenschaft, München 1948; Tiainen (1971) S. 27. 
sind die Kalender und Almanache mit jährlicher Erscheinungsweise, in denen auch häufig tagespolitische Themen behandelt werden. $\mathrm{Zu}$ erwähnen sind außerdem zahlreiche Kultur- und Literaturzeitschriften mit politischen Stellungnahmen.

Neben den Zeitschriften spielen für die öffentliche Diskussion die in Form und Umfang sehr unterschiedlichen Flugschriften eine Rolle von größerer Bedeutung. Die Flugschriften enthaliten mutige Stellungnahmen zu aktuellen Fragen und waren ein Mittel, mit dem versucht wurde, die öffentliche Meinung in eine gewünschite Richtung zu lenken. In den Zeitschriften sind dagegen sehr häufig verschiedene politische Standpunkte vertreten, während die Flugschriften immer eine bestimmte Stellungnahme enthalten, die sich oft in einer einzigen Detailfrage konzentrient. Zur Zeit der Revolutionskriege war die Friedensfrage einer der am meisten intressierenden Diskussionspunkt. Dies wird an der großen Zahl der Flugschriften deutlich, die sich mit dieser Frage beschäftigen. So erwähnt TSCHIRCH, daß er allein in preußischen und sächsischen Staatsbibliotheken 80 Flugschriften aus den Jahren 1795-96 zum Baseler Frieden gefunden habe. ${ }^{12}$ Die Mainzer Klubisten veröffentlichten in den Jahren $1792-93$ ca. hundertfünfzig Flugblätter, ${ }^{13}$ und den Rastatter Kongreß bedrängten und belehrten über hundert Flugschriften. ${ }^{14}$ Jeder einzelne Problemkreis rief eine regelrechte Flut von Flugschriften hervor: der Baseler Frieden und der Rasitatter Kongreß, die Friedensschlüsse von Campo Formio und Lunéville, die verschiedenen Pläne zur Neuordnung der Staaten, die württembergischen Reparationen, der Regierungswechsel in Preußen usw.. Der Schriftsteller, Buchhändler und Kritiker Friedrich Nicolai schätzte die Zahl der in der Zeit von 1750 bis 1760 jährlich neu erschienenen Schriften auf 1300. Zu Beginn des ersten Jahrzehnts des 19. Jahrhunderts sei diese Zahl schon auf 5000 angestiegen. Alles in allem zählt die »Allgemeine Deutsche Bibliothek» ca. 8000 Schriften. ${ }^{15}$ Eine zuverlässige Sohätzung der Flugschriften, die die Friedensfrage behandeln oder berühren, ist nicht möglich. Das Untersuchungsmaterial dieser Arbeit umfaßt ca. 300 Flugschriften.16 Der überwiegende Teil davon ist anonym und mit fingiertem Druckort erschienen, was die Arbeit mit ihnen besonders erschwerte. Der größte

12 Tschirch I (1933) Anm. S. 64.

13 Eisner, Kurt, Das Ende des Reichs, Berlin 1907, S. 52 (erwähnt das Zahl 114); Revolutions-Almanach 1794 S. 146-155 (143 Titel der Schriften).

14 Gothaische gelehrite Zeitungen 1799-1800 erwähnt 111.

15 Ost, Günter, Friedrich Nicolais Allgemeine Deutsche Bibliothek, Berlin 1928, S. 19 und Anm. S. 20, S. 36.

16 Vgl Tiainen (1971) Anm. S. 28. 
Teil der verwendeten Flugschriften kann jedoch einem bestimmten Verfasser zugeschrieben werden. Wegen ihrer politischen »Ehrlichkeit» und ihrer mutigen Haltung stellen die Flugschriften einen besonders wichtigen und fruchtbaren Teil des Quellenmaterials dar. ${ }^{17}$

Auf Zeitungen wurde weniger Aufmerksamkeit gerichtet. Die in der Zeit zwischen 1790 und 1800 erschienenen deutschen Zeitungen sind im allgemeinen Blätter von geringerem Umfang für ein literarisch-ästhetisch gebildetes Publikum. Außer Literaturbesprechungen enthalten sie Ernennungen und Auszeichnungen. Politische Fragen werden selten oder überhaupt nicht behandelt. Eine bedeutende Ausnahme bilden Schlözers »Stats-Anzeigen», die ihr Erscheinen 1794 einstellten und keinen unmittelbar gleichwertigen Nachfolger hatten. Außenpolitische Ereignisse - oder richtiger Vorgänge im Ausland - werden in den Zeitungen größtenteils durch direkte Zitate aus ausländischen Zeitungen wiedergegeben. Wegen der strengen Zensur hatten die Herausgeber keine Möglichkeit, mit eigenen Kommentaren $\mathrm{zu}$ diesen Vorgängen Stellung $\mathrm{zu}$ nehmen, und nicht allen Herausgebern enschien dies als empfehlenswert. ${ }^{18}$

Unter »tagespolitischer Literatur» werden hier die drei obern erwähnten Haupttypen verstanden. Dazu treten dann nooh die anderen Krieg und Frieden behandelnden verschiedenartigen Veröffentlichungen: Reisebeschreibungen, historische Werke (besonders zur jüngsten damaligen Vergangenheit), strafrechtliche und staatsrechtliche, theologische und philosophische Untersuchungen und Darstellungen und außerdem viele belletristische Werke, besondens Gedichte, die oft tagespolitische Stellungnahmen enthaliten. Dieses Material konnte zwar nicht systematisch durchgearbeitet werden; es wurde aber nach Möglichkeit auf seine Bedeutung für die Tagespolitik untersucht.

Für eine Untersuchung der Einstellung verschiedener Persönlichkeiten $\mathrm{zu}$ Krieg und Frieden ist von Bedeutung, wieviele leute unter an der öffentlichen Diskussion teilnahmen. Die allgemeine Belebung des Kulturlebens in Deutschland zu Ende des 18. Jahrhunderts wird auch im Anstieg der Anzahl der Schriftsteller deutlich. 1795 schreibt Friedrich Nicolai: „Wir Deutschen sind Buchmenschen, eine schreibende Nation.»19 Er hatte

17 Über das Benutzen der Flugschrifiten als historische Quelle s. z.B. Tiainen, Saksalaiset lentakirjaset julkisen kseskustelun väylänä uskonpuhdistuksen ajasta vuoden 1800 tienoille, Historica III, Studia historica Jyväskyläensia IX, Vammala 1972 (Tiainen 1972 a).

18 Tiainen (1971) S. $27-28$.

19 v. Göckingk, L.F.G., Friedrich Nicolai's Leben und literarischer Nachlass, Berlin 1820, S. 128. 
recht. Es ist natürlich unmöglich, die Anzahl der Teilnehmer an der öffentlichen Diskussion genau zu bestimmen, aber eine ungefähre Schätzung wurde durchgeführt und kann gemacht werden. Der bekannte Revolutionär Georg Forster schätzte die Anzahl der Schriftsteller in Deutschland für das Jahr 1793 auf 7000.20 »Das gelehrte Teutschland» von Hamberger-Meusel aus dem Jahre 1806 enthält einen umfangreichen Katalog von Schriftstellern der verschiedensten Gebiete für die Zeit von 1795 bis 1806. Dieser Katalog nennt 11000 Schriftsleller.21 Bei diesen Zahlen wurden alle Personen mitgerechnet, die gedruckte Texte in den erwähnten Jahren verfaßt hatten: Flugschriften, Artikel in Zeitschriften, Untersuchungen auf den verschiedensten Gebieten. Wenig sinnvoll wäre es, die Zahl der Schriftsteller zu ermitteln, die sich zum Thema Krieg und Frieden geäußert haben. Eine solche Schätzung würde jeden zuverlässigen Grundlage entbehren.

Deutlich wird der Umfang der Diskussion auch in den Auflagenhöhen der Druckerzeugnisse. W. H. BRUFORD nennt als Charakteristikum ihre niedrige Auflagenhöhe. Während nach ihm die größeren deutschen Zeitschriften im allgemeinen in einer Höhe von 2000 Stück verbreitet waren und bei vielen ein Rückgang auf einige Hundert festzustellen sei, bewege sich die Zahl für die entsprechenden englischen Zeitschriften bei einer Auflagenhöhe von Zehntausenden.22 Die in Deutschland verbreitetsite Zeitschrift war Schlözers »Stats-Anzeigen», deren Auflage zeitweise bis auf 4400 Stück anstieg. ${ }^{23}$ In Erfurt erschien der für Bauern bestimmte »Geschichtskurir», der zeitweise eine Auflage von ca. 3000 Stück hatte. ${ }^{24}$ Die literarischen Zeitschriften fanden im allgemeinen eine verhältnismäßig gute Verbreitung, so wurde z.B. die »Jenaer Literaturzeitung» in 2000 Exemplaren gedruckt.25 Friedrich Nicolais lange erschienene und wichtige »Allgemeine Deutsche Bibliothek» erreichte 1787 eine Auflage von 2000, fiel dann aber bis zum Jahre 1800 auf 1250 Exemplare zurück.26 Christoph Martin Wielands »Teutscher Merkur», die für lange Zeit in Deutschland führende litera-

20 Habermas, Jürgen, Strukturwandel der Öffentlichkeit, Politica Bd. 4, Neuwied 1962, S. 117.

21 Hamberger-Meusel, Das gelehrte Teutschland XII (1806) enthält ein Kata$\log$ von 326 Seiten.

22 Bruford, W. H., Die gesellschaftlichen Grundlagen der Goethezeit, Weimar 1936, S. $286-287$.

23 Fürst, Friederike, August Ludwig von Schlözer, Heidelberg 1928, S. 82.

24 Gratthoff, Erich, Deutsche Bauern- und Dorfzeitungen des 18. Jahrhunderts, Diss. Heidelberg (Würzburg) 1937, S.

25 Bruford (1936) S. 283.

26 Ost (1928) S. 90, 116. 
risch-politische Zeitschrift, erreichte zwischen 1770 und 1780 sogar eine Auflage von 2500, die aber nach 1790 unter 1000 absank. ${ }^{27}$ Die von Schiller zusammen mit einem namhaften Mitarbeiterstab herausgegebenen »Horen» begannen 1795 mit 2000 Exemplaren zu erscheinen, wurden dann aber jährlich mit 500 Exemplaren weniger verbreitet. ${ }^{28}$

Die Auflagen der Zeitschriften blieben also verhältnismäßig klein. Dafür gibt es mehrere Gründe. Tratz eindringlicher Aufforderungen der Herausgeber, die Zeitschriften zu abonnieren, vergrößerte sich die Leserschaft kaum. ${ }^{29}$ Das einfache Volk hatte seinerseits kein Interesse für Zeitungen und Zeitschriften, obwohl es die nötige Lesefertigkeit besaß. Die für Bauern bestimmten Zeitungen behandelten im allgemeinen nur in geringem Maße politische Themen, wenn auch die Regierungen nach dem Ausbruch der großen Französischen Revolution durch sie versuchten, auf ihre Untertanen Einfluß zu nehmen. ${ }^{30}$ Als offensichtliche Ausnahme bei der allgemeinen Teilnahmslosigkeit des einfachen Volkes sei aus dem Jahre 1801 das Interesse von Hamburger Arbeitern an der Politik und ihr Wunsch, Zeitungen und Flugschriften zu lesen, erwähnt. ${ }^{31}$ Auch wirkte sich auf die Presse das Fehlen eines starken geistigen Zentrums, wie z.B. London oder Paris, aus. Jedes Territorium und jede etwas gröBere Stadt wollte eine eigene Zeitung herausgeben, was dann zu einem erbarmungslosen Konkurrenzkampf unter diesen Zeitungen führte. Auch die Kriegszeit hatte Auswirkungen auf die Presse. Obwohl die großen Ereignisse dieser Zeit das Interesse an den von diesen berichtenden Druckerzeugnissen vergrößerten, mußte die Presse andrerseits auch wirtschaftliche Verluste hinnehmen. Eine Ursache für den Konkurs von Schillers »Horen» ist darin $z u$ suchen, daß es in einem der wichtigsten Verbreitungsgebiete der Zeitschrift, in Süddeutschland, im Jahre 1796 häufig zu Kriegshandlungen kam. ${ }^{32}$ Wieland mußte sich 1795 für das verspätete Erscheinen einer Nummer des »Merkurs» mit Schwierigkeiten bei Papierlieferungen entschuldigen, ${ }^{33}$ und das für Archenholtz' »Minerva» bestimmte Material blieb lange Zeit wegen Kriegshandlungen beschlagnahmt. ${ }^{34}$

27 Sengle, Friedrich, Wieland, Stuttgant 1949, S. 408-409.

28 Fürst, Friederike, August Ludwig von Schlözer, Heidelberg 1928, S. 82. S. 20.

29 z.B. Neue Kielische gelehrte Zeitung (Thiess) 1797 I S. IV; Annalen der Braunschweig-Lüneburgischen Churlande 1795 IV $\quad$ S. 682-683 (Jacobi und Benecke).

30 Gratthoff (1937) S. 29-30.

31 Skizzen über Hamburg 1801 I S. 44-45.

32 Meyer (1941) S. 23.

33 Neuer Teutscher Merkur (NTM) 1795 IV S. 328.

34 Minerva 1795 II S. 381-382. 
Die Auflagenhöhen der Flugschriften sohwankten zwischen einigen Dutzend und Tausenden. ${ }^{35}$ Immanuel Kants mit einer Flugschrift vergleichbare Studie »Zum ewigen Frieden» wurde zuerst (1795) in einigen hundert Exemplaren gedruckt, aber schon die zweite Auflage des folgenden Jahres hatte eine Auflage von 1500, die sofort verkauft wurde. ${ }^{36}$ Die höchste Auflage nennt ein Angebot des Deutsch-Polen K. G. G. Glave-Kolbielski von 1796, der berufsmäßig Streitschriften verfaßte. In diesem Angebot an die österreichische Regierung schlägt er vor, eine Flugschrift in einer Auflage von 40-50 000 Exemplaren drucken zu lassen, in dem die innerhalb von vier Jahren begangenen Freveltaten der Franzosen angeprangert würden. ${ }^{37}$ Eine so hohe Auflage wurde jedoch offensichtlich nie gedruckt, wenn auch die Schriften von Glave zu den am meisten gekauften gehörten. Eine 1795 erschienene Flugschrift »Syrach der Enkel» hatte eine erste Auflage von 2000 Exemplaren. Später erschienen dann noch über zehn Neuauflagen sowohl innerhalb als außerhalb Deutschlands. ${ }^{38}$ Literarische Werke erschienen manchmal in höheren in der Regel aber in niedrigeren Auflagenhöhen. ${ }^{39}$ Als Kuriosität sei von R. Z. Becker das »Not- und Hülfsbüchlein» erwähnt, von dem bis 1798 schon 150000 Exemplare verkauft wurden. Nach der Bibel war es bei den deutschen Bauern das am meisten gelesene Buch.40

Für eine Untersuchung der tagespolitischen Literatur sind Kenntnisse über die Bedingungen, unter denen die entstand, ebenso wichtig wie Kenntnisse über ihren Umfang. Besonders hat die Zensur die in der tagespolitischen Literatur geführte Diskussion beeinflußt, die zur Zeit der Revolutionskriege in Deutschland geführt wurde. Weil sich die Zensur auf die verschiedenen Druckerzeugnisse auch noch in verschiedener Weise und in den einzelnen Territorien auf verschiedene Art auswirkte, muß man die Zensurverhältnisse dieser Zeit unbedingt kennen, wenn man zu einem richtigen Bild kommen will.

Zuerst kann man feststellen, daß in Deutschland im 18. Jahrhundert die Zensur wie in allen absolutistischen Staaten gehandhabt wurde. Die Regierungen der einzelnen Teilstaaten versuchten auch oft, nicht nur im

35 Genaue Daten gibt es nichit. Vgl. Tiainen (1971) Anm. S. 156 und Tiainen (1972 a) S. 183.

36 Hemleben, Sylvester John, Plan for World Peace, Chicago 1943, S. 88.

37 Pribram, Alfred Francis u. Fischer, Erich, Ein politischer Abenteurer, Wien 1937, S. 74.

38 Ibid. S. $40-41$.

39 z.B. v. Göckingk (1820) S. 40.

40 Kummer, Paul, Sippen um Rudolf Zacharias Becker, Görlitz 1938, S. 4. 
eigenen Gebiet sondern auch in den Nachbarstaaten auf den Inhalt der Druckerzeugnisse Einfluß zu nehmen. Besonders streng war die Zensur in Österreich. Dort gelang es nach 1795 fast vollständig die öffentliohe Diskussion in eine Richtung auszurichten. Die österreichische Presse selbst, vor allem die einflußreiche »Wiener Zeitschrift» und ihre Nachfolger, forderten immer wieder eine Verschärfung der Zensur. ${ }^{41}$ Österreich nahm auch aktiv Einfluß auf die Diskussion in seinen Nachbarstaaten und 1799 verlangte es von Preußen, man solle die auf seinem Gebiet sehr regen österreichfeindlichen Journalisten zum Schweigen bringen. ${ }^{42}$ So mußte schon früher, 1796, der in Berlin ansässige französisch gesinnte Literat Andreas Riem vor allem auf Intervention der Höfe Österreichs und Rußlands aus Preußen fliehen. ${ }^{43}$ Die preußischen Zensur war milder als die österreichische, aber bei aller Inkonsequenz verhältnismäßig streng. Friedrich Wilhelm II. mystische Religiosität ließ seine Regierung besonders mißírauisch die religiöse Literatur und die religiöse Fragen behandelnde Presse verfolgen. Darunter hatten am meisten die Aufiklärungsphilosophen zu leiden. Kant war ständig von der Zensur bedroht, ${ }^{44}$ und Nicolai bekam unzählige Verwarnungen von den Zensurbehörden, so daß er zeitweise gezwungen war, den Erscheinungsort seiner Schriften in ein freizügigeres Gebiet $\mathrm{zu}$ verlegen.45 Ebenso mußten J. F. Reichardt und der oben erwähnte Riem ihren Wohnort wechseln. ${ }^{46}$ Nach der Thronbesteigung Friedrich Wilhelm III. hegte man die Hoffnung auf eine mildere Zensur, aber die angespannte außenpolitische Lage zwang die Regierung der Presse den Maulkorb der Zensur sehr eng anzulegen. Besonders den Frankreich freundlich gesonnenen Schriftstellern entstanden daraus Schwierigkeiten. ${ }^{47}$ So beaufsichtigten die Regierungen der beiden deutschen Großmächte das öffentliche Wort ziemlich genau.

Im »dritten Deutschland» herrschten recht untenschiedliche Zensurbedingungen. Allgemein läßt sich sagen, daß die Zensur in Süddeutsch-

41 Eisner (1907) S. 39; Bulling, Karl, Johann Babtist von Alxinger, Diss. Leipzig 1914 S. 113-116, 119; Bettex, Albert, Der Kampf um das klassiche Weimar, Zürich und Leipzig 1935 S. 45; Eder, Karl, Der Liberalismus in Altösterreich, Wien und München 1955, S. 59.

42 Tschirch I (1933) S. 399.

43 National-Zeitung der Teutschen 1796 N.r. 40, S. 886.

44 z. B. Röhrdanz, Günther, Die Stellung Kants in und zu der Presse seiner Zeit, München 1936, S. 88; Eisner (1907) S. 42-45; Czygam I (1910) S. 2-7.

45 Ost (1928) S. 66-67, 74-75, 87-89; Eisner (1907) S. 172-173; v. Göckingk (1920) S. 35-40, 55.

46 Bobeth, Johannes, Die Zeitschriften der Romantik, Leipzig 1911, S. 19-23.

47 Ibid. S. 47; Röhrdanz (1936) S. 85; Eisner (1907) S. 16-19, 42-45 usw. 
land strenger als in Norddeutschland war.48 In den geistlichen Territorien war man im allgemeinen intoleranter;49 als besonders strenger Wächter über das Wort war der Mainzer Erzbischof-Kurfürst Karl Friedrich von Erthal bekannt. ${ }^{50}$ Im säkularen Süddeutschland waren die Bedingungen uneinheitlich. In Baden war die Zensur besonders streng, ${ }^{\mathbf{1 1}}$ während in Württemberg und in Bayern zumindest zeitweise eine verhältnismäßig freie öffentliche Diskussion zugelassen war.52 Weiter nördlich in den Ländern Hessen-Kassel und im Kurfürstentum Sachsen war die Zensur für ihre Strenge bekannt. Dort waren nach 1790 Verbote und Requisitionen an der Tagesordnung. ${ }^{33}$ Hannover galt dank der für England typischen Zensurbestimmungen als freies Land, ${ }^{54}$ aber trotzdem hatte der bekanntesite Journalist dieses Gebiets, August Schlözer, dort Schwierigkeiten. Auf Veranlassung der Höfe von Wien und Berlin griff William Pitt persönlich nach der Freiheit des Wortes im kontinentalen Teil seines Reiches: im Frühjahr 1794 ließ die Regierung von Hannover die »Stats-Anzeigen» verbieten. ${ }^{55}$ So läßt sich feststellen, daß die Pressefreiheit stark von der persönlichen Einstellung der Herrschenden der Territorien abhing. So ist die milde Zensur in Anhalt-Dessau die sich allerdings später durch den Krieg und auf Druck der größeren Nachbarländer verschärfte - auf die liberale Einstellung von Herzog Leopold Friedrich Franz zurückzuführen.56 In Sachsen-Weimar war die verhältnismäßige Freiheit der Presse Herzog Karl August zu verdanken. ${ }^{57}$ Obgleich dort der Hof die zahlreiche Weimarer Literatur frei sprießen ließ, wurde auch dort die Presse durch Druck von außen eingeschränkt.58 Die eigentlichen zensurfreien Oasen waren die dänischen Gebiete in Norddeutschland. Die liberale Regierung des Ministerpräsidenten A. P. Bernstorffs beseitigte schon nach 1770 in Praxis die Vorzensur vollständig. Diese liberale Praxis wurde bis zur Jahrhundert-

48 v. Wrasky, Nadeschda, A. G. F. Rebmann, Diss. Heidelberg 1907, S. 6.

49 Herse, Wilhelm, Die Goethezeit in Deutschland, Hannover 1947, S. 30-31; Merkle, Sebastian, Die katholische Beurteilung des Aufklärungszeitalters, Berlin 1909, S. 53.

50 v. Wrasky (1907) S. 31.

51 Eisner (1907) S. 15-16.

52 Tiainen (1971) S. 29, 35.

53 Voegt (1955) S. 43 :v. Wrasky (1907) S. 53.

54. Eisner (1907) S. 15-16.

55 Herse (1949) S. 75.

56 v. Wrasky (1907) S. 31.

57 Andreas, Willy, Carl August von Weimar in und nach der Kampagne gegen Frankreich, Diss. München 1955.

58 Gleichen-Russwurm, Alexander, Die Klassiker und Politik, Baden-Baden 1947, S. 151. 
wende fortgesetzt, als man dann unter den herrschenden Bedingungen gezwungen war, die Aufsicht über die Presse zu verstärken. ${ }^{59}$ Eine Folge der liberalen Pressegesetze in Dänemark war, daß die in den anderen Staaten verfolgten Literaten gern Schutz auf der sicheren Seite der Grenze von Holstein suchten. Dieser Umstand erklärt die große Bedeutung Kiels und besonders Altonas als Verlagszentrum für politische Literatur. ${ }^{60}$ Die radikalste Literatur geriet zeitweise auch auf dänischem Gebiet vor allem auf Veranlassung anderer Staaten unter Druck. ${ }^{61}$ Im Gegensatz zu Dänemark wurde durch die Schwedische Regierung die Zensur in Pommern besonders streng gehandhabt, wobei man genau darauf achtete, daß zumindest keine gegen Schweden gerichtete Literatur erscheinen konnte. ${ }^{62}$

Die Reaktion der Deutschen auf den Druck der Presse war verschieden. Sehr häufig beklagten sich die Journalisten und Schriftsteller über die Strenge der Zensur und forderten die Regierungen und die Herrschenden auf, die gesetzlichen Bestimmungen zu liberalisieren. Diese Klagen und Aufforderungen wurden unabhängig von den politischen Einstellungen erhoben. Die scharf gegen Frankreich und einen Frieden argumentierenden »Neue Zeitblätter», die allerdings in Göttingen, das im liberalen Staat Hannover lag, erschienen, bedauerten, daß die Zensurbestimmungen auch für die Flugschriften galten, die dann oft zweideutig abgefaßt werden müßten. ${ }^{63}$ J. F. Reichardt, dessen Veröffentlichungen eine stark frankreichfreundliche Linie vertraten, beschwerte sich 1796 in einem Brief an Immanuel Kant über die Strenge der preußischen Zensur:

"Die berlinische Censur, die für alles was Journal heißt, seit einem Jahr in den Händen der Policei ist, hat den Verleger in allem, was Statistik und neuere Geschichte betrifft, so widersinning eingeengt, dass ihm Muth und Geduld vergangen und er mich versucht hat auf jene Artikel Verzicht zu thun und dem Werke eine andere Form zu geben, damit es aus den Händen der Censur komme».64

59 Eisner (1907) S. 12.

60 S. später.

61 Schwierigkeiten hatten z.B. Hennings und v. Knigge. Eisner (1907) S. 26.

62 Hokkanen, Kari, Pohjoismaiden ulkopolitiikka Saksan päivänpoliittisessa kirjallisuudessa 1795_1801, Historica III (1972) S. 139; Struck, Joachim Lorenz, Die Kgl. Regierungsbuchdruckerei, Die Stralsundische Zeitung und ihre Beziehungen zu Schweden, Stralsund 1928, S. 8-9; Stuckmann, Werner, Geschichte der Stralsundischen Zeitung, Stralsund 1928, S. 42.

03 Neue Zeitblätter 1795 I S. 3.

64 Röhrdanz (1936) S. 85. 
Die Regierungen wurden von Vertretern so entgegengesetzter Richtungen wie Friedrich Gentz, der sich an den neuen preußischen Herrscher Friedrich Wilhelm III.65 und Joseph Görres, der sich an die Regierung des französischen Rheingebietes und an das Pariser Direktorium wandte, aufgefordert, die Zensurbestimmungen zu liberalisieren.6 ${ }^{66}$ Allgemein wurden die liberalen Bedingungen in Dänemark gelobt und Dänemark als positives Beispiel den Regierungen der deutschen Territorien empfohlen. ${ }^{67}$ Andererseits wurde nicht von allen die Notwendigkeit der Pressefreiheit anerkannt. In Österreich wurde nach 1790 von Seiten der Presse die Möglichkeit einer Verschärfung der Zensur vorgeschlagen und, wie schon oben erwähnt, viele Vertreter des »dritten Deutschland» schlossen sich dieser $\Lambda$ uffassung an. ${ }^{\text {is }}$ Goethe als $\Lambda$ ristolsrat hiclt Pressefreiheit für unnötig. ${ }^{69}$ Der ständige Mitarbeiter an Wielands »Merkur», Christoph Lenz, vertrat in einem Vortrag anläßlich der Leipziger Ostermesse des Jahres 1795 den Standpunkt, daß die Zensur überhaupt keinen Einfluß auf die deutsche Literatur gehabt habe. ${ }^{70}$

Die oben erwähnten Umstände müssen auch bei der Bewertung der Wirkung beachtet werden, die die öffentliche Diskussion über Krieg und Frieden auf die politischen Entscheidungsträger und natürlich auf die einzelnen Staatsbürger hatte. Es ist klar, daß die Flut der Flugschriften, die auf Bezahlung der österreichischen Regierung verfaßt worden waren, die Regierung nicht im geringsten beeinflußte, obwohl es den Anschein hatte, als ob diese Flut eine Zeit lang ganz Deutschland überflutet hätte und den bedeutendsten Teil der im Lande geführten öffentlichen Diskussion vertreten würde. Auch die preußische Regierung schenkite den von regierungstreuen Beamten herausgegebenen monarchistischen Zeitschriften eine kaum größere Bedeutung. In diesen Zeitschriften wurden Jahr für Jahr die Verdienste dieser Regierung und ihre segensreiche Tätigkeit für die Untertanen gepriesen. Eine absolutistische Regierung hatte es nicht einmal formal nötig, eine spontane öffentliche Diskussion zu beachten.

Äußerst schwer ist es, die Wirkungen der politischen Tagesliteratur abzuschätzen. Unbestreitbar ist jedoch, daß sie Wirkungen ausübte. Die besten politischen Schriftsteller waren sogar an den absolutistischen

65 Pertz, G. H., Das Leben des Ministers Freiherrn vom Stein I, Berlin 1850, S. $179-180$.

66 Görres, Joseph, Gesammelte Schriften I, Köln 1928. S. 19.

67 Hokkanen (1972) S. 139.

68 Vgl. S. 8.

69 Mann, Thomas, Goethe und die Demokratie, Uppsala 1951, S. 16.

70 NTM 1795 II S. 59. 
Höfen gefürchtet. Der Einfluß von Schlözers »Stats-Anzeigen» war besonders groß. So wurden die Ansichten dieser Zeitschrift von Maria Theresia und Josef II. verfolgt und auah Vorschläge Schlözers berückssichtigt. Von den kleineren deutschen Potentaten wird berichtet, daß sie die spitze Feder des Göttingers geradewegs fürchteten. ${ }^{71}$ Die deutschen Fürsten und Entscheidungsträger hatten die Zeitschriften abonniert und lasen sie. In einigen Fällen meldeten sie sich auch in diesen Zeitschriften mit Beiträgen zu Wort und nahmen so an der öffentlichen Diskussion teil. ${ }^{72}$ Eine andere Frage ist jedoch, in welchem Umfang sie die Meinungen der Journalisten bei ihren Entscheidungen berücksichtigten. Sehr oft erschienen in den Zeitschriften öffentliche Aufrufe an die Regierungen, indem man Einsprüche erhob oder zu einem bestimmten Vorgehen aufforderte. Einer der bekanntesten ist Wielands Plan zur Rettung Europas, der sich in einer Reihe von Dialogen, »Gespräche unter vier Augen», im Jahre 1798 an den König von Preußen, Friedrich Wilhelm III. richtete, der gerade den Thron bestiegen hatte. HANS WAHL stellt zu diesen Gesprächen fest: Man kann nur hinzufügen, daß der König sie lag. ${ }^{73}$ Der schon erwähnte Aufruf von Friedrich Gentz an Friedrich Wilhelm III. zur Erweiterung der Pressefreiheit hatte keinerlei Wirkung bei dem Herrscher. Einige Schriften erregten allerdings Verärgerung bei den Fürsten und Machthabern, ${ }^{74}$ aber die Vorschläge der Presse wurden nicht berücksichtigt. Die Mächtigen in Deutschland faßten ihre Beschlüsse nicht nach dem, was ihre Untertanen schrieben, sondern nach anderen Motiven.

Trotzdem ist eine Analyse der politischen Tagesliteratur nicht ohne Wert. Natürlich hatte sie, sei sie nun spontan oder von bezahlten Federsöldnern verfaßt, irgendwelche Wirkungen. Sie hat den gewöhnliohen Deutschen der Jahre zwischen 1790 und 1800 die Situation vor Augen geführt, in der sie lebten. Die Zeitschriftenartikel und Flugschriften sollten vor allem auf die Leser und nicht nur auf diejenigen einwirken,

71 Joachimsen, Paul, Vom deutschen Volk zum deutschen Staat, Göttingen 1956, S. 34 .

72 z.B. die preußische Königin Louise war eine fleissige Leserin und sogar Mithelferin des Teutschen Merkurs von Wieland. Gooch, G. P., Germany and the French Revolution, London 1927, S. 157. Einige Zeitschriften veröffentlichten Katalogen von ihren bedeutendsten Abonnenten. „Schleswig-Holsteinische Provinzialberichte» nennt drei (1795 I S. VII) und Schleswig-Holsteinische Blätter (1799 I, Vorbericht) vier Fürsten als ihre Abonnenten.

73 Wahl, Hans, Geschichte des Teutschen Merkur, Palaestra 128, Berlin 1914, S. 247.

74 z.B. Boas, Eduard, Schiller und Goethe im Xenienkampf I, Stuttgart und Tübingen 1851 , S. 6 . 
die die Entscheidungen fällten. Diese Darstellung und Untersuchung der sich mit Krieg und Frieden befassenden politischen Tagesliteratur soll ein Bild von der Situation ergeben, wie es sich für den Deutschen am Ende des 18. Jahrhunderts zeigte, der häufig wenig mit den Kräften, die die lebhafte und zeitweise heftige Diskussion im Hinitergrund bestimmten, vertraut war. Durch die Untersuchung der genannten, im Hintergrund wirksamen Kräfte, kann dann geklärt werden, wie richtig dieses Bild war, das er von der Situation erhalten hatte.

\section{Das Heilige Römische Reich Deutscher Nation und die Französische Revolution}

Das Deutsche Reich, das seit 1789 von den Umwälzungen der Französischen Revolution erschüttert wurde, hatte alte und veraltete Grundlagen.75 Mit kleinen Veränderungen war immer noch die Kreiseinteilung Kaiser Maximilians von 1500/1512 in Kraft. Die wichtigsten Grundgesetze waren die Bestimmungen des Westfälischen Friedens aus dem Jahre 1648. Seit diesem Frieden befand sich Deutschland in einer äußerst schwachen Position, die vor allem auf die politische Zersplitterung des Reiches zurückzuführen ist. Seit dem Dreißigjährigen Krieg hatten alle deutschen Teilstaaten, alle Territorien zumindest formal die Rechte eines nahezu souveränen Staates. Diese zweitausend oder über zweihundert Staaten, je nach dem wie man sie berechnet, bildeten das Reich. Das Verhältnis der Ternitorien zum Kaiser, dem formalen Oberhaupt, war sehr unterschiedlich. Die Gesanditen der Höfe und Teilstaaten stritten auf dem ständigen Reichstag in Regensburg über die Sitzungsordnung, aber es war natürlich auf Grund der Souveränität der Einzelstaaten äußerst schwierig gemeinsame Beschlüsse zu fassen.

Die Hierarchie der deutschen Einzelstaaten untereinander war kompliziert: es gab kurfürstliche Länder, geistliche Mitglieder des Fürstenkollegiums und weltliche Fürstentümer, die Gebiete der sogenannten Reichsgrafen und Reichsprälaten und schließlich unabhängige Reichsstädte und dazu noch eine unzählige Reihe von Reichsrittertümern. Diese »verfassungsmäßige» Teilung hatte jedoch keine praktische politische

75 Dieser Überblick begründet sich hauptsächlich auf das obengenannte Werk W. H. Brufords (1936), in derer Ende eine gute statistische Zusammenfassung steht. Siehe auch z.B. Valentin, Veit, Deutsche Geschichte I, München-Zürich 1965; Streisand (1961); Huber, Ernst Rudolf, Deutsche Verfassungsgeschichte seit 1789 I, Stubtgart 1957; Hartung, Fritz, Deutsche Verfassungsgeschichte, Stuttgart 1950 , S. $166-169$. 
Bedeutung. An ihre Stelle war eine neue Teilung getreten. Der Dualismus, zu dem die schnelle Erstarkung Brandenburg-Preußens seit dem 17. Jahrhundert geführt hatte, dominierte in Wirklichkeit in der Innenpolitik des Deutschen Reiches. Die Großmächte Preußen und Österreich hatten die größten Besitzungen innerhalb des Reichsgebietes, zu denen noch ausgedehntere Gebiete außerhalb des Reichsgebietes traten. Zum habsburgischen Machtbereich gehörten u.a. das Königreich Ungarn, während die Hohenzollern über Ostpreußen herrschten, das nicht zum Reich gehörte. Die Teilungen Polens brachten den beiden Großmächten noch einen weiteren Machtzuwachs. Nach 1795 lebten in den österreichischen Gebieten, die zum Reich gehörten ungefähr 9,1 Millionen Untertanen und in den Gebieten außerhalb der Reichsgrenzen über 14 Millionen. Für Preußen lauten die entsprechenden Zahlen ca. 2,8 und fast 5 Millionen.

Die Territorien außerhalb dieser zwei miteinander konkurrierenden Großmächte bilden das sogenannte »dritte Deutschland». Sowohl seinem Gebiet als auch seiner Einwohnerzahl nach war es größer als Preußen und Österreich, (wenn man nur die zum Reich gehörenden Gebiete berücksichtigt), aber die totale staatliche Zersplitterung verringerte seine Bedeutung gegenüber diesen zwei Großmächten. Die wichtigsten Länder des »dritten Deutschland» waren die Kurfürstentümer Pfalz-Bayern und Sachsen, die beide mehr als zwei Millionen Einwohner zählten, und das Kurfürstentum Hannover (Kurbraunschweig-Lüneburg), dessen Selbständigkeit allerdings durch die Personalunion mit England in gewissem Grad beeinträchtigt war, mit nahezu 800000 Einwohnern. ${ }^{76}$ Die nächstgrößeren Territorien waren dann nach den Einwohnerzahlen HessenDarmstadt (ca. 650 000), Württemberg (über 600 000) und Hessen-Kassel (ca. 440 000). Mehr als hunderttausend hatten dann noch MecklenburgSchwerin, Holstein (dessen Herzog König von Dänemark war), SachsenWeimar, Sachsen-Gotha, Braunschweig-Wolfenbüttel, das schwedische Pammern und Baden. Dazu gab es noch 27 Fürstentümer mit weniger Einwohnern.

Die deutsche Landkarte wird noch bunter durch die 95 Reichsgrafen, die sich in die vier Grafenkollegien teilten, mit ihren Grafschaften und die 50 freien Reichsstädte, die sich in zwei »Bänke» gruppierten. Noch kleiner und bedeutungsloser waren die von den sogenannten Reichsrit-

76 Die Schwache des Personalunions zeigt wohl z.B. das, daß Hannover in Reichstag i.J. 1797 die Neutralitätspolitik Preußens und die Neutralität Norddeutschlands unterstützte, was natürlich gegen die Interessen Englands war. Hüffer, Herrmann, Die Rastadter Congress und die zweite Coalition, II, Bonn 1878, S. 92 . 
tern beherrschten Territorien, wo man die Auffassung vertrat, daß man unmittelbar dem Kaiser unterstehe. Die Zustände in diesen Kleinstaaten mit über 400000 Einwohnern in Schwaben, Franken und im Rheinland waren schlecht, meistens schlechter als in den eigentlichen Fürstentümern. ${ }^{77}$ In den Reichsstädten, äußerst aristokratischen Gemeinschaften, die von erblichen Kaufmannspatriziern beherrscht wurden, lebte der größte Teil der Einwohner ganz ohne Staatsbürgerrechte. Die Existenz der Reichsgrafen, Reichsritter und Reichsstädite war vom Kaiser und von der andauernden Geltung der für das Reich eigenartigen Reichsverfassung abhängig. Die herrschende Schicht in diesen Kleinstaaten hatte außerdem noch sehr enge Beziehungen zur Kirche. So ist die geistliche Laufbahn für ihre Mitglieder ganz üblich. Im Reich waren diese Kleinstände ein konservativer und gegenüber Veränderungen feindlich eingestellter Faktor.

Der Uneinheitlichkeit des »dritten Deutschland» gaben die geistlichen Territorien noch ihr eigenes Gepräge; auch unter ihnen, die eine Gesamtbevölkerung von zweieinviertel Millinnen Einwohnern hatten, gab es verschiedene »Rangstufen».78 Offensichtlioh war sowohl die geistige als auch materielle Rückständigkeit der geistlichen Territorien, ${ }^{79}$ die sich andauernd den Machitbestrebungen der schwachen weltlichen Fürsten ausgesetzt sahen. Sie hatten ja keine Erbfolge in der Regierung, vielmehr bestimmte der jeweilige geistliche Herrscher die Politik nach eigenem Gutdünken oder nach dem seines Fürstengeschlechts. Die wichtigsten geistlichen Länder waren drei Kurfürstentümer: die Erzbistümer Mainz (ca. 225000 ), Köln (beinahe 200000 ) und Trier (280 000 Einwohner). Diese und die 28 anderen eigentlichen geistlichen Fürstentümer hatten insgesamt über zwei Millionen Einwohner. Dazu kamen noch 24 kleine Territorien, die von sog. Reichsprälaten (Reichsäbten, Reichspröbsten) beherrscht wurden.

Infolge der schwachen Zentralverwaltung war das Reich nach außen schwach. Besonders deutlich war diese Schwäche auf militärischem Gebiet, so befand sich bei Ausbruch der Revolutionskriege das Militär

77 Valentin I (1965) S. 279-281; Müller, Heinrich, Der letzte Kampf der Reichsritterschaft um ihre Selbständigkeit, Berlin 1910 (Nachdr. Vaduz 1965) S. 16, 19, 24-25. Vgl. Rössler, Hellmuth, Zwischen Revolution und Reaktion, Göttingen 1958 , S. $50-51$.

78 Dieser sowie die anderen Zahlen sind von Bruford. Nach Hüffer wäre die Einwohnerzahl über 3 Millionen gewesen, Hüffer II (1878) S. 193.

79 z.B. Herse (1949) S. 30-31. Der Katolik Hüffer hat eine andere Meinung und er behauptet, daß die Verhältnissen in den geistlichen Territorien nicht schlimmer als in sekulären Territorien derselben Grösse waren. Hüffer II (1878) S. 194. Auch die Zeitgenossen bestritten gegeneinender streng daran, siehe später. 
weitgehend in einem erbärmlichen Zustand. Das gemeinsame Reichsheer war »eine aus sehr vielen kleinen Stücken zusammengesetzte schwerbewegliche Maschine», das seit der Schlacht von Roßbach in einem sehr schlechten Ruf stand. Von den mittelgroßen Ländern hatten nur Hannover, Hessen-Kassel und das Kurfürstentum Sachsen gut organisierte und ausgebildete Truppen. Die sächsischen Soldaten wurden in den Armeen des Bundesgenossen Preußen ausgebildet, die Hannoveraner und Hessen dagegen kamen zu Erfahrung und Ruhm - wenn auch auf fragwürdige Weise bei der Rekrutierung - im Dienste Englands. Das pfalzbayrische Heer war kklein und befand sich in desolatem Zustand und die geistlichen Herren dachten oft wie der Fürstbischof von Hildesheim, dessen Soldaten auf ihren Mützen die Aufschrift tragen mußten: $» D a$ pacem Domine in diebus nostris» ${ }^{80}$ Militärisch wurde das Reich noch dadurch geschwächt, daß viele Territorien an erklärten Reichskriegen nur in Form von finanziellen Aufwendungen teilnahmen und keine Truppen zum Kriegsschauplatz schickten: so z.B. die reichste und größte Reichsstadt Hamburg 1793-95.81 Einige Territorien wiederum beteiligten sich überhaupt nicht an gemeinsamen Kriegsanstrengungen. $\mathrm{Zu}$ diesen zählte besonders Dänemark, dessen Ministerpräsident Anders Peter Bernstorff sich hartnäckig weigerte, am Reichskrieg teilzunehmen, obwohl Hostein nach der Verfassung natürlich seinen Anteil hätte leisten müssen, ${ }^{82}$ und auch Schweden, das sich nur teilweise und dann auch nur im Form von Geldaufwendungen beteiligte. ${ }^{83}$ Die Interessenlosigkeit der Königreiche im Norden gegenüber dem Reich erregte häufig Verärgerung in der »patriotischen» deutschen Presse. ${ }^{84}$ Die Verteidigung des Reiches ruhte fast ausschließlich auf den Hauptmächten Preußen und Österreich und war in hohem Maße von der Bereitschaft und den Möglichkeiten zur Zusammenarbeit dieser Länder abhängig. Diese Zusammenarbeit verlief von Anfang an nur unter großen Schwierigkeiten und hörte 1795 völlig auf.

Der Ausbruch der großen Französischen Revolution hatte auch für Deutschland unmittelbar eine starke Wirkung. Ein großer Teil der Gebildeten, der Adel, die protestantische Geistlichkeit und das Bürgertum empfingen ihre Ideen mit Jubel. Herder, Schiller, Klopstock, Wieland,

80 Pertz (1850) S. 87-88.

81 Böttiger, Theodor Fr., Hamburgs Patrioten 1800-1814, Leipzig 1926, S. $2-3$.

82 Holm, Edvard, Danmark-Norges udenrigske historie I, København 1875, S. $51-52,78-80$.

83 Dalgren, Lars, Sverige och Pommern 1792-1806, Uppsala 1914, S. 33-34.

84 Hokkanen (1972). 
Schlözer, Kant und Fichte zählten alle anfangs zu den Bewunderern der Revolution und »kleinere» Namen könnte man in die Hunderte aufzählen. ${ }^{85}$ Sogar Männer wie Johannes von Müller und Friedrich Gentz, die später zu scharfen Gegnern der Revolution wurden, begrüßen sie anfangs mit Freude. ${ }^{86}$ Nach der Meinung der Initelligenz in Deutschland schien die Französische Revolution alle Bestrebungen der Aufklärung, für die sie sich einsetzten, zu verwirklichen; die bisher ästhetisch und philantropisch ausgerichteten Deutschen schienen in einem Augenblick zu einem Volk von Politikern geworden zu sein.87 Aber tief in den Reihen des Volkes, dessen Zustimmung erst die wirkliche Verbreitung der Revolution im Reich ermöglicht hätte, blieb man dagegen zum überwiegenden Teil passiv oder geradezu ablehnend.88 Das bedeutet nicht, daß es an einigen Onten unter dem Volk keine Zustimmung zur Französischen Revolution gegeben hätte. Stellenweise war der Beifall groß und man zeigte ausgesprochene Lust dem Beispiel Frankreichs zu folgen. Sofort nach Ausbruch der Revolution im Sommer 1789 kam es zu lokalen Bauernaufständen in Baden und in den anderen kleineren Territorien am Mittelrhein; besonders in Trier und im Januar dann in Köln und in den umliegenden Gebieten. Im darauf folgenden Herbst kam es in Sachsen zu schweren Bauernunruhen, die sich so ausbreiteten, daß im August 1790 die Revolutionäre den größten Teil des Kurfürstentums beherrschten, (wenn auch nicht die wichtigen Zentren). ${ }^{89}$ Die größte Anhängerschaft fand die Französische Revolution jedoch in Mainz, ${ }^{90}$ wo

85 z.B. Mommsen, Wilhelm, Geschichte des Abendlandes von französischen Revolution, München 1960, S. 65; Kemiläinen (1956) S. 52; Streisand (1961) S. 1620; Tiainen (1971) S. 51-55.

86 Spengler, Karl, Die publizistische Tätigkeit des Freiherrn Adolf von Knigge, Diss. Bonn 1931, S. 19.

87 Joachimsen (1956) S. 42.

88 Valjavec, Fritz, Die Entstehung der politischen Strömungen in Deutschland 1770-1815, München 1951, S. 145; Franz, Günther, Die Geschichte des deutschen Bauernstandes vom frühen Mittelalter bis zum 19. Jahrhundert, Stuttgart 1970, S. 17; Tiainen (1971) S. 51-55; Herse (1949) S. 17. Die Forschung in der DDR, die das Zeitalter der französischen Revolution behandelt, betont Weite und Stärke der revolutionären Bewegung im Gegensatz der älteren »bürgerlichen» Forschung, z.B. ZfG 4/1966 S. 686-687 (Hellmuth Book), 9/1969 S. 1133 (Heinrich Scheel) und 10/1971 S. 1326-1327 (Gerhard Becker). Diese Tendenz verursacht scheinbar Übertreibung, nhwohl der Fonschung selbst nützlich gewesen ist, daß auch diese früher zu wenig geforschte Sektoren mitgekommen sind.

89 Streisand (1961) S. 14-16; Voegt (1955) S. 12; Heinl, Otto, Heereswesen und Volksbewaffnung in Vorderösterreich im Zeitalter Josephs II. und der Revolutionskriege, Diss. Freiburg 1941, S. 28-29.

90 Droz, Jacques, Deutschland und die französisohe Revolution, Mainz 1955, S. 30 . 
sich in der Hauptstadt eines geistlichen Kurfünstentums, das von einem konservativen Erzbischof regiert wurde, all die Unzufriedenheit mit dem alten Reich und gerade mit den geistlichen Staaten zu konzentrieren schien.91 Als Gründe für die relativ umfassende Unterstützung der revolutionären Umsturzbewegung in Deutschland nennt JOACHIM STREISAND aus der DDR drei: die alte Verbindung der deutschen Intellektuellen zu Frankreich und ihr Interesse an allem, was in Frankreich geschah; das schon damals in Deutschland aufsprießende Nationalgefühl, das die Revolution zu nähren sohien, und die Idee von Evolution und Fortschritt, die die Diskussionen im aufgeklärten Deutschland bestimmte und die ohne Zweifel die Französische Revolution $\mathrm{zu}$ bestimmen schien.92

In den folgenden Jahren kam es zu neuen revolutionären Aufständen in Deutschland. Das Zentrum war wieder das mainz-pfälzische Gebiet. Durch das Eingreifen der französischen Truppen weiteten sich die Aufstände aus. Im Mai 1792 hatte Frankreich Österreich den Krieg erklärt, das schon im Winter zusammen mit Preußen mit Interventionen gedroht hatte. Zu Beginn der Revolution lag außenpolitisch das Hauptinteresse der deutschen Hauptmächite im Osten, in Richtung Polens und den Balkan; allerdings waren diese Interessen nicht gleichgerichtet. Graf von Hertzberg, der die Preußische Außenpolitik gestimmte, war ein alter Gegner Österreichs und versprach sich Vorteile aus der Revolution, die sich auch gegen das seit der Zeit des Siebenjährigen Krieges bestehenden Bündnis zwischen Frankreich und Österreich richtete. Ein drohender Krieg zwischen Preußen und Österreich wurde von England verhindert, das von Anfang an wegen der Ereignisse in Frankreich besorgt war und befürchtete, daß sich die Revolution schnell auf die österreichischen Niederlande ausbreiten würde. Im Jahre $1790 \mathrm{kam}$ es in Preußen zu einem Machtwechsel, als Friedrich Wilhelm II. Hertzberg durch seinen Günstling Bischoffswerder ersetzte. Dieser wandte sich gegen Frankreich und unterstützte die Interventionspolitik. Die Verhandlungen zwischen Bischoffswerder und dem die österreichische Politik bestimmenden Grafen von Cobenzl wurden mit einem Bündnisvertrag abgeschlossen, der sich eindeutig gegen Frankreich richtete. Kaiserin Katarina II. setzte sich für die Allierten ein. Im Sommer 1792 drangen die Truppen der Allierten in Frankreich ein und errangen überall Siege. Die Offiziere der französischen Armee waren zum größten Teil royalistisch und keineswegs loyal gegenüber dem Vaterland eingestellt, das Republik geworden war. Ein großer Teil der Armee hatte das Land als

91 Id.; Herse (1949) S. 31.

92 Streisand (1961) S. 18-21. 
Emigrant verlassen und richtete jetzt seine Waffen gegen die eigenen Landsleute; so vor allem das adelige Offizierkorps. Am 20. September kam es jedoch zu einer überraschenden und entscheidenden Wendung, die dazu führte, daß der Krieg sich über Jahre hinziehen sollte: die Franzosen errangen den ersten Sieg in der Kanonade bei Valmy über die preußischen Heere, deren Vormarsch gegen Paris so aufgehalten wurde. Im folgenden Winter waren die Revolutionsarmeen an der Reihe zu siegen. Sie drangen rasch an dic natürlichen Grenzen Frankrcichs vor, zu den Alpen und an den Rhein. Für die revolutionären Bewegungen in Deutschland eröffneten sich so völlig neue Möglichkeiten.93

Die rheinischen Kleinfürsten wagten im allgemeinen nicht einmal den Versuch, Widerstand zu leisten, sondern flohen mit ihrem Hof nach Osten über den Rhein. Viele wichtige Städte gerieten so unter französische Herrschaft. Am meisten Aufsehen erregte die Kapitulation des stark befestigten Mainz. Die Ankunft der französischen Truppen führte zur Vertreibung der erzbischöflichen Mannschaft und zu einem wirklichen Umsturz, so daß die schon lange auf der Seite der Revolution stehenden Mainzer die Macht in der Stadt übernahmen. Der von Andreas Hoffmann und Georg Forster gegründete Jakobinerklub übernahm die Führung in der Stadt. ${ }^{94}$ Der Führer der französischen Truppen, General Custine schuf zwischen Mainz, Hanau und Bingen ein Verwaltungsgebiet, in dem u.a. die Verbreitung gegenrevolutionärer Schriften verboten und eine Reihe sozialer Neuerungen durchgeführt wurde. Unter dem Schutz der französischen Truppen riefen die Mainer Klubisten im März 1793 einen rheindeutschen Nationalkonvent zusammen. Der Konvent erklärte, daß sich das Rheingebiet vom Deutschen Reich gelöst habe und rief die Mainzer Republik aus. Die feudale Ordnung wurde beseitigt. Der Versuch scheiterte jedoch am Gegenangriff der preußischen Truppen vom Frühjahr 1793, der zur Belagerung und Rückeroberung von Mainz führte. Wie man jedoch später sehen sollte, blieb die revolutionäre Einstellung der Mainzer erhalten. Eine große Zahl von Klubmitgliedern und revolutionären Führern floh nach Frankreich, um dann häufig als Beamte der Republik zurückzukehren, nachdem sich das Kriegsglück gewendet hatte. ${ }^{95}$

Die Unruhen breiteten sich nun stärker als früher aus. In den Städten kam es zu kleineren Aufständen und Empörungen unter den Handwerks-

93 Valentin I (1965) S. 326-330; Gaxotte, Pierre, Geschichte Deutschlands und der Deutschen II, Freiburg im Br. 1967, S. 106-107.

94 Eine gründliche Beschreibung über die Jakobinmacht in Mainz z.B. Benedey, Jakob, Die deutschen Republikaner unter der französischen Republik, Leipzig 1870; Herse (1949) S. 90-92.

95 Streisand (1961) S. 36-41. 
gesellen, so u.a. in Nürberg (1791), Bremen (1793) und Stuttgart (1794). Im Sommer 1794 streikten in Dresden 3000 Gesellen und Hamburg wurde in der Zeit von 1791 bis 1794 fortwährend von Streiks und Unruhen heimgesucht. Auch in Berlin kam es 1794 zu Zusammenstößen zwischen Gesellen und Soldaten und zu Streiks. Der revolutionäre Mittelpunkt Preußens lag jedoch in Schlesien, wo die Empörung der Weber und anderer Handwerker das größte Ausmaß annahm und mit harten Maßnahmen unterdrückt werden mußte. ${ }^{96}$ Obgleich es noch viel später zu Unruhen unter dem Volk kam, blieb ihre Bedeutung und Wirkung fast bedeutungslos. Die unaufgeklärte Klasse des Volkes vermochte nicht in entscheidender Weise an der öffentlichen Diskussion teilzunehmen. Die deutschen Hauptstaaten behersschten die Situation vollkommen, und auch die kleineren Territorien waren dazu mehr oder weniger in der Lage. Im ganzen gesehen nahm man in Deutschland gegenüber einer gewaltsamen Revolution eine ablehnende Haltung ein. ${ }^{97}$

Im Februar 1793 weitete sich der Krieg mit der Kriegserklärung Englands und seines Bundesgenossen Holland an Frankreich aus, das seinen König hingerichtet hatte. England begann gleichzeitig unter seinem energischen Premierminister William Pitt (dem Jüngeren) eine große Koalition gegen den Friedensstörer in Europa zu errichten. Es kam zu der ersten Koalition gegen Frankreich, der sich außer den genannten Ländern noch Spanien, Neapel und Sardinien anschlossen, außerdem versprach Rußland die Koalition zu unterstützen. Für die Deutschen war von Bedeutung, daß der Reichstag in Regensburg Frankreich den Reichskrieg erklärte, auch wenn die Kriegsanstrengungen des gebrechlichen Reiches mit Ausnahme einiger Territorien bedeutungslos bleiben sollten. Man kann sagen, daß neben Preußen und Österreich nur Hessen-Kassel und Sachsen ihren Anteil an den Kriegsbemühungen leisteten, während die anderen mehr oder weniger unwillig Krieg führten. ${ }^{98}$

Das Kriegsglück wechselte von Seite zu Seite. Das Jahr 1793 begann für Frankreich unter einem schlechten Vorzeichen. Die Österreicher schlugen in Belgien General Dumouriez, der mit dem Feind geheime Verhandlungen aufnehmen mußte. Die Preußen eroberten, wie schon erwähnt, im Sommer Mainz zurück. Zu einer Wende kam es erst, nach-

96 Ibid. S. 38-43; Laufenberg, H., Hamburg und die französische Revolution, Hamburg 1913, S. 51-52.

97 Darüber sind die Forscher im Osten und Westen nicht einig, vgl. oben Anm. 88. Z.B. Buhr, Manfred, Revolution und Philosophie, Berlin 1965, S. 9; Scheel, Heinrich, Deutsche Jakobiner, ZfG 9/1969, S. 1133-1134.

98 Valentin I (1965) S. 330. 
dem das französische Kriegswesen von Carnot gründlich reformiert worden war. Durch die Einführung der allgemeinen Wehrpflicht wurde die Zahl der Soldaten in bisher nie gekannter Weise erhöht. Die Soldaten dieser Riesenarmeen wurden noch durch die Revolution und ihre Ideen begeistert. Im Herbst 1793 besiegten die Franzosen den Feind und vertrieben ihn wieder vom Boden des eigenen Landes. Frankeich verdankte seine Siege nicht nur seiner Kriegstüchtigkeit sondern auch der 7.wietracht unter den Alliierten, die immer größer wurde und den Wert der gemeinsamen Kriegsanstrengungen verringerte. Besonders Preußen begann des erfolgosen Kampfes an der Seite des alten Feindes und Konkurrenten Österreich überdrüssig zu werden. Auch mit Polen kam es zu Schwicriglscitcn, das untor der Führung von Kosciusko scinc Freihcitsreste zu verteidigen begann. Das Jahr 1794 brachte für die Franzosen eine Reihe neuer Siege. Sie drangen wieder bis zum Rhein vor und machten sich daran, in die inneren Teile des Deutschen Reiches vorzudringen. Die Kriegsmüdigkeit wandelte sich in Deuitschland zu einer aktiven Friedensbereitschaft. ${ }^{99}$

Sowohl auf der Seite derjenigen, die einen Frieden verlangten, als auch auf der Seite der Befürworter eines Krieges erkannte man die Macht des öffentlichen Wortes. Das Jahr 1794 war eine Zeit besonders aktiver politischer Stellungnahmen. In Zeitschriften und besonders in Flugschriften stritt man über Vor- und Nachteile eines Friedensschlusses. Es bildete sich eine Partei, die jegliche Friedensbemühungen scharf ablehnte. Sie gruppierte sich vor allem um die »Wiener Zeitschrift» und deren Nachfolger, das »Magazin der Kunst und Literatur» und »Eudämonia». Hier wurde der Standpunkt vertreten, daß die friedliche Koexistenz mit einer atheistisch revolutionären Republik unmöglich sei. Eine Gruppe von Schriftstellern und Wissenschaftlern, die vorher zur Revolution eine positive Haltung eingenommen hatte, gab jetzt diesen Standpunkt auf und zog sich auf ästhetische und andere unpolitische Gebiete zurück. Die Weimarer Klassiker sind ein gutes Beispiel dafür.100 Unter der Presse gab es aber auch eine aktive Partei, die einen Friedensschluß forderte. Sie wurde einerseits im Schutz der freien Zensurverhältnisse Norddeutschlands und andererseits in den von den Franzosen besetzten Gebieten und den unmittelbar von ihnen beeinflußten Gebieten Westdeutschlands aktiv. Wekherlin, Mauvillon, Forster, Laukhard, von Knigge, Rebmann,

99 Wendland, Wilhelm, Versuche einer allgemeinen Volksbewaffnung in Süddeutschland, Berlin 1901/Nachlr. Vaduz 1965, S. 216 usw.

100 Arnold, Robert F., Fremdherrschaft und Befreiung 1795-1815, Leipzig 1932, Vorwort; Buhr (1965) S. 50. 
Fröhlich, Reimarus und viele andere schrieben eifrig für einen Frieden und setzten sich auch für Reformen im Reich ein. ${ }^{101}$

Die meisten Schriftsteller, die sich an der Diskussion um Krieg oder Frieden beteiligten, argumentierten mit militärpolitischen Ereignissen und Fakten der Zeit. Mit Siegen oder Niederlagen auf den Schlachtfeldern, millitärischer Stärke oder Schwäche, wirtschaftlicher Prosperität oder A.rmut wurde oft begründet, ob es nötig oder unnötig sei, einen Frieden zu schließen oder den Krieg fortzusetzen. Das waren jedoch nicht die einzigen Argumente. Daneben brachte man eine Fülle von ideellen Begründungen vor, die die theoretische Diskussion über den Frieden zunächst zwischen den Philosophen schon jahrhundertelang bestimmt hatte. Im 18. Jahrhundert war dann diese Diskussion besonders lebhaft.

\section{Krieg und Frieden in der philosophischen Diskussion im Jahrhundert der Aufklärung}

So wie die Kriege im Laufe der ganzen Geschichte die Plage der Menschheit gewesen sind, so erörtert man schon seit der Antike die Möglichkeiten, wie man sie verhindern könnte. Hunderte von mehr oder weniger realistischen Plänen und Programmen wurden entworfen, um einmal zu einem System zu gelangen, daß den ewigen Frieden sichern sollite, oder um zumindest einen zeitweiligen Friedensschluß zu erreichen. $\mathrm{Ab}$ und $\mathrm{zu}$ erhoben sich jedoch Stimmen, die feststellten, daß der Krieg ein natürlicher Zustand der Menschheit sei, in dem siesich am besten verwinklichen könne.

Die Idee von einem ewigen Frieden und von der Einheit und Zusammengehörigkeit den ganzen Menschheit ist schon alt, und man triff sie schon in Quellen aus der Zeit Mesapotamiens, der Juden und Parsen.102 Die Friedensfrage spielte in der vielseitigen Philosophie der Hellenen eine besonders wichtige Rolle. Andrerseits schuf Herakleitos sein den Krieg verherrlichendes System und den Begriff »stolzer Asketismus» und Empedokles entwarf eine Theorie, nach der sich in der Geschichte Streit und Liebe abwechseln würden, auch hielt er einen ewigen Frieden für unmöglich. Die Spartaner sahen im Krieg das Ziel eines Menschenlebens. Aber

101 Eisner (1907) S. 14-15.

102 v. Grauert, Herrmann, Zur Geschichte des Weltfriedens, des Völkerrechts und der Idee einer Liga der Nationen, HJb 39, 1919, S. 115-116. Der ganze Überblick begründet sich an das Werk Rauhanajatus historiassa (Friedensidee in der Geschichte) Porvoo 1970, Kapitel I-VII. 
auch die »fröhliche Philosophie» der hellenistischen Epoche verachtete die kriegerischen Tugenden und der Stoizismus forderte von einer kosmopolitischen Grundanschauung aus dazu auf, auch den Feind zu lieben. ${ }^{103}$ Die zur Zeit der Kriege erduldeten Leiden, die als unerträglich empfunden wurden, ließen besonders während der Peloponesischen Kriege sowohl in der Literatur als auch in der Philosophie verzweifelte Äußerungen einer Friedenssehnsucht laut werden.104 Auch der Sieg des Christentums brachte für die Menschheit keine Festigung des Friedenszustandes, obgleich die Urchristen daran glaubten. Im Gegenteil bedeutete er in mancher Hinsicht vom spätantiken Philosophiegebäude aus gesehen eine Zunahme religiöser Intoleranz und religiöser Verfolgungen. Das Auftreten der kriegerischen Religion des Islams in der Weltgeschichite ließ auch die Vorstellung von einem heiligen Krieg immer deutlichere Züge annehmen. Die Vorstellung von einem Reich Gattes, die auch einen ewigen Frieden beinhalten sollte, führte ihrerseits zur Schwertmission und $\mathrm{zu}$ hoffnungslosen inneren Kämpfen unter den Christen. ${ }^{105}$

Das Christentum hat trotzdem Bedeutung als Förderer der theoretischen Friedensdiskussion. Der Gedanke vom göttlichen Reich auf Erden, den besonders Augustinus vertrat, führte zur Idee eines Universalkaisertums. Das von Augustus verwirklichte Pax Romana wurde vom Pax Cristiana abgelöst, die sich beide in der Gestalt Karls des Großen mit einander verbanden. ${ }^{106}$ Die Idee vom Universalkaisertum, die den Frieden garantierte, lebte dann während des ganzen Mittelalters, begann aber jedoch seit dem 13.-14. Jahrhundent zu zerbrechen, als die sich ihrer Nationalität bewußt werdenden neuen Staaten begannen, den Gedanken von einem gemeinsamen Kaiserreich aufzugeben. In Deutschland blieb die Idee jedoch noch über Jahrhunderte lebenskräftig, und Gedanken, die den heiligen und vereinigenden Charakter des Kaisers betoniten, tauchten noch zu Ende des 18. Jahrhundert in großer Zahl in der Friedensdiskussion auf, wenn auch nicht immer in den sich für einen Frieden einsetzenden Schriften. Andererseits blieb der sich mit dem christlichen Glauben verbindende Gedanke von dem absolut grundsätzlichen Vorzug des Friedens vor dem Krieg ein ständiges Element in der Friedensdiskussion, wenn auch lange völlig verschwommen.107 Mit dem Ende des Mittelalters entstand neben der Idee von einer Universalmonarchie als ein

103 Russell, Bertrand, History of Western Philosophy, I, London 1947, S. 61, 76, 316; Grauert (1919) S. 116.

104 Rauhanajatus historiassa (Jaakko Suolahti) S. 9-25.

105 Russell I (1947) S. 388, 403, 495.

106 Grauert (1919) S. 131-132.

107 Ibid. S. 142-143; Rauhanajatus histoniassa (Veikko Litzen) S. 49-52. 
System zur Sicherung des Friedens vor allem die eines Völkerbundes sich zu verbreiten. Auch sie sollte von Anfang an der Idee vom Gottesfrieden dienen. Im 13. und 14. Jahrhundent versuchten die Päpste die Völker Europas - oder eigentlich Regierenden - dazu zu überreden, die gegenseitigen Streitigkeiten zu vergessen und sich gegen die Nichtchristen, wie z.B. die Mongolen, zu verbinden. Solche Gedan'ken von einem europäischen Völkerbund wurden in großer Zahl vorgetragen. ${ }^{108}$ Alle diese Pläne zur Friedenssicherung gingen von der Unterscheidung zwischen "gerechten» und »nicht-gerechten» Kriegen und von einer Bestrafung der Schuldigen aus. Schon im Mittelalter begann man jedoch stärker den Gedanken zu vertreten, daß man in keinem Fall einen Krieg als berechtigt ansehen könnte. Indem sich zu Beginn der Neuzeit die Lehre von einem gerechten Krieg zu einer immer starreren Doktrin zu wandeln begann, stieß sie auch auf schärfere Kritik. Thomas More, Jean Bodin und Erasmus von Rotterdam waren beinahe absolute Pazifisten. ${ }^{109}$ Sowohl Gelehrte des internationalen Rechts als auch Verfasser von Utopien entwarfen Programme, die einen beständigen Frieden durch eine Völkerbundorganisation garantieren sollten. Man wollte auf diese Weise zumindest die Entstehung ungerechtfertigter Kriege verhindern. Mit der Entwicklung der Nationalstaaten zu Beginn der Neuzeit gründete man immer mehr Friedensprogramme auf eine Machtbalance der Staaten. Im 17. Jahrhundert erschien eine ganze Reihe Programme dieser Art und pazifistisch gefärbte Programme. ${ }^{110}$

Besonders rege entwickelte sich die ideel-grundsätzliche Diskussion über Krieg und Frieden im 18. Jahrhundert. Die Menschen dieses Jahrhunderts der Aufklärung, der Vernunfit und des Nützlichkeitsdenkens erkannten deutlicher denn je die Schädlichkeit der Kriege und begannen als Optimisten, die an die Tugendhaftigkeit des Mensohen glaubten, das Problem zu lösen. Man veröffentlichte mehr als je zuvor Programme und Pläne. Von besonderer Bedeutung war das zu Beginn des Jahrhunderts (1713) ersohienene dreibändige Werk »Projet de traité pour rendre la paix perpétuelle entre les souverains chréthiens», das von einem französischen Geistlichen, dem Abt St. Pierre verfaßt worden war. Die Kriege Ludwig XIV. ließen überall in Europa und nicht zuletzit in Frankreich Stimmen laut werden, die die Schaffung eines Systems zur Sicherung des Friedens forderten. Von besonderer Bedeutung ist der Plan des

108 Hemleben (1945) S. 1; Ter Meulen, Jacob, Der Gedanke der internationalen Organisation $1300-1800$, o.O. 1917, S. 82-83, 85-87.

109 Ter Meulen (1917) S. 68, 72; Grauent (1919) S. 149-150.

110 Hemleben (1945) S. 49-50; Rauhanajatus historiassa (Pelkka Suvanuto) S. $91-103$. 
Abbé St. Pierre, ${ }^{111}$ dessen Vorbilder Pläne zur Schaffung einer internationalen Organisation waren, die man im 17. Jahrhundert vorgetragen hatte. Die 24 Staaten Europas sollten untereinander einen Staatenbund schließen. Der Bund sollte einen Senat haben, der für die Gesetzgebung, die Exekutive und das internationale Recht zuständig sei, außerdem sollte er auch für die Verteidigung Europas gegenüber einem gemeinsamen Feind (vor allem die Türken) sorgen. Die Mitglieder des Bundes würden sich gegenscitig dic Unverlctzlichkcit ihres Gebietes und ihre Souveränität garantieren.112 Überall erklärten bald die Staatsmänner, daß dieser Plan nicht zu verwirklichen sei, trotzdem folgten ihm weitere. Der zwanzig Jahre später erschienene Plan des Kardinal Alberoni schlug ebenfalls einen Bund gegen die Türken und eine Teilung des Osmannischen Reiches vor. ${ }^{113}$ Ihm folgten Saintard, von Loen, von Palthen u.a. mit weiteren Plänen. ${ }^{114}$ Jonathan Swift entwickelte kein eigentliches Friedensprogramm, sondern argumentierte im Sinne der antimilitaristischen Aufklärung, indem er die Ursachen der Kriege analysierte. ${ }^{115}$

Den Utbergang vom Pazifismus der ersten Hälfte des 18. Jahrhunderts des »'ancien régime» zum Messianismus der Revolution charakterisiert deutlich der Wandel, der in der Mitte von drei Jahrhunderten in der einflußreichen Aufklärungsphilosophie fesitzustellen ist. Monitesquieu, der sich im wesentlichen dem großen internationalen Rechtsgelehrten des 17. Jahrhunderts, Grotius, anschloß, hielt z.B. noch den Präventivkrieg für einen rechtlich zu akzeptierenden Grund, mit dem man einen Krieg beginnen konnte. Voltaire widersprach diesem Standpunkt in schärfster Weise, indem er eindeutig als Pazifist argumentierte. Diese Entwicklung wurde durch Rousseau zu einem konsequenten Ende geführt.116 Die bedeutendsten Werke in der Geschichte der Friedensideen sind vor allem »Projet de paix perpétuelle» (1761) und »Jugement sur la paix perpétuelle» (1762), die sich vielfach auf die Gedanken St. Pierre's gründen. ${ }^{117}$ Rousseau erörterte die Frage eines ewigen Friedens in seinen besten Schaffensjahren; seine Gedanken sind von ganz besonderer Bedeutung.

1.1 v. Raumer, Kurt, Ewiger Fricde, München 1953; S. 127-132; Dic Bedcutung des Plans betont auch z.B. Ter Meulen (1917) S. 90 und Rauhanajatus historiassa (Aira Kemiläinen) S. 121-125; Fritz, Kurt, Goethes Stellung zum Kriege, Diss. Marburg 1931, S. 3.

112 Hemleben (1945) S. 62; Grauert (1919) S. 153.

113 Ter Meulen (1917) S. 92.

114 Ibid. S. 90-92.

115 Rauhanajatus historiassa (Aira Kemiläinen) S. 106-109.

116 Ibid. S. 110-112; v. Raumer (1953) S. 127.

117 Hemleben (1945) S. 73-74. 
In Abweichung zu St. Pierre lehnte er ein Staatensystem ab, das auf einem Gleichgewicht zwischen den größeren Staaten besteht, und glaubte, daß die kleineren Staaten einen beständigen Frieden viel besser garantieren könnten. Schon Rousseau trug einen Gedanken vor, der in der Friedensdiskussion zur Zeit der Französischen Revolution einen so großen Raum einnehmen sollte: die Idee von einer Universalrepublik. In seinem Fortschrittsglauben war er davon überzeugt, daß sich die Regierungsform der Republik unausweichlich überall in der Welt durchsetzen werde. Obwohl er in begrenztem Maße eine Möglichkeit für einen ewigen Frieden auch ohne Revolution sah, so war er doch sehr skeptisch. ${ }^{118}$ Zur Zeit der Revolution und besonders der Revolutionskriege trat an die Stelle der Rousseauschen Skepsis allgemein die unbedingte Forderung, nach der zur Verwirklichung eines Friedens die Revolution notwendig sei. Auch in der Analyse der Kriegsursachen ging Rousseau weiter als die meisten seiner - Zeitgenossen, indem er die Ideologie von »Handel und Geld» für den schlimmsten Vergifter der Beziehungen unter den Völkern und der Herzen der einzelnen Menschen hielt.119 Der Einfluß Rousseaus erwieß sich dann auch in Deutschland als besondens groß.

Rousseaus bedeutendste Nachfolger vor Kant waren in England Jeremy Bentham und in Deutschland Anacharsis Cloots, die beide auf ihrem Gebiet seine Gedanken weiter entwickelten. Bentham's Utilitarismus gab auch der Friedensdiskussion in Deutschland bedeutende Anreize. Er widersprach dem Großmacht-Gedanken und dachte dabei auch an das Englische Imperium. Der ständige Friede solle durch internationale Gesetze und durch Abrüstung garantiert werden, mit der England, Frankreich, Holland und Spanien zu beginnen hättiten. Der Kampf um die Kolonien solle beendet werden. Von Bedeutung ist auch seine Anregung, nach der die Geheimdiplomatie abgeschafft und durch gemeinsame Kongresse der Staaten ersetzt werden solle, auf denen öffentlich zu verhandeln sei. ${ }^{120}$ Genau wie Rousseau setzte er die Beziehungen zwischen Menschen und zwischen Staaten prinzipiell gleich. ${ }^{121}$ Eine Art Höhepunkt der Entwicklung stellen die Veröffentlichungen von Anacharsis (eig. Johann Baptist) von Cloots, eines rheinischen Barons, dar. Zu einer Zeit, als schon die Revolutionskriege begonnen hatten, entwarft er den Plan von einer Universalrepublik, die von allen Völkern gebildet werden solle und in der Mittelpunkt natürlich Frankreioh und Paris stehen solle.

118 v. Raumer (1953) S. $132-140$.

119 Ibid. S. $142-150$.

120 Ter Meulen (1917) S. 95; Grauert (1919) S. 158-159; Rauhanajatus historiassa (Aira Kemiläinen) S. 125-126.

121 Ter Meulen (1917) S. 93-95. 
Er konkretisierte also eine von Rousseau vorgebrachte Idee. Diese eindeutig frankreichfreundliche Gesinnung erregte im Krieg führenden Deutschland starken Widerspruch, das auf keinem Fall bereit war, für den ewigen Frieden eine Weltrevolution hinzunehmen. Es gab aber auch Stimmen, die diesen Plan verteidigten, eine der bedeutendsten war die von Immanuel Kant. ${ }^{122}$

Indem die Forderung nach Pazifismus und ewigen Frieden lauter wurde, wurden auch entgegengesetzte Meinungen hörbar. So besonders in Deutschland, wo zwei verhältnismäßig bedeutende Gelehrte sich für den Krieg einsetzten und seine positiven Seiten aufzählten. Für sie war ein Krieg nicht nur unumgänglich, sondern er brachte als Ganzes gesehen auch Vorteile. In seinem Buch aus dem Jahre 1792 »Die allgemeine Christliche Republik in Europa» griff der Mecklenburger Professor Eobald Toze die Pläne an, die von Heinrich IV. von Frankreich und später von Abbé St. Pierre entworfen worden waren. ${ }^{123}$ Eine sohärfere und theoretischere Kritik kam von Valentin Embser im Jahre 1779. Seine Schrift »Die Abgötterey unseres philosophischen Jahrhunderts. Erster Abgott. Ewiger Friede» enthielt besonders scharfe Angriffe gegen die französischen Pazifisten und wies auf den positiven Einfluß der Kriege auf die Kondition der Völker hin. Embser nannte als Beispiel den politischen Verfall Schwedens seit Karl XII. und dankte später Gustav III. für sein »heroisches Element», das die Schwedische Nation positiv beeinflußt habe. ${ }^{124}$ Bemerkenswert ist auch die allgemeine Zunahme des Militarismus im 18. Jahrhundert. In vielen Ländern hielt man die militärische Laufbahn für beinahe die einzig ehrenvolle für einen Adligen; auf dem Schlachtfeld für König und Vaterland zu sterben, galt immer noch als allgemeines Ideal. Vaterlandsliebe war ein gewöhnlicher Bestandteil der Schriften der Kriegsbefürworter. ${ }^{125}$

In der theoretischen Diskuission über Krieg und Frieden blieben dieseart von »Kriegsgeist»-Schriften im 18. Jahrhundert eindeutig in der Minderzahl. Auch in der frühen politischen Tagesliteratur zur Zeit der Revolutionskriege berief man sich abgesehen vom Patriotismus sehr selten auf diese Art von Kriegsgeist. Die theoretische Friedensdiskussion wurde dadurch bestimmt, daß man im Geiste der Aufklärung von der Nützlichkeit des Friedens überzeugt war und seine Bedeutung für die Evolution betonte.

122 Grauert (1919) S. 159-160.

123 Lange, Chr. L. - Schou, August, Histoire de l'internationalisme II, Oslo 1954, S. $269-272$.

124 Ibid. S. $278-280$.

125 Rauhanajatus historiassa (Aira Kemiläinen) S. 131-132. 


\section{DAS FRIEDENSJAHR 1795: DER FRIEDE VON BASEL UND KANT'S "ZUM EWIGEN FRIEDEN»}

\section{Preußen schließt einen Sonderfrieden}

Das Jahr 1795 stellt besonders für Deutschland in der Geschichte der Revolutionskriege eine große Wende dar. In diesem Jahr brach das Kriegsmüde Preußen, das sich besonders wegen der dritten Polnischen Teilung mit seinen Bundesgenossen zerstritten hatte, aus der gemeinsamen Front gegen Frankreich aus und schloß mit dem ehemaligen Feind einen Sonderfrieden. Schon Ende 1794 zeigte sich die Unlust Preußens am Krieg daran, daß es häufig nur noch zu Scheinoperationen gekommen war und man sofort mit dem Jahresbeginn von 1795 geheime Verhandlungen mit Frankreich aufnahm. Am 5. April 1795 unterschrieben in Basel Preußen und Frankreich einen Friedensvertrag, in dem man niederlegte, daß die Feindseligkeiten sofort aufhören würden und Frankreich offiziell bis auf weiteres das besetzte Westufer des Rheins bekommen würde. Preußen hatte dabei einen verhältnismäßig kleinen Teil seiner Besitzungen aufgegeben, dessen endgültiges Schicksal in einem gemeinsamen Friedensvertrag zwischen Frankreich und dem ganzen Deutschen Reich entschieden werden sollte. Einen Monat später wurde die Neutralisierung von ganz Norddeutschland beschlossen. Man bestimmte eine Demarkationslinie, die von Nordfriesland über Münster, Duisburg, Darmstadt und Nördlingen bis an die Böhmische Grenze verlief. Die Gebiete nördlich und östlich dieser Linie wurden im andauernden Reichskrieg für neutral erklärt und als Garantie für ihre Neutralität besetzten preußische Truppen die vereinbarte Demarkationslinie. Im folgenden Jahr wurde sie in der Weise etwas nach Osten verlegt, daß sie sich in Ostwestrichtung an Ruhr und Fulda entlang zog, deren oberen Lauf sie überschritt. ${ }^{1}$

1 Wahl, Adalbert, Geschichte des europäischen Staatensystems 1789-1815, Darmstadt 1967 (1912), S. 63-67. Über die Demarkationslinie z.B. Putzger's Historischer Schulatlas, Bielefeld und Leipzig 1939, S. 88 und National-Zeitung der 
Für Frankreich war die Aufgabe der Koalition durch Preußen ein großer Sieg. Es konnte nun seine Kräfte auf das restliche Deutschland konzentrieren, dessen Kampfbereitschaft nach der Kapitulation der zweiten Großmacht wesentlich geschwächt war. Obgleich die außerhalb der Demarkationslinie gebliebenen Territorien gezwungen waren, den Krieg fortzusetzen, folgten viele Länder außerhalb Deutschlands dem preußischen Beispiel. Holland bot seinem Besieger einen Frieden an und schloß nach einer inneren Revolution - zu der Frankreich entscheidend beigetragen hatte - als Batavische Republik sogar ein Bündnis mit seinem Besieger. Spanien und ebenso viele italienische Staaten folgten diesem Beispiel. Nur noch England und Österreich nahmen von den Mitgliedern der ersten Koalition aktiv am Krieg teil. ${ }^{2}$ Sie waren auch nicht bereit aufzugeben, sondern erneuenten nur das Bündnis, das Rußland in einem Vertrag vom 28.9.1795 zu unterstützen versprach. ${ }^{3}$

Die Entwicklung innerhalb Franikreichs bestimmte entscheidend die französiche Außenpolitik und das Verhältnis zu anderen Staaten. So war der Friedensschluß von Basel in dieser Beziehung unter sehr günstigen Umständen entstanden: nach dem Sturz der Schreckensregierung von Robespierre im Juli wurde Frankreich von umsichtigen Republikanern regiert, den sog. Thermidorianern. Sie waren auf diplomatischem Gebiet sehr aktiv und versuchten überall zu einem Frieden unter möglichst günstigen Bedingungen $\mathrm{zu}$ gelangen. Die Thermidornegierung nahm die Beziehungen zu Schweden und Dänemark auf und begann mit Friedensverhandlungen nicht nur mit den genannten Ländern sondern auch mit Neapel und Sardinien, ja sogar unter strenger Geheimhaltung mit Österreich, wenn diese auch ergebnislos blieben. ${ }^{4}$ Innenpolitisch beendeten die Thermidorianer die Religionsverfolgungen, unter denen besonders die Priesterschaft zu leiden gehabt thatte. Durch die Wiedereinführung der Religionsfreiheit wurden auch die Beziehungen nach außen erleichtert. Die ganze Zeit hatte die Regierung mit großen wintschaftlichen Schwierigkeiten, mit Inflation, Lebensmittelmangel und der durch sie verursachten Unzufriedenheit, ja sogar mit Aufständen zu kämpfen. Der schwachen Thermidorregierung stand die ganze Zeit eine starke jakobinische Linksopposition gegenüber. Dies alles ließ die Regierung eine ausgeglichene Außenpolitik führen.5 Die größte innen-

Teutschen 1796 Nr. 48. v. Ranke, Leopold, Denkwürdigkeiten des Staatskanzlers Fürsten von Hardenberg, Leipzig 1877, S. 231-234.

2 Streisand (1961) S. 62-63.

3 Wahl (1967/1912) S. $72-73$.

4. Ibid. S. 71.

5 v. Sybel, Heinrich, Geschichte der Revolutionszeit 1789-1800 VII, Stuttgart 1899 , S. $240-255$. 
politische Aufgabe der Thermidorianer lag in der Fertigstellung einer neuen Regierungsform für Frankreich. Diese wurde im Oktober 1795 angenommen und es begann die Zeit des Direktoriums.

Das fünfköpfige Direktorium mit Barras, Carnot, Letourneur, La Revelliére-Lépeaux und Rewbell begann, das Staatsschiff der Republik durch die immer noch andauernden Stürme zu lotsen. Für die Kriegsangelegenheiten war zunächst Lazare Carnot zuständig, der »Vater des Sieges», wie man ihn auf Grund des errungenen Erfolgs von 1793-94 nannte. Das Direktorium mußte zwischen zwei außenpolitischen Linien wählen. Die Vorsichtigeren waren mit den sog. verfassungsmäßigen Grenzen zufrieden, nach denen zu Frankreich Nizza, Savoyen, Belgien und Luxemburg $\mathrm{zu}$ gehören hätten. Die gleiche Auffassung hatten die Thermidorianer vertreten. Die Mehrheit forderte jedoch als Preis für einen Frieden die sog. natürlichen Grenzen, nach denen die Alpen und der Rhein Frankreichs Ostgrenze zu sein hätte. Für diese entschied sich das Direktorium. Das historische Gallien hatte sich bis zum Rhein erstreckt. Unter den Bewohnern der Rheinländer herrschte unbestreitbar eine Stimmung zugunsten Frankreichs und der Revolution; das hatten die Ereignisse der vorangegangenen Jahre deutlich gezeigt. Viele Rheinländer wanden sich wiederholt mit der Bitte an Frankreich, ihr Heimatgebiet mit der großen Republik zu vereinigen. Preußen hatte in geheimen Zusatzbestimmungen zum Basler Frieden seinerseits den natürlichen Grenzen schon zugestimmt. Das große und unerfüllt gebliebene Ziel Ludwig XIV. schien jetzt unerwartet leicht erreichbar zu sein. Diese Politik bedeutete jedoch die Fortsetzung des Krieges. ${ }^{6}$

In einem Kriegszug in Richitung Süddeutschland hatte Frankreich schon im Jahre 1795 versucht, den österreichischen Widerstand zu brechen, aber der Angriff unter der Führung der Generäle Pichegru und Jourdan endete mit einem Mißerfolg. Österreich konnte seine Stellung am Rhein festigen und war keineswegs bereit, den Friedensbedingungen des Direktoriums zuzustimmen, die die Aufgabe der Niederlande und anderer wichtiger westrheinischer Gebiete bedeutet hätten. Der Kaiser war auch das Oberhaupt des Deutschen Reiches und glaubte deshalb nicht, den oben genannten großen Verlusten zustimmen zu können, die offensichtlich eine einschneidende Neuorganisation im Inneren des Reiches erfordert hätten. Die ablehnende Haltung des Kaisers wurde von vielen sog. "Reichsdeutschen» unterstützt, die an der Verfassung des Reiches festhielten. Die katholische Kirche versprach unter der Führung

6 Gaxotte, Pierre, Geschichte Deutschlands und der Deutschen II, Freiburg im Br. $(1969$,$) S. 58-61.$ 
des Papstes Österreich und die den Widerstand fortsetzenden Fürsten zu unterstützen. Den Widerstand unterstützte auch die Gruppe der hunderttausenden von aus Frankreich geflohenen Emigranten, deren großer Teil Berufssoldaten war und so einen bedeutenden militärischen Kraftzuwachs für die Gegner der Republik darstellte. Österreich hatte zwar bis 1795 eine Reihe von Niederlagen hinnehmen müssen, aber es war noch in der Lage, die enormen Verluste an Menschen und Material zu ersetzen. Die wirtschaftliche Unterstülizung Österreichs durch England war bedeutend. Österreich plante in Süddeutschland einen "Landsturm", die Bewaffnung des Volkes und andere militärische Maßnahmen. Es erhielt dabei Unterstützung von einigen Fürsten und Reichsständen. Andrerseits war man des Krieges überdrüssig und wollte dem preußischen Beispiel folgen; so wollite z.B. Baden einen Sonderfrieden schließen und nur der Anmarsch der österreichischen Truppen führte zur Fortsetzung des Krieges gegen Frankreich durch Baden. ${ }^{7}$

Die lebhafte öffentliche Diskussion, die in Deutschland in der tagespolitischen Literatur im Jahre 1795 geführt wurde, verbindet sich mit den oben geschilderten Ereignissen. Die sich für einen Krieg einsetzende und die einen Krieg ablehnende Literatur suchte Unterstützung und Argumente einmal in der innenpolitischen Entwicklung Frankreichs, zum anderen in den wechselnden militärischen Machtverhältnissen in Deutschland und an den anderen Fronten. Außerdem wiederholte man in den gleichen Schriften die Grundideen, die in den vorangegangenen Jahrzehnten vorgetragen worden waren, und entwickelte sie weiter.

\section{Die dankbaren Preußen}

Es ist natürlich, daß die öffentliche Meinung in Preußen den Baseler Frieden verteidigte. Allgemeine Kriegsmüdigkeit und traditionelle Treue zu König und Regierung - teilweise unter dem Zwang der Umstände, genauer gesagt der Zensur - bewirkten eine ziemlich einheitliche Literatur für den Frieden. Überall äußerte sich Dankbarkeit gegenüber Friedrich Wilhelm II. Die bedeutendsten Dichter und Schriftsteller des Landes priesen den Frieden: Hans von Held, Rudolf Agricola, O. F. Köhler und K. Müchler sind seinerzeit bekannte, heute in Vergessenheit geratene Lobpreiser des Baseler Friedens. Der Pädagoge Friedrich Gedike hielt anlässlich des Friedens begeisterte Vorlesungen, der Königsberger Philosophieprofessor Kant jubelte ebenfalls über den Frieden. In

7 Holborn, Hajo, Deutsche Geschichte in der Neuzeit II, München-Wien 1970: S. 58-61; Wendland (1901) S. 216-219; Heinl (1941) S. 32-33. 
geschlossener Front verteidigte die Presse die Friedenspolitik der Regierung. ${ }^{8}$ Gleichwohl zeihneten sich in der öffentlichen Meinung Preußens von Anfang an zwei grundsätzlich recht verschiedene Gruppen ab. Es gab in Preußen von jeher eine Menge Leute, die Frankreich bewunderten, seine neuen Ideen zunächst der Aufklärung, aber auch der Revolution. Sie verfochten um der gemeinsamen Sache willen den Friedienszustand, der nun zwischen ihrer Regierung und der Bewunderung Frankreichs herrschte. Andererseits gab es in Preußen eine stark konservative und monarchistisch eingestellte Presse. Diese billigte zwar den Frieden, den der gelobte König geschlossen hatte, konnte sich freilich aber nicht enthalten, Frankreich und sein neues System anzugreifen. Diese Unterschiede wurden mit der Zeit immer deutlicher.

Als hervorrangende Gestalt der franzosenfreundlichen Presse in Preußen kann der Komponist, Musikkritiker und Journalist Johann Friedrich Reichardit angesehen werden. Er hatte wie viele andere preußische Intellektuelle zu Beginn der Revolution Sympathie für die republikanischen Ideen gezeigt und war zeitweise sogar so feindselig gegen den König aufgetreten, daß er 1794 seine Stelle als Hofkapellmeister verlor und keine Pension erhielt. Danach zog er sich auf sein Landgut in der Nähe von Halle zurück und widmete sich reger und vielseitiger publizistischer Tätigkeit, wozu auch Politik wie Kompositionen gehörten. Reichardts politische Schriften konzentrierten sich im zwei Zeitschriften, »Deutschland» und »Frankreich».9 Die zuerst genannte war politisch interessanter und bedeutungsvoller; sie erschien 1792-96 in Berlin. »Frankreich» veröffentlichte hauptsächlich Artikel von französischen und deutschen Journalisten aus Paris und wurde 1795-1802 in Altona gedruckt — also außerhalb der Preußischen Grenzen und von der Zensur nicht erreicht.

Den politisch interessantesten Teil des Jahrgangs 1795 bilden Reichhardts Aufsätze, in denen er die Möglichkeiten eines Friedens in Europa abhandelt. In der Mainummer - unmittelbar nach dem Baseler Frieden - bespricht er die Ereignisse vom Jahresanfang in recht positivem Sinne. Frankreich habe in seinen Friedensbestrebungen grosse Fortschritte gemacht: Toskana und Venedig hätten bereits Frieden geschlossen, Schweden habe die Republik anerkannt und was am wichtigsten sei: Preußen und Frankreich hätten gerade den Baseler Friedensvertrag unterschrieben. Dies wurde äusserst positiv beurteilt:

8 Tschirch I (1933) S. 101-102; Hausherr, Hans, Hardenberg I, Köln 1963, S. 156 .

9 Allgemeine Deutsche Biographie (ADB) Bd. 27 (Schletterer) S. 629-644. 
»Der Friedensschluß mit Preußen war ehrenvoll für beyde Theile, indem er der französischen Nation die freye Disposition aller gemachten Eroberungen liess, und dem Norden von Deutschland wie allen deutschen Staaten die sich an der König als ihren Beschützer anschliefen wollten, den Frieden zusicherte».

Nach Reichardt war Frankreich bereit, einen allgemeinen Frieden zu schließen, der sichere Grenzen garantiert hätte. Als geeignete Grenze betrachitete Reichardt den Khein. ${ }^{10}$ Gegen Ende des Jahres veröffentlichte Reichardt eine neue Übersicht. Seiner Meinung nach hätten sich die Möglichkeiten für einen Frieden weiter verbessert. Venedig sei inzwischen neutral, mit Preußen hätte man sich über eine Neutralitätslinie geeinigt, mit Hessen sei Frieden und mit Holland ein Bündnis geschlossen. Frankreich wolle Verhandlungen auch mit Österreich, käme damit aber leider nicht voran. Die Angliederung Belgiens an Frankreich, nach dem Grundgesetz vollzogen, hätte den Widerstand Österreichs verstärkt. Das Bündnis zwischen Frankreich und Holland hätte in England einen zweiten Widersacher, vermehre auch die Kriegsbestrebungen, was sich in Aufständen und in der Uniterstützung von Emigranten zeige. Die Stellung Frankreichs sei trotzdem sehr gut. England habe schwere wirtschaftliche Verluste durch die Schwächung seines Handels erlitten. Die französischen Truppen hätten die Österreicher über Lahn und Main zurückgedrängt und Düsseldorf und Mannheim eingenommen. Es sei zu bedauern, daß die Österreicher gegen Ende des Jahres einige Erfolge hätten verbuchen können, da das zur Verdichtung ihres Widerstandes und $\mathrm{zu}$ einem verstärkten Kriegswillen bei einigen deutschen Fürsten geführt habe. Dies verzögere leider den allgemeinen Reichsfrieden. ${ }^{11}$

Reichardt hatte eine ganze Reihe Helfer, die ebenfalls den Frieden $\mathrm{zu}$ Basel befürworteten. Solche politische Literaten, die übrigens auch anderswo fleissig schrieben, waren u.a. Georg Kerner und Georg Friedrich Rebmann (s.u.) sowie K. F. Cramer, dessen Briefe aus Paris, unter der Chiffre »Nordländer» veröffentlicht, häufig zur Friedensfrage Stellung bezogen. ${ }^{12}$ Reichardt benutzte auch französische Texte, die die preußische Politik stützten und England, Österreich, Russland, die Emigranten, Pfaffen und Mönche wie überhaupt alles »Reaktionäre» angriffen, in denen aber auch das scharf Revolutionäre und der Terror der Robespierrschen Zeit deutlich verurteilt wurden.13 Hierzu gehört auch

10 Frankreich im Jahr 1795 II S. 3-9.

11 Ibid. IV S. $374-377$.

12 Ibid. III S. 73-76; Tschirch I (1933) S. 184.

13 Frankreich im Jahr 1795 II S. 88-90; III S. 32, 92-94, 263-336 usw. 
General Miranda, der Frieden wünschte und gegen Eroberung war und dessen maßvolles Grenzprogramm (anstelle des Rheins sollte sich Frankreich mit einer befestigtigten Grenzzone zufrieden geben) nach dem Baseler Frieden in Deutschland zu zahlreichen hoffnungsvollen Diskussionen Anlaß gab.14 Charles Theremin von der preußischen Botschaft in London bezeichnet in seiner Preisung des Baseler Friedens den ewigen Frieden als natürlichen Zustand unter den Völkern; als schlimmster Gegner des Friedens wird England genannt, das nur durch eine erfolgreiche Invasion gebeugt werden könnte. Gerade wegen des Geldes der Briten schicke Österreich seine Soldaten weiterhin auf die Schlachtbank, obwohl der Sieg Frankreichs sicher sei.15

Unpolitischer, aber deutlich auf der gleichen Linie im positiven Verhalten zu Frankreich, waren die in Erlangen herausgegebenen »Englischen Blätter» des preußischen Botschaftssekretärs Ludwig Schubart. Die Zeitschrift vermittelte vor allem Informationen aus England, und als Grundgedanken traten dabei Lob der friedenswilligen Opposition und Tadel der Regierung Pitts hervor. In grosser Zahl wurden Parlamentsreden der Oppositionellen für den Frieden veröffentlicht, und die Redaktion der Zeitschrift stellte sich in vielen Kommentaren auf deren Seite. Die französische Revolution und besonders die Terrorepoche wurden zwischendurch streng verurteilt, aber in der Friedensfrage blieb man konsequent. Die Besonnenheit der französischen Regierung nach der Zeit Robespierres hatte die Friedensmöglichkeiten verbessert. Im Frühjahr 17.95 beurteilte man positiv, daß sich Preußen aus dem Krieg zurückgezogen hatte und glaubte, Preußen könne auch als Vermittler für einen allgemeinen Frieden auftreten. Schubart betonte den allgemeinen Friedenswillen, die grosse Kriegsmüdigkeit und die militärische Übermacht Frankreichs. ${ }^{16}$

$\mathrm{Zu}$ den Franzosenfreundlichen in Preussen kann man, wenn auch mit einigen Einschränkungen, auch Karl Ludwig Woltmann rechnen, wohnhaft bis 1797 in Jena und danach in Berlin. Er studierte in Göttingen Geschichte und Jurisprudenz und wurde als 25-jähriger Geschichitsprofessor an der Universität Jena. Der zukünftige Historiker beschäftigte sich in vielen Zeitschriftenartikeln mit politischen Fragen, u.a. in "Minerva», "Neuer Teutscher Merkur» und in Schillers "Horen». $\mathrm{Zu}$ den bedeutendsten Kommentaren über den Baseler Frieden gehört seine 1795 in den »Horen» veröffentlichite Untersuchung »Beitrag zu

14 Ibid. II S. $144-148$.

15 Ibid. III S. 156-163.

16 Englische Blätter (Engl.Bl.) 1795 I S. 45-49, 219, 270-277. 
einer Geschichte des französischen National-Charakters». Er versuchte darin $\mathrm{zu}$ beweisen, daß die Revolution eine Folge des französischen Nationalcharakters gewesen sei. Obwohl er die Revolution selbst verurteilte, befürwortete er bei der Behandlung des französisch-deutschen Verhältnisses doch den Frieden und die Verbesserung der Beziehungen. $\mathrm{Zu}$ realisieren wäre dies seiner Meinung nach so, daß durch »ästhetische Erziehung» die Französen auf das gleiche Niveau eines Weltbürgertums gebracht würden, auf dem die Deutschen schon standen. Auf diese Weise könnte seiner Meinung nach sogar »eine neue fränkische Universalmonarchie aus beiden Staaten errichtet werden».17

Die Haltung der zahlreichen monarchistischen preußischen Blätter zur Friedensfrage war selbstverständlich positiv. Die monarchistischen Zeitschriften standen natürlich unter derselben Aufsicht durch die Regierung wie andere Veröffentlichungen auch, was eine freie Meinungsbildung verhinderte. $\mathrm{Da}$ aber in der Redaktion solcher Zeitschriften häufig verdiente Staatsbeamte verantwortlioh tätig waren, von denen man wohl annehmen kann, daß sie die Bestrebungen der Regierung spontan unterstützten, besteht Grund genug, auch sie bei der Analyse der öffentlichen Diskussion zu berücksichtigen.

Ein typisches Beispiel für eine von treuen Untertanen redigierte preußische Provinzzeitschrift war das Königsberger »Preußische Archiv», für dessen Herausgabe die Königsherger Königliche Deutsche Gesellschaft verantwortlich zeichnete. Die Veröffentlichung war Seiner Majestät dem König von Preußen zugeeignet. Die Bemühungen der Zeitschrift in der Friedensdiskusion bestanden in treuer Bewunderung für die Friedenspolitik der preußischen Regierung und in der Versicherung, wie segensreich dieser Frieden sei. Dagegen wurden die Prinzipien der französischen Revolution überhaupt nicht akzeptiert und teilweise wurde auch die Aufklärung kritisiert, wenigstens ihre radikalsten Erscheinungen. Der Frieden mit der Republik war für die Königsberger eine realpolitische Lösung.

Der Baseler Friedensschluß veranlasste eine Reihe örtlicher Gelehrter und Beamte, zur Feder zu greifen und die Entscheidung ihres Königs in Dichtung und Prosa aufs höohste zu loben. Zu diesen aktiven Schreibern gehörten der Kirchen- und Schulrat G. E. S. Hennig und dessen jüngerer Verwandter, der Kandidat A. E. Hennig. Ihre Werke ähnelten sich stark - den Frieden preisende Gedichte, in denen niemals vergessen wurde, dem König Dank zu sagen, dem Spender alles Guten. Das Gedicht

17 Horen 1795 II S. 26-49 (Zitat S. 49). Über die Reaktion der Schrift z.B. Schulz, Günter, Schillers Horen, Heidelberg 1960, S. 103 und 106-107. 
»Wunsch nach Frieden» des älteren Hennig, abgedruckt in der ersten Nummer des Jahrgangs 1795, spiegelt schon deutlich die Bestrebungen der preußischen Regierung, zu einem Frieden zu kommen. Es stellt die Schrecken des Krieges dar und erhofft von Gott den Segen des Friedens:

»Millionen edler Krieger / sanken kämpfend in den Staub / feste Städte, Heiligthümer / wurden stolzer Feinde Raub. - Singt nicht mehr von edlen Reben / uns das Lied: am Rhein, am Rhein - / ach - des Krieges Ungeheuer, / keltert Menschenblut statt Wein.»18

Der Friedenswunsch aus religiösen Gründen blieb auch später typisch für die Schriften des Kirchenrats. Revolutionäre Ideen waren den Hennigs völlig fremd. Der Kirchen- und Schulrat tadelt in dem Gedicht »An die Freiheit der Neufranken» die Gewalttätigkeit der Franzosen schwer und meint, die Deutschen verstünden unter Freiheit etwas ganz anderes: ein kluger Fürst erhalte teutsche Freiheit. ${ }^{19}$ Die Franzosen sollten auch in den Schoß der christlichen Glaubens zurückkehren und Frieden schließen:

»Ruf in die entweihte Halle / bald zurück nach Religion; / stürze nieder Freiheitsbaum; / lodre nicht mehr Kriegesflamme !!! » 20

Der Sekretär der Königlichen Deutschen Gesellschaft, Johann Daniel Funk, schrieb zahlreiche Gedichte, die in gleichem Geist den Friedensschluss preisen. Im dem Gedicht, »Genius der Zeit» rühmt er Preußen als Insel des Friedens inmitten einer durch Krieg und Verluste bedrückten Welt. Natürlich dankt er dafür dem väterlichen König:

»aber auch den Trokner jener Zähren / einen V ate $\mathrm{r}$ auf dem Fürstenthron - - statt durch Blut den Lorbeer zu erkämpfen, / lieber sich des Friedens Palme brach».21

August Samuel Gerber, Oberlehrer und Bibliothekar, behandelte die Friedensfrage in zwei Artikeln in der gleichen Weise. Auch er billigte den Friedensschluß und lobt den König deswegen, gleichzeitig aber verurteilt er scharf die Verhältnisse in Frankreioh. Er hebt hervor, daß der Krieg von seiten der Fürsten aus völlig berechtigt gewesen sei. Eine

\footnotetext{
18 Preußische Archiv (Pr.Archiv) 1795 Januar S. 1.

19 Ibid. März S. 125-128.

20 Ibid. 1796 Jan. S. $1-4$.

21 Ibid. 1795 Oct. S. 583-584.
} 
Festigung des Friedens setze nach Gerber auch zunächst eine Rückkehr Frankreichs zum früheren System voraus:

"Sollte eine grosse Nation, wie es die Französische ist, wieder zur Moralität zurückgebracht, und ihre die sanften Gefühle der Menschheit, die sie zur verlornen Begrif war, wieder eingeflösst werden, so müsste ein Friede mit ihr zu Stande kommen.»22

Zwischen der franzosenfreundlichen und ider monarchistischen Presse Preußens war die politisch recht vorsichtige "Berlinische Monatschrift» angesiedelt, die gemeinsam von dem Bibliothekar Johann Erich Biester und dem Pädagogen Friedrich Gedike herausgegeben wurde. ${ }^{23}$ Der Baseler Frieden wurde in der Zeitschrift selbstverständlich positiv aufgenommen. Biester dankte dem König und patriotischen Staatsmännern für den Frieden. Sie hätten durch ihr Handeln und durch die Beendigung des verlustreichen Krieges dem Vaterland Glück und Wohlstand beschert. Ausser den für die Aufklärung typischen Begründungen enthält der Artikel Biestens auch religiöse Elemente, wenn auch mehr oder weniger phrasenhaft.24 Den Frieden rechtfertigende Artikel wurden 1795 in der »Berlinischen Monatschrift» wiederholt veröffentlicht. L. Bendavid rügt Österreich und charakterisiert dessen Willen, den Krieg im Vertrauen auf Gott und die gerechite Sache des Vaterlands fortzusetzen, mit dem alten Ausspruch »O sancta simplicitas».25 In der ersten Nummer des Jahrgangs 1795 wurde eine Rede veröffentlicht, gehaliten anlässlich der Krönung Karls, Herzog von Mecklenburg-Strelitz, die auf das Typischste die friedenswilligen monarchistischen Anschauungen vertritt. Die Rede hebt Vaterlandsliebe und Eintracht zwischen Fürsten und Völikern hervor, prangert den in Europa wütenden Krieg an und vermerkt mit Dankbarkeit, daß »unser geliebtes Vaterland bisher mit ungestörter Ordnung, mit innerer Ruhe und Frieden gesegnet» ist. ${ }^{26}$

In der gleichen Nummer erhofft ein im Januar 1795 in Elbing geschriebenes »Neujahrslied, das neue Jahr möge ein Jahr der Beendigung des Krieges, der Menschlichkeit und des Friedens sein».27 Der F'rieden wurde also einhellig positiv aufgenommen. Die Revolution hingegen wurde von der »Berlinischen Monatschrift» abgelehnt. Das Gedicht des

22 Ibid. Dec. S. 739-747 (Zitat S. 745). Dergleiche Schrift von Gerber auch 1796 Febr. S. 65-85.

23 Tschirch I (1933) S. 101-102.

24 Berliner Monatschrift (Berl. Mon.) 1795 I: 5 S. 380-384, 461-470.

25 Ibid. I: 6 S. $521-522$.

26 Ibid. I: 1 S. 5-9.

27 Ibid. S. $10-12$. 
Magdeburgers von Köpke »Die wilden Thiere» griff alles Revolutionäre scharf an während gleichzeitig der Baseler Frieden gewürdigt wurde und betont die Achtung friedlicher Vernunft und der Gesetze. ${ }^{28}$ Die französische Glaubenspolitik wurde ebenfalls verurteilt und die Verfolgung der Pfaffen verglichen mit der Christenverfolgung durch Trajanus und Decius. ${ }^{29}$ Obwohl die »Berlinische Monatschrift» den auf katholische Priester ausgeübten Druck in Frankreich nicht billigte, war sie im allgemeinen doch gegen die katholische Kirche eingestellt. Im Kampf gegen den Aberglauben nahm die Zeitschrift sehr oft aufklärerisch die »düstersten» Beispiele aus katholischen Ländern, insbesondere von Mönchen, speziell Jesuiten. ${ }^{30}$ Deutlich war auch die negative Haltung gegenüber Österreich.

Die Einhelligkeit der preußischen Presse wird weiter durch eine Reihe von Flugschriften gestützt die um die Zeit des Baseler Friedens zahlreich erschienen. Der größte Teil dieser Flugschriften war auf Veranlassung der preußischen Regierung geschrieben, mit der Ausweitung der Diskussion kamen jedoch auch Privatpersonen hinzu, die sich für die Friedenspolitik des Landes einsetzten.

Die preußische Regierung veröffentlichte am 1. Mai 1795 im Namen König Friedrich Wilhelm II. eine offizielle an die Reichsstände gerichtete Erklärung über den Baseler Frieden, die Faktoren, die dazu geführt hatten und über die Folgen des Friedensschlußes. Diese Erklärung reinigte Preußen von allen Anschuldigungen, die gegen den Staat gerichtet worden waren. Danach hatte der Krieg Preußen und ganz Deutschland großes Leid gebracht, das jetzt abgewendet sei. Preußen habe keinerlei Privatinteressen am Krieg, sondern hätte nur aus vaterländischer Pflicht daran teilgenommen, um den Staat zu schützen. Trotzdem sei der Krieg für Preußen sehr teuer geworden da er weit vom eigenen Land entfernt geführt wirde. Die Rückeroberung von Mainz z.B. hatte Preußen 2083961 Taler, 11 Groschen und 2 Pfennig gekostet. Als schließlich auch noch Holland zusammenbrach, habe keine Hoffnung mehr auf den Sieg bestanden gewesen. Die einzige Möglichkeit für Preußen sei, den Kampf abzubrechen. Der Friedensschluß durch Preußen sei außerdem ein Dienst an ganz Deutschland das schon vor der Entscheidung Preußens deutlich ausgedrückt habte, daß es Frieden wünsche. Preußen habe in all seinem Wirken nur das Beste für das Reich gewollt, und daran solle sich auch nichits ändern. ${ }^{31}$

28 Ibid. I: 4 S. $341-342$.

29 Ibid. S. $478-516$.

30 Ibid. I: 1 S. $61-96$; I: 2 S. 153, II: 2 S. 243 und Anm. S. 258-260 usw.

31 Erklärung Sr. Königl. Majestät von Preußen ... 1795 S. 21-23, 31. 
Diese offizielle Erklärung - in Form einer Flugschrift weit unter dem Volk verbreitet - bekam als Gegenstück bald eine Reihe von Antischriften von Österreich und anderen an einer Fortsetzung des Krieges interessierten Deutschen. Da die Preußen ihrenseits deren Argumentationen widersprachen und so die Diskussion belebten entstand ein regelrechter »Federkrieg», der im Sommer und Herbst 1795 am regsten war, darüber hinaus aber auch noch im folgenden Jahr anhielt. Der größe Teil dieser Flugschriften stammte von anonymen Verfassern, so daß es, besonders was die preußischen Elemente anbelangt, recht schwierig ist, sie exakt von den anderen $\mathrm{zu}$ scheiden. ${ }^{32}$

Einer der bedeutendsten privaten Verfasser von Flugschriften war der Arzt und Botschaftssekretär Christoph Kaufmann. Vor seinem Tode Ende 1795 veröffentlichte er wenigstens zwei Flugschriften gegen den in österreichischen Diensten stehenden Johannes von Müller. Als typisches Beispiel für eine Preußen rechtfertigende Flugschnift sei hier sein 77-seitiger Artikel »Fragmente» genannt. Der Baseler Frieden wurde deshalb bcfürwortet, weil er zum Glück und Wohlstand von Millinnen von Menschen geschlossen worden sei. Kaufmann erklärt, auch die Kritiker $\mathrm{zu}$ verstehen, die immer auftauchten, da der Stein des Weisen moch nicht gefunden sei. Der Angriff Österreichs auf den Friedensschluß sei aber auf alle Fälle ungerecht. Die Österreicher — insbesondere von Müller behaupteten, der preussische König habe in habsüchtiger und egoistischer Absicht gehandelt, was eine völlig unsinnige Behauptung sei: der edle Geist des preußischen Monarchen hätte einzig im Gedanken an das Beste für Deutschland gewirkt. Schon im Kriege hätte Preußen am mannhaftesten gekämpft, während Österreich häufig heimtückisch vorgegangen sei und seine Truppen Niederlagen erlitten hätten, die die Preußen dann wieder wettmachen müssten. Die Kriegskosten Österreichs seien im Verhältnis zu denen Preußens geringer, und aus bloßer Vaterlandsliebe hätte Preußen englische Subsidien abgelehnt (!). Aber »alle, auch die edelsten Eigenschaften haben ihre Grenzen». Der Zerfall Preußens wäre ein schweres Unglück für Deutschland gewesen, da es das Gegengewicht zu dem knechtenden Österreich im Reiche halte. Hinzu komme, daß Österreich mit Frankreich gegen Friedrich II. verbündet sei und damals versucht habe, das deutsche Grundgesetz zu ändern. Auch dies lasse den jetzt geschlossenen Sonderfrieden berechtigt erscheinen. Frieden sei also gesohlossen. Er sei auch deshalb unumgänglich, weil Frankreich militä-

32 Tschirch I (1933) S. 82-107. Preußisch waren sicher Flugschriften PreuBens Friede mit Frankreich, 1795; Beantwortung der Frage ... im Jenner 1796; Rescript des Herrn Herzogs ... Nov. 1795 und die unten folgenden Schriften von Kaufmann. 
risch ziemlich stark sei. Es wäre nicht möglich gewesen, Franksreich zu zerschlagen, obwohl sich das noch immer »so viele Schwachköpfe» einbildeten. In allen Reichsständen des Staates sei der Frieden allgemein erwünscht, obgleich nicht alle das offen auszudrücken wagten, da sie in einem nahen Bindungsverhältnis zu Österreich stünden. Das Friedensbekenntnis Preußens habe die Unterstützung aller gefunden, im Reich sei man keineswegs befriedigt darüber, daß der Kaiser noch nicht einmal daran gedacht habte, ebenso zu handeln. Der Kaiser habe ganz im Gegenteil gegen den Frieden gearbeitet, was aus dem Gesichtspunkt ganz Deutschlands von großem Nachteil sei, da dadurch die Stände und der Kaiser in verschiedene Parteien zersplittert wurden. Das ganze Kaisertum sei nun in Gefahr zu zerbrechen, und Österreioh hätte wirklich allen Grund seine Situation neu zu überdenken.

»Kurfürsten, Fürsten und Stände, vereiniget euch mit teutschem Muth und mit teutscher Beharrlichkeit! Arbeitet dem reißenden Strome entgegen, der von Oesterreichs Hauptstadt her euch zu verschlingen droht! Vereiniget euch, macht dem verderblichen Kriege ein Ende!»

Die Schriften Müllers seien durchweg verfälschend und schlecht geschrieben. Es bestünde keinerlei Anlaß, die Teilung Polens mit dem Baseler Frieden in Verbindung zu bringen. Davon abgesehen sei nicht Preußen an der Teilung Polens schuld, sondern Österreich und Rußland. Gerade, um den Krieg zwisohen diesen beiden zu verhindern, hätte Friedrich II. den Vorschlag zur ersten Teilung Polens vorgebracht. Preußen werde den Kampf für den Frieden fortführen und »kan Germaniens Freiheit nie sinken Jassen».33 Bald danach gab Kaufmann ein zweites, ähnliches Werk unter dem Titel $»$ Fernere Beiträge» heraus. ${ }^{34}$

Als eine Zwischenform zwischen Flugschrift und Zeitschrift kann die 7-teilige Serie »Magazin der neuesten und merkwürdigsten Kriegsbegebenheiten» betrachtet werden, die 1794-96 in Frankfurt erschien. Herausgegeben wurde sie von dem Kapitän der Preußischen Armee und Adjutant Generals von Möllendorff, August Wilhelm von Leipziger, der offensichtlich den größten Teil der anonymen Artikel dieser Serie selbst schrieb.

Die im Laufe des Jahres 1795 erschienenen Teile II-V enthalten eine Reihe von interessanten Krieg und Frieden behandelnden Artikeln. Der Verfasser des Artikels »Was hat Deutschland zu thun und wie ist es zu

33 Fragmente. In Beziehung ... 1795. Zitaten S. 34, 60-61 und 77; Tschirch I (1933) S. 91.; Milch, Werner, Christoph Kaufmann, Leipzig 1932.

34 Fernere Beiträge ... 1795. Vgl. Kapitel II: 4. 
retten?» — offensichtlich Leipziger - weist mit Nachdruck auf seine deutschnationale Gesinnung hin und verurteilt scharf die anmaßende Eroberungspolitik Frankreichs. Der Verfasser stellt fest, daß Preußen offensichtlich einen Sonderfrieden anstrebe. Seiner Meinung nach habe sich dadurch die Lage für das ganze Reich bedrohlich verändert. Dessen ungeachtet heißt er die preußische Politik gut. Es lohne sich nicht zur Verteidigung der Provinz Westfalen zu kämpfen. Der Kampf würde wahrscheinlich zu einer Niederlage Preulßens oder höchstens zu einem Sieg führen, der nach einem Rückzug der Franzosen Preußen nur rauchende Trümmer nach der Rückkehr hinter dem Rhein bringen würde. Der Artikel versteht, daß Preußen nicht bereit, auf eigene Kosten fortgesetzt Krieg für die Sache des Reiches zu führen. Hervorgehoben werden die Verluste an Geld und Soldaten, die Preußen erlitten hatte. Das Schlimmste für Deutschland sei eine Fortsetzung des Krieges. ${ }^{35}$ Dieser Gedanke wurde in der Zeitschrift öfters wiederholt. Im Artikel »Maasstab zur Beurtheilung des jetzigen Krieges» wird die zahlenmäßige Überlegenheit der Franzosen gegenüber den Verbündeten vorgerechnet. Die Franzosen hätten sowohl die bessere Taktik als auch die republikanische Begeisterung seiner Truppen auf seiner Seite, außerdem würden sie über eine bedeutend größere Truppenstärke verfügen. ${ }^{36}$ Preußen habe richtig entschieden, als es sich aus dem Krieg zurückzog, weil eine Niederlage auf jeden Fall nicht zu verhindern gewesen sei. ${ }^{37}$ In einem Artikel, der die Kriegsereignisse seit dem Baseler Frieden bis zum Ende des Jahres 1795 schildert, setzt man sich sehr für einen Frieden ein. Man stellt fest, daß die Friedenssehnsucht größer denn je sei. Schon zu Beginn der Baseler Verhandlungen und nach dem Toskana eine Sonderfrieden geschlossen habe, sei bei jedem menschenfreundlichen Weltbürger der Wunsch nach einem allgemeinen Frieden wach geworden. Dieser kleine Staat habe die Koalition durchbrochen und gezeigt, daß man auch mit der Republik verhandeln könne. Überall zeige sich der Wunsch, diesem Beispiel zu folgen, und dieser Wunsch habe nur PreuBen bestärkt, seine Entscheidung zu treffen:

»Eine größere Bahn war nun durch eine der wichtigsten Mächte, der ganzen Koalition vorgezeichnet; eine größere Macht hatte sich von dem Interesse derselben losgerissen, und die Welt erwartete mit Recht von einem so wichtigen Schritte zum allgemeinen Frieden, dessen lang gewünschte Annäherung».

35 Magazin der neuesten und ... V 1795 S. 314-323.

36 Ibid. II 1795 S. 3-17.

37 Ibid. V 1795 S. $92-133$. 
Nach Meinung des Verfassers würde die Stimme für einen Frieden immer stärker im ganzen Reich und würde immer einstimmiger. Preußens Demarkationslinie sei eine gute Sache, weil sie den größten Teil des Deutschen Reiches vor weiteren Kriegsschäden schütze. Úberall werde ein Friedensschluß mit Frankreioh gefordert. Aber was sei darauf gefolgt? Den allgemeinen Frieden hätte man gerade in Deutschland begraben, wo ein Frieden wünschenswerter gewesen sei als nirgendwo anders. Es sei zu einem zügellosen Streit der Meinungen und Interessen gekommen, der mit $\mathrm{Haß}$ geführt würde. In Frankreich herrsche gleichzeitig nahezu der Bürgerkrieg, und obwohl ibeide Völker einen Frieden sehr notwendig hätten, sei er nicht gekommen. ${ }^{38}$

$\mathrm{Z}$ us a m menfassend läßt sich feststellen, daß die öffentliche Meinung einstimmig zum Baseler Frieden Stellung bezog. Der Baseler Frieden wurde in keiner Weise beanstandet. Alle hießen ihn gut zumindest öffentlich. Bei genauerer Betrachtung lassen sich jedoch auch widersprüchliche Positionen feststellen. Gemeinsam ist allen Verfassern, daß sie von einer Friedensvorstellung ausgehen, die im Sinne der Aufklärung einen Frieden als Segen für den Fortschritt der Menschheit hält: der Krieg habe für Deutschland, Preußen und für die ganze Menschheit so große Leiden gebracht, daß ein Friedensschluß unumgänglich gewesen sei. Einhellig wurde auch die militärische Úberlegenheit Frankreichs im Vergleich zu Deutschland hervorgehoben und eine Fortsetzung des Krieges als sinnlos bezeichnet. Alle Teilnehmer an der Diskussion äußerten ihre Hoffnung auf einen schnellen allgemeinen Frieden für das ganze Reich und für ganz Europa. Ansonsten wurden sehr unterschiedliche Ansichten vertreten. Die frankreichfreundlich eingestellten Verfasser setzten sich für das System der Republik ein und hofften, daß Preußen dem Beispiel in seiner Innenpolitik folgen würde. Die konservativere monarchistische Presse war antirepublikanisch eingestellt und glaubte, daß es dem Frieden zu verdanken sei, wenn sich die Revolution nicht weiter ausgebreitet habe. Die einen waren davon überzeugt, daß der Frieden der kosmopolitischen, die anderen, daß er der patriotischen oder der christlichen Sache dienen würde. Besonders in der monarchistischen Presse äußerte man den Wunsch nach einem Festhalten an der preußischen Kriegsehre: die militärische Niederlage sei auf die übermächtigen Umstände und auf die Schuld der Verbündeten zurückzuführen, und nicht Schuld Preußens. Als in den folgenden Jahren sich der allgemeine Frieden hinauszögern sollte, traten diese Gegensätze dann stärker hervor.

38 Ibid. S. $219-224$. 


\section{Zufriedenheit im »dritten Deutschland»}

In Verbindung mit dem Baseler Frieden kam es auch außerhalb der deutschen Hauptstaaten $z u$ einer äußerst regen öffentlichen Diskussion über Vor- und Nachteile des Friedens. Weil hier natürlich die Zensur weniger einheitlich war als in den Hauptländern des Reiches, fiel diese Diskussion verhältnismäßig farbiger aus. Als allgemeiner Zug läßt sich jedoch feststellen, daß der größle Teil der Schriftsteller im »drillen Deutschland» das preußische Vorgehen im Jahre 1795 guthieß und den Frieden allgemein erweitern wollte. Es gab jedoch eine Gruppe bedeutender Ausnahmen, wie im folgenden Kapitel gezeigt werden wird, aber die Mehrheit war für den Frieden.

Als ein typisches Beispiel für diese den Frieden verteidigende Literatur, die in den Territorien Süddeutschlands erschien, die vom Kriegsgeschehen noch unberührt geblieben waren, kann man die in Tübingen 17941802 von Dr. Ernst Ludwig Posselt herausgegebene Zeitschrift »Europäische Annalen» und deren Behandlung des Baseler Friedens anführen. Die »Europäischen Annalen» waren in der zweiten Hälfte der neunziger Jahre des 18. Jahrhunderts eine der bedeutendsten Publikationen, die sich für den Frieden einsetzten. Sie wurden oft zitiert, um die eigenen Auffassungen $\mathrm{zu}$ bekräftigen oder $\mathrm{um} \mathrm{zu}$ zeigen, wie sich verräterische und verbrecherische Aktivitäten im Reich ausbreiten würden. Neben den »Europäischen Annalen» gab Posselt noch eine ganze Reihe andere tagespolitische Publikationen heraus, wie das zehnbändige »Taschenbuch für die neueste Geschichte», »Kleine Schriften» und das »Lexikon der französischen Revolution».

Ebenso wie viele andere deutsche politische Zeitschriften kamen die »Europäischen Annalen» zum größten Teil ihrer Artikel, indem man geradewegs aus anderen deutschen, französischen und englischen Zeitschriften Artikel übernahm, sie übersetzte und aufs neue herausgab. Aber Posselt veröffentlichte auch viele seiner eigenen Artikel zur Weltpolitik und wichtige Kommentare. $\mathrm{Zu}$ Posselt's deutschen Mitarbeitern gehörten u.a. Johann Franz Ehrmann, Christian Wilhelm von Dohm und der bekannte Revolutionär Fr. Reinhard. Größtenteils veröffentlichte man anonym oder nannte die betreffende Zeitschrift oder Veröffentlichung, aber nicht den Namen des Verfassers.

Den Jahrgang 1795 der Zeitschrift eröffnete Posselt mit einem Überblick über die Ereignisse des vergangenen Jahres. Man erwarte das Ende Polens. Frankreich befinde sich in einer schwierigen Lage, aber nehme jetzt offensichtlich eine positive Entwicklung. Es gäbe zwei 
Staaten, die den Jahreswechsel von 1794/95 mit einem Sieg gefeiert hätten: Frankreich und Rußland. Posselt sagte - sehr weitsichtig voraus, daß diese beiden einmal ganz Europa behernschen und dann mit einander in Streit geraten würden. ${ }^{39}$ Von Anfang an wurde auch die besonders wohlmeinende Halitung der »Europäischen Annalen» gegenüber den damaligen Machthabenn in Frankreich deutlich. Posselt hieß die Maßnahmen der Thermidorianer gut und knitisiente besondens scharf die Zeit des Terrors der Jakobiner. Er verteidigte auch die französische Regierung gegenüber Angriffen in der deutschen Presse.40 Den Friedensschluß von Basel kommentierte Posselt sofort und sehr zustimmend. Er versichente, daß Preußen der erste Staat in Europa gewesen sei, der seine Waffen gegen Frankreich gerichtet habe, und er sei auch der erste gewesen, der sie wieder nieder gelegt habe. Posselt druckte den gesamten Text des Friedensvertrages ab und dazu noch die jubelnde Rede, die Rewbel in der Volksversammlung gehalten hatte. ${ }^{41}$ In der folgenden Nummer veröffentlichte er noch den Zusatzvertrag zum Friedensvertrag, der die Neutralisierung Norddeutschlands erläuterte, ${ }^{42}$ außerdem die lange und heftige Diskussion, die die offizielle Verlautbarung der preußischen Regierung an die Reichsstände in Zusammenhang mit dem Friedensvertrag hervorgerufen hatte. ${ }^{43}$ Weiterhin stimmte er dem formellen Friedensvertrag zwischen Frankreich und der Batavischen Republik zu. Dazu veröffentlichten die »Europäischen Annalen» eine Rede Carnot's, die dieser in der Volksversammlung in diesem Zusammenhang gehalten hatte, und kommentierten sie wohlwollend. ${ }^{44}$ Posselt begann sich als Bewunderer dieser Friedensschlüsse engagiert an der Diskussion zu beteiligen, die sich 1795 an der Frage erhitzte, ob in Deutschland ein allgemeiner Friede nützlich und erwünscht sei. Neben der offiziellen Korrespondenz zwischen Österreich und Preußen veröffentlichte er auch Stellungnahmen französischer Minister und Abgeordneter und verspottete den Kriegseifer der Emigranten. ${ }^{45}$ Im September veröffentlichte er einen umfangreichen Utberbliok, "Der Krieg am Rhein», in dem er etwas versteckt der Anerkennung des Rheins als französische Grenze zuzustimmen begann, weil es die Natur so bestimmit habe. Und außerdem stehe es ja in Wirklichkeit schon so: »Er ist es durch die That selbst;

\footnotetext{
39 Europäische Annalen (Eur. Ann.) 1795 I S. 3-6.

40 Ibid. S. 15, 28-30, 42-43, 251-266.

41 Ibid. II S. $48-61$.

42 Ibid. S. $151-154$.

43 Ibid. S. $154-164$.

44 Ibid. S. $283-297$.

45 Ibid. S. $301-306$, III S. $246-272,308-309$.
} 
aber wird er es auch durch einen Friedensschluß werden?» Posselt erwog die Angelegenheit grundsätzlich. In Bezug auf Savoyen und Nizza sei alles klar: sie liegen unbestreitbar innerhalb der natürlichen Grenzen Frankreichs. Für den Rhein sei der Fall etwas komplizierter. Es gehe um besonders große Gebiete, z.B. die österreichischen Niederlande, die Österreich nich't ohne weiteres aufgeben würde. Die Pfeiler des alten und morschen Reiches, die Kurfürstentümer, hätten schwere Verluste erlitten, und es sei keineswegs sichcr, daß dic deutschen Volksgruppen, die die möglicherweise abzutretenden Gebiete bewohnten, sich die Grundsätze des Republikanismus angeeignet hätten. Aiber habe nicht in Frankreich ein viel eroberungsfeindlicherer Geist geherrscht, und sei Frankreich nicht schon obne Eroberungen ein großer Freistaat? Die Sicherheit seiner Grenzen würde nicht durch Gebietsvergrößerungen vermehrt. Die Stärke Frankreichs liege in seiner Homogenität, und gerade diese würde durch den Anschluß der Rheingebiete geschwächt. Sogar Kriegswissenschaftler - Posselt meinte General Miranda würden sich für eine durch Festungen gesichente Grenze nach Westen einsetzen. Aber jetzt hätten die Éreignisse dazu geführt, dal\} die öffentliche Meinung in Frankreich den Rhein als Grenze fordern würde; besonders der große militärische Erfolg hätte dazu geführt. Professor A. J. Hofmann, früher Professor für Geschichte und Naturrecht an der Universität Mainz - ein bekannter Revolutionär und Klubistenführer - hätte ebenfalls den Rhein als einzig mögliche Grenze erklärt. Gleichzeitig hätten die sich in Regensburg versammelten Vertreter der Reichsstände erklärt, daß man auf keinen Fall den Grundsatz der Reichsintegrität aufgeben würde, und thätten sich scharf gegen eine »Amputation des linken Arms» ausgesprochen. ${ }^{46}$ Posselt hätte selbst gerne einen Frieden in den alten oder »verfassungsmäßigen» Grenzen akzeptiert, er gab aber zu verstehen, daß er auch bereit sei den Rhein als Grenze anzuerkennen. - Posselt's frankreichfreundliche Haltung ${ }^{47}$ wurde auch in seinem Verhältnis $z u$ anderen Staaten deutlich. Besonders ablehnend war er gegenüber England; seine egoistische Handelspolitik und die Unnachgiebigkeit seines Ministerpräsidenten Pitt wären die schlimmsten Hindernisse für einen Frieden. ${ }^{48}$

46 Ibid. III S. $323-329$.

47 Tschirch betont das meines Erachtens zu viel, z.B. I (1933) S. 314 »der feurige Freiheitsstürmer P.»), S. 326 (»der begeisterte Apostel der französischen Revolution P.») und II (1934) S. 59 (»P., der begeisterte Herold der französischen Freiheit»).

48 Eur. Ann. 1795 I S. $174-179$, II S. 62 , III S. $161-164,1796$ I S. $118-119$ usw. 
Ähnlich war die Einstellung des liberalen politischen Schrifstellers Ludwig Ferdinand von Huber, der ebenfalls in seinen tagespolitischen Schriften sehr produktiv war.49 Seiner in Berlin 1793-96 erschienenen Zeitschrift $»$ Friedenspräliminarien» gelang es, in der preußischen Hauptstadt ein Friedensevangelium zu predigen, wie TSCHIRCH formulierte, ${ }^{50}$ und 1795-98 erschien in Leipzig die von Huber herausgegebene Monatsschrift »Klio» (ab 1796 »Neue Klio»). »Klio» beschäftigte sich in der Hauptsache mit Zeitgeschichte. Der größte Teil ihrer Artikel bestand aus Übersetzungen aus französischen Journalen, aber viele interessante Übersichten und Kommentare ließen auch Hubers eigene Meinungen zu den Ereignissen der Zeit deutlich werden. Huber wollte, in frommer Hoffnung wie viele deutsche Journalisten, unparteiisch sein, wie er in seinem Vorwort zur ensten Nummer der »Klio» erklärte. Sohon hier führte er scharfe Angriffe gegen extreme Revolutionäre und verurteilte die Herrschaft Robespierre's und vor allem auch Marat's (mit den Attributen Maratism, Vandalism, Kannibalism). Huber bezeichnete auch Marat als Royalisten, womit er auf seine Stellung zur Konterrevolution hinwies. ${ }^{51}$ Huber war nicht unparteiisch; man kann ihn im Gegenteil zur von Posselt vertretenden Gruppe der frankreichfreundlichen und aufklärerischen Friedensverteidiger rechnen, die in der Besonnenheit der Thermidorianer eine neue Möglichkeit für einen Frieden sah. In Hubers Zeitschrift veröffentlichte eine Reihe der gleichen besonnenen Journalisten ihre Artikel wie in Posselt's Zeitschrift, z.B. Miranda, Röderer und Constant. Wie Possel.t so schätzte auch Huber besonders den Friedensplan von Miranda, den er ausführülich erläuterte. ${ }^{52}$ Huber war bei der Auswahl seines Materials in gewißem Grad freizügiger als Posselt und er versuchte, den verschiedenen Meinungsrichtungen besser Rechnung zu tragen. So konnte der militaristische Royalist und Emigrant Jacques Mallet du Pan, dessen Schriften in Deutschland in kriegerischgesinnten Kreisen verbreitet waren, auch in der »Klio» veröffentlichen. ${ }^{53}$

Huber stimmte mit der in Miranda's Friedensplan vertretenen Auffassung völlig überein. Indem man sich auf Rousseau bezog, wurde der Vorzug der kleinen Republiken gegenüber den großen begründet und die Gründung einer selbständigen Republik am linken Rheinufer gerechtfertigt, es wurde die Säkularisierung der geistlichen Kurfürstentümer am

49 ADB Bd. 13. (R. Elvers) S. 236-240; Tschirch I (1933) S. 56-57.

50 Tschirch I (1933) S. 56.

51 Klio 1795 I, Einleitung.

52 Ibid. II Anm. S. 129.

53 Tschirch I (1933) S. 57. 
Rhein in der Weise vorgeschlagen, daß man die Fürstbischöfe in entsprechender Weise abfinden solle. Ein auf diesen Grundsätzen geschlossener Friede sei für alle Beteiligten vorteilhaft:

»Ein Friede, der auf solchen Grundfesten ruhte, würde gewissermassen alles Unrecht verbessern, welohes die Franzosen gegen die Menschheit begangen haben. Er würde die verderblichen Folgen des berufenen Westphälischen Friedens vernichten, indem er dem protestantischen 'Theile Deutschlands den Einfluß gäbe, welchen er vermöge seiner Aufklärung, seiner Philosophie und seiner Anhänglichkeit an den wahren Grundsätzen der Freiheit, immer hätte haben sollen. Kurz das Resultat dieses Krieges würde dem Menschengeschlechte eben so nützlich werden, als das Resultat aller andern ihm verderblich geworden ist.» ${ }^{54}$

Einige Monate später veröffentlichte Huber in der »Klio» einen Artikel unter dem Pseudonym »Feldjäger», in dem in typischer Weise die Möglichkeiten einer Erweiterung des Friedens in der Situation nach dem Baseler Frieden eröntert wurden. Der »Feldjäger» fordert einen schnellen Abschluß eines allgemeinen Friedens und beschuldigte Österreich, das aus eigennützigen Interessen die Friedensverhandlungen behindere. Der Verfasser war frankreichfreundlich eingestellt und baute vertrauensvoll auf die Stärke Frankreichs. Er glaubte z.B., daß Frankreich die Seemacht England im Schach halten könne. Er stellte fest, daß Deutschland schwach sei und das Reich unbedingt große innere Reformen nötig habe. Die Bestimmungen des Westfälischen Friedens hätten ihre Bedeutung schon verloren und das geltende Grundgesetz sei hoffnungslos veraltet; seinetwegen sei schon genug unnötiges Blut geflossen. Der »Feldjäger» vertrat auch die Auffassung, daß Österreich sioh aus dem Krieg zurückziehen könne, indem es auf seine umstrittenen Besitzungen in Schwaben auf einige Gebiete in Italien verzichte und dafür Bayern erhalte. Interessant ist, daß der »Feldjäger» Österreich vor Rußland warnte. Wenn Österreich seinen wirklichen Feind im Norden kennenlernen und es verstehen würde, sich mit Frankreich zu verbünden, sei der Krieg auf dem Kontinent für ein halbes Jahrhundert von Westeuropa abgewendet und Frankreich könne seine Waffen gegen England richten. ${ }^{55}$

Eine Gruppe von Zeitschriften in Norddeutschland stimmte den Gedanken von Posselt und Huber zu. Die von dem Holsteiner August Hennings herausgegebene Monatsschrift »Genius der Zeit» gehört zu dieser Gruppe und soll hier vorgestellt werden. Hennings war Beamter

54 Klio 1795 II S. 143-144, 146-147 (Zitat).

55 Ibid. IV S. $229-232$. 
in dänischem Dienst gewesen, war dann aber wie viele andere Anhänger der Revolution zu Beginn der großen Ereignisse freier Journalist geworden. Er war besonders produktiv. Neben der wichtigeren Zeitschrift »Genius der Zeit» gab er noch u.a. das »Sohleswiger Journal» (1792—93) und die »Annalen der leidenden Menschheit» (1795-1801) heraus. Hennings' Zeitschriften wurden überall in Deutschland gelesen.56 Politisch gesehen war »Genius der Zeit» eine radikale Zeitschrift, und in der Geschichtsschreibung der DDR rechnet man sie auch zur sog. Jakobinerliteratur. ${ }^{57}$ Dies ist wohl jedoch übertrieben. Hennings venteidigte zwar den Frieden mit Frankreich konsequent, aber der begeisterte Revolutionsgeist, der in den Schriften von z.B. Görres, Rebmann oder der Mainzer Klubisten anzutreffen ist, findet man eben nicht in den Spalten von »Genius der Zeit», obgleich der größte Teil der in der Zeitschrift veröffentlichenden Schriftsteller frankreichfreundliche und aufklärerisch gesinnte Friedensverteidiger war, wie ein alter Gegner der Revolution J. W. Gleim schrieb. Der Verfasser einer Hennings-Biographie, JOACHIM HILD, stellt auch mit voller Berechtigung fest, daß die Tendenzen der Zeitschrift »monarchisch-demokratisch-aufklärerisch» und auf keinen Fall rein revolutionär seien. ${ }^{58}$

Der Jahrgang 1795 von »Genius der Zeit» zeigt sich natürlich sehr friedensbereit und konzentriente sich auf die Erwartung des Baseler Friedens. Vor dem Friedensschluß schrieb Hennings, daß er diesen sehnsüchtig erwarte. Er dankte den weisen Herrschern, denen es geglückt war, den Frieden für ihr eigenes Gebiet zu erhalten, und meinte damit vor allem Dänemark. Er versicherte, der Wunsch nach Frieden sei in ganz Deutschland größer geworden. Früher habe man diejenigen, die sich für einen Frieden einsetzten, als Vatenlandfeinde bezeichnet, jetzt sei aber der Wunsch nach Frieden »die Losung aller Völker und die Stimme aller Zeitungen». Als eindeutiger Anhänger der Aufklärung wies er darauf hin, wie segensreich der Frieden sei, indem er u.a. wirtschaftlich argumentiente:

»Wenn man nur erst kalt genug wird, um rechnen zu können, sieht man ein jeder bald ein, wie viel wohlfeiler ein Pflug ist, als eine Kanone.»59

56 ADB Bd. 11 (Wattenbach) S. 778-780; Biographisches Lexikon zur deutschen Geschichte (BLDG; H. Voegt) S. 206-207; Hild, Joachim, August Hennings, Erlangen 1932, s. 148-156.

57 Voegt (1955) S. 15 und BLDG (Voegt) S. 296-207.

58 Hild (1932) S. 126.

59 Genius der Zeit (Gen. d. Z) 1795 I S. 7 und 43. 
Eine Fortsetzung des Reichskrieges hielt er für unmöglich und lehnte sie strikt ab.60 Die kriegerische Partei tadelte er fortgesetzt und scharf und dankte entsprechend den Friedensventeidigern, wie die schon genannten J. F. Reichardt und Rebmann sowie Anreas Riem. Auch Immanuel Kant wurde mit Zustimmung genannt. ${ }^{61}$ Auf die gleiche Weise verfuhr der größte Teil der Mitarbeiter an »Genius der Zeit». Sie stammten zum größten Teil aus Norddeutschland und verfolgten Hennings Linie in Prosa und Reim. Herder, Gerning, Släudlin und Freudentheil besangen die Segnungen des Friedens und die Leiden des Krieges in ihren Gedichten, ${ }^{62}$ Klopstock, Lamprecht und J. H. Voss forderten einen schnellen Friedensschluß.63 Ein bedeutender Mitarbeiter war ein Oldenburger Beamter der Justizverwaltung, Gerhard Anton von Halem, der auch neben Hennings für andere deutsche friedensbereite Zeitschriftenherausgeber schrieb. So erschienen von ihm Beiträge in Wielands »Merkur» und in Woltmanns »Geschichte und Politik.»64 Im »Genius» veröffentlichte er zwei Gedichte für den Frieden. „Gerechtigkeit und Frieden» verherrlichte einen gerechten, das Glück des Volkes vermehrenden schnellen Frieden, »An das Voilk der Franken» besang die Franzosen und hoffte auf ein Bündnis mit ihnen. Ein wenig später sprach Halem sogar von der Entstehung einer europäischen Republik, die einen ewigen Frieden garantieren würde. ${ }^{65}$

Unter den deutschen Friedensventeidigern ragte die Gestalt eines politischen Schriftstellers besonders hervor, der ehemalige Prediger Andreas Riem, geboren in der Pfalz, aber zwischen 1795 und 1801 in verschiedenen Teilen Deutschlands wohnhaft, am Anfang in Berlin. Riem, der alle Nachteile eines deutschen Kleinstaates erfahren hatte, wurde wie viele andere Bewohner des linken Rheinufers ein begeisterter Anhänger der Französischen Revolution. Er war bereit, die Republik und den mit ihr geschlossenen Frieden mit seiner Feder zu verteidigen. Schon 1792 warnite er die europäischen Staaten davor, einen Krieg mit Frankreich zu beginnen. Als dann in preußischen Regierungskreisen die Bereitschaft $z u$ einem Frieden wuchs, nachdem sich das Kriegsglück zum Schlechteren gewendet hatte, versuchte er in leidenschaftlichen Artikeln auf die preußische Politik einzuwirken und, wenn möglich zwischen Preußen und

60 Ibid. II S. $314-315$.

61 Ibid. z.B. I $311-312$, II S. 127-128, 266; Tschirch I (1933) S. 104.

62 Gen. d. Z. 1795 I (Vorbericht), II S. 257-276, 393-395, 785-798, III S. $84-90,124,1796$ I S. $1-8,128--144$.

63 Ibid. 1795 I S. $1-3$, IV S. $318-320,481-484$.

64 ADB Bd. 10. (Mutzenbecher) S. 407-409; Lange, Gerhard, Gerhard Anton von Halem, Leipzig 1928, S. 18-22.

65 Gen. d. Z. 1795 III S. 392-393, 1796 I S. 262-263. 
der freien Republik Frankreich ein Bündnis zustande zu bringen. Die Baseler Friedensverhandlungen verfolgte er mit angespanntem Interesse und reiste sogar selbst nach Basel, wo er engere Kontakte mit französischen Agenten aufnahm. $\mathrm{Zu}$ dieser Zeit stellite er auch engere Kontakte mit radikalen Kreisen in Westdeutschland her, z.B. mit Georg Friedrich Rebmann. ${ }^{66} \mathrm{Zu}$ Anfang des Jahres 1795 veröffentlichte er eine anonyme Schrift »Politische Lage und Staatsinteresse des Königreichs Preußen», in der er einen schnellen Friedensschluß mit Frankreich forderte. In dieser Schrift zeigte Riem auch deutliche Sympathien gegenüber Frankreich und die neuen Ideen. ${ }^{67}$ Ab Sommer 1795 gab er zwei umfangreiche Zeitschriften heraus, »Europens politische Lage und Staatsinteresse und »Europa in seinen politischen und Finanz-Verhältnissen». Der eifrige Journalist füllte beinahe allein von Jahr zu Jahr die Seiten seiner Zeitschriften mit politischen Artikeln. Außerdem versuohte er noch, die preuBische Regierung mit verschiedenen Gedenkschriften zu beeinflussen. Riems Schriften, besonders die »Europa»-Veröffentlichung, erregte besonders in Norddeutschland große Beachtung. ${ }^{68}$

»Europa» begann sofort nach dem Friedensschluß von Basel zu erscheinen. Der Friedensschluß und seine möglichen Folgen wurden ausführlich behandelt. Die Reaktion der Zeitschrift war natürlich äußerst zustimmend. Riem stellte fest, die politische Lage in ganz Europa habe sich plötzlich geändert. Er spekulierte mit der Möglichkeit eines Bündnisses zwischen Österreich, England und Rußland gegen Preußen, die er dann aber selbst verwarf: seiner Meinung nach würde Österreich es nicht wagen, Rußland es nicht wollen und England dazu nicht in der Lage sein, Preußen anzugreifen. Preußen habe realistisch und im eigenen außenpolitischen Interesse gehandelt, als es den Frieden schloß.69 Eine möglichst schnelle Erweiterung des Friedens auf das ganze Reich wäre unbedingt für ganz Deutschland von Vorteil. Es sei unverständlich, wenn einige unbeirrt an der Reichsintegrität festhalten würden: obgleich sie für ganz Deutschland sprechen würden, hätten sie doch vor allem das Interesse Österreichs im Auge. In einem Angriff auf den Mainzer Graf Carl Christian von Benzel-Sternau und dessen Flugschrift, ${ }^{70}$ die eine Fortsetzung des Krieges empfahl, trug Riem energisch sein eigenes Friedens-

66 T'schirch I (1933) S. 127-133; v. Wrasky (1907) S. 59.

67 Politische Lage und Staatsinteresse ... 1795 z.B. S. 31-33.

68 Ibid. S. 144, 149 und 152.

69 Europa 1795 I S. 117.

70 Ibid. II S. 105, 112; Holzmann-Bohatta, Michael, Hanns, Deutsches Anonymen-Lexikon 1501-1850 III S. 354. Der Schrift hieß »Reichsintegrität erster Grundzug des Reichsfriedens, 1795. 
programm vor. Es sei dumm zu glauben, daß Frankreich freiwillig auf die besetzten Gebiete verzichten würde; Frankreich könnte unmöglich den Preis für einen so teueren Sieg »theatralisch» hergeben. Der Verlierer, also Deutschland, müsse durch Zugeständnisse versuchen, zu einem Frieden zu kommen. Die in Deutschland geltende Reichsverfassung könne unmöglich erhalten werden. Jetzt sei es möglich im Zusammenhang mit dem Friedensschluß, sie $\mathrm{zu}$ verbessern und $\mathrm{zu}$ vereinfachen. És bestehe sonst die Gefahr, daß man wie Polen dem Anarchlsmus zum Opfer falle. Die Untertanen der rheinischen Kleinfürsten würden auf die Verbesserung ihrer Verhältnisse hoffen und gegen das französische System hätten sie nichts einzuwenden. Auch sei ein Friede dringend notwendig, weil sich Deutschland nicht mehr verteidigen könne. Es sei klar, daß man einen Frieden nur unter großen Opfern erkaufen könne, und die seien zu entrichten. Die Rheingrenze sei für Deutschland sogar von Nutzen. Wenn das zu mächtige Österreich die Niederlande verlieren würde, so sei das nur von Vorteil für die Selbständigkeit des Reiches. In einem Schlußsatz weist der Prediger Riem noch einmal die Aufforderung BenzelSternau's zur Fortsetzung des Krieges scharf zurüok:

»Nein! Wir andern deutschen Bürger, die wir nicht Hofjunker sind, wollen lieber mit Asmus sagen: "Nun segne Gott von oben an, / Die Theil am Frieden nahmen, / Gott segne jeden Ehrenmann, / Und straf' die Schmeichler! Amen» ${ }^{71}$

In einem Artikel »Europa in seinen politischen Verhältnissen» fuhr Riem fort, sich für den Frieden einzusetzen. Hier empfielt er dem »dritten Deutschland», wie Preußen einen Frieden zu schließen. Damit würden sich die Siegesaussichten Österreichs verschlechtern und auch es wäre gezwungen, sich einem allgemeinen Frieden zu unterwerfen. Deutschland hätte zu wählen. Seine Existenz würde jetzt an einem dünnen Haar hängen: »An Oesterreichs Mäßigung, und Preußens gesunder Politik, und seiner eigenen Erhaltung».72 Ein einiges Deutschland wäre der mächtigste Staat in Europa. Dort gäbe es 28 Millionen Einwohner, 2350 Städte, 3000 Markflecken, 100000 Dörfer, 31750 Schlösser, seine Fürsten hätten aus den nicht zum Reich gehörenden Ländern Jahreseinkünfte von 150 Millionen Talern, das Reichsheer in Friedenszeiten eine Stärke von 650000 und in Kriegszeiten sogar von 750000 Mann. Ein einiges Deutschland könnte den Frieden in Europa garantieren. Aber bei allem stene das Grundgesetz im Weg, weil es systematisch die Anarchie aufrecht erhalten würde. Neben Österreich und Preußen würden nach Riems Mei-

71 Europa 1795 II S. 110-112.

72 Ibid. III S. 5-19. 
nung sechs Fürsten für das Reich genügen: Sachsen, Bayern, Hannover, Braunschweig, Hessen-Kassel und Württemberg. Die übrigen 293 souveränen Gebiete in Deutschland seien vollkommen unnötig. Für das neue Deutschland sei der Rhein die richtige Grenze: »Die Natur gab Deutschland den Rhein zur Gränze, und diese ist die einzige, die es vertheidigen kann.» Nur mit dem Rhein als Grenze käme Frankreich Deutschland zur Hilfe gegen Rußland, das mit Deutschland wie mit Polen verfahren wolle. Außerdem war Riem der Meinung, das Preußen und nicht Österreich die Kaiserwürde zustehen würde. Diese Veränderung wäre von großem Nutzen für das ganze Reich: Preußen sei zentraler gelegen und auch stärker, und es sei in der Lage, das Reich gegen seine Feinde zu verteidigen. Außerdem sei Preußen »natürlich Frankreichs Freund», würde ihm die Kaiserkrone gehören, »so wird Deutschland nothwendig in das engste Freundschafitsbündniss der Republik aufgenommen, und seine Ruhe und Sicherheit gegründet». Als Ersatz für die Kaiserwünde stand Riem Österreich Bayern zu. ${ }^{73}$

Riem ging also wie viele andere davon aus, daß nur durchgreifende Reformen im Reich Deutschland einen dauernden Frieden garantieren könnten, der für ihn das höchste Ziel war. Das gleiche Thema, wenn auch in Einzelheiten stark abgewandelt, behandelte er in einer längeren Publikationsreihe - eigentlich einer Zeitschrift — «uropens politische Lage und Staats-Interesse», die er anonym zwischen 1795 und 1799 herausgab. Im ersten Jahr entsprach sein Programm dem in der »Europa» vorgetragenen. Er pries Preußen in jeder Weise und tadelte die Kriegspolitik Österreichs. Er forderte für Deutsohland eine neue Verfassung, die möglichst der französischen ähneln solle. Eine Fortsetzung des Krieges lehnte er unbedingt ab. Es sei politisch unklug, den Krieg fortzusetzen, dessen Ziel nach menschlichen Kräften nicht zu erreichen sei. Die Wiedereinführung der Monarchie in Frankreich sei gerade so ein Ziel. Deshalb wäre es gut, wenn Preußen eine Vermittlertätigkeit aufnehmen würde, die dem Reich einen ehrenvollen Frieden bringen könne. Die verletzende Sprache der österreichischen Schriftsteller gegenülber Preußen sei unbegründet. Es bestehe überhaupt kein Grund für Deutschland, diese Vermittlung Preußens zu fürchten und an die östereichische Schreckenskampagne zu glauben. Die »Reichsintegrität» als Ausgangspunkt für einen Frieden sei ein leeres Schlagwort. ${ }^{74}$

Die oben behandelten zum Baseler Frieden zustimmend eingestellten

73 Ibid. S. $20-29,41-43,46-48,55$. Dasselbe auch später z.B. Europens politische Lage und Staats-Interesse (Eur. pol. L.) II 1796 S. 150-162.

74 Eur. pol. L. I 1795 S. 29-38, 55-60, 71, 94-96, 118-125. 
Schriftsteller des »dritten Deutschland» kann man schon grundsätzlich als An'hänger Frankreichs und der Revolution bezeichnen. Die Zustimmung zum Baseler Frieden blieb jedoch keineswegs auf sie beschränkt. 1795 war in Deutschland der Wunsch nach Frieden ganz allgemein. So traten auch viele für einen Frieden ein, die die Revolution an sich ablehnten. Oft änderten sie dann aber ihre Meinung radikal. Eine »neutrale» Zeitschrift dieser Artt waren Schillers »Die Horen», die in Tübingen 179597 erschienen. Die »IIuren» Waren zu ihrer Zeil eine der bedeutendsten Zeitschriftenversuche. Schiller hatte schon 1792 eine große, jeden zweiten Tag erscheinende Zeitschrift geplant, an der sich 30-40 der bedeutendsten Schriftssteller Deutschlands beteiligen sollten. ${ }^{75}$ Der Verleger Göschen, dem Schiller seinen Plan vorgetragen hatte, lehnte damals ab, aber drei Jahre später konnite der Plan in zwar anspruchsloserer Form verwirklicht werden. Man begann den Versuch mit 2000 Exemplaren, die monatlich erschienen. Der mit so großen Hoffnungen begonnene Versuch glückte jedoch nicht vollkommen. Die Auflagenhöhe sank von Jahr zu Jahr und der Krieg verhinderte die Verbreitung der Zeitschrift. ${ }^{76}$ Der Mitarbeitstab war jedenfalls groß und namhaft: nach einer Anzeige in der ersten Nummer hatten 23 Schriftsteller zugesagt, an Schillers Zeitschrift mitzuarbeiten, zu denen wirklich die bedeutendsten in Deutschland zählten.77 Ein Teil von ihnen lieferte zwar später keine Beiträge, aber an ihre Stelle traten andere. ${ }^{78}$ Schiller hatte auch Immanuel Kant um die Mitarbeit an den »Horen» gebeten, den vielleicht im Jahre 1795 geschätztesten Schriftsteller in Deutschland, aber von diesem waren keine Artikel in dieser Zeitschrift erschienen. ${ }^{79}$

Im Vorwort zur Eröffnungsnummer der Zeitschrift legte Schiller die Ziele der »Horen» fest. Sie waren betont unpolitisch. Der Herausgeber stellte fest, daß die Epoche durch den Krieg beunruhigt sei (»das nahe Geräusch des Krieges das Vaterland ängstiget») und bedauerte, daß überall die politischen Parteien und Meinungsrichtungen so kämpfen würden, daß die »Musen und Grazien» nur bedauerlich selten zu Wort kämen. Als Gegengewicht zur Kriegszeit sei jetzt ein noch allgemeineres Interesse am rein Menschlichen vonnöten, um die politisch geteilte Welt

75 Meyer (1941) S. 20.

76 Ibid. S. 23 . S. S. 6.

77 Horen 1795 I S. VIII-IX sagt die Namen Archenholtz, Dalberg, Engel, Erhardt, Fichte, Funk, Garve, Gentz, Gleim, Goethe, Gross, Herder, Hirt, Hufeland, A. und W. Humboldit, Jacobi, Matthisson, Meyer, Pfeffel, (Fr.) Schlegel, Schütz, Schulz und Woltmann.

78 Friederike Brun, Gries, J. H. Voss und Messerschmid. Seyffert, Wolfgang, Schillers Musenalmanach, Palaestra LXXX Berlin 1913, S. 27.

79 Vorländer, Karl, Kant, Schiller, Goethe, Leipzig 1907, S. 27, 32-33. 
»unter der Fahne der Wahrheit und Schönheit»zu vereinigen. ${ }^{80}$ Obgleich Schiller in dieser Weise seine unpolitische Einstellung betonte, wollte er trotzdem als politischer Erzieher auftreten, dessen Richtschnur die Erziehung zur Freiheit und Schönheit gefühnt von kosmopolitischer Friedenssehnsucht sein sollte. »Wohlanständigkeit und Ordnung, Gerechtigkeit und Friede werden also der Geist und die Regel dieser Zeitschrift seyn», formulierte Schiller programmatisch. ${ }^{81}$ Davon ging Sohiller auch in seiner bedeutendsten Artikel in den »Horen» »Ueber die ästhetische Erziehung des Menschen» aus. Hier erläuterte Schiller die wichtigsten Punkte seiner pädagogischen Ansichten. Aber zumindest auch teilweise beleuchtet dieser Aufsatz seine politischen Ansichten. Schiller hob die besondere Bedeutung Kants hervor. Er berief sich in seinem ganzen Program zur Besserung der Menschheit durch eine ästhetische Erziehung auf Kants Gedanken und auf Kants philosophisches System, das Schiller damit gleichzeitig volkstümlicher machen wollte. ${ }^{82}$ Möglicherweise betonte Schiller in seiner Schrift gerade unter dem Einfluß Kants ausdrücklich seine grundsätzliche Friedenssehnsucht. An mehreren Stellen bedauerte er die Unruhe und Rechtlosigkeit in seiner Zeit: das Recht des Stärkeren, Intoleranz und Gewalt hätten sich verbreitet. Sohiller setzte sich für das Ideal der Freiheit und die Verwirklichung der Menschenrechte ein: »Der Mensch ist aus seiner langen Indolenz und Selbsttäuschung aufgewacht, und mit nachdrücklicher Stimmenmehrheit fordert er die Wiederherstellung in seine unverlierbaren Rechte». Das sei gut. Aber leider versuche man, dieses Ziel mit Gewalt zu erreichen. Die »bürgerliche Ordnung» müsse seiner Meinung nach immer erhalten bleiben. Der Krieg sei a uf keinen Fall von Vorteil für die kulturelle Entwicklung. Die Griechen, Römer und Araber hätten sich zu aller erst im Krieg erschöpft und hätten sich durch einen kriegerischen Geist lähmen lassen, bevor ihre Kultur eine höhere Stufe erreicht hätte. Ein ständiger Friedenszustand, den Schiller wie Kant als Ziel der Menschheit betrachtete, sei nur zu erreichen, wenn man den Menschen durch eine ästhetische Erziehung die Bedeutung der Schönheit lehren würde.

»selbst die Waffen dürfen jetzt nicht mehr bloss Gegenstände des Schreckens; sondern auch des Wohlgefallens seyn, und das kunstreiche Wehrgehänge will nicht weniger bemerkt seyn, als des Schwerdtes todtende Scheide».83

80 Horen 1795 I (Vorbericht, von Schiller).

81 Ibid. S. 6. Vgl. Gleichen-Rußwurm (1947) S. 188 und Müller, Franz, Deutsche Grösse, Demmin 1905, S. 28.

82 Horen 1795 I S. 8-9.

83 Ibid. S. $11,21,22-23,26-30$. 
Schiller unterschied zwischen venschiedenen Staatstypen, dem dynamischen Staat, dem ethischen Staat und dem ästhetischen Staat. Für ihn könnten die Menschenrechte enst im ästhetischen Staat vollkommen verwirklicht werden. Eine ästhetische Republik gäbe es noch nicht, aber die Bestrebungen gingen schon »in jeder feingestimmten Seele» dahin, außerdem würde die Lehre von einer reinen Kirche und einer reinen Republik in Gelehrtenkreisen behandelt. Im Lärm der Revolution vertraute Schiller also auf eine deutsche Gelehrtenrepublik, die auf keinen Fall der französischen Republik gleichen würde. Schiller brachte deutlich seine ablehnende Haltung gegenüber den vorwärts drängenden Eroberern zum Ausdruck. ${ }^{84}$ In seiner Schrift zeigte er sich als Kind der Aufklärung, das der politische Erzieher seines Volkes sein wollte. ${ }^{85}$ Besonders für seine Einstellung zum Frieden hat Kant große Bedeutung. ${ }^{86}$ Dazu läßt sich noch eine Portion kosmopolitischer Friedenssehnsucht feststellen. ${ }^{87} 1793$ ernannte sogar die französische Regierung Schiller zum Ehrenbürger, was »Monsieur Gillé» jedoch ablehnte. ${ }^{88}$ Auch sonst kühlte sein Verhältnis zur Revolution schnell ab. Das wurde auch in seiner Einstellung zur Friedensidee und zu einem Friedensschluß mit Frankreich deutlich. Durch die Freundschaft mit Goethe wich im Laufe des Jahres 1795 Schillers Bewunderung für Kant fast völlig. Er zeigte der Schrift »Zum ewigen Frieden» gegenüber kein besonderes Interesse und beurteilte die Völkerbundsidee als Zeichen von Altersschwäche. ${ }^{89}$ Obgleioh die "Briefe über ästhetische Erziehung» zum größten Teil von der Kant'sohen Philosophie und von einem deutlichen Wunsch nach Frieden bestimmt werden, ${ }^{90}$ verändert sich seine Einstellung schon in eine den Frieden ablehnende Richtung.

Eine sich deutlicher für den Frieden einsetzende Haltung als Schiller nahm das an Jahren ältere und ursprünglich berühmteste Mitglied des Weimarer »Dichterhofes» Herder ein. ${ }^{91}$ Für Reichardt's "Deutschland» 92 schrieb er das Gedicht „Gebet», in dem er um die Befreiung von der schon Jahre dauernden Last der Kriege zu Gott, den Retter und Vater der Men-

84 Ibid. VI S. $120-122$ und Anm. S. 123-124.

85 Gleichen-Rußwurm (1947) S. 188.

86 Die Beziehung zwischen Kant und Schiller beschildert Vorländer (1907) S. $27-52)$.

87 Müller (1905) S. 28.

88 Berger, Karl, Vom Weltbürgertum zum Nationalgedanken, München 1918, S. 49 .

89 Borries, Kurt, Kant als Politiker, Leipzig 1928, S. 201.

90 z.B. Vorländer (1907) S. 32-35.

91 Ibid. S. 48. Brandt, Gustav-Adolf, Herder und Görres 1798-1807, Diss. Berlin 1939, S. 12.

92 Haacke, Wilmont, Zeitschrift, Schrift der Zeit, Essen 1961, S. 55-56. 
schen betete und gleichzeitig im Geiste der Aufklärung an die eigene heilige Vernunft der Menschen appellierte. ${ }^{93}$ In einem zweiten Gedichte ${ }^{94}$ betete er zu der Göttin des Frühlings um eine Beendigung des Krieges und eine Rückkehr zum gesegneten Frieden. ${ }^{95} 1795$ erschien von ihm in Hennings' »Genius der Zeit» das Gedicht »Der Janustempel», in dem er sich energisch für den Frieden einsetzte und betonte, daß der Krieg für beide Seiten Leid bringe. In seiner Bildersprache entlehnte Herder sowohl aus der Bibel als auch aus der antiken Mythologie. ${ }^{96}$

Neben Herder war Goethe der berühmteste Mitarbeiter an den »Horen», der in den ersten beiden Nummern erschienenen »Unterhaltungen deutscher Ausgewanderten» seine Vortellungen von der Weltlage zum Ausdruck ibrachte. Goethes Verhältnis zur Revolution erscheint in diesem Text recht ablehnend. Er hatte mit seinem Herzog an einem Teil des Feldzuges gegen Frankreich teilgenommen, obgleich ihm das Soldatenleben zuwider war. Er hatte deutlich die Unfähigkeit der Kriegsführung der Verbündeten erfahren und die Berufsarmeen der Koalitionsländer konnte ihn auch nicht begeistern. Im Laufe des Jahres 1794 nahm er eine immer ablehnendere Haltung gegenüber dem Krieg ein, und als der Baseler Frieden zustande kam und auch Weimar von Lärm des Krieges befreit wurde, war Goethe zufrieden. Die Vorstellung, daß der Krieg fortgeführt werden könnte, entmutigte ihn. Wie viele andere bedeutende Vertreter des Geistesleben in Deutschland begann Goethe sich von dem Gedanken an eine Gelehrtenrepublik fesseln zu lassen. Er plante, seine Stellung am Hof aufzugeben und sich aus der vom Krieg verrohten Welt völlig zurückzuziehen, um sich der Wissenschaft und der Kunst zu widmen. ${ }^{97}$ Zornig verfolgte er das immer weitene Vorrücken der Franzosen und ihrer Truppen in Deutschland und zeigte Verständnis für die Leiden der vor den Franzosen fliehenden adligen Familien, er verurteilte die durch die Mainzer Klubisten und durch andere Revolutionäre verbreitete Kapitulationsbereitschaft und warnte vor den Absichiten revolutionärer Kreise, auch in Deutschland die Guillotine einzuführen. ${ }^{98}$ Gleichzeitig griff Goethe ebenfalls in den »Horen» mit seinem Artikel »Literarischer Sanscülottismus» die revolutionäre Literatur in Deutschland an. ${ }^{99}$ Ander-

93 Brandit (1939) S. 12-13.

94 Horen 1795 IV S. 115.

95 Deutschland 1796 II S. 161 und 462.

96 Gen. d. Z. 1796 I, Vorbericht.

97 Fritz (1931) S. 22-30; Meinecke, Friedrich, Goethe und die Geschichte, München 1949, S. 65; Joachimsen (1949) S. 42.

98 Horen 1795 I S. 49-61.

99 Ibid. II S. $50-56$. 
enseits wollte Goethe aber nicht als aktiver Gegner der Revolution erscheinen. Er wollte keinen Krieg. Als der Reichsgraf Heinrich von Gagern ihm nach dem Baseler Frieden ein Plan vorlegte, nach dem der Widerstand Deutschlands durch einen Bund zwischen den »Fürsten und dem Geist» fortgesetzt werden müsse, zeigte Goethe zwar Verständnis, lehnte aber die Bitte, sich an dem Bund als Führer zu beteiligen, ab. ${ }^{100}$ Goethes Halitung läßt sich ziemlich gut mit jener »unterwürfigen Friedensbereitschaft» vergleichen, die besondens im südlichen Teil des »dritten Deutschland» für zwei Jahre besonders vorherrschend war. Er war gegen Frankreich und die Revolution, aber noch mehr gegen eine Fortsetzung des Krieges.

Die politisch gemäßigte Presse Norddeutschlands vertritt gut die von dem ehemaligen Hauptmann der preußischen Armee Johann Wilhelm von Archenholtz seit 1792 in Hamburg herausgegebene Zeitschrift »Minerva, ein Journal historischen und politischen Inhalts». Die monatlich erscheinende Zeitschrift konzentrierte sich auf die Schilderung der Ereignisse der Französischen Revolution, dabei wurde auch oft das Problem Krieg und Frieden erörtert.101 Archenholtz war einer der bedeutendsten politischen Kommentatoren in Deutschland. Die freie Atmosphäre Hamburgs erlaubte ihm, verhältnismäßig unabhängig von der Zensur (zumindest bis zum Jahr 1800) seine Meinungen zu äußern, die oft überall in Norddeutschland auf starken Widerspruch stießen.102 Die »Minerva» war zu ihrer Zeit eines der bedeutendsten Organe der Meinungspresse, deren Auflage nach 1790 bei 3000 Exemplaren lag. In Archenholtz erkannte man allgemein den Nachfolger Schlözers in der Führung der Presse in Deutschland.

Neben Wielands »Merkur» war sie die wichtigste Zeitschrift der liberalen Presse in Deutschland, am Ende des Jahrhunderts vielleicht sogar die wichtigste. ${ }^{103}$ Der in seiner Lebensanschauung liberale Archenholtz zählte nach einigen Quellen zu den Freimaurern und war bei Ausbruch der Französischen Revolution ihr leidenschaftlicher Anhänger. 1791 wanderte er sogar nach Paris, um in Zentrum der Revolutionsereignisse zu sein, aber ihre Radikalisierung ließ ihn dann wieder nach Deutschland zurüokkehren.104 Zweifellos bestimmte Archenholtz die Richtung der

100 Rössler (1958) S. 63.

101 Tschirch I (1933) S. 347; Eisner (1907) S. 12.

102 Ruof, Friedrich, Johann Wilhelm von Archenholtz, Berlin 1915, S. 128. Lindemann (1969) S. 275. Vgl. Tschirch I (1933) S. 270 und Laufenberg (1913) S. 54 und 62.

103 Lindemann (1969) S. 275; Ruof (1915) S. 116-117.

104 Wahl, Adalbert, Über die Nachwirkungen der französischen Revolution, 
"Minerva» und die von ihm verfaßten Artikel maohten ungefähr ein Viertel des Gesamtumfangs der Zeitschrift aus, zeitweise sogar mehr. Durch seinen großen Freundeskreis hatte er auch eine Reihe von berühmten Mitarbeitern, die politisch sehr verschiedene Standpunkte vertraten. Die bedeutendsten Vertreter der Gruppe der Revolutionsfreunde waren u.a. Oelsner, Reinhard und Forster, der Gruppe der Revolutionsgegner u.a. Gentz und Gleim. Nach eigenen Angaben von Archenholtz betrug die Zahl der einheimischen und ausländischen Mitarbeiter im Jahre 1798 63.105

Die aufsehenerregenden Ereignisse des Jahres 1792 hatten schon Archenholtz' Einstellung von einer vorbehaltlosen Anerkennung der Revolution gemäßigter werden lassen. Die Grundlinie blieb jedoch auch in der »Minerva» lange zustimmend. Diese Haltung prägte auch sein Verhältnis zu den Revolutionskriegen. Obgleich er z.B. den Raub von Kunstschätzen durch Napoleon als sarazenenhaftes und türkisches Gebaren verurteilte, ${ }^{106}$ wandte er sich nooh im Herbst 1797 scharf gegen den Gedanken von einer Unterdrückung der Revolution. ${ }^{107}$ Mit der Zeit jedoch korrigierte auch er seine Einstellung. Mit dem Baseler Frieden war Archenholtz zum größten Teil zufrieden. Er erwähnte ihn das erste Mal sofort im August und wies auf seine Bedeutung für eine engere Verbindung zwischen Norddeutschland und Frankreich hin. Schon wegen der besseren Nachrichtenverbindungen sei der Friede eine gute Sache. ${ }^{108}$ Obgleich ein Friede geschlossen wurde, hatte Archenholtz jedoch keine Hoffnungen auf einen allgemeinen und besonders auf einen ewigen Frieden. Seiner Meinung nach würden die Mensohen trotz ihrer Wohnplätze und ihrer Zivilisationsstufe so lange Kriege führen bis sie überhaupt Menschen seien. Derjenige, der in einer Welt ohne Krieg leben wolle, müsse in das Land der Utopie reisen. Archenholtz wollte auch nicht die grundsätzliche Berechtigung zum Kriegeführen bestreiten. Ein Soldat sei auf keinen Fall ein Mörder. Der ehemalige Offizier bedauerte, daß die Soldaten im jetzigen Krieg verglichen mit dem Siebenjährigen Krieg nicht die richtige Kriegskunst gelern't hätten. ${ }^{109}$ Eine vorsichtige Friedensbereitschaft bestimmte jedoch die Haltung Archenholtz' nach dem Baseler Frieden. Er stellte fest, daß u.a. die große Mehrheit des englischen Volkes

Stuttgart 1939, S. 47-48; Stern, Alfred, Der Einfluss der französischen Revolution auf das deutsche Geistesleben, Stuttgart und Berlin 1928, S. 30-34.

105 Ruof (1915) S. 129. Das Katalog in Minerva 1798 IV S. 565-.

106 Minerva 1796 I S. 201-204.

107 Ibid. 1797 III S. 2-3.

108 Ibid. 1795 II S. $374-375$.

109 Ibid. S. $381-382,390$. 
einen Frieden mit Frankreich wolle, daß dort eine Schreckensregierung herrsche und daß vor allem die Regierung Pitts an der Forsetzung des Krieges Schuld sei.110 Als die Zeitschrift 17.95 die kriegerischen Grenadierlieder Gleims veröffentlichte, die den Baseler Frieden direkt verurteilten, ${ }^{111}$ gab Archenholtz seinen Lesern zu verstehen, daß er selbst nicht der gleichen Meinung wie Gleim sei.112

In der gleichen Weise war auch die zweite große Zeitschrift des »dritten Deutschland», Wielands »Neuer Teutscher Merkur», bestimmt, die in Weimar herausgegeben wurde und in Leipzig erschien. Nach 1790 war Christoph Martin Wieland ein bejahnter und anerkannter Ästhetiker und Schriftsteller. Sein klassischer Humanismus stand in enger Beziehung zur französischen Aufklärungsliteratur und verband ihn eng mit dem »europäischen Kosmopolitismus».113 Wieland war zu seiner Zeit der am meisten gelesene deutsche Schriftsteller, dessen Ansehen zwar nach 1798 unter den Angriffen der Romantiker sohwand.114 . Alsdie große Französische Revolution ausbrach, gehörte auch Wieland zu ihren begeisterten Anhängern, da er auf vielen wichtigen Gebieten sehr weit mit den Leitideen der Revolution übereinstimmte. Eine eigentliche revolutionäre Einstellung hat Wieland jedoch nie vertreten. Den allgemeinen, humanistischen und liberalen Grundsätzen der Revolution stimmte er sehr gern zu, aber ihr grobes Vorgehen in der Praxis ließ ihn sich fürchten. ${ }^{115}$

Die wichtigsten Kommentare zur Revolution veröffentlichte Wieland in der Zeitschrift »Neuer Teutsoher Merkur», eine der bedeutendsten in der Geschichite der deutschen Zeitschriften. Wieland hatte sie unter dem Namen »Der Teutsche Merkur» 1773 begründet. In einem Zeitraum von zwanzig Jahren kämpfte sie um die Stellung der bedeutendsten kulturellen Zeitschrift in Deutschland.116 Die größte Auflage in den siebziger Jahren betrug 2000-2500 Exemplare, sank aber nach 1790 schon unter 1000 Exemplare. Jedenfalls bestimmte der Merkur bis zu Beginn des 19. Jahrhunderts in einem bedeutenden Maße die öffentliche Meinung in Deutschland. Besonders in den siebziger und achtziger Jahren stand Wieland ein ausgedehnter und repräsentativer Mitarbeiterstab zur

110 Ibid. IV S. 117.

111 Gedichte von Gleim in Minerva 1795 I S. 570-571, II S. 178-182, 370372, III S. 192-193. Vgl. später.

112 Minerva 1795 I S. 183.

113 Gollwitzer, Heinz, Europabild und Europagedanke, München 1964, S. 170.

114 Hirzel, Ludwig, Wielands Beziehungen zu den deutschen Romantikern, Diss. Bern 1904, S. 4; Georg Joachim Göschen, Berlin und Leipzig 1935, S. 5.

115 Kirchner (1958) S. 181 und 250; Herse (1949) S. 62.

116 Sengle (1949) S. 408-409; Wahl (1914) S. 40 und 252-255; Salomon II (1902) S. 53. 
Seite. Goethe, Schiller, Kant, Herder, Fr. Jacobi, Gleim und viele andere führendie Persönliohkeiten des geistigen Lebens in Deutschland arbeiteten $\mathrm{zu}$ verschiedenen Zeiten mit Wieland zusammen. Man kann sogar von einem Schriftstellerkreis unter der Führung Wielands sprechen, der erfolgreich mit Friedrich Nicolai stritt.118 Im Laufe der Jahre entstanden für den »Merkur» neue Konkurrenten, gegründet von Mitarbeitern und Kollegen, die sioh auch anderen Organen zuwanden — besonders den oben erwähnten »Horen» -, so daß der Einfluß von Wieland und seiner Gruppe in der zweiten Hälfte der neunziger Jahre ziemlich gering geworden war. Seinem Charakter nach ist der »Merkur» ästhetisch-literarisch und nicht politisch. Die Zunahme der Konkurrenz auf dem Zeitschriftenmarkt und das zunehmende Interesse des Publikums an politischen Themen führte zusammen mit Wielands eigenem Interesse dazu, daß nach dem Ausbruch der Französischen Revolution politische Themen einen größeren Raum im »Merkur» einnahmen. ${ }^{119}$ Wieland verfolgte die Ereignisse genau und kommentiente sie scharf und waohsam. ${ }^{120}$ Die großzügige Zensur in Weimar ermöglichte die Veröffentlichung eines eigenen politischen Standpunktes und die Diskussion gesellschaftlicher Fragen. So gelangte der »Merkur» zu noch größerer Bedeutung. ${ }^{121}$

Die ersten Kommentare zur Französischen Revolution veröffentlichte Wieland im September 1789. In ihnen bekannte er sich ohne Einschränkung zur Volksversammlung und der von ihr geleisteten Arbeit. Er wandte sich nur gegen einen zu großen Enthusiasmus. Mit der Entwicklung der Revolution in eine radikalere Richtung nahmen Wielands Artikel einen immer warnenderen Ton an. Seiner Meinung nach waren die Jakobiner Räuber und Demagogen und die von ihnen veranlaßten Septembermorde bezeichnete er als das »Rasen vom Pöbel». ${ }^{122} 1794$ veröffentlichte Wieland ein bedeutendes Resümee zur politischen Lage in Europa unter der Überschrift »Über Krieg und Frieden». Hier verurteilte er die Gewalttätigkeiten der Revolution, wandite sich aber gleichzeitig gegen den Gedanken eines »Ausrottungskrieges» und warnte die Monarchen Europas, die Repubilik zu vernichten. ${ }^{123}$

117 Wahl (1914) S. 29.

118 Ibid. S. 199, 204.

119 Herse (1949) S. 62.

120 Wahl (1914) S. 209-211.

121 Siehe S. 12.

122 Wieland, C. M., Sämmtliche Werke Bd. 29 S. 148-191, 233-234. Neuer Teutscher Merkur (NTM) 1790 II S. 42, später z.B. NTM 1792 IV S. 139, 193-197, 398. Vgl. Gooch, G. P., Germany and the French Revolution, London 1927, S. 144. 123 Wieland, S. W. Bd. 29 S. 513-514. Stern, Alfred, Wieland und die französische Revolution, Stuttgart und Berlin (1914) S. 114; Stern (1928) S. 111; Gooch 
Mit Ausnahme des Jahres 1798 ist Wieland in dem von dieser Untersuchung bearbeiteten Zeitraum in seiner journalistischen Tätigkeit nicht sehr aktiv gewesen. Auf das Jahr 1798 werden wir noch zurückkommen. Der Jahrgang von 1795 des »Menkur» ist politisch gesehen besonders farblos und eine klare Linie läßt sich nicht ohne Schwierigkeiten aufzeigen. In zwei Artikeln wurde die Verstärkung des deutschen Widerstandes gefordert, ${ }^{124}$ und Wielands bedeutendster Mitarbeiter und Mitherausgeber, Karl August Böttiger, vertrat eine deutlich frankreichfeindliche Position.125 Andererseits erschienen in der Zeitschrift aber auch Aufsätze, in denen man sich für einen Friedensschluß einsetzte. So wird in zwei Gedichten von Joseph von Hinsberg trotz ihres nationalistischen Hermann und Thusnelda-Themas die Sehnsucht nach Frieden laut, ${ }^{126}$ und ebenso äußert sich ein »R.H.» in einem Artikel, in dem scharf die Kriegsbereitschaft der Emigranten verurteilit wird. ${ }^{127}$ Auffallend ist, daß im »Merkur» der Baseler Frieden kaum mit einem Wort erwähnt wird. Erst zu Beginn des folgenden Jahres begann man ihn in zustimmender Weise ausführlich zu kommentieren. So fordert u.a. Wieland die europäischen Monarchen auf, nach dem Wunsch der Völker zu einem Frieden zurückzukehren. ${ }^{128}$ Der junge romantische Dichter Johann Daniel Falk verurteilt in scharfer Form Gedichte, die die Deutschen als Kherusker und Volk von Todschlägern danstellen wollten. Wieland schloß sich daran an. Er verurteilt die Agitation und die Vorstellung vom deutschen Patriotismus des militaristischen »Revolutions-Almanachs»: »Blitz, Hagel, Wetter! Herr, das ist ja unser Brot». Er verspottet weiterhin Burke und Rehberg mit ihren militaristischen Ansichten. ${ }^{129}$ Im Sommer 1796 wird schließlich im »Merkur» das Gedicht »Oskars Friedegesang», eine Verherrlichung des Baseler Friedens, veröffentlicht. ${ }^{130}$

Soweit die Darstellung der den Frieden verteidigenden Stimmen in der tagespolitischen Literatur des »dritten Deutschland», die sich in Zeitschriften zu Wort meldeten. Gleichzeitig erschien eine große Zahl von Flugschriften, die auch zu Krieg und Frieden Stellung nehmen. Während der größte Teil der auf preußischem und österreichischem Gebiet

(1927) S. 150. Vgl. Wahl (1914) S. 208 und Siegers, Walther, Menscheit, Staat und Nation bei Wieland, Diss. München 1930, S. 71.

124 NTM 1795 II S. 76, IV S. 399.

125 Ibid. I S. 315.

126 Ibid. III S. $225-236$.

127 Ibid. S. $144-146$.

128 NTM 1796 I S. 108-112.

129 Ibid. S. $362-363$ und Anm. S. 363 und 381.

130 Ibid. II S. 183. 
erschienenen Flugschriften auf Veranlassung der Regierungen erschienen war, vertreten die Flugschriften des »dritten Deutschland» spontanere und ehrlichere Meinungen. Natürlich gab es auch hier Einflüsse von Seiten der Regierungen, so ergriff z.B. der Gesandte Hannovers am Reichstag in Regensburg, Freiherr Dietrich Heinrich Ludwig von Ompteda, selbst anonym Partei in der dem Baseler Frieden folgenden Diskussion um Preußen und den Frieden. ${ }^{131}$ In den den Frieden gutheißenden Flugschriften sind alle die Meinungsrichtungen ventreten, die auch in den Zeitschriften deutlich werden. So gibt es eindeutig revolutionäre Schriften, die gegen die Gegner des Friedens, besonders Österreich und seine ausländischen Verbündeten England und Rußland, mit Spott und Hohn zu Felde ziehen. Man hebt die Bedeutung des preußischen Sonderfriedens für das ganze Reich hervor und empfiehlt allen Fürsten, diesem Beispiel zu folgen. Es gehe um die Bewahrung des Reiches vor der vollkommenen Zerstörung, und wenn nichts anderes helfen würde, müsse man sich mit den Feinden Österreichs und Rußlands verbünden. ${ }^{132}$ Auch in den Flugschriften mit monarchistischer Einstellung nahm man Frankreich gegenüber eine zustimmende Haltung ein und kritisierte scharf die Rückständigkeit im Reich, besonders die geistlichen Länder und Fürsten. ${ }^{133}$ Die vorsichtigeren, aber eindeutig sich für einen Frieden einsetzenden Flugschriften, beriefen sich gerne auf das Grundgesetz des Reiches und trugen ausführlich rechtmäßige Friedensvorschläge vor. Dazu gehört oft die Bewahrung der Ehre des Reiches. Damit verbindet sich, daß die Tapferkeit der deutschen Soldaten hervor gehoben und als Schuld für die Niederlage die französische Übermacht genannt wurde. Allgemein vertrat man den Standpunkt, daß sich das Reich auf Gebietsabtretungen vorbereiten müsse. Sogar der Rhein sei als Grenze denkbar. ${ }^{134}$

1795-96 erschien in Altona anonym eine zweibändige Untersuchung. unter dem Titel »Geschichte der menschlichen Ausartung» von einem Beamten der preußischen Justizverwaltung, Christian Ludwig Paalzow.

131 Tschirch I (1933) S. 91. Beytrage zur Erörterung der Frage . . 1795.

132 Der Congress zu Bopfingen, Im November 1795; Kennzeichen der Jakobiner, MDCCXCV: Ueber den Frieden zwischen der Franken-Republik und Sr. Majestät dem König von Preußen, 1795; Unpartheyische Geschichte des Aufenthalts der fränkischen Bürger ... 1795; Rückblicke auf den . . 1975.

133 Geheime Geschichte von Coblenz während der französischen Revolution, Frankfurt und Leipzig 1795.

134 Stimme eines Einzelnen über die Art der Beywürkung des Reichs zu dem gewünschten Frieden mit Frankreich, 1795; Staatsproblem; war er rathsam ... 1795; Flüchtliche Bemerkungen ... 1795; Ueber die Frage: ist es ... 1795; Einladung von Konfuz ... 1795; Ueber den Einfluss ... 1795. 
Das umfangreiche Werk behandelt philosophische Themen im Geiste der Aufklärung und teilsweise der Revolution und u.a. das Problem Krieg und Frieden. Der antiklerikale und sich gegen die Tyrannen-Fürsten wendende Paalzow schloß sich mit seinem Werk an die pazifistische Tradition an, die in Norddeutschland in Aufklärerkreisen herrschte und die gleichzeitig noch deutlicher von Immanuel Kant vertreten wurde. Der Revolution stimmte Paalzow zu, natürlich mit Ausnahme der Gewalttätigkeiten. Es sei verständlich, daß ein lange in Fesseln und Dunkelheit gehaltenes Volk bei seiner Befreiung auch Grausamkeiten begehen würde. »Die Natur ist mächtiger als alle geistliche und weltliche Vorurtheile, als alle Tyrannen und Priester.»135 In dem Kapitel »Vom Soldatenregimente, oder von dem militärischen Staate» spricht sich Paalzow gegen stehende Heere aus. In dem Abschnitt »Von dem Kriege» stellt er fest, daß im allgemeinen die Interessen der Tyrannen zu Kriegen führen würden und diese deshalb zu verurteilen seien. Paalzow verbindet seine Meinung von der Ungerechtigkeit der Kriege jedoch mit Vorbehalten, die ihn in die Nähe der später vorzustellenden Gruppe der »kriegerischen Friedensverteidiger» bringt:

»Der Krieg ist nur gerecht, wenn er nothwendig ist, wenn die Wohlfahrt einer Nation würklich in Gefahr ist. Eine Nation ist in Gefahr, wenn ungerechte Nachbarn ihr eine billige Regierung, einen zu ihrer Glückseligkeit nothwendigen Fürsten, die Freiheit, den Genuss ihrer wohlerworbenen Rechte rauben wollen. Endlich ist der Krieg gerecht und nothwendig, wenn man ohne denselben des Friedens nicht versichert sein kann.»136

Obgleich Paalzow z.B. scharf Eroberungskriege verurteilt, so wirft die obige Äußerung doch ein merkwürdiges Licht auf seinen Pazifismus.

Als $\mathrm{G}$ a $\mathrm{n}$ z e s gesehen hat die im Jahre $1795 \mathrm{im}$ »dritten Deutschland» erschienene Literatur, die sich für den Frieden einsetzte, viel Gemeinsames mit der in Preußen geführten Diskussion. Im Sinne der Aufklärung führte man das Zerstörerische des Krieges an, forderte Reformen im Reich und erklärte eine Fortsetzung des Krieges schon aus militärischen Gründen für sinnlos. Die Einstellung zur Französischen Revolution schwankte stark, obwohl man in der Friedensfrage selbst einig war. In den folgenden Jahren sollte mit der Veränderung der militärisch-politischen Lage diese Einstellung auch die Friedensfrage in besonderem Maße beeinflussen und starke Meinungsunterschiede hervorrufen.

135 Geschichte der menschlichen Ausartung I, Altona 1795, Vorwort. Eder (1955) S. $48-51$.

136 Geschichte der menschlichen Ausartung II (1796) S. 103-116, 42-51. 


\section{Enttäuschung und Zorn in Österreich und unter den »Reichsdeutschen»}

Österreich war der Hauptgegner Frankreichs auf dem Kontinent und natürlich auch im Deutschen Reich. Der Hof vertrat am deutlichsten das adelige Gegenwicht zur Französischen Revolution. Österreich war das erste Land gewesen, das militärisch gegen die Revolution aufgetreten war. Der seit 1792 regierende Kaiser Franz II. war der Neffe Marie Antoinettes, die man hingerichtet hatte, und das revolutionäre Frankreich hielt den Wiener Kaiser für den schlimmsten der Tyrannen. Die Habsburgische Monarchie hatte bis 1795 stark unter den Revolutionskriegen $\mathrm{zu}$ leiden gehabt. Es schien so, daß die Niederlande unwiederbringlich verloren waren, und Vorder-Österreich hatte viel durch französische Kriegstätigkeit $\mathrm{zu}$ erdulden. Aber für Österreich ging es um viel mehr als um reine territoriale Verluste, an die sich die Monarchie schon im Laufe ihrer langen Geschichte gewöhnt hatte. Der bevorstehende allgemeine Frieden zwischen Frankreich und dem Deutschen Reich würde nämlich eine große Umwälzung bedeuten, die zum völligen Auseinanderbrechen des zerbrechlichen und alten Reiches führen könnte. Das hätte zur Folge gehabt, daß die Habsburger die universale Macht der römischen Kaiser und Karls des Großen symbolisierende Krone des Heiligen Römischen Reiches Deutscher Nation verlieren würden, die sie über $300 \mathrm{Jahre}$ fast ununterbrochen getragen hatten. Österreich war die sicherste Stütze des alten Systems und für seine Fortexistenz war die Weiterführung des Krieges wenigstens bis auf weiteres notwendig. Preußen konnte durch seinen Rückzug aus dem Krieg möglicherweise nichts anderes verlieren als seine Autorität, für Österreich hätte ein Friedensschluß wesentlich mehr gekostet. Es ist natürlich, daß der Frieden von Basel für Österreich ein großes Unglück bedeutete. Das öffentliche Wort erhob sich einstimmig zum Kampf gegen Preußen und den Sonderfrieden. In diesem Streit erhielten die Österreicher in gewissem Grad Unterstützung auch aus konservativen, den Kaiser und das alte Reich verehrenden Kreisen des »dritten Deutschland». Diese werden hier als »Reichsdeutsche» bezeichnet.

Für die politischen Diskussion, die in Österreich geführt wurde, war es seit der Revolutionskriege typisch, daß gleichzeitig mit der Forderung nach Fortsetzung des Krieges Maßnahmen gegen Reformen, Aufklärungsideen und Liberalismus durchgeführt wurden. Der Aufklärung, die unter Josef II. auch in Österreich viele Anhänger gefunden hatte, wurde jetzt der letzte Schlag versetzt. Das führende Organ in der ersten Hälfte der neunziger Jahre des 18. Jahrhunderts in Wien, die "Wiener Zeitschrift», 
forderte u.a. die Rückkehr zur Inquisition und eine Verschärfung der Zensur und sprach sich gegen jede Art von Liberalismus aus. Der gleichen Geist bestimmte ihre Nachfolger. Es bildeten sich religiös-mystische Geheimgesellschaften, deren Aufgabe es war, zweifelhafte Kreise zu bespitzeln. Einer von diesen waren die »Elektriker», die besonders die Freimaurer bedrängten und überall Spuren des Jakobinismus witterten. ${ }^{137}$ Das politische und geistige Leben Österreichs beherrschte ein engstirniger Obskurantismus. Die zur 'Leit des Baseler Friedens die österreichische Regierung unterstützende öffentliche Meinung wandte sich gegen Preußen. Um diese öffentliche Meinung zu unterstützen, organisierte die österreichische Regierung noch eine Gruppe bezahlter Schriftsteller und Journalisten, die sich daran machte, in Flugschriften und Zeitschriftenartikeln den preußischen Sonderfrieden und den norddeutschen Neutralitätspakt anzugreifen. ${ }^{138}$ Eine sehr strenge Zensur ließ nur diese eine Art der Meinungsäußerung zu. ${ }^{139}$ Wegen revolutionärer Äußerungen und Verschwörungen wurde man zum Tode verurteilt. Spontane und gelenkte Diskussionen sind schwer von einander zu unterscheiden, weil beide bei ihrer Argumentation in gleicher Weise vorgingen. Hier werden zuerst die Diskussionsbeiträge behandelt, die für »spontan» gehalten werden müssen, daran anschließend wird die eindeutig von der Regierung veranlaßte Literatur behandelt.

1793 stellte die »Wiener Zeitschrift» ihr Erscheinen ein. Anfang 1794 begann ein gleichartiger Nachfolger $\mathrm{zu}$ erscheinen, das »Magazin der Kunst und Literatur», das in den folgenden drei Jahren das öffentliche Wort in Österreich anführte. Die Zeitschrift wurde von dem Wiener Felix Franz Hofstätter herausgegeben, dem bedeutendsten »Obskurantisten» in Österreich. Abgesehen vom Titel war das »Magazin» eine vollkommen politisch ausgerichtete Zeitschrift, die aktiv zu den tagespolitischen Ereignissen Stellung bezog. Den Baseler Frieden lehnt sie natürlich ab. Schon mit Beginn des Jahres 1795 begann Hofstätter zusammen mit seinen Mitarbeitern gegen einen möglichen Friedensschluß zu kämpfen. Die Zeitschrift warnt die Österreicher und anderen Deutschen vor verräterischen Friedensbemühungen und deren ernsten Folgen für das ganze Reich. Diejenigen, die einen Frieden herbei sehnten, verglich er mit Schafen, die dem Angebot des Wolfes trauten. Die folgende Fabel ist ein Beispiel dafür, wie die Partei der Friedensgegner versuchte, eine Ausbreitung der Friedensbereitschaft in Deutschland $\mathrm{zu}$ verhindern:

137 Eisner (1907) S. 39, 48; Bulling (1914) S. S. 115-116.

138 Siehe S. 31-32. Ein einheitlicher Überblick über diesen Federkrieg Tschirch I (1933) S. $64-107$.

139 Eder (1955) S. 59. 
»Die Lämmer und die Wölfe. Lämmer und Wölfe schlossen einen feyerlichen Frieden und versicherten sich einander durch Geisel. Die Lämmer gaben ihre Hunde und die Wölfe ihre Jungen. Als nun die Lämmer, des Friedens froh, freyer umher streiften, heulten die jungen Wölfe aus Verlangen nach ihren Müttern. Die Wölfe hörten das Geheul, stürzten auf die Lämmer ein, die jetzt ohne den Schutz ihrer Hunde waren, klagen über Treulosigkeit, und zerreissen sie. Ach! rief ein sterbendes Lamm, so nachtheilig war uns selbst der Krieg nicht.» ${ }^{140}$

In erster Linie versucht man zu beweisen, daß der atheistischen und verräterischen Republik nicht zu trauen sei und man unmöglich mit ihr einen Frieden schließen könne. Man wies nach, daß die Grundsätze der Revolution unsinnig seien. Die Forderung nach Gleichheit wird mit einer Fabel charakterisiert, in der einem Esel die Forderung nach Gleichheit mit einem Pferd zugestanden wurde. Von da an wollte dieser enthusiastische Esel auch mit seinem Herren gleichgestellt sein. Dieser mußte ihn dann zornig in seine Rolle als Esel zurückstufen. ${ }^{141}$ Es ist verständlich, daß ein so scharfes Urteil auch zu einer feindseligen Einstellung zu den Deutschen führte, die Freundschaft mit einer solchen Mörderbande wollten. Der Jahrgang von 1795 enthält eine große Zahl scharfer Angriffe gegen deutsche Schriftsteller, die sich für einen Frieden einsetzten, andrerseits dankte man denen, die für die Fortsetzung des Krieges waren. ${ }^{142}$ Nachdem der Friedensschluß eine Tatsache war, veröffentlichte Hofstätter einen umfangreichen Aufsatz, in dem er feststellte, daß Deutschland in keiner Zeit so tief gefallen sei: „Es hat Kraft, sich zu wehren, und bittet, verschont $\mathrm{zu}$ werden!». ${ }^{143}$

Hofstätter wurde vom größten Teil der bedeutendsten Schriftsteller Österreichs unterstützt. Vielleicht am eifrigsten war sein Mitarbeiter Lorenz Leopold von Haschka, der bekannteste Vertreter des Wiener Obskurantismus und eine Art Volksdichter in Österreich zur Zeit der Revolutionskriege. In Wien gebonen und von Jesuiten erzogen diente er am Anfang seinem Kaiser als Bibliothekar, dann als Professor für Ästhetik, daneben schrieb er in beredter Weise für zahlreiche Zeitschriften. Von Anfang an verfolgte er die Ereignisse der Revolution feindselig und kämpfte unermüdlich gegen sie. Seine vaterländischen Weisen erklangen sowohl bei Siegen als auch bei Niederlagen zur Ehre des Kaisers und

140 Magazin der Kunst und Literatur (Mag. d. K.u. L.) 1795 I S. 45.

141 Ibid. S. $10-11$ und 44.

142 Ibid. $2-11,26,72-120,254-255$, III S. $53,264-265,327-371$, IV S. 141 , 153, 240, 273 usw.

143 Ibid. IV S. $166-175$. 
seiner Armee und zur Stärkung des Kampfgeistes der österreichischen Untertanen. ${ }^{144}$ In den Nummern des Jahrgangs von 1795 des »Magazins der Kunst und Literatur» veröffentlichte er sechs Gedichte mit gleichem Inhalt. Das im Januar 1795 verfaßte Gedicht »Der Aufklärer» war antirevolutionär und richtete sich gegen Aufklärerkreise in Deutschland. Weiterhin verurteilte er den von jenen Kreisen umhegten »Gelehrtenrepublik»-Gedanken. Nach dem Baseler Frieden veröffentlichte Haschka eine kriegerische Ode, die zur Fortsetzung des Kampfes aufrief und den Friedensschluß als Verrat verurteilte. ${ }^{145}$ Neben Artikeln und Zitaten von Haschka veröffentlichte das »Magazin der Kunst und Literatur» Arbeiten von Österreichern, die alle nach dem Baseler Frieden beteuerten, es sei für Österreich und seine Völker notwendig zur Verteidigung von Kaiser, katholischer Kirche, des Grundgesetzes, der Moral und des Eigentums den Krieg gegen die verhaßte Revolution fortzusetzen. ${ }^{148}$ Neben Texten von Österreichischen Verfassern druckite man auch Emigranten und zitierte Schriften anderer deutscher Schriftsteller, wenn sie nur ihrer politischen Richtung nach in den Rahmen der Zeitsohrift paßten. ${ }^{147}$ Leopold Alois Hoffmann, der zur Redaktion des »Magazins» gehörte, führte den härtesten Angriff gegen den Frieden in einer zweiteiligen Flugschrift, »Höchst wichtige Erinnerungen», die zum Jahreswechsel von 1795-96 erschien. Er wïtete gegen die Revolution, die Jakobiner und Illuminaten, die der »heiligen Guillotine» dienen würden und Verräter des deutschen Vaterlandes seien. Pressefreiheit hielt er für gefährlich und schlecht, die schriftstellerische Tätigkeit der Aufklärer solle eingeschränkt werden. Es versicherte, »Deutschlands Völker» seien gläubige Anhänger ihrer Fürsten, zum Kriege bereit und unerschütterliche Mitglieder der Kirche. ${ }^{48}$ Im zweiten Teil setzten sich die Angriffe fort; besonderes Angriffsziel war Kant. ${ }^{149}$

Die oben genannten schriftstellerischen Aktivitäten unterstützte die österreichische Regierung noch dadurch, daß sie Schriftsteller gegen Bezahlung gegen den Frieden schreiben ließ. Ohne Zweifel war dic Tätigkeit dieser »Federsölner» zur Zeit des Baseler Friedens am größten.

144 Über Haschkas Schriften siehe z.B. Keil, Rober.t, Wiener Freunde 1784-1808 II, Wien 1883, S. 29-30.

145 Mag. d. K. u. L. 1795 I S. $215-222$, II S. $376-377$, III S. $1-5,229-234$, $260-263$, IV S. $293-297$.

146 Ibid. IV S. 64-68 usw.

147 Ibid. II S. 268 empfehlt »Eudämonia», aus deren Zitaten z.B. IV S. 46-47.

148 Hoffmann, L. A., Höchst wichtige ... I-II, 1795-96. Epstein (1965) S. $521-522$.

149 Hoffmann II Anm. S. 191-192. 
Von den Schriftstellern, die von der österreichischen Regierung bezahlt wurden, war Johannes von Müller, ein in der Schweiz geborener Historiker, der produktivste und bekannteste. Aus seiner Feder stammen mindestens 7-8, wahrscheinlich aber noch mehr Flugschriften, die gegen die preußische Friedenspolitik zielten. ${ }^{150}$ Die enste enschien im April 1795 in Ulm - es war üblich, daß die anonymen Schriften außerhalb Österreichs gedruck't wurden odes daß der Druokort nicht angegeben wurde — unter dem Titel »Die preussische Mitverwendung für den Reichsfrieden». Hier stempelte Müller das preußische Angebort, einen Frieden für das ganze Reich zu vermitteln, als Verrat ab. Der heldenhafte Befehlshaber der österreichischen Truppen, Graf Clerfayt, stände mit seinen 180000 Mann an der Rheingrenze auf Wacht gegen die entkräfteten und ausgehungerten Feinde. In dieser Situation einen Frieden vorzuschlagen, sei Verrat. Die Schrift wirft dem preußischen König vor, zum eigenen Vorteil zu handeln, genauer gesagt, er strebe nach der Kaiserwürde. Auch nationale Gesichtspunkte berücksichtigte Müller. Das preußische Vorgehen zeige seiner Meinung nach, daß es in Deutschland keine Deutschen mehr gegeben habe, als Preußen sich von dem Feind in die Führungsrolle des Reiches habe helfen lassen. Das sei die Leichenpredigt Preußens auf das Grundgesetz des Reiches gewesen. Zum Schluß wies Müller noch darauf hin, daß Österreich sich aus der Kaiserwürde überhaupt nichts machen würde. Der preußische »Nebenkaiser» könne gerne die schweren Lasten eines Oberhauptes des Reiches übernehmen. ${ }^{151}$

Nachdem die preußische Regierung in dieser Angelegenheit eine Erklärung abgegeben hatte, kam es zu einem richtigen »Federkrieg» zwischen Österreich und Preußen, in dem Müller besonders aktiv wurde. Er veröffentlichte ein Flugblatt, in dem die preußische Erklärung versehen mit spöttisohen Kommentaren als Ganzes abgedruckt war. Mit Vergnügen weist er auf das Abkommen von Pillnitz hin, in dem sich Österreich und Preußen gegenseitige Treue im Kampf beteuert hätten, solange bis sein Ziel, die Rückkehr der Monarchie in Frankreich, erreicht worden sei. Preußen hätte nun aufgehönt zu kämpfen und in aller Freundschaft mit der Republik dem Feind das uralte germanische Gebiet, das Westufer des Rheins, geopfert. Es hätte alle Bündnisse im voraus ohne vorherige Ankündigung gebrochen. Nach Meinung Müllens könne man auch keineswegs den Beteuerungen Preußens glauben, daß es zu schwach zum Weiterkämpfen sei. Er erinnerte an den Sieg Friedrich des Großen im

150 Tschirch I (1933) S. 82, 84-85.

151 Die preußische Mitverwendung ... 1795 S. 8-17, 25-26. Tschirch I (1933) S. $85-86$. 
Siebenjährigen Krieg. Es sei ganz und gar töricht, daß Preußen einen Krieg aufgäbe, in dem es weniger Gefallene zu beklagen habe als in zwei Schlachten des vergangenen Krieges. Auch Preußens Erklärung von der französischen Stärke sei übertrieben. Das preußische Elend - wie es in der Erklärung heißen würde - beklage man und man wundere sich, daß die Franzosen jetzt »der erschöpften, verarmten Monarchie,» einen Frieden schenken würde, »deren Feldherr noch vor einigen Jahren Paris zum Steinhaufen machen wollte». Auch auf die polnischen Teilungen wird zweimal hingewiesen. Nach Meinung Müllers sei es ergötzlich, wie Preußen jetzt sich mit den Republikanern verbrüdere, obgleich es am eifrigsten die Polen als gefährliche Republikaner und Revolutionäre vernichtet habe. Nach seiner Meinung gäbe es nur eine Möglichkeit und das sei, das Reich möglichst in seiner ursprünglichen Form zu erhalten. Preußen sei jetzt der gefährlichste Feind Deutschlands, gegen den der Kaiser das Reich stützen müsse. Ohne zu klagen habe der Kaiser schon sein Vermögen, ohne jeden Groschen mitgerechnet, dem Reich geopfert. Aber seine Länder hätten noch Kraft: „Böheims ungeschwächte Natur, des kriegerischen Ungarns noch lang nicht unerschöpfiter Menschentond, Inneröstereichs zahlreiche Jugend...». Das Reich müsse seinem Kaiser vertrauen. Die rauchenden Trümmer der Fronten würden noch Frankreich erreichen. Der Jakobinismus habe versucht, auch in Österreich einzudringen, aber dort gäbe Millionen von Gläubigen, die die Bedrohung zurückgewiesen hätten. Der Artikel endet mit einer Aufforderung zum Kampf an alle Deutschen. ${ }^{152}$ Im Juni und Juli veröffentlichte er neue Schriften gegen Frankreich, Preußen und den Frieden. ${ }^{153}$ Danach konnte Müllers Anonymität nicht mehr geheim gehalten werden und er mußte eine Reihe von Gegenschriften entgegen nehmen. Besonders in Regensburg, wo sich der Reichstag ständig versammelte, erschien eine große Zahl von Flugschriften zur Friedensfrage. Von dem Federkrieg Müllers und dem Preußen verteidigenden Kaufmann wurde schon gesprochen. Müller veröffentlichte gegen Kaufmann drei Schriften, welche den preußischen Verrat und das Recht der österreichischen Sache beweisen sollten. Die Schrift »Fernere Beleuchtung des zu Basel geschlossenen Friedens» ist ein stilechtes Beispiel für die Propaganda Österreichs. Das Büchlein beginnt mit einem scharfen Tadel des »Schundjournalismus», der sich in ganz Deutschland ausgebreitet habe und enthält eine lange Liste dieser Art von schriftstellerischen Produkten, u.a. werden von Kauf-

152 Erklärung im Namen Seiner Königlichen Majestät ... mit einigen Anmenkungen, 1795. Tschirch I (1933) S. 82, 86.

153 Die Uibereilungen, 1795, S. 9-11, 15. Tschirch I (1933) S. 84-87. 
mann zwei Titel genannt. Der von Preußen geschlossene Sonderfrieden wird von Müller als juristisch unmöglich bezeichnet. England gegenüber sei Preußens Verhalten Verrat. Es habe diesen Friedensvertrag trotz mehreren hunderttausend Pfund an Unterstützungsgeldern unterschrieben. Es sei nicht die Absicht Preußens gewesen, Zeit für einen allgemeinen Frieden zu gewinnen, sondern es hake nur freie Hand in seiner Politik gewinnen wollen und nur zum eigenen Nutzen auf Kosten Österreichs gehandelt. Im zweiten Teil der Schrift wird die norddeutsche Demarkationslinie Preußens kritisiert und als ungesetzlich bezeichnet; man habe nur Frankreich einen Dienst erweisen wollen. Der brandenburgische Kurfürst habe nichit das Recht, dem Kaiser und den Truppen des Reiches dieses Gebiet $\mathrm{zu}$ verbieten. Am Schluß der Schrift konzentrierte sich Müller darauf, die Behauptung zurückzuweisen, daß der Kaiser keinen Frieden wolle. Dieser Vorwurf sei zurückzuweisen. Der Kaiser wolle nur einen Frieden schließen, der der Verfassung des Reiches und dem Westfälischen Frieden entspräche. Das habe er auch im Februar 1795 öffentlich verkündet. Der Kaiser sei nicht g r u n d s ä t z li c h gegen einen Frieden, sondern er sei bereit, ihn unter den genannten Bedingungen zu schließen. Viel Raum wurde verwendet, um einen preußischen Verrat nachzuweisen. Preußen habe schon zur Zeit Ludwig XIV. gegen Österreich unterstützt. Es sei neidisch auf die innere Stärke, die Maria Theresia und Joseph II. geschaffen hätten. Es habe die wichtigsten Teile Polens an sich gerissen und ebenso die fränkischen Fürstentümer, als Österreich Schwierigkeiten mit den Fürsten hatte und es zu Aufständen in den Niederlanden kam und so das Gleichgewicht Europas gestört. »Alles positive Recht» sei für Preußen nur »ein Spott» gewesen. Die Schrift endete mit einer Aufforderung an eine möglicherweise kriegsbereite Opposition:

»In Berlin selbst leben viele vortreffliche Männer, welche diese unseligen Speculationen, wodurch einige glauben, sich Verdierıste $\mathrm{zu}$ erwerben, gewiss verachten. Sie müssen einsehen, daß kein vernünftiger Mann für so einen Frieden seyn könnte, welcher der Keim eines weit grösseren und verderblichern Krieges seyn würde, wenn er mit Einführung einer Präpoderanz vergesellschaftet wäre, die im Reich durchaus niemanden zukommt, als den Gesetzen, und wem die Gesetze sie geben.»154

Den gleichen Inhalt hat die folgende Flugschrift »Patriotische, aber ehrfurchtsvolle Bemerkungen», die noch im gleichen Jahr verfaßt wurde.

154 Fernere Beleuchtung des zu Basel ... 1795 S. 5-11, 15-30, 32-46, 67 (Zitat). Vgl. Tschirch I (1933) S. $84-87$. 
Hier wurden die schon angeführten Beschuldigungen gegen Preußen wiederholt. Ein allgemeiner Frieden sei eine Unmöglichkeit. Die Schrift wies außerdem auf die Möglichkeit hin, daß die Freundschaft zwischen Preußen und den Vernichtenn des Throns der Bourbonen zu einem aktiven Bündnis zwischen beiden führen könne. ${ }^{155}$ Die folgende Broschüre »Noch einmal Bemerkungen» wiederholt die genannten Anschuldigungen und äußert den Glauben daran, daß Rußland eingreifen und Deutschland vor der Bedrohung Frankreichs und Preußens retten würde. ${ }^{156}$

Nach dem Federkrieg um den Baseler Frieden verringerte Müller seine journalistische Produktion und das Hauptgewicht verlagerte sich auf mehrere Streiter. Der produktivste von ihnen war der Deutschpole Karl Gottfried Glave-Kolbielski, eine der schillensten, hemmungslosesten und rücksichtslosesten Gestalten in der Publizistik Deutschlands zur Zeit der Revolutionskriege. 1795 bot er seine Dienste dem Meistbietenden an, sowohl dem französischen Minister Barthélemy und dem Kronprinz von Preußen als auch Österreich. Das letztgenannte bot am meisten und Glave wurde zum Leiter der Österreichischen Propaganda und der bedeutendste Mitarbeiter Alois von Hügels für zwei Jahre.157 Glave schrieb natürlich vor allem gegen Frankreich und seine Absichten, aber Objekt seines größeren Haßes waren doch Preußen und Rußland, die Urheber der polnischen Teilung. Den Baseler Frieden lehnte er schon aus dem Grunde ab, weil ohne diesem Frankreich diese hätte zwingen können, Polen neu zu bilden. Eine Flut von gehässigen Schriften verfaßt von Glave - in den Jahren zwischen 1795 bis 1801 verfaßte er ganze 32 politische Flugschriften - sellten in den nächsten Jahren die Tische und Schubläden der Buchhandlungen füllen. So stellt auch TSCHIRCH fest, daß GlaveKolbielskis Lebensarbeit zeige, wie ein verbitterter und schreiender Skribent ein falsches Bild von der allgemeinen Meinung des Volkes geben könne. ${ }^{158}$ Glave konzentrierte sich in seinen zahlreichen Flugschriften darauf, gegen vermutete Bündnispläne Preußens und Frankreichs zu kämpfen. Außerdem itrug er eine Reihe verschiedener Forderungen vor. Seiner Meinung nach müsse Europa einen ewigen Frieden schließen und sich auf eine gemeinsame Verteidigung gegen Amerika und Asien vorbereiten (!). Österreich und Frankreich seien zusammen die Stützpfeiler Europas. Preußen ziele darauf ab, diese Einheit zu zerstören. Die Neutralisierung Norddeutschlands gehe in diese Richtung, weshalb Glave

155 Patriotische, aber ehrfurchtsvolle Bemerkungen ... 1795.

156 Noch einmal Bemerkungen ... 1795.

157 Pribram-Fischer (1937) S. 4, 37-39, 44.

158 Ibid. S. 44; Tschirch I (1933) S. 109-112, 125. 
sie ablehnte. Obwohl man Glave in keinem Fall als Patrioten bezeichnen kann, stieß sein flammender Zorn gegen Preußen mit einigen Büchern auf wirkliches Interesse. ${ }^{159}$

Seine Gegner behandelte Glave mit mohr Hohn und Spott, als es allgemein üblich war, indem er Mittel gebrauchite, die häufig außer in den betreffenden auch in den Kreisen der Anhänger Österreichs auf Widerspruch stießen. Als Beispiel dafür kann man den Federknieg anführen, den Glave gegen den jungen Ansbacher Freiherrn Karl Leopold von Seckendorff führte. Seckendorf war zu dieser Zeit ein in Göttingen Rechtswissenschaft istudierender Idealist, der sich entschlossen hatte, sich in die hefitige Diskussion um Frieden und Krieg einzumischen, die gerade im Gange war. ${ }^{160}$ Sofort nach dem Abschluß des Baseler Friedens veröffentlichte er eine kleine Flugschrift unter dem Titel »An Teutschlands Reichsstände. Ein Wort zu seiner Zeit». Das Büchlein schildert eindringlich die Schrecken des Krieges und schließt mit einer ernsten Aufforderung zum Frieden:

»So wird dann endlich das weinende Teutschland in dunkler Ferne eine heitere Sonne emporsteigen sehn unter dem Wehen der Friedenspalme werden die grausamen Wunden dieses schrecklichen Krieges vernarben. - - Dann kann der Patriot ungescheut sein Haupt empor heben, und itreten aus dem nächtlichen Dunkel, in das er sich hüllen muss.»161

Diese schönen Worte beeindruckten Glave-Kolbielski in keiner Weise. Er antwortete unmittelbar mit einer giftigen Schrift, »Epistel an den jungen Mann», die mit der väterlichen Anrede »mein Kind» beginnt. Zuerst dankt Glave Seckendorff herzlich für diese schöne Absicht und den glänzenden Stil, den er kunstvoll parodiert. Dann wendet er sich seinem Anliegen zu, der Sonderfrieden Preußens sei eine Schande. Die »PreuBischen Friedens-Galoppaden» verurteilt er mit den gleichen Argumenten, die schon Müller gebraucht hatte: die Neutralität sei juristisch gesehen ein Verbrechen, Frankreich sei militärisch schwächer als Deutschland und die Deutschen hätten ihre Kriegsanstrengungen nur verstärken müssen, um es zu schlagen; noch sei es möglich, die Kräfte zum Kampf zu vereinigen und die Franzosen hinter den Rhein zurückzuwerfen. Zur Verstärkung seiner Argumentation veröffentlichte er eine Übersetzung des Briefwechsels zwischen Hardenberg und Barthélemy, der den Verrat

159 Pribram-Fischer (1937) S. S. 40-55; Tschirch I (1933) S. 109-111.

160 Tschirch I (1933) S. 111. ADB Bd. 33 (Theodor Schön) S. 519.

161 An Teutschlands Reichsstände. 1795. 
der preußischen Politik aufdecken sollte. Um die Wirkung seiner Schrift noch zu vergrößern, schloß er am Schluß der Schrift noch eine Nachschrift an, in der er berichtet, die Franzosen hätten den Rhein überquert und seien auf die andere Seite der preußischen Neutralitätslinie vorgedrungen. Der Sonderfrieden sei also schon gebrochen, so daß dem König von Preußen nur die Möglichkeit bleibe, offen entweder dem Kaiser oder Frankreich zu helfen, eine Alternative gäbe es nicht. ${ }^{162}$ Den Streit mit Seckendorff setzte Glave noch im folgenden Jahr fort.

Im September, Oktober und November 1795 erschienen von Glave unter dem Pseudonym »Karl Graf von Strengschwerd» drei Flugschriften, die ihrem Inhalt nach in großen Zügen den voran gegangenen entsprechen. In allen wird von einem Verrat Preußens und von der Unrechtmäßigkeit seines Vorgehens gesprochen, die Furcht und das »privat und provincial Interesse» wird mißbilligt. In seiner ersten Schrift hatte Graf Strengschwerd den Ländern des »dritten Deutschland» vorgeschlagen, sich mit Österreich gegen Frankreich und Preußen zu verbünden und die Vermutung ausgesprochen, daß Rußland noch auf die Seite Österreichs treten würde — seine Gegnerschaft zu Rußland störte den Polen dann nicht, wenn es um die Sache Österreichs ging. Besonders streng sprach Strengschwerd-Glave von dem geheimnisvollen Hardenberg, dessen Briefwechsel mit den Führenn Frankreichs er veröffentlichte. In dieser Situation gäbe es nur einen Ausweg: »zur Rettung Teutschlands und seiner bedrängten Stände kann nur ein Mittel wirksam und nützlich erscheinen, nemlich die Franzosen tüchtig zu schlagen». ${ }^{163}$

Die zweite Schrift versucht die Kreise in Franken zu beeinflussen, die Preußen überredete, sich seiner Neutralität anzuschließen. Glave meint, es gäbe keinen Grund auf den Feind zu hören. Seine Situationsanalyse ist interessant: Jeder wolle Frieden. Die Dummen wünschten ihn um jeden Preis, sei die Grenze nun der Rhein oder die Elbe, während die Weisen sofort bemerkt hätten, daß der preußische Sonderfrieden nur zu neuen Kriegen und zu neuem Unglüok führen würde. Indem er Preußen und andere friedenswillige Länder des »dritten Deutschland» tadelt, bedrängt er einige Schriftsteller des »dritten Deutschland», wie den fränkischen Reichsgrafen Julius von Soden, der für Preußen besonders ver-. nichtende Dokumente veröffentlicht habe.164 Die dritte Schrift ist im gleichen Geist geschrieben und tadelt vor allem Herzog Karl Wilhelm

162 Epistel an den jungen Mann ... 1795; Gedanken über die Mittel . . 1795.

163 Strengschwerd, Karl Graf von, Beurtheilung der Nate ... 1795, Zitat S. 98.

164 Strengschwerd, Kommentar und Beurtheilung ... 1794 [1795] S. 8, 31-32. 
von Braunschweig-Lüneburg, der Niedersachsen empfohlen hatte, dem Sonderfrieden 'von Basel zuzustimmen. Auch der Landgraf von HessenKassel wird von ihm auf die selbe Weise scharf gerügt, man würde sich jetzt nach dem Sonderfrieden um so bitterer an dessen Vergangenheit erinnern. Der gleiche Fürst habe im vergangenen Jahr Katarina von Rußland gebeten, Suworow über den Rhein zu schicken, und sein ganzes Volk bewaffnet - offensichtlich in der Hoffnung als Kurfürst gewählt $\mathrm{zu}$ werden - und jetzt hätte ihn sein Mut vollkommen verlassen, daß er jetzt »opfert der Furcht für die Franzosen sogar seinen Menschenhandel mit England auf; diesen Handel, der schon so manchen Tropfen hessischen Nationalbluts in Goldmünze verwandelte». Interessant ist Glaves Warnung, das in der Zukunft bei einer türkischen, polnischen oder russischen Bedrohung aus dem Osten die westlichen Gebiete neutral bleiben würden und der Feind so die Länder zwischen Elbe und Oder ungestört verheeren könnte. ${ }^{165}$ Glave gebraucht nicht nur das eine Pseudonym Graf Strengschwerdt. Indem er die Schriften Andreas Riems nachahmte, veröffentlichte er unter dem Namen eines preußischen Bürgers, Bauchwitz, die Schrift »Ueber die politische Lage und das Staatsinteresse Preussens». In der Schrift werden scheinbar Preußens Expansionspläne gutgeheißen und Preußen dazu ermutigt, aber in Wirklichkeit werden natürlich die anderen davor gewarnt. Nach Glave sei es die Absicht Preußens, u.a. Hannover, Mecklenburg und das schwedische Pommern zu besetzen, aus der Verbindung mit dem Reich zu lösen und sich an die Spitze eines neuen Fürstenbundes $\mathrm{zu}$ stellen. In diesem Bund solle es auch neben Monarchien Republiken geben, un:d am Schluß der Schrift wird vorausgesagt, das Preußen eine Republik werden werde. Besonders nachdrücklich verurteilt die Schrift die polnischen Teilungen und Preußens Anteil dabei. ${ }^{166}$ Unter dem Pseudonym »Weltbürger Syrach» greift er die preuBische Friedenspolitik an. In diesem Zusammenhang empfielt er sogar die Zusammenarbeit zwischen Österreich und Frankreich, um die hinterlistigen Intrigen Preußens und Rußlands abzuweisen. ${ }^{167}$

Die Tätigkeit Glave-Kolbielskis befriedigte Österreich nicht vollkommen. Glaves Vorgesetzter, Johann Alois von Hügel, gebrauchte selbst den

165 Strengschwerd, Beurtheilung des Schreibens ... 1795, S. 9-21, Zitat S. 21.

166 Ueber die politische Iage und das Staatsinteresse Preussens nach der neuesten Holländischen Revolution von dem preussischen Bürger Bauchwitz, 1795. Von ihm soll auch mit dem Namen von Bauchwitz geschriebener Schrift Anmerkungen der preussischen Deklaration ...

167 1795, in dem der Baseler Frieden streng verurteilt wurde.

Tschirch I (1933) S. 67-71, 79-81. 
Namen »K. von Strengschwerdt»,168 und Glaves oft über das Ziel hinausschießende und schreiende Schriften hat man ihm zugeschrieben. Glave sei seiner Meinung nach in seinen Angriffen gegen die deutschen Fürsten $\mathrm{zu}$ weit gegangen und er verbot seinem Mitarbeiter auf dieser Linie fortzufahren. Auch würden diese Angriffe nicht vollkommen mit der östereichischen Politik übereinstimmen. So wurde auf das alte Mißtrauen der Deutschen gegenüber Rußland hingewiesen, als es für die östereichische Außenpulitik äußerst wichlig war, von Rußlarnd Unlerstülzung zu erhalten. Der Hinweis auf die englisch-deutschen Soldatenkäufe wiederum konnte ein fragwürdiges Licht auf das alte System werfen, das Österreich verteidigte. Bald sollten diese Schwierigkeiten sich vermehren und $z$ u einer Beendigung des »Arbeitsverhältnisses» führen. ${ }^{169}$

In einem $\mathrm{R}$ es üm e e zur politischen Tagesliteratur in Österreich im Jahre 1795 läßt sich sagen, daß sie besonders einheitlich und konsequent ist. Die im Lande herrschende strenge Zensur und die starke Beteiligung der Regierung an der Diskussion duroh bezahlte Kräfte und die Beamtenschaft zusammen mit einer Einstellung von Staatstreue, Religiosität und einem allgemeinen Konservatismus führte $z u$ einem einheitlichen Bild der Meinungen in Österreich. Bis zum Baseler Frieden war der Aufklärungsgeist und die Zustimmung zur Revolution, die Anfang der neunziger Jahre des 18. Jahrhunderts in weiten Kreisen Wiens herrschten, erstickt. Das öffentliche Wort in Österreich kämpfte konsequent gegen Frieden, neue Ideen und mögliche Reformen und Veränderungen.

Die frankreichfeindliche Schriftstellergruppe des »dritten Deutschland» veröffentlichte im wesentlichen in zwei Zeitschriften, die über einen längeren Zeitraum hin erschienen. Die »Eudämonia» erschien 1795-98 an verschiedenen Orten (1795 in Leipzig, 1796-97 in Frankfurt am Main und 1798 in Nürnberg) unter der Redaktion des Hofrates E.A.A. von Göchausen. Diese Zeitschrift vertritt den adeligen Konservatismus $\mathrm{zu}$ dieser Zeit in Deutschland am typischsten - und am extremsten. Mehr auf die gegen Frankreich gerichtete Politik konzentrierte sich der »Revolutions-Almanach», der 1795—99 von dem Gothaer Beamten H.A.O. Reichardt und seit 1800 von dem in Böhmen geborenen Reichsfreiherrn Franz Joseph v. Albini redigiert wurde.

Die »Eudämonia» begann $1795 \mathrm{zu}$ erscheinen. In der ersten Nummer legte Göchausen sein im März verfaßtes Programm vor, an das sich die

168 Weller, Emil Lexicon Pseydonymorum, Regensburg 1886, S. 542. Im J. 1795 zumindestens Rechtliches Gutachten die Uebergabe der Festung Mannheim, Regensburg [Leipzig].

169 Pribram-Fischer (1937) S. 58. 
Zeitschrift dann auch sehr konsequent halten sollte. Das deutsche Volk sei moralisch an einem Tiefpunkt angelangt. Man halte im Lande nichts mehr auf die Religion, auf gute Sitten, auf das Grundgesetz und Patriotismus, an ihre Stelle seien »Gottesverleugnung und Lästerung, Fürstenhass, öffentliche Verspottung der Fürsten und schwänmerische Revolutionslust» getreten. Es sei die wichtigste Aufgabe der neuen Zeitschrift, den $»$ Gemeinsinn der deutschen Völker, in religiöser und politischer Hinsicht» zu fördern. Religion, Treue gegenüber den Fürsten und der Verfassung des Reiches, bürgerliche Erziehung, National-Charakter der Deutschen und Glück des Volkes und jedes Einzelnen sind Termini, die in der Zeitschrift ständig in den folgenden Jahren wiederholt werden. Man müsse die Aufmerksamkeit auf das Glück des Volkes richten. Sogar die Aufklärung strebe gerade nach diesem Glück. »Eudämonia» vertritt einen in vieler Beziehung gegen die Grundsätze der Aufklärung gerichtete Linie, aber in diesem Fall verbindet sie sich mit der Vorstellung ihres Gegners, um sich Einfluß und Ansehen zu sichern. Schon in der Überschrift kommt der Begriff »deutsches Volksglück» vor. In dem erwähnten Programmentwurf für die Zeitschrift greift Göchausen Frankreich und die französisch gesinnten Deutschen an und verteidigt die in Deutschland herrschenden Verhältnisse. ${ }^{170}$

Auch in der Friedensfrage bezieht die Zeitschrift eindeutig Stellung. Ein Anonymus $\gg V »$ wendet sich scharf gegen die Jakobiner in Deutschland, besonders gegen den Freiherrn von Knigge, und ihre Forderung, Deutschland solle Frieden schließen. An einen Frieden mit den Franzosen sei überhaupt nicht zu denken. Sie seien gottlose Barbaren, die vielleicht Brüder »unter den Kannibalen, der Irokesen und unter den Wilden von Neu-Seeland» finden könnten, aber nicht in Deutschland. Es sei vergeblich, von den Deutschen eine Beendigung des Krieges zu verlangen, weil die Franzosen den Krieg wollten. Der Artikel lobt die Tapferkeit Hessens während des Krieges und schließt einen Friedensschluß völlig aus:

»O! dann zehnmal lieber Krieg, als solch ein Friede, von welchem Umsturz den Thronen und der Altäre, und allgemeines Elend die Früchte sah!»

In dem Artikel werden die Illuminaten angegriffen und die Zensur wird zur Verhinderung ihrer Unruhe stiftenden Wirkung befürwortet. Artikel im gleichen Ton erscheinen in der Zeit vor dem Baseler Frieden.

170 Eudämonia I: 1, 1795, S. III-XV. Siehe auch Krüger, Gustav, Die Eudämonisten, HZ 143 (1931) S. 467-468; Epstein (1966) S. 521. 
In der Aufsatzserie »Nachricht aus dem feindlichen Gebiete» gebraucht von Stolberg für die Franzosen erfinderisch die Bezeichnung »Westhunnen» und erklärt, daß Illuminaten und Freimaurer das Vaterland verraten hätten. ${ }^{171}$ Der Artikel "Mein Glaubensbekenntnis über Volksaufklärung» weist auf die Gefährlichkeit der Ideen der Aufklärung hin und verteidigt Religion gegen Umsturz, Atheismus und brutale Gotteslästerung. Ein aus dem Französischen übersetzter Aufsatz über den Aufstand in der Vendée ergreift völlig die Partei der Emigranten und Aufständischen. Zwei Aufsätze verteidigen die Bewaffnung des Volkes. ${ }^{172}$ Der Baseler Frieden wird im ganzen Jahr überhaupt nicht erwähnt, aber es erschienen immer wieder Artikel gegen einen Frieden. In einem anonymen Artikel, »Wem's glückt, der hat Reoht», lehnt man einen »schimpflichen Frieden» scharf ab und hält das ganze Gerede von einem allgemeinen Frieden für unvernünftig, weil es nur dem Interesse Frankreichs dienen würde. Der Verfasser hofft gleichzeitig auf eine Gegenrevolution in Frankreich, die die Friedenshoffnungen realistischer machen würde. Ein zu Ende des Jahres erschienener Artikel erklärt, daß Frarkreich die ganze Welt versklaven würde. Joachim von Schwarzkopf versichert in der letzten Nummer des Jahrgangs, die Nachkommen Hermanns, die Deutschen, würden den Krieg fortsetzen. ${ }^{173}$

In der »Eudämonia» wird auch ausführlich auf andere Diskussionsbeiträge zur Friedensfrage eingegangen. Zahlreiche Artikel und Verfasser werden vom eigenen Standpunkt aus kritisiert. Sehr oft und in scharfer Weise wird der schon erwähnte Illuminatenführer, der Freiherr von Knigge, angegriffen. ${ }^{174}$ Negative Kritiken erhalten auch Knigges $»$ Kampfgefährte» Adam Weishaupt, die Mainzer Klubisten Cranz, Dorsch, Likemeyer, Böhmer, Schneider und Anarcharsis Cloots, der Aufklärer Nicolai, die Philosophen Fichte und Immanuel Kant, wie auch die radikalen Journalisten Rebmann und Huber und eine Gruppe französischer Journalisten. ${ }^{175}$ Dank fanden wiederum die Gegner dieser Schriftsteller. An der Zeitschrift arbeiteten mit: von Stolberg, von Schirach und der Ritter von Zimmermann, der Abt Ignaz Joseph Martinovics, der Kastellan Focke und Professor Eberhard wie auch der in der Schweiz geborene Emigrant Richer-Serizi. Sie alle lehnten einen Friedensschluß ab und erhielten

171 Eudämonia I: 1, 1795, S. 3-42 ('Zitat Anm. S. 40) und 44-52.

172 Ibid I: 2, 1795, S. $97-102,105,150-156$ und I: 5 S. $391-400$.

173 Ibid. I: 3,1795 , S. $177-182$, I: 4 S. 283 , I: 6 S. $532-549$.

174 Ibid I: 1,1795 , S. $17-18$ (Anm.), 66-67, I: 2 S. 136-148, I: 3 S. 239.

175 Ibid. I: 1, 1795, Anm. S. 30, 44-52, 66-67, I: 2 S. 200, I: 4 S. 299, 352, 363, I: 5 S. 403, 438, I: 6 S. 517 und Anm. S. 520. 
Zustimmung. ${ }^{176}$ Die Begründungen der »Eudämonia» gegen einen Friedensschluß sind ungefähr dieselben, wie sie in Österreich vorgetragen wurden. Die katholische Religion - als dessen Gegengewicht man die französische atheistische Aufklärung und die Freimaurerei ansah -, Treue zum Kaiser und der heiligen Verfassung des Reiches, ein deutschnationaler »Hermann»-Geist und der Glaube an die eigene militärische Stärke bestimmen die Artikel. Obgleich man einen Frieden nicht grundsätzlich für unmöglich hielt, wie auch in Österreich nicht, forderte man einen Frieden unter ehrenhaften und rechtmäßigen Bedingungen, was in der Praxis die Fortsetzung des Krieges bedeutete.

Neben der »Eudämonia» waren noch weitere Zeitschriften des »dritten Deutschlands» zusammen mit Österreich bereit gegen einen Sonderfrieden zu kämpfen. Der von dem Gothaer Heinrich August Ottokar Reichardt herausgegebene »Revolutions-Almanach» ist in ihrer Art die radikalste Zeitschrift. Im Jahrgang von 1794 werden alle Friedensbemühungen energisch abgelehnt und eine entschlossene Fortsetzung des Krieges mit vermehrten Kräften gefordert. ${ }^{177}$ Der Friedensschluß von Basel wurde mit Verwirrung registriert, was in der Farblosigkeit des Almanachs von 1795 deutlich wird, wenn auch in diesem eine frankreichfeindliche Einstellung vorherrscht.178 In der Folgezeit wendet sich der »RevolutionsAlmanach» immer deutlicher gegen einen Frieden. Ottokar Reichardt gab noch andere Veröffentlichungen in ungefähr demselben Geist heraus. Die gleiche Linie schlug die in Berlin enschienene belletristische und als solche unpolitische Zeitschrifit »Olla Potrida» ein: 1794, zur Zeit des Reichskrieges veröffentlichte die Zeitschrift einige kriegerische, an die Herrmanns-Mythologie anknüpfende und patriotische Aufsätze, ${ }^{179}$ während sie nach dem Baseler Frieden zumindest einen scheinbaren den Frieden gutheißenden Standpunkt einnahm. Die Zeitschrift veröffentlichte u.a. einen umfangreichen Artikel zur Friedensfrage, in dem der Friedensschluß sowohl aus praktisch-politischen als auch aus militärischen und theoretischen Erwägungen gerechtfertigt wird; der Artikel entspricht ungefähr den in Preußen erschienenen Veröffentlichungen, die den Frieden gutheißen. ${ }^{180}$ Es ist ganz offensichtlich, daß hier die Zensur ihre Wirkungen hatte, denn Reichardts in Göttingen erschienener »RevolutionsAlmanach» und auch seine in Gotha erschienene »Gothaische gelehrte

176 Ibid. I: 1, 1795, S. 44, 60, 66-67, I: 3 S. 217, 193-199, 239, I: 6 S. 465 usw.

177 Revolutions-Almanach (Rev. Alm) 1794 Vorbericht, S. 65-155, 208-231 usw.

178 Ibid. 1795 S. I-IV.

179 Olla Potrida 1794 I S. $3-11$, II S. $3-5$ und $103-105$.

180 Ibid. 1795 IV S. 102-106. 
Zeitung» vertrat zum gleichen Zeitpunkt einen gegensätzlichen Standpunkt. ${ }^{181}$

»Eudämonia» hatte in sehr zustimmender Weise die in Göttingen erschienene und kurzlebige Zeitschrift »Neue Zeitblätter» erwähnt. Die 1795 erschienenen drei Hefte enthalten scharfe Angriffe auf die Sonderfriedenpolitik und die Forderung, daß der Kampf unter der Führung des Kaisers mit allen Anstrengungen des Reiches fortgesetzt werden müsse. ${ }^{182}$ ln gleicher Weise äul3erte sich der gegen die H'riedenspolitik kämpfencle, konservativ eingestellte Göttinger Arzt-Literat Christoph Girtanner in seiner Veröffentlichung, »Historische Nachrichten und politische Betrachtungen über die französische Revolution», die in 17 Nummern zwischen 1791 und 1803 erschien sowie der »Almanach der Revolutions-Charaktere für das Jahr 1796» des Jahres 1795.

Nach der Meinung Girtanners gab es keine Voraussetzungen für einen Friedensschluß, und die ihn forderten Deutschen, werden als Verräter bezeichnet. ${ }^{183}$

Die gegen einen Frieden kämpfenden 7eitschriften Österreichs und der »Reichsdeutschen» wurden durch auf private Initiative entstandene Flugschriften auch auf dem Gebiet des »dritten Deutschlands» unterstützt. Große Beachtung fand die umfangreiche, über 200 Seiten umfassende Schrift »Ensite Hinsicht auf sein Vaterland bei Annäherung des Friedens von einem biedern Deutschen» des Braunschweigischen Hofrates und Professors Eberhard August Wilhelm von Zimmermann, die »allen Edlen und Grossen Germaniens» gewidmet war. Die Schrift enthält fast alle typischen Argumente der konservativen Deutschen, für die eine Fortsetzung des Krieges unabdingbar war. Die Französische Revolution, das »fürchterliche Trauerschauspiel», bedrohe die ganze Menschheit und besonders Deutschland. Jeder brave Deutsche müsse deshalb die Verbreitung der Revolution mit allen Kräften verhindern. Zimmermann betont den Patriotismus ider Deutschen. Die schlechten Sitten Frankreichs würden die Moral der Deutschen verderben, der französische Wein und die französische Seide würden ihnen ihr Geld nehmen. Es sei ein Unglück, daß so viele deutsche Höfe Frankreich bewundern würden. Es läge nicht an der Verfassung des Deutschen Reiches. Vor dem Ausbruch der Revolution hätten die meisten Deutschen ganz zufrieden gelebt. Vielleicht hätte die Unzufriedenheit darin ihre Wurzeln, daß die schlechter regierten

181 Siehe Note 178. Goth. gel. Z. 1795 Nr. 78 S. $690 ; 1796$ Nr. 3 S. 20-21. 182 Neue Zeitblätter 1795 I-III.

183 ADB Bd. 9. (A. Hirsch) S. 189-191. z.B. Historische Nachrichten 1795 (X) S. 101 und 247. Eisner (1907) S. 37. 
Länder nahe bei Frankreich lägen. Das Benehmen der französischen Emigranten wurde kritisient und ihre herausforderden Sitten in ihren neuen Wohnsitzen in Deutschland getadelt. Es sei offensichtlich, Frankreich wolle die Revolution ins Ausland tragen, den Rhein zur Grenze machen, die Verfassung Deutschlands aufheben usw. Im Schluß seiner Schrift stellt Zimmermann Überlegungen darüber an, ob Frankreich stark genug sei, dieses Ziel zu erreichen. Er verneint dies. Die Bevölkerungszahl Deutschlands sei größes, es habe mehr Soldaten als Frankreich, das mindestens schon eine Million 16-60jährige Männer verloren habe. Frankreich fehle es an allem, an Pferden, an Gold und Silber und die Situation sei nicht mehr zu verbessern. Deutschland dagegen habe nur 650000 Männer verloren, seine Armee sei größer und besser ausgebildet. Deutschland sei auch reicher, es hätte genügend Gold und Silber, Pferde, Getreide, Wolle und Leinen zum Kriegführen. - In typisch feudalistischer Gedankenführung zählt Zimmermann die Menge an Edelmetallen, Menschen, Pferden oder Wolle als ausreichende Faktoren der Kriegsführung auf. Frankreich habe jetzt eine "grosse, bis jetzt nie unterjochte Nation» vor sich. Deutschland brauche nur seine Kräfte zu vereinigen. Man müsse eine gemeinsame Kriegskasse bilden, in die alle Besitzenden Geld einzahlen sollten. Die Fürsten sollten ihrem Kaiser vertrauen. Mit pathetischen Worten wurde nach Einigkeit verlangt:

»Einigkeit, innige Einigkeit, ihr Fürsten Deutschlands, diese fordert laut auf eine Nation, eure eigene Sicherheit. Dort, dort jenseits des Rheins ist der Erbfeind eurer ganzen Nation - Das Vaterland ist in Gefahr.»

In gleicher Weise wird den tapferen Soldaten Österreichs, Preußens, Sachsens und Hannovers gedankt und besonders Preußens große Macht und Kraft hervorgehoben. Um so schärfer werden die preußischen Verhandlungen mit den Franzosen verurteilt, ein »trügerischer Plan». Deutschland müsse an seine Halbbrüder Holland und Belgien denken, denen die Uneinigkeit Unglück gebracht habe. Wenn die Belgier ihrem guten Fürsten (dem Kaiser) geholfen hätten, so wären sie in der Lage gewesen, den verlogenen Galliern eine Ohrfeige zu versetzen. Jetzt dagegen sei das ganze Land ausgeraubt. Das Schicksal Polens stehe Holland bevor. Ein positives Beispiel wiederum sei die Einigkeit Englands. Am Schluß hebt Zimmerman die Bedeutung von Moral und Religion hervor und ermahnt alle deutschen Stände, wobei er besonders den Adel, die Priester und die Gelehrten anführt, außerdem verspricht er auch Frankreich die Freiheir. 184

184 Zimmermann, E. A. W., Erste Hinsicht ... 1795 (Zitat S. 209). 
Die gleichen Meinungen wurden auch in anderen Flugblättern vorgebracht. Der polnische Diplomat Scipion de Piattoli betonte Patriotismus, Religiosität und Treue zum Kaiser, den Fürsten und dem heiligen Reich gegenüber in einen kleinen, aber viel beachteten Broschüre »Weltbürger Sirach der Sohn an Deutschlands Reichsversammlung». Die Schrift wendet sich nicht direkt gegen den Frieden, aber verurteilt eine Reihe von Sonderfriedenversuchen und einen unehrenvollen Frieden. Der Kaiser sei in der Lage sich selbst und das Reich zu verteidigen, die Deutschen müßten sich jetzt um ihn scharen: würden sich doch während eines Sturmes auch die Tiere nicht in zwei Herden teilen, sondern »treten sich zusammen, schliessen sich um den Führer der Heerde und machen von allen Seiten Fronte». Nun müsse man für Kaiser und Reich kämpfen. "Franz wünscht und liebt den Frieden; verachtet aber und hasst Verrath, Traulosigkeit, Schleichwege!»185 Besonders Gewicht auf Religiosität legte der Pfarrer von Burgau Franz Xavier Christmann in seiner Schrift »Ueber den französischen Priester-Eid», der zur Barmherzigkeit gegenüber den von der Revolution vertriebenen Emigrantenpriestern aufforderte. ${ }^{180}$ Der Bayer Joseph von Sartori, der gründlich Staats- und Rechtswissenschaften studiert hatte, verurteilte die Sonderfriedenpolitik und die Revolution mit juristischen Begründungen. Für ihn war nicht das Grundgesetz am militärischen Mißerfolg der Deutschen Schuld, sondern »die Unentschlossenheit vieler deutscher Stände». ${ }^{187}$ In gleicher Weise wandte sich der Bayer Kaspar Lehmann von einen juristisch-historischen Standpunkt aus gegen Frankreich und die Revolution und betonte als deutscher Patriot, daß Österreich nicht für die eigene Sache sondern für die Sache der Verfassung ganz Deutschlands und Europas kämpfe. ${ }^{189}$ Dieselben Argumente wiederholte eine Reihe von anonymen Flugschriften. ${ }^{190}$

185 Weltbürger Sirach der Sohn ... 1795.

186 Ueber den französischen Priester-Eid ... 1795.

187 v. Sartori, Jos., Memoiren über die wichtigsten Staats-Materialien unserer Zeit Bd. I 1795, S. 140-141, 172.

188 Lehmann, Kaspar, Versuch einer Geschichte österreichischen Regenten ... 1795, S. $219-222$.

189 z.B. Nun auch patriotische Bemenkungen über das kaiserliche Hofdekret ... 1795; Preußens Benehmen nach seinem Separatfrieden ... 1795; Pragmatische Darstellung des constitutionswidrigen preußischen Separatfriedens ... 1795; Deutsohland und Pohlen ... 1795; Aufruf [1795].

190 z.B. Antifragmente ... 1795; Aufruf [1796]; Aufruf an die vorliegende Reichskreise ... 1795; Nun auch patriotische Bemerkungen ... 1795; Preußens Benehmen nach seinen Separatfrieden ... 1795; Pragmatische Darstellung ... 1795; Deutschland und Pohlen ... 1795; An Deutschlands Reichsstände; Rescript des Herrn Herzogs ... 1795; Fortsetzung der patriatischen Bemerkungen . . 1795. Vgl. Tschirch I (1933) S. 94-100. 
$\mathrm{Zu}$ der Gruppe der Schriftsteller, die sich gegen das »dritte Deutschland» und gegen einen Frieden Österreichs wandten, ist noch der in der Schweiz seßhafte, in Ulm geborene, Buchhändler Johann Georg Heinzmann mit seiner laute Töne anschlagenden Schrift »Ueber die Pest der deutschen Literatur. Apel an meine Nation» zu rechnen, in der er sich gegen die Aufklärung und die Aufklärer wendet. Religion, Vaterland, deutscher Patriotismus und Unverletzlichkeit der Gesetze sind seine Schlagworte. Als Verräter des deutschen Volkes werden von Heinzmann einige sich für den Frieden einsetzende Philosophen und Literaten, wie Immanuel Kant und Friedrich Nicolai, bezeichnet, dazu verteidigt er Alois Hoffmann und Gleim — "unsere Geldautoren».191

\section{Kant's "Zum ewigen Frieden» und sein Echo}

Ihrem Charakter nach war die Diskussion, die sich um den Baseler Frieden entzündet hatte, zum aller größten Teil auf die praktische Politik ausgerichtet. Obwohl auch ideell begründete Standpunkte vorgetragen wurden, so lag der Schwerpunkt deutlich auf realpolitischen Vorgängen. Die bedeutendste philosophische Arbeit, die zur Zeit des Baseler Friedens erschien, ist Immanuel Kant's kleine Untersuchung »Zum ewigen Frieden», vom Herbst 1795. Die hier vorgetragenen Gedanken sollten in der ideellen Friedensdiskussion der folgenden Jahre unablässig wiederholt werden. Auf sie bezog man sich und gegen sie protestierte man in Dutzenden von Schriften. Es ist deshalb notwendig Kant's Schrift hier ausführlicher $\mathrm{zu}$ ibehandeln. Über Kant's Friedensvorstellungen, den man zu den größten Namen in der Geschichte des Pazifismus rechnet, wurden Legionen an Untersuchungen verfaßt, ${ }^{192}$ trotzdem muß hier dazu etwas gesagt werden.

Der Königsberger Kant war preußischer Untertan, Professor an der Universität seiner Heimatstadt. In dem zu untersuchenden Zeitraum

191 Heinzmann, Johann Georg, Ueber die Pest ... 1795.

192 Die Auffassung Kants über den Frieden wird z.B. in folgenden Werken dargestellt: Vorländer (1907); ders. (hrsg.), I. Kant, Zum ewigen Frieden, Leipzig 1914; Zickendraht, K., Kants Gedanken über Krieg und Frieden, Tübingen 1922; Natorp, Paul, Kant über ewigen Frieden, Erlangen 1924; Ebbinghaus, Julius, Kants Lehre vom ewigen Frieden und der Kriegsschuldfrage, Tübingen 1929; Borries (1928) und später z.B. v. Raumer (1953) und Görland, Ingtraud, Die Kantkritik des jungen Hegel, Frankfurt a.IM. 1966. Die Forschung konzentriert sich also besonders in 1920er Jahren, die auch sonst eine sehr lebhafte Phase der Forschung von der Geschichte und Theorie des Pazifismus war. Auch Burg, Peter, Kant und die Französische Revolution, Berlin 1974. 
war Kant schon ein älterer (geb. 1724), bekannter und angesehener Philosoph. In der zweiten Hälfte der neunziger Jahre nahm er lebhaft an der Krieg und Frieden behandelnden öffentlichen Diskussion teil und äußerte sich danach in mutigen Vorlesungen und zahlreichen Zeitschriftenartikeln. Kant schrieb Artikel u.a. für Biestens und Gedikes »Berliner Monatsschriften», »Jenaer allgemeine Literaturzeitung» und Wielands »Merkur».193 Neben dem Buch »Zum ewigen Frieden» erschienen in den folgenden Jahren von ihm mehrere verschiedene Schriften, die häufig auf die Tagespolitik ausführlich Bezug nahmen. Es ist nicht ganz klar, welche Verbindung zwischen der Schrift »Zum ewigen Frieden» und dem Baseler Frieden eigentlich besteht. KARL VORLÄNDER vermutet, daß sie gerade zur Rechtfertigung des genannten Friedensschlusses entstanden ist. Dieser Meinung haben sich sehr viele Forscher angeschlossen.194 Für diese Vermutung spricht, daß Kant in einer Reihe von anderen Zusammenhängen seine Freude über diesen Frieden zum Ausdruck brachte. ${ }^{195}$ Kant war nämlich prinzipiell ein Freund der Französischen Revolution und unternahm alles, um ihre neuen Ideen zu verbreiten. Der Kampf seines eigenen Landes gegen das Land, in dem viele dieser neuen Ideen zu Hause waren, stellte für ihn die ganze Zeit einen Widerspruch dar, und er unterließ es auch nicht, dies öffentlich auszusprechen. ${ }^{196}$ Es scheint als natürlich, daß Kant gerade durch den Baseler Frieden dazu angeregt wurde, ein Programm zur Weiterführung des Friedens zu entwickeln. Offensichtlich sind vom Abbé Saint-Pierre die wichtigsten Einflüsse ausgegangen, von denen Kant viele aufnahm und weiterführte. ${ }^{197}$

Kant's Friedensphilosophie geht von dem moralischen Grundsatz aus, daß für den Menschen auch dann die Pflicht besteht, weil ihm sein Gewissen den Befehl gibt und die Humanität es erfordert, den ewigen Frieden als oberstes Ziel zu setzen, wenn auch der Verstand uns sagt, daß er nur

194 Vorländer (1914) S. 113-115. Dieselbe Einstellung haben auch z.B. Borries (1928) S. 200, Hemleben (1945) S. 87 und Eisner (1907) S. 105. Zickendraht (1922) S. 7 und die Geschichtsforschung in der DDR sehen das Buch umgekehrt als Protest gegen Baseler Frieden, z.B. Biographisches Lexikon zur Deutschen Geschichte (BLDG); 1967, Thom) S. 239.

195 Borries (1928) S. 200.

196 Tschirch I (1933) S. 423.

197 Reininger, Robert, Kant, seine Anhänger und seine Gegner, München 1923 S. 206; Natorp (1924) S. 10; Vorländer (1914) S. 160; Ebbinghaus (1924) S. 2-3. Röhrdanz (1936) hat die Tendenz zu nachweisen, daß Kant kein Pazifist oder Revolutionär war. 
im Grab möglich sei. Nach Kant braucht man bei der Friedensfrage wie auch bei der Bewertung anderer moralischer Fragen keine anderen Faktoren berücksichtigen. Die zweite ideelle Grundregel für die Forderung nach einem ewigen Frieden besteht für ihn darin, daß jeder Mensch seine eigenen Bestimmung habe und nicht das Werkzeug der Absicht eines anderen sein könne. Kant bezieht also die entgegengesetzte Position zur feudalistisch-merkantilen Denkweise. Weil der Krieg von allen am typichsten den Menschen als Werkzeug gebrauche, sei er schon deshalb moralisch abzulehnen. Kant glaubte nicht, daß sein Friedensprogramm einen großen Einfluß haben werde, er hielt es aber trotzdem für seine Pflicht, es zu veröffentlichen:

»Das bedingt sich aber der Verfasser des Gegenwärtigen aus, daß, da der praktische Politiker mit dem theoretischen auf dem Fuß steht, mit großer Selbstgefälligkeit auf ihn als einen Schulweisen herabzusehen, der dem Staat, welcher von Erfahrungsgrundsätzen ausgehen müsse, mit seinen fachleeren Ideen keine Gefahr bringe, und den man immer seine eilf Kugel auf einmal werfen lassen kann, ohne, dass sich der weltkundige Staatsmann daran kehren darf, dieser auf, im Fall eines Streits mit jenem sofern conseqvent verfahren müsse, hinter seinen auf gut Glück gewagten, und öffentlich geäusserten Meynungen nicht Gefahr für den Staat zu wittern; - durch welche Clausuln salvatoria der Verfasser dieses sich dann hiemit in der besten Form wider alle bösliche Auslegung ausdrücklich verfahrt wissen will.»138

Dieses Zitat zeigt nicht nur Kant's Besorgnis, daß er falsch verstanden werden könnte - vor allem wohl von der Zensur - sondern ist auch ein Beispiel für seinen gründlichen und verwickelten Stil, der allerdings keine besondere Ausnahme im schriftlichen Sprachgebrauch der deutschen Gelehrten zu dieser Zeit darstellt.

Kant's Untersuchung gliedert sich in zwei Hauptteile, in »Präliminarartikel» und in »Definitivartikel» zum ewigen Frieden unter Staaten. Nach den Präliminarartikeln muß ein Friedensvertrag abgelehnt werden, der nur als Zwischenfrieden gedacht ist. Unter den Dynastien soll Erbung, Tausch oder Kauf von Ländern verboten sein. »Stehende Heere sollen mit der Zeit ganz aufhören.» Für außenpolitische Auseinandersetzungen dürfen keine Staatsschulden gemacht werden. »Kein Staat soll sich in die Verfassung und Regierung eines andern Staats gewaltätig einmischen.» Außerdem sollen in einem Krieg bestimmte Regeln eingehalten werden, die es ermöglichen schneller zu einem Frieden zu kom-

198 Kant, Immanuel, Zum ewigen Frieden. Ein philosophischer Entwurf. Königsberg 1795, S. 3-4, 5-17. - Borries (1928) S. 120-121. 
men. ${ }^{198}$ Unter diesen Anfangsbedingungen befinden sich schon solche, die Kant einer bestimmten Position in der Friedensdiskussion in Deutschland zuweisen. Seine ablehnende Haltung gegenüber dem Erbrecht unter den Fürstenhäusern und das Annektieren der verschiedenen Staaten brachte ihn eindeutig in Gegensatz zur Verfahrensweise seines eigenen Staates. Die Verurteilung stehender Heere richtete sich vor allem gegen die alten Staaten Europas: Die französischen Armeen hatten mehr Miliztruppen zu den Waffen gerufen, als was man im 18. Jahrhundert unter stehenden Heeren verstand. Der Anstieg der Staatsschulden während des Krieges wies ganz deutlich auf England hin. ${ }^{199}$ Von Bedeutung ist das Verbot der Einmischung in die Verfassung eines anderen Staates. Die Koalitionsstaaten hatten oft verkündet, daß sie so lange kämpfen würden, bis in Frankreich die Monarchie zurückgekehrt sei.

In zweiten Teil legt Kant seinen endgülitigen Standpunkt dar. Unter den »Definitivartikeln» fordert der erste, daß die Verfassung in jedem Staat republikanisch sein müsse. Nach Kant's Auffassung kann man von einer republikanischen Verfassung sprechen, wenn sie sich auf den Prinzipien und Grundsätzen der Freiheit in einer Gesellschaft gründet, in der der Mensch als Mensch sie bildet, was die Abhängigkeit von einer einzigen einheitlichen Gesetzgebung voraussetzt, und wenn sie sich auf die Gleichheit ihrer Bürger stützt, so daß sie die einzige rechtmäßige Staatsordnung darstellit, die »aus der Idee des ursprünglichen Vertrages hervorgeht». Diese Republik sei die einzige, die, wenn sie verwirklicht wird, zu ewigen Frieden führe. Kant's Begründungen sind initeressant:

»wenn (wie es in dieser Verfassung nicht anders seyn kann) die Beystimmung der Staatsbürger dazu erfordert wird, um zu beschließen, ob Krieg seyn solle, oder nicht, so ist nichts natürlicher, als daß, da die alle Drangsele des Krieges über sich selbst beschließen müßten (als da sind: selbst zu fechten; die Kosten des Krieges aus ihren eigenen Haabe herzugeben; die Verwüstung, die er hinter :sich läßt, kümmerlich verbessern; zum Übermasse des Uebels endlich noch eine, den Frieden selbst verbitternde, nie (wegen naher immer neuer Kriege) zu tilgende Schuldenlast selbst zu übernehmen), sie sich sehr bedenken werden, ein so schlimmes Spiel anzufangen ... 200

In einer Monarchie sei die Situation anders. Für einen Herrscher sei das Beginnen eines Krieges »die unbedenklichste Sache in der Welt»,

199 Tschirch I (1933) S. 423: Tschirch betont (in negativischem Sinn) Kants Abneigung gegen England, z.B. S. 104.

200 Kant 1795 S. 23-24; Görland (1966) S. 42-44, 52. 
weil er kein gleichgestellter Bürger sondern der Besitzer des Staates sei, der den Beginn eines Krieges mit genauso ungerechtfertigten Gründen beschließen könne wie das Veranstalten eines Ausflugs oder eines Hoffestes. Seine Forderung nach einer Republik definiert Kan't in bemerkenswerter Weise noch genauer: das republikanische Staatssystem dürfe man nicht, »wie gemeinlich geschieht», mit dem demokratischen verwechseln. Damit will er sagen, daß seiner Meinung nach die Staatsform seines Idealstaates parlamentarisch sein müsse, wobei die Exekutive von der Legislative getrennt sei, und nicht die »demokratische» Form, in der z.B. die Volksvertretung sich selbst beide Formen der Gewalitanwendung nehmen würde. Trotz dieser Einschränkung hält es Kant jedoch für wesentlich, zwischen Despotie und Republik zu unterscheiden.

Genauso wichtig wie Kant's Forderung nach einer Republik ist der zweite Definitivartikel zum »Föderalism». „Das Völkerrecht soll auf einen Föderalism freyer Staaten gegründet seyn», heißt seine kategorische Forderung. Seiner Meinung nach lebiten die Völker in einem Naturzustand wie die Wilden, verletzten sich gegenseitig und würden die Forderung nach gegenseitiger Sicherheit nicht anerkennen. Der Völkerbund bürge dafür, daß eine Gemeinschaft der Völker gebildet werde. Kant will einen Völkerbund, keinen Völkerstaat, nach ihm der Zusammenschluß aller Völker der Erde zu einem Staat. ${ }^{201}$ Mit Hilfe des Völkerbundes sei es möglich, die Beziehungen zwischen den Völkern besser denn je zu regeln. Kant stand dem internationalen Recht seiner Zeit pessimistisch gegenüber. Man beziehe sich zwar immer auf die Rechtsvorstellungen von Grotius, Pufendorff und Vattel, aber nur um das Führen von Kriegen zu rechtfertigen. Im Gegenteil, es gäbe überhaupt keinen Staat, der auf Grund der Prinzipien der genannten Herren seine militärischen Unternehmungen aufgegeben hätte. Das Mittel, mit dem die Völker zu ihrem Recht zu kommen versuchen, sei nicht ein neutraler Gerichtshof sondern der Krieg. Für den Sieg entscheide jedoch nicht das Recht. Friedensverträge hätten bisher nur einmal einen Krieg beendet und den auch nur vorübergehend. Wenn man einen allgemeinen und beständigen Frieden erreichen wolle, so müßten die Völker anstatt einen normalen Friedensvertrag einen Friedensbund schließen (foedus pacificium), das alle Kriege beenden würde. Kant erörtert auch, wie seine Gedanken zu verwirklichen seien. Seiner Meinung nach sei ohne weiteres den Plan zu verwirklichen; er habe »objektive Realitäten». Diese »Realität» verbindet Kant ganz eindeutig mit der aktuellen Situation:

201 Kant 1795 S. 30-32; Reininger (1923) S. 204. 
»Denn wenn das Glück es so fügt: daß ein mächtiges und aufgeklärtes Volk sich zu einer Republik (die ihrer Natur nach zum ewigen Frieden geneigt seyn muß) bilden kann, so giebt diese einen Mittelpunkt der föderativen Vereinigung für andere Staaten ab, um sich an sie anzuschließen, und so den Freyheitszustand der Staaten, gemäß der Idee des Völkerrechts, zu sichern, und sich durch mehrere Verbindungen dieser Art nach und nach immer weiter auszubreiten.»

Daraus könnte man schließen, daß Kant grundsätzlich die Ziele der französischen Außenpolitik vertreten würden. Frankreich hatte schon 1792 verkündet, daß es seine republikanischen Staatsideale in ganz Europa verbreiten wolle. 1795 hatte es begonnen »Tochterrepubliken» an seinen Grenzen zu bilden. Einen Krieg hätte Kant jedoch zur Verwirklichung seiner Ziele nicht zugelassen. ${ }^{202}$

Im wesentlichsten Teil seines Friedensprogramms legt Kant seine Thesen ausführlich dar. Er verweist auf zahlreiche Quellen und Autoritäten, verurteilt die Kolonialpolitik und die wirtschaftliche Beraubung der außereuropäischen Länder. Seiner Meinung nach müßten die Philosophen der Länder auch bei der Bestimmung der Prinzipien der Kriege und Friedensvorschläge völlige Freiheit haben, ihre Gedanken zu äußern. In dieser Beziehung hatte Kant offensichtlich Grund unzufrieden zu sein, mußte er doch ein Leben unter der ständigen Bedrohung der Zensur führen. Weiter forderte er die bedingungslose Öffentlichkeit für die Diplomatie. Geheimdiplomatie würde konsequent zum Krieg führen. ${ }^{203}$ In den folgenden Jahren fügte er seiner Untersuchung noch Ergänzungen hinzu. Die zweite Auflage von 1796 enthält »Geheime Artikel zum ewigen Frieden», in denen er weiterhin seine Zustimmung zu den Prinzipen der Französischen Revolution und zu Frankreioh zum Ausdruck bringt. Er versichert, daß jene Revolutionsführer, die als Despoten regierten, moralisch trotzdem ein größeres Recht hätten als jene moralisierenden Gegner der Freiheitsideen, die im Namen von Freiheit und Ordnung versuchten, die Verwirklichung von notwendigen Rcformen zu verhindern. Weiterhin stellt Kant fest, daß man von einem Staat nicht verlangen könne, sein Staatssystem aufzugehen, sei es auch ein despotisches, wenn die Gefahr bestehe, daß er sofort der Gewalt anderen Staaten zum Opfer falle. ${ }^{204}$

Kant's »Zum ewigen Frieden» führte im Umkreis des Baseler Friedens zu keiner intensiven öffentlichen Diskussion, aber die Schrift erweiterte

202 Kant 1795 S. 35-36. Natorp (1924) S. 43-44; Zickendraht (1922) S. 21.

203 Natorp (1924) S. 25.

204 Immanuel Kants Werke (hrsg. v. Ernst Cassirer) Bd. VI S. 446-455. Görland (1966) S. 68-71. 
und vertiefte diese Diskussion in bedeutender Weise. Kant nahm nicht direkt Teil an den Veränderungen in der Politik wie seine Kollegen, aber »Zum ewigen Frieden» machte Kant auch zu einer Persönlichkeit mit politischem Einfluß.205 Das Büchlein fand eine weite Verbreitung. 1796 kam die zweite, 1500 Exemplare starke Auflage heraus, und auch diese wurde innerhalb von einigen Wochen verkauft. Auch englische und französische Ausgaben erschienen sofort.206 Kant's angesehene Position als Philosoph verschafte ihm die Möglichkeit, seine Meinungen zu den politischen Ereignissen seiner Zeit verhältnismäßig frei vorzutragen, obgleich sie im Widerspruch zur Regierungspolitik standen. Zur Kabinettspolitik in Europa seiner Zeit bezog Kant eine unbedingt ablehnende Haltung, auch könne er nicht die Bewunderung der unumschränkten Macht akzeptieren, die diese Politik bestimme. Er strebte vielmehr danach, als Gegengewicht ein Sicherheitssystem zu schaffen, das sich auf den gesunden Menschenverstand und auf völlig rationales Denken gründen sollte. In seinen Friedensforderungen gibt es vieles, 'was in den Programmen der späteren Friedensbewegungen am Leben geblieben ist. So verurteilte Kant u.a. die Bewunderung soldatischen Mutes und hielt ihn für gefährlich. ${ }^{207}$ Es lassen sich natürlich in Kant's Auffassungen Fehlerhaftigkeiten und falsche Hypothesen nachweisen. So hatte er eine zu optimistische Vorstellung von den Wirkungen der republikanischen Staatsform und er verstand nicht den agressiven Charakter der Revolutionskriege, sondern sah in ihnen nur »gerechte Abwehrmaßnahmen gegen die unbefugten Einmischungsversuche des absolutistischen Europas». ${ }^{208}$ Indem er den europäischen Staaten das Recht absprach, gegen Frankreich zu kämpfen, gestand er gleichzeitig Frankreich das Recht zu, sein Gebiet bis an seine "natürlichen Grenzen» auszudehnen und wurde so selbst zu einem ziemlich parteiischen Beobachter der Ereignisse. Dies beinflußte natürlich die Aufnahme seiner öffentlichen Worte in deutschen Kreisen. Auch die in Kant's Reden wiederholt vorgebrachte Forderung nach einem Bündnis zwischen Preußen und Frankreich vermehrte diesen Verdacht. ${ }^{209}$

Kant erhielt Kritiken von allen Seiten. Die Entrüstung, die Kant bei denjenigen im »dritten Deutschland» und in Österreich hervorrief, die sich für eine Fortsetzung des Krieges einsetzten, wurde schon erwähnt.

205 Borries (1928) S. III.

206 Hemleben (1945) S. 88.

207 Borries (1928) S. 204-205; Natorp (1924) S. 5, 33-34, 46.

208 Natorp (1924) S. 52-54; Borries (1928) S. 219 (Zitat).

209 Tschirch I (1933) S. 423. Tschirch karakteriziert Kants Gedanken als ein Beispiel von der »Krankheitsgeschichte des politischen Geistes». 
Am schärfsten wurde Kant von dem Berufsschriftsteller Glave-Kolbielski kritisiert, der ihn beschuldigte, seine eigenen Schriften und Ansichten plagiert zu haben. Die ganze Schrift »Zum ewigen Frieden» bestehe nur aus »metaphysischen Ideen ohne praktische Kenntnisse».210 Die konservative Literaturzeitschrift »Göttingische Anzeigen» drückte ihre Bewunderung der Artikel der Kantschen Schrift aus, stellt aber auch fest, daß sie zu Mißverständnissen Anlaß gäbe und so das ganze Werk mißlungen sei. In der gleichen Zeitschrift wurden auch Kritiken gegen Kant von Fr. H. Jacobi und Christoph Girtanner veröffentlicht. ${ }^{211}$ Auch außerhalb der eigentlichen Kriegspartei verhielt man sich Kant gegenüber zurückhaltend oder ablehnend. Goethe und Schiller sprachen keine Wertung über seine Untersuchung »Zum ewigen Frieden» aus, sondern griffen seine Gedanken auf Umwegen an, indem sie seine Anhänger, Kant's Schüler und Nachfolger tadelten. ${ }^{212}$ Friedrich Schlegel sprach sich nicht gegen das Werk selbst aus, aber er teilte nicht Kant's Standpunkt, daß die republikanische Staatsform eine unabdingbare Voraussetzung für einen allgemeinen Frieden sei..213 Am Rande sei erwähnt, daß das in Kant's Heimatstadt erschienene »Preussische Archiv»Kant's Schrift überhaupt nicht kommentierte, sondern sich damit begnügte, sie zu erwähnen und ein wenig aus ihr zu zitieren. ${ }^{214}$ Trotzdem blieben die ablehnenden Stimmen gegenüber den zustimmenden in der Minderzahl. $\mathrm{Zu}$ seinen Anhängern und Schülern gehörten Personen wie Fichte, die Königsberger Professoren Kraus und T. A. H. Schmalz, der Prediger Daniel Jenisch, die Dichiter Sömmering und Heinse usw., außerdem konnte seine Philosophie auch im preußischen Offizierskorps eine starke Anhängerschaft finden. ${ }^{215}$ Auch in jenen Kreisen fand die Schrift Zustimmung, die sich reserviert gegenüber der Französischen Revolution und später zum Friedensschluß mit Frankreich verhielten: Wieland und Archenholtz, der gerade erwähnte Friedrich Schlegel

210 Pribram-Fischer (1939) S. 77.

211 Göttingische Anzeigen von gelehrten Sachen 1796 I (Nr. 8) S. 77-79; III (Nr. 172) S. 1715.

212 Musen-Almanach 1797 S. 212. Schulz (1960) S. 137. Vgl. Löhde, Walther, Friedrich Schiller im politischen Geschehen seiner Zeit (1959) S. 310; Borries (1928) S. 201.

213 Deutschland 1796 III S. 10-35. Wieneke, Ernst, Patriotismus und Religion in Friedrich Schlegels Gedichten, Diss. München 1912, S. 24-15.

214 Preuss. Archiv. 1795 Nov. S. 713.

215 Buhr (1965) S. 9; Eisner (1907) S. 24-25; Tschirch II (1934) S. 9; Vorländer (1907) S. 37; Leitzmann, Albert, Wilhelm Heinse in Zeugnissen seiner Zeitgenossen, Jena 1938, S. 35. 
trotz seiner Vorbehalte und sogar Friedrich Gentz nahmen sie positiv auf. ${ }^{216}$

Kant's Schrift führte zur Veröffentlichung anderer Friedensprogramme. Dieser versuchten wie Kant Gründe für die prinzipielle Überlegenheit eines ewigen Friedens während der augenblicklichen Situation darzulegen. In möglichst realistischen Programmen sollte ein Ausweg gefunden werden. Als Beispiel kann man das eindeutig in der Nachfolge Kant's entstandene 47 seitige Büchlein »Heteroklitische Ideen über die natürliche Begränzung der europäischen Staaten, als Grundlage zu einem ewigen Frieden» des Rheinländers und Adligen Carl Theodor Edler von Traiteur anführen. Traiteur versuchte nachzuweisen, daß man die Idee St.Pierres und Kants verwirklichen könne, wenn ein Staat seine natürlichen Grenzen habe, zu denen er Gebirgszüge aber keine Flüsse rechnete. Seiner Meinung nach müßten im Gegenteil immer beide Ufer in gleichem Besitz sein; wenn Frankreich zum Beispiel den Rhein als Grenze fordere, so sei es notwendig, daß es beide Ufer des Rheins besitze, weil »die Freyheit des Handels, leiohter zwangloser Verkehr ist der Nerv des Staates, das einzige Mittel, eine Nation auf die höhere Stufe des Wohlstandes zu bringen». Die Waren des Rheins wären um die Hälfte billiger, ohne die Zölle Preußens und der anderen Länder am Fluß. Die Waren des Ostens wären viel billiger, wenn die Donau zu den Ländern einer Monarchie gehören würde und die weiten Gebiete der Mündung »kein asiatischer Despot, kein faules unaufgeklärtes Volk» beherrschen würde. $\mathrm{Zu}$ den Bedingungen für einen ewigen Frieden gehöre nach Traiteur wie für Kant auch die Freiheit der Meere. Es bestehe für Europa die Möglichkeit ohne Krieg zu leben, wenn man die Freiheit der Meere und die natürlichen Grenzenverwirklichen würde. Eventuelle Streitigkeiten und Zwischenfälle zwischen den Fürsten müsse »das allgemeine Gesetz gesitteter Völker» entscheiden. So könnte man einen ewigen Frieden erreichen. Die gemeinsame Religion müsse für alle die »europäische Aufklärung» sein. Zur Verwirklichung dieser Ideen müsse man radikal das bestehende System der Grenzen ändern. Die drei Großmächte Europas seien seiner Meinung nach zu sehr auf die Erweiterung ihres Machtbereiches bedacht. Frankreichs Drängen an den Rhein, Österreichs Drängen nach Italien und Polen sowie Preußens Dränge an den Rhein und nach Franken sei »unnatürlich und unpolitisch». Für Frankreich seien die richtigen Grenzen die Pyrenäen, die Vogesen und Alpen und die Quellen der Seine, Loire, Garonne, Maas und der Schelde. Österreich müsse sich von dem Ursprung bis zur Mündung

216 Siehe später. 
der Donau erstrecken. Das ganze Po-Gebiet solle man Sardinien geben. Preußen solle das zerfallene Polen erben und die Gebiete an Oder und Weichsel erhalten. Wenn Preußen sein Gebiet vergrößern wolle, so sei die Richtung Dnjestr-Dnjepr zu empfehlen. Preußen könne so eine gewaltige Schutzmauer gegen Rußland errichten. Auf dem eigentlichen deutschen Gebiet beabsichtigte Traiteur drei große Staaten zu bilden: das Gebiet der Elbe solle Sachsen und das von Weser-Ems Braunschweig -Hannover zustehen. Das Kheingebiet bis Holland solle die Pfalz bekommen. Zusammen würden diese drei Staaten »die vereinte deutsche Nation» bilden, die so natürliche Grenze hätte, die es nicht zu erweitern brauche. Kant war pessimistisch über die Verwirklichungsmöglichkeiten seines Friedensprogrammes gewesen. Traiteur seinerseits vermutete, daß man seinen Plan belächeln werde, aber dazu bestehe kein Grund. Die Verwirklichung seines Plans würde vor allem stehende Heere und »künstliche Befestigungen» beseitigen. Die Menschen hätten die Möglichkeit, anstatt Kriege zu führen, gut zu leben und »friedliche, duldsame Menschen, vereinte Brüder, das allgemeine Wohl befördernde Weltbürger, und bald verklärte Geschöpfe durch ein Dankgefühl für den Urheber der Natur, der uns, um weise $z u$ werden, geschaffen hat» zu sein. ${ }^{217}$

217 Heteroklitische Ideen über die Begränzung ... 1796. Zitat S. 46. 


\section{ERWARTUNG EINES ALLGEMEINEN FRIEDENS IN DEN JAHREN 1796-97}

\section{Die Kriegszüge der Franzosen $1796-97$}

Der Zeitabschnitt zwischen Anfang 1796 und Herbst 1797 war für Frankreich erfolgreich gewesen. Seine inneren Verhältnisse hatten sich entscheidend stabilisiert und die inneren Zwistigkeiten des fünfköpfigen Direktoriums hatten sich noch nioht ernsthaft auf die Außenpolitik und die Fortführung des Krieges ausgewirkt. Frankreioh gegenüber standen zwei immer noch ernstzunehmende militärische Gegner, England und Österreich, von denen nur das letzte zu direkten Kriegsanstrengungen in der Lage war. Es ist natürlich, daß Frankreich versuchte, einen entscheidenden militärischen Schlag gegen Österreich zu führen. Carnot plante eine weitreichende Operation. General Jourdan bekam die Aufgabe, mit der Hauptarmee über den Rhein bis in die Erblande vorzudringen, während der junge Napoleon Bonaparte in Italien und Hoche in Irland Unterstützungs- und Ablenkungszüge durchführen sollten. Der Anfang verlief gut. Die wichtigsten Befestigungen am Rhein wurden besetzt und Jourdan stieß tief in Franken ein. Im August erreichte er die Oberpfalz. Die Österreicher zogen sich vor den Franzosen zurück und immer mehr süddeutsche Fürsten und Territorien hielten es für das beste den Kampf aufzugeben und einen Sonderfrieden anzubieten. Dann kam es jedoch zu einer Wende. Im September errangen die Truppen der Habsburger unter der Führung ihres befähigten Oberbefehlshabers, Erzherzog Karl, einen Sieg und die französische Armee mußte sich wieder über den Rhein zurückziehen. Durch den Erfolg wurde die österreichische Haltung unbeugsamer denn je. Österreich wollte einem Frieden nur unter den eigenen Bedingungen zustimmen. Der Kriegszug der Franzosen vom Sommer 1796 beeinflußte auch besonders stark die Einstellung der Deutschen in den Kriegsgebieten zu einem Friedensschluß. Auch die Armeen der Republik hatten schon jahrelang Krieg geführt und die Gebräuche von Berufssoldaten angenommen. Raub und Verwüstung begleiteten die Revolutionsarmeen. Die Landbevölkerung in Süddeutschland erfuhr jetzt kon- 
kret die Hohlheit jener Propaganda, nach der die Franzosen den Palästen den Krieg erklärt hätten und nicht den Hütten. An vielen Stellen schlossen sich die erregten Bauern $z u$ bewaffneten Gruppen zusammen, die den sich zurückziehenden Franzosen im Spätsommer 1796 empfindliche Verluste beibrachten. Andrenseits verstärkte das Gebaren der Franzosen die Bereitschaft zur Kapitulation, die weitere Leiden verhindern sollte. So dachte man nicht nur in der Bevölkerung sondern auch in der Regierung. Lem Kriegssommer folgte eine besonders rege öffentliche Diskussiun, die die Möglichkeiten für einen Frieden im Liohte der vorangegangenen Ereignisse diskutierte. ${ }^{1}$

Der Kampf wurde jedoch nicht in Deutschland sondern in Italien entschieden, das nach Carnot's ursprünglichen Plänen nur Nebenschauplatz sein sollte. Der junge General Napoleon Bonaparte - damals noch in korsischer Schreibweise Buonaparte - hatte schon im Jahre 1796 den Österreichern und ihren italienischen Verbündeten schwere Verluste zugefügt. Auf dem Kriegszug von 1797 vervollständigte er seinen Sieg. Eine Reihe von glänzenden Siegen öffnete seinen Truppen den Weg nach Wien und am 18. April 1797 beugte sich der Kaiser dem Waffenstillstand von Leoben. Dieser Waffenstillstand berührte auch die Front am Rhein, wo der neue Oberbefehlshaber der Franzosen General Hoche beträchtliche Erfolge auf sein Konto verbuchen konnite. Den endigülitigen Frieden zwischen Österreich und Frankreich schloß man erst im Oktober. Im Frieden von Campo Formio wurden Frankreich auch offiziell die westrheinischen Gebiete zugesprochen - u.a. die östereichischen Niederlande —, für die Österreich auf Empfehlung Napoleons seinen Besitz auf Kosten Bayerns und Salzburgs und in Italien auf Kosten Venedigs erweitern durfe. Weiter wurde in Campo Formio beschlossen, daß ein endgültiger Friedensvertrag zwischen Frankreich und dem Deutschen Reich auf einem allgemeinen Kongreß beschlossen werden solle, auf dem auch die notwendige Neuorganisation der inneren Verhältnisse im Reich festgelegt werden soll.te. ${ }^{2}$

Der Vorfrieden von Leoben und der Frieden von Campo Formio zeigten natürlich auch Wirkungen auf jene Diskussionen, die in Deutschland zum Problem Krieg und Frieden geführt wurden. Die meisten jener Deutschen, die der Revolution in ihren Anfangsphasen positiv gegenüber gestanden hatten, äußerten jetzt ihre Enttäuschung darüber, daß Frankreich zu einer offenen Eroberungspolitik übergegangen sei und begannen, gegenüber einem Frieden eine immer zögerndere Haltung einzunehmen. ${ }^{3}$

1 Franz (1970) S. 250-253; Epstein (1966) S. 458.

2 Holborn (1970) S. 61-62.

3 Berger (1918) S. 57-58. 
Die ablehnenden Stimmen zu einem Frieden wurden zwar in gewisser Hinsicht weniger, begannen aber andererseits sich in neuer Art zu formulieren. Immer mehr wurden Meinungen über die Bedingungen laut, unter denen ein Friede geschlossen werden sollte. In vielen Fällen bedeutete dies in der Praxis jedoch, daß man gegenüber einen zu schließenden Frieden eine ablehnende Haltung einnahm. Man befürchtete große Veränderungen in der Gliederung des Reiches. Auf der einen Seite wurde gefordert und auf der anderen Seite strikt abgelehnt, daß die geistlichen Fürstentümer, die Reichsstädte und die Länder der Reichsritter den Fürsten als Ersatz für die abgetretenen linksrheinischen Gebiete zugestanden werden sollten. Mehr Farbe bekam die Debatte noch durch Zwischenfälle, die eine Verletzung des Waffenstillstandes an den F'ronten am Rhein darstellten. Die Franzosen gingen nach dem Vorfrieden von Leoben rücksichtslos vor, besetzten viele wichtige Orte, plünderten und führten umfangreiche Konfiskationen durch. Die Kleinstaaten hatten große Schwierigkeiten. Von diesen hatte zwar nur Hessen-Kassel einen offiziellen Friedensvertrag mit Frankreich geschlossen (im Frühjahr 1796), aber auch die anderen suchten nach einer entsprechenden Lösung und erklärten sich als neutral. Diese Neutralität wurde allerdings von den Franzosen kaum beachtet. Daran schloß sich erneut eine ablehnende Stimmung gegenüber Frankreich an. Allerdings wurden auch Stimmen laut, die den baldigen Abschluß eines Friedensvertrages forderten. Im Rheinland versuchte man, auf Initiative der Franzosen und republikanisch gesinnter Deutschen eine französische Tochterrepublik zu bilden, „Cisrheinische Republik». Dies geschah im September 1797 und rief seinerseits überall in Deutschland eine rege Diskussion hervor. Auch das Schicksal dieser Republik wurde dem Kongreß von Rastatt zur Entscheidung übergeben. ${ }^{4}$

\section{Das leidende und resignierende Süddeutschland}

Die öffentliche Meinung in den von den Kriegsereignissen betroffenen Gebieten verhielt sich im allgemeinen in Hinblick auf einen $\mathrm{zu}$ schlieBenden Frieden positiv. Die durch den Krieg verursachten Leiden wurden nach dem Sommer 1796 immer direkter spürbar und, obgleich man das militärische Vorgehen Frankreichs verurteilte, wollte man im allgemeinen kapitulieren, um größeres Leid zu verhindern.

Die öffentlichen Stimmen, die gegenüber Frankreich und dessen neue Ideen eine positive Haltung einnahmen und die den Frieden von Basel im

4 Holborn (1970) S. 61-62. 
vorangegangenen Jahr begrüßt hatten, fuhren fort, den Frieden zu verteidigen. Die in Tübingen enschienene Zeitschrift »Europäische Annalen» des Dr. Posselt, die zeitweise unter französische Zensur gefallen war, ist ein typisches Beispiel. In den Artikeln Posselts wird eine verständnisvolle und aufgeklärte Bereitschaft zum Frieden und eine optimistische Einschätzung der Möglichkeiten für einen Frieden sichtbar. Posselt betonte gerne die militärische Stärke Frankreichs und, daß sich die ganze politische Lage in Europa gegen die Koalitionsstaaten gewendet habe; diese sollten möglichst schnell dem Beispiel Preußens folgen und einen Frieden schließen, weil sie doch nicht in der Lage seien, eine militärische Entscheidung herbeizuführen. ${ }^{5}$ Posselt kritisierte England heftig, das seiner Meinung nach am hartnäckigsten einen Frieden ablehne. Die egoistische Handelspolitik Englands sei eine der wichtigsten Ursachen des Krieges und Pitt's unbeugsame Haltung das größte Hindernis für einen Frieden. ${ }^{6}$ Nachdem die Verhandlungen zu einem Frieden zwischen Frankreich und England in Gang gekommen waren, verfolgten die »Europäischen Annalen» sie genau und brachten ihren Standpunkt deutlich zum Ausdruck: gleichzeitig mit der Veröffentlichung von Reden und anderen Texten von Oppositionellen aus England und Vorwürfen gegen die Regierung Pitt's, daß sie den Krieg mit Frankreich nur als reine Transaktion ansehe, ${ }^{7}$ dankte die Zeitschrift wiederholt dem Direktorium für seine Politik und hob die persönlichen Eigenschaften der Direktoriumsmitglieder positiv hervor. ${ }^{8}$ Der Abbruch der Verhandlungen im Dezember war für Posselt eine große Enttäuschung. Europa hätte vergeblich auf einen Frieden gewartet. Es hätte sich deutlich gezeigt, daß die Völker den Frieden wollten, aber die Regierungen hätten sich nicht darum gekümmert. Als Gründe für das scheitern der Verhandlungen führten die »Europäischen Annalen» nur ein Zitat aus der französischen Zeitschrift »Redacteur» an, die natürlich die ganze Schuld den Engländern zuschob. England sei während der ganzen Verhandlungen nicht ehrlich vorgegangen, habe fortgefahren in Frankreich gegen die Revolution aufzuwiegeln, habe gefälschte Assignaten verbreitet usw. . Wenn in dieser Art die Verhandlungen abgebrochen würden, so bedeute das automatisch eine Zunahme des Kriegseifers. Jeder Franzose fühle sich persönlich verletzt und wünsche militärische Genugtuung. ${ }^{9}$ Im folgenden Jahr wurden die selben Gründe für den Abbruch der Verhandlungen genannt, und die Zeitschrift

5 Eur. Ann. 1796 I S. 25-28, 97.

6 Ibid. 1795 I S. $174-179$, II S. 62.

7 Ibid. 1796 I S. 118-119, 164-176 (Eschafferiaux).

8 Ibid. S. 101.

9 Ibid. IV S. $65,288-295$. 
brachte weiterhin einerseits die Anschuldigungen der Oppositon im englischen Parlament und andrerseits verbitterte Äußerungen der französischen Presse. ${ }^{10}$ An die deutschen Fürsten richtete Posselt direkte Friedensaufforderungen. Obwohl der größte Teil der deutschen Fürsten noch zum antifranzösichen Lager gehörte, so hofften sie doch nach Posselt's Meinung auf einen Frieden: viele von ihnen hätten sich schon als neutral erklärt. Sogar das vom englischen König regierte Hannover hätte sich zu diesem Schritt entschlossen. Einerseits beherrsche den Reichstag in Regensburg teilweise eine Haltung, die starr an dem Grundsatz der Reichsintegrität festhalite, andererseits wiederum werde die öffentliche Meinung in Paris von der Forderung nach der Annektion des ganzen linken Rheinufers bestimmt. Da offensichtlich keine Vermittlungsvorschläge zu erwarten seien, könnte die Situation nur durch die Waffen entschieden werden. In diesem Kampf sehe die Lage Deutschlands nicht günstig aus. Seine Kräfte seien zersplittert. Ihren Verpflichtungen gegenüber dem Reich würden neben dem Kaiser nur noch einige Stände nachkommen, und für das Reichsheer würde man nicht mehr als 30000 Mann zusammen bekommen. Für die deutschen Fürsten würde nur noch die Möglichkeit bestehen, einzeln einen direkten Waffenstillstand mit Frankreich zu schließen. Nach Posselt war es offensichtlich, daß man sich auf die Hilfe Preußens stützen wolle. ${ }^{11}$ Posselts Stellungnahmen zu den Kriegsereignissen waren realistisch und sind interessant. Er istellte fest, daß das Kriegsglück einen direkten Einfluß auf die französische Innenpolitik habe, so hätten die Anfangserfolge des Kriegszuges vom Sommer 1796 den Einfluß der Linken, der »Terroristen», vergrößert und entsprechend die österreichischen Erfolge im Herbst des gleichen Jahres besonnere und sich mehr für einen Frieden einsetzende Stimmen laut werden lassen. ${ }^{12}$ Posselt gehörte nicht zu den Deutschen, die hofften, daß die französischen Erfolge einen Frieden mit Deutschland herbeiführen würden. Auch Anfang 1797 beherrschte die »Europäischen Annalen» eine zustimmende Tendenz gegenüber Frankreich, und es wurde fortgesetzt die militärische Stärke Frankreichs hervorgehoben. Weiter wurde die günstigere diplomatische Position Frankreichs konstatient: Die europäischen Regierungen hätten den Königsmördern die Hand gereicht und Frankreich sei das Zentrum eines neuen und starken Paktsystems. In Italien sei Pius VI noch der einzige, der sich einem Frieden widersetze. Die Batavische Republik wird

10 z.B. ibid. 1797 I S. 47-66 und mehrere Artikel gegen Pitt, z.B. von Thomas Erskine (Bd. I-III) und Eschafferiaux (Bd. I).

11 Ibid. 1796 III S. 115-119, 130.

12 Ibid. S. 107-110. 
von der Zeitschrift begrüßt, und man versichert, daß sich die neue Staatsform unter dem Volk großer Beliebtheit erfreue. Die persönlichen Eigenschaften der Direktoriumsmitglieder werden ausführlich gelobt. ${ }^{13}$ Darüber, daß Österreich gezwungen war, den Vorfrieden von Leoben zu unterschreiben, war Posselt aufrichtig froh. Er erwähnt u.a., daß England jetzt in eine Situation geraten sei, die man schon früher vorher gesagt hätte. Die Hartnäckigkeit des Kaiser wird getadelt, weil er nicht einmal zur Zeit der großen französischen Siege bereit gewesen sei, die Existenz der ganzen Republik anzuerkennen. Erst nach Napoleons großen Siegen habe Österreich zu erkennen gezeigt, daß der Kaiser nichts sehnlicher wünsche als die Rückkehr zu einem Frieden in Europa, und der Kaiser hätte um Frieden gebeten. Posselt hob die beträchtlichen Verluste Österreichs hervor, so seien 1/7 seiner Gesamtfläche, über 2/9 (über 4,5 Millionen) seiner Untertanen und 1/6 seines Jahreseinkommens an Frankreich gefallen. Die eigentlichen Friedensverhandlungen verfolgten die »Europäischen Annalen» genau und veröffentlichten häufig sie betreffende Dokumente, kaiserliche Dekrete, Briefe, Reichstagsdebatten usw. Die Zeitschrift wies auch auf die finanziellen Schwierigkeiten Frankreichs hin, welche die Republik zwingen würden, die Herbeiführung eines Friedens zu beschleunigen und die eroberten Gebiete zu besteuern. So erwähnte Posselt u.a., daß die Rheinlande unter Umständen ungeheure Summen bezahlen müßten. Während der Friedens-verhandlungen vertrat die Zeitschrift eine besonders ablehnende Haltung gegenüber England. Man glaubte, daß die Engländer Österreich zum Krieg aufhetzen würden, ihre eigenen Verhandlungen mit Frankreich wurden als bloßer Schwindel abgestempelt. ${ }^{1 t}$

Eine deutlichere frankreichfreundliche Haltung nehmen die in vier Heften 1796 in Basel erschienen »Französischen Blätter» ein, die zum größten Teil Artikel deutscher Revolutionärer zur politischen Situation enthalten. Die in der Schweiz gedruckte Zeitschrift wollte ganz Deutschland ansprechen, so wie viele andere in der Schweiz zu tagespolitischen Ereignissen erschienene Druckerzeugnisse. In einem Vorwort versichert der anonyme Herausgeber die Unparteilichkeit der Publikation. ${ }^{15}$ Davon kann allerdings nicht die Rede sein. Die rheinischen Revolutionäre Böhmer, Dorsch und Löw verlangten eine Beendigung des schon verlorenen Krieges dadurch, daß man den Rhein als Grenze anerkenne. Ein Zitat aus einem ursprünglich in französischer Sprache erschienenen Buch Böhmers, »Das linke Rheinufer, Grenze der französischen Republik» macht die Intentionen der Zeitschrift deutlich:

13 Ibid. 1797 I S. $81-86,89-112,138-144,146-152$.

14 Ibid. II S. 149, 187, 221, 229, III S. 4-6, 184, 231-233, 283.

15 Französische Blätter 1796 Bd. I, Vorbericht. 


\begin{abstract}
»Friede - Ende des itzigen blutigen Krieges, den die französische Republik nun seit vier Jahren mit den meisten europäischen Mächten führt - ist der allgemeine Wunsch aller Menschenfreunde; ja man kann wohl sagen, aller $\mathrm{N}$ ation e $\mathrm{n}$, die unseren Erdtheil bewohnen.»16
\end{abstract}

Das Volk wolle den Frieden, die Regierungen aber nicht. Bemerkenswert ist die Vorstellung, daß nur die republikanische Staatsform die Annahme eines Friedens garantiere. Außerdem wird davor gewarnt, die Patrioten (d.h. die frankreichfreundlich Gesinnten) der Rache der Tyrannen preiszugeben. ${ }^{17}$ Diese Vorstellung wurde vor allem auch in den anderen in Deutschland besetzten Gebieten häufig von den "Schlichtern» vertreten und sollte in den folgenden Jahren noch deutlicher geäußert werden. Der bedeutendste Vertreter dieser Vorstellung ist Georg Friedrich Rebmann, auf den wir später ausführlicher zurückkommen werden.

Die Zeitschriften begleitete eine große Gruppe Flugblätter. Dazu gehören deutlich revolutionär eingestellte, aber die Mehrheit vertritt die Linie »man muß sich dem Zwang beugen». Ein gutes Beispiel dafür ist die Schrift des oberpfälzer Wasserbaumeisters K.Fr.v. Wiebeking »Der Utbergang der Franzosen über den Rhein», in der Haß gegen die Franzosen deutlich zu erkennen ist, dagegen wird die Tapferkeit der kaiserliche Truppen betont. Vorallem aus wirtschaftlichen Erwägungen bezieht der Verfasser jedoch eindeultig Stellung für einen Frieden und hält nicht an den alten Grenzen fest. ${ }^{18}$ Den gleichen Gedanken findet man in der im Mai 1796 in Basel erschienenen anonymen Schrift »Utber den bevorstehenden Frieden des teutschen Reichs mit Frankreich», in der auch die Zerstörungen des Krieges und die ständigen Utberfälle durch die Franzosen beklagt werden. Optimistisch sah man in den neuen Grenzen auch Vorteile. Als natürliche Grenze könne die zu einem dauennden Frieden und zu einem Bündnis führen, durch das Deutschland mit Hilfe Frankreichs dem polnischen Schicksal entgehen könne. Man glaubte, daß Rußland und die Türkei Deutschland aufteilen würden. ${ }^{19}$ Besonders scharfe Angriffe gegen Frankreich enthälit die Schrift eines Verfassers vom Unterlauf des Rheins, »Klagen eines Rheinländens», in der in kräftigen Farben geschildert wird, wie sich die französischen Truppen, die man als Befreier erwartet hätte, aufgeführt hätten. Die Franzosen werden als »Räuber-

16 Ibid. S. 46 (Zitat); auch z.B. S. 53-55, 67 usw.

17 Ibid. S. 53 (Böhmer-Dorsch).

18 Wiebeking, Der Übergang der Franzosen über den Rhein ... Frankfurt am Main 1796, z.B. S. 8 und 59-62.

19 Ueber den bevorstehenden Frieden ... 1796. 
band» und »Cannibalen» bezeichnet. Trotz allem ist die Schrift nicht für den Krieg. Sie ermahnt, man solle sich auch an die Absichten der Emigranten erinnern (u.a. wird von einem Emigranten berichtet, der nach einem Sieg aus den Häuten der Bauern Stiefel machen wolle) und erinnert an die Willkür des Adels und der Priester zur Zeit der früheren Regierung, was die Grausamkeiten der Republikaner verständlich mache. ${ }^{20}$ Vorsichtig bezog auch Johann Paul Sattler, der Staatswissenschaften studiert hatte, Stellung für einen Frieden. ${ }^{21}$ Die Broschüre »Ho - ! Ho —!», mehr auf der Seite Frankreichs und gegen Österreich gerichtet, setzt sich für die Sonderpolitik der Stände und der Fürsten ein und richtet sich gegen den zunächst unter dem Namen »Graf v. Strengschwerdt» für Österreich schreibenden Schriftsteller Alois von Hügel.22 Eindeutig dem revolutionären Lager zuzurechnen ist die umfangreiche Schrift eines wahrscheinlich bayerischen Verfassers »Bemerkungen über den Gang der Staatsumwälzung und Entwicklung der neuen Staatsverfassung von Frankreich». Die Schrift warnt davor, die militärische Stärke Frankreichs zu unterschätzen und tadelt besonders die Emigranten, die die deutschen Fürsten zu militärischen Aktionen aufhetzen würden. Auch das hartnäckige Fordern von Reparationen sei unklug. Das Deutsche Reich entbehre schon lange den Frieden und die Besitzungen einiger Herren könnten die Leiden des Krieges nicht ersetzen. Die Schrift versichert auch, daß man einen Frieden im vergangenen Jahr hätte schließen müssen, als die Bedingungen nicht so hart gewesen seien. Die Schrift schließt mit einer Utopie von einem freien und einigen Land:

»Edelleute, Mussiggänger, Bettler und dergleiohen Ungeziefer des Staats werden nicht geduldet - Die Menschen sind in diesem Lande nichts mehr als Menschen; aber desto besser, zwangloser, gesünder, natürlicher; die feinern Köpfe philosophisch helle, die gemeinen ohne Pfaffengezänke, ohne Aberglauben.»

In diesem Land würde es keine Kriege und keine Soldaten mehr geben. $^{23}$ In diesem Sinne äußerten sich auch andere Flugschriften. Außerdem erschienen noch französische und aus dem Französischen übersetzte Flugschriften, u.a. Sieyés politische Schriften. ${ }^{24}$

20 Klagen eines Rheinländers ... 1796.

21 Staatsrechtliche Bemerkungen eines deutschen Rechtsgelehrten ... 1796.

22 Ho - ! Ho - ! oder rechtliche Verwunderung ... 1796.

23 Bemerkungen über den Gang der Staatsumwälzung ... 1796, S. 16-20, 305-307, 328, 341 (Zitat).

24 Sieyes, Emmanuel, Politische Schriften, 1796. 
Ein gutes Beispiel für die zwei Jahre nach dem Baseler Frieden im »dritten Deutschland» herrschende Resignation in der öffentlichen Meinung stellt die hefitige Diskussion dar, die sich an dem Waffenstillstand (17. 7.96) und an dem Sonderfrieden (7.8.) in Württemberg entzündete, den der Herzog des Landes mit Frankreich geschlossen hatte. Die Forderungen der Franzosen waren besonders hart gewesen. Der Herzog hatte alle seine Forderungen auf seine linksnheinischen Gebiete aufgegeben (er versuchte jedoch Ensatz auf Kosten der geistlichen Territorien zu erhalten) und sich verpflichtet, beträchtliche Reparationen zu bezahlen. ${ }^{25}$ Neben vier Millionen Livre mußte das Herzogtum der Armee Moreaus an Naturalien 4200 Pferde, 100000 Zentner Brotgetreide und die gleiche Menge Heu, 50000 Säcke Hafer und 50000 Paar Schuhe überlassen, was nach einer zeitgenössischen Rechnung einem Gesamtwert von 425933 Florin und 20 Groschen entsprach. ${ }^{26}$ Darüber, wie diese Summe von den Bewohnern des Herzogtums einzuziehen und wie diese Last auf die einzelnen Stände und Gebiete zu verteilen sei, entspann sich eine weite öffentliche Diskussion. Bis zur zweiten Hälfte im September des Jahres 1796 seien, so stellte ein Teilnehmer an der Diskussion mit, schon 32 Schriften erschienen, und eine im November des gleichen Jahres erschienene Schrift zählte 56 Titel. ${ }^{27}$ Später erschienen mindestens noch 7 Flugschriften zur Reparationsfrage. Der größte Teil der Schriften erschien anonym, aber viele schrieben auch unter dem eigenen Namen. An der Diskussion beteiligten sich Pfarrer, Beamte, Universitätsgelehrte, Offiziere und auch niedriggestellte Bewohner des Herzogtums.

In vielen Einzelheiten waren die Verfasser verschiedener Meinung und stritten heftig unter einander. In ider wichtigsten Frage herrschte jedoch zumindest offiziell eine fast völlige Einstimmigkeit: Der Abschluß des Waffenstillstandes und des Friedens sei eine von allen gutzuheißende Maßnahme gewesen. Den eigentlichen Beginn in der Diskussion machte der Tübinger Rechtsgelehrte und Professor Johann Christoph Majer mit seinem kleinen Buch »Ưber das Prinzip der französischen Brandschazungs-Repartition», in dem er sich auf Machiavelli bezieht und feststellt, daß der Waffenstillstand »zum allgemeinen Besten» gereiche, weshalb man die Reparationen bezahlen müsse. Der deutsche Widerstand sei schwach geworden und die militärische Úberlegenheit des Feindes übermächtig, deshalb sei der Entschluß des Herzogs, einen Waffenstillstand zu schließen, »herzhaft». Der Fieind habe Wünttemberg an sich nach

25 Wahl (1967) S. 81.

26 Von der Vergeilung des Beitrags ... 1796, S. 3.

27 Vischer, Gedanken über die Reparation ... 1796; Majer, J. C., Ueber das Princip ... 1796. 
internationalem Recht richtig als »feindliches Reichsland» besonders hart geplündert und verwüstet. Viele Fürsten und Stände des Reiches hätten den Wunsch sich aus diesem unglücklichen Krieg zurückzuziehen; Württemberg hätte als Erster diesen Schritt getan.

Der Waffenstillstand sei »eigentlich nicht mehr, aber auch nicht weniger, als Loskaufung der Land und Leute von französisch feindseliger Behandlung». Weil als andere Alternative nur grausame Räubereien und Gewalttätigkeiten bestanden hätten, hätte man sich davon loskaufen müssen, sei es auch für den Preis vieler Millionen.28 Diesem Standpunkt Majer schloß man sich allgemein an. Sein Kollege, der Tübinger Professor W. G. Ploucquet ging von dem alten »vae victis»-Leitspruch aus. Wenn man die Reparationen nicht bezahle, so würden die Franzosen kommen und sich selbst das Verlangte nehmen, »und noch mehr dazu».29 In mehreren Schriften stellte man die französischen Forderungen als Rechtsverstoß und den Sonderfrieden sogar als Bruch des Grundgesetzes des Reiches dar. Trotzdem wurde er als unumgänglich hingestellt. An die Stelle von juristischen Erwägungen sollten praktische Überlegungen treten. ${ }^{30}$ Die Einstellung gegenüber Frankreich ist im allgemeinen feindlich. Mehr oder weniger heftig werden Plündereien und Verwüstungen verurteilt, die während der Feldzüge in den Jahren 1795 und 1796 auf das Konto der Franzosen gingen. Ebenso spricht man sich gegen die Revolution und ihre mögliche Verbreitung aus. ${ }^{31}$ Der einzige, von dem man sagen kann, daß er an Revanche dachte, ist der Astronom J. W. Camerer. Er stellte im September Überlegungen an, wie in der Zukunft die Enstehung einer entsprechenden Notsituation verhindert werden könnte. Er schlägt vor, die Landesmiliz besser auszubilden. ${ }^{32}$ Im folgenden Monat beeilte sich der ehemalige Leutnant Christian Hehl dem zu widersprechen, weil eine Landesmiliz »Freiheitsschwindel» hervorrufen könnte. ${ }^{33}$ Außerdom betonte er seine Vaterlandsliebe und Loyalität gegen den Herzog und dem Grundgesetz. Unabhängig von der Einstellung war es üblich, daß fast alle Schriftsteller ihren Patriotismus, ihre Vaterlandsliebe und ihre Loyalität gegen den Fürsten betonten. Die Einstellung zu

28 Majer 1796.

29 Reflexionen über die Art der Entrichtung ... 1796 S. 6-7.

30 Entwicklung der Grundsäze nach welchem ... 1796; Untersuchungen und Vorschläge über die Umlegung ... 1796.

31 Strengste Frankreich- und Friedensfeindliche Schriften waren z.B. Gedanken über das Princip ... 1796; Unvorgreicliche Gedanken eines patriotischen Wirtembergers, 1796; Ueber die Umlegung feindlicher Kriegsschazung ... 1796 .

32 Ueber die Beyziehung der Besoldungen ... 1796.

33 Patriotische Bemerkungen über 1) die Diminution ... 1796. 
Kaiser und Reich war jedoch weniger eindeutig. Einige verglichen die Schäden, die die französischen und kaiserlichen Truppen in Württemberg verursacht hatten, mit einander und kamen $\mathrm{zu}$ der Feststellung, daß sie in beiden Fällen groß gewesen seien. Auch die Führung des Reichskrieges von 1793 wurde nachträglich scharf kritisiert. ${ }^{34}$ Einige nahmen die Gelegenheit wahr, um die schlechten Grundgesetze des Reiches $\mathrm{zu}$ kritisieren und Reformen $\mathrm{zu}$ fordern, ${ }^{35}$ aber im allgemeinen verteidigte man die Friedenspolitik des Reiches deshalb, weil sie die Verbreitung der Revolution verhindern und die Verfassung des Landes (entweder Deutschlands oder Wünttembergs), die Religion, »Erwerbungsund Eigenthumsfähigkeiten und bürgerliche Ordnung» sichern würde. ${ }^{36}$ Besonders typisch dafür ist die Flugschrift des Apothekers der kleinen Stadt Nagold Friedrich Streim, der unter dem Pseudonym »Eremit Kaphta» schrieb. Dort rügt er mit kräftigen Worten die französischen Plünderungen, verurteilt alle Versuche das Grundgesetz anzutasten (»ich bin höchs't zufrieden mit unserer Verfassung»), und hält alle Reperationen für »höchst ungerecht». Aber trotz allem müsse man einen Frieden anstreben, weil der Krieg schlimmer sei als alles andere. Der »Eremit Kaphta» erklärt sich als eifrigen Pazifisten und hofft, daß alle Menschen den Krieg auf die gleichen Weise ablehnen würden. ${ }^{37}$ Stimmen, die Frankreich zustimmen, sind sehr wenig anzutreffen. Weit geht der »Official bey dem Umgeldskontrolle zu Stuttgart», Carl Benjamin Treffz, der eine Schrift von sechs Druckbogen unter dem Titel »Staatswirtschaftliche Betrachtungen» veröffentlichte. Er geht davon aus, daß die Reparationsforderungen Frankreichs berechtigt seien, und er stimmt den Sonderfrieden $\mathrm{zu}$, auch wenn sie unter Zwang zustande gekommen seien. Würden sie doch schließlich zu einem allgemeinen Frieden führen, beim Einzug der Reparationen solle man vor allem die unteren Volksklassen und die armen Menschen verschonen, lautet seine Forderung. ${ }^{38}$

In der gleichen Weise diskutierte man, meistens bestimmt von einer

34 Hartmann, Johann Georg, Gutächtliche Gedanken ... 1797; Pfaff, Friederich Burkhard, Vorschläge zu einer Steuer-System ... 1797; Theorethische und praktische Abhandlung ... 1797; Reflexionen über die Art der Entrichtung ... 1796, S. 6; Majer, J. C., Ueber das Princip ... 1796, S. 5.

35 An meine Mitbürger über die Repartition ... 1796.

36 z.B. Theoretische und praktische Abhandlung ... 1797; Stimme eines Wirtembergers über das Prinzip ... 1796; Auch ein Wort ... 1796; Einzig mögliche Art ... 1797.

37 Der Eremit Kaphta an die Bürger ... 1796.

38 Staatswissenschaftliche Betrachtungen über die Bezahlung ... Bd. I-VI, 1796 , St. I S. 3, IV S. 4, VI S. 1. Irgendwie positiv war auch Materialien zur Erörterung der Frage ... 1796. 
resignierenden Friedenssehnisucht, in den anderen Kriegsgebieten, wobei man sich oft auf Einzelfragen konzentrierte. Der Streit der Theologen in Bayern um die Bedeutung des Zölibats verband sich mit der Diskussion zur Säkularisation und deren Bedeutung als Voraussetzung für einen kommenden Frieden oder deren Folgen. ${ }^{39}$ Der im Frieden von Campo Formio festgelegte allgemeine Friedenskongreß führte zu einem regen Meinungsaustausch, mit dem sich auch Stellungnahmen zu den Voraussetzungen des Friedensschlusses verbanden." Zusammen mit der in Süddeutschland verhältnismäßig häufig der Revolution zustimmenden Schriften bildete bis zum Sommer 1797 diese sich für den Frieden einsetzende Diskussion eindeutig die größte Gruppe in der Gesamtdiskussion. Daneben kamen auch eine Reihe anderer Meinungen zu Wort.

\section{Kampf und Niederlage Österreichs und der 'Reichsdeutschen'}

Obgleich unterwürfige Friedensbereitschaft oder sogar Bereitschaft zur Zusammenarbeit mit Frankreich zur Zeit zwischen dem Baseler Frieden und dem Frieden von Campo Formio auch eine gewöhnliche Reaktion den Bewohnen den vom Krieg getroffenen Gebiete war, so wurde auch die gegenteilige Haltung vertreten. Die französische Agressionspolitik ließ viele einen verstärkten Widerstand und die Vorbereitung eines Gegenschlages mit vereinten Kräften fordern. Dies wurde natürlich an erster Stelle von Österreich aus gefordert. Seine Gebiete lagen größtenteils außerhalb des Kriegsgeschehens und die österreichische Bevölkerung hatte vorerst als Kriegsbürde nur höhere Steuern und zunehmende Aushebungen zu ertragen. Österreich erhielt auch aus den Kreisen der sogenannten 'Reichsdeutschen' in Süddeuitschland Unterstützung. Im geringeren Umfang wurden auch die gleichen Ansichten in den nördlich der Neutralitätslinie gelegenen Territorien und sporadisch sogar in Preußen vertreten. Der Frieden von Campo Formio unterbrach jedoch für einige Zeit die Verbreitung dieser Ansicht.

In der österreichischen Presse war weiterhin das »Magazin der Kunst und Literatur» tonangebend. Die Zeitschrift fuhr unermüdlich fort, sich für die Fortsetzung des Widerstands einzusetzen, indem sie beinahe die gleichen Argumente gebrauchte, die sie gegen den Basler Frieden ange-

39 z.B. Staatsrechtliche Bemerkungen über die neueste fürstbischöfliche . 1796.

40 Siehe später. 
führt hatte. Verfasser von Schriften, die den Frieden verteidigten, wurden als Betrüger und heimliche Jakabiner bezeichnet, die zur Vernichtung des deutschen Vaterlandes beitragen würden. Nicolai, Adam Weishaupt, Gedike, Biester, Knigge und Rebmann seien solche Schurken, auf die man achten müsse. ${ }^{41}$ Dagegen betont die Zeitsohrift unablässig mit Nachdruck die militärische Stärke Österreichs und Deutschlands und vertritt einen ungebrochenen Siegesglauben. In der Zeitschrift erschienen ununterbrochen vaterländische Beiträge, die auf den Kaiser und den Sieg seiner Armeen bauten. Sehr aktiv waren Universitätsgelehrte. Der im Jahre 1796 zum Rektor der Wiener Universität gewählte Joseph von Sonnenfels und der Procurator der österreichischen Nation an der selben Universität, Dr. Joseph Ragg, widersprachen in ihren im »Magazin» abgedruckten Reden zu Beginn des Jahres 1796 ausdrücklich dem Jakobinismus, den Illuminaten, der Aufklärung, den »Vernunftsstürmern», und wandten sich gegen Sittenverderbnis und gegen Frankreich. Sie betonten, daß sie Religion, bürgerliche Ordnung, Kaiser und Vaterland treu ergeben seien.42 Die Bedeutung der Religion hob auch der Professor der deutschen Staatsrechte und der Reichsgeschichte der Wiener Universität, Johann Bernhard Fölsch, in seiner Flugschrift »Kurze Darstellung des Ursprungs und Fortgangs der französischen Revolution» hervor, aus der das »Magazin» Auszüge veröffentlichte. Nur eine richtige Religiosität würde nach Fölschs Meinung Deutschland vor »Freydenkerey» und der revolutionären Vergiftung schützen, die ins Reich von Westen her vorgedrungen sei.43 Das »Magazin» pflegte die Ansichten von Personen aus den verschiedenen Provinzen Österreichs ausführlich $\mathrm{zu}$ veröffentlichen und wollte offensichtlioh auf diese Weise zeigen, daß die verschiedenen Gebiete des weiten Reiches ihrem Kaiser treu ergeben und von einem unermüdlichen Kampfwillen gegen den gemeinsamen Feind erfüllt seien. In seinen »Slovanischen Briefen» versicherte Stefan Ignaz Raicevich, daß die Vaterlandsliebe unter der Bevölkerung vorhanden sei und griff heftig die Franzosen an: diese seien durch die Revolution verroht und in die Barberei zurückgefallen. ${ }^{44}$ Die Schrift »V:on der böhmisohen Mark» versichert die Treu der Böhmen gegen den Kaiser und ihre unerschütterliche Vaterlandsliebe. ${ }^{45}$ Eine Fülle von Angaben über Vorderösterreich, das dem Kriegsschauplatz am nächsten lag, werden dargelegt. Der tapfere Widerstand der Breisgauer Bauern gegen die

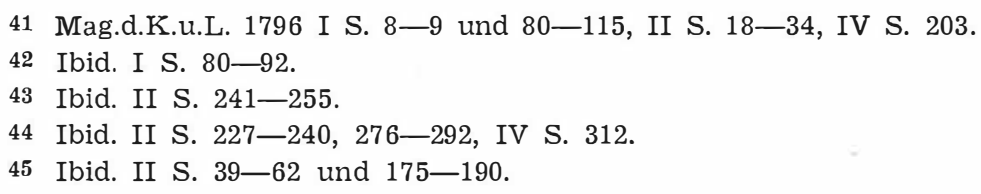


französischen »Räuberhorden» wird mit Bewunderung geschildert.46 Ende des Jahres wurde die Begrüßungsrede der Freiburger Universitätsgelehrten an Erzherzog Karl vom Dezember 1796 veröffentlicht, nachdem dieser mit seinen siegreichen Truppen die Franzosen über den Rhein vorläufig zurückgestoßen hatte. Die vom Rektor Joseph Maria Weißegger und vier anderen Professoren untersohriebene Grußadresse lobt den siegreichen Karl, dessen geliebten Kaiserbruder und seine mächtige Armee und versichert, dal3 die Bevölkerung bereit sei, die Religion und die bürgerliche Ordnung zu verteidigen und wenn es nötig sei, für Vaterland und Erzhaus zu sterben. ${ }^{47}$ Im »Magazin» wurden geeignete Texte aus allen Teilen des Reiches veröffentlicht. Interessant und teilweise auch komisch ist die umfangreiche Schrift »Beyträge zur Kenntnis der wahren Ursachen» des Arztes Johann Andreas Kob aus Hildburghausen in Sachsen. An mehreren Stellen äußert er seine Betrübnis über das Schicksal der deutschen Wälder. Die Franzosen würden an vielen Orten viele Bäume fällen und sie abästen, um aus ihnen ihre Freiheitsbäume zu errichten. Dadurch würden große und schwer behabbare Schäden entstehen. »Die jetzigen Regenten Frankreichs, und vorzüglich die kriegslustigen, jungen und in der Naturkunde und andern Wissenschaft meistens unerfahrene Generale werden endlich durch eigenen Schaden erfahren, daß die Natur sich selbst an denen rächt, welche ihr aus Unwissenschaft oder aus leidenschaftlichen Ursachen Gewalt anthun».48 Obwohl man nach Meinung Dr. Kobs schon wegen der Zerstörung der Natur nach einem Frieden streben müsse, zeigt seine Schrift keine einheitliche Linie. Er führt in seiner Schrift eine Fülle von grausamen Schilderungen an und berichtet bewundernd von dem Widerstand der Landbevölkerung. Indem er von zwei Mädchen berichtet, die einen Hühnerdieb, der sie belästigt hatte, erschlagen hatten, stellt er zufrieden fest, daß »viele Franzosen einen solchen Heidentod im Dunkeln gestorben» seien. ${ }^{49}$

Das »Magazin der Kunst und Literatur» war ein treues Organ der Regierung. Es verbreitete die ganze Zeit den Glauben an einen Sieg und versuchte auch die Schwankenden zu überzeugen. Die Schwäche und der baldige Zusammenbruch Frankreichs wurden unermüdlich vorausgesagt und daneben die österreichische Kriegskunst und auch die der Bundesgenossen betont. Äußerst freundlich wurde über England berichtet. Die Taten der Pitt'schen Regierung wurden gelobt und die

46 Ibid. IV S. 219-228, 274.

47 Ibid. S. $280-284$.

48 Ibid. S. 175, 285-294 (Zitat in 294).

49 Ibid. S. 195, 288-289, 192. 
Aktionen der Opposition als Landesverrat bezeichnet wie auch die der friedensbereiten Deutschen. ${ }^{\circ 0}$ Ende des Jahres 1796 hörte die Zeitschrift zu erscheinen auf, als der Erfolg der österreichischen Waffen groß war, und sie mußte so nicht die endgültige Niederlage des folgenden Jahres feststellen. Eine Zeitschrift mit der gleichen führenden Stellung ist dann nicht mehr erschienen. Fortan stritten die Österreicher in den Spalten von mehreren Zeitschriften. Die Österreicher schrieben auch in vielen anderen Publikationen, die in Deutsohland erschienen, und auf den Gebieten Habsburgs erschienen zahlreiche sich für die Fortsetzung des Kampfes einsetzende Flugschriften.

Unter den einzelnen Verfassern zeigte im Laufe des Jahres 1796 der schon erwähnte Lorenz Leopold Haschka die größte Aktivität. In diesem Jahr veröffentlichte er seine bekanntesten Gedichte, »An die Befreier Deutschlands», der Armee Erzherzog Karl's gewidmet, und »Gott erhalte Franz den Kaiser», das später an die Stelle der österreichischen Nationalhymne trat. ${ }^{51}$ Außer der österreichischen Presse veröffentlichte auch die einen Frieden ablehnende Presse des »dritten Deutschland» eine große Zahl von Texten von Haschka. In der »Eudämonia» sind zwei seiner Gedichte abgedruckt, außerdem werden seine Ansichten in vielen anderen Artikeln zitiert.52 Im »Revolutions-Almanach» von Ottokar Reichardt, der Frieden und Revolutions scharf ablehnt, erschienen zahlreiche Gedichte von Haschka. Im Almanach für das Jahr 1797 steht u.a. sein Gedicht »Dem Retter Deutschlands», das zu Ehren der Siege Erzherzog Karls geschrieben wurde. Das Gedicht lobt die österreichische Armee und ihren Befehlshaber sowie deren heldenmütige historische Vorgänger. Die Franzosen sind verhaßte Gallier, die sich an den deutschen Germanen nicht messen können. Über die Lage seiner eigenen Nation Deutschland drückte Haschka sein Betrübnis aus: Deutschland sei eine »Zerrissene, ausgelöschte Nation». Glücklicherweise habe Deutschlands Hauptland, Österreich, seine Kraft bewahrt. Besonders die Talente des Erzherzogs als Befehlshaber sowie die Unerschütterlichkeit des Kaisers hätten das bewirkt.

»Von Oesterreich (dess preisen wir Gott!) vollibracht: / Vollbracht durch seinen Feldherrn Talent und Kunst / - - / Ja! Franzens felsenfeste Beharrlichkeit, nicht durchzuschlagen schlauer Verretherey / nicht $\mathrm{zu}$ bewegen bösem Beispiel / nicht zu erschüttern dem Schicksal selibst». ${ }^{53}$

50 Ibid. z.B. 1796 I S. $35-37,57,71-73$.

51 Keil (1883) S. 29-30.

52 Eudämonia III: 2, 1796, S. 177, V: 1, 1797, S. 10-11, V: 2 S. 147-150.

53 Rev.-Alm. 1797 S. 59-70. 
Haschkas Schriften erschienen auch in Periodica des »dritten Deutschlands», die nicht zum Lager der Kriegspartei gehörten, wenn sie auch dann oft negativ bewertet wurden. Die »Minerva» von Archenholtz und der »Merkur» von Wieland führten 1797 seine Schriften gegen den radikalen Journalisten Hennings an und stimmten hauptsächlich den Auffassungen des letzteren zu. ${ }^{54}$ Der zu den Friedensverteidigern zurechnende L. F. Huber bezeichnete in seiner »Klio» die Kriegsdichtung Haschkas in bezug auf Inhalt und Form als minderwertig und dumm und belegte seine Auffassung mit Zitaten aus Haschkas Versens, die seines Erachtens am unglücklichsten waren. Nach Hubers Meinung schadete Haschkas schriftstellerische Wirksamkeit ganz Deutschland.55 Man veröffentlichte gegen ihn Flugschriften. Andererseits wiederum zitierte man seine Texte mindestens ebenso gern in der Gruppe derjenigen, die ebenso dachten und ihn für die Verkörperung eines entschlossenen vaterländischen Deutschen hielten. $\mathrm{Zu}$ seiner Verteidigung wurde 1796 eine kleine anonyme Flugschrift »An Wien über Hatschka» veröffentlicht, die wiederum gegen die politische Flugschrift »Das politische Kehraus» gerichtet war. Die Schrift verteidigt nachdrücklich Haschkas Ode »Das gerettete Deutschland» (1795), deren kriegerisch und national gesinnte Verse am Anfang der Broschüre abgedruckt wurden. Preußen hatte nach der Schrift die Verbreitung dieses Gedichtes zu verhindern versucht, so wie es auch andere Veröffentlichungen verboten habe. Der offensichtlich österreichische Autor preist Wien als einzig literarisch freie Stadt. Die Schrift endet mit einem Gedicht, das auch von Haschka hätte sein können:

»Der eine, tjef beleidigte, rettete; / Er, und mit ihm war keiner! errettete Germanien vom Gall'sohen Joche / Ohne zu merken auf Dank und Undank.»56

Haschka war die zentrale Gestalt im Kreis der Wiener Schriftsteller, Journalisten und Beamten, die in der zweiten Hälfte der neunziger Jahre gegen die Verbreitung der französischen Gesinnung kämpfte. Neben ihm lassen sich mehrere produktive Schriftsteller nennen, deren Texte in ganz Deutschland gedruckt wurden.57 Einer der streitbarsten ist der Sekretär des kaiserlichen Theaters Johann Babtist v. Alxinger, ein von vielen gehaßter Obskurantist, dessen Aufrichtigkeit jedoch Anlaß zum

54 Minerva 1797 II S. 364 und 561-565, III S. 559-561, IV S. $153-163$ und Anm. S. 163. NTM 1797 IV S. 241.

55 N. Klio 1797 Jan.-Febr. S. 258-159.

56 An Wien über Hatschka, 29. Januar 1796.

57 z.B. Bettex (1935) S. 44-45 und Eder (1955) S. 53-55. 
Mißtrauen geben dürfte. Zur Zeit Joseph II. war er einer der bedeutendsten Vertreter des österreichischen Liberalismus, ein Freimaurer und Aufklärer, der mit konservativen Kreisen harte Auseinandersetzungen führte. Mit vielen anderen Mitarbeitern des »Wienerischen MusenAlmanach» wurde auch Alxinger durch die Zensur und ein hohes Gehalt zum Schweigen gebracht, wie er selbst in einem Brief an Wieland feststellte.58 Er hielt jedoch an seinem Antiklerikalismus fest und entzweite sich u.a. mit Haschka. ${ }^{59}$ 1796-97 veröffentlichte er jedenfalls einige »vaterländische» Gedichte, die sehr erfolgreich unter das Publikum gebracht wurden. Dazu gehört die kriegerische Kantate zu Ehren Erzherzog Karls von 1797, die u.a. im »Merkur» und in der »Nationalzeitung» von R. Z. Becker abgedruckt wurde. ${ }^{60}$ Am Beispiel Alxingers könnte man vermuten, daß der Patriotismus und die Kriegsbegeisterung mancher Wiener »Obskurantisten» eher Solidarität gegen die Regierung als wirklich spontane Begeisterung gewesen sind. Dieselbe Erscheinung läßt sich ja mit umgekehrten Vorzeichen in der monarchistischen, den Frieden unwillig verteidigenden Presse Preußens beobachten. Darauf weist auch hin, daß ein großer Teil der Österreicher, die 1795-1801 den Krieg unterstützt hatten, zur liberalen Zeit Joseph II. zu den Liberalen gehört hatten. ${ }^{61}$ Ein weiteres Beispiel dafür ist Johann (János) Batsányi, der u.a. kriegerische und gegen Frankreich gerichtete Gedichte im »Merkur» veröffentlichte und dann einige Jahre später wegen seiner revolutionären Ansichten gefangen genommen wurde. ${ }^{62}$

Trotzdem gibt es keinen Grund, an der Aufrichtigkeit der meisten zu zweifeln. Neben Haschka gehörte der Obskurant und Gegner der Aufklärung, der Professor der Theologie Leopold Alois Hoffman zu den schärfsten und gewiß überzeugtesten Gegnern eines Friedens. Er hatte schon an der Redaktion der »Wiener Zeitschrift» mitgearbeitet und schrieb nun aktiv für das »Magazin der Kunst und Literatur» und für andere Zeitschriften. ${ }^{63}$ Teils unter seinem eigenen Namen teils anonym veröffentlichte er auch einzelne Flugschriften. Vor allem ging es darin darum, vor den Absichten der Illuminaten und Jakobiner Österreich und Deutschland und sogar die ganze Welt zu revolutionieren, zu warnen.

58 Bulling (1914) S. 125.

59 Ibid. S. 133.

60 Ibid. S. 135. Hamberger-Meusel IX S. 20. NTM 1797 II S. 391-393, National-Zeitung 43/1796 S. 933.

61 z.B. Sonnenfels, Denis, Retzer, Ratschky, Blumauer, Leon und sogar Haschka. Bulling (1914) S. 6-12.

62 NTM 1797 I S. 162-166. v. Krücken, Oskar - Parlagi, Imre, Das geistige Ungarn I, Wien und Leipzig 1923, S. 78-79.

63 Epstein (1966) S. 521-524. Eder (1955) S. 60. Eisner (1907) S. 37. 
Die revolutionäre Bewegung verbreite sich fortwährend und Gegenmaßnahmen seien notwendig. Die Deutschen sollten Gott und ihrem Kaiser trauen und die verräterischen Friedensangebote der Franzosen zurückweisen. $^{64}$ Die sich für einen Frieden einsetzenden Deutschen griff Hoffman heitig an und bezeichnete sie als Illuminaten, Freimaurer, Jakobiner und Vaterlandsverräter. ${ }^{65}$ Hoffman trat auch als Verfasser aktueller politischer Schauspiele auf, in denen das Volk zum Kampf für Religion, den Kaiser und die Staatsverfassung aufgefordert wurde. In den Gebieten des »dritten Deutschland» erregten diese viel Ärger, in denen man seine Neutralität bewahren wollte oder danach strebte, sie zu bewahren. So sprach die bayerische Zensur im Laufe der Theatersaison von 1796/97 für 18 seiner Stücke das absolute Verbot für die Aufführung aus. ${ }^{66}$ Außer den oben genannten beteiligte sich an der öffentlichen Diskussion über Krieg und Frieden eine große Zahl anderer Österreicher innerhalb und außerhalb Österreichs. ${ }^{67}$ Die Ziele dieses Wiener Kreises waren mehr oder weniger gleich; man wollte zeigen, daß ein Friedensschluß nicht möglich sei. Auch in den persönlichen Eigenschaften der Schriftsteller lassen sich viele gemeinsame Züge finden. Ein großer Teil von ihnen gehörte der älteren Generation und dem oberen Beamtenstand an. Oft entstammten sie dem Adel und verteidigten so, indem sie sich einem Frieden und den republikanischen Ideen widersetzten, die eigene, ohne Zweifel sichere und angenehme Welt, um sie als solche zu erhalten. Typisch für diesen Kreis ist, daß man alle Reformversuche ablehnte und an der Verfassung des Staates, der katholischen Kirche und der Treue zum Kaiser festhielt. Die Nationalitätsidee, die einige — von den erwähnten besonders Haschka — her-

64 Hoffmann, Leopold Alois, Aktenmässige Darstellung der Deutschen Union ... 1796; Die zwo Schwestern ... 1796.

65 Hoffmann, Leopold Alois, Höchst wichtige Erinnerungen zur rechten Zeit ... I-II, 1795-96. Als Verräter erwähnte er z.B. Biester, Blau, Bode, Böhmer, Campe, Cloots, J. Fr. und C. Fr. Cramer, Dorsch, Ehlers, Eikıneier, Fischer (?), Forster, Gedike, Halem, Hennings, Hinze, Huber, Kämmerer, Klopstock, Knigge, Knoblauch, Kronemann, Mauvillon, Metternich, Münch, Nicolai, Pape, Salzmann, Schiller, Schneider, Sonnenfels, Stamm, Trapp, Wedekind, Weisshaupt und Zech.

66 Friess, Hermann, Theaterzensur, Theaterpolizei und Kampf um das Volksspiel in Bayern, Diss. München 1934, S. 247.

67 z.B. im Neuen Deutschen Merkur schrieben Hofrat, Zensurbeamter Johann Melchior v. Birkenstock, Jesuit, Professor Michael Denis, Jesuit, Professor zu Wien Joseph Hilarius v. Eckhel, Freiherr Joseph v. Hammer-Purgstall, Theaterdichter Karl Friedrich Hensler, Der Herausgeber der »Oesterreichischen Monatschrift» Joseph Franz Ratschky, Hofrat, Freiherr Joseph Friedrich von Retzer und Hofrat, Professor und Reichsfreiherr Joseph v. Sonnenfels. 
vorhoben, war den Wiener Herren fremd, wenn man sie auch als Stärkung des Kampfwillens akzeptierte. - In Österreich wurden auch zahlreiche anonyme Flugschriften in diesem Sinne gedruckt. ${ }^{68}$

Die österreichische Regierung unterstützte die oben vorgestellte öffentliche Meinung durch den Einsatz besoldeter Schriftsteller. Der schärfste Kritiker des Baseler Friedens, Johannes v. Müller, setzte seine Tätigkeit im Sommer 1796 mit einer kleinen Schrift fort, »Die Gefahren der Zeit», die in bekannter Weise die Macht Österreichs, die unerschütterliche Treue des Volkes zu seinem Kaiser preist und das neue französische Evangelium der Freiheit und Gleichheit verspottet.69 Mit noch stärkerem Geschütz führte Glave-Kolbielski diesen Federkrieg weiter. Seine Flugschrift gegen den Freihernn v. Seckendorff »Germania im Jahre 1795» führte zu einem literarisch-politischen Skandal. Zu Beginn verurteilt Glave eine ganze Reihe von Schriften der Gegenpartei, u.a. die des Baron von Ompteda und einigen anderen Diplomaten.70 Den eigentlichen Skandal rief jedoch ein Lustspiel am Ende der Schrift hervor, »Die Liebe im Reichsnarrenspitale», in der Glave seine Gegner zu Patienten einer Irrenanstalt macht. Neben Seckendorff, Ompteda und Kaufmann gehören zu den Patienten u.a. ausländische Gesandte, was den Sturm der Entrüstung verständlich macht.71 Glaves Anonymität war damals noch nicht preisgegeben worden und man betrachtete allgemein Glaves Vorgesetzten v. Hügel als Verfasser der Schrift. Überall erschienen mißbilligende Äußerungen, auf die Glave zornig antwortete. Die »Germania» erschien in mehreren Auflagen und der Zorn nahm zu. Der Reichstag in Regensburg setzte eine Belohnung von 2500 Florin für die Aufdeckung des Verfassers aus. ${ }^{72}$ Eine zu große Begeisterung und die über das Ziel hinausschießende Propaganda führten 1797 schon vor dem Frieden von Campo Formio zur Amtsenthebung Glaves, der dann auch für eine kurze Zeit seine schriftstellerische Tätigkeit auf Bezahlung gegen Frankreich in Österreich beendete. ${ }^{73}$

In gewißem Grad kann man den Historiker K. F. v. Justin, der eine Geschichte der vorangegangenen Kriegszüge verfaßt hat, als im Dienste der Regierung stehend betrachten. Der Historiker wird in einem Maße von einem heroischen Patriotismus bestimmt, daß man von Objektivität

68 Aufschrift eines Denkmahls deutscher Dankbarkeit ... 1797; Umbefangene Blicke ... 1796; Gott regiert die Welt . . 1796.

69 Die Gefahren der Zeit, 1796.

70 Germania im Jahr 1795, 1796 Anm. S. 29 und 30-31.

71 Ibid. S. 80-96. Pribram-Fischer (1937) S. 61-62.

72 Pribram-Fischer (1937) S. 63.

73 Ibid. S. 58, 75-76. 
kaum noch sprechen kann. Die formellen Friedenswünsche ${ }^{74}$ gehen in einem unersättlichen $\mathrm{Haß}$ gegen Frankreich und in einem Lobgesang auf die Tapfenkeit der eigenen Soldaten und die Tüchtigkeit der Befehlshaber unter. Indem Justin den Sonderfrieden verurteilt, die Volksbewaffnung akzeptiert, die animalische Grausamkeit der Franzosen hervorhebt und den Tod der österreichischen und anderen deutschen Patrioten für das Vaterland verherrlicht, unterstützt er eindeutig die Kriegspropaganda. ${ }^{75}$ Auch anderswo wurde aktuelle politische Propaganda in an sich nicht aktuellen politischen Texten vorgebracht. ${ }^{76}$

Weitere Unterstützung fand Österreich in der Presse des »dritten Deutschland». Von den schon genannten Zeitschriften setzten »Eudämonia» und der »Revolutions-Almanach»ihren Kampf weiter fort. Ihr Vorgehen ist dabei am typischsten und konsequentesten. Vereinzelt fanden die Österreicher auch Unterstützung bei den vielen anderen Zeitschriften und natürlich auch durch Flugschriften, aber die zwei genannten sind die wichtigsten. Das Interesse der »Eudämonia» lag weniger auf dem Gebiet der Außenpolitik sondern mehr auf dem der inneren kulturellen Verhältnisse in Deutschland, wobei sie sich gegen Aufklärung und Revolution wandte. Der gegenwärtige Krieg wurde relativ selten behandelt, wenn auch mit deutlichen Stellungnahmen. Friedrich Leopold Graf zu Stolberg verfaßte zweimal Verse für die Zeitschrift, in denen zum Kampf aufgefordert wurde. In Zusammenhang mit dem Gedicht »West-Hunnen» entlud »Eudämonia» ihren $\mathrm{Haß}$ gegen die Franzosen und hob hervor, daß man ein solches Mischvolk nicht als Franken bezeichnen dürfe. ${ }^{77}$ Weiter nahm die Zeitschrift Texte von so hartnäckigen Friedensgegner wie dem Stiftsuperintendenten und Konsistorialassessor zu Merseburg Gottlob August Baumgarten-Grusius, der das Pseudonym Hippofilos verwendete, und von dem »edlen Schweizer» (Johannes v.) Müller auf.78 Auch verteidigte man die österreichische Kriegspartei vor den Angriffen aus dem »dritten Deutschland». Besonders erwähnte man »die drei $\mathrm{H}: \mathrm{S}$, Haschka, Hoffman und Hofstätter, die Zentralfiguren des »Wiener Magazins».79 Dagen

74 v. Justin, K. F., Geschichte des ... 1796 S. 26 und 88; ders. 1797 S. 3.

75 v. Justin 1796 z.B. S. 8, 52-53, 58-59, 118; ders. 1797 S. 16-17, 28-29, $32-34,47-48$.

76 z.B. de Luca, Ignaz, Practische Staatskunde von Europa, Wien 1796, S. X-XI; Geschichte des K. K. militärischen Marie Theresie Ordens . . 1796.

77 Eudämonia III: 2, 1796, S. 95-98 (»Kassandra»), IV: 1, 1797, S. 28-37 (»Die West-Hunnen»), IV: 3, 1797, S. 272.

78 Ibid. III: 5, 1796, S. 408; IV: 1, 1797, S. 6-7, IV: 3, 1797, S. 262.

79 Ibid. III: 2, 1796, S. 177; V:2, 1797, S. 147, 150 usw. 
wurden Illuminaten, Aufklärungsphilosophen und frankreichfreundlich gesinnte Personen nicht geschont. Der Freimaurer v. Knigge war weiter das Ziel scharfer Angriffe, die auch nach seinem Tode nicht aufhörten. ${ }^{80}$ Auch der "Rabbi Nicolai» wurde fortgesetzt angegriffen. ${ }^{81}$ Rebmann oharakterisierte man als »der wüthendste unter allen Schreiern, Fürstenlästerern und Feinden der christlichen Religion» und seine schriftstellerische Tätigkeit als ekelhafter Betrug dargestellt. ${ }^{82}$ Vielleicht am schlimmsten beurteilte man jedoch Kant, gegen des mehrmals Artikel erschienen. ${ }^{83}$ Nach der Meinung der »Eudämonia» sei es unmöglich, überhaupt an einen Friedensschluß mit dem atheistischen Frankreich zu denken. Ein Artikel unter der Überschrift »Von dem Frieden» faßt diese Meinung zusammen:

»Der Krieg verewigt die Revolution, und die Revolution verewigt den Krieg - - Der Gordische Knoten ist also nur auf die Art aufzulösen: Den Krieg und die Revolution $\mathrm{zu}$ gleicher Zeit zu endigen $\gg .84$

Die Einheit des Reiches wurde ständig hervorgehoben und die Sonderfrieden natürlich verurteilt. Man berief sich fortwährend auf den Nationalgeist, dabei wurden hier die Grausamkeiten der Franzosen als Hilfe benutzt:

»Die französischen Barbareyen haben den Nationalgeist wieder geweckt, und unsere Landsleute daran erinnert, daß wir eine Nation, und nicht ein von entarteten Italienern, entlaufenen Griechen, unterjochten Gaulen und verdrängten Franken zusammengemischtes Volk, daß wir Allemannen sind, wo einer für alle und alle für einen standen».8j

Auch die christliche Religion müsse nach Meinung der Redakteure der »Eudämonia» dem gemeinsamen Kampf dienen. Der Kampf gegen Frankreich sei nicht nur ein Kampf für das Vaterland sondern auch für den Altar Gottes. Obwohl die Zeitschrift vor allem katholische Standpunkte vertrat, forderte man auch die Zusammenarbeit zwischen Katholiken und Protestanten gegen Illuminaten und Revolutionäre. In der Zeitschrift wurde der Briefwechsel eines »Christen» mit einem »Patrioten», des Marburger Professors Johann Heinrich Jung mit dem Geheim. Refer.

80 Ibid. III : 1,1796 , S. 81 und IV: 3,1797 , S. 237-246.

81 Ibid. III: 2 , 1796, S. 177 und IV: 3, 1797, S. $196-197$.

82 Ibid. IV: 1, 1797, S. 12.

83 Ibid. IV: 3,1797 , S. $277-282$, V: 3, 1797 S. 258-.

84 Ibid. III: 3 , 1796, S. $278-280$.

85 Ibid. III: 6,1796 , S. $504-507$. 
v. Wreden, die beide zwei verschiedene Bekenntnisse repräsentierten, veröffentlicht, in dem die Bedeutung der Zusammenarbeit zwischen allen Christen in der Fortführung des Kampfes hervorgehoben wird. ${ }^{86}$ In die gleiche Richtung gingen einige antisemitische Äußerungen in der Zeitschrift. ${ }^{87}$ Während »Eudämonia» Gesetz, Religion und Vaterland verteidigte, sprach sie sich scharf gegen die Pressefreiheit aus. Die schlimmste Höhle des Schundjournalismus sei Altona, »der Fleck in Deutschland, von woher die giftigsten Anfälle auf Religion, Fürsten und deutsche Verfassung, wie aus einem Bombenkessel unaufhörlich auf das übrige Deutschland ausgeworfen werden».88 Weil nach der »Eudämonia» die Presse für die allgemeine Meinung des Volkes wichtig sei, müsse man die schriftstellerische Tätigkeit der Jakobiner einschränken. ${ }^{89}$ Als »Eudämonia» jedoch zur Zeit des Friedens von Campo Formio selbst das Verbot in Wien traf, klagte man natürlich über das Verbot sehr und beschloß, den Kampf unermüdlich weiterzuführen, und als die Zensur im folgenden Jahr die Zeitung zwang, ihr Erscheinen ganz einzustellen, waren die Proteste laut.90

Neben der »Eudämonia» stand in der friedensfeindlichen Front auch unerschütterlich der »Revolutions-Almanach». Das Schwanken im Jahre des Baseler Friedens wich und der Almanach des Jahres 1796 ist schon durch eine unbedingte kriegerische Haltung geprägt. Reichardt behandelte u.a. die Härte der französischen Besetzer und ihr schlechtes Betragen in den Rheingebieten ${ }^{91}$ und pries den Patriotismus der Österreicher und Sachsen, weil diese ihren Regierungen Geld gaben, um die Kriegskosten decken zu können. Zur Bekräftigung wird von einem österreichischen Invaliden erzählt, der dem Vaterland sein letztes Vermögen opferte. ${ }^{92}$ Auch sonst verwendete man gern Anekdoten, um den Gegner lächerlich zu machen oder um seine Schwäche zu zeigen. Der »Revolutions-Almanach» von 1796 erzählt in einer Anekdote von elsässischen Bauern, die auf ihrer Flucht nach Deutschland von einer französischen Patroullie überrascht worden waren. Nachdem die Soldaten erfahren hatten, daß noch niemand die Flüchtlinge gesehen hatte, sammelten sie untereinander Geld. Der Anführer bat sie das Geld irgendeinem Emigrantenpriester zu übergeben, damit dieser für sie bete. ${ }^{93}$ Aus-

86 Ibid. IV: 5, 1797, S. 458-459 und Anmerkungen.

87 z.B. ibid. III: 2 , 1796, S. 177 und VI: 1,1798 , Anm. S. 85, VI: 6, 1798; S. 534.

88 Ibid. IV: 2,1797 , S. 160.

89 Ibid. IV: 3, 1797, S. 199.

90 Ibid. IV: 1,1797 , S. $1-2$ und IV: 6, 1798, S. 534.

91 Rev.-Alm. 1796 S. 178-201.

92 Ibid. S. $271-272$.

93 Ibid. S. 239. 
führlich wird im selben Jahrgang die Friedensfrage von einem hannoverschen Theologen, Heinrich Ludwig Fischer, behandelt: »Der Krieg ist eine Strafe der Welt; und welcher Menschenfreund wird nicht die segnende Palme der Friedens, den blutigen Lorbeer von jenem vorziehn» beginnt er versöhnlich, um dann aber in der Fortsetzung für diejenigen Partei zu ergreifen, die den Krieg weiterführen wollten. Heftig greift er die an, die im Augenblick einen Friedensschluß fordern. Fischer konnte das Mißtrauen der Deutschen gegen England und Österreich nicht verstehen. Man unterstelle diesen Großmächten, daß sie eine Expansionspolitik betreiben würden und man befürchte, daß sie ihren Vorteil auf Kosten der anderen im Auge hätten. Doch hätte die eine von i.hnen in diesem Krieg eher verloren als gewonnen und auch die andere, »die so stolz und bewundert in ihrer vollen Manneskraft da steht», wolle Deutschland keines einzigen Dorfes berauben. Man habe keinen Anlaß aus Furcht vor den Bundesgenossen einen ungünstigen Frieden zu erstreben. Viele deutsche Zeitschriften seien bei der Behandlung des Krieges die eifrigsten Prediger der Schwäche und würden für Frankreich arbeiten, indem sie Mißtrauen gegen Österreich und Rußland säten. Die große Mehrheit des deutschen Volkes sei jedoch nicht »revolutionert», sondern zeige die dem deutschen Volkscharakter typische Treue und kühle Utberlegung. Natürlich tadelte Fischer die Deutschen, die über den Rhein gezogen seien und dort mit den Vaterlandsfeinden brüderlich verkehren würden. Weiter forderte er, daß man die Emigranten, die von der anderen Seite des Rheins geflohen kämen, gut empfangen solle. ${ }^{94}$

Der Almanach des Jahres 1797 beginnt mit einem von Reichardt im Juli 1796 verfaßten Überblick über die Kriegsereignisse. Die militärische Lage habe sich verschlechtert, und so sei die Bedeutung der Liebe zum Vaterland noch wichtiger als früher geworden. Reichardt äußert, daß er einen baldigen Frieden erwarte: »Krieg ist ja Kampf um Frieden, und rühmlich ist's, um einen guten Frieden zu kämpfen».95 Die versöhnliche Haltung entwickelte sich jedoch nicht zu einer konkreten Friedensbereitschaft. Heftig werden revolutionäre Schriftsteller angegriffen, die Revolution theoretisch abgelehnt und ausführlich über die Grausamkeiten der französischen Soldaten im Rheinland berichtet, offensichtlich um Nationalhaß zu erwecken. Seinen Artikel ergänzte Reichardt mit einem Brief eines »Freundes» aus Köln, in dem bewiesen werden sollte, daß die Vereinigung des Rheinlands mit Frankreich oder die Bemühungen, es zu einem separaten Staat zu erklären, von einigen jungen Leuten unter-

94 Ibid. S. $164-172$.

95 Ibid. 1797 S. 196-225. 
stützt würde, die nichts zu verlieren hätten, aber der Meinung seien, sie würden durch die französische Verfassung gewinnen. Alle gesetzestreuen und vermögenden Männer wollten nur den Rücken der Franzosen sehen und würden sich nicht um frankreichfreunliche literarische Aktivitäten kümmern.96 Die Kriegsfrage wird im Almanach von 1797 in zwei Artikeln besonders eindeutig behandelt. In einer Serie von Kupferstichen "Die alten und neuen Deutschen» und »Die alten und neuen Franzosen» verfaßte Reichardt bluttriefende Texte zu den Bildern, die von Franzosen hundert Jahre früher begangene Freveltaten darstellen, und hob die ewige Grausamkeit der Franzosen und den Patriotismus und die Opferbereitschaft der alten Deutschen in einer Weise hervor, die zeigt, daß er sich eindeutig auf die Gegenwart bezieht.97 Der Almanach enthält noch einen Anhang, der nach zeitweiligen Kriegserfolgen der Alliierten im Spätsommer 1796 abgefaßt wurde. Er enthält u.a. Berichte über die im August-September errungenen Siege des Prinzen von Coburg in den Niederlanden. Schadenfroh werden die deutschen Demagogen verspottet, die schon von einer Revolutionsregierung am offenen Grab des alten Deutschland geträumt hätten. Reichardt stellte fest, daß der Kriegserfolg der kaiserlichen Heere ein besonderer Anlaß für den bedeutenden Dichter Haschka sei, Hymnen zu verfassen. Eine dieser Siegeshymnen ist im Almanach abgedruckt, daran schließt sich von einem anonymen Verfasser »Lied für deutsche Vaterlandsfreunde» an, das nach der Melodie der englischen Nationalhymne (»God save the King») gesungen wurde. Der Dichter versucht den Nationalgeist seiner Landsleute zu erwecken und stellt »Eintracht» und »Freiheitsschwärmerey» als begriffliche Gegensätze hin. ${ }^{98}$

Neben den Zeitschriften setzten sich auch Flugsohriften für die Fortsetzung des Krieges ein. Die meisten erschienen in Zusammenhang mit dem französischen Feldzug von 1796 und mit den sich daran anschließenden Ereignissen. Wenn auch unterwürfige Friedensbereitschaft die gewöhnliche Reaktion war, so erregten die Grausamkeiten der Franzosen auch Zorn und Rachegier. Kriegerische Flugschriften exschienen noch 1796 und auch im folgenden Jahr. Außerdem wurden diese Schriften gleichzeitig in der kriegerischen Presse - und dann wieder 1798, als sich die öffentliche Meinung gegen einen Friedensschluß zu wenden begann - abgedruckt. Schriften, die die Stimmung des Jahres 1796 zusammengefaßt schilderten, erschienen noch mehrere Jahre später.

96 Ibid. S. $335-355$.

97 Ibid. S. $59-70$ und Beilage.

98 Ibid. Anhang (Die Seiten sind nicht numeriert). 
$\mathrm{Zu}$ den eifrigsten Gegner Frankreichs und eines Friedens gehörte in Süddeutschland ein Verwaltungsbeamter aus Nassau-Weilburg, Philipp Bernhard Horstmann, der mindestens drei bluttriefende Schriften herausgab. 1796 erschien »Gute Nacht, Republik». In der Schrift wird Frankreich vor der Emigrantenarmee gewarnt, deren wirksamer Einsatz als Stütze der alliierten Truppen den Krieg mit einer Niederlage Frankreichs beenden würde.99 Sehr drastisch schildert die zweiteilige Sohrift »Die allerneueste Kriegszucht der Franzosen» das Vorgehen der Besatzungsheere an der Lahn. Von den Besatzern wird ein äußerst negatives Bild gegeben. Es gäbe keine Zuoht, Räubereien und Gewalttaten könnten unbestraft geschehen. Dieselben unbarmherzigen Besetzer seien jedoch Feiglinge, die heimlich gegen das Direktorium und die Republik intrigieren würden.100 Horstmann gibt sich sehr kaisertreu und preist Erzherzog Karl und lobt die Emigranten.101 In der Schrift »Bemerkungen eines französischen Bürgers» werden Grausamkeiten der Franzosen, Verfolgungen von Priestern geschildert und die Emigranten verteidigt. Es sollte nachgewiesen werden, daß die Franzosen nur widerwillig und aus Furcht vor der Guillotine kämpften. Es wird versichert, die Deutschen könnten den Sieg erringen, wenn sie aktiver kämpfen würden. ${ }^{102}$

In zumindest ebenso scharfer Form schrieb der fränkische Pfarrer Friedrich Johann Albert Muck, von dem 1797 »Anekdote und Charakterzüge aus dem Einfalle der Neufranken in Altfranken im Jahre 1796» erschien. Nach Mucks Schilderung verhielt sich die trotz des zähen Widerstands der Deutschen eingedrungene französische Armee völlig zuchtlos. Ihr Verhalten habe manchen ehemaligen Republikaner sich schämen und seine Haltung ändern lassen. Die Soldaten hätten unverschämt Päderastie und Sodomie getrieben und sogar schwangere Frauen geschändet. Kirchen seien geschändet und Priester gequält, gedemütigt und ermordert worden. Die Soldaten würclen saufen, stinken und rauben und mit Juden und örtlichen »Gleichheit-Bauern» brüderlich verkehren. Mucks Texte verwendete auch die frankreichfeindliche Presse, u.a. der oben genannte »Revolutions-Almanach».103 Auch sonst beteiligten sich die Pfarrer aktiv an der öffentlichen Diskussion. Der Neubronner Pfarrer Johann Gottfried v. Pahl veröffentlichte 1797-98 drei Bände zu den Ereignissen des Kriegsjahres 1796 in Schwaben. Zu seinen Mit-

99 Gute Nacht, Republik! Die Emigrirten stehen auf ... 1796.

100 Die allerneueste Kriegszucht ... I 1796 z.B. S. 3-6 und 41.

101 Ibid. S. 38, II 1797 z.B. S. 57-59, 64-66.

102 Bemerkungen eines französischen Bürgers ... 1796 z.B. S. 91-92.

1.03 Anekdote und Charakterzüge ... 1797. Rev.-Alm. 1798 S. 212-222. 
arbeitern gehörten sechs Pfarrer, deren Texte mehr oder weniger dem oben angeführten gleichen.104 Daneben bekämpften noch viele andere Kleriker in ihren Schriften den Frieden und forderten nach einer Fortsetzung des Kampfes. ${ }^{105}$

$\mathrm{Zu}$ diesen gehört noch eine Reihe von anonymen Flugschriften im gleichen Ton. Der tapfere Widerstand der Bauern des Lahngebietes und anderer Gebiete gegen die Franzosen wird in »Aechte Nachricht von dem Krieg der leulschen Bauern» geschtldert. Stolz wird von den örtlichen Siegen erzählt, die die freiwilligen Truppen aus deutschen Bürgern und Bauern über die Franzosen errangen. In der Schrift wird festgestellt, daß ein solcher Krieg von Bauern nach internationalem Recht ungesetzlich sei, aber wegen des Verhaltens der Franzosen müsse man ihn verstehen und akzeptieren. Das französische Volk wünsche auch den Frieden. Darum müsse man mit allen Mitteln verhindern, daß Frankreich neue militärische Siege erringe. Man würde sich sonst in Frankreich mehr für den Krieg begeistern und es würde noch lange bis zu einem Frieden dauern. Die Schrift stellt auch fest, man müsse nur noch ein Jahr Widerstand leisten, dann sei ein Frieden sicher. Die Schrift fordert noch: »Brüder Teutschlands! es ist besser mit Ehren zu sterben, als mit Schande zu leben».106 Die Schrift eines Anonymus »Dringende und gründliche Vorstellung» hebt die Pflichten der Reichsstände hervor. Auch sie bezeichnet die französischen Armeen als »Räuberhorde». Ein baldiger Friedensischluß wird für notwendig gehalten, aber solche Friedensbedingungen genannt, die eine Fortsetzung des Krieges bedeutet hätten. Die Schrift beruft sich bei ihrer Argumentation auf die Verfassung. Alle Sonderfrieden, sowohl der mit Preußen als auch der zuletzt mit HessenKassel geschlossene, seien zu verurteilen. Nur der Kaiser und die Stände seien nach der »Westfälischen Verfassung» berechtigt einen Reichsfrieden zu schließen, nicht die einzelnen Territorien. Es sei Ziel des deutschen Kampfes »der Friede, aber nur der Friede des ganzen teutschen Reiches». Dieser könne nur durch einen einigen und beständigen Kampf unter der Führung des Kaisers und durch Erweckung des »Reichspatriotismus und den altteutschen Rittermuth» bei den Deutschen erreicht werden. Das Reich sei Ziel eines französischen Überfalls geworden und es habe

104 v. Pahl, Johann Gottfried, Materialien zur Geschichte ... Lief. I-III 1797-98.

105 z.B. Ohanny, A. R., Anmerkungen gegen die staatsrechtlichen Bemerkungen ... 1796; Unpartheyische Prüfung der staatsrechtlichen Bemerkungen ... 1796; Widerlegung der Druckschrift ... 1796.

106 Aechte Nachricht von dem Krieg der teutschen Bauern ... 1796. Auch Briefe deutscher Bürger ... 1796. 
gesetzlich das Recht, sich zu verteidigen. Der Krieg müsse für die Reichsintegrität, den verletzten Wohlstand und die beleidigte Ehre des Vaterlandes weitergeführt werden. Nach der Meinung des Verfassers habe Deutschland genügend Kräfte, um den Feind zu schlagen. Es müsse nur seine Kräfte vereinigen. Obwohl die Schrift das Vorgehen Preußens nicht akzeptierte, fordert sie dazu auf, auch am Kampf teilzunehmen und sich an den Geist Friedrich des Großen zu erinnern. Die gleichen Aufforderungen gehen auch an Karl Theodor von Pfalzbayern und an Kursachsen. ${ }^{107}$ Außerdem erschienen weitere Flugschriften, deren einzige Absicht es war, den Baseler Frieden und das Vorgehen Preußens $\mathrm{zu}$ verurteilen. ${ }^{\mathbf{1 0 8}}$ Der Glaube an einen Sieg wurde durch Schriften verstärkt, die über vergangene Kriegsereignisse berichteten, die Tapferkeit der Deutschen hervorhoben und zeigten, wie der Kampf gewonnen werden könnte. 109 Im gleichen Geist konnten Schriften politischer Gegner als Beweis für Sittenlosigkeit und Zunahme an »unreiner Begeisterung, einseitigen und eingeschränkten Parteygeistes» herausgegeben werden.110 Auch wurden Texte von Emigranten dazu verwendet, Stimmung gegen die Republik zu machen. ${ }^{111}$

Die militärische Niederlage Österreichs im Frühjahr und Sommer 1797 beendete für eine Weile das Erscheinen von Schriften in dem geschilderten Ton. Man konnte jetzt nicht mehr behaupten, daß Frankreich militärisch schwach sei und bald zusammenbrechen werde, daß die tapferen Germanen ihm überlegen seien. Öffentlich mußte Österreich zumindest scheinbar den Frieden akzeptieren, den die kaiserliche Regierung mit Napoleon geschlossen hatte. Der unermüdliche Kriegsdichter Haschka veröffentlichte ein Gedicht zu Ehren den Friedens von Campo Formio.112 Der hartnäckige Gegner eines Friedensschlußes Ottokar Reichardt schrieb im Vorwort des »Revolutions-Almanachs» für das Jahr 1798:

»Friede, Friede! schallt's durch Deutschland, und wenn gleich in dem Augenblicke wo ich dieses schreibe (Carlsbad im Junius

107 Dringende und gründliche Vorstellung ... 1796.

108 z.B. Abdruck Kaiserlichen Handschreiben an die Herren Kurfürsten ... 1797; Des Herrn Heinrich Wilhelm von Bülow ämtliche . . . 1796.

109 z.B. Militairische und politische Bemerkungen ... I-II, 1795-96; Beiträge zur richtigen Beurtheilung der Kapitulation von Mannheim, 1796; Gemälde aus der Belagerung von Mannheim ... 1796.

110 Freiheits-Gedichte I-II, Paris auf Kosten der Republik 5; Lord Aukland, Einige Anmerkungen ... 1796; Des Freiherrn Knigge Welt- und ... 1796. 111 z.B. Leben Charetté's, 1796; La Harpe, Johann Franz, Vom Fanatismus in der Revolutionssprache ... 1797.

112 Keil (1883) S. 30. 
1797) noch Manches im Dunkel und Ungewissenheit gehüllt scheint, so ist doch diese tröstende Gewissenheit, daß Deutschland am Ziel seiner langen Leiden steht, und daß jeder Patriot Gott und den edlen Kaiser dafür segnen muss.»113

Dank und Ehre für die Entstehung des gesegneten Friedens käme Gott und besonders dem Kaiser zu, der aus Liebe zu seinen Untertanen und keineswegs aus Schwäche den Frieden geschlossen habe. Das war die Erklärung der treuen Österreicher und Reichsdeutschen zur Situation. Die Einstellung gegen Frankreich und zur revolutionären Bewegung blieb jedoch unverändert. Ein gutes Reispiel für dif Stimmung in Österreich nach dem Frieden von Campo Formio stellt das umfangreiche Werk des Theologieprofessors Joseph Lauber aus Brünn dar, "Denkmal der Vaterlandsliebe und Fürstentreue», in dem er die letzten Kriegsereignisse und den Friedensschluß behandelt. Schon der Titel läßt Laubers Einstellung erkennen. Patriotismus, Treue zum Kaiserhaus und Antipathie gegen Frankreich und seine Revolution bestimmen das Werk. Am Krieg sei Frankreich allein Schuld gewesen. Die Franzosen hätten im Laufe des Krieges große Grausamkeiten begangen, die Kirchen geschändet und Gott verspottet. Frankreich habe auch offen erklärt, daß es keinen Frieden ohne »natürliche» Grenzen schließen würde, und in keinem Fall mit England, Österreich und Rußland. Die Sonderfrieden mit Preußen und den anderen seien gesetzeswidrig gewesen, wie auch die norddeutsche Neutralitätslinie. Die Tapferkeit und Kaisertreue und der Untertanengeist der österreichischen Armeen finden in der Schrift Anerkennung. Man habe »zum Schutze des Vaterlancles, des Landesfürsten, des Gottesdienstes, des eigenen Heerdes» gekämpft. Zur Armee seien unaufhörlich Freiwillige geströmt und andere hätı̂en sie mit Geldspenden unterstützt. $^{114}$ Trotzdem akzeptierte Lauber vollkommen den geschlossenen Waffenstillstand von Leoben und den Frieden von Campo Formio. Der F'rieden sei ehrenvoll für Österreich und zum Wohle des Volkes.115 Auf dieselbe Weise dankte dem Kaiser eine anonyme Flugschrift, verfaßt von dem Regensburger Bibliothekar Franz Wilhelm Rothammer. Der Kaiser habe nach der Verfassung gehandelt, als er den Frieden zwischen seinen eigenen Landesteilen und Frankreich schloß. Die Ausweitung dieses Friedens auf das ganze Reich entspräche dem Wunsche des Kaisers. ${ }^{116}$ Die Erwartung eines allgemeinen Friedens, die in der

113 Rev.-Alm. 1798 Vorbericht.

114 Lauber, Joseph, Denkmahl der Vaterlandsliebe ... 1797, S. 38-39, 115, 173, 236-239, 243, 287, 300-301, 325-330.

115 Ibid. S. $337-340,476$.

116 Ueber Kaisermacht, Friedenskongreß . . 1797. 
Zeit zwischen dem Baseler Frieden und dem Frieden von Campo Formio herrschte, dehnte sich zumindest zeitweise auf das ganze Reich aus.

\section{4. "Das glückliche Norddeutschland»}

Der geschilderte Zeitraum wird dadurch geprägt, daß Norddeutschland im Schutze der preußischen Neutralitätslinie sich in der öffentlichen Diskussion mit dem Frieden einverstanden erklärte. Das öffentliche Wort trat natürlich in Preußen im Sinne seiner Regierung für eine Politik des Friedens ein. Diese Bereitschaft zum Frieden ist auch für die Stellungnahmen in den anderen neutralen Territorien typisch. Gerne verglich man den eigenen glücklichen Friedenszustand mit den Leiden in Süddeutschland und häufig stellte man fest, daß diese Leiden unnötig seien, weil es zwecklos sei, den ganzen Krieg weiterzuführen. Der Krieg diene zunächst den Privatinteressen des Kaisers oder auch den russischen oder englischen Interessen.

In diesem Zeitabschnitt bietet die öffentliche Meinung in Preußen ein ziemlich einheitliches Bild. Es werden die gleichen Argumente wie bei der Diskussion verwendet, die sich sofort nach dem Baseler Frieden entzündet hatte. Auch die bedeutendsten Schriftsteller wurden schon vorgestellt. J. F. Reichardt setzte seine frankreichfreundlichen Artikel in seinen Zeitschriften »Deutschland» und »Frankreich». fort. Die in Berlin erschienene Zeitschrift »Deutschland» schloß sich nahtlos an die übrige preußische Presse an. Der Jahrgang von 1796 ist mit einem Aufsatz eingeleitet, der auf Kant's »Zum ewigen Frieden» basiert und besonders zustimmend ist.117 Reichardts Aufsätze enthalten zum größten Teil heftige Angriffe gegen jene Deutsche, die nicht verstanden hätten, wie notwendig ein schneller Friedensschluß gewesen sei. Reichardt behandelt besonders abweisend einige Mitarbeiter an Schillers »Horen», wie Goethe und Woltmann. Deren Haltung im damaligen Krieg, zur Revolution and zu Frankreich sei so gewesen, daß sie der Sache des Friedens keinen guten Dienst erwiesen hätten.118 Negativ wurde auch Archenholtz' vorsichtige »Minerva» kritisiert.119 Selbstverständlich ist, daß Johannes von Müllers Flugschrift »Die Gefahren der Zeit» (1796) besonders scharf verurteilt wurde. Nach Reichardt sei die Schrift »trotz des antiken Kostums nichts anders als eine leider echt deutsche Travestirung

117 Deutschland im J. 1796 I S. 263-268.

118 Ibid. S. 55. Tschirch I (1933) S. 183 und Fambach, Oscar, Goethe und seine Kritiker, Düsselsdorf 1953, S. 14-15.

119 Deutschland im J. 1796 I S. $389-391$. 
des französischen Nationalenthusiasmus». Sie weiche von der Wahrheit ab und sei schlecht geschrieben. Besonders verwerflich sei Müllers Angewohnheit, Friedensbereitschaft als Verrat abzustempeln, ein solcher Fanatismus sei »mehr als Robespierrisch». Die Franzosen seien militärisch stark, was weiterhin für einen Friedensschluß mit ihnen spreche. Die »friedensstiftende Weisheit» der preußischen Regierung wurde von Reichardt natürlich mit Anerkennung bedacht, obgleich Müller sie mit der Zusammenarbeit der katholischen Könige mit den Feinden des Christentums (d.h. das Bündnis zwischen Frankreich und der Türkei gegen das Deutsche Reich) verglichen hatte. Nach der Meinung Reichardts müsse jeder edeldenkende vor Scham erröten, wenn er sähe, welch große Talente so falsch gebraucht würden. ${ }^{120}$ Zustimmung erhielten jedoch Schriften, die dem Friedensschluß zustimmten. Besonders dankte man Posselts »Europäischen Annalen», und weiterhin stimmte Reichardt mit der scharfen Verurteilung der Handelstyrannei durch den Herausgeber überein. ${ }^{121}$ In der gleichen Weise wurde dem »Deutschen Staatsarchiv» und seinem Herausgeber, Karl Friedrich Häberlin, für seinen Kampf gegen die den Baseler Frieden ablehnenden österreichischen Publizisten gedankt. ${ }^{122}$ Begrüßt wurde auch in der Zeitschrift die literarische Produktion von Hennings, Rambach und Knigge. ${ }^{123}$ Besonders hervorgehoben wurde die anonym erschienene Flugschrift »Rückblicke auf den, wenn Gott will, für Teutschland nun bald geendigten Krieg» des zu den bedeutendsten Vertretern der Friedenspartei gehörenden Freiherrn Adolf von Knigge. ${ }^{124}$ In diesem Zusammenhang trug Reichardt seine eigene Aufforderung an die deutschen Fürsten vor:

»Wählet also bessere und edlere Mittel, Ihr Fürsten! um Ruhe, Gehorchsam, Ordnung, Zutrauen und Eintracht herzustellen und $\mathrm{zu}$ erhalten! Machet sobald als möglich unter leidlichen Bedingungen dem unglücklichen Kriege ein Ende-Jeder Friede ist ehrenvoll, der geschlossen wird, um Bürgerblut zu schonen. Zaudert nich't lange, sonst möchte vielleicht unter den Verbündeten selbst das Feuer der Zwietracht aufloderen, und das zweite Übel ärger als das erste werden».125

Die letzte Nummer des »Deutschland» enthält einen langen und mutigen politischen Artikel, der wahrscheinlich Anfang Januar 1797 geschrie-

120 Ibid. IV S. $316-322$.

121 Ibid. I S. 393-394.

122 Ibid. II S. $416-421$.

123 Ibid. S. 427-, III S. $97-98$ und 225.

124 Katalog der UB Göttingen.

125 Deutschland im J. 1796 II S. 151-154. 
ben wurde. Der anonyme Artikel (möglicherweise von Reichardt), »Nachrichten aus Frankfurt am Main», ist eine polemische Schrift gegen die zahlreichen Schreckensschilderungen der Ereignisse im Rheinland in den Zeitschriften und Flugblättern der Kriegspartei. Die Schrift widerlegt die österreichischen Behauptungen, daß der Waffenstillstand nicht eingehalten werde und behauptet, daß sich die Truppen beider Seiten in die Winterlager zurückgezogen hätten. »Wenn dies nun kein Waffenstillstand ist, so sieht es doch genau so aus.» Dieser Waffenstillstand sei ein schwacher Hoffnungsschimmer von einem Frieden für die Bevölkerung. Die Verhältnisse seien auch sonst nicht so miserable, wie die Kriegspartei behauptet hätte. Die Bauern hätten im Gegenteil durch den Lebensmittelhandel Nutzen gehabt. Die Gewalttätigkeiten der französischen Soldaten würden in der Presse der Kriegspartei stark übertrieben dargestellt. Es entbehre nicht der Komik, wenn gebrechliche, häßliche, zerlumpte, zahnlose und abstoßende Bettlerweiber den französischen Soldaten Gewalttaten vorwerfen würden. Der Verfasser glaube den ganzen Geschichten nicht:

»Ich, für meinen Theil, halte einmal diese Periode für ihre schönste seit vielen Jahren, und vielleicht wünschen sie selbst sie wieder zurück - - Doch, die jungen Mädchen und Frauen klagten bei weitem nicht so sehr über Mißhandlungen dieser Art, als die aliten.»

Die Schrift wollte die Vorkommnisse nicht völlig bestreiten, sondern glaubte, daß es weniger gewesen und daß sie verständlich seien. In bezug auf Rousseau glaubt der Verfasser, daß Kriege in einer Republik grausamer seien. Die Republik verwende die Kraft eines Individuums besser: während der Soldat in der Monarchie nur eine Maschine sei, fühle und handle der Soldat der Republik selbst. Der schlechte Nachschub habe auch die Franzosen vereinzelt zum Rauben gezwungen. Weiter bringt der Verfasser vor, daß die Franzosen die Deutschen nicht schätzen würden, und dieser Nationalhaß sei eine Folge des schlechten Verhaltens der deutschen Soldaten während der letzten Kriege in Frankreich. Auch schätzt der Verfasser nicht gerade seine eigenen Landsleute: Deutschland sei nicht in der Lage, militärischen Widerstand zu leisten. Der süddeutsche Bauer könne zwar einzelne Kuriere berauben und töten, aber ein Soldat sei aus ihm nicht geworden, wie $\mathrm{zu}$ Beginn des Krieges behauptet worden sei. Der Deutsche könne seine Gegner beschimpfen »als die verabscheuungswürdigsten Mordbrenner, Königsmörder, Schändler, Räuber, Kannibalen; als die Auswürfe der Hölle; als die Zerstörer aller Religion». Die Sprache der Zeitungen sei verroht. Von 25 Mil- 
lionen Franzosen spreche man wie von »wütenden Hunden, die man um Gottes Willen alle totschlagen müsse». Eine solche Hetze sei desto mehr $\mathrm{zu}$ verurteilen, weil ein Frieden unumgänglich sei. Es sei sehr zu bedauern, daß sich die Österreicher im Spätherbst (1796) keinem Frieden unterworfen hätten, sonst würde man sie heute als Retter des Rheinlandes betrachten und verehren. Aber damals habe man nicht daran gedacht, daß der französische Rückzug nur eine Verlängerung des Krieges und Vcrmchrung der Lciden für dic Bcvöllscrung bedcutc. Dicscr günstige Zeitpunkt sei nun leider vorbei und werde nicht wieder zurückkehren. Österreich müsse auf alle Fälle einen Frieden anstreben. Es sei ein Unglück, daß der Kaiser seine eigenen Interessen von denen Englands nicht unterscheiden könne. Preußen haben vernünftig gehandelt und seine Neutralitätspolitik sei von Vorteil (»uns die so wohlthätige Neutralitätslinie»). Die Abtrennung des linken Rheinufers von Deutschland brauche man nicht abzulehnen. Sie gewähre die Freiheit des Schiffsverkehrs auf dem Rhein und sei so förderlich für Industrie und Handel. ${ }^{126}$ Dieser Artikel sollte der letzte bedeutende poiitische Aufsatz im »Deutschland» bleiben. Die Zeitschrift stellıe ihr Erscheinen ein. Als Ursache nennt Reichardt die auf die historischen und politischen Artikel gerichtete Zensur. ${ }^{127}$

Unerreichbar für die Zensur setzte »Frankreich» ihr Erscheinen fort. Besonders fleißig schrieb der Pariser Korrespondent der Zeitschrift K. F. Cramer (»Nordländer»), der fortgesetzt die Friedensbereitschaft des Direktoriums betonte und England und Österreich der Verzögerung des ersehnten Friedens beschuldigte. Im Sommer 1796, als die Franzosen bis an die Böhmischen Grenzen vordrangen, drückte er seine Verwunderung darüber aus, wie der Kaiser seine Truppen so schlagen lassen könne, und warum er keinen Frieden schließe, obwohl die französische Überlegenheit ganz offensichtlich sei. ${ }^{128}$ Cramer trug auch einen Plan zur Erneuerung Deutschlands nach einem Friedensschluß vor. Der Rhein müsse seiner Meinung nach als Grenze anerkannt werden, die große Zahl der Staaten müsse durch 10-12 Großherzogtümer ersetzt werden, und die geistlichen Territorien seien zu säkularisieren.129 Im gleichen Sinne sind auch die übrigen Artikel der Zeitschrift geschrieben und sie gleichen sehr denen im »Deutschland». »Frankreich» hielt auch nicht viel von den Berichten über Grausamkeiten der Franzosen und

126 Ibid. IV S. 255-280.

127 Ibid. S. 372. Tschirch I (1933) S. 183-184, Bobeth (1911) S. 23 und Röhrdanz (1936) S. 85.

128 Frankreich 1796 II S. 79-80, 118-119, 147.

129 Ibid. Bd. III S. $40-41$. 
glaubte, daß der Kaiser selbst Schuld an den Leiden seiner Untertanen trage. Weiterhin dankte man den deutschen Friedensverteidigern und besonders Immanuel Kant. ${ }^{130}$

Von den anderen frankreichfreundlichen Zeitschriften blieben Schubarts »Englische Blätter» auf der gleichen Linie. Die Zeitschrift war für die preußische Friedenspolitik und tadelte Österreich. Sie forderte einen allgemeinen Frieden und die Anerkennung des Rheins als Grenze nach der »Lehre von den natürlichen Grenzen».131 Im gleichen Sinne wurden die Artikel der von dem Hallischen Professor Christian Daniel Voss von November 1796 bis Anfang 1798 herausgegebene Zeitschrift »Der Kosmopolit» verfaßt. Man könnte von einer kosmopolitisch-aufklärerischen Linie sprechen. Die Zeitschrift war Anhänger der preußischen Friedenspolitik und hoffte, daß sich der Frieden auf das ganze Reich ausdehnen würde. Das wichtigste Thema war für die Zeitschrift die Philosophie Kant's, dessen Ideen von Anhängern wie Professor Tieftrunk, dem Philosophen Beck und dem Leutnant Leopold von Boyen erläutert wurden. ${ }^{132}$ Die $»$ Kosmopoliten» hielten eine aktive Teilnahme an der politischen Diskussion der Zeit für notwendig und verurteilen z.B. Goethes und Schillers Rückzug auf das nur geistige Gebiet in den Xenien. ${ }^{133}$

Die monarchistische Presse hielt ebenso nach dem Basler Frieden den einmal gebildeten Standpunkt. Biester-Gedikes »Berliner-Monatsschrift» griff die Kriegspartei an, Aloys Hofmann, den Giessener Köster und die »Eudämonia», ${ }^{134}$ unterstützte Kant ${ }^{135}$ und zeigte Verständnis für republikanische und revolutionäre Ideen. ${ }^{136}$ Ab Sommer 1797 erschien die Zeitschrift wöchentlich unter dem Namen »Berlinische Blätter», die Anfangs die gleiche Linie fortsetzte. Ein Artikel des Franzosen Tissot über die Lebensarbeit v. Zimmermans kritisierte diesen und seine geistigen Anhänger, die als Grund von allem Bösen die »Illuminaten und Aufklärer» sahen. ${ }^{137}$ Auch wurden die Angriffe gegen die katholische Kirche fortgeführt; Kant's Philosophie dagegen enkannte man an. ${ }^{138}$ Gleichzeitig erschienen streng monarchistische Artikel. Der Artikel »Patrio-

130 Ibid. Bd. II S. 140 und 198, III S. 33, 39-41, 363. Bd. I S. 339.

131 Engl. Bl. 1796 III S. 165-169 und IV S. 284-293 usw.

132 z.B. Kosmopolit 1797 I S. 82-87. Tschirch I (1933) S. 190; Röhrdanz (1936) S. 86.

133 Kosmopolit 1797 I S. 27-37.

134 Berl. Mon. 1796 II: 2 S. 150.

135 Ibid. S. $279-292$.

136 Ibid. II: 4 S. $327-351$.

137 Berliner Blätter (Berl. Bl.) 1797 I S. 225-249, besonders S. 242-243 und 249.

138 Ibid. II S. $65-83$ und $94-96$. 
tismus Preussischer Soldaten» vom Herbst 1797 rühmte die Tapferkeit der Soldaten des Vaterlandes, ${ }^{139}$ und der Tod Friedrich Wilhelm II. bot eine gute Gelegenheit, den »Friedenskönig»zu preisen. Der König habe sein Schwert »für die Wohlfahrt Europas, und vorzüglich des Deutschen Reichs» gebraucht, und seine weise Friedenspolitik sei ein Glück für Preußen und ganz Norddeutschland gewesen. Ihm habe Norddeutschland jetzt für den glücklichen Friedenszustand nach den blutigen Kriegsjahren $\mathrm{zu}$ danken. In patriulischer Weise darkte die Zeitschrift dem verstorbenen König auch dafür, daß er klug mit den Mitteln des Friedens das Vaterland vergrößert habe. ${ }^{140}$

Das »Preussische Archiv» in Königsberg setzte auch seine Aktivität zur Verteidigung des Friedens und zum Preis des Vaterlandes fort. A. E. Hennig preist in seinen Gedichten fortgesetzt die Segnungen des Friedens und die Weisheit der Könige und verurteilt republikanische Ideen, Anarchismus, Terrorismus und Atheismus. ${ }^{141}$ Johann Daniel Funk, von dem acht Gedichte zur Verteidigung des Friedens erschienen, drückte die allgemeine Haltung der Norddeutschen, die Mitleid mit den noch kriegführenden Teilen des Reiches empfanden, so aus:

»Sieh des Rheinlands jammernde Bewohner! / Seegensquelle liegt in ihrer Flur / aber ach! von ihren Thränen weichet / jede Spende güitiger Natur».142

Der schon erwähnte A. S. Gerber veröffentlichte weiter. ${ }^{143}$ Auch neue Schriftsteller begannen zu veröffentliohen. Die Mehrheit schrieb für den Frieden: Pastor Ralle, Magister Kaatzky und der Kammer- und Domherr Graf von Klingsporn. Alle verteidigten den bestehenden Friedenszustand, und z.B. lehnte Kaatzky wie ein echter Aufklärer den Krieg allgemein ab, weil er »Stadt und Land verheert, / und Vieh und Menschen schlachtet»,144 aber wenn es um die Erweiterung des Vaterlandes ging, wurde der Krieg für nicht so besonders schlimm gehalten. ${ }^{145}$

In Berlin begann 1796 eine Provinzzeitschrift mit der gleichen Richtung $\mathrm{zu}$ enscheinen, die »Denkwürdigkeiten und Tagesgeschichte der Mark Brandenburg», deren Titel dann zweimal mit der Erweiterung des Ver-

139 Ibid. I S. $301-314$ und II S. $33-64$.

140 Ibid. II S. 225-236.

141 Preuss. Archiv 1796 Jan. S. 1-4, Aug. S. 445-447, 1798 Febr. S. 68-93 und Aug. S. 492-504.

142 Ibid. 1796 Oct. S. $573-575$.

143 Ibid. Febr. S. 65-85.

144 Ibid. 1797 Aug. S. 481-490.

145 Ibid. 1798 Jun., siehe später. 
breitungsgebietes, anfangs auf Magdeburg und Pommern und dann sogar auf ganz Preußen, geändert wurde. Die Zeitschrift wurde von dem Magister der Philosophie, Professor der königlichen Militärakademie, Johann Wilhelm Andreas Kosmann und dem Gymnasiallehrer Theodor Heinsius herausgegeben. Die Herausgeber der Probenummer der Zeitschrift hoben ihren Patriotismus hervor und lobten die Tugenden der preußischen Herrscher, besonders die Friedrich des Großen und seines Nachfolgers Friedrich Wilhelm II. ${ }^{146}$ Politisch gesehen blieb die Zeitschrift ohne Bedeutung. Die bestehende politische Lage beurteilte man mit Zustimmung und bezeichnete das Vorgehen der Regierung beim Baseler Friedensschluß als vernünftig. Zum Regierungswechsel erschien ein Artikel von Klipfel (Name oder Pseudonym), »An Preußens Patrioten», zur damaligen weltpolitischen Situation. Auch Klipfel hob die Friedensliebe des verstorbenen Herrschers hervor und erklärte den Friedensschluß von Basel für ein Werk, das der König »zum Besten der deutschen Reichsverfassung und zum Wohl seiner Länder that».147 In gleicher Weise lobte Kosmann Friedrich Wilhelm II. Einsatz für den Frieden, und besonders den Baseler Frieden begrüßte er mit Dankbarkeit:

»Dieser Friede ist der ehrenvolliste, den bis jetzt eine Macht mi1 der französischen Republik geschlossen hat, da alles im status quo ante bellum blieb, und das Schicksal der preußischen Länder jenseits des Rheins, die die Franzosen bis zum allgemeinen Frieden besezt behielten, in diesem, ohne Nachtheil unsrer Krone, entschieden werden sollte.

Im Mai kam man über die Demarkationslinie auf 3 Monat überein, die nachher näher bestimmt bis zum allgemeinen Frieden festgesetzt wurde. Diese Demarkationslinie verschaffte dem nördlichen Deutschland, was auch die Verleumdung dagegen sagen mag, Ruhe, freien Handel und ein neues Aufleben aller Gewerbe.» ${ }^{148}$

Auch später lobte Kosmann den Baseler Frieden, indem er ihn als Meisterstück der Weisheit und Politik charakterisierte und verteidigte den herrschenden Friedenszustand in zwei historischen Artikeln. ${ }^{44}$ Als Gleim 1796 in der Zeitschrift eine kriegerische Grabinschrift (auf General von Scheel) veröffentlichte, rechtfertigten die Herausgeber dies wie folgt:

146 Denkwürdigkeiten und Tagesgeschichte d.M. Brandenburg I (1796 Jan.), Vorbericht.

147 Ibid. VI (1797 März) S. 1276-79.

148 Ibid. V (1798 Jan.) S. 57.

149 Ibid. S. 5 und 1801, S. 42,67 und 504. 
»Nur einem Gleim kann man es verzeihen, daß er sich zum Schiedsrichter zwischen Weisen und Kriegern aufwarf, und sich selibst den Namen eines Kriegssängens beilegt, wie weiland ein bekannte Dichiterin den Namen Sappho.»150

Sowohl zur tagespolitischen Literatur Preußens als auch der des »dritten Deutschland» kann man die von dem bekannten Berliner Aufklärer, Verleger und Literaten Friedrich Nicolai seit 1792 herausgegebene und in Kiel erschienene Literaturzeitschrift »(Neue) Allgemeine Deutsche Bibliothek» rechnen. Die preußische Zensur hatte das Erscheinen der in religiösen Fragen liberalen Zeitschrift verboten, und auch Nicolai mußte sich ständig mit den Behörden seines Landes auseinandersetzen. ${ }^{151}$ Die »Neue Allgemeine deutsche Bibliothek» war eine Literatur- und Kulturzeitschrift, die sich nioht direkt mit politischen Themen beschäftigte. Nicolais politische Linie läßt sich jedoch sehr deutlich in seinen Literaturkritiken enkennen. Bei der Rezension Krieg und Frieden behandelnder Literatur setzte sich die Zeitschrift wie die tagespolitische Literaturr in Preußen ausnahmslos für den Frieden ein. In seiner »negativen» und überkritischen Art verurteilte Nicolai sowohl die frankreichfreundliche und den Frieden verteidigende Literatur als auch die sich für einen Krieg einsetzende Literatur. Den nach dem Baseler Frieden einsetzenden Federkrieg bewertete Nicolai als besonders niveaulos (»es sind wahre Schmähschriften») wie auch die politische Literatur allgemein (»immer langweilig, complimentierend und seicht»). ${ }^{152}$ Besonders wurden die den Krieg verteidigenden Schriftsteller verurteilt. Schriften von Emigranten, die einen Krieg forderten, wurden angegriffen,153 Ottokar Reichardts „Friedenspräliminarien» wurden heftig kritisiert, obwohl man sich der A:blehnung des französischen Systems anschloß,154 Friedrich Gentz' Übersetzung von Burkes gegen die Revolution gerichtetes Werk wurde wegen seiner Einseitigkeit kritisiert 155 und Christoph Girtanners heftige antirevolutionäre Schriften wurden scharf verurteilt.156 Besonders streng beurteilte man ein Buch des reaktionären Buchhändlers J. G. Heinzmann, das sich gegen Aufklärung, Revolution und die Kreise Nicolais richtete,

150 Ibid. 1796 II (Julius) S. $725-727$.

151 Ost (1928) S. 66-87.

152 v. Göckingk (1820) S. 130. N.allg.d.B. Bd. 25:2, (1796) S. 344.

153 N.allg.d.B. Bd. 15: 1, 1795, S. $35 ; 22: 2,1796$, S. 527.

154 Ibid. $17: 1,1795$, S. $54-60$.

155 Ibid. $20: 1,1796$, S. $3-33$.

156 Ibid. 22:1, 1796, S. 202-203. In demselben Artikel tadelt man auch Reichardts Revolutions-Almanach. 
indem es sich auf Religion, Moral und Patriotismus berief. ${ }^{157}$ Auch die gegen die Revolution gerichteten Schriften Johannes von Müllers wurden in den Spalten der »Allgemeinen deutschen Bibliothek» verurteilt. Er habe dadurch seinem Ruf als Historiker und Schriftsteller geschadet. Als besonders verabscheuungswürdige Agitationsschrift wurde von GlaveKolbielski »Genmania im Jahr 1795» enwähnt. ${ }^{158}$ Natürlich fiel die den Krieg verteidigende Schriftstellergarde mit dem gleichen $\mathrm{Ha}$ über Nicolai her. ${ }^{159}$ In gleicher Weise setzte sich Nicolai jedoch auch mit den meisten Friedensverteidigern auseinander. Schriften, die mit der Revolution sympathisierten, wurden in seiner Zeitschrift regelmäßig ablehnend kritisiert. Ein Beispiel ist die Schrift »Einige patriotische Worte» des Bremers G. W. F. Beneken, die man als »ein seichtes im leidenschaftlichen Tone abgefasstes, demokratisch-kosmopolitisches Pamphlet» charakterisierte, von dem man hoffe, daß es bald vergessen werde. Ein republikanisches Witzblatt beurteilte man vor allem deshalib positiv, weil es die Zensur herausfondern konnte. ${ }^{160}$ Das Verhältnis zwischen Kant und Nicolai war äußerst gespann.t, so hielt es die »Allgemeine deutsche Bibliothek» überhaupt nicht für notwendig, Kants Schrift »Zum ewigen Frieden» zu besprechen. ${ }^{161}$ Kant wiederum erwies Nicolai seine Hochachtung, indem er 1798 die Schrift »Ueber die Buchmacherey. Zwey Briefe an Hernn Friedrich Nicolai», veröffentlichte, in der er seinen Gegner äußerst überheblich behandelt.162 Außerdem stritt Nicolai mit Goethe und Schiller, Fichte und den Freimaurern - obgleich man ihn selbst zu ihnen rechnete - mit den Jesuiten und anderen Katholiken, mit dem österreichischen und dem preußischen Hof.163 Nicolai gründete seinen den Frieden verteidigenden Standpunkt nicht auf die Grundsätze der Revolution oder auf die preußische Regierungspolitik, sondern verhielt sich indifferent. Er urteilte als ein Vertreter der Aufklärung, der grundsätzlich nicht davon überzeugt war, daß Kriege die Menschheit vom Weg zum Glü.ck abbringen könnten. Offensichtlich ist seine Haltung auch davon bestimmt, daß er die sich für einen Krieg einsetzende Partei noch weniger schätzte als ihre Gegner.

157 Ibid. $23: 1,1796$, S. $259-269$.

158 Ibid. 25:2, 1796, S. $344-360$ und 23: 1, 1796, S. 192.

159 Vgl. S. 84.

160 N.allg.d.B. Bd. $14: 1,1795$, S. $3-23 ; 17: 1,1795$, S. $75 ; 20: 1,1796$, S. $243-$ $244 ; 25: 1,1796$, S. $62 ; 27: 2,1796$, S. $339-342$.

161 Röhrdanz (1936) S. 93.

162 Kant, Immanuel, Ueber die Buchmacherey, 1798. v. Göckingk (1820) S. 72.

103 Göckingk (1820) S. 55 und 120; Ost (1928) S. 86-87; Tschirch I (1933) S. $378-380$. 
Die tagespolitische Diskussion des übrigen Norddeutsch1 a n $d$ verlief in gleicher Weise wie in Preußen. Auf die gleiche Weise wie in Preußen kann man zwischen einer monarchistischen und einer revolutionären Presse unterscheiden, nur ist die Teilung in der Presse des übrigen Norddeutschland noch deutlicher zu erkennen. Die größere Pressefreiheit erlaubte es den Parteien ihre Meinungen möglicherweise noch spontaner vorzubringen.

Von der frankreichreundlich gesinten Presse wurde schon die leipziger Zeitschrift »Klio» vorgeführt. Sie setzte ihren Kampf für den Frieden wie bisher fort. Das Zögern Österreichs verurteilte »Klio» mit dem Hinweis auf die wachsende Bedrohung, die Rußland für Deutschland und ganz Europa dar stelle:

»Oestreich, beyständig träg und langsam in seinen Bewegungen, wird sich am Ende auch zum Frieden entschliessen, und so gut wie Preußen einsehen lernen, daß sein natürlicher Feind nicht im Westen, sondern ebenfalls im Nordosten ist; die Gefahr für Oestreich von Seiten Rußlands ist gleich groß wie für Preußen, und vielleicht nur um weniges entfernter. - - Der Zeitpunkt kommt gewiß, aber s p ät». ${ }^{164}$

Es sei vergeblich, den Friedensschluß hinauszuzögern, weil er unvermeidbar sei. Die Haltung der Zeitschrift zur Frage der Rheingrenze schwankte. So wurden sich untereinander widersprechende Standpunkte vorgetragen. ${ }^{165} \mathrm{Im}$ Sommer 1796 änderte die Zeitschrift ihren Titel in »Neue Klio». In diesem Zusammenhang veröffentlichte Huber einen Aufsatz zur allgemeinen politischen Lage, in dem er das niedrige Niveau der öffentlichen Diskussion in Deutschland beklagte und seine Absicht vortrug, daß dieses »Neue Klio» heben wolle. Für die d e u ts c h e Leserschaft wollte »Klio» gegen jenen rasenden Antigallikanismus und blinden Fanatismus ankämpfen, den man fälschlicherweise als Patriotismus bezeichne. Die Zeitschrift wolle den Frieden verteidigen. Der Patriotismus heilige keine Kriege, Zerstörung begleite sowohl die Siege Jourdans und Moreaus als auch die des Coburger Prinzen und Clerfayts. Deutschland müsse schnell einen Frieden schließen zu seiner eigenen und zur Rettung Europas. Wieder wurde vor Rußland, dem Kolossalen Bedroher Europas, ${ }^{166}$ gewarnt. Den größten Teil der »Neuen Klio» bildeten umfangreiche von Huber verfaßte Literaturüberblicke, sowie eine Kritik deutscher und französischer tagespolitischer Literatur. Diese Kri-

164 Klio 1796 I S. 4-6.

165 Ibid. S. 161-165 und 36-40.

166 Neue Klio 1796 July S. 5-10. 
tik ist konsequent. Huber verurteilte fortgesetzt die Veröffentlichungen der Kriegspartei, der Emigranten, Österreichs und des »RevolutionsAlmanachs». Besonders kritisierte Huber, daß die Kriegspartei die Erfolge der österreichischen Armeen übertreibe. Seiner Meinung nach gäbe es überhaupt keinen Grund, auf militärische Erfolge zu starren, wenn man als endgültiges Ziel den Frieden im Auge habe. Die französischen Kräfte würden keineswegs versiegen, wie z.B. die Emigranten behauptet hätten. Hubers Ansicht nach zeigte die Situation das Gegenteil: die Engländer und Österreicher begännen zu ermüden, während sich für die Franzosen der Krieg von selbst bezahlt habe. Nach Hubers Vorstellung war im Sommer 1797 das Endergebnis des Krieges für Frankreich deutlich positiv:

»Schon längst wurde es von allen unpartheyischen Menschen, von allen patriotisch denkenden Deutschen betrauert, daß der Krieg zwischen Oesterreich und Frankreich, vermöge des Bündnisses zwischen der ensteren Macht und England, so geführt wurde, als könnte er nur vor den Thoren von Wien, oder vor Thoren von Paris beendigt werden. Wie es scheint, wird er jetzt vor den Thoren von Wien würklich sein Ziel erreicht haben; die bedrängte Menschheit kann vor der Hand nichts anderes wünschen, als daß er nur sein Ziel erreiche.»167

Seinen Kampf für einen Friedensschluß setzte auch der Holsteiner August Hennings fort. Im Zusammenhang mit einer Besprechung von Kants »Zum ewigen Frieden» vom Januar 1796 gab er seinem Bedauern darüber Ausdruck, daß der Krieg nooh immer fortgesetzt werde, obgleich für einen Frieden alle Bedingungen erfüllt seien. Eifrig verteidigte Hennings die preußische Friedenspolitik. Zusammen mit einem Friedensschluß wünschte er, daß es zu großen Veränderungen im Innern des Reiches kommen würde. $\mathrm{Er}$ beführwortete eine neue Republik am Rhein zwischen den Reichen und forderte die Säkularisation. ${ }^{168}$ Seinen Kampf gegen die Kriegsparteien setzte Hennings in alter Weise fort und kritisierte besonders die »drei H's» der Wiener Obskurantisten, Haschka, Hofstätter und Hofmann. ${ }^{169}$ Obgleich er auch gegen den Koalitionskrieg Stellung bezog, war Hennings kein Pazifist. 1795 stellt er u.a. fest: »Solange es Kriege gibt, müssen wir stehende Heere haben» ${ }^{170}$ und später

167 Ibid. S. $62-63,75-77,109,116$; Sept.-Oct. S. 167 ; Nov.-Dec. S. $351-357$, 349, 412-413, 414-422; 1797 Jan.-Febr. S. 166-167, 174, 184; März-April S. 458; May-Jun. S. 47-49 und 51 (Zitat).

168 Gen.d.Z. 1796 I S. 156 und 161-162. Hild (1932) S. 130 und 168.

169 Minerva 1797 II S. 364; NTM 1797 IV S. 241.

170 Gen.d.Z. 1795 V S. 570. Hild (1932) S. 164-165. 
sogar: »Krieg ist nun einmal des Menschen Natur, und Bewaffnung die einzige Wehr. Von diesem Übel wird kein Erlöser uns retten, mag seine Lehre auch nicht so menschenfreundlich sein.»171

Hennings war zwar Aufklärer und Anhänger der Revolution, aber trotzdem ein treuer dänischer Untertan, der die Außenpolitik seiner Regierung in allem guthieß und sich sogar in jener Gegnerschaft gegen Rußland zurückhielt, die gewöhnlich in den frankreichfreundlichen Kreisen Deutschlands herrschte. ${ }^{172}$ Die gleiche Stellung bezog im allgemeinen die auf dänischem Gebiet erschienen Presse. So wie in Preußen die monarchistische Presse ihres Königs als Friedensfürsten hervorhob, lobten die dänischen Holsteiner die Allmacht des Ministerpräsidenten Bernstorff und dessen unerschütterliche Friedenspolitik. Gewöhnlich hob man die Leiden hervor, denen die Untertanen der kriegführenden Länder fortgesetzt ausgesetzt seien, und verglich sie mit dem Segensreichen Wohlergehen, das die Außenpolitik Bernstorffs mit sich brächte:

»Das Bewußtsein einer gerechten Sache, von Klugheit begleitet, sprach aus seinem Munde, führte seine Feder. Unstreitig war es die Frucht seines klugen, gerechten und standhaften Betragens, daß Dänemark fortdauernd des Friedens genoß, während der Krieg immer weiter und immer heftiger um sich griff».173

Man begrüßte die Friedenspolitik, aber nicht die Revolution. So kritisierte die »Neue Kielische Zeitung» scharf die Fehlerhaftigkeit und übermäßige französische Gesinnung von Hennings »Genius». Besonders verurteilte man Hennings Behauptung, daß Deutschland Schuld am Ausbruch des Krieges :sei. ${ }^{174}$

Die für einen Frieden eintretende aufklärerische Presse in Norddeutschland vertritt auch der Helmstädter Professor Karl Friedrich Häberlin, Historiker und Zeitungsmann, der seinen Standpunkt in seinem 1796 erschienenen »Deutschen Staatsarchiv» und in mehreren Flugschriften vertrat. Die erforderlichen Reformen nach einem Friedensschluß würden garantieren, daß es in Deutschland nicht $\mathrm{zu}$ revolutionären Umwälzungen kommen würde. Besonders notwendig sei die Säkularisation. Entgegen Österreich und den »Reiohsdeutsohen» legte Häberlin besonderen Nachdruok auf das Recht der deutschen Territorien, selbst

171 Hild (1932) S. 164-165.

172 Gen.d.Z. 1795 VI S. 257-276, 260 usw. Hokkanen (1972) S. 145.

173 N. Kiel. gel. Z. 1797 Nr. 47 S. 372-376 (D. H. Hegewisch).

174 Ibid. 1797 Nr. 36 S. 287 und Nr. 51-52 S. 401-402 (J. O. Thiess). 
ihre Politik zu bestimmen, z.B. einen Sonderfrieden zu schließen. ${ }^{175} \mathrm{Er}$ wiederum wurde von der Kriegspartei angegriffen. ${ }^{176}$

Auch Andreas Riem fuhr fort, in der für ihn typischen Weise politische Schriften $z u$ veröffentlichen. Unermüdlich verfaßte der außergewöhnlich scharfzüngige Geistliche monatlich hunderte von Seiten, deren Ton sich kaum gegenüber den vergangenen Jahren geändert hatte. Zunächst wandte er sich an Preußen, das jedoch seine Ratschläge sehr ablehnend entgegennahm. Die Behörden zensurierten seine Zeitschrift »Europens politische Lage und Staatsinteresse» und zwangen ihn Ende des Jahres 1795 nach Leipzig umzuziehen. Im folgenden Jahr wurde Riem durch Druck Preußens auf die Regierung des Kurfürstentums Sachsen auch von dort vertrieben. Die dritte Nummer des Jahres 1796 erschien dann in Paris. Die Bedeutung des verfolgten Riem ist beträchtlich. Die liberalen Kreise Süddeutschlands verteidigten ihn und trotz der Zensurvorschriften wurden seine Schriften gelesen. ${ }^{177}$ Andererseits setzte Riem seine wohlmeinenden Äußerungen über Preußen fort. Er dankte Frankreich für seine edelmütige Haltung bei den Baseler Friedensverhandlungen und erinnerte die Republik daran, auch dem Landgrafen von Hessen-Kassel den Frieden zu schenken. Für Riem war natürlich die Grenzfrage zwischen Frankreich und Deutschland das zentrale Problem. Er betrachtete den Rhein als natürliche Grenze. Es sei vergeblich, sich vorzustellen, daß Frankreich, so wie französischerseits Miranda u.a. behauptet würde, seine eroberten Gebiete zurückgeben wünde. Nach Riem hätten auch die Bewohner des Rheinlands nichts gegen die französische Herrschaft. Deutschland müsse besonders Preußen vertrauen. Als erstes müsse man sofort die geistlichen Fürstentümer in Deutschland säkularisieren. Die jetzige Grenze sei unzweckmäßig, weil eine Grenze, die von Priestern bewacht würde, schutzlos sei. Preußen müsse bei einer Neuverteilung der Gebiete die pfälzischen, badischen und schwäbischen Befestigungen als Grenzzone erhalten. Nur auf diese Weise hätte Deutschland einen Nutzen von der Rheingrenze. Österreich und England wurden wegen ihrer Starnköpfigkeit scharf getadelt. Die Fehler der österreichischen Regierung seien unglaublich. Frankreich sei nicht mit den Guineen Pitts $\mathrm{zu}$ besiegen. Ob Österreich solange mit einer Zustimmung zum Frieden warten wolle, bis die Franzosen ganz Deutschland

175 Tschirch I (1933) S. 213. z.B. Häberlin, Sammlung einiger Actenstücke die Rechtssache ... 1797; ders., Ueber das dem Freyherrn Moritz von Brabeck ... 1800.

176 Gegen Häberlin z.B. Actenmässige Darstellung der Sache ... 1797; Ein Beitrag zur Beurtheilung ... 1797.

177 Tschirch I (1933) S. 144-145 und 149-150. 
besetzt hätten? Pitt habe überall seine Hand im Spiel. Er besteche sein Parlament, schlösse immer neue Koalitionen und behandle Irland in niederträchtiger Weise. Auch wiederholte er ständig seine Warnungen vor Rußland. Rußland ziehe absichtlich den in Europa tobenden Krieg in die Länge, um daraus Nutzen zu ziehen. Nur ein allgemeiner Frieden mit Frankreich könne Deutschland vor dem Schicksal Polens bewahren. Was Preußen betraf, so ging er so weit, daß er Preußen aufforderte, sich mit Frankreich $\mathrm{zu}$ verbündcn, um so Österreich $\mathrm{zu}$ einem allegemeinen Frieden zu zwingen. ${ }^{178}$ Die in Paris erschienene dritte Nummer läßt schon einen deutlichen Wandel erkennen. Riems Glaube, daß Preußen den allgemeinen Frieden herbeiführen könne, scheint geschwunden zu sein. Er wiederholte iseine Forderung nach der Säkularisation, warnte vor Intrigen Englands und schlug vor, man solle auf »die Integrität des Reichs und der Verfassung» verzichten, da sie sowohl für Frankreich als auch für Deutschland mehr Nachteile als Vorteile bringen. Die preußische Außenpolitik habe unter der Führung von Hardenbergs einen ironischen Ton angenommen und es sei zu fürchten, daß Preußen dabei sei, der österreichischen Kriegspolitik zuzustimmen. ${ }^{179}$ Schon nach einem Jahr seien deutliche Veränderungen zu erkennen: Preußen, der Wohltäter des Reiches, war nach Riems Meinung zum verabscheuungswürdigen Feind des Reichs geworden. Im Laufe des Jahres 1797 wechselte Riem in das Lager der »kriegerischen Friedensverteidiger», das einen völligen Sieg der französischen Waffen als Voraussetzung für einen beständigen allgemeinen Frieden ansah. ${ }^{180}$

Auch die gemäßigten Zeitschriften wie Archenholtz' »Minerva» und Wielands »Merkur» verfolgten in den Hauptzügen weiterhin eine dem Frieden zustimmende Linie. Archenholtz begrüßte die Demarkationslinie Preußens, die viele Gebiete sowohl vor den Gewalttaten der französischen Truppen als auch vor der österreichischen Besetzung schützen würde.181 In seinen Literaturkritiken vertrat Archenholtz gemäßigte Standpunkte, wobei er sich mehr den Befürwortern eines Krieges als den Anhängern der Revolution anschloß. Den Franzosen brachte Archenholtz wenig Sympathie entgegen, und so wurde ihr Verhalten während der Kriegszüge vom Sommer 1796 auch mit einigen Artikeln in der »Minerva» verurteilt. Einige Beschuldigungen erinnern geradewegs an Schriften der kriegerischen »Reichsdeutschen», die in

178 Eur.pol.L. II, 1796, S. 29, 32-44, 50, 100-105, 149-154, 202.

179 Ibid. III, 1796, S. 1-29, 41-59, 115, 121, 181.

180 Siehe später.

181 Minerva 1796 II S. 338. 
allen Einzelheiten von Raubüberfällen, Vergewaltigungen und Kirchenschändigungen berichteten. ${ }^{182}$ Ein Artikel, »Aufruf an die Fürsten und Völker Deutschlands», von »G.F.W.» ging besonders weit. Archenholtz berichtete, daß dieser zuerst Beckers »Reichsanzeiger» angeboten worden sei, aber die Zensur des Herzogs von Gotha habe ihn verboten. Als Freund der Freiheit habe er ihn drucken lassen. Der Artikel enthält wohl die schärfisten Angriffe gegen Frankreich. Die Truppen Frankreichs hätten im Sommer 1796 zahllose Greueltaten begangen, und wenn sich derartige Fälle wiederholen würden, müßten die Deutschen nach Meinung des Verfassers zu entsprechenden Gegenmaßnahmen greifen:

»Es giebt, glaubt es mir! nur Ein Mittel, die Franzosen aus Deutschland $\mathrm{zu}$ vertreiben und einen schnellen Frieden herbey $\mathrm{zu}$ führen, und das ist - e in a llgemeiner A $\mathrm{g}$ s $\mathrm{t}$ and des ganzen Deutschlandes oder wenigstens derjenigen Provinzen desselben, welche bisher von den Franzosen besetzt waren, nun aber davon frey, und $\mathrm{nach}$ der grossen Mehrhe it hierzu willig und bereit sind.»

Der kriegenische Schreiber forderte auch Reformen, durch die man den Kampf gegen den gemeinsamen Feind verstärken könnte. Es sei sinnlos, die Völker zum Kampf für Religion, Ordnung und Verfassung aufzufordern, weil die Völker sich unter diesen Begriffen etwas ganz anderes vorstellen würden wie die Fürsten. Das alte System mit seinen faulen Geistlichen werde von den Völkern abgelehnt. Jetzt müsse man von den Taten der Franzosen sprechen. Die Franzosen seien keineswegs gekommen, die Leiden des Volkes zu beenden, wie sie gesagt hätten, sondern nur um zu rauben, zu vergewaltigen und zu morden. Man müsse von den wirklichen Erfahrungen der Völker ausgehen. Es gäbe nur ein Mittel: »ein allgemeiner Aufstand». Der Preis einer nur so gezeigten Tapferkeit könne der Frieden sein. Wenn man das Volk zu einem allgemeinen Aufstand bewegen könne, müsse man dafür die notwendigen Reformen vensprechen, »allgemeine Freyheit und Gleichheit in so ferne, daß jeder Einwohner unserer Länder durch das Gesetz in gleichem Maaße geschützt und keiner vor dem andern begünstigt werden soll.» Nach dem Sieg müsse man die Hofgünstlinge und die Anhänger des Aberglaubens aus ihrer Stellung vertreiben. An ihre Stelle müßten Wahrheit und Menschenrechte sowie eine vollkommene Pressefreiheit treten. Unter solchen Bedingungen werde jeder Deutsche bereit sein, für sein Vaterland $\mathrm{zu}$ sterben. ${ }^{183}$ Der Artikel vertritt also eine Reihe von

182 Ibid. III S. $450-457$.

183 Ibid. II S. 321-331. Der Verfasser soll Giessener Ingenieuroffizier Georg 
Ansichten, die zur Zeit des zweiten Koalitionskrieges und der Ära Napoleons von den radikalsten Friedensgegnern vorgetragen wurden obgleich sich Archenholtz diesen Vorstellungen nicht anschloß, so läßt ihre Veröffentlichung schon einen deutlichen Gesinnungswandel bei ihm erkennen.

Die Richtung von Wielands »Merkur» entspricht der oben geschilderten. Die Herausgeber forderten 1796 die Herrscher in Europa auf, zum Frleden zurlickzukehren, so wie es die Vülker ersehnten, ${ }^{181}$ und kritisierten scharf die Kriegspropaganda. Als der junge Dichter J. D. Falk Gedichte verurteilte, die die Deutschen als Cherusker, als Tötervolk darstellte, schloß sich Wieland diesem Standpunkt an und kritisierte scharf besonders die Vorstellungen des "Revolutions-Almanach» vom deutschen Patriotismus: »Blitz, Hagel, Wetter! Herr, das ist ja unser Brot». Er kritisierte Burke und August Wilhelm Rehberg wegen ihrer kriegerischen Äußerungen. In diesem Zusammenhang wies er auf die Grausamkeiten Suworows in Warschau hin. ${ }^{185}$ Die im Laufe des Jahres 1796 unter dem Namen »Norddeutschen» veröffentlichten Briefe aus Paris des Freimaurertheologen Heinrich Zschokke setzten sich eindeutig für den Frieden ein und vertraten sogar ein frankreichfreundliche Haltung. ${ }^{186}$ Im übrigen setzte sich die Zeitschrift im Jahre 1796 eindeutig für den Frieden ein. Die Politik der Direktoriumsregierung stellte man mit Zustimmung vor, England tadelte man, weil es nicht bereit sei, Frieden zu schließen, und man veröffentlichte eine Reihe von Friedensgediohten. ${ }^{187}$ Um neutral $\mathrm{zu}$ enscheinen, veröffentlichte man auch Stimmen ider Kriegspartei, u.a. von Gleim. ${ }^{188}$ Der Ton des Jahrgangs 1797 blieb der gleiche. Die Kriegshetze der Emigranten wurde verurteilt, und man erwartete mit Optimismus den allgemeinen Frieden. ${ }^{189}$ Mit der Friedensfrage beschäftigte sich auch der Kasseler Professor Friedrich Tiedemann in seinem Artikel »Ueber die Friedens-Aussichten auf dem Gebiet der Philosophie». Darin bezog er eindeutig Stellung für den Frieden und forderte vor allem die Philosophen auf, mehr für den Frieden zu tun. Die Philosophen würden zwar vom Frieden sprechen und Systeme konstruieren, um ihn zu sichern, aber nur für Philosophen:

Friedrich Werner sein; er schrieb später mehrere Artikel mit seinem eigenen Name.

184 NTM 1796 I S. 108-112.

185 Ibid. S. 362-363 und Anm. S. 363 und 381.

186 Ibid. II S. 183 und Anm. in ders. Seite, III S. 93, 284, 410-419, IV S. 210, $219,280-299,320,399$.

187 Ibid. II S. 433-435, 1797 I S. 8.

188 Ibid. 1797 I S. 153 und III S. $74-84$.

189 Ibid. II S. 128. 
»Friede ist jetzt die Stimme, welche jetzt aus allen Enden von Europa ertönt; Friede ist das Wort, welches selibst aus den oft sehr dunkeln Kämmerlein der abstrakten Metaphysiker hervorschallt. Wer Frieden bietet und Frieden verspricht, ist eines fast allgemein Beyfalls der Menschen von aller Altern, Ständen, und Geschäftigungen sicher; selbst die grössere, mit der Philosophie sich nicht ausdrücklich beschäftigende Menge, will Frieden im Lande der Philosophie, um dann desto sicherer und mit mehrerer Bequemlichkeit auf dem Frieden beliebten Systeme ruhen zu können.»190

Die sich für den Frieden einsetzende liberale Presse erhielt noch im Jahre 1797 einen neuen Bundesgenossen, das »Magazin der Europäischen Staatsverhältnisse», das auch die oben vorgetragenen Themen behandelte. Die vom Geist der Aufklärung bestimmte Zeitschrift wies auf die Zerstörungen des Krieges hin und forderte einen allgemeinen Frieden. Man nahm an, daß Frankreich zum Frieden bereit sei, weshalb man seinen Bedingungen zustimmen müsse. Zur Verstärkung der Argumente wies man nach, wie Frankreich militärisch übenlegen und Österreich geschwächt sei. Man gab die Hinfälligkeit der Reichsverfassung zu und sprach die Vermutung aus, daß zusammen mit einem Friedensvertrag große Reformen durchgeführt würden. Es sei deshalb unmöglich, von der »Reichsintegrität» als Grundlage für die Friedensverhandlungen auszugehen. Eine Säkularisation erklärte man als unabdingbar. Die preußische Sonderfriedenspolitik bezeichnete man als politisch vernünftig: »Das Staatsintresse ist die Regel für alle Fürsten: es ist besser, daß der Fürst seinen Bund breche, als daß sein Vollk zu Grund gehe.» Außerdem wurde, wie üblich, Deutschland vor Rußland gewarnt, das aus dem bestehenden Kriegszustand am meisten Nutzen ziehe. Ein Artikel hielt sogar Preußen für den natürlichen Verbündeten Frankreichs. Andererseits erkannte die Zeitschrift auch den heldenhaften Kampf der Freiwilligen Österreichs gegen die Truppen Napoleons an.191

Eine bedeutend gemäßigtere und konservativere Zeitschrift ist das 1796 in Göttingen erschienene »Teutsohe Staats-Magazin», das von dem Rechtsgelehrten an der dortigen Universität, Professor Günther Heinrich von Berg herausgegeben wurde. Das Organ bezeichnete sich selbst als »reichs-patriotisch», und das war es auch in vieler Hinsicht. Die Zeitschrift wies auf die großen Sohwierigkeiten des Vaterlandes und auf

190 NTM 1796 II S. $176-180$ usw.

191 Magazin der Europäischen Staatenvergältnisse, 1797 Bd. I-II. Dasselbe Text wurde neuerdings 1799 unter dem Titel »Politische Aufklärungen der Geschichte und Verbindlichkeiten Europäischen Staaten gegen einander I-II, 1799, veröffentlicht. 
die allgemeine Friedensbereitschaft der Reichsstände im Jahre 1796 hin. ${ }^{192}$ Ende des Jahres empfahl die Zeitschrift u.a. die Aufgabe der deutschen Gebiete im Elsaß zur Erreichung eines beständigen Friedens. ${ }^{193}$ Die Zeitschrift äußerte ihre Hoffnung auf eine baldige Beedigung des fürchterlichen Krieges, ${ }^{194}$ aber sie hatte trotzdem eine sehr eigenständige Vorstellung von den Friedensbedingungen. Sie widersprach allen Sonderfrieden - dem Baseler Frieden gegenüber verhielt man sich neutral — und jeder Art von partikularistischer Politik. Nur ein allgemeiner Reichsfrieden sei nach der Verfassung. ${ }^{195}$ Fast ukriegsbegeistert lobte v. Berg den österreichischen Patriotismus, bedauerte die Zwietracht unter den Deutschen und beklagte, daß aller militärischer Ruhm im Kampf den anderen Deutschen entgegengebracht worden sei. Er schlug vor, daß die Schlagkraft der Reichs-Armeen erneuert werden müsse. ${ }^{196}$ Die Friedensrichtung der Zeitschrift Bergs in den Jahren 1796-97 charakterisiert auch gut ihre Ziele in der deutschen Politik: „Der Hauptcharakter der Politik des teutschen Reichs muß also nothwendig Friedensliebe seyn.» Aber gleichzeitig müsse das Reich auch auf seine Verteidigung bedacht sein. Wenn es den Frieden wolle, müisse es sich zum Krieg rüsten. ${ }^{197}$ Die Zeitschrift akzeptierte den Frieden von Campo Formio, behielt aber immer eine ablehnende Haltung gegenüber Frankreich und der eigentlichen Friedenspartei. ${ }^{198}$

Im gleichen Ton, aber nur bedeutend theoretischer, waren die Artikel einer Zeitschrift, die im gleichen Jahr zu erscheinen begonnen hatte, des »Magazins für die Geschichte der Menschenrechte», von der aber nur die Probenummer erschien. Die Zeitschrift beschäftigte sich kaum mit tagespolitischen Themen, ist aber trotzdem eine der bedeutendsten, die sich mit der Friedensfrage auseinandersetzte. Im Vorwort teilten die anonym bleibenden Herausgeber mit, daß das Magazin das Erbe der nicht mehr erscheinenden »Annalen der Rechte der Menschen» des Professor Schmalz fortsetzen wolle. Im Streit der Ideen wolle das neue Magazin in der Mitte stehen. Es äußerte seine Gegnerschaft zu Tyrannei, Despotismus und Anarchie und, daß es aufzeigen würde, wo die Menschenrechte verletzt würden, sei es auch »vom Fürsten oder vom

192 Teutsches Staats-Magazin I: 1, 1796. S. 7, 24, 42-43.

193 Ibid. II: 2, 1796, S. 185-123.

194 Ibid. II: 3,1797, S. 451.

195 Ibid. I: 1 , 1796, S. $59-68$, I: 2 S. 193 , II: 1,1797 , S. 32 , $38-39$, 41-42, II: 3

S. $530-534$.

196 Ibid. I: 3 , 1796, S. $353-355$, II: 1,1797 , S. 32.

197 Ibid. II: 1,1797 , S. 33 .

198 Ibid. III: 1,1798 , S. $1-43$, z.B. ibid. S. $166-168$. 
Volk» »in einer Monarchie oder in einer Republik». Ihre Position liege, so erklärten die Herausgeber, »in der Mitte, wo die Wahrheit liegt». ${ }^{199}$ Besonders heftig griff die Zeitschrift den unumschränkten Absolutismus an, der »vom türkischen Grosherrn bis zum kleinsten deutschen Sultan» vertreten werde. Der Krieg gehöre zur Natur der despotischen Staaten. Stehende Heere lehnte man ab. Sie würden eine außerondentliche wirtschaftliche Belastung für die Völker darstellen und schon ihre bloße Anwesenheit würde besonders zu häufigen Kriegen führen. Die Unterhaltung von stehenden Heeren sei unvernünftig:

»A.ber warum soll denn ein Staat seine Sicherheit und Vertheidigung iblos auf ein immer unter dem Gewehr und in unaufhörlichem Solde stehendes, und doch, wenn der Fall der Noth komm't, meistens unzulängliches, und wenigstens in Absicht auf den gemeinsamen Mann unzuverlässiges Kriegsheer ankommen lassen? Warum soll er nicht vielmehr die Bürger des Staats bewaffnen, die sich zu Friedenszeiten selbst nähren, und nur während der Kriege dem Staate zur Last fallen, und auf eine solche Einrichtung denken, wodurch sie zur Vertheidigung des Vaterlandes eben so tüchtig werden, als sie in der Absicht ihres Willens und der Treue zuverlässig sind?»201

Dazu kommentierte die Zeitschrift bis dahin erschienene philosophische Überlegungen zur Beendigung des Krieges. Besonders erwähnt wurden die Pläne des Abts St. Pierre und von Kant. Man bewunderte die Tiefe von Kants Gedanken und forderte die Menschen auf, nach der Verwirklichung seines Programms zu streben. Das betreffe auch den Teil, in dem von der republikanischen Regierungsform gesprochen wird.202 Der starke aufklärerische Geist, der die Zeitschrift bestimmte und sich den Standpunkten der Französischen Revolution näherte, ließ sie auch für die Freiheit des Wortes und einen offenen Antiklerikalismus eintreten, der in der Verurteilung der Kreuzzüge und der Religionskriege deutlich wurde. ${ }^{203}$ - Obgleich die Zeitschrift nicht direkt Bezug auf tagespolitische Ereignisse nahm, war ihre Tendenz deutlich zu erkennen, und nach den oben geschilderten Ansichten, ist es nicht verwunderlich, daß sie ihr Erscheinen so sohnell wieder einstellte.

Als Ergänzung zur Presse ist noch eine Reihe von Flugschriften zu erwähnen, die die gleichen Ansichten vertrat. Ein Bewunderer Kants, der Leipziger Johann Adam Bergk, der sich in Selbststudien fortgebildet

199 Magazin für die Geschichte der Menschenrechte 1797 I Vorwort.

201 Ibid. S. 27.

202 Ibid. S. 63.

203 Ibid. S. $28,30-61,66-67$. 
hatte, setzte sich praktisch und theoretisch für den Frieden ein. Er betonte in Rebmanns revolutionärer Publikation, »Neue graue Ungeheuer», daß schon genug Ströme deutschen Blutes geflossen seien, und forderte ein Bündnis zwischen Deutschland und Frankreich.204 Nach Kants Schrift, »Zum ewigen Frieden», versuchte auch er, ein Programm $\mathrm{zu}$ entwickeln, das einen ewigen Frieden garantieren sollte. Er empfahl den Staaten einen »Staatenbund» zu gründen, für den er eine genaue Verfassung entwickelte. Auch nach der Meinung Beryks müsse jedes Mitglied des Bundes eine Republik sein. Den zu erwartenden Idealzustand schilderte er begeistert:

»Mit Freuden und Innigkeit hängt das Menschengeschlecht an dem Gedanken von einem ewigen Frieden, benuzt immer thätig die Zeit und steuert unermüdet auf den Hafen des Glücks und der Ruhe loss. - - Diese Erscheinung beurkundet die Annäherung des Menschengeschlechts zu seiner Mündigkeit.»205

Bergk wiederholte seine Gedanken auch noch später und blieb ein führender Anhänger der Friedensvertreter. ${ }^{206}$ Eine Schrift des Hamburger Naturwissenschaftlers Johann Gottfried Schmeisser, die sich mit den Wissenschaften in Frankreich auseinandensetzte, verurteilte in scharfen Worten die Greuel, Morde, Verwüstungen und hyänischen Räubereien der Revolution. Aber trotzdem müsse man die Erfolge der Revolution anerkennen, die dann deutlicher $\mathrm{zu}$ erkennen seien, wenn »die Künste des Friedens einst wieder blühen und die Wunden geheilt seyn werden». Nach Schmeissers Meinung war es ganz natürlich, daß das französische Volk den Frieden anstrebe.207 Gegen England wandten sich zwei anonyme, sich für den Frieden einsetzende, Schriften.208 Besonders weit ging eine in Altona ohne Autorennennung erschienene Flugschrift, deren Verfasser sich als preußischer Soldat ausgibt. Sie verurteilte u.a. den Aufstand des Volkes in der Gegend von Aachen, tadelte »Nationalhass» und »Nationalzuneigung», was es in Deutschland genügend gäbe, und mißbilligte die Kriegsziele der Koalitionsstaaten.

204 Neue graue Ungeheuer IV, 1797, S. 75-76. Siehe später.

205 Bergk, J. A., Briefe über Immanuel Kant's Metaphysische ... 1797, S. 239, 242-246, 248 (Zitat).

206 Der Congreß in Rastadt ... 1799; Philoleutheros Orthodoxos, N. Bonaparte als Mensch 1801.

207 Schmeisser, G., Beyträge der näheren Kenntniss . . I Hamburg 1797, z.B.

S. VI-IX, 2 und 16.

208 Reflexionen über die Verschiedenheit ... 1796; Beantwortung der Frage:

Ob die königl. ... 1796. 
Weiter lehnte sie den deutschen Patriotismus ab: »Alle Völker haben noch etwas für die Freyheit gethan, nur wir nicht». Gegen die österreichische-deutsche Dummheit würde noch nicht einmal die Philosophie Kants helfen. Den sog. kriegerischgesinnten Friedensverteidigern steht die Schrift nahe, indem sie feststellte, daß jeder Krieg sowohl seine guten als auch seine schlechten Seiten habe. »Nie war ein Krieg so allgemein wichtig für das ganze Menschengesohleoht, als dieser».209 Die Schrift enthält auch ein Gedicht von Friedrich Heinrich Jacobi, das das Wüten des Krieges beklagte. ${ }^{210}$ Ähnliche Schriften erschienen in Norddeutschland in größerer Zahl. ${ }^{211}$

Als ein besonders typisches Beispiel für die nach dem Frieden von Campo Formio in Deutschland hernschende optimistische Friedenserwartung kann noch die umfangreiche Schrift, „Zwei staatsrechtliche Erläuterungen», genannt werden, die 1797 anonym erschienen. Die Schrift bezog zu allem eine zustimmende Haltung: sie verherrlichte den Kaiser, die Tapferkeit der österreichischen Soldaten und Österreichs militärische Stärke und Friedenisbereitschaft, sie forderte die Deutschen dazu auf, ihre Kräfte $z u$ vereinigen, um Frankreich zu einem die Reichsintegrität anerkennenden Frieden zu bringen, man berief sich auf Hermann und die Kriegstugenden der Germanen und bewunderte Napoleon als Friedensbringer. Nach der Schrift wollten alle Frieden, und der anonyme Verfasser erklärte einen Friedensschluß als sicher. Denjenigen, die einen ewigen Frieden forderten und von ihm träumten, wollte sich der Verfasser jedoch nicht anschließen:

»Der Krieg allezeit ein Uebel, aber in gerechten Fällen ein nothwendiges Uebel, ist zugleich der Zunder zu Großthaten, zu Verdiensten des Heldenmuths, und vorzüglich der Anlass die Wohlthaten des Friedens desto besser schmecken zu können. - - So lange die Menschen Menschen bleiben, bleibt auch der Gedanke an einen ewigen Frieden nichts als ein leerer Gedianke...».212

209 Neue Briefe eines preussischen Augenzeugen ... 1706, S. 4-6, 19, 22, 30$31,36-37,104-105,203$.

210 Ibid. S. 7.

211 Geschichte und Darstellung der polnischen ... 1796; Buonaparte's ruhmvoller Feldzug ... 1797.

212 Zwei staatsrechtliche Erläuterungen ... 1797. Zitat Bd. II S. $33-34$. 


\section{DIE WENDE VON 1797/98: DER STAATSSTREICH VOM 18. FRUCTIDOR, DER KONGRESS VON RASTATT UND DIE REVOLUTIONEN IN ITALIEN UND IN DER SCHWEIZ}

Mit dem Frieden von Campo Formio erwartete man in Europa und Deutschland einen schnellen allgemeinen Frieden, und beim Zusammentreten des Rastatter Kongresses war die allgemeine Stimmung größtenteils optimistisch. Diejenigen, die größere Verluste befürchteten, verfaßten natürlich Ratschläge für den Kongreß, aber zu direkter Ablehnung eines Friedensschlusses kam es kaum. Die Ergänzungswahlen der Mitglieder des Rates von Fünfhundert und des Ältestenrates in Frankreich im Sommer 1797 trugen noch zur Steigerung dieses Optimismus bei. In Frankreich errang nämlich die politische Rechte einen klaren Sieg, und fast alle neugewählten Volksvertreter waren entweder Royalisten oder gemäßigte Republikaner. Die für links gehaltene Direktoriumsregierung erhielt so eine beachtenswerte Opposition. Man erwartete allgemein, daß sich aus dieser Situation eine mäßigende Wirkung auf die Außenpolitik ergeben würde. Die Friedenshoffnungen verstärkten sich, als der Hauptunterhändler für den Baseler Frieden, der als gemäßiger Schlichter bekannte Barthélemy, ins Direktorium gewählt wurde. Es sah so aus, als wolle Frankreich unter gemäßigten Bedingungen mit allen Feinden Frieden schließen.

Anfang September kam es jedoch zu einem Umschwung. Die drei linken Mitglieder des Direktoriums (Barras, Rewbell, La RevellièreLépeaux) unternahmen mit Unterstützung Napoleon Bonapartes einen Staatsstreich (der Staatsstreich vom 18. Fructidor) und kehrten zur bisherigen politischen Linie zurück. Die Außenpolitik verschärfte sich beachtlich. Die mit England im Gang befindlichen Friedensverhandlungen wurden sofort abgebrochen. In Campo Formio diktierte man trotz des Widerstandes und der Verzögerungsversuche Österreichs schnell einen Frieden. Man gab die Absicht auf, am Rhein eine Tochterrepublik $\mathrm{zu}$ gründen, und beschloß statt dessen, ohne zu zögern weitere Gebiete 
zu besetzen. Die Einberufung des Rastatter Kongresses wurde beschleunigt. ${ }^{1}$

Im Oktober konnte die Arbeit des Kongresses beginnen. Diese Versammlung war eine der letzten Gelegenheiten, wo das alte Kaiserreich als Ganzes vertreten war, und deshalb erwartete man viel von ihr. Die Erwartungen wurden nicht erfüllt. Der Kongreß stritt isich über untergeordnete Fragen, und man hatte sehr große Schwierigkeiten eigentliche Abkommen zustande zu bningen. Auf der einen wie auf der anderen Seiten schwankten die Forderungen, und die Zwischenfälle an der Front störten die Verhandlungen. Auch die vielen Zwischenfälle auf dem Kongreß selbst erschwerten das Zustandekommen eines günstigen Ergebnisses. So wurde der schwedische Vertreter (aus Pommern) Graf Axel von Fersen auf Veranlassung Napoleons mitten aus einer Versammlung verjagt, weil er früher zum französischen Königshaus enge Beziehungen gehabt hatte. ${ }^{2}$ Das gleiche Schicksal teilte der gewählte kurpfälzische Vertreter, Reichert, weil er während des Kongresses gegen Frankreich gerichtete Flugschriften verfaßt hatte. ${ }^{3}$ Die deutschen Staaten waren unter einander uneinig. Besonders das Mißtrauen zwischen Preußen und Österreich war groß.4 Während der Kongreß tagte, verstärkte Frankreich seine militärischen Stellungen in Italien und in der Schweiz, und Österreich rüstete heimlich für einen neuen Krieg seine Truppen aus. Im Frühling 1798 kam man so weit, daß man den Rhein grundsätzlich als französische Grenze anerkannte. Ein endgültiger Reichsfrieden verzögerte sich jedoch, weil sich die außenpolitische Lage erneut geändert hatte.

Im Laufe des Jahres 1798 wurde init den inneren Schwierigkeiten die Außenpolitik des Direktoriums immer. In Italien und in der Schweiz organisierte man zusammen mit den dortigen Revolutionären Aufstände und bildete neue Tochterrepubliken. Besonders die Revolution in der Schweiz spielte eine große Rolle für die öffentliche Meinung in Deutschland. Die Sohweiz lag nahe, und die Schweizer betrachtete man allgemein als Deutsche. So schloß man aus der veränderten Situation in der Schweiz auf Pläne der Franzosen in bezug auf Deutschland. Die Agression Frankreichs setzte sich fort. Der Papst wurde gefangen-

1 Wahl (1967) S. 88-92.

2 Hüffer (1878) S. 9-10.

3 Briefe eines Abgeordneten ... 1798, S. 43.

4 Hüffer (1878) S. 72-73. Die Diplomatie während des Kongresses schildert grundzüglich Hüffers Werk Der Krieg des Jahres 1799 und die zweite Koalition I, Gotha 1904, etwa bis S. 100. Gothaische gelehrte Zeitungen nennt zusammen 74 Flugschriften, die an den Kongress gezeigt waren, 1799 Nr. 49 und $1800 \mathrm{Nr}$. 3. 
gesetzt, und man erwartete jeder Zeit eine Landung in England. Im Mai 1798 sohiffte sich Napoleon nach Ägypten ein und dehnte damit den Krieg auf einen neuen Erdteil aus. Es wurde immer deutlicher, daß man in Rastatt nur verhandelte, um Zeit zu gewinnen, und nicht, um ein wirkliches Ergebnis zustandezubringen. Die ganze Zeit erschienen Schriften die sioh mit der Arbeit des Kongresses beschäftigten. Einerseits forderte man vom Kongreß einen schnellen Friedensschluß und andererseits nannte man immer wieder neue Bedingungen, unter denen ein Frieden zu akzeptieren sei. Außerdem waren immer wieder Stimmen zu hören, die den ganzen Kongreß für überflüssig erklärten und einen neuen Krieg forderten. Besonders forderte man die preußische Regierung auf, ihre Neutralität aufzugeben und gegen den Feind des Reiches zu kämpfen. So unterstützten die deutschen Schriften die diplomatischen Bemühungen Englands, Österreichs und Rußlands Preußen mit in den Krieg zu ziehen. ${ }^{5}$ Der Druck auf Preußen verstärkte sich noch durch den Regierungswechsel vom Sommer 1797, als von allen Seiten versucht wurde, Friedrich Wilhelm III. zu beeinflussen.

Der Zeitabschnitt vom Staatsstreich des 18. Fructidor bis zum Ausbruch des zweiten Koalitionskrieges im November 1797 bedeutete für die öffentliche Diskussion in Deutschland, die sich mit der Frage ob Krieg oder Frieden beschäftigte, eine Zeit der Verwirrung und Unsicherheit. Einerseits schien der Frieden zum Greifen nahe, und man wollte ihn beschleunigen. ${ }^{6}$ Andererseits wurde von Monat $\mathrm{zu}$ Monat deutlicher, wie aggressiv und egoistisch die französische Außenpolitik ausgerichtet war, was natürlich Widerstand hervorrief. Diejenigen, die in ihrer Friedenspolitik auf Frankreich bauten, äußerten immer deutlicher ihre Hoffnung auf einen militärischen Sieg Frankreichs zur Beendigung des verwickelten politischen Spiels, diejenigen wiederum die soviel wie möglich von dem alten System erhalten wollten, begannen einer militärischen Entscheidung den Vorzug zu geben. Typisch für diese Zeit ist, daß Schriftsteller oder Zeitschriften, die sich für den Frieden eingesetzt hatten, zu Anhängern des Krieges wurden. Es lassen sich zwar auch einige entgegensätzliche Fälle nachweisen, aber die Hauptrichtung ist deutlich zu erkennen: ehemalige Friedensanhänger befürworten jetzt eine militärische Lösung.

5 Über diesen intensiven Druck siehe z.B. Hüffer II (1905) S. 133-137 und Tschirch I (1933) S. 416-449. 


\section{DIE MEHRHEIT IST FÜR KRIEG}

\section{Die letzten Siege des Reiches}

Noch während der Rastatter Kongreß tagte, führte man um die Jahreswende von 1798/99 Geheimverhandlungen über eine neue Koalition gegen Frankreich. Im November 1798 erhob sich der König von Neapel gegen Frankreich und wurde vollständig besiegt. Die Umwandlung seines Landes in die Parthenopäische Republik zwang die Verbündeten, ihre Aktionen zu beginnen, schon bevor die Pläne ganz abgeschlossen waren. Es begann der zweite Koalitionskrieg, an dem sich als Verbündete Rußland, England und Österreich unterstützt von einigen kleineren Ländern beteiligten. $\mathrm{Zu}$ diesen kleineren Ländern kann man auch die verschiedenen deutschen Territorien rechnen, die zumindest formell der 1793 erklärte Reichskrieg betraf. Der Beginn des zweiten Koalitionskrieges fiel mit dem skandalösen Abschluß des Rastatter Kongresses vom April 1799 zusammen, als ungarische Husaren die französischen Gesandten auf ihrer Heimreise ermordeten.

Schon davor hatten die Kämpfe mit vollem Einsatz am Rhein begonnen. Die Annektion Ehrenbreitssteins noch mitten im Frieden war jetzt für Frankreich von großer Hilfe, und im März 1799 stießen zwei starke französische Heeresgruppen über den Rhein bis an den Inn vor. Dann kam die Wende: Erzherzog Karl besiegte in der Schlacht von Stockach am 25. März 1799 die von Jourdan befehligten Franzosen, die über den Rhein zurückgeworfen wurden. Auch auf den anderen Kriegsschauplätzen mußte Frankreich Rückschläge hinnehmen. Im Spätsommer landete eine große Zahl englisch-russischer Truppen in Holland. Besonders kritisch war die Lage an der Front in der Schweiz, wo die Russen und Österreicher siegten und die alte Staatsordnung wieder in der Schweiz einführten. Auch in Italien mußten die Franzosen Niederlagen, besonders gegen die Truppen Suworows, hinnehmen. Napoleon befand sich nach Nelsons Sieg von Abukir abgeschnitten in Ägypten und konnte die Türken in Syrien nicht besiegen. Im Sommer schien sich Frankreich in einer 
aussichtslosen Lage zu befinden. Seine mehr oder weniger künstlichen Tochterrepubliken stürzten infolge der Siege der Verbündeten zusammen. Die Staaten Süddeutschlands, die in der vorangegangenen Jahren direkt in Reichweite der siegreichen französischen Truppen gelegen hatten und dann auch ihrem stärksten Druck ausgesetzt waren, erlebten nun die Siege und Gegenwart der kaiserlichen - oder eigentlich der österreichischen - Truppen. Die an militärische Siege nicht gewöhnten Deutschen glaubten, daß die »Germanen» die »Gallier» wieder besiegt hătten, was auch die Schwankenden zu militärischer Begeisterung führte. Die Enttäuschung im Lager der Friedensbefürworter zur Zeit des Rastatter Kongresses schlug jetzt in vielen Fällen in offene Feindseligkeit gegenüber Frankreich um. Die »allgemeine Meinung» in Deutschland schien zum größten Teil neuen militärischen Anstregungen zuzustimmen, um den Erbfeind zu schlagen. In diesem geistigen Kampf wurden wiederum alle Waffen gebraucht, die schon früher eingesetzt wurden: Glaube, Vaterland, Treue gegenüber Kaiser und Reich, die alten Germanen und der republikanische Barbarismus erschienen in der bekannten Art in den kriegerischen Schriften. Außerdem wurde jetzt in viel stärkerem Maße als früher die letzte-Schlacht, die Entscheidungsschlacht, als Motiv angefährt, auf die alle erreichbaren Kräfte zu konzentrieren seien und in der Sieg schon sicher sei, wenn jeder Deutsche sein Bestes gäbe. ${ }^{1}$

\section{Herrmanns Enkel, der Kampf für Kaiser, Glaube und bürgerliche Ordnung}

Es wurde schon nachgewiesen, daß der Vorfrieden von Leoben für kurze Zeit das Erscheinen von kriegerischen Schriften in Österreich unterbunden hatte. Die Regierung hörte auf Schriftsteller finanziell zu unterstützen, und u.a. Glave-Kolbielski mußte mit seiner schriftstellerischen Arbeit pausieren. Viele der kaiserlichen Untertanen, die sich früher besonders scharf gegen einen Frieden ausgesprochen hatten, lobten jetzt die Segnungen des Friedens von Campo Formio und sein Zustandekommen als weisen Entschluß der Staatsmänner.

In Wirklichkeit verstand man von Anfang an in Österreich den Frieden von Campo Formio als zeitlich begrenzt, und die allgemeine Meinung des Landes hatte noch nicht eine dem Frieden zustimmende Haltung eingenommen, als erneut eine Wende zu erkennen war. Bis auf einige offizielle den Frieden gutheißende Schriften erschienen unzählige österreich-

1 Wahl (1967) S. $93-108$. 
ische Artikel zur Zeit des Friedens von Campo Formio und danach in und außerhalb Österreichs, die weiterhin besondens kriegerische Töne anstimmten. Der »Neue Teutsche Merkur», der in großer Zahl österreichische Artikel veröffentlichte, brachte zur Zeit des Friedens besonders viele kriegerische Texte von Österreichern heraus: Joseph von Sonnenfels, Joseph von Hammer-Purgstall und der Prager Professor A. G. Meissner hoben den Kampfeswillen der Habsburger Untertanen und ihren unzerstörbaren Glauben an den Kaiser und seinen Heldenbruder hervor.? In gleicher Weise veröffentlichte die »National-Zeitung» von R. Z. Becker in Erwartung des Friedens fortgesetzt österreichische Kriegsgedichte und andere Schriften. ${ }^{3}$ Auch »Eudämonia», die bis zu ihrer letzten Nummer selbst gegen den Frieden eingestellt war, enthielt fortgesetzt kriegerische Beiträge aus Österreich. ${ }^{4}$ Auch in den von J. E. von Sartori herausgegebenen Nürnberger Zeitschrift, »Der deutsche Redakteur», erscheinen während des ganzen Jahres 1798 kriegerische Artikel aus Österreich. Zweimal wurden Gedichte von Haschka abgedruckt. Sofort zu Beginn des Jahres erschien seine Ode auf den Frieden von Campo Formio. Sie vertrat den offiziellen Friedensstandpunkt. Ein guter Kaiser, der heldenhaft wie Anminius gegen die wie tobende Tiger kämpfenden Fransosen Krieg geführt habe, hätte zum Glü.ck seiner Untertanen den Frieden geschlossen. In diesem Zusammenhang bedauerte Haschka Belgien, das Beute der Franzosen geblieben sei. ${ }^{5}$ Ein wenig später veröffentlichte Sartori eine Schilderung eines »Jahresfestes des Patriotismus» in Österreich, in der auch Haschkas Gedicht »Vaterlands-Lied» angeführt wird. In diesem Gedicht wird vom Frieden nicht viel gehalten. Fortgesetzt wird in ihm der Heldenmut der Nachkommen der Cherusker angeführt, und die kriegerische Einstellung wird in der Äußerung deutlich, daß man im Notfall bereit sei, wieder zu den Waffen greifen, um für Kaiser und Kirche zu kämpfen: »Wir opfern mit Freuden den letzten Hauch/ für Oesterreichs Kirche, Verfassung und Brauch.»6 Auch die Gedanken Johannes von Müllers und seine Kampfesaufrufe an die Schweizer Landsleute veröffentlichte Sartori in der sonst verhältnismäßig neutralen Zeitschrift. $^{7}$ Stimmen gegen den Frieden in der tagespolitischen Diskussion lassen sich auch in der Zeit zwischen dem Frieden von Campo Formio und dem Beginn des zweiten Koalitionskrieges in der nicht-tages-

2 NTM 1797 I S. 161-162, II S. 271, III S. 115-134, 1798 III S. 335-336.

3 N-Z 1797 Nr. 15 S. $339-341$.

4 Eudämonia IV: 51797 S. 458-459.

5 Deutsche Redakteur 1798, S. $14-16$.

6 Ibid. S. $356-357$.

7 Ibid. S. 151. 
politischen Literatur finden, ${ }^{8}$ Verständlicherweise bezog man während des Zwichenfriedens sowohl in Österreich als auch in den anderen Teilen des Reiches Stellung gegen die Aktionen Frankreichs. Eine besonders heftige Reaktion riefen die mitten im Frieden von den Franzosen vorgenommenen Besetzungen von Mainz und Ehrenbreitstein hervor, und in vielen Schriften verurteilte man das Vorgehen der Franzosen als einen Verstoß gegen das Völkerrecht. Obwohl in diesen Artikeln selten direkt entsprechende Gegenaktionen gefordert wurden, so betonte man jedoch die Notwendigkeit von Patriotismus, Vaterlandsliebe und Einigkeit, und daß man die Wiederholung eines entsprechenden Falles durch gemeinsame und angemessene Aktionen verhindern werde. Man beklagte nach den bedauernswerten Zustand der Reichstruppen und forderte seine Verbesserung. So gesehen unterstützten auch diese Schriften deutlich die in Österreich beginnende Kriegspropaganda. ${ }^{9}$

Während der Rastatter Kongreß tagte, enschienen fortgesetzt Schriften, die davor warnen wollten, daß man Frankreich zu große Zugeständnisse mache. Die einzelnen Verfasser legten dabei auf verschiedene Einzelheiten Gewicht. Besonders aktiv waren die Vertreter der kleinen Stände, die sich immer bedroht gefühlt hatten. Sie werden im folgenden Kapitel gesondert behandelt werden. Aber auch viele andere äußerten sich aktiv, und fortgesetzt wurden die Meinung vorgetragen, daß ein neuer Krieg eine bessere Alternative sei als die Zustimmung zu den immer größer werdenden Forderungen der Franzosen. Schriften dieser Art erschienen sehr oft anonym und ohne Angabe der Druckortes, so daß es oft unmöglich ist festzustellen, aus welchen Teilen des Reiches sie stammen. Offensichtlich ist jedoch, daß sie in allen Gebieten des Reiches teils als Propaganda der Höfe und Regierungen und teils als spontane Meinungsäußerungen erschienen.

Gemäßigte, wenn auch deutschnationale Ansichten, trug eine umfangreiche Schrift, »Briefe eines Abgeordneten bey dem Congresse zu Rastadt», von 1798 vor, deren Verfasser wirklich einer der vielen Teilnehmer des Kongresses gewesen sein kann. Die Schrift, eine Briefsammlung, beginnt mit den optimistischsten Briefen, die für den Frieden von Campo Formio dankten und die Hoffnung auf eine Friedensordnung auf der Grundlage der Integrität zum Ausdruck brachten. Aber schon der

8 v. Eiberg, Karl, Tyrols Vertheidigung ... 1798, besonders S. 99-100; Neue Kronik der Kais. Kön. V. Oesterr. Stadt Konstanz . . 1798, z.B. S. $72-73$ und 78 -79 .

9 z.B. Die Occupation der Stadt und Festung Mainz ... 1798 S. iii und 5; v. Faber (Der Befehlshaber von Ehrenbreitsstein), Documentirte Beleuchtung ... 1798 S. 3-4, 13, 109-113; Bemerkungen über das Schwäbische Kreiskorps . . 1797. 
Staatsstreich vom Fructidor habe die Teilnehmer des Kongresses sohlimmes erwarten lassen, und die Aktionen Frankreichs während des Kongresses habe wachsende Besorgnis hervorgerufen. Die Besetzung Mainz wurde verurteilt und den französischen Forderungen nach Aufgabe der übrigen Grenzbefestigungen durch Deutschland wurde widersprochen. Ein auf Januar 1798 datierter Brief ist sohon beinahe kriegerisch. Er stellt fest, daß sich der Rastatter Kongreß als Leitspruch gewählt habe: "Der Mächtige kann und darf alles gegen Schwächere», und gibt der Hoffnung Ausdruck, daß die Deutschen auch militärisch Widerstand leisten würden. Der letzte Brief, datiert auf März, ist sehr pessimistich und stark frankreichfeindlich.10 Eine im gleichen Jahr enschienene Schrift drückt die Überzeugung aus, daß ein Krieg besser sei. Sie warnt besonders davor, den Franzosen das rechte Rheinufer als Stützpunkt zu überlassen, weil sonst das ganze Reich den französischen Heeren offenstünde und das zu seiner Vernichtung führen würde. Die Schrift schließt schon mit einer offenen Aufforderung an die deutschen Fürsten, ihre Kräfte $z u$ vereinigen, um Frankreich zur Aufgabe seiner Forderungen $\mathrm{zu}$ zwingen. Wern das nicht möglich sein sollte, müsse man Krieg führen und wiederum die »deutsche Tapferkeit» unter Beweis stellen. Deutschland würde diesen Krieg sicher gewinnen, und danach könne man den Frieden schließen, den alle wollten. Um dieses Ziel zu erreichen, müßten besonders Österreich und Preußen ihre Kräfte vereinigen. ${ }^{11}$

Einen Zusammenschluß gegen Frankreich forderte auch eine verbittert klingende Schrift, »Die Neurepublik Alles und das teutsche Reich Nichts», vom Sommer 1798, in der die möglichen Ergebnisse der Rastatter Verhandlungen gegeneinander abgewogen wurden. Die Schrift enthält einen scharfen Angriff auf die Schwäche Deutschlands: von der Teutonennatur sei nichts mehr übriggeblieben, weshalb Frankreich machen könne, was es wolle. Wegen der politischen Schwäche Deutschlands sei das Ergebnis der Rastatter Verhandlung auch kurz gesagt: Die Neufrankenrepublik Alles und das teutsche Reich Nichts. Der Verfasser hieß dies jedoch nicht gut, sondern wollte nur ohne Einschränkung an der Reichsverfassung festhalten. Besonders müsse man die Zurverfügungstellung von Stützpunkten am rechten Rheinufer verhindern. Den Frieden von Campo Formio akzeptierte die Schrift jedoch: den habe Kaiser Franz geschlossen, der »Vater und Retter des teutschen Reichs», und der Vertrag würde »die möglichste Aufrechterhaltung der Konstitution» in Ehren halten. Jetzt seien die französischen Forderung in einer

10 Briefe eines Abgeordneten ... 1798, S. 1-2, 25-27, 48, 69, 73-76, 98-99.

11 Die von - - Forderungen ... 1798 S. 9-12, 86-95. 
Weise gestiegen, daß die Zustimmungspolitik nicht mehr helfen würde, sondern nur noch die Zusammenarbeit der deutschen Staaten nötig sei, besonders zwischen Preußen und Österreich, um diese abzuwehren. Der Verfasser verwies auch auf die Leitideen Frankreiohs und der Republik, Freiheit und Gleichheit, die auch einen Frieden und nicht Besetzungen voraussetzen würden. Der aufklärerische Verfasser äußert auch, daß er den Krieg ablehne, weil er für die Bildung, die Wissenschaften, die Literatur und dic Kunst Schaden bringen würdc. Zum Schluß richtet der Verfasser warnende Worte an die Franzosen: wenn Frankreich keinen Frieden schließen sollte, »rüttelt Herrmanns Asche, und den schlummernden Gemeingeist der alten Germanen mit Gewalt auf». Frankreich sei keineswegs unschlagbar: „Siegreiche Gallier! syndigt nicht auf die Sirenen-Schmeicheleien des Glücks, sie straft oft undankbar ihre Anbeter diese wandelbare Kokette».12

Neben diesen zum Krieg aufrufenden Schriften erschien eine große Zahl, die grundsätzlich einem Friedensschluß zustimmte, aber Forderungen stellte, die unter diesen Umständen keinerlei Aussicht hatten, akzeptiert $\mathrm{zu}$ werden. ${ }^{13}$

Der Beginn des zweiten Koalitionskrieges ließ dann diese Propaganda ganz offen auftreten, und die anfänglich bedeutenden Erfolge der Deutschen führten zu einer Ausdehnung der Diskussion auch auf einen großen Teil der spontanen Literatur. Der Zeitabschnitt zwischen dem Beginn des Krieges und den ersten großen Erfolgen (Ende 1799) bedeutete für die allgemeine Meinung in Deutschland, daß die Zustimmung für einen Krieg ihren Höhepunkt erreichte. Viele kriegerische Schriften schlossen sich schon an das tragische Ende des Rastatter Kongresses mit den Gesandtenmorden an. Die Österreicher und ihre Helfer verfaßten eine große Zahl von Flugschriften, um die Unschuld Österreichs nachzuweisen und um zu zeiten, daß das Direktorium in Frankreich selbst hinter der Tat mit der Absicht gestanden habe, einen baldigen Frieden zu verhindern. Damit hatte man auch die Gelegenheit, zum Haß gegen die verbrecherischen Machthaber in Frankreich anzustacheln und zu versichern, daß sie noch vernichtend geschlagen werden würden. ${ }^{14}$ Das

12 Die Neufrankenrepublik Alles ... 1798 S. 1-3, 27-30. Andere kriegerische an den Kongress gezeigte Schriften z.B. Merkwürdiges Sendschreiben an den Kardinal Ezbischoff Migazzi ... 1798:, Briefe aus Italien ... 1798; Die von den französischen Gesellschaft — - gemachten Forderungen . . 1798.

13 Ueber Teutschlands Frieden mit Frankreich ... 1798; Antwortschreiben des Herzogs von ... 1798; Die Abtretung des linken Rheinufers ... 1798.

14 Betrachtungen über die Darstellung und die Wirkung ... 1799; Bemerkungen über das Schicksal ... 1799; Kurze Bemerkungen über den authentischen 
Ereignis wurde natürlich auch in anderer Weise kommentiert. So wurde im Gegenteil gegen die Österreicher gehetzt und dazu aufgerufen, die verbrecherischen Tyrannen von Wien $z u$ vernichten. ${ }^{15}$ Daneben wurde das Vorkommnis auch neutral besprochen. ${ }^{16}$

Die Österreicher waren jetzt bei den kriegerisohen Schriften führend. Diejenigen, die schon früher in dieser Weise geschrieben hatten, setzten jetzt ihre Tätigkeit fort. Der alte Federkrieger Glave-Kolbielski veröffentlichte eine kleine Broschüre, in der er nachzuweisen versuchte, daß Frankreich und sein vermessener Botschafter Bernadotte die Schuld am erneuten Ausbruch des Krieges hätten. Fürstentreue, wahrhaftige Friedensbereitschaft des Kaisers zum Besten der Untertanen und die siegesbewußten österreichischen Truppen waren von Glave häufig verwendete Wendungen. ${ }^{17}$ Dazukamen auch viele neue Stimmen. Der Pfarrer Joseph Wührer veröffentlichte in einer Flugschrift seine im Mai 1799 gehaltene Predigt. Den gerade ausgebrochenen Krieg verglich er mit den Kriegen Davids und Israels gegen ihre Feinde. Ebenso wie zu Davids Zeit werde Gott jetzt Österreich zu Hilfe kommen, und das würde zur Niederlage des Feindes führen. Die Untertanen müßten jetzt, da der Krieg ausgebrochen sei, noch deutlioher ihrem Fürsten dem Vaterland und der Religion ihre unverbrüchliche Treue erweisen, damit der Feind geschlagen werden könne, der »keinen Gott, keine Religion, keine Treu gegen Fürsten, kein Gesetz und Rechtschaffenheit kennet». Die österreichischen Heldensoldaten stünden unerschütterlich unter der Führung des kaiserlichen Bruders dem Feind gegenüber. Der Herr habe Österreich zum Sieg verholfen, und dem Herrn müsse man für diesen Sieg danken. Schon der heidnische Marc Aurelius habe der Gottheit für den Sieg über die Markomannen gedankt. Die österreichischen Christen hätten noch viel mehr Grund zu danken. ${ }^{18}$ Noch kriegerischer ist die Flugschrift »Syrach der Enkel» von Joseph Maria Weissegger. Er stammte aus der Steiermark und lehrte an der Universität Freiburg/Br. als Professor für Geschichte. So wie das Pseudonym von Kolbielski übernommen ist, wird auch in dessem Stil von Weissegger einem Friedensschluß widersprochen und die dazu neigenden Deutschen angegriffen.

... 1799; Gentz, Friderich, Ueber die Ermordung . . 1799; Nähere Nachricht über das traurige endliche Schicksal ... 1799.

15 Ermordung der bevollmächtigen Minister ... VII.

16 Das allgemein ausserordentliche Kaiserliche ... 1799; Gemeinschaftliche Erklärung ... 1799. Über die Diskussion in Preussen vgl. Tschirch I (1933) S. 385 -415 .

17 Getreue Darstellung des Aufenthalts ... 1798.

18 Wührer, Joseph, Rede am feyerlichen ... 1799. 
Die französischen Siege würden unnötigerweise zu sehr bewundert: sie seien das Ergebnis des Mutes eines Wahnsinnigen, der Begeisterung eines Betrunkenen und nur dank der Anstrengungen von Verzweifelten errungen. In Frankreich habe es keine Demokratie gegeben, sondern nur eine »wahre Oligarchie» beherrscht von »fünf Plebejen und Ränkemacher». Weissegger wandte sich auch gegen das Schlagwort der Franzosen »Friede den Hütten», das sich als vollkommen unzutreffend erwiesen haben. Besonders Weisseger richtete sich an die Bewohner des »dritten Deutschland», die er aufforderte, sich Österreich im neu ausgebrochenen Krieg anzuschließen:

»Jetzt, tapfere Deutsche, ist der Zeitpunkt, wo ihr euch groß und mächtig zeigen, wo ihr mit eben jenem Maaße den Franzosen ausmessen könnet, mit dem sie euch eingemessen haben. - Rasches, thätiges Wirken ist das Mittel, wodurch ihr euren Feinden zuvorkommen, sie in ihrem eigenen Lande erschüttern und zu einem ehrenvollen und dauerhafien Frieden, den ihr bisher immer gewünscht, aber von den stolzen Machthabern der Republik nicht erlangen konntet, zwingen künnet».18

Weisseggers Vorgehen war für die österreichische Propaganda typisch. Um die Deutschen zum Kampf zu ermuntern, appellierte man einerseits an Rachegefühle und erinnerte andererseits daran, daß mit einem raschen Schlag auch ein bleibender Frieden möglich würde, dessen Notwendigkeit man nicht $\mathrm{zu}$ bestreiten versuchte. Auch Weissegger hob die militärische Stärke Österreichs hervor und schätzte die Möglichkeiten der Franzosen, einen Sieg zu erringen, gering ein. Die Broschüre endet mit einem Hochruf auf den Kaiser und auf das Vaterland der Deutschen und mit einer für die französische Seite bestimmten Feststellung: »Sie wollten Krieg, und sollen ihn haben».20

Von den österreichischen Flugschriften des Jahres 1799 erschienen besonders viele anonym. Die in Wien gedruckten »Merkwürdigkeiten des achtzehnten Jahrhunderts» rühmten die österreichischen Erfolge in dem zuendegehenden Jahrhundert und versicherten, das Reich stehe »blühend, aufrecht und hochgerüstet da, um andern Völkern Religion, Ruhe, Eigenthum und Sicherheit diese sanften Bande der menschlichen Gesellschaft wieder zu geben».21 »Österreich im Jahre 1799» lobte den Kampfgeist des Volkes, den es gezeigt habe, nachdem der Kaiser erneut beschlossen habe, Krieg gegen die Tyrannen Frankreichs zu führen.

19 Syrach der Enkel; oder: Ein Wort der Wahrheit ... 1799 S. 45.

20 Ibid. S. 80.

21 Merkwürdigkeiten des achtzehnten Jahrhunderts . . 1799. 
Während die anderen in Apathie gelegen hätten, habe Österreich seine Haltung bewahrt. Die französische Politik verurteilte man vollkommen. Sie habe alle Verträge gebrochen, u.a. den Frieden von Campo Formio, und überhaupt nicht vensucht, bei den Rastatter Verhandlungen zu positiven Ergebnisen zu kommen. Die Direktoren wurden als »die fünf Blutmenschen in Paris» betitelt und als »raubgierige und mordsüchtige Pentarchen», die die Friedenschoffnungen der Völker dazu verwenden würden, den Machtbereich ihres eigenen Landes zu erweitern. Noch nicht einmal der Rhein als Grenze habe Frankreich genügt. Deshalb begrüße man jetzt seine Niederlagen überall mit Jubel: es sei in Abukir geschlagen worden, und die Türkei habe ihm den Krieg erklärt. Die Russen und Österreicher würden heldenhaft unter der glänzenden Führung von Suworow und des Erzherzog Karl kämpfen, und überall in Österreich und in der Schweiz sei es zu antirevolutionären Volkserhebungen gekommen. Ein Sieg Österreichs und seiner Venbündeten sei sicher. ${ }^{22}$ - Die Frage der russischen Beteiligung am Krieg war für die österreichische Kriegspropaganda ein Problem: obgleich z.B. die oben angeführte Flugschrift und viele andere eine zustimmende Haltung einnahmen, ${ }^{23}$ wurde die entgegengesetzte Meinung vertreten, die die Teilnahme des östlichen Barbarengiganten an den Kämpfen in Mitteleuropa ungern sah. U.a. enklärte Weissegger die Ankunft der Russen im Herzen Europas als Unsicherheitsfaktor und versicherte, nicht der Kaiser, sondern das Direktorium selbst habe das veranlaßt. ${ }^{24}$

Die scharfe Kritik am Direktorium wurde fortgesetzt, von der Schriften »Geist der herrschenden Franzosen», die betonte, daß an Frankreichs Spitze nur Königsmörder stünden. Jetzt würde diesen jedoch die Vernichtung drohen, denn »bald werde zum Trost aller friedlichen Fürsten und Völker die Stunde schlagen, wo es heissen wird: Tod und Verderben ohne alles Geschwätz über die Königsmörder und Tyrannen zu Paris».25

Gedanken dergleichen Art wurden auch in Gedichtsform vorgetragen, und Kriegslieder druckte man in Österreich, überall in Deutschland und in der Schweiz sowohl auf einzelnen Blättern als auch als Sammlungen in großer Zahl. In dieser Kriegslyrik nahm die Frankreichfeindlichkeit und die Kriegsbegeisterung zum Teil groteske Formen an. Man forderte Rache an den Franzosen und mit Gottes Hilfe werde man die »Satansbrut» schlagen und das »Schurkenblut» vergießen. Man verspottete jetzt das

22 Oesterreich im Jahre 1799, 1799, S. 3-6, 11-16, 23-24, 89.

23 z.B. Botschaft des französischen Direktorium ... 1799 S. 26. Das Mißtrauen gegen Rußland war groß auch bei den Regierungen. Wahl (1967) S. 106-107.

24 Syrach der Enkel ... 1799 S. 50.

25 Geist der herrschenden Franzosen ... 1799. 
Bedrängnis der Franzosen, da sie sowohl von Prinz Karl als auch vom "groben Bauersmann» geschlagen würden. Als mögliches Kriegsziel für Österreich betrachtete man sogar die Besetzung von ganz Frankreich, wenn man sang:

"So gebe der Himmel, es werde gewiß, / Dieß Jahre zu sehen das schöne Paris; / Man pflanzet auch gänglich den Friedenschuß ein / Daß Prinz Karl der König in Frankreich soll seyn.» ${ }^{26}$

Texte von Österreichern enthielt auch die im Juni 1799 gedruckte Schrift »Eine Sammlung von deutschen Biedersinn zur Stärkung der Schwachen». Die Schuld für den Ausbruch des Krieges trage vollkommen das Frankreich der »Volkstyrannen», und die Österreicher würden unersohütterlich in den Krieg ziehen:

»Noch sind wir Oesterreicher; noch / Belastet uns kein fremdes Joch, / noch unerschüttert, ungeschwächt / Steht Glaub' und Sitte, Macht und Recht, / Noch herrschet Vater Franz / in Habsburgs angestammten Glanz»27

Unter der Führung des Kaisers und seines Heldenbruders stünden die österreichischen Völker für Religion, Fürsten und Vaterland als Verbündete der vom Helden Suworow geführten Russen. Für Frankreich würden in Deutschland nur »einzelne Schwärmer, verschrobene Köpfe, Taugenichtse, bezahlte Bösewichte» eintreten. Ein idealer Frieden sei nicht mehr weit, da man die Franzosen bald schlagen würde. ${ }^{28}$ Zwei Texte appellierten an die französischen Soldaten mit der Aufforderung, sie sollten nicht länger dem Direktorium erlauben, sie selbst zur Schlachtbank zu führen. Die Übermacht der Verbündeten, Österreich, England, Rußland und der Türkei, sei übergroß. Noch deutlicher würde sie die Stellung dieser Völker machen, denn

»es ist nioht mehr Krieg der Souveraine, welohe diese gewaltige Staaten beherrschen; es ist der Krieg der Völker, die aufgehört haben, vor Euern Waffen zu zittern, und Eure Grunsätze anzunehmen. Es gilt Seyn oder Nichtseyn! Sieg oder Tod.»

26 Drey Volks-Lieder über die Geschichte ... 1799. Andere gleiche sind z.B. Neue lustige Lieder ... 1799; Kriegs-Lied für die tapfern Schweizer ... 1799; Ruhm-Gesang der Kaiserl. Königl. Armee ... 1799; Antwort eines K.K. Offiziers ... 1799; Aufruf eines rechtschaffenen Schweizers ... 1799; Taschenbuch von J. G. Jacobi ... 1798; Ueber die Wichtigkeit der Besitznahme . . 1799; Schlachtgesang für die ... 1799; Zwey schöne alte Lieder ... 1799; Lavater, Johann Caspar, Christliche Belehrungen ... 1799.

27 Eine Sammlung von deutschen Biedersinn ... 1799 S. 3.

28 Ibid. S. 18-21. 
Um der Menschheit weitere Leiden $\mathrm{zu}$ ersparen, das Vaterland $\mathrm{zu}$ netten und $\mathrm{Ha} \beta$ zu verhindern, müßten die Soldaten Frankreichs ihre Despoten zu einem schnellen Frieden zwingen. ${ }^{99}$ Das gleiche Thema behandelt die Flugschrift »Antwort eines französischen Soldaten auf den Aufruf eines Deutschen», die offensichtlich auch österreichischen Ursprungs ist. In der Schrift versichert der französische Soldat, daß er zusammen mit seinen Kameraden vollkommen genug habe von den unendlichen Opfern, die man von ihnen fordere: Schande, „Sklavenfesseln und ein ruhloser Tod» seien ihr Anteil. Die Schuld an dem neuen Krieg trügen die Machthaber Frankreichs, weil sie die geschlossenen Verträge gebrochen hätten. Deshalb sei zu erwarten, daß sich die französischen Soldaten zum gemeinsamen Kampf gegen den Feind, die Despoten Frankreichs verbünden würden. Die ganze Revolution wurde grundsätzlich verurteilt. Sie sei ein Irrtum und ein Verbrechen, das »dem gegenwärtigen Geschlechte und den kommenden Jahrhunderten» ein warnendes Beispiel bleiben würde. ${ }^{30}$ Viele anonyme Schriften wiederholten diese Gedanken. ${ }^{31}$

Wie in den Jahren 1795-97 erhielt Österreich auch jetzt Unterstützung aus den Kreisen der sog. Reichsdeutschen. Eine der heftigsten Schriften der Kriegspartei war die von L. C. Wiesser in Nürnberg anonym und mit falschem Druckort versehene Flugschrift »Ernsthafte Blicke auf die Moralität der fränkischen Regierung». Wiesser verurteilte zuerst von Grund auf die Revolution, deren Anhänger und Agenten seiner Meinung nach Verbrecher waren. Dem Wort des Direktoriums dürfe man auf keinem Fall trauen, und jeder Herrscher, ider sich mit den Machthabern Frankreichs auf eine Diskussion einlassen würde, bereite seine eigene Vernichtung vor. Besonders nach dem 18. Fructidor sei der mit dem Direktorium geschlossene Friedensvertrag vollkommen wertlos. Diese fünf Jakobiner, die Frankreich beherrschen, würden ihre Waffen nicht eher niederlegen, bis es in ganz Europa keine Monarchie mehr geben würde. Es sei unbegreiflich, daß solche Menschen »an den vornehmsten Höfen von Europa» Freunde hätten. Dieser Hinweis richtete sich vor allem gegen Preußen, das man überall in Deutschland mit in den Krieg zu ziehen versuchte. Frankreich habe nach dem 18. Fructidor in der Schweiz die Revolution durchgeführt, die Republik von Rom errichtet

29 Ibid. S. 23.

30 Antwort eines französischen Soldaten ... 1799.

31 z.B. Wörterbuch der französischen Revolutionssprache, 1799 (dasselbe »Lexikon» gehörte auch zur obenerwähnten Schrift Eine Sammlung von deutschen Biedersinn, S. 29-); Botschaft des französischen Direktoriums ... 1799; Bitt-Psalm guter österreichischer und teutschen Bürger . . . 1799; Zur Geschichte des Anfangs ... 1799; Erklärung zur Herstellung ihres Vaterlandes ... 1799. 
und ganz deutlich auch in Baden, Württemberg, der Pfalz und Schwaben die Revolution vorbereitet. In Rastatt habe man deshalb nicht die Absicht gehabt, Frieden zu schließen, sondern die Verhandlungen seien eine reine Komödie gewesen. Die Schrift nannte auch die Namen von vier Männern, die mit Frankreich zusammengearbeitet, Informationen geliefert und deren Absichten unterstützt hätten, in den Territorien am Rhein einen Aufstand anzuzetteln. Bei der Ernennung des Corporal Bernadutle zum Wiener Gesandten sei es die Alssichl des Pariser Dircktoriums gewesen, die österreichischen Jakobiner zu entsprechenden Aktivitäten $\mathrm{zu}$ ermuntern, und das sei eine Afforderung für die Soldaten zu einem Aufstand gewesen. Zur gleichen Zeit unterbreitete Sieyes dem König von Preußen seine Säkularisationspläne. ${ }^{32}$ Große Beachtung schenkte man auch »dem grossen Buonaparte», der heimlich »auf dem Mittelländischen Meer herumspazirt» und »mit dem gleichen Grad von Redlichkeit», mit dem er Italien erobert habe, gerade Malta okkupiere. Den Ruf Napoleons malte man in den schwärzesten Farben. Seine Aktionen hätten deutlich gezeigt, daß er ein listiger Betrüger und kein Held sei. ${ }^{33}$ Am Schluß der Schrift verurteilte man die Sonderpolitik der Höfe in Deutschland und forderte alle Völker zum gemeinsamen Kampf auf. Besonders alle norddeutschen Höfe müßten ihre Kräfte vereinigen und dem Direktorium den Krieg erklären. Dieser Krieg sei nicht den Völkern Frankreichs zu erklären, sondern man müsse im Gegenteil versprechen, daß die Gebiete des alten französischen Königreiches nicht berührt würden und man sich nicht an den Franzosen rächen würde. So würde dem Quintumvirat bald eine Gegenrevolution blühen. Ziel des Krieges sei es vor allem, die R e p u b lik zu stürzen, denn wenn »Frankreich nicht wieder eine Monarchie wird, so wird die ganze Erdkugel auf eine blutige Weise republikanisirt werden».34 Ignaz Heinrich von Wessenberg, der sich selbst als deutschen Partioten vorstellte, forderte zum Kampf auf und betonte dabei, daß überall in Deutschland die guten Eigenschaften der alten Germanen anzutreffen seien. »O Vaterland! mir rinnt die bittre Thräne/für Herta's Töohter und 'Tuiskons Söhne», beginnt ein trauriges Gedicht, das Frankreich als Heimat der Mode und der Leichtsinnigkeit verschmäht und die deutschen Aufklärungsphilosophen lächerlich macht. ${ }^{35}$ Zahlreiche anomyme Flugschriften verbreiteten in gleicher Weise Kampfesgeist. ${ }^{36}$

32 Ernsthafte Blicke ... 1799 S. 4-11, 19-22.

33 Ibid. S. 28-29. Auch Briefe aus Italien . . 1798 und Buonaparte General ... 5799, besonders S. 4.

34 Ernsthafte Blicke ... 1799 S. 38 und 47.

35 v. Wessenberg, Ignaz Heinrich, Ueber den Verfall der Sitten ... 1799.

36 Siehe oben. 


\section{Die bedrohten Reichsstände stützen Österreich}

Eine eigene Gruppe innerhalb der gegen den Frieden eingestellten »Reichsdeutschen» bilden Schriftsteller aus jenen Territorien, deren eigenstaatliche Existenz durch den nahenden Frieden bedroht schien. Das waren vor allem geistliche Territorien, aber auch Reichsstädte und Gebiete der sogenannten Reichsritter. Über die Mediatisierung aller dieser Stände wurde besonders nach dem Frieden von Campo Formio heftig diskutiert, als ein allgemeiner Frieden vor der Tür zu stehen schien. Die Meinungsäusserungen nahmen weiter $\mathrm{zu}$, als man in Rastadt über die Einzelheiten der Friedensbedingungen $\mathrm{zu}$ verhandeln begann. Immer deutlicher wurden sie direkt an die Verhandlungspartner gerichtet mit der Absicht, deren Beschlüsse zu beeinflussen. Ein neuer Ton kam in die Diskussion, da sich die Rastadter Verhandlungen in die Länge zogen und sich besonders die Haltung Österreichs vensteifte. Nun begannen die Verteidiger der bedrohten Reichsstände immer offener die Ansichten Österreichs zu stützen und forderten gemeinsamen Kampf für das alte Reich.

Eine der zentralsten Fragen war die der Säkularisierung. Man sah in den geistlichen Staaten Vertreter der antiquiertesten und verfallensten Elemente des Deutschen Reiches und forderte allgemein ihre Auflösung und Vereinigung mit Ländern weltlicher Fürsten. Diese Forderungen wurden außer von grundsätzlich antiklerikaler und die Revolution bejahender Seite auch von sehr konservativen und selbstsüchtigen weltlichen Fürsten und im Kreise ihrer Befürworter vertreten. Die Säkularisation betrachtete man allgemein als Voraussetzung für den Frieden, weil man sonst eigentlich keine Möglichkeit sah, den weltlichen Fürsten ihre Unkosten zu ersatten. Die Verteidiger der geistlichen Staaten waren so oft gezwungen, gegen einen Friedenschluß Stellung zu nehmen und viele Verfasser reihten sich in die Front derjenigen ein, die zu einem neuen Kampf aufforderten.

Erörterungen über die Argumente für eine Existenz der geistlichen Staaten erschienen im ganzen hier behandelten Zeitraum. Die Befürworter versuchten natürlich, die Berechtigung ihrer Existenz und das Glück ihrer Untertanen nachzuweisen. Solche Schriften erschienen in geistlichen wie in säkularen Gebieten, und viele Schriften, die sich für die geistlichen Länder aussprachen, gehören zu dem auch sonst den Frieden billigenden Schrifttum. ${ }^{37}$ Die Mehrheit hingegen bekannte sich, beson-

37 z.B. Canonisch-historische kurze Darstellung einer Geschichte ... 1797; Auch eine Entschädingungsplan ... von Riphelius von Solemel, 1798; Auflösung der Frage, Ob, wie und von wem ... 1798. 
ders nach 1798, klar zur anderen Seite. Eine besonders eindeutige Stellungnahme findet sich in der anonymen, in Würzburg herausgegebenen Schrift »Über die Geistlichen Staaten in Deutschland und die vorgebliche Nothwendigkeit ihrer Säcularisation». Der unbekannte Verfasser bezog darin kräftig Stellung zugunsten der geist]ichen Fürsten und brachte ziemlich alle die Gründe zur Sprache, mit denen die Vertreter der bedrohten Reichsstände sich dem Friedensschluß widersetzten. Die geistlichen Sldalen würden wesentlich besser regiert als die welllichen. Der Wahlstaat sei in vielen Beziehungen günstiger als ein Erbstaat. Die geistlichen Fürsten hätten darüberhinaus ihre Pflicht im Reichkrieg gut erfüllt. Es sei Verrat, sie jetzt zu bedrohen. Die protestantischen Fürsten aber hätten ja den Patriotismus verschmäht und einen schmachvollen Sonderfrieden mit dem atheistischen Frankreich abgeschlossen; der schlimmste dieser Staaten sei Preußen, der beschämendste der Friedenschlüsse der Baseler Frieden. ${ }^{38}$

Die erwähnte anonyme Schrift enthielt außerdem eine der offensten, den Krieg schon im Prinzip bewundernden Äußerungen, die in den 90er Jahren des 18. Jh. in Deutschland geschrieben und gedruckt wurden. Es heißt, das Deutschland, das aufgehört hatte »ein erobernder Staat zu seyn», sich selbst dazu verurteilte zu verlieren. Das sei die Regel. »Sobald ein Staat die Absicht aufgiebt, zu höherer Macht fortzuschreiten und sich zu vergrößern; so verliert er auch die Kraft, sich unter dem anstrebenden Drucke der benachbarten Staaten zu wehren: denn die Staaten drücken, wie Körper-Massen, an einander nach allen Richtungen».39 Um einem solchen Druck entgegenzuwirken, habe der Staat beständig nach neuen Eroberungen im Krieg wie auch in Friedenszeiten zu streben. Ein Ruhen der Kräfte sei teilweise tödlich, jeder Stillstand bedeute Rückschritt. Unter diesem Gesetze »der physischen und moralischen Natur» stehen und fallen auch die Staaten.

»- - Bewegung, Thätigkeit, Streben, Kampf ist das ewige und erste Gesetz der Natur - - Frieden, ewigen Frieden findet sie nur jenseits des Grabes»40

Kants »Zum ewigen Frieden» wurde vom Verfasser entschieden angegriffen. Seiner Meinung nach hatte Kant zwar viele schöne Worte über die Moral der Völker verloren, dabei aber die wichtigste und einzige Voraussetzung für den ewigen Frieden außer acht gelassen. Diese war,

38 Ueber die geistlichen Staaten in Deutschland ... 1797, Vorrede, S. 12, 40, 60-61, 121-129.

39 Ibid. S. 40.

40 Ibid. S. $42-44$. 
»dass alle Völker sich zum ewigen Kriege rüsten, unermüdet sich zum Kampfe anschicken müssen; wenn sie Frieden nicht nur von außen, sondern auch von innen haben wollen.» Folge des von Kant vorgeschlagenen Völkerbunds sei ein völliges Chaos: die Staaten fielen auseinander und überall entistünden Aufstände und Unordnung. Natürlicher Zustand der Völker sei der ewige Krieg. Die Franzosen hatten das ganz richtig begriffen. Auch Rom war sofort zusammengebrochen, als es seine Erweiterungsziele aufgegeben hatte. Deutschland war in die Anarchie geraten, nachdem es die Kriegführung gegen andere Staaten eingestellt hatte. Der Grund dafür war 'vor allem in den protestantischen Fürsten zu sehen, die die geistlichen Stände hassten. Der schwache Erfolg im Kriege lag keineswegs in der Schwäche der katholischen Länder, wie hauptet worden war, sondern der Grund steckte viel tiefer. Frankreich war wesentlich stärker, es war »ein Lager». Deutschland müßte, um imstande zu sein zu siegen, unverzüglich die allgemeine Wehnpflicht einführen. Die deutsche Jugend war von der Natur zu dem Kriege bestirnmt und wollte dem Vaterland auf dem Felde der Ehre dienen. Der Apell an die Jugend scheint seiner Zeit um Jahrzehnte voraus zu sein:

»Schütze dich und schütze mich; schütze dein väterliches Erbe, deine künftige Gattinn, und zieh einst deine Kinder zu gleich muthigen Vertheidigern des Vaterlandes heran!»

Das Reich sollte sich zum zielstrebigen Kampf unter der Führung des Kaisens rüsten und der Kaiserwürde ihre Ehre zurückgeben. Der Kaiser konnte das Reich retten und die geistlichen Staaten, die ohne Reich nicht weiterexistieren konnten. ${ }^{41}$

Im gleichen Jahr erschien, ebenfalls in Würzburg, eine ähnliche anonyme Schrift »Freymüthige Gedanken eines teutschen Staatsbürgers. . .». Auch sie verwahrte sich gegen die Säkularisation und fordert, einen möglichen Frieden nur auf dem Boden der Reichsintegrität zu schließen; falls der Feind nicht darauf einginge, sei der Kampf fortzusetzen. ${ }^{42}$

Fortgeführt wurde der Kampf zugunsten der geistlichen Staaten dann durch einige anonyme Flugblätter des Würzburger Professors und Domkaplans Franz Berg. Er wandte sich ausser gegen die Säkularisationsforderungen auch gegen die Sonderfrieden und besonders scharf gegen die »Revolutions-Verbrechen». Alle Hoffnungen, durch die Säkularisation und durch Zugeständnisse einen allgemeinen Frieden zustande zu bringen waren unbegründet. Er tadelte insbesondere Professor Weiss, für den der

41 Ibid. S. 48-49, 67 (Zitat) usw.

42 Freymüthige Gedanken eines teutschen Staatsbürgers . . 1798. 
Frieden nur durch Säkularisation erreichbar schien, und Fichte, der alle Länder zu Republiken umgewandelt sehen wollte, die dann untereinander einen allgemeinen Friedensvertrag hätten aushandeln können. Die Deutschen sollten nicht wie das alte Karthago den Weg der Zugeständnisse gehen, sondern zielbewußt eine Front bilden und ihre Kräfte vereinigen. ${ }^{43}$

Mit Berg verband sich in noch schärferem Ton der Herausgeber der anonymen Flugschrift »Was sind eigentlich unsere Teutschen Domkapitel?» aus dem Jahre 1800, der sich als Untertan eines geistlichen Fürsten vorstellte. Die Schrift beklagt Neid und Geiz der weltlichen Fürsten, die hinter den Säkularisationsforderungen standen: auf Kosten der geistlichen Staaten wollten nun »alle Pächter, Zöllner und Sünder» Gewinne erzielen. Der Gegner wurde durch Namen charakterisiert, die sogar angesichts des geraden und unumwundenen Stils der Zeit ungewühnlich hart waren:

walle Minervaknaben, nasutuli und doctores umbratiles, welche von Sohulen und Universitäten heimkommen, deren Hohlschedel von Kantischen Terminologien und Sophistereyen aufgebunden, deren Herz vom Gifte der französischen Freyheit und Gleicheit angeschwollen ist, und welche euch nach der Fülle ihrer Wissenschaft und Untrüglichkeit —- alle Nichtshaber, Gleichmacher, Rollensüchtigen, Fürstenfeinde, Königsmörder, Beutel- und Gurkelschneider - mit einem Worte: alle Anarchisten, welche die ganze Welt umzukehren, um sich bey der allgemeinen Unordnung bereichern und geltend machen zu können.»44

Am schlechtesten kam Kant weg; auch Fichte wurde unter den wichtigsten Schuldigen genannt. Er hatte sich gegen die Adelsmacht, gegen das Reichsritterwesen und gegen die geistlichen Staaten ausgesprochen, die alle jedoch für das Deutsche Reich unabdingbar waren. Die geistlichen Staaten waren wichtig, um die Anarchisten, Räuber und frechen Gotteslästerer abzuwehren, die die Revolution hervorgebracht hatte. Die innere Verwaltung der geistlichen Staaten war besser, als man im allgemeinen glaubte. Die Fürsten waren darin keineswegs alleinherrschend, sondern die grösste Macht hatten die Domkapitel. Falsche Informationen waren durch die Freimaurerorganisationen verbreitet worden, die in Verbindung standen »mit der teutschen litterarischen Revolutions-Clique». Gegen Frankreich brauchte man die Zusammenarbeit aller Christen;

43 Die Unrechtsmässigkeit der Säcularisirungen ... 1799; Ueber die Staatsnothrecht als Grund ... 1800.

44 Was sind eigentlich unsere Teutschen Domkapitel? 1800, S. 16. 
gemeinsame Bemühungen würden zum Siege führen. - Interessant ist der Umstand, dass sich die Schrift stark gegen England richtete, wo man doch annehmen konnte, daß sich die gemeinsamen Feinde vereinigen würden. Das englische Staatssystem wurde als völlig unbrauchbar bezeichnet, da sich das Parlament auf den Pöbel von London stützte. ${ }^{45}$ Nicht irgendwelche Verwaltungserneuerungen könnten für Deutschland die Rettung bedeuten, sondern nur striktes Festhalten am bestehenden System.

Auf geistlichem Territorium wurde also vielseitig gegen den Abschluß des Friedens geschrieben. Der Wunsch, die Bewohner zu beeinflussen war auch andernorts offenkundig. Der österreichische »Söldner» Johannes von Müller veröffentlichte 1797 unter dem Pseudonym »Alexander von Suchbein» eine Flugschrift, deren Verfasser behauptet, Untertan eines geistlichen Fürsten zu sein. Die Schrift ist den oben behandelten ähnlich: sie behandelt in der Hauptsache die Greuel der Franzosen in den geistlichen Gebieten am Oberrhein und hebt besonders die Gewalttätigkeiten gegenüber den Priestern. Natürlich bezieht Müller Stellung gegen den mit Frankreich zu schliessenden Frieden, betont die Nachteile und Unrechtmässigkeit der Säkularisierung und verweigert jeglicher Änderung der Reichsgrundgesetze seine Billigung. Auch Suchbein-Müller tadelt Fichte und Kant.46

Die Diskussion über die Säkularisation dauert die ganze hier behandelte Zeit über an. Die Fürsprecher der geistlichen Territorien waren fast ausnahmslos auch Verfechter einer Fortsetzung des Krieges - bis zum Frieden von Luneville, wonach sich die Ansichten der meisten zwangsläufig änderten.

Eine andere deutsche Kleinstaatengruppe, die sich im Wirbel der Revolutionskriege in ihrer Existenz bedroht fühlte, war das R e i c h s r i t t e rt u m. Mit Recht hatte das Reichsritterwesen seit Jahrzehnten in erster Linie aus Kreisen der Aufklärung scharfe Kritik erfahren; Josef II. z.B. hatte sich ihm gegenüber recht lau verhalten. Die Artikel von Kant und Schiller hatten überall Widerwillen gegen die kleinen Tyrannen hervorgerufen und die Männer der Aufklärung verlangten im Namen der Humanität eine Verbesserung der Stellung der Bauern. ${ }^{47}$

Die Reichsritterschaft nahm natürlich am ersten Koalitionskrieg gegen die Revolution teil, ging es dabei doch auch um die eigenen Privilegien und Vorteile. Der Krieg war für sie schwer; die Gebiete der meisten Rit-

45 Ibid .., besonders S. 3-4, 35-36 u. Anm. S. 31, 66, 74-76 und 60-61.

46 Suchbein, Alexander von, Scenen und Züege ... 1797, bes. S. 3-11, 47-48 und 64 .

47 Müller (1910) S. 39-41. 
ter lagen in Reichweite der Kriegshandlungen der Franzosen und sie belasteten einerseits Plünderungen und Zwangssteuern, andererseits die steigenden Steuerforderungen im Reich. Die verarmte Ritterschaft versuchte damit so gut es ging fertig zu werden. Als auf dem Rastadter Kongress über eine Neuorientierung des Reichssystems verhandelt wurde, bemühten sich die Reichsrittervertreter, u.a. Philipp von Gemmingen und Franz von Sickingen, zu ihrem Stand zu halten und möglichst viel zu retten. Die Ergebnisse blieben bescheiden; es war daher natürlich, daß in öffentlichen Schriften, veranlaßt vom Reichsrittertum, Zweifel und Ablehnung angesichts des bevorstehenden allgemeinen Friedens geäußert wurden. ${ }^{48}$

Ein gutes Beispiel für den Kampfeswillen der Reichsritterschaft zur Zeit um den Beginn des zweiten Koalitionskrieges ist die Schriftenreihe "Deutschland über alles, wenn es nur will», erschienen 1798-99 in zehn Heften. Verfasser der Serie war Reichsfreiherr Philipp v. Gemmingen, damals Botschaftsrat auf dem Reichstag zu Regensburg. Durch seinen Beruf hatte er die besten Mögliohkeiten, die Politik zu verfolgen. Seine Flugblattserie gehört zum Bedeutendsten seiner literarischen Tätigkeit. ${ }^{49}$ Es war die Wiederholung einer und derselben Sache auf hundert Seiten: Deutschland war stark, und es wäre in der Lage, Frankreich zu schlagen, wenn es nur wollte. Dieses Problem wurde durch umfassende geographische und wirtschaftliche Vergleiche mit den meisten europäischen Ländern bewiesen. Gemmingen wollte vor allen Dingen zeigen, daß Deutschland unabhängig von fremder Hilfe Krieg zu führen fähig sei, da es alles hatte, was zur Kriegführung notwendig war:

»1) hinlänglicher Vorrath an Getreide zu Errichtung der Magazine 2) Mannschaft 3) Pulver und Bley 4) hinlänglicher Vorrath an Rindvieh, besonders 5) Vorrath an guten und brauchbaren Pferden, sowohl zum Fuhrwesen, als vorzüglich zu der schweren Kavallerie 6) Holz 7) Eisen 8) baares Geld ${ }^{50}$

Deutschland war also im Besitz alles Notwendigen. Es fehlte nur Einigkeit. Auch die deutschen Soldaten waren von ausgezeichneter Qualität, was nach Gemmingen schon durch den Export von Soldaten erwiesen sei, der seinerzeit nach Frankreich und Italien und jetzt immer noch nach England erfolgte. ${ }^{51}$ - Auffallend ist, daß der Soldatenverkauf ans Ausland nicht mit Mißfallen zitiert wird. Gewöhnlich wurde

48 Ibid. S. 46-49. Die Revolution in der Schweiz . . 1798.

49 Hamberger-Meusel XI (1805) S. 263-264:, Müller (1910) Register.

50 Deutschland über alles ... III, 1798, S. 4.

51 Ibid. IX, 1799, S. 21. 
das immer im Tone der Entrüstung vorgebracht oder doch wenigstens unerwähnt gelassen. - Wie viele andere Schreiber zugunsten des Krieges im »dritten Deutschland» verherrlichte auch Freiherr von Gemmingen den Kaiser und sein Land, Österreich. Wenn alle Reichsstände ihre Pflicht und wie der Kaiser ihr Kontingent erfüllten, wäre das Reich gerettet und Deutschland stiege zum führenden Land in Europa auf. Den Schluß der langen Artikelserie bildete ein gedrängter Aufruf an alle Deutschen, die Kräfte unter dem Kaiser zum gemeinsamen Kampf $\mathrm{zu}$ vereinigen. ${ }^{52}$

Viele Reichsritter und -grafen bewarben sich um Dienste in grösseren Reichsfürtentümern. Da ihre Heimat und damit ihre eigene Position der Vernichtung anheim zu fallen drohte, war es verständlich, daß sich diese Ritter an ihre Herren wandten. Graf Carl Christian von der LippeWeissenfeld diente als Beamter in Wien. 1798, als die Streitlust Österreichs immer offenkundiger wurde, veröffentlichte er ein die allgemeine Meinung stützendes anonymes Flugblatt, das energisch alle Deutschen zu neuem Kampf gegen die Eroberer aufforderte. Er berief sich auf das gute und heilige Grundgesetz, Vaterlandsliebe, allgemeine Freiheit, die Traditionen des Stammes der Tuiskonen, auf Glauben, gute Sitten und deutsche Redlichkeit und forderte die Deutschen auf, ihre Kräfte unter der Führung des Kaisers zu sammeln, um zu verhindern, daß sich die kranke Revolution weiter ausbreitet. ${ }^{53}$ Besonnener aber ganz offensichtlich im gleichen Geist, äußerte sich der Kapitän der Preußischen Armee, Reichs- und Burggraf Albrecht zu Dohna im gleichen Jahr in seiner dreiteiligen Geschichte des preußischen Feldzuges 1793 nach Holland. Die dem König gewidmete Untensuchung enthält eine ganze Reihe allgemein tagespolitische Hinweise, in denen Preußen $\mathrm{zu}$ einem neuen Kampf aufgefordert wird. Die Revolution wird gänzlich abgelehnt, die Ziele des ersten Koalitionskrieges hingegen werden gebilligt. Im gleichen Mass, wie die Tapferkeit der preußischen Truppen gelobt wird, werden Einigkeit und Patriotismus als unbedint notwendig hingestellt. 54

Auch die Schriften des Reichsgrafen Hans Christoph Ernst von Gagern richteten sich scharf gegen Revolution und Frieden. Er hatte schon um die Zeit des Baseler Friedens einen "Landsturm» und nationale Einheit gegen Frankreich gefordert und vorgeschlagen, zur Fortführung des Krieges einen Bund der »Fürsten und des Geistes» zu sahaffen. Das

52 Ibid. X, 1799, S. 34-35.

53 Nähere Beleuchtung ... 1798.

54 zu Dohna, Albrecht Burggraf, Der Feldzug der Preußen ... 1798, z.B. Bd. I S. $1-2$ und $14 ;$ Bd. II S. $16-17$. 
Schrifttum gegen den Frieden wächst an, besonders vor dem und während des zweiten Koalitionskrieges. ${ }^{55}$

Einen Vertreter der Sache der bedrohten Reichsstädte kann man in dem Sekretär des Reichskammergerichts Alexius Anselmus Kleber (geb. in Wetzlar) sehen. Er vertrat ebenfalls eine Fortsetzung und Verstärkung des Widerstands in der Phase, da der zweite Koalitionskrieg in die Entscheidung ging. In seiner von einem anonymen »deutschen Biedermann» herausgegebenen Flugschrift suchte er vor allem zu beweisen, daß die Fürsten bei drohender Gefahr das Recht hätten, ihre Untertanen zum Kriegsdienst zu rufen.56 Der Professor der Staatslehre Johann Ludwig Klüber (geb. in der Reichsstadt Tann) war im Zusammenhang mit der Gebietsangliederung Ansbach-Bayreuth 1791 preußischer Untertan geworden, aber auch er schildert in seinen Artikeln mehr die Einflüsse der Herkunft aus einer Reichsstadt. In seiner Ende 1797 erschienenen anonymen Flugschrift, die an den Rastadter Kiongress adressiert war, fordert Klüber eindringlich, das Integritätsprinzip des Reiches als Ausgangspunkt für die Verhandlungen $\mathrm{zu}$ nehmen und mißbilligt die Handlungen der Franzosen am linken Rheinufer, die dort zusammen mit ihren besoldeten »unteutschen» Helfern an der Zersplitterung der Reichseinheit arbeiten. Klüber kritisierte auch die Neutralitätspolitik des Berliner Hofes und sagte voraus, die Verteidigungsunlust werde dahin führen, daß die Freiheitsfahnen noch an Donau, Elbe und Weichsel flattern würden wie jetzt sohon am Rhein. Die Anerkennung der Rheingrenze mit ihren Reparationsplänen würde Deutschland in das gleiche Schicksal wie Polen führen. Das Ziel der Franzosen war die Universaldemokratie, aber dieses Ziel war dadurch abzuwenden, daß der Abschluß eines Friedens, der die Unantastbarkeit des Reiches verletzte, absolut verweigert wurde. ${ }^{57}$ Das im Januar des folgenden Jahres ebenfalls anonym erschienene wneue Licht» war im Ton noch viel schärfer. Klüber schimpft über den Frieden von Campo Formio, wo der Kaiser so große Zugeständnisse gemacht hatte, daß im Reich Entsetzensschreie ausgestossen wurden. In Rastadt schein es sich nicht um Verhandlungen $\mathrm{zu}$ handeln, ssondern um ein Diktat der Bedingungen. Wenn man die Säulen stürzte, wäre Vernichtung des ganzen Reiches die Folge. Der Säkularisierungsgedanke sei ein solcher Versuch, den Grundpfeiler zu erschüttern und deshalb scharf zu verurteilen. Die Säkularisation wäre der Anfang einer endlosen Kette von Änderungen -

55 Nach ADB Bd. 8. (K. Wippermann) S. 303-307 ist das Erscheinungsjahr 1795, nach HEINRICH RÖSSLER (1958) S. 58 das Jahr 1794.

56 Rechtliche Untersuchung ... 1800, S. 45-46 und 56.

57 Das erste und wichtigste Artikel ... 1797. 
also u.a. die Mediatisierung der Reiohsstädte — die das Reich schließlich vernichten würden. Die Deutschen sollten sich nicht selibst durch die Versprechen von Handelsvorteilen betrügen. »Henmanns Söhne» und »Tuiskons Heldenstamm» sollten vielmehr entschlossen in den Kampf gehen, den wackelnden Reichsthron $\mathrm{zu}$ erhalten. ${ }^{58}$ - Offensichtlich führte jedoch der Wunsch, mit der eigenen Regierung solidarisch zu sein, bei Klüber dazu, den Baseler Frieden mehr oder weniger zu bejahen, da er $\mathrm{zu}$ einer geeigneteren Zeit geschlossen wurde und den Staat nichts besonderes gekostet hatte. ${ }^{59}$

A 1 lg e me in kann man feststellen, daß die Vertreter der bedrohten Reichsstände in der Zeit zwischen dem Frieden von Campo Formio und dem von Lunéville zu den Kräften gehören, die den Krieg befürworteten. Ähnliche Abschauungen fanden sioh bei ihnen schon früher, gegen Ende 1797 freilich und in der Folge wurden diese Artikel aggressiver und vorhernschend. Bei der Untersuchung der Argumente der Verfasser lässt sich feststellen, daß sie denen der Österreicher grundsätzlich gleichen. Als bedeutendste Gründe wurden angeführt: Nationalgesinnung, Bewunderung des Kaisers, Berufung auf den Glauben, glänzende militärische Vergangenheit und besonders der heilige Charakter des bestehenden Grundgesetzes im Reich, sogar dessen Brauchbarkeit und Vorzüge, verglichen mit vielen anderen Systemen (»deutsche Freiheit»). In einigen Punkten waren diese »Reichsdeutschen» sogar schroffer als die Österreicher und kritisierten die »Weichheit» des Kaisers in den Verhandlungen und den Frieden von Campo Formio. Die Verurteilung der Sonderfrieden und die selbstsüchtige Isolierungspolitik der anderen weltlichen - besonders »protestantisohen» Fürsten war absolut und natürlich, da die bedrohten kleinen Territorien in der Situation der herrschenden Unordnung berechtigterweise die Ausweitungsgelüste der grösseren fürchteten. Dieser Zug tritt noch deutlicher nach dem Frieden von Lunéville hervor, als man sich dem Friedensschluß nicht mehr widersetzte, aber die Existenz der kleinen Stände noch zu retten versuchte.

\section{Die kriegerischen Friedensverteidiger - kein Frieden ohne Revolution}

Die Erscheinung, daß sich seit der zweiten Hälfte des Jahres 1797 die allgemeine Stimmung in der öffentliohen Diskussion immer weniger dem Frieden zuwandte, wurde auch von einer meuen Einstellung in den am

58 Das neue Licht . . 1798 S. 5-7, 10-16. Tschirch I (1933) S. 350.

59 Ibid. S. 3 
meisten frankreichfreundlich gesinnten Kreisen beeinflußt. Besonders ist dies in den von Frankreich besetzten Gebieten links des Rheins und den daran anschließenden Gebieten zu beobachten. Die großen militärischen Siege Frankreichs und die deutlich erkennbare Schwäche des Deutschen Reiches ließ die eifrigsten Revolutionäre eine Fortsetzung des Krieges fordern, bis das verhaßte morsche Reich vollkommen vernichtet sei. Ein Friedensschluß war für die Bewohner dieser Gebiete kein Problem, weil sie sschnn nach der Besetzung offiziell als gleichberechtigter Teil, als Departement der Republik angegliedert worden waren. Gewöhnlich identifizierten sich die Bewohner dieser Grenzdepartements mit den Franzosen und betrachteten Deutschland als feindliches Land. Auch wandte man sich gewöhnlich gegen einen Friedensschluß mit dem Kaiserreich und betrachtete als Voraussetzung für einen Friedensvertrag die Revolution auch in Deutschland.

In den besetzten Gebieten entwickelte sich eine besondens heftige Diskussion. Überall am Rhein wurden neue Zeitungen und Zeitschriften herausgegeben. Zwischen 1795 und 1801 erschienen u.a. die folgenden revolutionären Blätter: »Brutus» (F. Th. Biergan), »Aachener Zuschauer», »Bonner Intelligenzblatt», »Anzeiger des Ruhrdepartements» (Dorsch), »Der Beobachter von Donnersberg», »Patriotische Beiträge» (Hetzrodt), »Der Beobachter des Ruhrdepartements» (P. Chr. Reinhard), „Der Bewohner des West- Rheins» (F. Lassailx) und »Politische und literarische Iris vom Niederrhein».60 Eine noch größere Bedeutung hatten jedoch zwei hier genauer vorzustellenden Literaten, Joseph Görres und Georg Friedrich Rebmann. - Neben der politischen Tagesliteratur, die auf eigentlich deutschem Gebiet erschien, wurden auch in weiter entfernteren deutschsprachigen Gebieten Literatur zur Unterstützung Frankreichs verfaßt. Das bedeutendste Propagandazentrum war Straßburg, wo zahlreiche, oft mit falschem Druckort versehene, anonyme Schriften gedruckt wurden. Diese stimmten oft den Gedanken der »kriegerischen Friedensverteidiger» des Rheinlandes zu. ${ }^{61}$

In der öffentlichen Diskussion der zweiten Hälfte der neunziger Jahre des 18. Jahrhunderts in Deutschland nimmt Joseph Görres und sein Werk wegen seiner absoluten Zustimmung zur Revolution, seiner extremen Ansichten und seines Stilniveaus eine besondere Stellung ein. Der 1776

60 Julku (1969) S. 258-260. Reisse, Roman, Die weltanschauliche Entwicklung des jungen Joseph Görres (1926) S. 36-37. Benedey (1870) S. 250.

61 z.B. Ueber die Nothwendigkeit einer allgemeinen Secularisation ... 1798; Erläuterungen und Zusäze zu dem politischen ... 1797; Von der Nothwendigkeit eines $\mathrm{zu}$... 1798 . 
in Koblenz geborene Görres war zu der untersuchenden Zeit noch ein sehr junger Mann. Der Ausbruch der Revolution war für den 13jährigen Schüler ein Anlaß die Jesuitenschule zu verlassen und sich den örtlichen Revolutionären anzuschließen. Der begeisterte Jüngling trat als Redner und Schriftsteller seiner Heimatgegend auf und errang beachtlichen Einfluß auf die Bewohner der Gegend. WILMONT HAACKE vergleicht Görres mit dessem Gegner Gentz als geborenen Politiker, der wie der begabteste Dichter schreiben konnte. ${ }^{62}$

1795 veröffentlichte Görres mit 19 Jahren seine erste politische Schrift: »Der allgemeine Frieden, ein Ideal». Darin erörtert er theoretisch die Probleme von Krieg und Frieden. Die Untersuchung des Jünglings vom Rhein erschien also im gleichen Jahr wie die des greisen Königsbergers, »Zum ewigen Frieden». Ein Vengleich dieser beiden Schriften ist interessant. Görres war mit den Ideen Kants vertraut und hatte auch Einflüsse von Abbé St. Pierre aufgenommen.63 Ebenso wie Kant schätzte auch Görres seine Einflußmöglichkeiten gering ein, aber er versicherte auch gleichzeitig, daß es die Pflicht eines Weltbürgers sei, Regierungen $\mathrm{zu}$ unterstützen, die nach Aufklärung strebten. ${ }^{64}$ Nach Görres Meinung war die französische Regierung eine solche Regierung, und dieser widmete er seine Untersuchung. Der Zeitpunkt für das Zustandekommen eines Friedens war seiner Meinung nach gut. Die Völker könnten miteinander nur über einen Frieden diskutieren, wenn sie nicht vorher eine angemessene Zeit den Kriegszustand erlebt hätten. Der jetzige Krieg habe gute Bedingungen für das Zustandekommen eines Friedens geschaffen. Aber andererseits gäbe es Kräfte, die die Welt mit einem totalen Krieg bedrohen würden. So würden der französische Emigrant Barrere und der englische Vertreter der Torys im Parlament, Fitzwilliam, den Gedanken des Ausrottungskrieges predigen. Dies würde nach Meinung von Görres zu »Menschenfresserkriegen» führen, was das schlimmste von allem sei, einmal wegen seiner Grausamkeit, zum anderen weil danach ein Friedensschluß äußerst schwierig sei. ${ }^{65}$ Der Zweck eines jeden Friedens sei die Vermehrung des Glücks der Völker. Nur ein beständiger Frieden könne dieses Ziel erreichen. Ein Friedensschluß, der schon in sich selbst einen neuen Krieg enthalte,

62 Haacke, Wilmont, Handbuch des Feuilletons I, Emstetten (Westf.) 1951, S. 190-191. Vgl. Dempf, Alois, Görres spricht zu unserer Zeit, Freiburg im Br. 1933, S. 5. ADB Bd. 9. (Friedrich) S. 378-389.

03 Reisse (1926) S. 35; Dempf (1933) S. 6.

64 Görres, Joseph, Gesammelte Schriften (G. S.) I, Köln 1928, S. 19-23. Reisse (1926) S. 35.

65 Görres, G.S. I S. 25. 
füge der Menschheit mehr Leid zu als ein Krieg.66 Das Streben der Menschheit nach einem ewigen Frieden sei sein ewiges Ideal. Es sei ein Gehorchen der Stimme der Natur. Einen jeden Friedensvertrag müsse man daraufhin untersuchen, ob er für seine Beständigkeit Voraussetzungen enthalte. Man könne nicht mehr wie früher Friedensschlüsse fassen, als noch »Schranzen und Maitressen» Frieden schlossen, als der Genius der Menschheit in Tränen ausbrach, weil er zusehen mußte, daß die Mordlust nicht erloschen sondern nur verdeckt sei, bis sie sich wieder entzünden könne. Jetzt dagegen seien die Voraussetzungen gegeben, die Friedensverhandlungen mit gesundem Verstand $\mathrm{zu}$ beginnen. Seine eigene Schrift bezeichnete Görres als einen Versuch, den philanthropischen Absichten der Natur zu entsprechen. ${ }^{6 \tau}$ Im Vorwort wird der Aufklärungsgeist am deutlichsten, dessen Einfluß in der Mittelklasse des Rheinlandes traditionell groß war, ${ }^{68}$ und es zeigt sich, daß Görres Weltanschauung die gleiche Grundlage hat wie bei Rousseau, Kant oder Herder. Auch nach der Auffassung von Görres war es das Ziel der Menschheitsgeschichte, die Humanität zu fördern und einen allgemeinen Frieden als Voraussetzung dafür zu erreichen. ${ }^{68}$

Wie Kant ging Görres bei der Abwägung der Voraussetzungen für einen allgemeinen Frieden von einem Vergleich der Staatsformen aus. Seiner Meinung nach seien die Staaten ihrem Wesen nach organische Wesen, die die Gesetze der Naturgeschichte beeinflußt hätten. Er trug ein Theorie von der Entwicklung der Staatsformen von der Monarchie bis zur Polyarchie über die Helarchie (die Macht aller) vor, Termini, die er für die Demokratie gebrauchte. Nur die allgemein akzeptierte Staatsform der Helarchie mache »die völlige Realisierung eines ewigen Friedens möglich» ${ }^{69}$ Die Universaldemokratie sei also die Lösung des Problems. Wenn die Staaten und die Völker miteinander verschmelzen und ihre despotische (d.i. monarchistische) Staatsform bewahren würden, so hätte das Ende der persönlichen Freiheit und der Persönlichkeit zur Folge. Wäre aber diese Form demokratisch, würde der allgemeine Wille verwirklicht. Weil jedoch nach der Ansicht von Görres die momentane Situation die Umsetzung dieser Albstraktionen in die Wirklichkeit nicht zulasse, müsse man das Problem durch Teillösungen behandeln. Nach Görres sei ein Krieg immer zu verurteilen. Besonders dann, wenn die S. 11 .

66 Berger, Martin, Görres als politischer Publizist, Bonn und Leipzig 1921,

67 Görres, G. S. I S. 24-26.

68 Saitschik, Robert, Joseph Görres und die abendländische Kultur, Olten \& Freburg im Br. 1953, S. 10.

69 Kemiläinen (1956) S. 57. 
zivilisierten Völker Europas untereinander Krieg führen würden, weil man diese zur gleichen Völkerfamilie rechnen müsse. ${ }^{70}$ Das von Frankreich entwickelte Programm von den natürlichen Grenzen erschwerte die Friedensfrage und Görres widmete ihm viel Aufmerksamkeit. Er akzeptierte die Alpen und den Rhein als Grenzen Frankreichs. Seinen Standpunkt begründete er ausführlich und theoretisch. Schon der Ausgangspunkt ist zustimmend, denn seiner Meinung nach sei »dem Gange der Menschheit und dem Zwecke ider Natur gemäss», daß der Staat sich auf seine natürlichen Grenzen ausdehne. Es gäbe zwei Arten von natürlichen Grenzen, trockene und nasse: Gebirge und Wüsten, Meere und Flüsse. Grundsätzlich seien beide Arten gleichwertig. Görres gestand Frankreich den Rhein als Grenze zu und begründete den Vorteil einer solchen Grenze ausführlich und teilweise auf sehr eigenwillige Weise. Man habe zuviel nur von den materiellen Vorteilen gesprochen, die der Anschluß des linken Rheinufers an Frankreich diesem Lande bringen würde. Das wichtigste habe man jedoch vergessen. Das sei der Geist des Volkes, der unter dem Einfluß der Kant'schen Philosophie im Rheinland herrsche. Frankreich habe eine lange Zeit der Anarchie erlebt, die nicht ohne Einfluß auf die Moral des Volkes sein konnte. In Deutschland dagegen herrsche die hohe kantische Moral. So gesehen sei die Mischung der französischen und deutschen Volkselemente eine glückliche Entscheidung:

»Dann wind das französische Flogiston mit dem deutschen Oxyde cementirt, einen philosophischen König bilden, wie ihn die Welt nie sah; und dem gleich dem Steine der Weisen, die Existenz der Nation, die ihn besitzet, auf Ewigkeiten verlängert.»

Wenn eine Neuorganisation der Grenzen durchgeführt sei, müsse man einen Bund der "paciscirenden Freystaaten» und »die Regierung der Völkerrepublik» als Gerichtshof bilden, der mögliche Klagen zu behandeln habe. So wäre ein allgemeiner Friedenszustand zwischen den demokratischen Staaten zu erreichen.

Die Gegner seines Programmes griff Görres mit scharfen Worten an. Österreich mit seinen arroganten Teilungsplänen werde noch in Asche fallen und das ganze »Wort 'Integrität' wird im Lexikon der Reichssprache eine neue einschrenkende Clausel erhalten», Rußland müsse seine lächerlichen Drohungen zurüaknehmen und sohließlich müsse Pitt, der unversöhnlichste der Gegner, noch seinen steifen Nacken vor den

70 Ibid. S. 57-58. Görres, G. S. I S. 30-34.

71 Görres, G. S. I S. 42-44. Kemiläinen (1956) S. 271. 
freien Völkern beugen. Frankreich könnte einen allgemeinen Frieden durch eine vernünftige Politik herbeiführen, wenn es je nach der Situation mal diplomatisch zögernd mal hartnäckig auf seinen Forderungen bestehend vorgehen würde. Frankreich dürfe nicht nur an die Leiden, die die nächste Generation durch Krieg zu erleiden habe, sondern müsse auch an die Leiden, die die jetzige Generation zu erleiden habe, denken. Diese Generation fordere den Rhein als Grenze Deutschlands und das linke Flußufer als »eirne besondere unabhängige Republik». Sollte dieser Plan verwirklicht werden, so hätte Frankreich alle genannten großpolitischen Ziele erreicht, sollte dies nicht geschehen, so thabe Frankreich über zu geringe Kräfte verfügt. ${ }^{72}$

»Der allgemeine Frieden» wurde von Görres mit 19 Jahren verfaßt, ein Umstand, der sich auch im Text widerspiegelt. Während sich Kant konsequent auf der theoretischen Ebene bewegt und nur auf die konkrete politische Situation verweist, vermischt Görres ohne zu zögern beide Ebenen. Stellenweise ist er auch inkonsequent. So geht Görres einmal davon aus, daß der Rhein die Grenze zwischen den Staaten sein müsse, dann fordert er wiederum eine unabhängige Zwischenrepublik. Am meisten befürchtete Görres offensichtlich eine Situation, die die alten Grenzen und die alte Ordnung wieder herbeiführen würde. Görres, der in einem geistlichen Fürstentum aufgewaohsen war, vertrat eine stark antiklerikale Position. ${ }^{33}$ Schon in seiner ersten Schrift griff er heftig die Kirche und den Papst an. ${ }^{74}$ Görres' Schrift ist ein interessantes Beispiel für diese Einstellung, die allgemein die radikalen Kreise in Deutschland nach 1790 beherrschte. Auch das Denken von Görres wird von zwei widersprüchlichen Elementen bestimmt: einerseits republikanischer Kosmopolitismus und andererseits ein Nationalismus, der noch durch eine ungewöhnlich starke Bindung an die Heimat verstärkt wurde. ${ }^{75}$ In der Forschung ist die Bedeutung dieser beiden Elemente in der ersten Schrift des jungen Görres verschieden beurteilt worden, aber nach den obigen Ausführungen kann man sagen, daß der Kosmopolitismus zumindest als »europäischer Kosmopolitismus» das Übergewicht hatte. ${ }^{76}$

72 Görres, G. S. I S. 61-63, Kemiläinen (1956) S. 58-59.

73 Daran sind die Forscher nicht einig. Die katholische Forschung vermindert die Anti-Christlichkeit ihres populären Philosophes, z.B. Schubert, Eduard, Der Ideengehalt von Görres' Schriften, Köln 1922, S. 48. Vgl. Reisse (1923).

74 Görres, G. S. I S. $48-51$.

75 z.B. Saitschick (1953) S. 54-56.

76 Kemiläinen (1956) S. 271. Berger (1926) sucht übertreibend Franzosenfeindlichkeit. Dasselbe Tendenz hat auch Dempf (1933, S. 6). 
Nachdem Görres seine Schrift »Der allgemeine Frieden» veröffentlicht hatte, unternahm er einen größeren Versuch, den MARTIN BERGER als gewagtes Unternehmen charakterisierte, wenn man sein Alter und die unbeständigen Verhältnisse berücksichtige. Er begann nämlich damit, eine jede zehnten Tag erscheinende Zeitung (»Dekadenschrift») herauszugeben. ${ }^{77}$ Er gab seiner Zeitung den Namen Das rothe Blatt», um damit ihr revolutionäres Programm zu verdeutlichen. Das wichtigste Ziel für »Das rothe Blabt» sei, die am linken Rheinufer herrschenden französisohen Behörden zu kritisieren. ${ }^{78}$ Es stimmt, daß Görres auch diese Art von Kritik übte, aber der Sohwerpunkt der Zeitung und der ihr folgenden Schrift lag jedoch unbestreitbar darauf, die Revolution in die deutsohe Öffentliohkeit zu tragen.

Den größten Teil der Zeitung »Das rothe Blatt» machten Görres' politische Reden an die Landsleute in Koblenz und Mainz aus, die er in "patriotischen Vereinigungen» gehalten hatte. An diesen Reden ist deutlich zu beobachten, daß Görres während des Jahres den Standpunkt eines kantischen Friedensfreundes in eine immer kriegerische Richtung verläßt. Immer häufiger betonte er, daß eine siegreiche Beendigung des Krieges die Voraussetzung für einen bleibenden Frieden sei. Es setzte sich für Frankreich ein und hoffte, daß die französischen Waffen siegen würden. In seiner Rede vom 12. Rivose-Monat begrüßte er triumphierend die Rückkehr von Mainz in französische Hände: »Maynz ist unser!». Diese Rede zeigt deutlich Görres' Sympathien. Da die österreichischen Despoten nun in die Flucht geschlagen worden seien, könnten die Mainzer als freie Menschen atmen. Besonders ermahnte er die Franzosen, in den gerade begonmenen Friedensverhandlungen von Rastatt die Stadt nioht einmal für den Preis eines beständigen Friedens wieder aufzugeben. Scharf griff Görres den Grundsatz von der Unverletzbarkeit des Reiches als Ausgangspunkt für die Friedensverhandlungen an:

»Integrität schrieen seit einigen Jahren die Reichsfürsten aus vollem Halse, In'tegrität belferten ihre Repräsentanten auf dem Reichstage $\mathrm{zu}$ Regensburg, Integrität quikte der ganze Trotz von Aristokraten, und Speichelleckern, Interität hallite es wieder aus den Kabinetten der Erdengötter, Integrität erscholl es von Undine. Und doch fällt jetzt eine ihrer festesten Stützen». ${ }^{79}$

Der zwkünftige katholische Volksphilosoph parodierte weiterhin Kaiser und Reich mit einem Zitat aus dem Buoh der Offenbarung, sagte den

77 Berger (1921) S. 12.

78 Görres, G. S. I S. $82-89$.

79 Ibid. S. 99. Hüffer (1878) S. 58. 
Untergang des Reiches voraus und verspottete die Priester. Die Rede endete mit einem Hochruf auf die Frankenrepublik. ${ }^{80}$ In der folgenden Schrift bezog Görres Stellung für den Staatsstreich vom Fructidor. Im Gegensatz zu den frankreichfreundlichen Kreisen in Deutschland hieß er ihn gut. Am 18. Fructidor sei die Republik gerettet worden, an diesem Tag seien die Gegenrevolutionäre, die Adligen, die Priester und der verräterische Pichegru gestürzt worden. Genauso bezog Görres eindeutig Stellung für die »Befreiung» der Schweiz aus der Gewalt des Adels. ${ }^{81}$

Am bekanntesten von Görres' Artikeln aus der Zeitung »Das rothe Blatt» ist ohne Zweifel seine Rede vom 18. Rivose-Monat 1798, in der er u.a. einen Nachruf und Testament auf den 'Tod' des Heiligen Römischen Reiches Deutscher Nation vortrug. Er berichtete, das Reich sei am 30. Dezember 1797 nach der Eroberung von Mainz durch die französischen Truppen im Alter von 955 Jahren 5 Monaten und 28 Tagen, »sanft und seelig an einer gänzlichen Entkräftung und hinaufgekommenen Schlagflusse, bey völligem Bewußtsein, und mit allen heiligen Sakramenten versehen ...» verschlafen. Das Testament wurde in feierlicher Form unter Berufung auf die Heilige Dreieinigkeit und die Jungfrau Maria mit allen Heiligen, besonders der Heiligen Ursula und ihrer 1100 Jungfrauen veröffentlicht. Das Testament enthält 16 Punkte, von denen ein Teil realistische Friedensvonschläge und der andere geschmacklosen Spott ausmacht. Der erste Artikel verpflichtete zur Übergabe des linken Rheinufers an die Republik und bat die verehrenswerte Republik, dieses kleine Geschenk als ein Zeichen der Verehrung und der Liebe entgegenzunehmen. Der zweite Artikel behandelte Grenzverschiebungen im Inneren des Reiches. Österreich wurde ein Teil Bayerns und die geistlichen Territorien von Passau und Salzburg überlassen. Preußen sollte Hannover und die Hansestädte erhalten. Von den übrigen Teilen des Reiches hielt Görres nicht viel:

»Und das Uebrige unseres Gebietes soll zu einem Mignaturgemählde unserer ganzen Person und Physiognomie, in den Tempel der Unsterblichkeit, verwandt werden, nachdem vorher die zehn Reichskreisen durch geschickte Hände eine moderne Façon erhalten haben.»

Dann wurden spöttischen Bestimmungen zur Verteilung der Reichinsignien erlassen. Die Bischöfe und Kurfürsten sollten verschiedene Gegenstände erhalten und auch einige ausländische Staaten sollten etwas bekommen. Der russischen Armee wurden die Sandalen vermacht und

80 Görres, G. S. I S. 89.

81 Vgl. Berger (1921) S. 11-12. 
der Minister Pitt sollte als Zeichen für die Weltherrschaft den Reichsapfel erben. Der Papst müsse sich mit der Reichsoperationskasse zufrieden geben - bekannt für ihre Bedeutungslosigkeit - sowie seiner eigenen Goldenen Bulle. Die Hoheitsrechte des Kaisers sollten an die Reichsbauern verteilt werden. Die in Rastatt versammelte Reichsdeputation solle ständig zusammentreten und sie müsse sich der Aufgabe widmen, einen Vertrag für einen ständigen Frieden zustande zu bringen. Für jeden Artikel dieses Vertrages müßten mindestens 50000 Sitzungen einberufen werden. Die Reichsarmee vermachte man dem Landgrafen von Hessen Kassel, damit sie dieser bei der nächsten Gelegenheit an England verkaufen könne, das sie dann nach Amerika oder Indien bringen werde. ${ }^{82}$ Der 16. Punkt bestimmte dann schließlich, daß alle Nonnen den Mönchen übergeben werden müßten und der Sterbende drückte seine Hoffnung aus, daß beide Teile zufrieden sein würden. Schließlich verteilte der Verstorbene seine Köpperteile. Österreich solle das Gehinn, wenn man es finden könne, erhalten, Pitt seinerseits das Herz. Als Testamentvollstrecker wurde »seine Exellenz, Herr General Buonaparte» bestimmt, den man sehr höflich aufforderte, diese Aufgabe zu übernehmen.83 In dem dem Testament folgenden Teil der Rede wunde die Revolution und die völlige Vernichtung des alten Reiches vorhergesagt, was innerhalb von zehn Jahren geschehen werde. Die Ordenssterne und Ordensbänder der Adels würden vernichtet, der Landbesitz der Kirche würde an die Laien verteilt, den Mönchen würde die Kutte und den Nonnen der Schleier weggenommen. Räte und Direktorien würden an die Stelle der gesalbten Häupter treten. ${ }^{84}$

In der Forschung ist Görres' Testament ausführlich behandelt worden, und besondere Beachtung fand der Anteil Napoleons an der Ausführung des Testamentes. Wieland hatte den gleichen Gedanken zu Beginn des Jahres 1798 vorgetragen und Schiller hatte schon früher Napoleons Aufstieg zu Weltansehen vorhergesagt. ${ }^{85}$ Görres hat wahrscheinlich diese Schriften gekannt und ist durch sie beeinflußt worden. Es ist jedenfalls interessant festzustellen, daß der später zu Napoleons eifrigsten Gegnern gehörende Freiheitskämpfer von ihm forderte, daß er in dem zerfallenden Deutschen Reich die notwendigen Reformen durchführen solle. Görres sprach von Frieden, sogar von einem ewigen, erklärte aber den Sieg der Revolution und der republikanischen Staatsform in Deubschland als seine Voraussetzung. Görres' einen Frrieden fordernde Schriften feuerten also zum Krieg an, der das gealterte Reich zerstören isollte.

82 Görres, G. S. I S. $97-99$.

83 Ibid. S. $99-102$.

84 Ibid. S. 99.

85 Siehe S. $217-218$. 
»Das rothe Blatt» setzte auch noch später diese Linie fort. Ein Gedicht von »W.M.», »An die Deutschen», verspottete den Deutschen, der sein Blut vergebens vergießen würde, um sich einem übermächtigen Feind entgegenzustellen und um die Tyrannen und den Schmuck ihrer Maitressen zu verteidigen. ${ }^{86}$ Görres selbst begrüßte die »Befreiung» Roms und besonders die Besetzung des Vatikans. Rom sei »die Metropole des Reiches der Dummheit». England beschuldigte er der Beraubung der Kolonien. Alle despotischen Staaten würden ihrer Verniohtung entgegen gehen. Der ewige Krieg, der zwischen ihnen und in ihnen wüte und die ganze hinter der Religion verborgene Schurkerei würden jetzt ihre Belohnung erhalten. Eine große Universaldemokratie sei im Entstehen, die der Welt einen ewigen Frieden garantieren würde. ${ }^{87}$ Die Zeitung war sehr angriffslustig. Ein Unternehmen, »Barras \& Co», warb in der Zeitung für Freiheitsbäume, die bei allen Generälen der Republik in deren Gebieten bestellt werden könnten: bei Joubert in Holland und Norddeutschland, bei Hatry in Süddeutschland, bei Buonaparte in England, Irland und Schottland Görres erwartete offensichtlich eine Besetzung der Britischen Inseln durch Napoleon - usw. Gleichzeitig bot der Landgraf von Hessen-Kassel Wilhelm IX. eine Auswahl von 12000 Köpfen einer Menschenherde an, die auch tonnenweise à 40 Pfund verkauft werden könne. Bezeichnend ist auch, daß auch unter den Verkäufern die französischen Gesandten beim Rastatter Kongreß auftreten, die Kurfürstenmäntel, Bischofsmützen, Orden von Herzögen und Äbten, Reichsstädte und Adelstitel anboten. ${ }^{88}$ Görres war ein Kompromisse hassender extremer Charakter, 89 der Verhandlungen zwischen der Republik und den deutschen Fürsten nicht akzeptieren konnte. Der Frieden, an den er dachte, konnte nur nach einem völligen Sieg geschlossen werden. Offensichtlich um bei den Franzosen Haßgefühle zu erweoken, veröffentlichte er zu Beginn des Krieges eine Karte, die die Absichten der Koalitionsstaaten aufdecken sollte, nach dem Geheimabkommen von Pillnitz Frankreich aufzuteilen. Görres forderte den Abschluß eines Reichsfriedens unter den französischen - und den eigenen - Bedingungen. Diese seien die Säkularisation, Anerkennung des Rheins als Grenze, Anerkennung der Republik Holland, Rückzug der Österreicher aus Italien, Aufhebung des Kirchenstaates und Anerkennung der Grenzverschiebungen in der Schweiz. Die in Rastatt ausführlich behandelte Frage von Reparationen beantwortete Görres mit einem eigenen Reformprogramm, nach dem u.a. der Kaiser die ehelichen

86 Görres, G. S. I S. 104.

87 Ibid. S. $102-108$.

88 Ibid. S. $111-113$.

89 Saitschick (1953) S. 51. 
und unehelichen Kinder des Saturns und dessen Ringe, die anderen europäischen Fürsten und Herrscher die übrigen Planeten erhalten sollten. Nur der König von Preußen sollte das Recht erhalten, Jupiter für sich selbst a $u f z u$ teilen. Auf einer Insel in der Südsee solle ein neuer Vatikan errichtet werden. ${ }^{90}$

Zu Beginn des Jahres 1799 geriet »Das rothe Blatt» in Schwierigkeiten u.a. wegen der Zensur der französischen Behörden und stellte sein Erscheinen ein. ${ }^{91}$ Der junge Revolutionär gab sich jedoch nicht geschlagen, sondern begann ein ähnliches Blatt, das später als Monatsschrift herauskam, den »Rübezahl», herauszugeben. Im Juli 1799 setzte »Rübezahl» den von der Zeitung »Das rothe Blatt» begonnenen Kampf fort. Auch im »Rübezahl» ist Görres' Moralismus deutlich zu erkennen. Indem er die Verwirklichung eines allgemeinene Friedens forderte, wandte er sich auch gegen seine Landsleute, »gegen die Aristakraten, Zeloten und Obskurantenbande», von denen or glaubte, daß sie einem Friedensschluß im Wege seien. Auch wandte er sich gegen französische Beamte im Rheinland, deren moralische Verkommenheit ihn reizte. In einigen Artikeln des »Rübezahl» ist schon ein gewisses Abrücken von der Revolution zu erkennen, aber erst während des Jahres 1800 nimmt Görres eine deutlich antirevolutionäre Haltung ein. ${ }^{92}$ Der »Rübezahl» stellte im Juli 1799 sein Erscheinen ein. Damit endete die journalistische Tätigkeit des jungen Görres und gleichzeitig ein Zeitabschnitt, in dem er sich für eine militärische Lösung der Friedensfrage eingesetzt hatte. Die 1800 erschienene bedeutende Flugschrift »Resultate meiner Sendung nach Paris im Brumaire des achten Jahres» läßt schon einen vollkommenen Gesinnungswandel erkennen; Görres hatte sein Lieblingsthema, daß durch einen Krieg ein allgemeiner oder ewiger Frieden $\mathrm{zu}$ erreichen sei, völlig aufgegeben. ${ }^{93}$

Neben Görres ist ohne Zweifel Andreas Georg Friedrich von Rebmann der bedeutendste Vertreter der »Jakobinerliteratur» in Deutschland und der bekannteste »kriegerische Friedensverteidiger» des westlichen Deutschland. Der in Franken 1768 geborene Rebmann ist auch zu der zu untersuchenden Zeit ein verhältnismäßig junger Mann. Er hatte eine juristische Ausbildung durchlaufen und eine normale Karriere als Regierungsbeamter in Erlangen gebonnen, als die erregenden Ereignisse der Revolution auch ihn veranlaßten, Berufsschriftsteller zu werden. Von

90 Görres, G. S. I S. 115-123.

91 Brandt (1939) S. 19 und 22.

92 Görres, G. S. I S. $126-128$.

93 Görres, Resultate meiner Sendung nach Paris ... 1800. Kemiläinen (1956) S. 61 . 
Anfang an stimmte er der Französischen Revolution zu, und seine immer deutlicher werdende revolutionäre Einstellung führte $\mathrm{zu}$ seiner Flucht aus seiner Heimat. Um weiter veröffentlichen $\mathrm{zu}$ können, ging er nach Altona (1795), wo ihn die liberale Zensur Dänemarks schützte. Im folgenden Jahr reiste er über Holland nach Paris, von wo aus er fortgesetzt seine revolutionären Schriften in Deutschland verbreitete. Rebmann konnte zahlreiche Zeitschriften herausgeben, deren bedeutendste wohl die an verschiedenen Ürten gedruckte Zeitsohrift $\gg D a s$ neue graue Ungeheuer» (1795-1800) ist, weitere sind »Die Schildwache» (1796), »die Geissel» (10 Nummern 1797-98), »die Laterne» (3 Nummern 1798-99) und »Obskuranten-Almanach» (1798-1800). Daneben verfaßte Rebmann ungezählte selbständige Schriften. 1798-99 stand er in französischen Diensten im Rheinland. ${ }^{94}$

»Das neue graue Ungeheuer» erschien mit kleinen Titeländerungen in den Jahren 1795-1800 in zúsammen 14 umfangreichen Heften (jedes mit 200-300 Seiten) vorwiegend in Hamburg, obwohl auch als Druckort manchmal Paris, Köln oder Upsala angegeben wurde.95 Den größen Teil der Texte in seinen Publikationen verfaßte Rebmann selbst, erhielt aber zum Teil Unterstützung durch Mitarbeiter. Der schon verstorbene Wekherlin war Rebmanns große Bewunderung und Vorbild, - so gebrauchte er u.a. das gleiche Pseudonym „Anselmus Rabiosus» ${ }^{96}$ - und mit einem Gedenkartikel zur Lebensarbeit dieses radikalen Publizisten begann Rebmann die erste Nummer des »Ungeheuers» vom Jahre 1795. Rebmann bekannte, daß er die Arbeit Wekherlins fortsetzen werde und veröffentlichte das Programm seiner Publikation.97 In ihrer revolutionären Einstellung war die Zeitschrift konsequent. Man war gegen den gerade herrschenden Kriegszustand und versicherte, daß das Deutsche Reich diesen Krieg nur sehr widerstrebend führen würde. In diesem Krieg könne Deutschland zwar vernichtet werden, zu gewinnen gäbe es aber nichts. Andererseits druckte man fortgesetzt republikanische Kriegslieder, weshalb sich in Rebmanns Publikationen keine Art von aufklärerischem Pazifismus finden läßt.98 Die Emigranten und Priester bezeichnete man als die Schlimmsten von allen.99 Obgleich Rebmann davon sprach, daß

94 BLDG (H. Voegt) S. 387-388, ADB Bd. 27. (Franz Brümmer) S. 283-285. Voegt charakteriziert Rebmann als »bürgerlich-radikaler Publizist». Siehe auch v. Wrasky (1907) S. 7-9, 33.

95 Weller I (1864) S. 162.

96 Voegt (1955) S. 28:, v. Wrasky (1907) S. 33.

97 N.gr.Ung. I (1795) S. 9. Vgl. Scheel (1962) S. 140-142.

98 N.gr.Ung. II (1796) S. 46, 52, 58 und III (1797) S. 128 usw.

99 z.B. ibid. V (1797) S. 12-41 und VIII (1797) S. 103-120. 
er das Ende des Krieges herbeisehne, jubelte er über jeden französischen Sieg. Rebmann veröffentlichte gerne französische Gedichte und Artikel. Ein gutes Beispiel ist ein Gedicht von Auguste »L» über den französischen Sieg in Italien:

»Dann singen wir: Victoria! / Die Pfaffenburg ist leer! / Und wo man sonst nur Mönche sah, / Da herrscht der Franken Heer.»100

1797 tauchten in der Zeitschrift Artikel auf, die eine völlige Niederlage Österreichs forderten, nach der die Kriegsstimmung endgültig von der Forderung nach Frieden abgelöst werden würde. Kriegerische Freiheitslieder forderten die völlige Vernichtung des alten Reiches, der Tyrannen, der Priester und Obskurantisten und warnten neben Österreich auch England und Rußland. ${ }^{101}$ Auch die anderen Veröffentlichungen Rebmanns lassen deutlich seinen Anschluß an die Gruppe der »kriegerischen Friedensverteidiger» während des Jahres 1797 erkennen.

Zwischen 1797 und 1798 veröffentlichte Rebman in Paris eine in drei Nummern erschienene Zeitschrift oder eigentlich eine Flugschriftenreihe, »Laterne bey Tag für die mittlere Volksklasse», die eine ganz deutlich revolutionäre Einstellung vertritt und oft vom Krieg spricht. Die Zeitschrift wollte an erster Stelle die Mittelschicht, die Gebildeten und das Bürgertum in Deutschland beeinflussen, so daß diese durch eine Revolution in ihrem eigenen Land eine Beendigung des Krieges herbeiführen würden. Die »Laterne» ist als ganzes ein typisches Beispiel für die Taktik der »kriegerischen Friedensverteidiger». Man sprach in einem Atemzuge vom Weltfrieden und den Segnungen eines allgemeinen Friedens und seiner Notwenigkeit und wandte sich gleichzeitig gegen Sonderfriedensschlüsse zwischen Frankreich und den deutschen Fürsten. In der ersten Nummer betont Rebmann anonym, daß er Deutscher sei, und bedauerte, daß er aus Deutschland fliehen mußte, weil ihn seine Freiheitsliebe gezwungen habe, sich gegen die Despoten zu erheben. Frankreich sei ein Land der Freiheit, gegen das die Tyrannen unter der Führung Österreichs einen Kreuzzug begonnen hätten. Neben Österreich wurden auch andere deutsche Fürsten aufs heftigste beschimpft. Die geistlichen Fürsten seien Priester, die den Altar schänden und Witwen und Waisen berauben würden. Der Mainzer Kurfürst beraube seine ärmsten Untertanen, um dann die Emigranten zu unterstützen. Auch an den Soldatenhandel des Landgrafen von Hessen-Kassel wurde erinnert. Trotz des geschlossenen Sonderfriedens wurde Preußen heftig kritisiert.

100 Ibid. VIII (1797) S. $29-30$.

101 Ibid. z.B. XII (1798) S. $9-10,18-20$, usw. 
Es trage die Hauptschuld an der verbrecherisohen Teilung Polens. "Laterne» hob besonders die sog. schicksalshafte Bindung des 'dritten Deutschland' hervor und, daß dessen Interessen im völligen Gegensatz zu denen der Großmächte Preußen und Österreich stehen würden. Nach der Meinung Rebmanns müsse das 'dritte Deutschland' mit Frankreich einen Frieden schließen und ein bewaffnetes Neutralitätsbündnis gegen die Habsburger und Hohenzollern eingehen. Die geschlossenen Sonderfrieden wurden zwar gutgeheilsen, aber das bewaffnete Neutralitülsbündnis Norddeutschlands lehnte man ab, weil es ganz Norddeutschland von Preußens Gnaden abhängig mache. Ein Frieden sei immer unumgänglicher, weil Frankreich militärisch vollkommen überlegen sei. Bonaparte brauche die mit dem Geld Pitts gekauften deutsohen Rekruten nicht zu fürchten, die wie Pferde behandelt würden. Obgleich Rebmann auch versicherte, daß er weder ein Jakobiner nooh ein Revolutionär sei, schloß die Nummer doch mit einem äußerst kriegslustigen Gedicht:

»Wer nicht für Freyheit sterben kann, / Der ist der Kette werth, / Ihn peitsche Pfaff und Edelmann / um seinen eignen Heerd.»102

Die zweite Nummer enthält in gleicher Weise das 'dritte Deutschland' bedauernde und Preußen und Österreich angreifende Äußerungen. Rebmann forderte die kleineren Staaten des Reiches auf, in Frankfurt ohne Preußen und Österreich zu einem Kongreß zusammenzukommen, auf dem man auf die Integrität (!) des Reiches bedacht sein müsse. Das Gedicht »Letzte Hoffnung an die Pohlen» forderte die Polen auf, sich gegen die Unterdrücker zu erheben. ${ }^{103}$ Die zu Beginn des Jahres 1798 erschienene dritte Nummer der »Laterne» ist interessant. Rebmann verurteilt nämlich offen den Frieden von Campo Flormio, weil er eine Teilung Deutschlands zulassen würde. Jetzt würden Frankreich, Österreich und Preußen die Trümmer Germaniens unter sich aufteilen. Trotzdem setzte Rebmann seine Hoffnungen auf einen völligen Sieg der französischen Waffen:

»Darum, braver Buonaparte! nach England. Vollende den großen Entwurf, bey dessen Ausführung du jetzt auf halbem Wege stehen bleiben mußtest. Möge die Armee gegen England so viele

102 Laterne ... I (1797) S. 3-6, 8-9, 13-14, 21-25 und 29 (Zitat). Dasselbe Gedicht wurde schon in Büchlein Rebmanns »Holland und Frankreich» (1796 I S. 166) gedruckt, und es erschien auch anderswo in der revolutionären Publizistik. Vgl. Voegt (1955) S. 26.

103 Laterne II (1797) S. 12-13, 17-18, 28-29. Tschirch I (1933) S. 213 betont die Preußenfeindlichkeit Rebmanns. 
Wunder thun, als die Italienische. Die Freyheit, läßt sich nicht aufhalten, zwischen Wahrheit und Lüge kann kein Waffenstillstand, kein Friede stattfinden. Wir schreiten vorwärts!»104

Es sei zu bedauern, daß der Krieg nicht fortgeführt worden sei und Augereau als deutsoher Buonaparte die Transrhedanische Republik nicht gegründet habe. In der gleichen Nummer nahm Rebmann auch für den Staatsstreich vom Fructidor Stellung. Er stimmte ihm ganz zu. Barthélemy habe versagt, als er u.a. die Intrigen der Oligarchen in der Schweiz zugelassen habe, Carnot sei »nichtswürdig», und ihr Sturz sei so angebracht und zum Wohle der Republik geschehen. Zum Schluß werden die Völker, vor allem die süddeutschen, aufgefordert, das Joch abzuwerfen, den sinnlosen Kampf gegen ihre Befreier für ihre eigenen Unterdrücker und die Fortsetzung ihrer Sklaverei zu beenden.105 Den gleichen Kampf führte Rebmann in seinem »Obskuranten-Almanach», der 17981800 besonders gegen die antirevolutionären Artikel des »RevolutionsAlmanach» gerichtet war. ${ }^{\mathbf{1 0 6}}$

Neben über einen längeren Zeitraum hin erschienenen Publikationen entstammte der unermüdlichen Feder Rebmanns noch ein große Anzahl einzelner Flugschriften, die die gleichen Themen behandelten. 1796 veröffentlichte er in Hamburg ein Büchlein, »Die Wächter der Burg Zion», dessen Ziel es war, die Behauptung der Obskuranten zu widerlegen, daß die republikanische Bewegung in Deutschland ein Geheimbund der Illuminaten sei. ${ }^{107}$ Die 1797 veröffentlichte und in Paris gedruckte Schrift »Die fünf Männer» befaßt sich mit dem französischen Direktorium und vertritt einen konsequenten linken Standpunkt.108 Das im gleichen Jahr erschienene »Satyrisches Hand-Wörterbuch» verspottete das Reich, die Priester, die Junker und die katholische Christenheit.109 1796 erschien ein zweiteiliges Reisetagebuch, »Holland und Frankreich», das bedenkenlos die neue Ordnung Frankreichs und der Republik Batavia bewunderte und ebenso bedenkenlos die alte Ordnung Deutschlands verwarf. Die kriegerische revolutionäre Einstellung wird

104 Laterne III (1798) S. 8.

105 Ibid. S. 3, 9, 15-16. Dieselbe Einstellung zu den Ereignissen des Fructidors hatte er schon im Büchlein "Geschichte der Revolution von 18. Fructidor» im vorigen Jahre. Wrasky (1907) S. 91-92.

106 Voegt (1955) S. 14.

107 v.Wrasky (1907) S. 71.

108 Rebmann, Georg Friedrich,. Die fünf Männer. Im Vten Jahre [1797] z.B. S. 166.

109 Rebmann, Satyrisches Hand-Wörterbuch ... 1797 z.B. I S. $4-6$ und II S. $24-15$. 
deutlich, wenn eine Zusammenarbeit zwischen Frankreich und Preußen verurteilt wird.110 In einem ähnlichen Reisebericht »Wanderungen und Kreuzzüge durch einen Theil Deutschlands» von 1796 kritisierte Rebmann scharf die Verhältnisse in Norddeutschland und besonders in Kursachsen. Es wurde die Hoffnung ausgedrüokt, daß die Posaunen von Josua die Jerichomauern der Klöster in Meissen zerstören würden. ${ }^{111}$ Es ist verständlich, daß Rebmanns Aktivitäten in Deutschland unterbunden wurden, und der Magistrat von Leipzig 230 Exemplare des genannten Büchleins beschlagnahmte. ${ }^{112}$

Görres hatte verhältnismäßig wenig an der öffentlichen Diskussion in Deutschland teilgenommen und nur selten Namen seiner Zeitgenossen genannt. Rebmann verhielt sich völlig anders. Er führte in jeder seiner Veröffentlichungen einen heftigen Federkrieg mit seinen politischen Gegnern. Besonders oft und heftig griff er »Eudämonia» und den »Revolutions-Almanach» mit ihren Mitarbeitern an: Schirach, Zimmermann, Rehberg, Ottokar Reichardt, Grollmann, Göchausen und L. A. Hoffmann waren das ständige Objekt seiner gehässigen Angriffe. ${ }^{113}$ Gegen Gleims Kriegsgedichte veröffentlichte Rebmann ein Gegenstück, »Die blinden Menschen», in dem gezeigt wunde, wie dumm die Untertanen der deutschen Fürsten seien, indem sie freiwillig in ihrer Sklaverei bleiben und sogar gegen ihre eigene Freiheit kämpfen würden:

»So blind seyd ihr gemacht! ihr opfert den Tyrannen / Ihr opfert eurer Kinder Blut - Ihr laßt euch willig / in das Joch der Knechtschaft spannen / Unid euren Heldenmuth.»114

Entsprechend bedankte er sich und suchte Unterstützung bei Friedensverteidigern wie Kant, - dessen Werk »Zum ewigen Frieden» er nach seinen Worten sehr schätzte ${ }^{115}$ — Hennings und Huber. ${ }^{116}$

Rebmanns Schriften sind besonders typisch für die in Deutschland vertretene revolutionäre Einstellung. Er griff Österreich an, die geistlichen Fürsten und die Kirchen, die Verfassung des Reiches, England und

110 Rebmann, Holland und Frankreich ... 1796. v. Wrasky (1907) S. 133

111 Anselmus Rabiosus, Wanderungen und Kreuzzüge ... 1797 I S. 68-69, $110-111,117-119$ und $125-126$.

112 v.Wrasky (1907) S. 53.

113 z.B. N.gr.Ung. I, 1795 S. 53-54, II, 1796 S. $92-93$, V, 1797 S. 42-55, Laterne I, 1797 S. 7 und 13, III, 1798, S. 5. v.Wrasky (1907) S. 35 und 71; Voegt (1955) S. 20.

114 Laterne III, 1798, S. 15-16.

115 Holland und Frankreich I, 1796, S. 50. N.gr.Ung. V, 1796, S. 134-135.

116 N.gr.Ung. III, 1796, Anm. S. 5. 
Rußland, außerdem die Emigranten. Obgleioh er auch von seiner deutschen Herkunft sprach, betrachtete er Frankreich als seine geistige Heimat und identifizierte sich mit den Zielen der Republik. Er bewunderte die Siege der Truppen Frankreichs über die Deutschen und besonders Napoleons Siege und glaubte, daß nur über einen gewonnenen Krieg ein Frieden entstehen könne: 1796 schrieb er mit Hinweis auf Napoleon: »Der Friede muß unter den Mauern von Wien und London in Gegenwart unsrer siegreichen Armeen geschlossen werden».117 Den Staatsstreich vom 18. Fructidior hieß er gut, weil er die Republik gerettet habe. In seiner Ausdrucksweise war er radikal und aggressiv und übertraf darin auch den jungen Görres. Typisch ist auch, daß er sich gegen das Theoretisieren aussprach und für die praktische Außenpolitik war.

Den schon früher behandelten Andereas Riem kann man als Beispiel dafür anführen, daß sich ein anfangs führender pazifistischer Friedensverteidiger mit der Zeit $\mathrm{zu}$ einem »kriegerischen Friedensverteidiger» wandelte. Riem, der früher Preußen wegen seiner Friedensbereitschaft gelobt hatte, tadelte jetzt dieses Land enbarmungslos. Hardenberg, der Tag und Nacht wegen einer Unterwerfung verhandle, sei »bekanntlich ein erkiärter Feind aller vernünftigen und unvernünftigen republikanischen Grundsätze». Die über die Neutralität Norddeutschlands wachenden Truppen Preußens, die er noch zwei Jahre früher als edle Friedensschützer gelobt hatte, würden jetzt nach Meinung Riems vollkommen nutzlos auf Kosten anderer leben. Gegen wen sei die Demarkationslinie überhaupt notwendig? Die Vernichtung Polens, an der die preußischen Staatsmänner die größte Schuld tragen würden, sei ein schweres Verbrechen und eine große Dummheit.118 Riems Gegnerschaft zu Preußen führte auch dazu, daß er seine Haltung gegenüber den anderen deutschen Staaten änderte. Die früher von ihm verspottete »Reichsintegrität» war für ihn jetzt in gewisser Weise ein Mittel, um einen Friedensschluß herbeizuführen. Die für die Rheingrenze erforderlichen Entschädigungen dürften seiner Meinung nach nicht dazu führen, daß »die geographische Reichsintegrität dabey litte».119 Bis zum Ende des Jahres wurde Riems Haltung immer radikaler. Besonders die Neutralitätslinie Norddeutschlands griff er fortgesetzt an. Sie sei teuer, unnötig und überhaupt keine Neutralitätslinie, sondern eine Front des

1.17 Holland und Frankreich I, 1796, S. 35 und 46 und II S. 190 (Zitat). v. Wrasky (1907) S. 133.

118 Eur.pol.Lage V, 1797, S. 33-36.

119 Ibid. S. 41. 
Hasses gegenüber Frankreich. Außerdem sei Preußen gar nicht in der Lage, sie zu verteidigen, wenn Frankreich oder Österreich sie überschreiten wollten. ${ }^{120}$ Der Staatsstreich vom Fructidor brachte Riem einen Augenblick in Verwirrung. Einerseits bedauerte er, daß nach diesem Staatsstreich die französischen Pläne einer cisrheinischen Republik aufgegeben wurden. Andererseits sei es gut, daß mit dem Staatsstreich in Deutschland der vergebliche Wunsch nach der Rückkehr des Rheinlandes gesturben sei.121 Mit dem Jahre 1798 wurden Rtems Schrlften immer aggressiver. Besonders setzte er sich mit Archenholtz auseinander, der zu dieser Zeit eindeutig für einen Krieg eintraf. Im Januar 1798 wurden in der "Minerva» von Archenholtz Riem, Rebmann und Anton Joseph Dorsch als »antigermanische Schriftsteller» bezeichnet. ${ }^{122}$ Dagegen protestiert Riem in seinem Artikel »Wer ist ein antigermanischer Schriftsteller?». Er bewies, daß seine Forderung nach einem Frieden für Preußen die ganze Zeit vernünftig gewesen sei. Ist es Antigermanismus, wenn jemand rechtzeitig bemerkt hat, daß die Republik nicht zu besiegen sei? Er habe sich so "gerade für Curbrandenburg oder Preußen, welches ihm seine guten Absichten sehr inconsequent belohnte», eingesetzt. Dagegen sei die Schrift des Herrn Etatsrath von Müller zu Wien »ein Meisterstück eines antipreußischen und antigermanischen politischen Unsinns». Er, Riem, habe nur Deutschlands Interessen für einen Frieden verteidigt. Auch Archenholtz habe sich antigermanisch verhalten und die übrigen Gegner der Republik. Dorsch, Rebmann oder Riem könne man nicht wegen der Besetzung des linken Rheinufers anklagen. ${ }^{123}$ Riems Flugschrift $»$ An den Congress zu Rastadt», die den Streit hervorgerufen hatte, ist nach TSCHIRCH am meisten von Preußenhaß bestimmt. Ferner wollte Riem die Ostgrenze Frankreichs bis an die Flüsse Ems und Lippe verschieben, um so die Batavische Republik gegenüber England zu stärken. So gesehen erscheint Archenholtz' Terminus »antigermanisch» sehr gut verständlich. ${ }^{124}$ Nach dem Frieden von Campo Formio schwärmte Riem davon, daß durch die Zusammenarbeit von Frankreich und Österreich Preußen geschlagen werden könnte. Österreich würde dann Schlesien und Bayern mit dem Lech erhalten, die preuBischen Gebiete in Westdeutschland würden an Frankreich - und zwar im Tausch gegen Mecklenburg — fallen. ${ }^{125}$

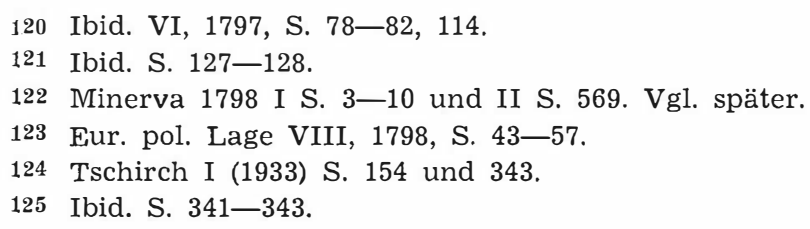


Riem veröffentlichte dann noch ein Flugschrift, die sich besonders an den Rastatter Kongreß richtete. Als »deutscher Patriot» fordert er dort einen Friedensschluß unter den Bedingungen Frankreichs und die Úbergabe der Befestigungen am Rhein, besonders von Ehrenbreitsstein, an Frankreich. Schon so empfahl er die Gründung des Rheinbundes. ${ }^{126}$ Auch die Sohrift »Europäische politische Lage» setzte diese Linie fort. Sie warnte den Rastatter Kongreß vor einem Scheitern, das einen besonders sschweren Krieg bedeuten würde, und vermutete, - mit Recht - daß Österreich während des Kongresses zu einem neuen Krieg rüste. Riem beendete seine Schriftenreihe mit einer ernsten Warnung an die europäischen Staaten vor einem Krieg, der für sie dennoch mit einer Niederlage enden würde. ${ }^{127}$

Der Gesinnungswandel von Riem war in den ihm widersprechenden Kreisen nicht unbemerkt geblieben, und er wurde das Ziel scharfer Kritik. Archenholtz' Reaktion wurde schon angeführt. Ein Anonymus, »Wahrheitsfreund», erklärte 1798 Riem für einen verdonbenen Glüıcksjäger, der sogar der Türkei dienen würde, wenn er dafür Geld bekäme. Der Anonymus erklärte, daß Riem früher als Prediger in einem Waisenhaus gearbeitet habe und schon dort bewiesen habe, daß er »ein höchst unruhiger Kopf» sei. Die Schriften Riems wurden geradezu als niveaulos chrakterisiert:

»- - schmeichelte er in seinen Schriften bald der Kaiserin von Rußland, bald dem Direktorium der französischen Republik. Man hätte ihm indessen micht ohne Urtheil und Recht des Landes verweisen sollen, denn nun gab er sich für ein Opfer des Demokratismus aus, flüchtete nach Frankreich und that Deutschland und seinem Vaterland vielen Schaden.»128

Auch viele andere aus dem Lager der Kriegspartei, z.B. R. Z. Becker und Ottokar Reichardt, verurteilten seine Schriften. ${ }^{129}$

$\mathrm{Zu}$ den oben angeführten Vertretern der »kriegerischen Friedensverteidiger» könnte man noch eine große Zahl Schriftsteller aufzählen, die ungefähr in gleicher Weise schrieben. Der größte Teil von ihnen gehörte zu den Mainzer Klubisten, die mit dem Wechsel des Kriegsglücks nach Paris gegangen waren oder in den französischen Departements am Rhein in französischen Diensten standen. Dazu gehört der Theologe Felix Anton Blau, ein Illuminat und scharfer Gegner der katholischen

126 Ibid. S. 361-362. Vgl. NTM 1798 II S. 227.

127 Eur. pol. Lage XII, 1799, S. 46-48, 82.

128 Die preußischen Staaten vor und ..., 1798.

129 National-Zeitung 1796 I S. 7-8; Goth. gel. Z. 1796 Nr. 38 und 1799 Nr. 49. Briefe eines Abgeordneten ... 1798 S. 24. 
Kirche. Er gab in Paris die revolutionäre Zeitschrift »Pariser Zuschauer» heraus. ${ }^{130}$ Sein näohister Mitarbeiter stammte auch aus Mainz; der Illuminatentheologe Anton Joseph Dorsch arbeitete nicht nur als Schritsteller sondern auch als Verwaltungsibeamter für die Republik. ${ }^{131}$ Ein in Paris und im Rheinland tätiger Klubist, der Professor für Philosophie und Geschichte Andreas Joseph Hoffmann, vertrat eine besonders revolutionäre Position. ${ }^{132}$ Illuminat war auch der ehemalige Beamte aus der Pfalz Georg Friedrich List, der nach Paris übersiedelle. Hier forderte er in seiner Flugschrift (1795) die Anerkennung des Rheins als französische Grenze, organisierte in Baden einen Aufstand (1796) für Frankreich, der scheiterte, und arbeitete intensiv gegen den Rastatter Kongreß, den er mit einem Volksaufstand auflösen wollte. Sein Extreminismus führte auch zum Bruch mit dem Direktorium, und der tüchtige Revolutionär mußte zeitweise im Gefängnis sitzen, um dann jedoch seit 1799 als republikanischer Beamter im Rheinland tätig zu sein. ${ }^{133}$ Fragwürdig ist, ob man zu dem oben geschilderten Lager auch gemäßigte Republikaner wie Konrad Engelbert Oelsner oder Karl Friedrich Cramer rechnen kann. ${ }^{134}$ In den verschiedenen Teilen Deutschlands erschien eine große Zahl ähnlicher Schriften anonym. ${ }^{135}$

\section{5. „Das sich schämende Norddeutschland»}

Der Beginn des 2. Koalitionskrieges bedeutete für Deutschland so eine erneute Zweiteilung. Die Territorien hinter der preußischen Neutralitätslinie blieben neutral und außerhalb des Kriegsgeschehens, dagegen wurden die südlichen Teile des Reiches wiederum zum Kriegsschauplatz. $\mathrm{Zu}$ Beginn der ersten Kriegsoperationen, die für die Koalitionsstaaten erfolgreich waren, standen auch die Norddeutschen dem Krieg immer wohlwollender gegenüber. In für die Verhältnisse recht scharfen Artikeln wandte man sich jetzt in den verschiedenen Territorien an die

130 v. Wrasky (1907) S. 108. ADB Bd. 2. (Leser) S. 625-670.

131 BLDG (Scheel und Kobuch) S. 218-219; ADB Bd. 12. (Leser) S. 625-626.

132 BLDG (Scheel) S. 290-291. Scheel, Heinrich, Jakobinische Flugschriften aus dem deutschen Süden Ende des 18. Jahrhunderts, Berlin 1965, S. 127.

133 ADB Bd. 24. (Ratjen) S. 339-341 und Bd. 4. (Ratjen) S. 557-558. Nach VOEGT ist er ein »Jakobinschriftssteller» sowie auch z.B. August Hennings und Samuel Reimarus. Voegt (1955) S. 29; v. Wrasky (1907) S. 93-94.

134 Berl. Mon. 1795 II:s S. 468-471.

135 z.B. Julku II (1969) S. 185-186. Des alten Vater Gerhards Gespräche ... VII (1799) Der Prediger in den Wüsten ... 1798; Kritik des Jahres 1797 . ., 1798. 
Regierungen, besonders an den neuen preußischen König, um eine Beteiligung auch der norddeutschen Staaten am gemeinsamen Kampf $\mathrm{zu}$ erreichen. Die national und »reichsdeutsch» denkenden Norddeutschen betonten die Schändlichikeit und Schädlichkeit der dauernden Neutralität für die Zukunft. Zu Beginn des Krieges erschienen besonders viele Schriften, die sich für eine Beteiligung am Krieg einsetzten, aber auch nach der Jahrhundertwende, als sich immer deutlicher abzuzeichnen bagann, da der Krieg verloren sei, gab es Stimmen, die für eine Kriegsteilnahme plädierten. ${ }^{130}$

Aus den verschiedensten Kreisen setzte man sich für eine Beteiligung am Krieg ein. Dazu gehören u.a. viele, die sich schon früher an der öffentlichen Diskussion beteiligt und als Verteidiger des Friedens bezeichnet hatten. Außerdem erhoben jetzt diejenigen ihre Stimme, die bisher geschwiegen hatten und jetzt mit dem Wandel in der öffentlichen Meinung mutiger geworden waren. Natürlich schwiegen auch die alten Gegner eines Friedens nicht, sondern vermehrten im Gegenteil ihre Aktivitäten. Deutlich ist eine Änderung im Ton der öffentlichen Diskussion des »dritten Deutschland» mit Ausnahme Preußens zu erkennen.

In Preußen stellt sich die Situation komplizierter dar. Trotz des Thronweohsels und dem starken Druck von außen wurde hier die Friedenspolitik konsequent weitergeführt. Eine zu kriegerische Einstellung wollte die Zensur in der Öffentlichkeit nicht zulassen. Dazu war es für die traditionell regierungs- und königstreue Presse schwierig, die Regierung $\mathrm{zu}$ kritisieren, obwohl ihre Sympathien dem Krieg galten. Auch in der monarchistischen Presse ist eine Veränderung des Tons zugunsten des Krieges nicht zu übersehen. Von den schon erwähnten Zeitschriften zeigt z.B. das »Preußische Archiv» besonders nach dem Staatsstreich im Fructidor-Monat eine besonders ablehnende Haltung gegenüber Frankreich. Der Königsberger Kammersekretär Georg Friedrich John verurteilte den Staatsstreich der »Fünfherren» in seinem Gedicht »Wer ist frei?» und vensicherte, daß nur die Preußen im Schutze ihres Königs frei seien, »ohne Freiheitsbäume, / Ohne Käppchen und Laternenpfahl, / Ohne Volksgericht und Gleichheitsträume / Ohne Wahlrecht, ohne Freiheitssaal ...».137 Auoh zu Napoleon war das Verhältnis der Zeitschrift besonders feindlich. In einem Artikel vom Sommer 1798 behandelt ein Arzt aus Königsberg, Jacob Friedrich Hoffmann, die Taten Napoleons sehr kritisch und tadelt J. W. Archenholtz wegen seiner unkritischen Heldenanbetung.

136 Tschirch I (1933) S. 376-387.

137 Preuss. Archiv 1797 Dec. S. 741-742. 
»Eben der Archenholtz, dessen natürlioher Beruf es zu seyn scheint, den glänzenden Triumph ider brittischen Macht und Kunst $\mathrm{zu}$ verkündigen und das panische Schrekken bei Rossbach zu verewigen, fühlt sich gedrungen die grösste persönliche That des an Heldenthaten so überreichen siebenjährigen Krieges einem Franken zuzueignen.»

Der Zweok heiligt nie die Mittel. Verbrechen werden immer Verbrechen, Gräuel Gräuel und Schandthaten Schandthaten bleiben, ob sie zu Paris oder zu Rom verübt werden, ob man für die unbeflekte Empfängnis Mariens Menschen schlachten ——.138

In der vorletzten Nummer des "Arohiv» vom November 1798 wurde ein Gedicht des alten Kriegssängers Gleim veröffentlicht, das andeuten will, der alte Grenadier lebe immer noch und warte nur auf ein Zeichen, um den Kampf wieder aufzunehmen. In derselben Nummer warnt ein blinder Schriftsteller aus Königsberg, Ludwig von Baczko, die vielen jungen Kantianer vor allzu großer Bøgeisterung. ${ }^{139}$ Wie früher veröffentlichte die Zeitschrift Artikel, die sich für einen Frieden einsetzten, in denen man natürlich besonders dem Regenten für den Frieden dankte. Der Artikel des Domherrn von Klingsporn vom Sommer 1798 ist ein typisches Beispiel dafür und zeigt, wie wenig Raum Kant's Denken in seiner eigenen Stadt eingenommen hatte. Der Artikel weist auf die Staatsweisheit des verstorbenen Friedrich Wilhelm II. hin. Die große Staatsraison des Königs habe sich nicht nur beim Baseler Frieden sondern auch bei der dritten Teilung Polens gezeigt. Der Verfasser vergaß nicht die Fähigkeiten des Königs auch als Soldaten zu betonen:

»Nach dem Vorbilde seines grossen Onkels war er Held im Schlachtfelde, Staatsmann, Beschüzzer der Künste und Wissenschaften. - - Mit musterloser Politik endete er jene mühevollen Feldzuge am Rhein, durch einen für seine Staaten so glücklichen Frieden, und befördente dabei das Interesse und die Vermehrung seines Reichs durch die Besiznehmung grosser Provinzen ——.140

Obwohl die königstreuen Ostpreußen der neunziger Jahre den Krieg ablehnten, weil er nach einem Königsberger Magister Kaatzky »Stadt und Land verheert, / und Vieh und Menschen schlaohtet», ${ }^{141}$ wurde der Krieg als Mittel zur Erweiterung des Vaterlandes gutgeheißen. Dieselbe Erscheinung ist auch in einer anderen schon behandelten -

138 Ibid. 1798 Aug. S. 505, 511-512, 540.

139 Ibid. Nov. S. $689-690,761-762$.

140 Ibid. Jun. S. 369.

141 Ibid. 1797 Aug. S. 481-490 (Zitat S. 481). 
Provinzzeitschrift »Denkwürdigkeiten und Tagesgeschichte der Mark Brandenburg...» zu beobachten. Obwohl besonders der Redakteur der Zeitschrift, Kosmann, an mehreren Stellen die Friedenspolitik ${ }^{\mathbf{1 4 2}}$ der preußischen Könige preist, sind doch viele der Artikel für den Krieg. An der preußischen Kriegsehre wird immer festgehalten und man erklärt, daß die Österreicher an den Niederlagen im vorigen Krieg schuld seien.143 Im Frühjahr 1799 erschien ein Artikel von einem anonymen Verfasser, der sich für stehende Heere einsetzt und sogar die Einführung der allgemeinen Wehrpflicht nach französischem Vorbild fordert. Auch diese Zeitschrift verhält sich gegenüber Napoleon am Ende des Jahrhunderts abweisend. ${ }^{144}$

Deutlicher wird die Haltung der »Scham» in den Berliner »Jahrbücher der preußischen Monarchie», die unter der Leitung von Professor Friedrich Eberhard Rambach zu Beginn des Jahres 1798 zu erscheinen begannen. Der in der ersten Nummer veröffentlichte umfangreiche Überblick über die Situation in Europa im November 1797 ist noch recht friedfertig. Der Verfasser stellte fest, daß die Stellung der jungen französischen Republik stark sei und hielt einen Friedensschluß für sicher.

»Der Friede zu Rastadt giebt dem Gebiete dieses Freistaats eine weitere Ausdehnung, als die stolzesten Hoffnungen desselben erwarten durften».

England sei in Not. Sein egoistisches Streben nach einem Sieg habe für seine eigenen Bundesgenossen Nachteile gebracht. Österreich sei schwächer geworden und bedürfe unbedingt des Friedens. Der Friede von Campo Formio sei für Österreich von Vorteil. Was das Deutsche Reich und den allgemeinen Frieden anbelange, der zu erwarten sei, so wäre er für Preußen günstig und würde seine Stellung neben Österreich verbessern, das am meisten verlieren würde. Für das Reich selbst sei die Situation schwer überschaubar und »sein Schicksal liegt im heiligen Dunkel der Zukunft».145 Dazu, daß Preußen schon lange außerhalb des Kriegsgeschehens lag, verhielt man sich anfang 1798 noch sehr positiv und betonte, welcher Segen der Frieden für das Wirtschaftsleben in Preußen sei.146 Bald begannen jedoch immer mehr Texte $z u$ erscheinen, die versuchten, die Regierung auf den Weg der Kriegspolitik zu

142 z.B. Merkwürdigkeiten und Tagesgeschichte ... VI, 1798, S. 57, V, 1798, S. 5.

143 Ibid. VIII, 1799, S. 1325-1327 (Winkelmann).

144 Ibid. VII, 1799, S. 453-460.

145 Jahrbücher der pr. Mon. 1798 I S. 28 (Zitat) und 32.

146 Ibid. VI S. $260-264$. 
bringen. Immer öfter begann man sich an den letzten Krieg zu erinnern und auf die Greueltaten der Franzosen hinzuweisen. ${ }^{147}$ Wiederholt griff man die französische Staatsverfassung an und verurteilte in scharfer Form die Gründung der Republiken außerhalb Frankreichs. Dazu bezog man Stellung gegen die französische Außenpolitik während des Waffenstillstandes. ${ }^{148}$ Preußen müsse als Gegengewicht $\mathrm{zu}$ so einem Revolutionismus seine Bürger zu Vaterlandsliebe und Treue zum Regenten erziehen. Im Herbst 1798 bezieht die 'Leitschrift eindeutig Stellung für einen Krieg. In einem umfassenden Überblick über die politische Lage in Europa stellt man jetzt im Oktober im Gegensatz zu einem Jahr früher fest, daß die Situation sehr schwierig sei. Ein Friede stehe nicht in Aussicht. Man erkennt zwar an, daß die militärische Lage Frankreichs sehr günstig sei, aber andererseits macht man darauf aufmerksam, daß sich gegen Frankreich eine starke Koalition zu bilden beginne, nachdem England, Rußland, die Türkei und die nordamerikanischen »Frey-Staaten» ihre Seestreitkräfte gegen Frankreich konzentrieren würden. Auch der Kongreß zu Rastatt scheine ohne Erfolg zu bleiben. Wenn der Kaiser in den Krieg eintreten würde, so würden sicher die neuen französischen Operationen in Italien gefährdet. Allerdings schließt der Artikel damit, daß man den Krieg als zu teuer ablehnt und einen Frieden fordert. Die preußische Regierung sei wegen ihrer Weisheit zu loben, weil sie das Land weiterhin aus dem Krieg herausgehalten konnte. ${ }^{149}$

In anderen Artikeln wird die Kampflust ganz deutlich. Ein anonymer Verfasser handelte in der folgenden Nummer darüber, wie man das den Preußen verloren gegangene vaterländische Heldentum fördern könne. Der Verfasser klagt darüber, daß Preußen seinen Kriegsruhm verloren habe, obwohl früher sogar Frankreich anerkennen mußte, daß ihm Preußen überlegen sei. Schuld sei vor allem die falsche Religiosität im Lande: es gäbe Mennoniten, Herrnhutter und Juden. Diese würden zu wenig Steuern bezahlen und keinen Kriegsdienst leisten, obwohl »es ist unstreitig die erste Pflicht eines jeden Staatsbürgers, sein Vaterland $\mathrm{zu}$ vertheidigen» und "wer nicht das Vaterland $\mathrm{zu}$ vertheidigen bereit ist, so bald er dazu aufgefordert wird, der verletzt die erste Pflicht die er dem Staate schuldig ist».150 Als Argument wurde auch die innere Schwäche Frankreichs angeführt. Obgleich nach der Zeitschrift das

147 Ibid. V S. 53 ff.

148 Ibid. VI S. 177 und Bd. VIII und IX. Vgl. Tschirch I (1933) S. 330-331.

149 Ibid. 1798 X S. 130-135.

150 Ibid. S. 245-256 (Zitat S. 247 und 248). 
Direktorium die innere Unzufriedenheit durch eine vermehrte Zahl an Volksfesten zu dämpfen versuche, sei die Republik nicht beliebt. Interessant ist eine Anmerkung der Redaktion, die Veröffentlichung dieses Material - von Frankreich aus eingesandte Briefe - gehöre eigentlich nioht zum Aufgabenkreis der Zeitschrift, daß man aber die Briefe wegen ihres außerordentlichen Interesses veröffentlicht habe. ${ }^{151}$ Es läßt sich vermuten, daß das außerordentliche Interesse in dem Wunsch lag, Preußen möge sich der sich gerade bildenden zweiten Koalition anschließen. Außerdem wird wieder in feindlichem Ton von Grausamkeiten der französischen Truppen in der Schweiz und von ihren harten Vergeltungsmaßnahmen berichtet. ${ }^{152}$ Auch veröffentlichte die Zeitschrift ein Preußen kaum berührendes Dokument wie den Hirtenbrief des Patriarchen von Konstantinopel an die Bewohner einiger griechischen Inseln, die unter französische Herrschaft geraten waren, in dem die Eroberer mit scharfen Worten verurteilt werden. Der Satan habe die Franzosen zum Mord am König verleitet; die Einwohner sollten Widerstand leisten. ${ }^{153}$

Der Jahrgang von 1799 wird zwar mit einem Gedicht des Baron Friedrich Eberhard von Rochow eingeleitet, in dem geäußert wird, wie sehr man einen Frieden brauche und wie dankbar man Friedrich Wilhelm und seiner Louise für den Segen eines Friedens sein müsse. ${ }^{154}$ Aber im ganzen wird der Jahrgang von Artikeln gegen Frankreich beherrscht. Rambach scheint eindeutig zwischen 1798 und 1799 zu der Gruppe derjenigen übergegangen zu sein, die an die Regierung appelierten, in den Krieg einzutreten. Die Bestrebungen Frankreichs, seine republikanische Verfassung in den Nachbarländern einzuführen, wurde streng verurteilt: es habe kein Recht die Länder, die bisher mit ihren Verfassung zufrieden gewesen seien, zu republikanisieren. Die Führer Frankreichs werden als Despoten bezeichnet und die absolutistische Monarchie als die beste Staatsform verteidigt. ${ }^{155}$ Es wird auf die Verdienste des Braunschweigischen Herzogs verwiesen, dem Oberbefehlshaber der preußischen Truppen auf dem Feldzug von 1792, und die militärischen Erfolge der Franzosen herabgesetzt.156 Der brandenburgische Steuerbeamte Hans von Held dichtete eine begeisterte Verherrlichung auf den König, der die preußischen Truppen in kampfbereiter Stellung an der Demarkations-

151 Ibid. XI S. 272-276, Anm. S. 272.

152 Ibid. S. 277-278. Vgl. Tschrich I (1933) S. $363-364$.

153 Ibid. S. $279-304$.

154 Ibid. 1799 I S. 81-82.

155 Ibid. II S. $157-163$.

156 Ibid. III S. 245-269. 
linie inspiziert.157 Man lobt den Patriotismus der »Minerva» von Archenholtz zu einer Zeit, als die Zeitschrift die heftigsten Angriffe gegen Frankreich führte. ${ }^{158}$ Der Gymnasialdirektor aus Stargard Gotthelf Samuel Falbe betonte die Treue des preußischen Volkes zu seinem Monarchen und äußerte sein Unbehagen gegenüber dem revolutionären Frankreich; besonders mißbillige er die Schändung der Altäre und Kirchen in Süddeutschland. ${ }^{159}$ Die »Jahrbücher der preußischen Monarchie» zeigen für ihren 'l'eil deutlich die Kichtigkeit von HÜ:H'E'ÉS 'l'hese, daß̉ sich die öffentliche Meinung in Preußen im Jahre 1799 für einen Kriegseintritt ausgesprochen habe, was besonders im Sommer des genannten Jahres deutlich geworden sei. ${ }^{160}$

Es wurde gerade ausgeführt, wie die Halbung der preußischen Presse 1797-98 immer ablehnender gegenüber einem Frieden wurde. In diesem Lande hatte es jedoch schon früher eine bedeutende Oppositionsgruppe gegeben, die schon von Anfang an die Sonderfriedenpolitik der Regierung mißbilligt hatte. Die konservativen Kreise in Preußen lehnten natürlich die Republik ab und waren gegen eine friedliche Koexistenz mit ihr. Diese Gruppe war allerdings so königstreu, daß von ihrer Seite aus niemals eine eigentliche Empörung zu erwarten war, aber einen stillen Widerstand hatte es die ganze Zeit in vielen Schriften gegeben. Die religiöse Einstellung dieser Gruppe war mehr pietistisch und neben ihrer Königstreue verwies sie auch auf die Religiosität eines echten patriotischen Preußen im Gegensatz zum atheistischen Revolutionismus. ${ }^{161}$

Die Verkörperung des oben geschilderten stillen Widerstandes war Johann Wilhelm Ludwig Gleim. Er vertrat das Preußentum der älteren Generation (geb. 1719), stammte aus einer Beamtenfamilie, bekam seine juristische Ausbildung an der pietistischen Universität Halle und diente dann seinem König mehrere Jahrzehnte als Beamter. Neben seinem Verwaltungstalent verwendete Gleim auch sein Dichtertalent zu Ehren seines Königs. Im Verlauf des Siebenjährigen Krieges wurde er durch seine vaterländischen Heldengedichte auf Friedrich II. bekannt. In diesen »Grenadierliedern» idealisierte Gleim einen deutsohen Soldaten, was einen wichtigen Faktor für die Entwicklung des Nationalgefühls in Norddeutschland darstellte. ${ }^{162}$ Gleim gehört zu den ensten, die als Gegengewicht zum

157 Ibid. VI S. $170-171$.

158 Ibid. VIII S. 397. Vgl. später.

159 Ibid. XI S. 209-227.

160 Hüffer II (1905) S. 150 und 157.

161 Joachimsen (1956) S. 42-43. Epstein (1966) S. 449-450.

162 Wiegand, Julius, Deutsche Geistesgeschichte im Grundriss, Frankfurt a. M. 1932 , S. 89. 
Kosmopolitismus der Aufklärung eine nationale Bewegung zu propagieren begannen, was von EISNER als »Bardenpatriotismus» bezeichnet wird.163 Der Beginn der Französischen Revolution bedeutete für Gleim eine neue Epoche dichterischer Aktivitäten. Von Anfang an äußerten seine Gedichte Unbehagen und $\mathrm{Haß}$ gegen die Ideen der Revolution, und nach dem Ausbruch der Revolutionskriege wurden sie zu Kampfgedichten. Seine Einstellung zur Französischen Revolution gründete sich ganz und gar auf die Tradition Friedrich des Großen, ${ }^{164}$ und die Kriegszeit gab seinen Gedichten einen neuen Hintergrund, der sie noch beliebter als früher machte.165 Die Philosophie Kant's lehnte Gleim völlig ab. Ebenso widersetzte er sich dem Sonderfrieden seiner Regierung. Der Baseler Frieden wurde ja zumindest anfänglich fast einmütig gutgeheißen, so daß Gleims Stimme vereinzelt wie die eines Predigers in der Wüste blieb und im allgemeinen Friedensjubel unterging. Gleim tröstete sich jedoch schon damals mit der Vorstellung, daß der Frieden nicht lange dauern würde.166 Den Rest seines Lebens widmete Gleim dem Kampf gegen den preußischen »Schandfrieden». Seine dicht hintereinander enschienenen Gedichte versuchten immer wieder Preußen zu einem neuen Kampf aufzuhetzen - und erwiesen natürlich dem König allgemeine Verehrung. Er äußerte, daß er sich schäme und über die unerschütterliche Fortsetzung der preußischen Friedenspolitik traure. Besonders berührte den alten Kriegsdichter die entehrende Abtretung Ehrenbreitsteins. ${ }^{167}$

Gleims Gedichte wurden in dieser Darstellung auch schon mehrmals erwähnt. Er war sehr produktiv und seine Gedichte wurden in den neunziger Jahren des 18. Jahrhunderts beinahe überall in Deutschland gedruckt. Die Literaten der verschiedensten Richtungen veröffentlichten seine Gedichte, so Hennings, Archenholtz, Wieland, Rambach oder Leipziger. Die Freunde zitierten seine Gedichte zur Unterstützung ihrer Argumentation, die Feinde zum Beweis für die Dummheit der Reaktion. Gleim änderte seine Worte nicht auf Druck von außen. Er blieb immer derselbe unbewegliche Preuße, der sein Land zum Kampf gegen Frankreich aufforderte.

1795 veröffentlich.te Gleim u.s. die Sammlung »Fabeln für's Jahr 1795», in der er die Revolutionäre und Königsmörder angreift und die Deutschen zum Kampf auffordert. Eine dieser Fabeln, die sich besonders kriege-

163 Eisner (1907) S. 7.

164 Hölschner, Eberhard, Gleim und Voss in ihren persönlichen und literarischen Beziehungen, Berlin 1921, S. 4.

165 v. Arx, Oskar, Lavaters Schweizerlieder, Diss. Zürich 1897, S. 106.

166 Tschirch I (1933) S. 102-103.

167 Ibid. S. 423. 
risch gebärdet, wurde in Archenholtz' »Minerva» abgedruckt. ${ }^{168}$ Erschüttert über den Baseler Frieden dichtete er traurig idie Verse: »Krieg ist mein Lied nicht mehr».169 Nach dem Krieg erschienen von ihm unpolitische Dichtungen und die folgenden Jahre blieben ohne nennenswerte Produktion. Trotz des Friedens konnte sich der alte Mann jedoch nicht enthalten, die Herrlichkeit des Krieges zu preisen. Besondens kriegerisch ist die Grabinschrift für den General Hanns Joachim Scheel von Frühling 1796. Gleim preist die Tapferkeit des alten Soldaten und die Ehrenhaftigkeit zur Zeit Friedrich des Großen. ${ }^{170}$ Nach einem Zeitgenossen, WILHELM KÖRTE, sei die Zeit des Rastatter Kongreß die traurigste in Gleims Leben gewesen. Gleim schrieb offen gegen den Kongreß. In der im Dezember 1797 erschienenen »Instruction für die deutschen Friedensgesandten zu Rastatt» wendet er isich besonders gegen den Plan, die Grenze an den Rhein zu verschieben:

»Sie sollen Frieden schließen, sollen / Im mindesten, wie sie (= die französischen Gesandten) nicht unversöhnlich seyn! Wenn aber sie vom Rhein / Von unserm lieben, alten Vater Rhein / Nur Einen Tropfen haben wollen. Dann sage jeder Patriot, / So Sachs' als Preusse, Löwenstimmig, / und laut und grimmig: / Krieg noch, a uf Leben und a uf Tod!»171

Mit dem Ausbruoh des zweiten Koalitionskrieges begann eine äußerst rege Periode in Gleims Schaffen. Im Laufe des Jahres 1798 enschienen u.a. »Held Ferdinand», »Schweizerische Kriegeslieder», »Nelson» und »Friedrich des Einzigen Epistel an seinen Geist» und im folgenden Jahr »Manifest aller Völker an das französische Volk» und »Zeitgedicht vom alten Gleim». Gleim träumte, daß Friedrich der Große aus seinem Grab aufersteht und die Franzosen besiegt, er nennt Napoleon einen gewalttätigen Despoten und ruft die Deutschen auf das Schlachtfeld: »Im Kriege Heldenruhm erwerben / Ist leicht / man braucht ja nur zu sterben!».172 In der Fabel »Der Schafmann und das Schaf» stellt er fest, daß man mit Wölfen keinen Frieden schließen könne, und meinte Frankreich. ${ }^{173}$ Gleim führte seinen eigenen privaten Federkrieg nur in Gedichtform, aber seine Texte wurden auch zur Unterstützung und

168 Über das Schaffen Gleims siehe Wilhelm Körtes Johann Wilhelm Ludewig Gleims Leben, Halberstadt 1811, S. 533-535. Minerva 1795 IV S. 178--182.

169 Minerva 1795 VII S. 192-193.

170 Körte (1811); Denkwürdigkeiten und Tagesgeschichte ... 1796 II S. 725726.

171 Körte (1811) S. 293, 295-296.

172 NTM 1799 I S. 197-199.

173 Ibid. II S. $316-317$. 
Verstärkung in Prosatexten verwendet. Die an den Rastatter Kongreß gerichtete anonyme Flugschrift »Freymüthige Betrachtungen», die besonders scharf einen Friedensschluß ablehnt, schließt mit zur Weiterführung des Krieges auffordernden Versen.174

Gleim ist typisch für die konservativen Kräfte in Preußen. Er verurteilt alle Bemühungen zu einem Kompromiß mit der Revolution zu kommen und verweist gerne auf die Vergangenheit als Gegenistück zur traurigen Gegenwart. Er beschwört Huttens und Herrmans Vergangenheit und glaubt fest an die Überlegenheit der Deutschen über die verachteten Gallier. Nach dem Frieden von Campo Formio droht er u.a., daß die Seine noch zur östlichen Grenze Frankneichs werden würde. TSCHIRCH meint, daß diesem Ausspruch keinerlei Glaubwürdigkeit zukomme, er sei als Worte des mit dem Lorbeer gekrönten Siegers von Rossbach zu verstehen und nicht als die eines Beobachters der neunziger Jahre. ${ }^{175}$

Eine ganz andere Richtung als Gleim vertritt ein anderer führender Preuße, der sich ebenfalls für eine Fortsetzung des Krieges einsetzte, Friedrich von Gentz. ${ }^{176}$ Gentz gehört zu einer viel jüngeren Generation als Gleim (geb. 1764) und er argumentiert ganz anders, obwohl auch er sich einem Friedensschluß mit Frankreich hartnäckig widersetzte. Gentz hatte in Königsberg studiert und Kant's Vorlesungen besucht. Bei Ausbruch der Französischen Revolution gesellte er sich zu ihren Anhängern und seine ersten literarischen Versuche von 1791 zeigen deutliche Sympathien mit Frankreich. Wie viele andere Deutsche wendete auch er in der »Berlinischen Monatsschrift» sich jedoch von der Revolution wegen ihrer Radikalisierung ab und mit der Zeit wurde er zu einem ihrer schärfsten Gegner. In seiner Zeitschrift »Neue deutsche Monatsschrift», die 1795-1800 in Berlin ersohien, erklärte er sich offen als einen Revolutionsgegner und besonderen Bewunderer Englands. ${ }^{177}$

Im Dezember 1798 gründete er eine neue Zeitschrift, die noch bedeutender wurde, das »Historische Journal». Es wurde zum bedeutendsten Organ der preußischen Kriegspartei. In diesen Zeitschriften ermahnte Gentz Deutschland nachdrücklich zum Kampf gegen die Oberherrschaft und die univensalen Bestrebungen Frankreichs. Ein erfahrener Journalist, ein Kollege Wielands, August Böttiger, unterstützte Gentz' erste Zeitschrift und machte ihn mit Johannes von Müller bekannt, mit dem ein

174 Freymüthige Betrachtungen ... 1798 S. 51.

175 Tschirch I (1933) S. 367.

176 Ibid. S. 427 charakterisiert Gentz als "veltbürgerlicher Konservativ", nicht "preußischer Patriot» wie Gleim.

177 ADB VIII (Beer) S. 577-593. 
reger Briefwechsel begann. Anhand dieser Briefe kann man sagen, daß er ebenso frankreichfeindlich eingestellt war wie seine Zeitschriften. Er lobte Burkes Schriften und lehnte Napoleons Siege und Raubzüge in Italien ab. Besonders streng venurteilte er den Machtwechsel im Fructidor-Monat. ${ }^{178}$ Bei der Thronbesteigung durch Friedrich Wilhelm III. wendet er sich an diesen mit einer Flugschrift, in der er u.a. die Hoffnung auf eine größere Freiheit für die Presse aussprach. Damit deutete er offensichtlich auf die strenge Zensur der Regierung Friedrich Wilhelm II. hin, die die preußischen Kriegsantreiber im Zaum hielt.179 Während des Jahres 1798 setzte er sich immer eifriger für den Krieg ein, tadelte v. Müller, weil dieser seltener veröffentlichte, und Posselt, der soweit gegangen sei, daß er sogar den Staatsstreich im Fructidor akzeptiere. Wielands »Gespräche unter vier Augen» wurden von ihm besondens gründlich rezensiert und Gentz distanzierte sich von Wielands Auffassung, daß Napoleon der zukünftige Diktator Frankreichs sei. Auch mit besonders frankreichfreundlichen Journalisten führte Gentz fortgesetz Auseinansersetzungen. ${ }^{180}$

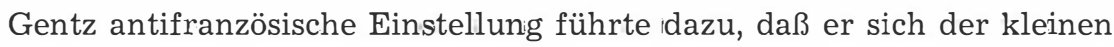
Gruppe anschloß, die sich nach dem Botschaftermord in Rastatt für die Österreicher einsetzte und das sogar unter seinem eigenen Namen. In der dieses Thema behandelnden Flugschrift gab Gentz zu, daß ein Mord eine schändliche Tat sei, fügte aber hinzu, daß denjenigen die Schuld zukomme, die den Krieg angefangen hätten, also den Franzosen. Österreich sei seiner Meinung nach für den Vorfall überhaupt nicht verantwortlich, der lediglich nachteilige Folge gehabt habe: grausame Soldaten hätten die Tat ohne irgendwelche Befehle von ihren Vorgesetzten begangen. Besonders mißbilligte Gentz, daß die Franzosen die Situation benutzt hätten, um $\mathrm{Haß}$ und Rachegier gegen Österreich zu erwecken: »Ein Staat, der, Krieg zu führen, zu solchen Waffen greifen muß, verdammt sich selbst und alle die er berührt — zum ewigen Kriege». Diejenigen, die die österreichischen Soldaten als Mörder bezeichnen würden, seien Lügner. ${ }^{281}$

Gentz stand seit 1799 in Verbindung mit dem österreichischen Minister Thugut und erhielt für seine Zeitschrift Unterstützung von Österreich. ${ }^{182}$

178 Wittichen (1909) Bd. I S. 212 und 224, Bd. II S. 51.

179 Pertz I (1850) S. 179-180.

180 Wittichen I (1909) S. 246-248, 251-252, 210, 317-325, II S. 73, 363-364.

181 Gentz, Friedrich, Ueber die Ermordung der französischen CongressGesandten, 1799, S. 3-5 und Anm. S. 5, 8-24.

182 ADB Bd. 8 (Beer) S. 577-593. Er bekam auch von der Preussischen Regierung 2000 Rthlr/Jahr. Tschirch I (1933) S. 427. 
Sein Briefwechsel zeigt jedoch deutlich, daß er in seiner feindlichen Einstellung zu Frankreich aufrichtig war und daß man ihn nicht zu den besoldeten $»$ Federkriegern» rechnen darf. Man kann die Stellungnahmen im »Historischen Journal», seiner wichtigsten Publikation, als seine eigenen betrachten. Das »Historische Journal», das in Berlin 1799-1800 erschien, wurde zum führenden geistigen Organ des konservativen Norddeutschland. Schon daß die Zeitschrift in der Hauptstadt Preußens zugelassen wurde, zeigt die Veränderung, die sich in der öffentlichen Meinung in der Anfangsphase des zweiten Koalitionskrieges vollzogen hatte. TSCHIRCH ist der Meinung, daß Gentz' Ablehnung der gegenwärtigen Politik noch sschärfer auisgefallen wäre, wenn ihn nicht die Zensur daran gehindert hätte. So blieben seine Ermahnungen an die preußische Regierung vorsichtig und andeutend. ${ }^{183}$ Aber seine Ziele fanden in jeder Nummer der Zeitschrift deutlich ihren Ausdruck. Fast alle Texte wurden von ihm selbst verfaßt, ${ }^{184}$ auf jedes Ereignis gab es eine scharfe und deutliche Reaktion. Nur in wenigen Zeitschriften läßt sich eine so eindeutige Richtung feststellen wie in dem »Historischen Journal». Vom Januar 1799 bis zum November 1800 behandelt er die Erscheinungen und Ereignisse seiner Zeit konsequent konservativ und beendet seine Betrachtungen in der letzten Nummer seiner Zeitschrift mit dem umfangreichen Artikel »Über den ewigen Frieden». Dieser soll in einem anderen Zusammenhang erläutert werden.

Im Januar 179.9 begann Gentz eine Reihe philosophischer Betrachtungen »Über den Gang der öffentlichen Meinung in Europa in Rüaksicht auf die Französische Revolution».185 Dort berichtet er mit ausführlichen Erörterungen seine antirevolutionären Prinzipien. Dabei bezieht er sich häufig auf tagespolitische Ereignisse. ${ }^{186}$ Napoleons Zug nach Ägypten wird besonders kritisch und - wie sich später zeigte - treffend kritisiert. Gentz bedauert die zu leichte Eroberung Maltas. Bonapartes Möglichkeiten Indien in ernste Bedrängnis zu bringen, schätzt er gering ein: Alexander der Große habe seinerzeit viel bessere Möglichkeiten gehabt. Der Zug nach Ägypten sei schon deshalb dumm, weil er zu einem Krieg mit dem ehemaligen Freund Frankreichs, mit der Türkei, geführt habe. ${ }^{187}$ Die französische Expansion in Italien wird von Gentz verur-

183 Tschirch I (1933) S. 437. v. Hase, Alexander, Friedrich (von) Gentz: 'Von den politischen Zustande von Europa', Diss. Nürnberg 1968, S. 67.

184 Haacke (1961) S. 62.

185 Die Artikel erschienen in Historichen Journal (HJ) 1799 Jan., S. 3-61, Febr. II S. 195-234, März S. 267-330, Juni S. 121-176 und Aug., S. 345-400. 186 Vgl. Tschirch I (1933) S. 427. v. Hase (1968) S. 68-69.

187 HJ Jan. 1799 S. 62-65, 78. 
teilt und ebenso die italienischen Fürsten, die mit dem Angreifer einen Frieden geschlossen hätten. In einem Satz verurteilt er die Begriffe »Weltbürger-Republik» und »der ewige Friede».188 Im Streit zwischen Frankreich und England tritt Gentz ohne zu zögern für das letztere ein und mißbilligt den »delenda est Carthago» - Geist der Franzosen. ${ }^{189}$ Bei der Behandlung des Schicksals der cisalpinischen Republik spottet er unbarmherzig über die »Mutter-Republik» und ihre »gefallene Tochter', der die Mutter zu ihrem Schutz jührlich 18 Millionen Livre geraubt hätte. ${ }^{190}$ Im Juni 1799 trägt das »Historische Journal» Gentz' Einstellung $\mathrm{zu}$ den Gesandtenmorden von Rastatt vor und wiederholt den Standpunkt aus der Flugschrift.191 Dabei führt Gentz auch einen heftigen Federkrieg mit seinen Zeitgenossen. Besonders Hennings, der vielleicht bedeutendste Repräsentant der norddeutschen Friedenspartei während des zweiten Koalitionskrieges, ist fortwährend Gegenstand seiner Angriffe. ${ }^{192}$ Konsequent kritisiert Gentz auch die innere Entwicklung Frankreichs. Er begriff vollständig die Bedeutung der Machtübernahme im Fructidor-Monat für die Erweiterung der französischen Aggressionspolitik und meint, daß gerade diese zusammen mit der Eroberung der Schweiz dazu führe, daß die große Anhängenschaft der französischen Politik in allen europäischen Ländern ihre Worte mildern und ihre Einstellung überprüfen müsse. Es ist natürlich, daß Gentz die Linksdirektoren ablehnte, während Carnot und Barthélemy sein Verständnis und seine Sympathie genossen. ${ }^{193}$ Die neuen Staatsstreiche von 1799 wurden einerseits mit ironischem Mitleid bedacht, weil die Fructidorianer so belohnt worden wären, und andererseits wurden sie als Beweis für die totale Verrottung des französischen Systems hingestellt: es sei »die bitterste Satyre gegen Volks—Rechte, Wahlversammlungen und politische Verfassungen, die sich eine demokratische Regierung wohl jemals erlaubt haben mogte».194 Wie es für eine Kriegspartei üblich ist, so betont auch das »Historische Journal» die innere Schwäche der Gegenpartei, also Frankreichs, wobei es besondens die schwachen Finanzen hervorhebt; deshalb sei die militärische Macht des Landes nur scheinbar.

188 Ibid. Febr. I S. 132 ff., 150, 161.

189 Ibid. März S. $331-340$.

190 Ibid. May S. 50.

191 Ibid. Juni $211-232$.

192 Ibid. Juli S. 323-324, Anm. S. 323 und Okt. S. 272-276. Tschirch I (1933) S. $432-434$.

193 HJ Febr. II S. 265 und 257-259, März S. 240, 277, May S. 61, Aug. S. 401, 412, 416, Juli S. 344 und 1800 Jan. S. 95-96.

194 HJ 1799 Aug. S. 407-408. 
Es sei durchaus möglich, Frankreich militärisch zu besiegen.195 Obw.ohl sich Gentz niemals an die preußische Regierung mit Vorschlägen $\mathrm{zu}$ einem neuen Kurs in der Außenpolitik wandte, ist seine Absicht deutlich zu erkennen.

Gleim und Gentz fanden mit ihren Vorstellungen in Preußen zwischen 1798 und 1799 große Zustimmung, und viele ehemalige Anhänger Frankreichs und sogar der Revolution im Lande näherten sich der Kriegspartei an. Dies ist besonders für die Zeit der österreichischen Siege im Sommer 1799 festzustellen, als ider Druak auf Friedrich Wàlhelm III. am größten war. Dieser Druok blieb jedoch ohne Wirkung. Preußen blieb neutral, bis 1800 eine Änderung in der militärisch-politischen Situation eintrat und dem Druck im großen und ganzen eine Ende setzte. ${ }^{196}$

Deutlicher als in Preußen ist in den anderen Teilen Norddeutschlands das Übergewicht der kriegerischen Stimmung wahrzunehmen, wo in den meisten Territorien die Redefreiheit zumindest in diesem Punkt größer war als in Preußen. Auch in den Ländern des nördlichen »dritten Deutschlands» wiederholte man dieselben Argumente; man schäme sich, daß man an dem gemeinsamen Kampf Deutschlands - oder ganz Europas - nicht teilnehmen könne. Der Gothaer Ottokar Reichardt, der von Anfang an sich heftig einem Frieden widersetzt hatte, publizierte weiter im kriegerischen Ton. Er veröffentlichte Schilderungen von blutigen Greueltaten, die von französischen Truppen begangen worden seien, und zitierte u.a. aus den oben erwähnten Flugschriften J. G. von Pahls, ${ }^{197}$ lobte die militärische Stärke Englands und Österreichs 198 und versuchte zu beweisen, daß Flrankreich ein gefährlicher Grenznachbar sei, den man unbedingt militärisch schlagen müsse. ${ }^{199}$ Auch Angriffe auf die Friedenspartei gehörten dazu. Über diese berichtete er außer in seinem »Revolutions-Almanach» auch in der von ihm redigierten »Gothaischen Gelehrten-Zeitung», in ider Hunderte von politischen Flugschriften und Zeitschriften aggressiv kritisiert wurden.200 Aber auch in Zeitschriften, die sich früher für den Frieden eingesetzt hatten, kann man diesen kriegerischen Ton antreffen. Ein Beispiel dafür, wie sich die Standpunkte veränderten, sind die zwei bedeutenden Zeitschriften »Minerva» von

195 Ibid. Sept. S. $1-107$ und $109-142$ und Okt. S. 143 ff.

196 Tschirch I (1933) S. 440-441.

197 Revolutions-Almanach 1798 S. 207-250.

198 Ibid. S. 267 und 1799, S. 95.

199 Ibid. 1799 S. $161-169$.

200 Ibid. 1798 S. 7, 1799 Vorbericht. Gothaische Gel. Z. z.B. 76/1798 673, $89 / 1798$ S. $795,49 / 1799$ S. $412-413,3 / 1800$ S. $22-24$. 
Archenholtz, die in Hamburg erschien, und der Weimar-Leipziger »Merkur» von Wieland. Während des Baseler Friedens und der folgenden Jahre hatten die beiden eine besonnene Richtung für iden Frieden eingeschlagen, um dann 1797 eine gegen Frankreich und für den Krieg gerichtete Linie $\mathrm{zu}$ verfolgen.

Bis zum Ende des Jahres 1797 nahm die »Minerva» eine dem Frieden zustimmende Position ein, und den Frieden von Campo Formio begrüßte Archenholtz nooh mit Bcfricdigung. Während des Frühjahırs 1798 kam es jedoch zu einem Wandel. Der Verlauf des Kongreß von Rastatt war für Archenholtz eine große Enttäuschung, als sich erwies, daß die Abtretung des linken Rheinufers eine der unabdingbaren Forderungen der Franzosen war. Der Staatsstreich vom Fructidor hatte zur Folge, daß sich die Einstellung Archenholtz' sohnell in Richtung auf eine A.blehnung des Friedens wandelte. Im Frühjahr 1798 berichtet er in besondens negativer Weise vom Kongreß in Rastadt:

»Mit dem Wort Rastadt ist jetzt die Idee von NationalDemüthigung allor Art, von Hohn und Schmach verbunden, wie sie im 18ten Jahrhundert kein Volk, keine Völkerschaft ertragen hat».201

Trotz seiner Freundschaft mit vielen revolutionären und frankreichfreundlichen Personen begann Archenholtz diese anzugreifen. So beschuldigte er Riem, Rebmann und Dorsch u.a. antigermanischer Schriften, was zu dem oben geschilderten Streit führte.202 Anfang 1798 verurteilte Archenholtz noch nachträglich den Frieden 'von Basel und von Campo Formio, die er früher völlig akzeptiert hatte. Besonders der Baseler Frieden sei eine Schande, weil damals Österreich von Preußen betrogen worden sei. Die Abtretung deutscher Gebiete an den Feind sei eine nationale Schande.203 Immer häufiger forderte er seine Landsleute auf, nicht zu verhandeln sondern in den Kampf zu ziehen. Er wandte sich scharf gegen die norddeutsche »bleierne Gleichgültigkeit». Nachdem der zweite Koalitionskrieg schon ausgebrochen war, forderte er im März 1799 in seinem wichtigen Artikel »Über die Apathie der Nationen, die Kriegsthaten der Franzosen und die jetzigen Zeitumstände» dazu auf, man solle das Volk aufwecken und zum Kampf aufrufen. Preußen solle zumindest den Kampf der Alliierten dadurch unterstützen, daß es die Operationen der Franzosen in Norddeutschland kontrolliere. Es wäre

201 Minerva 1798 IV S. $136-137$.

202 Ibid. I S. 3-10.

203 Ibid. S. 10. 
natürlich das beste, wenn die ganze Nation den Kampf gegen den Erbfeind führen würde:

"Die deutsche Nationalkraft ist dahin und mit ihr auch die Ehre der Deutschen, selbst ihr seit Jahrtausenden bestandener Kriegsruhm ist in Augen aller Nationen wie ein Morgentraum verschwunden. Die Abtretung der Rheinprovinzen an einen trotzenden Feind, die Demüthigungen in Rastatt und der über allen Ausdruck schändende Fall von Ehrenbreitstein, dies sind in Deutschlands Jahrbüchern solche Flecken, die keine Blutströme abwaschen können. Von dieser gehäuften, unauslöschbaren Schande ist jedoch nicht mehr die Rede, sondern nur von der ungestörten Fortdauer unsrer glücklichen Apathie in Norddeutschland.»204

Weitere Beweise für die feindliche Einstellung Archenholtz' finden sich in großer Zahl auf den Seiten der »Minerva». Archenholtz hielt die Franzosen für noch schlimmer als die Hunnen, weil jene für ihren Krieg keine Motive hätten: sie würden nicht für ihr Vaterland sondern aus Raublust kämpfen. Weiter verharmloste er die Siege Napoleons, veröffentlichte einen scharf tadelnden Bericht über den Staatsstreich im Fructidor und seine traurigen Folgen des Emigranten d'Ivernois, machte auf das agressive Vorgehen der Franzosen in der Schweiz besonders aufmerksam und forderte sogar die rheinländischen Bauern auf, zu den Waffen gegen den Nationalfeind zu greifen. Die preußische Neutralitätspolitik wurde von ihm überhaupt nicht akzeptiert. ${ }^{205}$

Obwohl sich Archenholtz' Einstellung so gegen einen Frieden wendete, bleibt er jedoch zurückhaltener als die eigentliche Kriegspartei, wie z.B. der erwähnte Gentz. Der Gesandtenmord von Rastatt wurde von ihm nicht akzeptiert, wenn er auch die Schuld nicht unmittelbar der österreichischen Regierung zuschob. Seine Einstellung gegenüber den Emigranten blieb kühl und gegen England war er auch während der Kriegszeit distanziert. Die geistlichen Staaten wurden von ihm nicht akzeptiert, er war vielmehr der Meinung, daß diese mit Schuld seien an der Schwäche Deutschlands. Auch gegenüber Österreich blieb er mißtrauisch.206 Man könnte Archenholtz' Einstellung als deutsch-nationalen Unmut über die französische Politik bezeichnen. Sie unterscheidet sich deutlich von dem "kosmopolitischen Konservatismus», den Gentz repräsentiert und der bereit war, alle Mittel im Kampf gegen Frankreich

204 Ibid. III S. 532. Tschirch I (1933) S. 397.

205 Ibid. IV S. 21 und X S. 136-137, V S. 222 usw., XII S. 393 und X S. 1-16

(Richer-Serizi), 1799 VII S. 184-186.

206 Ibid. 1799 V S. 378-382 und VI S. 566. 
einzusetzen.207 Die Veränderung in der Linie der »Minerva» wurde noch dadurch venstärkt, daß neben Archenholtz auch einige seiner Mitarbeiter von einer Idealisierung des Friedens und der Neutralität zu einer Aufforderung zum Krieg übergingen. ${ }^{208}$

Die gleiche Richtungsänderung ist auch in den Stellungnahmen des "Neuen teutschen Merkur» in den betreffenden Jahren zu beobachten. Obgleich Wieland nie aufhörte, sich für den Frieden einzusetzen, verändertc sich der Gesamtton der Zeitschrift deutlich. Karl August Böttiger, der bedeutendste Mitanbeiter Wielands, übernahm nach 1798 fast allein die redaktionelle Verantwortung. Während des zweiten Koalitionskrieges bezog er offen Stellung gegen die Rheingrenze und kritisierte besonders kühl Wielands sich für den Frieden einzetzende »Gespräche unter vier Augen».209 Böttiger lehnte Napoleon, ein Schwertapostel des neufränkischen Evangeliums der Freiheit und Gleichheit», ab und vertrat die Auffassung, daß am Mißlingen des Kongreßes in Rastatt der listige Barthélemy und der »viel zu hoch gepriesene Bonaparte» die Schuld trügen. ${ }^{210}$ Ende des Jahres 1798 forderte der Norddeutsche Karl Wilhelm Dassdorf versteckt den neuen preußischen Regenten auf, einen Krieg gegen Frankreich zu beginnen und so zum Retter Deutschlands zu werden:

»Denn Dich beseelet Friedrichs hoher Muth / Auch bey den nahen Ungewittern: / Und Teutschland, das auch Dich entzückt / Als seinen Stolz und Retter bliokt, / Darf für die Zukunft nicht mehr zittern».211

Auffallend häufig zitierte man in den Anfangsstadien des zweiten Koalitionskrieges in der Zeitschrift eine große Zahl gegen Frankreich gerichtete Texte von Österreichern und Schweizern. ${ }^{212}$

Die feindliche Einstellung des für die Linie des »Merkur» verantwortlichen Böttigers zeigl sich auch in seiner zweiten Zeitschrift »London und Paris», die er zusammen mit dem Weimarer Buohhändler-Schriftsteller Friedrich Justin Bertuch herausgab. Auch in dieser Zeitschrift wird der Staatsstreich vom Fructidor und die Politik der Triumviri scharf verurteilt. Diese würden die Schuld für das Scheitern der Verhandlungen in Rastatt tragen. Utber die Verluste der Franzosen zu Beginn des zweiten Koalitionskrieges wird besonders ausführlich berich-

207 Schmeisser, J. G., Beyträge zur näheren Kenntniss . . 1797 S. VI-VII.

208 Unmassgebliche Gedenken ... 1797, Beantwortung der Frage ... 1796.

209 Wahl (1914) S. 246.

210 NTM 1799 III S. 273 und IV S. 179-185.

211 Ibid. 1798 IV S. 171-174.

212 Ibid. III S. $20-21,21-22,73,249-251$. 
tet. Die Zeitschrift glaubte - und hoffte offensichtlich auch -, daß auch Preußen, das 100000 Mann mobilisiert haben sollte, in den Krieg eintreten würde. Sehr genau verfolgte man das Vorgehen Napoleons in Ägypten, über dessen Schwierigkeiten sich Bertuch und Böttiger offen freuten. ${ }^{213}$

Deutlicher als in Zeitschriften ist die Sinnesänderung in Flugschriften zu beobachten, die nicht in dem Maße die Zensur zu fürchten hatten. So erschienen überall in Norddeutschland kriegerische Flugschriften. Sogar in den dänischen Gebieten, wo man vielleicht am wohlwollensten Frankreich gegenüber gestanden hatte, läßt sich eine Sinnesänderung beobachten. Als Beispiel kann man den holsteinischdänischen Professor, den Vertreter der Aufklärung Freiherr Christian Ulrich Detlev von Eggers anführen, der ein begeisterter Anhänger der Friedenspolitik des Ministenpräsidenten Bernstorff gewesen war. In seinem umfassenden Werk »Geheime Geschichte der Rastadter Friedensverhandlungen», das er 1799 anonym veröffentlichte, wendet er sich eindeutig gegen Frankreich. Für den Ausbruch des zweiten Koalitioskrieges trage allei Frankreich die Schuld. Eggers verurteilt jetzt die Revolution selbst, die Priesterverfolgungen, iden Baseler Frieden, die Raubtaten und Verwüstungen durch die französischen Truppen während der vergangenen Kriegsjahre, den Staatsstreich im Fructidor und den Utberfall auf die Schweiz. Er preist den tapferen Kampf der deutschen Bauern und meint, daß das Vorgehen Frankreichs den Krieg unvermeidlich gemacht habe.214 In der gleichen Weise änderte ein Mitarbeiter von Archenholtz, der Rechtsanwalt aus Altona Friedrich Johann Jacobsen, seine Einstellung. Auf den im Sommer 1797 verstorbenen Ministerpräsidenten Bernstorff schrieb Jacolbsen einen Nachruf, in dem er die Friedenspolitik und die vernünftige Neutralität des Ministerpräsidenten pries und den Segen hervorhob, den der Frieden Dänemark gebracht habe. Zum Vergleioh wies er auf das blutende Mitteleuropa. Ein Jahr später mißbilligt derselbe Mann die Neutralitätspolitik und hebt seine antifranzösische Haltung hervor. ${ }^{215}$

Als einen sehr typischen kriegerischen Schriftsteller in den Anfangsphasen des zweiten Koalitionskrieges kann man den Oldenburger

213 z.B. London und Paris 1798 III Anm. S. 338, 1799 III S. 181 und Anm., 258-259 und 193-194; 1799 Anm. S. 351 und Anm. S. 351-352. v. Heinemann, Albrecht, Friedrich Johann Justin Bertuch, Bad Münster am Stein 1950, S. 22-23 und 32 .

214 Geheime Geschichte der Rastadter Friedens-Verhandlungen ... 1799 S.

VI, 2-3, 7, 27, 57-58, 65, 78, 81, 102-107, 208-213, 222-223 usw.

215 Minerva 1797 II S. $171-179$ und 1798 III S. 
Hofarzt Heinrich Matthias Marcard betrachten, der seine mehrere Jahre dauernde publizistische Tätigkeit 1799 mit zwei Flugschriften. »PreuBens Neutralitäts-System, dessen Ursachen und wahrscheinliche Folgen» und »Nachtrag zu der Schrift ...», begann. Marcard vertrat sehr konservative und rückschrittliche Anschauungen, was auch in diesen Schriften deutlich wird.216 In dieser Zeit erschien eine große Zahl an Flugschriften in Norddeutschland, die den Krieg unterstützten. ${ }^{217}$ Als Beispiel dafür sollen Marcards Schriften angeführt werden.

In seinen Schriften trug Marcard sein Programm und seine Ansichten in klarer Weise vor, ohne sich hinter grundsätzlichen Erörterungen zu verstecken. Er freute sich über die Siege der Engländer und tadelte die kurzsichtige Politik Kontinentaleuropas, besonders »trügerische Friedensvorschläge». Alle europäischen Länder, aber besonders Deutschland, seien von der Revolution bedroht. Die Deutschen seien auf Grund geschichtlicher Beweise ein tapferes Kriegsvolk: die Cherusker von heute hätten ihren Hermann in Erzherzog Karl und, wie die Heldentaten Friedrich des Großen von Rossbach gezeigt hätten, seien die Gallier noch immer Gallier und die Deutschen noch immer die alten. Deutschland brauche nur Einigkeit. Bedauerlicherweise habe sich Preußen von seinen natürlichen Bundesgenossen, den anderen von der Revolution bedrohten Ländern, getrennt. Friedrich Wilhelm II. hatte sich persönlich gegen die Revolution gewandt und Marcard bewunderte seine Äußerung: »Es ist eine Bande von Räubern». Wenn Preußen für dauernd außerhalb der Koalition bleiben würde, so sei dies zum Unglück Europas. Es gäbe natürlich Hindernisse für eine Zusammenarbeit zwischen Österreich und Preußen, aber die wirklichen Patrioten würden daran glauben, daß man sie in der Not aus dem Weg räumen könne. Gewiß gäbe es Nationalhaß, aber eine Annäherung sei doch im wesentlichen von der Politik der Höfe abhängig, und die Höfe hätten sich ja auch bei der Teilung Polens zusammengefunden. Wenn die Länder nicht zusammen kämpfen wollten, so könnten sie doch in verschiedenen Gegenden gegen Frankreich Krieg führen: der eine mit den Russen in Italien und am Oberrhein und der andere mit den anderen Alliierten am Niederrhein und in Holland. Marcard verurteilt in diesem Zusammenhang die selbstsüchtige Kabinettspolitik der beiden Länder. Schon im vorigen Krieg habe Zwietracht geherrscht: die Österreicher seien in der Entscheidungsschlacht bei Valmy »vielleicht zufällig» den Preußen zu spät zur Hilfe gekommen. Auch haben

216 ABD Bd. 20. (Krause) S. 294; Tschirch I (1933) S. 418. Vgl. Ost (1928) S. 51.

¿17 Siehe später. 
die Preußen nicht immer mit ihrer ganzen Stärke gekämpft. Trotzdem sei der Frieden von Basel, »das erste Signal der Auflösung von Europa», nicht notwendig gewesen. Die europäischen Staaten könnten sich nicht auf das Direktorium, die Pariser Pentarchen, verlassen. Tausendmal hätten die Franzosen verkündet, daß sie alle Monarchien vernichten wollten. Es hätte sich gezeigt, daß sie sich auch nicht um die Interessen der Völker kümmern würden: Venedig sei zuerst geplündert und dann an Österreich abgetreten worden. Das Direktorium hätte innere Schwierigkeiten und könne schon deshalb keinen Friedensschluß unterzeichnen. Eben wegen ihrer Schwierigkeiten hätten die Direktoren den Weg der Offensive eingeschlagen. Ein Krieg stehe bevor. Österreich könne nicht dem Aufmarsch der Franzosen an allen Fronten zusehen. Alle soliten sich der starken Koalition Österreich - England - Rußland anschließen. Eine günstige Gelegenheit zum Schlag gegen den Feind sei zwar schon verloren gegangen, weil man nicht gleich nach dem Sieg Nelsons im Oktober 1798 angegriffen habe. Frankreich verfüge über die großen Mittel Italiens. Aber eine andere Gelegenheit würde kommen, wenn der Kampf zwischen den Österreichern und den »Weltstürmern» wieder ausbrechen wird. Mit der Teilnahme an diesem Krieg habe Preußen eine Möglichkeit, einen wbilligen und dauerhaften Frieden $\mathrm{zu}$ erkämpfen».218

In einer weiteren Schrift, die vor allem wegen der Kritik an der ersten verfaßt wurde, berichtet Marcard über das Echo auf seine Pläne. Er erwähnt, daß seine Schrift eine Sensation gewesen sei und alle nach dem Verfasser gesucht hätten. In Altona, wo der Jakobinismus ein Zentrum habe, seien sogleich zwei Flugschriften gegen ihn veröffentlicht worden und man habe ihn mit den verschiedensten Spottnamen versehen (»Herostrat», »Petrus Eremita»). Zumindest eine dieser Schrift war nach Marcards Auffassung das Werk von Illuminaten. ${ }^{213}$ Diese würden jedoch vergebens auf einen Kapitulationsfrieden hoffen. An dem Ausbruch des zweiten Koalitionskrieges trügen allein die schlauen Pariser Pentarchen die Schuld. Die Russen seien erfolgreich gewesen, und die Franzosen hätten Angst vor Suworow. Das Mittelmeer würde schon von den Alliierten behernscht, und der »Räuber-General» Buonaparte sei das Opfer seiner Verwegenheit geworden. Napoleon habe bisher nur durch sein Glück Erfolg gehabt, ungeachtet seiner Dummheit und Verwegenheit. Jetzt würde das Schicksal Europas entschieden. Die Franzosen nähmen

218 Preußens-Neutralitäts-System ... 1799.

219 Nachtrag zu der Schrift . . 1799, S. 3-7. Tschirch I (1933) S. 421 erwähnt als Schriftssteller Hennings und »anderen unbekannten Demokrat». 
jetzt, da die Lage für sie hoffnungslos sei, Zuflucht bei ihren Bundesgenossen. Illuminaten und deutsche Jakobiner würden die ganze Zeit zugunsten der Franzosen arbeiten. Zahlreiche deutsche »VaterlandsVerräther»-Zeitschriften kämpften gegen den Anschluß Preußens, obwohl sie gut wüßten, daß Frankreich die Absicht habe, auch Preußen zu vernichten. Es sei wirklich bedenklich, wenn Preußen die »Thronenund Altarstürmer» gegen die alliierten Staaten schützen würde. In PreuBen habe man nicht erkannt, daß Frankreich danach strebe, eine Weltmacht zu werden, obwohl dieses Frankreich dies oft offen verkündet habe. Weiter seien die Franzosen im Begriff Helgoland zu besetzen, um die Herrschaft über die Elbe zu erringen, trotz des höchst freundlichen und höflichen Verhaltens der dänischen Regierung gegenüber den nichtswürdigen Despoten Luxembourgs. Beispiele für die Gefährlichkeit der Neutralität gäbe es also. Preußen müsse unbedingt an die Seite Österreichs treten. Stürze Österreich, so sei auch das Ende Preußens nahe. Der Frieden von Campo Formio sei bedeutungslos, da ihn Österreich in einer Zwangslage unterschrieben habe, nämlich als Napoleon vor den Toren Wiens stand. Jetzt dagegen sei es gewiß, daß das Bündnis zwischen Österreich und Rußland den Sieg davon tragen würde, wenn Preußen sich anschließen würde. Marcard gab zu, daß der Beitritt Preußens zur Koalition keineswegs sicher sei, und er deutet an, was geschehen würde, wenn die Alliierten ohne Preußen den Sieg davon tragen würden:

»Wie würde alsdenn die Lage des preußischen Cabinetts seyn? Es hatte nicht wollen die Hand bieten gegen den allgemeinen Feind, der theoretisch und practisch die Ruhe von ganz Europa störet - - Sollte sogar in Frankreich die Monarchie ohne Preußens Beystand hergestellt werden, so würde es dann vorerst ganz isoliert stehn.»

Norddeutschland dürfe sich die Früchte eines sicheren Sieges nicht entgehen lassen. Nur eine allgemeine Koalition könne Europa und die Welt vor den Franzosen schützen. Die Schrift schließt mit einer Zusammenfassung der Botschaft Marcards:

»Bleibt Frankreich in der Gestalt und in allen Vortheilen, welche ihm der $\mathrm{zu}$ Rastadt beabsichtigte Friede noch vor kurzem einräumen wollte: so ist auch damit die blutige Revolution von Europa unterschrieben. Neutralité n'est pas toujours Prudence.»2020

Marcard gebrauchte also fast alle Argumente, die von den Repräsentanten verschiedener Richtungen, die für eine Fortsetzung des Krieges

220 Nachtrag zu der Schrift ... 1799. Zitaten S. 83 und 88. 
waren, gebraucht wurden, um ihre Standpunkte zu begründen: Nationalgefühl, Kaiserbewunderung, Religiosität, allgemeine Angst vor der Revolution, Agriffe auf Anhänger Frankreichs im eigenen Land, besonders auf Illuminaten. Die Úbereinstimmung in den Argumenten mit den österreichischen Friedensgegnern mag daher rühren, daß Marcard Verbindung mit dem österreichischen Obskurantisten L. A. Hoffmann hatte. ${ }^{221}$ Bemerkenswert ist auch, daß Marcard England wie auch Rußland sehr wohlwollend beurteilte, denen man im allgemeinen in Deutschland Mißtrauen und besonders bei dem letzteren Angst entgegenbrachte. Ausgefallen ist seine Äußerung von dem »edeldenkenden Paul» als Retter Europas. - Marcards Briefe sollten zunächst die Versuche des englischen Sonderbotschafters Sir Thomas Grenville unterstützen, Preußen in der zweiten Hälfte des Jahres 1798 in den Krieg hineinzuziehen, und die Anfang 1799 schnell zunehmende Kriegspartei stärken. TSCHIRCH hält es für fraglich, ob Friedrich Wilhelm III. diese Schriften gelesen hat, sie blieben jedenfalls wirkungslos.222

Typisch für die »schamvolle» Haltung der Norddeutschen zu Beginn des zweiten Koalitionskrieges ist auch die stark anwachsende Kritik an dem bedeutendsten Theoretiker der Friedenspartei, an Immanuel Kant. Während des Jahres 1798 und kurz danach erschienen zahlreiche Schriftten, in denen sowohl theoretisch als auch mit Hinweisen auf die Wirklichkeit Kant's Ansichten scharf kritisiert wurden.

Der Dozent für Theologie und Philosophie an der Universität Wittenberg Wilhelm Traugott Krug kritisierte Kant's Friedensvorstellungen in seiner Studie »über das Verhältniss der kritischen Philosophie zur moralischen, politischen und religiösen Kultur des Menschen». Krugs Ausgangspunkte sind das Christentum und Patriotismus. Obgleich er den Frieden für eine gute Sache hielt und stehende Heere ablehnte und außerdem sioh gegen Revolution und Despotismus aussprach, gestand er dem Fürsten das Recht $\mathrm{zu}$, von seinen Untertanen den Waffendienst $\mathrm{zu}$ fordern:

»Wenn aber der Suverän Abgaben verlangt, Kriegsdienste fordert u.s.w., so ist diess noch keine Sklaverey, sondern eine zur Erreichung des Staatszwecks in allen Bürgern als selbständigen Wesen nothwendige Anordnung, die also von ihnen selbst, wenn die vernünftig urtheilet, gebilligt werden muss.» ${ }^{223}$

221 Epstein (1966) S. 524.

22: Tschirch I (1933) S. 416, 419-421.

223 Krug, Wilhelm Traugott, Ueber das Verhältniss der kritischen Philosophie ... 1798 z.B. S. VI-VII, 88-89, 98 (Zitat). Siehe auch Röhrdanz (1936) S. 43 und 45 . 
Schärfer wurde Kant von dem Leipziger Verleger Johann Gottfried Dyk kritisiert, der einen heftigen literarischen Kampf gegen die Französische Revolution führte. Schon als er das stark antirepublikanische Werk »Frankreichs monarchische Staats-Verfassung im Kampfe mit seiner Regierung» des französischen Emigranten Charles Louis Francois de Barentin veröffentlichte, trat er für Burke und die Emigranten ein und hielt eine Rückkehr der Monarchie nach Frankreich für unumgänglich. Er lehnte die Politik des Direktoriums nach dem Staatsstreich von Fructidor strikt ab, verurteilte Ausweisungen, Priesterverfolgungen und die Bestrebungen, die republikanische Verfassung überall in der Welt zu verbreiten, erklärte Frankreich für den Schuldigen an den Kriegen, tadelte die Deutschen, die Frankreich verteidigten, wie Forster, Berlepsch, Huber und den Verlag Vollmers.224 Als Fortsetzung zu dem genannten Werk veröffentlichte Dyk das Sammelwerk »Natur, Ursachen und Resultate der französischen Revolution», das Burkes, Adrian Lezays und seine eigenen Schriften enthält. Die Revolution und ihre deutschen Anhänger werden von ihm ausführlich getadelt: Auf der französischen Seite stünden die Atheisten, Deisten, Socinianer und Juden, alle die »die Geistlichkeit hassen und den Aidel beneiden».225 Der schlimmste von allen sei Kant. Seine Sekte sei mit den Enzyłklopädisten zu vergleichen. Kant's Friedensphilosophie sei sinnlos:

»Wenn selbst Kant in seinem Büchlein zum ewigen Frieden den Zunder zum ewigen Kriege unbesonnenerweise dadurch legte, daß er die repräsentative Republik für die einzig gedankbare gute Regierungsform erklärt; so sieht man wohl, dass die blosse Theorie selbst den scharfsinnigsten Mann oft in einen Sumpf, statt zum Tempel der Wahrheit führt. - - oder sollte Herr Kant nicht erzittern, wenn er den Auftrag erhielte, die Richter, Gesetzgeber und Directoren für den Preußischen Staat zu ernennen? Ja, für mich allein! wird er sagen. Nun, und in Verbindung mit Schneidern, Schustern, Bürstenbindern und Holtzheckern hoft er auf überirdische Inspiration?»226

224 Barentin, Frankreichs monarchische Staats-Verfassung ... 1798, S. 3-7, 17, 23-26, 37, 274-275, 339-340, 424-427. Damals erschienen viele Flugschrifte gegen Frieden von Emigranten, z.B. Mallet du Pan, J., Zerstörung des SchweitzerBundes ... 1799; desselben (als Anonym) Europa nach seinen politischen undmilitärischen ... 1800; Dümouriez, Über den Krieg, im Aprill 1799; Marquis de Bouillé, Memoiren über die Französische Revolution, 1798. Tschirch I (1933) S. $368-370$ und $376-377$.

225 Natur, Ursachen und Resultate ... 1798 S. 3-8.

226 Ibid., Anm. S. 158-159. 
Ein Krieg zwischen Frankreich und Deutschland sei unvermeidlich, und es gäbe keinen Grund nach Frieden zu streben. Dyk zitiert Gleims Vense, in denen er den Mangel an Patriotismus in Deutschland beklagt. Dy:k schloß sich Gleim vollkommen an. Man habe jetzt Anlaß, sich auf große Veränderungen vorzubereiten. Österreich habe die Kräfte das Reich allein zu schützen, und weil »die Reichsprälaten und die unmittelbare Reichsritterschaft ein ständisoher Geist beseelt» und ein »Gemeingeist» im Entstehen sei, müßten die Kleinstände mit den Gebieten der Kreisfürsten verbunden werden. Wenn diese Verfassungsreform nicht durchgeführt werde, würde das ganze Reich von Frankreich erobert werden. Dyk kam auch auf den Aufruf des Emigrantengenerals Dumouriez an Preußen zu sprechen, in dem Preußen aufgefordert wurde, sich am Krieg zu beteiligen, und Friedrich Wilhelm III, um eine persönliche Entscheidung gebeten wurde - offensichtlich in der Hoffnung auf eine positive Antwort. ${ }^{227}$

Theoretischer wurde Kant von der Berlinerin Charlotte Friederike von Promnitz kritisiert. Die dem preußischen König alleruntertänigst gewidmete Schrift (Unterschrift: »allerunterthänigste Magd, Ch. Fr. v. Promnitz, geb. v. Somnitz») fordert das Verbot der schlimmsten Schrift von Kant für die Jugend, weil Kant ein Gegner der Monarchie sei. ${ }^{228}$ Frau Promnitz' Schrift ist unpolitisch und erwähnt z.B. die Schrift »Zum ewigen Frieden» überhaupt nicht.

Um so deutlicher ist der Angriff auf Kant in einer anonymen Flugschrift, »Acht Briefe üiber einige Widersprüche und Inconsequenzen in Herrn Professor Kants neuesten Schriften», des folgenden Jahres. Die Schrift erschien in Berlin, verlegt von einem alten Gegner Kants, Friedrich Nicolai, und repräsentiert offensichtlich auch Nicolais damalige Einstellung. ${ }^{29}$ Kant wird der Begünstigung der Französischen Revolution beschuldigt. Man wirft ihm vor, daß er als Voraussetzung für eine Beendigung des Krieges die republikanische Verfassung fordere. Nach der Meinung der Verfassers zeige die Wirklichkeit das Gegenteil: die Neigung der Franzosen zum Kriegführen und sogar zu Offensiven habe sich nach der Erklärung zur Republik nicht im mindesten geändert. Der Verfasser

227 Ibid. S. 194, 201, 204-213, Anm. S. 73-74.

228 v. Promnitz, Charlotte Friederike, Vertheidigung der Vernunft und Religion .... 1798 S. 90-91.

229 Acht Briefe über einige Widersprüche ... 1799. Von demselben Schriftssteller wurde schon früher — auch aus dem Verlag Nicolais — das Buch Neun Gespräche zwischen Christian Wolff und einem Kantianer» veröffentlicht. Vgl. Natur, Ursachen ... 1798 S. 201. 
wendet sich auch gegen einige Gedanken Kant's über das Übel des Krieges. Der Krieg sei keineswegs die Quelle allen Bösens und aller Sittenverderbtheit. Im Gegenteil, »Feigheit, Ueppigkeit, Weichlichkeit usw. gehören doch wohl auch zu den Uebeln unter den Menschen, und zum Sittenverderbnisse.» Diese habe vor allem der Frieden verursacht, gegen die der Krieg das Gegengift sei. Der Krieg verhindere auch nicht den Fortschritt. Weil der Krieg auch bisher nicht den Fortschritt der Menschheit verhindert habe, werde er es auch kaum in der Zukunft tun. ${ }^{230}$ Daran und an eine gegen Kant gerichtete Kritik im Vorwort zu eines Schrift des oben genannten Verfassers, »Neun Gespräche zwischen Christian Wolff und einem Kantianer», von Nicolai schloß sich im nächsten Jahr der Doktor der Theologie, »geheimer Rat des württembergischen Herzogs, Johann Christoph Schwab an. Er bezichtigt Kant des Revolutionismus und Atheismus.231 In zwei Werken der Hamburgers Jonas Ludwig v. Hess wird der Vorwurf des Atheismus wiederholt. Kant's Schriften seien ins besondere in bezug auf die Sexualmoral unmoralische Predigten der Revolution. Durch die zu große Verbreitung der Philosophie Kant's habe die ganze Autonomie des Denkens gelitten.232 Um 1800 gerieten noch Kant und Herder in einen offenen Streit miteinander,233 und im selben Jahr gipfelte die Kritik an Kant in der Schrift »Über den ewigen Frieden» von Gentz.

Gegen Kant's Philosophie richtete sich um 1800 eine umfassende und strenge Kritik. ${ }^{234}$ Ein Teil davon wandte sich gegen seine erkenntnistheoretischen und logischen Lehnsätze. Der Anteil, der sich gegen die Friedensphilosophie und seine politische Einstellung richtet, ist aber auch verhältnismäßig groß. Kant verteidigte sich in zahlreichen Schriften ${ }^{235}$ und hatte eine große Zahl Verbündete, aber während des zweiten Koalitionskrieges waren die Gegner eindeutig in der Überzahl. Der Anstieg in der Kant-Kritik hängt wohl damit mit zusammen, daß die öffentliche Meinung in Norddeutschland zwischen 1798 und 1800 für einen Krieg war.

230 Acht Briefe über einige Widersprüche ... 1799 S. 6-7, 12-16.

231 Schwab, Johann Christoph, Vergleichung des Kantischen Moralprincips ... 1800 S. VII-IX, XLV, 199-200.

232 Versuche zu sehen I 1797 S. 19, 25, 30-33 und II 1800 S. $471-477$.

233 Vorländer (1907) S. 185.

234 z.B. Stimme eines Artikels über Fichte und sein Verfahren gegen die Kantianer ... 1799; Kant, Immanuel [Heynig, Johann Gottlob], Verkündigung des nahen Abschlusses eines Traktats zum ewigen Frieden ... 1798.

235 z.B. gegen Nicolai Ueber die Buchmacherey, 1798 Kant, Immanuel, Sämmtlinhe kleine Shriften, 1798 und Immanuel Kant's vermisrhte Schriften III Bd., 1799. 


\section{Die abnehmenden Friedensstimmen}

Obgleich man nicht bestreiten kann, daß die allgemeine Meinung in Deutschland nach der Jahreswende von 1798/99 aufhörte, für einen Frieden zu plädieren und immer mehr begann, die Beteiligung am Krieg $\mathrm{zu}$ verlangen, so geschah dies doch nicht einstimmig. Viele Friedensverteidiger blieben trotz des Wandels in der allgemeinen Lage und der Veränderung der politischen Situation Anhänger eines Friedens und schrieben in diesem Sinne weiter. Dazu traten noch einige neue Stimmen, die sich für den Frieden einsetzten.

Auch für diejenigen, die zumindest in den Grundzügen die Ideen der Französischen Revolution guthießen, war es nicht leicht, im Lager der Friedensverteidiger $\mathrm{zu}$ bleiben. Dabei soll die Zahl derjenigen Extremisten ausgenommen bleiben, die zur Gruppe der »kriegerischen Friedensverteidiger» überging.

Ein gutes Beispiel ist E. L. Posselt, dessen "Europäische Annalen» 1793-97 eine der führenden Publikationen im »dritten Deutschland» war, die den Frieden konsequent unterstützte. Der Staatsstreich vom Fructidor überraschte Posselt wie auch andere deutsche frankreichfreundliche Journalisten, und er war gezwungen, den Staatstreich ausführlich zu erläutern. Dabei bezog er eine zustimmende Haltung. Er meinte, daß nach der Wahl im Mai, bei der die Rechtsparteien die Oberhand gewonnen hätten, die Royalisten eine so große Gefahr für die Republik gewesen wären, daß der Staatsstreich berechtigt sei. Auch die landesverräterische Tätigkeit von Angehörigen der Rechtspartei sei zu beachten.236 Posselt äußerte auch deutlich, daß er sich über die Wirkung des Staatsstreiches auf die Friedenshoffnungen im klaren sei: sie seien besonders durch die Verdrängung Barthélemys und Carnots deutlich geringer geworden. ${ }^{237}$ Dies hatte jedoch keinen Einfluß auf Posselt. Der Friedensschluß bereitete ihm natürlich große Genugtuung. Er sprach begeistert sogar von einer Weltrepublik. Der Republikanismus spreche schon alle Sprachen der Welt: außer Französisch Englisch in Amerika, Italienisch am Po und Deutsch am Rhein und in der Schweiz. ${ }^{23}$ Die Artikel des Jahres 1798 beherrscht dann eine frankreichfreundliche Einstellung. Die Entstehung neuer Tochterrepubliken wird begrüßt. In seinem Artikel »Der Rhein Frankreichs Gränze» vom Sommer 1798 tritt er offen für die Anerkennung des Rheins als Reichsgrenze ein, weil dies die absolute Voraussetzung $\mathrm{zu}$ einem ständigen Frieden sei. Posselt

236 Europäische Annalen 1797 IV S. 22-74, 75-107, 117 usw.

237 Ibid. S. 117.

238 Ibid. Sl $139-172$. 
forderte den Rastatter Kongreß auf, die Grenzforderungen der Franzosen anzuerkennen und die Säkularisation zu verwirklichen.239 Den Rastatter Kongreß und die ihn begleitenden Ereignisse - u.a. idie härter werdenden Forderungen der Franzosen und Napoleons Zug nach Ägypten — verfolgte er regelmäßig und genau. Einige Bemerkungen wie die, daß die Forderung der Franzosen auch auf die Festungen östlich des Rheins eine Abweichung vom Programm der natürlichen Grenzen darstelle, zeigen schon, wie seine Einslellung vursiuhliger wurde. ${ }^{210}$

$\mathrm{Zu}$ Beginn des Jahres 1799 wurde dann die Friedensrichtung der »Europäischen Annalen» am härtesten geprüft. In einer umfassenden Utbersicht in der ersten Nummer den Annalen über die politische Lage in Europa zeigt sich deutlich Posselts Unsicherheit. Wie früher hebt er die großen Leistungen der Revolution hervor und bewundert die bisherigen großen militärischen Erfolge der Franzosen. Es habe so ausgesehen, daß es zu einem Frieden mit Deutschland komme und man hätte vermuten können, daß der Rastatter Kongreß nur die geheimen Verträge des Friedens von Campo Formio bekräftigen werde. Frankreich habe ein starkes Bündnis geschlossen. Trotzdem sei es wegen einiger bedeutender Ereignisse zu einer neuen Koalition gegen Frankreich gekommen. Die Forderungen der Franzosen bei den Verhandlungen seien zu hart gewesen. Besonders das Deutsche Reich habe große Opfer bringen müssen, um zu gesicherten Grenzen zu kommen und eine weitere Verbreitung der Revolution abzuwehren. Frankreich habe im Verlaufe der Verhandlungen seine militärischen Aktionen fortgesetzt, Mainz und Ehrenbreitstein erobert und die Revolution in der Schweiz und in Rom durchgeführt. Zumindest bis zur Besetzung Neapels habe man in Deutschland an ein Zustandekommen eines Friedensvertrages zwischen den Staaten geglaubt und die Reichsdeputation habe, um einen Friedensabschluß zu ermöglichen, sehr vielen Forderungen zugestimmt. Trotzdem sei es zum Krieg gekommen. Das Vordringen der französischen Truppen über den Rhein zeige, daß Frankreich auch in Deutschland und nicht nur in Italien »während des Unterhandels über den Frieden, sich alle Vortheile einer fruchtbaren Kriegsstellung zugeeignet». ${ }^{241}$ Posselt ging also sehr weit in seiner Kritik an Frankreich. Dieser Ton setzte sich immer deutlicher fort. Die Revolution in Neapel und seine Eroberung sowie die Bildung der

239 Ibid. 1798 I S. 3-37, Bd. I und II mehrere zu den Ergeignissen in der Schweiz geeignete Schriften, I S. 206-212 und 213-258, II S. 140-153.

240 Ibid. 1798 II S. $237-240,263-270$, III S. 5-6, 109-113, IV S. 167-169, und 194-195. Das ganze Nummer 12 (Bd. IV) behandelte den Ägypten-Zug Napoleons.

241 Ibid. 1799 I S. 4-48 (Zitat S. 48). 
parthenopäischen Republik wurden in den »Europäischen Annalen» mit Bedauern kommentiert: Die Republik sei »zum Schreoken aller Freunde des Friedens in Europa» entstanden. ${ }^{242}$ Das Ende des Rastatter Kongreßes wurde bedauert. Posselt verurteilte absolut die Gesandtenmorde, für welche er die kaiserlichen Truppen verantwortlich machte, ${ }^{243}$ Frankreich hielt er zumindest für mitschuldig am Mißlingen des Kongreßes. ${ }^{244}$ In den ersten Nummern des Jahrgangs sind verhältnismäßig viele Texte gegen Frankreich abgedruckt. Posselt veröffentlichte den Bericht Carnots über den Staatsstreich vom Fructidor, der sioh natürlich gegen den Staatsstreich aussprach. Außerdem enthält er die Behauptung, die Friedensverhandlungen seien in Rastatt vor allem an den übermäßigen Forderungen des Direktoriums gescheitert. Das Direktorium sei eine despotische Regierung. ${ }^{245}$ Die Maßnahmen Frankreichs in der Schweiz wurden verurteilt und damit auch die Revolutionen in Italien und in Rom. Eben diese hätten zur neuen Koalition gegen Frankreich geführt. Auch Bonapartes Zug nach Ägypten wunde als Irrtum bezeichnet, obwohl seine militärischen Fähigkeiten Anerkennung finden. ${ }^{246}$

Eine besonders ablehnende Haltung gegen Frankreich nimmt Posselt im Herbst 1799 ein. Bei der Kommentierung des Staatsstreichs von Napoleon im Brumaire stellt er fest, daß es durch die militärischen Mißerfolge Frankreichs dazu gekommen sei, die wiederum von der Unfähigkeit des Direktoriums herrühre. Die französisohe Politik nach dem Fructidor wurde jetzt außergewöhnlich scharf kritisiert:

»Ein ewiges Monument seines Uebermuths wird der Congreß in Rastadt seyn. Unter allen Königen, die über Frankreich herrschten, hatte keiner es so weit gebracht, einen Frieden zu schließen, wie er hier dem Directorium geboten ward, aber mit dem plumpen Troze, womit dieses hier zu Werke ging, unterhandelte kaum das alte Rom, im Besize der Weltherrschaft, gegen die kleinen Könige in Asien und Nordafrika. - - Seit dem 18 Fructidor war das Direktorium im Besize der vollsten AlleinGewalt; es warf Könige vom Thron, es revolutionirte die Länder aller Bundesgenossen, es plünderte und tyrannisirte die FilialRepubliken - und kein Mensch in Frankreich wagte die Stimme dagegen zu erheben; den Journalisten, den Mitgliedern der gesetzgebenden Räthe, schwebte beständig »Cayenne» vor dem Blik.»247

242 Ibid. S. 236.

243 Ibid. II S. 83, 92-93 (C. W. von Dohm).

244 Ibid. S. 83

245 Ibid. S. $3-47$.

246 z.B. ibid. III Anm. S. 27.

247 Ibid. IV S. 34. 
Es ist schwer zu sagen, ob dieser starke Ausbruch gegen Frankreich aus Posselts wirklichem Verdruß herrührte oder daher, daß bei der Abfassung des Artikels die Alliierten in Richtung Tübingen vorrückten. Jedenfalls schrieb auch so ein absoluter Verteidiger des Friedens wie Posselt zu Beginn des zweiten Koalitionskrieges sehr aiblehnende Texte gegen Frankreich - und mittelbar natürlich gegen den Friedensschluß - , wenn er auch nicht gerade in Kriegsgeschrei gegen Frankreich ausbrach. Diese gleiche zeilweise Änderung in der Einstellung der Friedensverteidiger ist z.B. in den Schriften vieler Publizisten auf dänischem Gebiet $\mathrm{zu}$ beobachten. ${ }^{248}$

Die meisten Friedensverteidiger der aufklärerisch-demokratischen Richtung blieben jedoch ihren Ideen treu trotz der Veränderungen in der militärischen und politischen Situation. August Hennings schrieb auch in den Anfangsphasen des zweiten Koalitionskrieges unermüdlich für den Frieden und warnte besondens Preußen davor, sich an dem Krieg zu beteiligen, der in jedem Fall mit einem Sieg Frankreichs enden würde. Sehr nachdrücklich tadelte er Gentz wegen seiner Sohriften für den Krieg und forderte die preußische Regierung auf, diese Giftsaat zu unterbinden. Hennings bezeichnete die Pläne der Koalition als Torheit und hielt einen Reichskrieg für unmöglich. Auch den »Kriegsrezepte» verfassenden Arzt Marcard verspottete und tadelte er. ${ }^{249}$ Hennings hartnäckiger Einsatz für den Frieden erregte viel Aufsehen, und auch in Berlin wurden "die heftigen Angriffe des holsteinischen Volkstribunen» beachtet.250

Ein anderer treuer Friedensverteidiger war der Oldenburger Justizbeamte Gerhard Anton voon Halem, der Hennings fleißig unterstützte. ${ }^{251}$ Unerschütterlich hielten auch die »Schleswig-Holsteinischen Blätter» an der Friedenslinie fest, die von August Niemann aus Kiel herausgegeben wurden. Die Zeitschrift begann Anfang $1799 \mathrm{zu}$ erscheinen und geriet so sofort in die heftige Diskussion, die mit dem Beginn des zweiten Koalitionskrieges vor allem in Norddeutschland geführt wurde. Die neue Monatsschrift begann sogleich die Einhaltung der Neutralität für Norddeutschland zu fordern. Sie kritisierte die kriegerischen Kreise in Wien und dankte wiederholt dem dänischen König für den Segen, den Schleswig und Holstein durch den Frieden genießen könne..252 Als 1799

248 Vgl. S. 203-204.

249 Tschirch I (1933) S. 434-436, 441-442.

250 Lange (1928) S. 18-20 und 180. Genius der Zeit 1795 VII S. 392-393, 1796 II S. 262-264, Geschichte und Politik 1800 VIII S. 364-366.

251 Schleswig-Holsteinische Blätter 1799 I S. 8-9, V S. 8 und NTM 1799 IX S. $87-88$.

252 Schleswig-Holsteinische Blätter 1799 II S. 158-168. 
Gerüchte auftauchten, Dänemark wolle Nutzen aus dem ausgebrochenen Krieg dadurch ziehen, daß es sich möglicherweise mit Hilfe von Frankreich Hamburg oder andere norddeutsche Gebiete ${ }^{253} \mathrm{zu}$ bemächtigen beabsichtige, widersprachen die »Schleswig-Holsteinischen Blätter» diesen Gerüchten in einem von sieben Pensonen unterschriebenen Artikel. Diese Gerüchte wurden als völlig unbegründet bezeichnet und man wies auf den großen Nutzen hin, den Dänemark aus seiner Neutralität ziehe. Nach dem Artikel würde zwar in Holstein Kriegspropaganda betrieben, aber vergebens. ${ }^{254}$

In der Nachbarschaft der dänischen Gebiete, in Bremen, begann 1799 das »Hanseatische Magazin» des Professors J. Smidt zu erscheinen, das dieselbe aufklärerisoh-pazifistische Linie vertrat. Smidt versicherte wiederholt, daß er den Zustand des Friedens unterstütze und bedauerte die Wirkungen des Krieges auch in Bremen, obwohl er die eigentlichen Kriegsereignisse nicht erreichen könnte. ${ }^{255}$ Die Zeitung war ausgesprochen bürgerlich: sie griff Aristokratie, Emigranten und Standesprivilegion an und hatte eine feindliche Position gegenüber Österreich und Rußland.256 Gleichzeitig pries sie die Freiheit der Verfassung in Bremen und den anderen Hansestädten und versicherte, daß von Revolutionismus nichts $\mathrm{zu}$ entdecken sei.

Genauso stand es mit den meisten preußischen Schriftstellern. Immanuel Kant schrieb und hielt Vorlesung während der ganzen neunziger Jahre für den Frieden. ${ }^{257}$ Auch z.B. Johann Friedrich Reichardt war in dieser Weise aktiv. ${ }^{258}$ Die monarchistische Presse in Preußen, deren Schwanken und auch zeitweilig kriegerische Einstellung schon erwähnt wurde, blieb auch im großen und ganzen auf der Friedenslinie und veröffentlichte fortwährend Texte für den Frieden wenn auch ihre Aufrichtigkeit in vielen Fällen Anlaß zum Zweifel geben dürfte. ${ }^{259}$ Biesters Tätigkeit im Sinne der Aufklärung und für einen Frieden wurde seit Beginn des Jahres 1799 durch die »Neue Berlinische Monatsschrift» fortgesetzt. Hier warnten Biester und seine zahlreichen Mitarbeiter ihr Land, den Verlockungen den Koalition nachzugeben. Obwohl sich zu Beginn des Jahres einige Artikel gegen Frankreich wand-

253 Böttiger (1926) S. 5 und 57.

254 Tschirch I (1933) S. 184.

255 Hanseatisches Magazin I:2, 1799, S. 305, 312-313, 321, II:1 S. 331-332.

256 Ibid. I: 1, 1799, S. XIII, 308, II: 1 S. 3-4, 7, 17-18, 23.

257 Ibid. I: 1 , 1799, S. III, I: 2 S. $300-303,315$.

258 Tschirch I (1933) s.

259 z.B. Frankreich im J. 1797 IV S. 63 und 74. Röhrdanz (1936) S. 85 und Tschirch I (1933) S. 184. 
ten und dem österreichischen Patriotismus huldigten und so der Haltung des »sich schämenden» Norddeutschland nahestehen, ${ }^{260}$ spiegelt sich die Linie der Zeitschrift in einer Äußerung des Herausgebers vom Sommer 1799: „Wir haben Gesundheit, haben Frieden, und haben einen guten König. Der segnende Schuzgeist unsrer Stadt und unisens Landes erhalte uns diese drei Kleinode!261 Auch in manch anderem Zusammenhang verteidigten Biester und seine Mitarbeiter die Neutralität. ${ }^{262}$ Wie schon festgestellt wurde, erschienen viele Flugschriften gegen die Friedenspolitik der Regierung. $\mathrm{Zu}$ denselben Zeit erschienen jedoch wiederholt Schriften, in denen vor Kriegshetzern gewarnt und die Fortsetzung der Neutralitätspolitik unterstützt wurde. Gewöhnlich profezeite man, daß der Krieg den Koalitionsstaaten Verluste bringen würde. Außerdem gebrauchte man die gleichen Argumente wie früher: Aufklärung, Religion, Humanität. ${ }^{263}$

Diese publizistischen Aktivitäten für einen Frieden, die jedenfalls im ganzen Reich um 1798-99 einer Minderheit zugehörten, der jene angehörten, die für die Sache Frankreichs und der Revolution eintraten, bekamen mit dem Frühjahr 1798 überraschenderweise Unterstützung von bedeutender Art. Damals veröffentlichte nämlich Wieland teilweise im »Neuen Teutschen Merkur» and teilweise in Sonderdnucken die Dialoge „Gespräche unter vier Augen», ${ }^{264}$ in idenen er in bemerkenswerter Weise seine Einstellung zu Franikreich und zum Frieden, der in naher Zukunft geschlossen würde, berichtet. Wieland bekräftigte, daß er zu Beginn der Revolution ihr Anhänger gewesen und schließlich von ihren wichtigsten Prinzipien abgerückt sei. Aber zugleich legte er ein überraschend realistisches und weitblickendes außenpolitisches Programm vor, das ihn an die Seite Ider schwankenden Friedensverteidiger stellte. ${ }^{265}$ Für Wieland

200 Vgl. S. 138-141. z.B. Preußisches Archiv 1798 Jun. S. 369 und Magazin für Westphalen 1798 II-III S. 192 und 217. Tschirch I (1933) S. 377.

261 Neue Berlinische Monatschrift 1799 I: 5 S. 360-362 (A. G. Kästner), Anm. S. $362-363$ (Biester), I: 6 S. $423-425$, II: 1 S. $27-29$ (Gleim) usw.

262 z.B. ibid. I: 4 S. $289-306,312$, I: 5 S. $369-383$ (Bendavid), II: 4 S. 302307, II: 6 Anm. S. 377 (Nicolai).

263 z.B. Teller, W. A., Die Zeichen der Zeit angewendt auf ... 1799; An Deutschland. Eine Beantwortung ... 1799; Geschichte der Unterhandlungen ... 1799; Patriotisches Aufruf und herzliche Bitte ... 1798; Authentische Geschichte des ... 1798; Die preußischen Staaten ... 1798. Tschirch I (1933) S. 308-313.

264 Als Separatdruck erschien unter Wielands Namen eine 48-seitige Schrift Ueber den fränkischen Staatseid, Hass dem Königthum, die das politisch interessanteste Teil der Serie enthielt.

265 Sengle (1949) S. 453. 
waren diese Dialoge sein politisches Testament. ${ }^{266}$ Sie hatten offensiohtlich das Ziel, die politischen Entscheidungen zu beeinflussen und wandten sich $\mathrm{zu}$ erst an der preußischen König. ${ }^{267}$

In dieser Schrift erläutert Wieland seine Einstellung zu den Staatsformen, wie man sie miteinander verbinden und aneinander anpassen könne, seine Vorstellung von der Bedeutung der Religion, sein Reformprogramm zur Beendigung des in Europa wütenden Krieges und zur Beseitigung des hernschenden internationalen Mißtrauens, sein Programm zur Erneuerung des Deutschen Reiches usw., dabei berührt er fast jedes aktuelle nationale und internationale Problem. Vor allem beschäftigt er sich jedoch mit dem Krieg. Wieland stellt fest, daß in Frankreich unstabile innere Verhältnisse herrschen. Ein Beweis dafür ist für ihn die törichte Forderung, daß jeder $\mathrm{Haß}$ gegen das Königtum schwören solle. Das französische Volk habe erkannt, daß die Worte seiner Führer von Gleichheit und Freiheit nur Worte seien. Jetzt, da das Direktorium diesen Eid fordere, greife es zu Schlagworten, was ein Beweis für die innere Schwäche der Republik sei. ${ }^{268}$

Dagegen war Wieland nicht bereit, den Versicherungen zu glauben, die Frankreichs militärische Schwäche beweisen wollten. Er stellt fest, daß die Offensivpolitik Frankreichs und seine Bestrebungen, eine Universaldemokratie zu errichten, bewirkt hätten, daß sich ganz Europa zu einer großen Koalition zusammenzuschließen beginne, die die Pläne Frankreichs unterbinden könnte. Wieland hatte jedoch nicht die Absicht, die Monarchien zu militärischem Vorgehen gegen Frankreich aufzufordern. Er begründet dies mit dem zu erwartenden großen Menschenverlusten. Seines Erachtens gäbe es auch eine friedliche Lösung. ${ }^{269} \mathrm{Als}$ Lösung schlägt er das System Napoleons vor.

Seiner Auffassung nach sei die Situation in Frankreich reif für eine Diktatur. Der geeignete Diktator sei niemand anderes als der General Buonaparte. Nur dieser könne das französische Volk wie ein »wildes Pferd» behandeln, das ibrauche dieses Volk. ${ }^{270}$ Und Napoleon könne auch die Angelegenheiten des Deutschen Reiches ordnen. Das Reich sei mit allem am Ende. Wie viele seiner Zeitgenossen sah Wieland ein, daß das Deutschtum mehr eine Bildungsaufgabe als ein politisches Organ war. ${ }^{271}$

266 Wahl (1914) S. 244.

267 Ibid. S. 246.

268 NTM 1798 I S. 279-284 und II S. 36. Auch: Wieland, C. M., Ueber den Staatseid ... 1799.

269 Wieland, C. M. Gespräche unter vier Augen, S. W. Bd. 31, S. 220-223.

270 NTM 1798 I S. $185-287$.

271 Kemiläinen (1956) S. 27, 251. 
Die Deutschen seien keine Nation sondern zusammengewürfelt aus über 200 größeren und kleineren, noch kleineren und winzig kleinen Völkern und Volksresten. Es sei vergeblich zu erwarten, daß dieser Block plötzlich zu einer Nation werde, die mit vereinten Kräften zusammen aufstehe und ihre Mittel, ihre Körper und ihre Leben opfere, um den Bestand der unerträglich gewordenen Verfassung zu verlängern und die hohen Privilegien des römisch-kkatholischen Rittertums beizubehalten. Man spreohe viel vom Wiedererwachen des alten Nationalgeistes und berufe sich auf die Taten Franz von Sickingens oder Ulrich von Huttens zur Rettung des Vaterlandes. Das sei aber nutzlos. Die Integrität des Reiches interessiere den größten Teil des Volkes überhaupt nicht. Diese bedeute nur den Rittern etwas, den eigentlichen Bürgern des Reiches. Aber auch deren Begeisterung zur Verteidigung des Vaterlandes lasse zu wünschen übrig. Das Deutsche Reich sei ein altes gotisohes Erbschluß und die Familie, die dort wohnen wolle, müsse sehr große Ausbesserungsarbeiten vornehmen, bevor sie darin gemütlich wohnen könne. Wenn nur ein fremder Baumeister das Gebäude reparieren könne, sn solle man ihm die Arbeiten überlassen. Es sei zwecklos, zu fest an den außenpolitischen Forderungen festzuhalten. Frankreich handele nämlich letzten Endes nicht so falsch, wenn es das Rheinland, das es erobert habe, behalte. Die Eroberung des Rheinlandes sei so wenig gesetzeswidrig wie die Teilung Polens oder die Streichung der Republik Venedig von der Weltkarte. In der Außenpolitik müsse man nicht auf Rechtsparagraphen starren, sondern von den Tatsachen ausgehen. Ein Faktum sei, daß Frankreich das linke Rheinufer in seinen Besitz genommen habe und es freiwillig nicht wieder freigeben werde. Es gehe nicht darum, ob man vom Deutschen Reich fordern könne, im guten auf einen so wichtigen Teil seines Staatskörpers zu verzichten, sondern darum ob man das Deutsche Reioh zur Rüokeroberung dieser Gebiete auffordern könne, d.h. ob man mit kühlem Verstand und gutem Gewissen zur Weiterführung des Krieges raten könne. Wieland verneint diese Frage. Eine Zusammenarbeit zwischen Österreich und Preußen sei unwahrscheinlich, und wenn sie zustande käme, so sei trotzdem ein militärischer Sieg Deutschlands gar nicht sicher. Im Gegenteil sei eine völlige Niederlage für Deutschland sicher. Deutschland könne noch dürfe den Krieg weiterführen. Man starre vergeblich auf die Wunschträume guter Patrioten. Alle Politik müsse sich auf die Rettung des Ganzen gründen. Um das Leben zu retten, müsse man ein Glied opfern. Dafür spreche auch, daß sich der Revolutionismus im Lande mehr verbreitet habe, als man im allgemeinen annehme. Die Weiterführung des Krieges könne eine allgemeine Revolution auslösen. Mit der Abtretung des 
Rheinlandes könne man mit gutem Willen zu einer Neuorganisation kommen, die für das Reich noch von Nutzen sein könne. Duroh die Säkularisierung der geistlichen Fürstentümer und anderer Territorien könne man die Fürsten, die am linken Rheinufer Gebiete verloren hätten, voll entschädigen. Dies würde dem geistlichen Leben nützen und das Reich befestigen. ${ }^{272}$ Für FRIEDRICH SENGLE, dem Biographen Wielands, sind die „Gespräche unter vier Augen» ein Plan zur Rettung Europas. Das chaotische Frankreich würde sich unter einer Diktatur zusammenschließen und das erstarrte und zerstrittene Deutschland würde sich durch eine Verfassungsreform und unter Druck Napoleons erneuern. Zwischen beiden würde dann der langensehnte Frieden geschlossen. Das wäre eine harmonische Lösung der Entwicklungskrise der europäischen Völker. ${ }^{273}$

Es ist natürlich, daß die oben geschilderten Gedanken im Jahre 1798 auf wenig Widerhall stießen. Wieland stieß vielmehr auf heftige Kritik von allen Seiten. Goethe verspottete die Dialoge als Bastarde eine aristodemokratischen Ehe ${ }^{274}$ und forderte zusammen mit Sohiller Wieland auf, sie zu erdrosseln und in aller Stille im Keller zu begraben. Auch Wielands Mitherausgeber Böttiger sprach nach dem dritten Dialog offen von »allerlei Dummheiten» und versuchte, einen weiteren Abdruck im »Merkur» zu verhindern. ${ }^{275}$ Insgesamt erschienen im »Merkur» vier Gespräche, aber an anderer Stelle konnte man sie weiterverfolgen. Sogar die Zensur in Wien beachtete die Voraussagen des alten Wieland und verbot das Erscheinen eines Sonderdruckes. ${ }^{276}$ Die Kritilk kann jedoch die politische Scharfsichtigkeit Wielands nicht bedeutungslos machen — sein Programm wurde ja in der ausführlich vorgetragenen Form bei den allgemeinen Anordnungen nach dem Frieden von Lunéville im Jahre 1803 durchgeführt.

Nach dem Erscheinen der »Gespräche unter vier Augen» beendete Wieland seine Tätigkeit als politischer Schriftsteller fast völlig. Er zog sich von der Redaktionstätigkeit am »Merkur» zurüak und die Verantwortung ging ganz auf Böttiger über, der in diesen Jahren recht unterschiedliohe politische Positionen vertrat. ${ }^{277}$

Im Laufe des Jahres 1799 schien die allgemeine Meinung in Deutschland trotz der relativ zahlreichen und bedeutenden Ausnahmen eine stark

272 NTM 1798 I S. 355-373, 380.

273 Sengle (1949) S. 453.

274 ibid. 452.

275 Wahl (1914) S. 246.

276 Ibid. S. 247-248.

277 NTIM 1799 III, Vorbericht. 
kriegerische Haltung angenommen zu haben. Andauernde Demütigungen und der ohne Zweifel nationale Zustand der Erniedrigung, in dem Deutschland seit der Mitte der neunziger Jahre lebte, hatten die kriegerische Stimmung sich ausbreiten lassen und die zeitweilige günstige militärisch-politische Lage für die Koalitionsstaaten begünstigte die Aktivitäten. Im folgenden Jahr kam es dann ebenso plötzlich zu einem Meihungsumschwung, als sich die militärische Lage deutlich zugunsten der Franzosen veränderte. 


\section{NIEDERLAGE UND UNTERGANG DES DEUTSCHEN REICHES}

\section{Rückkehr Napoleons und Niederlage der Koalition}

Mit Ende des Jahres 1799, als die völlige Vernichtung der Französischen Revolution und der Republik nicht mehr weit zu sein schien und als man in Deutschland stärker als während der Kriege einen entscheidenden Schlag gegen den Erbfeind forderte, kam es jedoch zeiner völligen Wende. An allen Fronten mußten die Koalitionsarmeen Mißerfolge hinnehmen. Masséna konnte Suworow schon im September in der Schweiz schlagen, und es folgte der berühmte aber folgenschwere Rückzug über die Alpenpässe zu den Österreichern. Der eigensinnige Suworow war jetzt gegen ein gemeinsames Vorgehen mit den österreichischen Truppen und beschränkte sich darauf, nur die Schweiz zu verteidigen. Erzherzog Karl war deshalb auch gezwungen, sich vom Rhein zurückzuziehen. So wandelte sich die strategische Lage bis zum Ende des Jahres schnell zugunsten Frankreichs. Auch an der Front in Holland mußten die Verbündeten Mißerfolge hinnehmen, und aus den geplanten Angriffen gegen Frankreich auch von dieser Richtung wurde nichts. ${ }^{1}$

Die Lage hatte sich also eigentlich schon vor der Rückkehr Napoleons aus Ägypten im Oktober 1799 geändert. Trotzdem brachte seine Rückkehr die Entscheidung und besiegelte in vieler Hinsicht sowohl das zukünftige Schicksal Frankreichs als auch der Koalitionsstaaten. Einen Monat nach seiner Rückkehr übernahm er die Macht in dem sog. Staatsstreich vom Brumaire-Monat, der unmittelbar Frankreichs politische Machtstellung durch die so auf eine Person konzentrierte Macht verstärkte. Im Frühjahr 1800 konnte Frankreich unter seinem ersten Konsul einen großen Gegenangriff gegen die Koalitionsstaaten beginnen. Die Österreicher blieben praktisch den Angriffen wieder allein ausgesetzt. Der launische Zar Paul hatte die russischen Hilfstruppen zurückgezogen, und die Bedeutung der übrigen Verbündeten blieb gering. Die Öster-

1 Wahl (1967) S. 107-108. Hüffer II (1905) S. 222-272. 
reioher verloren an beiden Hauptfronten in Deutschland und Italien. In Italien befehligte Napoleon selbst die Franzosen und besiegte seinen Gegner in der gleichen Weise wie drei Jahre früher. An der Front in Deutschland wurde ausgeglichener gekämpft, aber Frankreichs Waffen waren erfolgreicher: Moreau drang im Frühjahr 1800 tief in Schwaben ein und zwang im Sommer die Österreicher zu einem vorläufigen Waffenstillstand. Nachdem die Kämpfe im Spätherbst erneut begonnen hatte, wurde Österreich endgültig geschlagen: In der Schlacht von Hohenlinden vom Dezember 1800 wurden die letzten einsatzfähigen Armeen Habsburgs vernichtend geschlagen, und es war nur noch eine Frage der Zeit, daß sich der Kaiser einem Frieden beugen würde. Die Erblande und Wien waren aus zwei Richtungen bedroht, als man am 9. Februar 1801 den Friedensvertrag von Lunéville unterschrieb. ${ }^{2}$

Seit 1792 befand sich das Deutsche Reich so zum ersten Mal wieder in einem Friedenszustand mit Frankreich. Ein endgültiger Friedensvertrag blieb noch bis auf weiteres aus, aber in seinen Hauptzügen wurde er schon bei den Verhandlungen in Lunéville festgelegt. Im großen und ganzen wurden die Friedensbedingungen von Campo Formio bestätigt: der Rhein wurde als Grenze des Reiches anerkannt und die Reparationsfrage wurde grundsätzlich so entschieden, daß die Säkularisation und möglicherweise die Mediatisierung für die geistlichen Territorien und die weltlichen Kleinstände durchgeführt werden sollte. Besonders demütigend erscheit die Bedingung, auch die wichtigen Befestigungen rechts des Rheins - u.a. die während des Zwischenfriedens mit großem Aufwand ausgebauten Festungen Kehl und Ehrenbreitsstein - an Frankreich zu übergeben. Deutschland war vollkommen schutzlos dem von Westen drohenden Feind gegenüber. Österreich mußte sich auch der völligen Republikanisierung Italiens und der Schweiz beugen, so dai rankreichs Stellung als unbestritten führender Staat in Kontinentaleuropa gefestigt war. Der deutsche Reichstag bestätigte den Friedensvertrag im März 1801, und die Diskussion um die endgültige Verwirklichung der Friedensbedingungen konnte beginnen. ${ }^{3}$

\section{Der Kampf um Ehre und bessere Friedensbedingungen}

Die oben geschilderte völlig veränderte Lage beeinflußte auch entscheidend die tagespolitische Literatur, die sich in Deutschland mit der

2 Wahl (1967) S. 113-119.

3 Ibid. S. 119-120. 
Frage von Krieg und Frieden beschäftigte. In Kreisen, die sich für einen Krieg einsetzten, gebrauchte man jetzt das Schlagwort von der Kriegsehre. Weil die Kreigsereignisse gezeigt hätten, daß es schwierig oder unmöglich sei, einen Sieg zu erringen, müsse man vor allem für die germanische Kriegsehre und die heroische Tradition der Deutschen kämpfen. Außerdem äußerte man fortgesetzt die Meinung, daß ein zäher Kampf Frankreich doch zu einem Frieden mit milderen Bedingungen zumindest für Deutschland zwingen würde, als es bei einer Kapitulation zu erreichen seien. Die sich für einen Frieden einsetzende Literatur, die verglichen mit 1800 beachtlich zugenommen hatte, kritisierte ihrerseits diese Vorstellungen, indem sie forderte, man sollte das Blutvergießen sofort beenden.

Wie schon früher vertraten die Österreicher auch jetzt am konsequentesten die kriegerische Linie. Viele der schon erwähnten fleißigen Untertanen des Kaisers fuhren unermüdlich fort, für den Krieg zu schreiben: Haschka, Hofstätter, Leopold Alois Hoffimann und die anderen bekannten Wiener Obskurantisten lobten Erzherzog Karl und den Kaiser und beschworen den Siegesglauben oder zumindest den Kampfeswillen ihrer geschlagenen Landsleute. ${ }^{4}$ Der Kriegsdichter Johann Rautenstrauch begeisterte sich für die Truppen des Erzherzogs in dem Gedicht »Der Kampf für Frieden». ${ }^{5}$ Patriotische Schrifte für einen Krieg erschienen noch um 1800 überall in den Ländern Habsburgs. Viele Schriftsteller blieben anonym. Als Beispiel für eine solche anonyme Schrift läßt sich die 1800 in Freistadt in Oberösterreich erschienene Flugschrift »Etwas über Krieg und Frieden an die Fürsten, Herren, Bürger und Bauern Deutschlands» anführen. Wie man schon nach der strengen Standesteilung in der Überschrift schließen kann, strotzt die Schrift von Konservatismus und Angriffen auf die Revolution. Die Franzosen hätten immer »den gutmüthigen Deutschen» betrogen. Das ganze französische Volk zeiohnen sich durch List und Falschheit aus; die Franzosen seien grausam, hochmütig und Verbrecher, »sie waren immer gefährliche Taschenspieler, ausgelernte Gauner, Windbeutel, Schwätzer, Prahler, Heuchler, Lügner und Beutelschneider». Diese Schurken hätten zu Beginn des Krieges Freiheit und Gleichheit, den Palästen Krieg und den Hütten Frieden erklärt. Die Deutschen hätten sich so selbst an der Nase herum geführt. In Wirklichkeit hätten die Französischen Marodeure die Messen, die sittliche und bürgerliche Ordnung gestört. Sie würden von Frieden sprechen, aber in Wirklichkeit hätten sie ihn nie gewollt. Ihre Führer beehrte die Flugschrift mit der Bezeichnung »Sprudelköpfe», und besonders Napoleon Bonaparte, dessen

4 Hüffer (1878) S. 152.

5 Etwas über Krieg und Frieden ... 1800 S. 3-7, 12-13. 
Herkunft man völlig dunkel erklärte, behandelte man mit Vorbehalten und Haß. Man spottete über iseinen Zug naah Ägypten und versicherte, daß es keinen Grund geben würde, daran zu glauben, er werde in Europa einen Frieden zustande bringen. Da es keine Hoffnung auf einen Frieden gäbe, müsse man den Widerstand verstärken. Die Schrift endet mit einem Aufruf an die deutschen Bauern, sich zu bewaffnen, ihr Land entschlossen $\mathrm{zu}$ verteidigen und dann den Angreifer $\mathrm{zu}$ einem Frieden $\mathrm{zu}$ zwingen:

»Auf also zum letztenmal fürs Vaterland! Gott ist mit Euch! Gott und der Erzherzog mit seinen Helden! Auf! Nicht zum Angriff! Nein! Zur Vertheidigung, zum Schutze Deutschlands! Wer solls vertheidigen, wenn seine Kinder es nicht thun? Auf zur heiligsten Pflicht! — - Auf also in Gottes Namen! — Erst Sieg und dann Friede.» 6

Sohriften mit der gleichen Tendenz und andere Veröffentlichungen erschienen in großer Zahl in den verschiedenen Teilen des Reiches. Es schien, als ob Österreich trotz der Verschlechterung in der militärischpolitischen Lage seine Einigkeit bewahrt hatte. ${ }^{7}$

Österreich erhielt auch wieder Schützenhilfe aus dem Reich, dieses Mal besonders aus der Schweiz, wo die Konservativen ihre Zukunft besonders eng an den Erfolg der Habsburger Waffen gebunden hatten und wo man deshalb wollte, daß die Österreicher den Kampf möglichst entschlossen fortführen würden. Schweizer Sơhriftsteller zogen nach Östrreich und viele standen direkt in Wiener Diensten. Johannes von Müller verfaßte weiterhin Texte gegen den Frieden. ${ }^{8}$ Ein anderer aktiver Schriftsteller war Carl Ludwig von Haller, ein Berner Patrizier, der sich wie viele seiner Standesbrüder vor den Anhängern der Republik Helvetia und den Franzosen nach Österreich zurückziehen mußte. Er veröffentlichte zahlreiche Flugschriften, in denen er sich gegen Frankreich wandte. ${ }^{9}$ Besonders heftig war die in Nürnberg 1800 annnym erschienene Schrift »Was ist besser Krieg oder Frieden mit den Franzosen?», in der Haller die Situation nach den französischen Siegen untersuchte. Die Greueltaten der französischen Truppen in de besetzten Ländern wurden im Geiste der Jahre 1796 und 1799 beschrieben. Frankreich würde seine Freunde wie seine Feinde berauben. Es sei unmöglich mit ihm in Frieden zu leben. Besonders bedau-

6 z.B. N. Berl. Mon. 1800 II: 1 S. 5-23 (St. Wydra), Ein Wort unter guten Freunden ... 1800

7 Wurzbach XXV S. 67.

8 HZ 145 1932, (Andreas) S. 70-71.

9 Haasbauer, Adolphine, Die historischen Schriften des Karl Ludwig von Hallers, Diss. Basel 1949, S. VII, XII, 7-17, 35, 113-118. 
erte Haller, daß Preußen 1798 nicht mit den anderen gegen Frankreich gekämpft habe. Auch Norddeutschland habe seiner Meinung nach nicht wirklich in Frieden leben können. Die Neutralität habe nur Frankreich Vorteile gebracht. Die Aufgabe des Rheinlandes verurteilte Haller scharf und wandte sich gegen die Reden von einer Säkularisation und von den »natürlichen Grenzen». Napoleon griff Haller leidenschaftlich an. Ihm dürfe man überhaupt nicht trauen: »oder trauet Ihr — — auf die Billigkeit, die Mässigung, die Redlichkeit des neuen Consuls, jenes Corsikaners, der in Frankreich die Gewalt an sich gerissen hat?». Die Deutschen hätten nur die Möglichkeit, mit neuen, vereinigten Kräften in den Krieg zu ziehen. Die Frieden'ssondierungen müsse man beenden und Krieg führen:

»Durch den Krieg ist schon unendlich viel gewonnen und erhalten worden, alles was Ihr noch besizet, duroh den Krieg allein kann es für die Zukunft erhalten und noch das übrige gerettet werden. - - Ja, gesegnet sey der Krieg, der diese heiligen Zweke hat! Gott wolle ihn erhalten, erweitern, ihn mit Kraft und unaufhaltsamen Nachdruck begleiten _ - - Wolle uns der Himmel vor französischen Frieden, gleichwie vor französischer Freyheit bewahren. Diese ist ärger als die drückendste Sklaverey, jener ist vergeblicher als der schräcklichste Krieg».10

Neben Haller schrieben in gleicher Weise viele Schweizer sowohl in der Schweiz als auch in Deutschland. ${ }^{11}$ In den anderen Teilen Deutschlands enschien eine Reihe anonymer Flugschriften, die mehr oder weniger heftig einem Friedensschluß widersprachen. $\mathrm{Zu}$ den leidenschaftlichsten ihrer Art gehört die zwanzigseitige Schrift »Noch ein Wort an Deutschland» vom Februar 1800. Die Schrift begann mit einer Schilderung der dem Krieg vorausgegangenen Zeit, als Deutschland die Segnungen des Friedens habe genießen können. Am Ausbruch des Krieges sei es vollkommen unschuldig. Der Herrschaftsanspruch der Franzosen sei schuld an allem. Die Schreckensschilderungen sind besonders stark. Die Franzosen seien "wie das griechische Feuer: wo sie auffielen, da brannten sie, frassen um sich und verzehrten». Die Schrift lobte neben dem Erherzog auch »den nordischen Held Suwarow» und die Helden Rußlands und Österreichs. Besonders hob man die Herkunft der Deutschen von der kriegerischen Germanen hervor, die das Römische Reich vernichtet hätten. Man ermahnte zum Patriotismus - man solle

10 Was ist besser ... 1800 S. $1-6,10,13,40-48,59-62$.

11 z.B. Müller (geb. Maisch), Wilhelmine, Gedichte an Se. Königliche Hoheit den Erzherzog Carl von Oestreich, 1799; Staehlin, Ernst Johann, Johann Caspar Lavaters Deportation nach Basel im Jahre 1799, Basler Jahrbuch 1945, S. 34, 39, 45. 
edlen Nationalgeist beweisen — und erinnerte daran, daß »wir von Thuiskons Stamme sind». Indem sich der Verfasser auf Schirach bezog, versicherte er, daß Deutschland das mächtigste Land der Erde sei, wenn man dort nur Patriotismus zeigen würde. Mit genügend Gemeinschaftsgeist könne Deutschland den Krieg gewinnen: man brauche Zusammenarbeit und Übereinstimmung »zwischen Haupt und Glieder, Kaiser und Stände». Die Schrift hielt weiterhin an der Reichsintegrität und der Unveränderbarkeit der Verfassung fest. ${ }^{12}$

Ebenso wiederholte die Schrift »Ueber die Gleichgültigkeit der meisten Teutschen» etwas ausführlicher die Forderung, daß der Kampf fortgesetzt werden müsse. Man bedauerte, daß sich so wenig Deutsche darum kümmern würden, ob sie einen guten oder einen schlechten Frieden bekommen würden. Man fragte: Woher kommen eigentlich diese »allgemeinen, den teutschen Nationalcharakter schändenden Fehler?». Die Antwort war die gleiche wie die des vorangegangenen Verfassers: „Mangel an Patriotismus». Die, die einen schnellen Frieden fordern würden, seien Feiglingc. Auch die Deutschen in den besetzten Gebieten seien »Mitbürger», die man bei der Planung von Friedensvorschlägen nicht ihrem eigenen Schicksal überlassen dürfe. Heftig kritisierte die Schrift Napoleon. Gerade er habe den Staatsstreich vom 18. Fructidor organisiert und die Ideen der Revolution nicht aufgegeben. Napoleons Graumsamkeit und seine Selbstherrlichkeit, sowie seinen menschenverschlingenen Zug nach Ägypten hob man ausdrücklich hervor. Mit der Eroberung Wiens könne er keinen Frieden herbeiführen, wie einige »Illuminaten und Revolutionsmänner» glauben würden. Der Kaiser würde nur Krieg führen, um für sein Volk einen beständigen und allgemeinen Frieden zu erreichen. Der Verfasser hoffe, daß ihn Gottes Segen bei diesem Unternehmen begleiten werde. ${ }^{13}$ Diese gegen Napoleons gerichtete scharfe Kritik, wie sie der oben genannte Sch ifitsteller vortrug, läßt sich auch bei vielen anderen finden. Sie wurde oft gebraucht, um zum Kampf zu ermuntern. ${ }^{14}$

Die trotz der veränderten Lage sich weiterhin gegen einen Friedensschluß wendende Literatur erschien so weiterhin in Österreich als auch in den anderen Teilen des Reiches. Die deutliche Mehrheit bezog jedoch schon während des Jahres 1800 die entgegensetzte Position. Der Teil der deutschen Zeitschriftenpresse, der in allen vergangenen Jahren beständig die Friedensidee vertreten hatte, sah sich jetzt in seiner Auffassung

12 Noch ein Wort an Deutschland ... 1800.

13 Ueber die Gleichgültigkeit ... 1800.

14 Vgl. Tiainen (1971) S. 102-104. Andere anti-friedliche Schriften, die Angriffe gegen Napoleon machten z.B. Anekdoten, Karakterzügen und .... 1800; Können die Europäischen Mächte ... 1800; Die Stimme Europas ... 1800; Noch ein Wort an Teutschland ... 1800. 
bestärkt, da der trotz ihrer Warnungen begonnene zweite Koalitionskrieg den Verbündeten eine verniohtende Niederlage zu bringen schien. Die aufiklärerische Presse in Preußen schrieb weiterhin einstimmig von den Segnungen des Friedens, von Aufklärung und Fortschritt, der mit einem Frieden kommen würde, und forderte die Regierung auf, ihre glückbringende Politik fortzusetzen. Woltmanns »Geschichte und Politik» jubelte über den Sturz des Direktoriums und nahm Napoleon gegenüber eine besondens zustimmende Haltung ein. Wegen der Fortsetzung des Krieges beschuldigte man die Pitt'sche Regierung und gab der Hoffnung Ausdruck, daß Georg III. selbst gegen seinen Premierminister intervenieren würde. ${ }^{15}$ Biesters "Neue Berlinische Monatsschrift» vergaß ihr Zögern vom vergangenen Jahr und setzte sich energischer denn je für den Frieden ein. Die meisten Preußen verteidigten in dieser Zeitschrift Preußens Neutralität, und obgleich man an die Heldentaten Friedrich des Großen erinnerte, betonte man, daß ein Frieden besser sei.16 Eine deutliche Hinwendung zum Frieden ist in Rambachs »Jahrbücher der preussischen Monarohie» zu erkennen, die im vorangegangenen Jahr einen sehr schwankenden Standpunkt eingenommen hatten. Jetzt erschienen im ganzen Jahrgang von 1800 Artikel, die die Segnungen eines Friedens und Friedrich Wilhelm III. priesen. Man bedauerte die Schreoken des Krieges, die dank der Weisheit der preußischen Politik Preußen nie erreicht hätten. Man dankte jetzt der weisen Neutralität, anstatt wie im vergangenen Jahr mehrmals eine Beendigung des Krieges zufordern. Sogar dem noch ein Jahr früher gehaßten Napoleon dankte man jetzt für seine Friedensbereitschaft. Ende des Jahres gab Rambach seiner Hoffnung Ausdruck, daß Friedrich Wilhelm III. einen Frieden zwischen den kriegführenden Parteien vermitteln werde. ${ }^{17}$

Während des Jahres 1800 stimmte die Presse in Preußen einem Frieden mehr oder weniger einstimmig - die Ausnahmen werden später behandelt $-z u$. Auch in den anderen Teilen Norddeutschlands war man sehr zustimmend. In der ersten Nummer des Jahres 1801 von Niemanns »Schleswig-Holsteinische Blätter» wurde im Vorwort die Hoffnung geäußert, daß ganz Europa sohnell einen Frieden ibekommen werde:

15 Geschichte und Politik 1800 I S. 1-12, III A. 302-305. Tschirch II (1934) S. 8 .

16 N. Berl. Mon. 1800 II: 6 S. $401-408$ (Biester), III: 6 S. 261-272 (J. Chr. Schmid), 1801 I S. 20-23 (Gramberg), I: 3 S. 201-203 (F. W. A. Schmidt), II: 4 S. 306-312 (Gedike) usw.

17 Jahrbücher der preußischen Monarchie 1800 I S. 5-6 (Rambach), 11 und 113-114 (From), 72, III S. 630-631, IV S. 204, 1801 I S. 231-238 usw. Hüffer, Hermann, Die Kabinetsregierung in Preußen und Johann Wilhelm Lombard, Leipzig 1891, S. 107 . Tschirch II (1934) S. 9-25. 
»Mögte die Friedenshoffnung, womit das meue Jahrhundert die Menschheit begrüsset, bald erfüllt werden! Mögte im Genusse eines dauernden Friedens die Verädlung der menschlichen Verhältnisse und Verbindungen zur Gerechtigkeit und Geselligkeit immer redlicher befürdert werden, jmmer glücklicher gelingen!» 18

Johann Smidts »Hanseatisches Magazin» verteidigte wie ein Jahr früher den Frieden. Es dankte zum Jahreswechsel von 1800 der Weisheit der Regierung von Hamburg für den Frieden, der so segensreich für die Vaterstadt gewesen sei, und verachtete die vom Kriege heimgesuchten Reichsstädte in Süddeutschland. Die Zeitschrift setzte sich auch eindeutig für die Republik und gegen die Monarchie ein.19 Napoleons Machtergreifung und die Friedensangebote veranlaßten sogar 1800 Archenholtz' »Minerva» vorübergehend in das Lager der Friedensverteidiger überzutreten, ${ }^{20}$ um aber schon Ende des Jahres wieder gegen Frankreich aufzutreten. ${ }^{21}$ Auch für den »Merkur» läßt sich die gleiche durch die Kriegsereignisse bedingte Änderung der Meinungsrichtung feststellen. In Frühling 1800 wandte sich Böttiger energisch gegen jene, die einen »Ausrottungskrieg» fordern würden, und zu Beginn des folgenden Jahres gab er seiner Hoffnung auf einen Frieden Ausdruck. ${ }^{22}$ In gleicher Weise dankte während des Jahres 1800 seine zweite Zeitschrift »London und Paris» Napoleon herzlich, in dem Böttiger und Bertuch den Rächer des Unrechts vom Fructidor sahen. Der $\mathrm{M}$ a $\mathrm{n} \mathrm{n}$ habe »das Altweiber, Dummköpfe und Schurken-Regiment (wenigstens größtentheils, Gott gebe auf immer!)» vernichtet. Napoleon sei ein »Mann von Kopf und Herz», der Verwirklicher des Geistes des Jahres 1789 und Friedensbringer. Den Frieden von Lunéville begrüßte man sehr zustimmend, und die Jahrgänge von 1800 und 1801 werden von gegen England gerichteten Artikeln und Stichen bestimmt. ${ }^{23}$

Weiter südlich kehrten Posselts »Europäische Annalen», die ein Jahr frühcr cinc sehr schwankende Haltung eingenommen hatten, wieder $7 . \mathrm{u}$ der alten den Frieden verteidigenden Linie zurüdk. In einem Überblick zu Beginn des Jahres stellte Posselt fest, daß die Aussichten auf einen Frieden gut seien. Österreich habe seine Ziele in Italien glücklich erreicht,

18 Schleswig-Holst. Bl. 1801 I, Vorbericht.

19 Hanseatisches Magazin III: 1, 1800, S. 33, III: 2 S. 289-290, IV: 2 S. 250260 usw.

20 Minerva 1801 S. 183. Tschirch II (1934) S. 14-15. Auch Archenholtz' Pseudonym Hippolytos a Lapide, Gemälde von Europa, 1801.

21 Minerva 1800 II S. 185-188. Tschirch I (1933) S. 437.

22 NTM 1800 II S. 185, 1801 I S. 3-7, 12.

23 London und Paris 1800 I S. $85-87,123-124$, II S. 50, 1801 I S. $55-57,71$. 
und andererseits habe Frankreich die Gebiete verloren, die viel zu weit von seinen Grenzen entfernt lägen, und sei jetzt sicher eher bereit, einen gemäßigten Frieden zu schließen. Das Verschwinden Rußlands vom Kriegsschauplatz sei auch sicher von Vorteil für einen Friedensschluß. Preußen sei an einem Gleichgewicht interessiert, und England sei so die einzige Macht, die fortgesetzt einen Friedensschluß zu verhindern versuche. Der Augenblick sei günstig, und man müsse ihn nutzen. Man fuhr fort die Fructidorianer zu tadeln und Napoleon für den Staatsstreich zu danken. Besonders Posselt betonte, wie seine oben erwähnten norddeutschen Kollegen, daß die neue Regierung des Konsuls Bonaparte zum Frieden zurückkehren wolle. Der Umistand, daß England den ihm von Napoleon angebotenen Frieden abgelehnt habe, rühre nur daher, daß die Regierung Englands »noch trunken vom Waffenglüok seiner Alliirten im vorigen Feldzüge» sei. Wegen der Weigerung der Verbündeten müsse Bonaparte also »den Frieden erobern» oder die Österreicher mit Waffengewalt zu einem allgemeinen Waffenstillstand zwingen. Posselt jubelte dann auch winklich, nachdem Napoleons Siege Österreich zu einem begrenzten Waffenstillstand gezwungen hatte, und er pries den Konsul. ${ }^{24}$ Eindeutig Stellung für Frankreich bezog Posselt in Zusammenhang mit den Friedensverhandlungen von Lunéville. ${ }^{25}$ Die gleiche Zustimmung äußerte Posselt auch bei seiner Kritik an England und an der »AustroRussen Koalition». ${ }^{26}$ Das unglückliche Süddeutschland, das unter dem aus der Zeitung kenne, brauche unbedingt Frieden. ${ }^{27}$

Neben den erwähnten Zeitschriften, nahmen an der Friedensidiskussion während des Jahres 1800 zwei neue, jetzt begründete Publikationen teil. Julius Graf von Soden veröffentlichte zwischen 1800 und 1801 »Der Französische Merkur» mit insgesamt 17 Heften. Obgleich den Herausgebern politische Ziele völlig fremd zu sein schienen, so ist doch eine aufklärerisch-friedensbereite Grundhaltung der Zeitschrift zu erkennen. Der Person Napoleons schenkt man viel Aufmerksamkeit, und man hoffte, daß der erste Konsul Europa den Frieden bringen werde. ${ }^{28}$ Eindeutiger behandelt Th. F. Ehrmanns in Hamburg - und nicht in MainzLeipzig, wie die Zeitschrift selbst bahauptete ${ }^{29}-1800$ in ein drei

24 Europäische Annalen 1800 I S. 248-267, II S. 25-26, 38-46, 130-143.

25 Ibid. 1801 IV S. $64-65$.

26 z.B. Posselt, E. L., Taschenbuch für die neueste Geschichte, 1801, S. 106107.

27 Europäische Annalen 1800 III S. 248.

28 Der Französische Merkur 1800 I S. 3-5, 6-7, 24-25, II S. $138-141,166$, 1801 S. 407.

29 Weller I S. 189. 
Heften erschienener Versuch "Staatswissenschaftliches Magazin» politische Fragen, der die Tradition von »Neueste Staatsanzeigen» fortsetzte. Die Zeitschrift wollte in erster Linie den Ideen der Aufklärung in Deutschland zum Sieg verhelfen. Sie kritisierte heftig die Zensur der Regienungen in den verschiedenen Staaten, Engherzigkeit und Obskurantismus, und griff besonders scharf die geistlichen Territorien an, indem sie sich bei jeder Gelegenheit für die Säkularisation einsetzte. ${ }^{30}$ Frankreich sollte die Zeilschrifl in jeder Beziehung Bewunderung, wenn sie auch den besonders radikalen Revolutionarismus ablehnte, wie den Staatsstreich vom Fructidor und seine anderen extremen Enscheinungsformen. ${ }^{31}$ Napoleon gegenüber zeigte Ehrmann Vertrauen und ibefürwortete einen Frieden zwischen Frankreich und Deutschland. Die Regierungen der zweiten Koalition, Österreich, England und besonders Rußland wurden fortgesetzt angegriffen. ${ }^{32}$ Besonders warnte man vor der Hoffnung, daß Frankreich mit Hilfe der russischen Truppen geschlagen werde. Dem barbarischen Gebaren der russischen Soldaten schenkte man viel Aufmerksamkeit: "Nie werden Böhmen und Mähren den freundschaftlichen Besuch vergessen, den sie ihnen ablegten». Die Russen hätten keine Manieren, würden mit Stiefeln in die Betten der Offiziere steigen, die Möbel in den Wohnungen zerschlagen, sie seien Säufer und Diebe.33 Einem solchen Verbündeten dürfe man nicht trauen, man müsse vielmehr unverzüglich Frieden mit Franikreich ischließen. ${ }^{34}$

Neben der eigentliche Presse behandelten auch sehr viele Flugschriften die veränderte Situation. Der größte Teil vertrat jetzt den Standpunkt, daß man mit Frankreich Frieden schließen müsse. Ein beträchtlicher Teil der sich für einen Frieden einsetzenden Flugschriften verband sich mit den Schriften, die in Deutschland nach dem Staatsstreich vom Brumaire Napoleon bewunderten. Die gleiche, Napoleon als Friedensbringer preisende Tendenz, die in den oben angeführten Zeitschriften $\mathrm{zu}$ beobachten war, ist noch deutlicher in den Flugschriften. ${ }^{35}$ Auch

30 Staatswissenschaftliches Magazin 1800 (1) S. 10, 15, 24, 57, (2) 108, 116, 139141, 152-179 usw.

31 Ibid. 1800 (1) S. 35, 55-56, Anm. S. 22-23.

32 Ibid. 1800 (2) S. 5-6, 15, 84.

33 Ibid. 1800 (3) S. 273.

34 Ibid. 1800 (2) S. 179 uns Anm. S. 195 usw.

35 Tiainen (1971) S. 103-104, 84-94. z.B. Cisrhenanien unter den Franken ... 1801; Neue und merkwürdige Staats-prophezeiung ... 1800; Die Stimme Europas . . 1800; Heinzmann, Meine Frühstunden in Paris . . 1800; Die süddeutsche Unterthanen ... 1800; Republikanischer Bruderkuss ... 1800; Wohlverdientes Todesurtheil ... 1800; Umschlag oder Appendix ... 1800; Die Stimme der öffentlichen Meinung ... 1800; Die privilegien des ... 1800; Bayerische Nationallieder ... 1800 . 
revolutionär eingestellte Schriften enschienen in großer Zahl. Die gepeinigten Bewohner Süddeutschlands, die idie sowohl von iden Armeen Frankreichs als auch von den Armeen Österreichs herbeigeführten Schrecken erfahren mußten, seien jetzt des ständigen Kampfes überdrüssig und stünden jetzt auf der Seite der Revolution. Man forderte die Vertreibung der Wiener Tyrannen, ${ }^{36}$ verurteilte idie Kriegspolitik der eigenen Fürsten ${ }^{37}$ und forderte Freundschaft mit Frankreich, was auch die französische Kriegspropaganda der gleichen Zeit betonte. ${ }^{38}$

Als typisohes Beispiel dieser Meinungsrichtung zu Ende des zweiten Koalitionskrieges in Süddeutschland soll hier die Broschüre »Über das mittägige Deutschland» angeführt werden, die in deutlich revolutionärem Geist der Gründung einer »Süddeutschen Republik»zustimmte. Die Bildung einer solchen Regierung sei durchaus möglich, und idie Republik würde auch wirtschaftlich gut zurechtkommen. Das Volk sei bereit für eine solche Veränderung. Das jetzige Regierungssystem sei in Bayern - der Verfasser was aus Bayerm - wie überall bejammernswert. Der Aidel und die Priester würden jeden Ertrag an sich reißen. Die Politik des Herzogs sei töricht, besonders:

»Die Allianz mit Rußland, die gestellten Hilfstruppen, die Widerherstellung des Malteserordens, der abscheuliche englische Subsidien-Traktat, der in idiesem so schwachbevölkerten Land noch 20000 Menschen dem Pflug und ihrem väterlichen Heerd entzieht, haben das äußerste Mißvergnügen in Bayern enregt.»

Wenn die Republik nicht anders zu erreichen sei, müsse man sie mit den französischen Bajonetten einführen. In München sei schon alles bereit »zu diesem großen Gegenstand». Ein Frieden sei erst zu schließen, wenn in Süddeutschland die Revolution verwirklicht worden sei. Erst nach der Besetzung Wiens durch die Franzosen »kann die Palme des Friedens grünen».39

Neben diesen revolutionären Schriften erschienen auch viele, die einen Friedensschluß forderten, auch wenn man gegen eine Revolution war, ${ }^{40}$ in einigen Fällen auch deshalb, weil man hoffte, so die Revolution zu

36 Sur l'Allemagne ... 1800; Wahrer Ueberblick der Geschichte ... 1800.

37 Ueber Krieg, Subsidien ... 1800; Ueber Wirtemberg an die Wirtemberger ... 1800; Danksagungsadresse von der baierischen Nation ... 1800.

38 Der französische Soldat an den deutschen Bauersmann ... 1800; Nachtrag zum französischen Soldaten ... 1800.

39 Ueber das mittägige Deutschland ... 1801.

40 z.B. Ein Wort unter guten Freuden ... 1800; Baiern nach den Bestimmungen des Friedens ... 1800; Die Zeichen der Zeit ... 1800. 
verhindern. Der Kölner Franz Eugen Joseph Freyherr v. Seida und Landensberg veröffentlichte eine Schilderung des Kriegszuges von 1799, in der man die Aggressionspolitik Frankreichs und des Firektoriums verurteilte, den zweiten Koalitionskrieg für vollkommen rechtmäßig erklärte, die Tapferkeit Erzherzog Karls und des Kaisers lobte, die Kirche verehrte und die Franzosen als Frauen- und Kindsmörder schilderte. Dabei ver sicherte man, der Kaiser habe nur immer den Frieden im Auge, weil der Krieg den Untertanen nur Leiden bringen würde. Ebensú halue das Deutsche Reich nur das Ziel eines schnellen und bleibenden Friedens. Deshalb akzeptiere der Verfasser auch den Waffenstillistand vom Sommer 1800 und erwarte von Napoleon einen ehrenhaften Frieden. ${ }^{41}$ Die Flugschriften, die zu Ende des zweiten Koalitionskrieges erschienen, erinnern in vieler Hinsicht an die zum Frieden von Campo Formio erschienen.

\section{Gentz' „Ưber den ewigen Frieden»}

Während der Schlußphase des zweiten Koalitionskrieges, die dazu führte, daß man sich im größten Teil der politischen Literatur für einen möglichst schnellen Friedensschluß einsetzte, bildeten sich zwei Gruppen, die einem Friedensschluß hartnäckigen Widerstand leisteten. Der Widerstand der konservativen Kreise in Österreich und Süddeutschland wurde schon beschrieben. Der gleiche Standpunkt wurde auch in den konservativesten Kreisen Norddeutschlands vertreten, wenn er auch recht unterschiedliche Ausprägungen fand. Von den geschilderten Konservativen in Preußen kann man den Kriegsdichter Gleim als den beharrlichsten bezeichnen. In den Jahren 1800-1801 schrieb er pausenlos Aufrufe an seine Landsleute an, Preußen und die andern Deutschen, um sie an die verlorene Kriegsehre zu erinnern und züm Kampf aufzurufen. ${ }^{42}$ Gleim schlossen sich andere an: Daniel Jenisch, Hans von Held und Friedrich Gentz verfaßten gegen Frankreich gerichtete Texte, denen noch z.B. der ehemalige Preuße Archenholtz und der zukünftige Preuße Ernst Moritz Arndt folgten.43 Der aus dem schwedischen Pommern stammende Arndt veröffentlichte 1800 zwei beachtenswerte Schriften, die sich deutlich mit den konservativesten Traditionen in Norddeutschland verbanden, die durch eine eigene romantische Grundhaltung ergänzt

41 Ein Wort für das Vereinigungsfest ... 1800; Staatsveränderungen ohne revolutionären Sinn ... 1800; Bemerkungen über den Charakter ... I-II, 1800; Betrachtungen über die letzten ... 1800.

42 Körte (1811) S. 533-535, Tschirch II (1934) S. 29.

43 Tschirch II (1934) S. 3-43. 
wurden. Die Reiseschilderung »Reisen durch einen Theil Deutschlands, Ungarns, Italiens und Frankreichs in den Jahren 1798 und 1799» beklagte die politische Zersplittenung Deutschlands und erklärte, daß gerade diese vielen Greueltaten der Franzosen am Rhein ermöglicht hätte. ${ }^{44}$ In seiner Schrift Ein mensohliches Wort über die alten Republiken» verurteilte Arndt die französischen Revolutionäre, weil sie vom Weg der antiken Republiken abgewichen seien. ${ }^{45}$ Ähnlich argumentierte eine zuerst anonym erschienene Schrift Friedrich Ludwig Jahns, des späteren Kampfgefährten Arndts. ${ }^{46}$ Auoh die Romantiker Novalis und die Gebrüder Schlegel im Umkreis der Zeitschrift »Athenäum» vertraten die gleiche Position, wenn auch etwas indirekter und weniger politisch. ${ }^{47}$ Ü.berall in Norddeutschland erschienen gleichgerichtete Schriften. Girtanner setzte in Göttingen seine Kritik an der Revolution fort, ${ }^{48}$ und Marcard veröffentlichte in Oldenburg zahlreiche Flugschriften. ${ }^{49}$ Die Bewunderung Napoleons, die gleich nach dem Brumaire in den konservativen Kreisen Deutschlands ziemlich allgemein verbreitet war, ließ sie nur für einen Augenblick ihre kriegerische Einstellung mit der Hoffnung aufgeben, daß man sich mit dem neuen Machthaber Frankreichs arrangieren könne. Ende des Jahres 1800 und im folgenden Jahr war dann wieder eine kriegerische oder zumindest eine gegen Frankreich gerichtete Einstellung vorherrschend. ${ }^{\mathbf{5 0}}$

Die Haltung der konservativen Kreise Norddeutschlands in der Friedensfrage faßt Friedrich Gentz in seiner Untersuchung »Über den ewigen Frieden» zusammen, die im Dezember im »Historischen Journal» erschien. Sie verdient eine nähere Untersuchung, weil sie von interessanten theoretischen Erwägungen ausgeht. Schon ein Jahr früher hatte Gentz seinen die Revolution und den mit Frankreich geschlossenen Frieden ohne Einschränkungen ablehnenden Standpunkt präzisiert. Während des Jahres 1800 zeigte Gentz wie viele andere Bewunderung für den Staatsstreich Napoleons und überprüfte sogar seine Haltung gegenüber

44 Fahrner, Rudolf, Arndt (1937) S. 87; Müsebeck, Ernst, Ernst Moritz Arndt (1914) S. 65-66; Ruth, Paul Hermann, Arndt und die Geschichte (1930) S. 4-5.

45 Meisner, Heinrich, Ernst Moritz Arndts Leben und Schaffen (1909) S. 17.

46 Tschirch I (1933) S. 332-333.

47 Grauert (1939) S. 117-118, 124; Wieneke, Ernst, Patriotismus ud Religion in Friedrich Schlegels Gedichten (1913) S. 16-18, 66; Athenäum 1800 I S. 20 und II S. 56, 79, 133 und 165.

48 Girtanner, Christoph, Historische Nachrichten und politische Betrachtungen über die französische Revolution, Heft 1-17, 1791-1803. Girtanner starb im Jahr 1800; bis seinem Tod hatte er eine sehr heftige schriftliche Tätigkeit.

49 Tschirch I (1933) S. 418.

50 Vgl. Tiainen (1971) S. 104. 
dem Frieden. Gentz begrüßte Napoleon als den Mann, der die Revolution beendet habe, und erwartete von ihm, daß er einen Frieden zustande bringen werde. ${ }^{51}$ Dieses Vertrauen wurde schon während des Frühjahrs von Enttäuschung abgelöst, und das »Historische Journal» kritisierte erneut Frankreich und seine Kriegspolitik. ${ }^{52}$ Im Dezember präzisierte Gentz dann seine Position in der erwähnten Sohrift.

In der Einleitung zu seinem Artikel übernimmt Gentz den Gedanken des vaterländisch-christlichon Philosophen W. T. Krug, einem Gegner Kants, daß Kriege unvermeidbar seien: die Völker leben im Naturzustand wie die einzelnen Menschen untereinander in einem ständigen Krieg. Nur ein Bund zwischen den Völkern könne seiner Meinung nach einen ewigen Friedenszustand herbeiführen. Dieser sei aber nicht zu verwirklichen. Gentz hielt einen solchen Friedenszustand in jedem Fall für besser als die Fortsetzung ständiger Kriege. Die viel gelobten Vorteile der Kriege könnten auch nie die von ihnen verursachten Nachteile aufheben:

»Der ewige Friede, oder vielmehr die völkerrechtliche Verfassung unter den Staaten, die man als die Grundlage des ewigen Friedens anzusehen pflegt, ist kein willkürliches Hirngespenst einer dichternden oder träumenden Einbildungskraft, sondern eine ernste, tiefe, überschwenglich große Idee, eine bestimmte Aufgabe, sogar eine Forderung der Vernunft, ein notwendiges Resultat der fortschreitenden Entwicklung unserer Begriffe von Recht und Ordnung und Sittlichikeit in dem grossen und Ganzen der Menschen-Verbindung».

Für die Streitigkeiten der Völker müsse es einen eigenen Gerichtshof geben. Bis dahin würden die Beziehungen der Völker untereinander von Anarchie beherrscht werden. Einzelne Verträge seien unzureichend. Die Vernunft sagt, daß es unvernünftig sei, Streitigkeiten durch Kriege zu entscheiden, aber trotzdem gäbe es immer Kriege. »Es soll kein Kriege seyn» werde eine vergebliche Fordenung sein, obgleich sie natürlich bcrcchtigt sei. So sei es "nichts weniger als unnütz, zu zeigen, wie und wanum der ewige Friede ein ewiges Ideal der Vernunft seyn muss».53

Theoretisch gäbe es drei Mittel, um zu verhindern, daß Streitigkeiten der Völker einen Krieg hervorrufen würden: die absolute Vereinigung der Nationen zu einem Staat, die absolute »Absonderung» der Völker von einander und schließlich die Schaffung einer gemeinsamen Organisation der Völker zur friedlichen Schlichtung der Streitigkeiten. Seine ersten zwei Vorschläge verwarf Gentz sofort wieder. Sie würden bedeuten, daß man den Knoten durchschneide und nicht löse. Er

51 Historisches Journal Jan. 1800 S. 102-103 und Febr. S. 107, 208-220.

52 Ibid. May S. 92, Juli S. 193-271 und Aug. 298-404.

53 Ibid. Dez. S. $711-719$. 
begründete ausführlich, warum die Vereinigung der Völker zu einem Staat die von den jetzigen Regierungen verursachten Streitigkeiten beseitigen würde. Der Versuch eine solche Universalmonarahie - die Universalrepublik erwähnte Gentz überhaupt nicht - zu gründen, würde jedoch seiner Meinung nach mehr Unglück bringen als all die Kriege, zu denen es nicht kommen solle. Die Weltherrschaft eines einzigen Staates würde die Ursachen ider Kriege nicht beseitigen. Es sei ein verlockender Gedanke, die Welt in Ermangelung natürlicher Grenzen in zwei oder drei Universalmonarchien aufzuteilen, aber die Oberherrschaft des Krieges bestehe trotzdem. Je mehr man diese gigantische Idee überdenke, desto eindeutiger sei sie zu verwerfen. Z.B. sei ein Europa unter einer einzigen Regierung unvorstellbar. Die politische Einigung Europas würde nicht die Ursachen für die inneren Kriege beseitigen. Die Einigung würde entweder nur $\mathrm{zu}$ einer erbarmungslosen Tyrannei und Sklaverei oder $\mathrm{zu}$ Anarchie und Zwietracht führen. Rom sei kein rühmenswertes Beispiel gewesen. Aus Blut und Trümmern sei die Welthernschaft dieses Universalreiches entstanden und in Blut und Trümmern sei sie wieder versunken. Die »Absonderung» der Völker könne andererseits auch keine richtige Lösung sein, obgleich man besonders in der zweiten Hälfte des 18. Jahrhundert die Auffassung vertreten habe, daß kleiner Staatswesen glücklicher seien. Solche Kleinstaaten seien nur verführerische Angriffsobjekte. Die ganze Wirtschaft der Welt verlange Zusammenarbeit, so daß eine Trennung der Völker von einander auch gegen das Streben der Menschheit nach Wohlstand gerichtet sei. Fichtes Vorstellung von den von einander getrennten Nationen (»Der geschlossene Handels-Staat», Tübingen 1800) akzeptierte Gentz nicht.54

Als einzig mögliche Alternative bleibe die Gründung einer internationalen Organisation. Die Entstehung der Nationalstaaten, besonders von mittlerer Größe (Frankreich, Spanien, England, Rußland, die großen Monarchien in Deutschland) akzeptierte Gentz: weniger Staaten geben weniger Anlaß zu Kriegen. Man müsse nun zwischen zwei praktikablen Entscheidungen wählen. Man könne zum Zustand von 1792 zurückkehren oder eine neue Aufteilung unter Berücksichtigung der Ergebnisse der Französischen Revolution vornehmen. Gentz Entscheidung entsprach seiner konservativen Grundhaltung:

»Mit dem Theilungs-System kann überall kein Völkerrecht bestehen; und so lange noch eine Revoluzion für eine erlaubte Unternehmung gilt, darf man überhaupt nicht von $\mathrm{Recht}$ in der bürgerlichen Gesellsohaft sprechen».

54 Ibid. S. $719-736,740-751$. 
Revolutionen würden in der Regel für längere Zeit einen Frieden unmöglich machen. Ein freier Vertrag zwischen den Völkern sei also besser. Dieser könne mit der Rückkehr zu den alten Grenzen erreicht werden. Frankreichs Erklärung, daß man nicht mehr zu den alten Grenzen zurückkehren könne, sei ideshalb zu verurteilen. Die Französische Revolution habe den Völkern deutlich gemacht, daß ein besseres und friedensgemäßeres internationales Syistem notwendig sei. Ein Schiedsgericht könne mit einem ständigen Kongrel3 geschatien werden, wie St. Pierre es vorgeschlagen habe. Gentz trug auch die Gedanken des Abbé ausführlich vor, kam aber zu einem sehr pessimistischen Ergebnis über die Aussichten auf einen ewigen Frieden. Zur Verwirklichung der Idee von einem ewigen Frieden müsse man die Idee von einem vollkommenen Staat verwirklichen, was jedoch unmöglich sei:

"Der ewige Friede ist freilich eine Schimäre: aber er ist nur in sofern als eine vollkommen rechtliche Verfassung unter den Menschen überhaupt eine Schimäre bleibt. Wir isollen nach beiden mit Ernst und Muth und unermüdeter Thätigkeit streben; aber so lange wir Menschen sind, werden beide unerreichbar für uns seyn.»

Obgleich Gentz die Aussichten auf die Verwirklichung eines ewigen Friedens nur sehr pessimistisch beurteilte, forderte er, daß man ständig nach einem ewigen Friedenszustand streben müsse. Interessant ist seine Vorstellung, daß das Problem wissenschaftlich gelöst werden könne: Gentz versicherte, es gäbe eine Wissenschaft, die die Wege zur Erreichung eines ewigen Friedens aufzeigen könnte, »so wäre diese unter allen menschlichen die höchiste». Trotzdem müisse man davon ausgehen, daß die Aufgabe unlösbar sei. ${ }^{55}$

Gentz beschäftigte sich auch mit einem zweiten interessanten Problem, indem er die Vorteile des Krieges theoretisch erörterte. Er begründete sein Vorgehen damit, daß man so lange wie ein Krieg nicht zu verhindern sei, auch seine nützlichen Seiten abwägen müsse. Gentz versicherte, der Krieg habe eine belebende Wirkung. »Der Krieg hat den menschlichen Geist auf Tausend Wegen entwiokelt und gebildet». Die größten Erfindungen in Wissenischaft und Kunst seien durch die Wirkung des Krieges gemacht worden. Die Industrie habe sich ausgebreitet und entwickelt, und da durch hätten sich in jeder Beziehung die Fähigkeiten der Menschen belebt. Der Krieg habe auch neue Verbindungen unter den Völker geschaffen. Auch die Verwaltung habe er intensiviert, und er habe »sogar wohlthätig auf die Bildung des Charakters gewirkt».

55 Ibid. S. $736-739,751,778,781$. 
Ein ewiger Frieden hätte im Laufe der Geschichte den Fortschritt zu sehr behindert. Trotz dieser Ausführungen versicherte Gentz, daß er grundsätzlich für einen Frieden sei. Es sei vergebens, Viorteile und Nachteile des Krieges gegeneinander abzuwägen, wenn sich der Verstand doch immer wieder gegen den Krieg wenden würde.56

Am Schluß seiner Schrift trägt Gentz seinen Standpunkt zur Tagespolitik vor. Er fragt, ob es im Jahr 1800 überhaupt Aussichten auf einen Frieden gegeben habe. Auch in diesem Punkt war er pessimistisch. Europa habe sich schon bis zum Ausbruch der Französischen Revolution sehr weit auf einen stabilen Friedenszustand zubewegt und schon »einige bedeutende Schritte - - zu einer friedlichern Völker-Verfassung» getan. Bedeutungsvoll sei die Entwicklung neuer volkswirtschaftlicher Prinzipien (Physiokratismus, Smith) gewesen. Anfangs sei es der Französischen Revolution geglückt, viele auf ihre Seite zu ziehen, aber jetzt sei die Wahrheit aufgedeckt worden: der Umsturz habe zu einem schreoklichen Weltkrieg geführt. Frankreich und die Revolution würden die Sohuld tragen, daß man einem Frieden überhaupt nicht näher gekommen sei, geschweige denn einem allgemeinen und einem ewigen Frieden.57

Gentz' Schrift »Über den ewigen Frieden» erinnert im Titel, im Aufbau und teilweise in ihrer Argumentation an Kants fünf Jahre früher erschienene Veröffentlichung. Sie ist aber von einem völlig anderen Geist bestimmt. Während Kants Schrift zur Zeit des Baseler Friedens von einer stark optimistischen Grundstimmung getragen wird, die einen allgemeinen Frieden für möglich hält, verdichtet sich in Gentz' Ausführungen die tiefe Enttäuschung, die die vergangenen Kriegsjahre in den Kreisen der Gebildeten hervorgerufen hatte. Gentz' Schrift griff besonders die aufgeklärten Kreise in Norddeutschland an, die davon träumen würden, daß sich bald nach einem Friedensschluß ein ewiger Frieden einstellen werde. ${ }^{58}$ Die Schrift selbst äußert sich über die Möglichkeiten für einen Frieden pessimistisch und ist keineswegs kriegerisch eingestellt, aber sie läßt alle Möglichkeiten offen, um vom gleichen Standpunkt aus auch zú einer offenen kriegerischen Alternative zu kommen. So ist Gentz bei anderen Gelegenheiten viel eindeutiger gegen einen Frieden aufgetreten, wobei er auch die französische Politik verurteilte und die Höfe Europas zur Fortsetzung und Verstärkung des Widerstandes aufrief. ${ }^{59}$ Das Ende des Krieges durch einen völligen Sieg Napoleons machte

56 Ibid. S. 775, 782-784.

57 Ibid. S. 786-789.

58 Rauhanajatus historiassa, (Aira Kemiläinen, 1970) S.

59 Gentz, Friedrich, Von den politischen ... 1801, z.B. S. 14; dess., Ueber den Urspring ... 1801. 
Gentz' Aufenthalt in Berlin unmöglich, und im folgenden Jahr zog der Schriftsteller-Politiker nach Wien, dem Zentnum der gegen die Revolution gerichteten Aktivitäten, um seine Karriere in österreichischen Diensten fortzusetzen. ${ }^{60}$

\section{Der Frieden von Lunéville}

Die Unterzeiohnung des Friedensvertrages vion Lunéville im Februar 1801 rief noch einmal eine besonders heftige öffentliche Diskussion hervor, in der man überall in Deutschland die Friedensibedingungen diskutierte. Wie sich aus der Richtung der Diskussion im vorangegangenen Jahr schließen läßt, war man allgemein mit dem Ergebnis des Friedens zufrieden. Die verbittersten Kreise, wie die oben geschilderten zur romantisch-konservativen Richtung gehörenden Schriftsteller und Journalisten in Norddeutschland - die in all den Jahren nach 1795 die Kriegsereignisse als Beobachter verfolgen konnten, ohne persönlich die schlechteren Seiten des Krieges erfahren zu müssen - akzeptierten den Frieden von Lunéville überhaupt nicht, sondern stempelten ihn als schändlichen Diktatfrieden ab, den man in seiner Art nur als zeitlich begrenzt $\mathrm{zu}$ betrachten habe. Dem schlossen sich einige Österreicher an, wenn auch jetzt das öffentliche Wort in Österreich besser als 1797 die Entscheidung seiner Regierung verteidigte. Bedeutend ist der Widerspruch der radikalen Anhänger der Revolution, die die Auffassung vertraten, daß Napoleon die Sache der Revolution verraten und den Kriegszug ganz ohne Grund abgebrochen habe, der sonst zu der Revolutionierung von ganz Deutschland geführt hätte. Schließlich gab es noch jene, die dem Frieden nicht direkt widersprechen, aber seine wichtigsten Bedingungen so kritisierten, daß man sit zum Lager der Friedensgegner rechnen muß. Zu ihnen gehörten vor allem die Vertreter der sog. bedrohten Reichisstände, die jetzt ihr Schicksal endgültig gekommen sahen, das ihnen schon seit dem Frieden von Campo Formio gedroht hatte.

Die Mehrheit der Reaktionen war zustimmend. Die Zeitschriftenpresse trat in diesem Fall fast geschlossen auf. Die Zeitschriften Preußens äußerten ihre Freude über die gute Entscheidung des Kaisers und schloßen daran den Hinweis an, daß man den Frieden auch schon früher hätte schließen können. Die unerschütterliohe Friedenspolitk der eigenen Regierung wurde bei passender Gelegenheit als vernünftig, human,

60 ADB Bd. 8. (Beer) S. 593. 
christlich und ehrenhaft gepriesen. Mit besonderer Begeisterung wurde in Woltmanns »Geschichte und Politik» der Frieden begrüßt, indem man sowohl religiöse als auch nationale Argumente gebrauchte. Es sei für ganz Deutschland, ein ehrenvoller und glücklicher Frieden, der es vor allem Norddeutschland ermögliche, sich im Schutze des preußischen Aidlers zu entfalten. Woltmann warnte vor dem falschen Gebrauch von Glauben und Nationalgeist und forderte alle auf, den Frieden zu akzeptieren:

»Jesus und Herrmann sind die beiden glänzenden Namen, oben an die Hallen der Welt geschrieben sind, des großen Tempels der Menschheit, in welchen mehr Völker als Brüder eingehn, einst alle als Brüder eingehn werden. In den düsteren Zeiten schimmerte unter Jesus eime Schrift »Römischer Bischof» und unter Herrmann »Römischer Kaiser».61

Auch in Rambachs »Jahrbücher»62 und Biestens »Monatsschrift» 63 wurde der Frieden gepriesen. Eine Gruppe von Provinzzeitschriften schloß sich diesem Chor an. ${ }^{64}$ In anderen Teilen Norddeutschlands unterstützte in bekannter Weise die aufklärerische Zeitschriftenpresse das öffentliche Wort in Preußen. Hennings »Genius der Zeit», Niemanns »Schleswig-Holsteinische Blätter», Smidts »Hanseatisches Magazin», der »Neue Teutsche Merkur» und »London und Paris» der Weimarer begrüßten alle den Frieden von Lunéville mit Freude.65 Böttiger, der zeitweise eine sehr kriegerische Position vertreten hatte, verfaßte zu Ehren des Friedens von Lunéville wohlgebaute Sätze:

»Jetzt, wo der Friede sein segensvolles Füllhorn über erschöpfte Länder auszugießen verspricht, jetzt dürfen neue Hoffnungen den Kunstfleiss wieder beleben, und Kunstliebhaber zur freundlichen Aufmunterung der Talente wieder in Thätigkeit bringen».66

Posselts »Europäische Annalen» zeigten offene Begeisterung über den Frieden. Posselt pries Napoleon als Friedensbringer und tadelte besonders England deswegen, weil es immer noch den hoffnungslosen Krieg fortsetze. $^{67}$ In den $»$ Europäischen Annalen» enschien auch der Text einer

61 Geschichte und Politik 1800 II-III S. 214-215.

62 Jahrbücher d. Pr. Mon. 1801 III S. 231-238.

63 N. Berl. Mon. 1801 I: 1 S. 23 (Gramberg) und I: 3 S. 201-203 (F. W. A. Schmidt).

64 Niederrheinische Blätter 1801 I S. 199-201; Magdeburg-Halberstädtische Blätter 1801 I S. 285 usw.

65 London und Paris 1801 I S. 55-57; Schleswig-Holst. Bl. 1801 V S. 453,

66 NTM 1801 I S. 316.

67 Europäische Annalen 1801 II S. 64-65, 111-116, 133. 
Flugschrift, »Blick in die Zukunft bei dem Luneviller Frieden», des Republikaners J. F. Emerioh aus dem Rheinland. Er pries den Frieden, begeisterte sioh für Napoleon und warnte die Koalitionsstaaten besonders vor der Bedrohung, die Rußland für Europa bedeute. ${ }^{68}$

Zur Ergänzung der Presse erschien wiederum eine große Zahl von Flugschriften, die noch stärker über die Rückkehr zum Frieden jubelten. Die stellenweise vertretene revolutionäre Einstellung, die in den vorangogangenon Jahren fcstzustclien war, wurde auch jetzt beibehalten. Der junge Leipziger Dozent der Philosophie Dr. Christian Friedrich Michaelis veröffentlichte $\mathrm{zu}$ Beginn des Jahres 1801 einen dringlichen Aufruf an die Menschheit und besonders an die Deutschen, sie sollten endlich die mörderischen Kriege beenden und sich zu einem einzigen großen Staat der Völker vereinigen, so wie es dem Geist der Aufklärung und der Humanität entspräche, »in weltbürgerlicher Gesinnung»:

》Gemeingeist und Weltbürgersinn fürt zu Eintracht; Eintracht ist das sicherste Mittel, der Nation ihre politische Ordnung und Freiheit zu erhalten. Die Führer der Nationen werden viel vermögen, allen Nationalhaß endlich $z u$ vertilgen, und ein gemeinseitiges Vertrauen zwischen den Völkern zu erwecken und $\mathrm{zu}$ ennähren! - - Bürgertreue, Vaterlandsliebe, Humanität!» 69

Zustimmung zum Frieden äußerte auch der große Bewunderer der Friedensphilosophie Kants Johann Adam Bergk in seiner Schilderung Napoleons, ${ }^{70}$ obgleich er dessen Vorgehen keineswegs guthieß. Begeisterung über den Frieden ist im Jahre 1801 in Flugschriften aus allen Teilen Deutschlands $\mathrm{zu}$ finden. ${ }^{71}$

Schwieriger fand man zu einer zustimmenden Haltung zum Frieden dort, wo die Niederlage zu konkreter Unterwürfigkeit geführt hatte. In Österreich hatte man bis zum Sohluß mit einem Sieg gerechnet und auch im Augenblick der endgültigen Niederlage zur Fortsetzung des Kampfes aufgefordert. Sn konnte dort der Jubel üher den Frieden nicht sehr echt klingen, wenn man auch der Entscheidung des Kaisers nicht offen widersprechen wollte. Der Haß gegenüber dem Sieger existierte immer noch. Die Stimmung in Österreich wird in den Schriften deutlich, die die Schandtaten der Franzosen in den Ländern Habsburgs schilderten. Diese Sohilderungen erinnern an die heftigste Propaganda der Kriegsjahre.72

68 Ibid. S. 213-238.

69 Aufruf an die Menschheit ... 1801 (Zitat S. 42).

70 Napoleon Bonaparte als Mensch, Bürger ... 1801. Tiainen (1971) S. 82.

71 z.B. Freymüthige Bemerkungen ... 1801; v. Hoff, Karl Ernst Adolf, Das Teutsche Reich ... 1801, Kellner, J., Freunden des Friedens ...[1801].

72 Streifzüge durch Innerösterreich ... 1801. 
Einen extremeren Standpunkt als die Österreicher vertraten diesmal die Vertreter der geistlichen Territorien. Ein Teil von ihnen - der größte Teil - kritisierte allerdings nicht den Friedensschluß an sich, sondern bekannte sich sogar zum Kaiser und seiner weisen Entscheidung, aber man protestierte scharf gegen 'die Säkularisation als Preis für den Frieden.

J. H. K. von Wessenberg, der sich früher in der öffentlichen Diskussion sehr für einen Krieg stark gemacht hatte, veröffentlichte zwei Flugschriften, in denen er den Negativismus der Zeit beklagte und Aufklärung, Christentum und Vaterlandsliebe gegen Parteigeist, Weltbürgertum und Kosmopolitismus verteidigte. Den Frieden an sich hieß er gut und versicherte, daß »das Ende eines unter ungünstigen Gestirnen geführten Krieges - - längst der Wunsch aller patriotischen Deutschen» gewesen sei. Die Reparationsfrage sei allerdings schwierig, und besonders auf die Schädlichkeit der Säkularisation wies Wessenberg eindringlich hin. Sie würde den »Untergang der deutschen Staatsverfassung, die Erniedrigung des Kaiserthrons und der Verfall des Erzhaus Oesterreichs, Unterdrückung der katholischen Kirche in Deutschland, !der prekärste Zustand aller kleinern Staaten und die augenscheinliche Gefahr derselben, von den grössern verschlungen $\mathrm{zu}$ werden, die völlige Unisicherheit alles Eigenthums» bedeuten, und »insbesondere die Folgen der Unterdrückung der geistlichen Reichsstände für jeden einzelnen Staat», die Fürsten, die Geistlichen und den Adel wären ein großer Verlust und der gemeine Bürger- und Bauernstand hätte davon nicht den mindesten Vorteil. Die patriotischen Deutschen müßten den »Säkularisations-Dämon» vertreiben. ${ }^{73}$ Auch der Würzburger Johann Michael von Seuffert führte ausführlich juristische Einwände gegen die Säkularisation an. Schon in den Jahren 1798-99 hatte er sich für die Existenz der geistlichen Staaten eingesetzt, ${ }^{74}$ und nach dem Frieden von Lunéville veröffentlichte er drei Flugschriften gegen die Säkularisation, in denen er allerdings den Frieden guthieß.75 Auch in einigen anonymen Schriften wurde dieser Standpunkt verteten. ${ }^{76}$ Die Befürworter der Säkularisation hatten es jetzt nicht nötig, genauso aktiv zu sein, denn das Problem schien gelöst zu sein, aber auch von ihrer Seite erschienen einige Schriften. Der Württemberger Beamte August Friedrich Batz verteidigte die Säkularisation, weil das

73 Der Geist des Zeitalters ... 1801, S. 37-38, 99; Die Folgen der Säkularisationen, 1801, S. 3, 16-17.

74 ADB Bd. 34. (Heigel) S. 53-58, Hamberger-Meusel VII S. 474.

75 Der siebente Artikel des Friedens von Lüneville ... 1801; Rechtfertigung des Versuchs ... 1801; Versuch einer doctrinellen Auslegung . . 1801.

76 Noch ein Wort über das Säkularisationswesen ... 1801; Wichtige Staatsfrage: Möchte die Säkularisation ... 1801; Ueber Deutschlands Verlust ... 1801. 
Reich darunter am wenigsten zu leiden hätte. ${ }^{77}$ Der Regensburger Bingel pries den Frieden von Lunéville als goldenen Frieden und tadelte die Gegner der Säkularisation, weil sie den Friedensschluß verhindern wollten. ${ }^{78}$ Diesen ischlossen sich andere an. ${ }^{79}$

Besonders viel protestierte man in Nonddeutschland gegen den Frieden von Lunéville. Diese romantisch-konservativen Schriftsteller, von denen viele während des Krieges die »sich schämende» Haltung eingenommen hatten, widersetzten sich weiterhin. Der kriegerische Oldenburger H. M. Marcard veröffentlichte die Flugschrift »Was haben die Mächte von Bonaparte zu erwarten». Die Schrift stellte einen scharfen Angriff auf Napoleon dar. Gleichzeitig fordente sie die Deutschen und die übrigen Europäer auf, sich im Kampf gegen ihre Versklavung zu vereinigen, gegen den Verräter Bonaparte. ${ }^{80}$ Archenholtz schrieb für die »Minerva» einen gehässigen Artikel über den Frieden. Der unumgängliche Verlust des Rheinlandes berührte ihn stark, und er betrachtete den Frieden von Lunéville als nichts anderes als ein Diktat des Diktators Napoleon. Er warnte, daß ein unter diesen Bedingungen geschlossener Frieden nur ein Waffenstillstand bleiben werde. ${ }^{81}$ Besonders heftig griff der junge Romantiker Arndt den Frieden von Lunéville in seiner Schrift »Der Rhein, Deutschlands Strom, und nicht Deutschlands Grenze» an, in der er eine besonders scharfe Sprache gebrauchte:

»Durch den traurigen Frieden zu Lüneville behielt Frankreich das deutsche Land jenseits des Rheins mit allen Festungen und Wehren, was aber von festen Städten diesseits des Rheins lag, ward niedergerissen und geschleift, damit Germanien, weiland der Schrecken der Jenseitswohnenden, unbeschirmt vor ihnen läge». 82

In zwei Flugschriften berichtete Gentz 1801 von der Zusammenarbeit zwischen den deutschen Hauptstaaten Preußen und Österreich gegen Frankreich. ${ }^{83} 1801$ war der Widerstand gegen den Frieden in den konservativen Kreisen Norddeutschlands allgemein noch sehr schwach, und

77 Versuch einer natürlichen Erklärung ... 1801.

78 Bedarf der siebente Artikel ... 1801, S. 3-4; Der Friede von Lüneville ist über alle ... 1801 .

79 Freymüthige Bemerkungen über das jüngste Kaiserlichen Kommissionsdekret (ist gegen die Mediatisierung der Reichsstädte, aber nicht gegen die Säkukarisation); Resultat der Reichs-Friedens-Unterhandlungen ... 1801; Ueber die gerechteste und geschwindlichste Weisen ... 1801; Patriotische Wünsche für Teutschland ... 1801.

80 Was haben die Mächte von Bonaparte ... 1801. Tiainen (1971) S. 102-103.

81 Minerva 1801 I S. $550-551,1800$ I S. $185-187$.

82 Arndt, E. M., Der Rhein ... 1801 S. 7.

83 Siehe S. 237. 
nur wenige traten damit an die Öffentlichkeit. Er ist jedoch insofern von Bedeutung, als im folgenden Jahr Stimmen gegen Frankreich laut wurden, und es langsam dann in der zweiten Hälfte des Jahrzehnts zum offenen Konflikt und zum Krieg zwischen Preußen und Frankreich kam.

Außerdem ist noch die Lauheit zu erwähnen, die einige Revolutionäre dem Frieden gegenüber zeigten. Görres, der sich als Führer der »kriegerisohen Friedensverteidiger» nach 1790 für das Rheinland eingesetzt hatte, zeigte in einer 1800 erschienenen Schrift $»$ Resultate meiner Sendung nach Paris» die ersten Zweifel am französischen System. ${ }^{84}$ Hennings, der in all diesen Jahren sich am konsequentesten für einen Frieden eingesetzt hatte, war tief enttäuscht von Napoleon, den er für den Mann hielt, der die Revolution beendet und den Senat betrogen hatte. 1800 forderte er vom Reich militärische Aktionen gegen Napoleon. Er betonte auch in einer Art, die diesem Aufklärer früher völlig fremd gewesen wäre, daß der Krieg eine moralische Berechtigung habe:

»Krieg ist nun einmal des Menschen Natur, und Bewaffnung die einzige Wehr. Von diesem Übel wird kein Erlöser uns retten, mag seine Lehre auch noch so menschenfreundlich sein».85

Hennings traute Napoleon als Friedensbringer nicht, wenn er sich auch gegen einen Friedenschluß nicht aussprechen wollte. Schriften mit gleicher Tendenz erschienen auch in begrenzter Zahl in Süddeutschland. ${ }^{86}$

Alles in allem bedeutete der Frieden von Lunéville für die politische Diskussion in Deutschland ein Vereinheitlichung der Meinungen. Die Beendigung des langjährigen Krieges beseitigte einen bedeutenden Streitpunkt, der das öffentliche Wort des Landes in zwei gegeneinander kämpfende Lager geteilt hatte. Die Stabilisierung der Regierung Napoleons, die die Republikaner der französischen Sache entfremdete, führte in diesem Punkt zu einer einheitlichen Meinung. Abgesehen von den verhältnismäßig seltenen Gegenstimmen, kann man sagen, daß in Deutschland der Frieden von Lunéville mit Zustimmung aufgenommen wurde.

84 Görres, Resultate meiner Sendung nach Paris, 1800. Kemiläinen (1956) S. 61; Berger (1921) S. 24.

85 Genius der Zeit 1800, Bd. 19., S. 10.

86 HEINRICH SCHEEL übertreibt die Weite und die Wichtigkeit dieser publizistische Tätigkeit, Scheel (1965) Siehe z.B. Die Bekanntmachung an die Bewohner ... 1801 und Ueber die Folgen des Friedens in Bayern ... [1801]. Die beiden sind nicht gerade gegen Frieden, obwohl die den Reaktion fürchten. 


\section{QUANTITATIVE UNTERSCHUNG UND SCHLUSSFOLGERUNGEN}

\section{Schwankungen im Umfang der Zustimmung für Krieg oder Frieden}

Die vorliegende Arbeit beruht auf der Untersuchung von 382 deutschen oder in deutscher Sprache schriftlich vorgetragenen Meinungsäußerungen aus den Jahren 1795 bis 1801 zur Frage 'Krieg oder Frieden'. Dazu kommen noch 139 anonyme Flugschriften, von denen wahrscheinlich ein Teil von in der oben genannten Zahl mitgerechneten Personen und ein Teil auch von den gleichen Schriftstellern verfaßt wurde. Sicher wurde für diese Arbeit nur der kleinere Teil all der Deutschen berücksichtigt, die in der Zeit zwischen dem Baseler Frieden und dem Frieden von Lunéville schriftlich und öffentlich ihre Meinung zu Krieg und Frieden als theoretische oder tagespolitische Frage vortrugen. Außerdem mußte der größte Teil der anonymen Flugschriften unberücksichtigt bleiben, weil sie für den Verfasser der Untersuchung unerreichbar blieben. Trotzdem handelt es sich um ein umfangreiches Quellenmaterial, das gewisse vorsichtige Schlüsse zuläßt, die dieser Untersuchung als Vergleichsmaterial bei der Anwendung der »historisch-qualitativen» Methode dienen können. ${ }^{1}$ Da das Material aus den verschiedenen Gebieten des damaligen Deutschen Reiches stammt, ist es als repräsentativer anzusehen. ${ }^{2}$

1 Für die Personen siehe das Personenregister am Schluss der Arbeit, für die Flugschriften das Quellenverzeichnis. Vgl. S. 7-8.

2 Der größte Teil wurde in der UB Göttingen zusammengetreten, außerdem konnte eine beträchtliche Zahl an Schriften in folgenden Bibliotheken benutzt werden: Bayerische Staatsbibliothek München, UB Wien, Österreichische Nationalbibliothek Wien, Schweizerische Zentralbibliothek Zürich, Bibliothek des British Museums, London; einzelne Schriften auch in Kongelige Bibliotek Kobenhagen, UB Upsala, UB Helsinki, UB Turku und sogar UB Jyväskylä. Durch Fernleihe wurde das material aus Bibliotheken in Leipzig, Braunschweig und Marburg vervollständigt. 
Da die politische Tagesliteratur Deutschlands auf die Schwankungen des Umfangs in der Zustimmung zu Krieg oder Frieden und auf seine zeitlichen Schwankungen hin untersucht wurde, müssen zu dem oben Gesagten einige Einschränkungen gemacht werden. Es war nicht möglich, alle Schriften der in der Untersuchung berücksichtigten 382 Personen zusammenzutragen. Abgesehen von einigen bekannteren und von der Forschung untersuchten Personen ${ }^{3}$ konnte die Klassifizierung der Meinungen der Diskussionsteilnehmer nur anhand eines Teiles, manchmal des kleineren Teiles, aller Schriften vorgenommen werden. In einigen Fällen kann man überhaupt nicht von einer Zustimmung zum Frieden oder dem Gegenteil sprechen, was an den angeführten Beispielen sehr gut deutlich wird.

Deutlich läßt sich enkennen, daß sich die Zahl der Stimmen für einen Frieden änderte, wie aus der folgenden Tabelle ersichtlioh ist:

$\begin{array}{lccccccc} & 1795 & 1796 & 1797 & 1798 & 1799 & 1800 & 1801 \\ \text { für Frieden } & 73 & 98 & 45 & 37 & 42 & 36 & 44 \\ \text { gegen Frieden } & 40 & 40 & 54 & 65 & 51 & 37 & 10 \\ \text { zusammen } & 113 & 138 & 99 & 102 & 93 & 73 & 54\end{array}$

Diese Zahlen stützen also das in den Hauptkapiteln II-VI vorgetragene Ergebnis, daß in den Jahren 1795-96 die Zustimmung zu einem Frieden verhältnismäßig groß war, während in den Jahren 1798—99 (1800) die Schriften für einen Krieg überwogen. Offensichtlich haben die Ereignisse des Jahres 1797 (die Machtergreifung vom 18. Fructidor und die daran anschließend zunehmend agressiver werdende Außenpolitik Frankreichs) die Wende in entscheidender Weise beeinflußt. Da jedoch bei den meisten Schriften nicht festzustellen ist, wann sie verfaßt wurden, spiegelt sich der Wandel erst in den Zahlen des Jahres 1798. Die Bedeutung des Jahres 1797 als Auslöser für die Wende wurde in Zusammenhang mit den einzelnen Zeitschriften behandelt.5 Der Umstand,

3 z.B. Goethe, Schiller, Gentz, Wieland, Johannes v. Müller, Archenholtz, Glave-Kolbielski, Posselt, Gleim, Kant usw., d.h. die Personen, die den vorgangenen Kapiteln ausführlicher behandelt wurden.

4 Gemeint sind die anonymen Schriften, deren Verfasser nicht nachgewiesen werden konnten. Zur Bestimmung der Anonyma vgl. Tiainen (1971) S. 208209. Zur Bestimmung von Anonyma wurden vor allem folgende Werke verwendet: Holzmann-Bohatta, Deutsches Anonymenlexikon (1902-1928), dergl., Deutsches Pseudonymenlexikon (1961) und Weller, Die falschen und fingirten Druckorte (1864). Zusätzlich wurden Biographien und Spezialuntesuchungen benutzt. Siehe oben.

5 Siehe oben. 
daß die kriegerische Stimmung auch im Jahre 1799 weiterhin bestimmend war, erklärt sich natürlich mit dem Beginn des zweiten Koalitionskrieges und dessen ersten großen Erfolgen. Die Ausgeglichenheit der Zahlen des Jahres 1800 findet eine Erklärung im Wechsel des Kriegsglücks, der mit ider Niederlage der Koalition und dem Frieden von Lunéville zu einer deutlichen Abnahme der Zahl der Stimmen für einen Krieg führte.

Bei den angeführten Zahlen haben die Zeilschrriften einen besonders gnoßen Anteil. Von vielen Schriftstellern gibt es Äußerungen aus mehreren Jahren, und häufig blieben sie unverändert. Die monarchistische Presse Preußens schrieb schon unter dem Druak der Verhältnisse für die Friedenspolitik ihrer Regierung, und die österreichische Presse war noch enger an die Politik ihrer Regierung gebunden. Dies führte natürlich zu geringeren Schwankungen. Die anonymen Flugschriften sind als eine spontanere Form der Meinungsäußerung zu betrachten, wenn man die auf Bezahlung hergestellten Schriften außer Betracht läßt. Ihr Meinungswandel entspricht ziemlich genau der Entwioklung in den Meinungen der bekannten Schriftsteller:

$\begin{array}{lcrrrrrr} & 1795 & 1796 & 1797 & 1798 & 1799 & 1800 & 1801 \\ \text { für Frieden } & 16 & 8 & 5 & 14 & 5 & 16 & 11 \\ \text { gegen Frieden } & 10 & 17 & 6 & 13 & 27 & 10 & 2 \\ \text { zusammen } & 26 & 25 & 111 & 27 & 32 & 26 & 23\end{array}$

Die einzige Ausnahme von Bedeutung stellt das Jahr 1796 dar, in dem die Mehrheit der anonymen Flugsohriften gegen einen Frieden ist, während der größte Teil der unter ihrem Namen schreibenden und der identifizierbaren Personen ihn verteidigt. Es besteht natürlich die Möglichkeit, daß bei der allgemeinen Zustimmung zu einem festen Frieden dem widersprechende Meinungen leichter anonym zu veröffentlichen waren. Diese Annahme wird möglicherweise auch durch die Lage im Jahre 1800 gestützt, als eine deutliche Mehrheit bei den anonymen Schriften für den Frieden war.

Bei der Bewertung der zahlenmäßigen Veränderung in der Zustimmung zu Krieg oder Frieden läßt sich zusammenfassend feststellen, daß der Baseler Frieden 1795 im Reich allgemeine Zustimmung fand. Daran schloß sich dann eine Zeit an, in der man allgemein einen Frieden für das ganze Reich erhoffte. Diese Hoffnung war noch in der ersten Hälfte des Jahres 1797 vorherrschend, während man in der zweiten Hälfte immer mehr begann, die Möglichkeiten für einen allgemeinen Frieden pessimistisch zu beurteilen und Verbitterung gegenüber Frankreich zu äußern. 
Diese Verbitterung führte dann im Jahre $1798 \mathrm{zu}$ einer allgemeinen Zustimmung zum Krieg: man glaubte, daß ein Frieden durch einen Sieg über Frankreich zu erreichen sei, der auch die Gelegenheit ibieten würde, die Demütigungen der vergangenen Jahre zu rächen. Während des Jahres 1799 breitete sich die kriegenische Stimmung weiter aus, die noch durch die Kriegspropaganda zu Beginn des zweiten Koalitionskrieges und die Anfangserfolge gefördert wurde. Die Wende des Krieges zur Niederlage im Jahre 1800 führte dann dazu, daß die kriegerische Stimmung zurückging und erneut der Wunsch nach Frieden laut wurde, der bis zum Frieden von Lunéville in einer zahlreichen Literatur für den Frieden gipfelte. Die oben geschilderte Literatur, die diesem Gesamtbild entgegengerichtet war, war nicht so stark, daß sie sich hätte durchsetzen können. Die erwähnte Verbitterung, die sich 1796 infolge der französischen Kriegszüge in Süddeutschland ausgebreitet hatte, führte zwar auch zu zahlreichen kriegerischen Meinungsäußerungen, aber sie blieben doch hinter einer erwartungsvollen und unterwürfigen Friedensbereitschaft zurück. Die österreichische Kriegspropaganda, die in der Zeit zwischen Idem Baseler Frieden und dem Frieden von Campo Formio die Fortsetzung des Reichskrieges forderte und die Sonderfriedenspolitik verurteilte, blieb alles in allem in der Minderheit. Ebenso verhält es sich mit der 1798 in Norddeutschland vorhernschenden tradionell für einen Frieden sich einsetzende Literatur der Aufklärer. Eine Minderheit blieb auch die Literatur der Kreise, die sich am stärksten für Frankreich und die Revolution einsetzten, und die dann schließlich in Zusammenarbeit mit Frankreich die für Deutschland als unumgänglioh angesehenen Reformen mit Waffengewalt verwirklichen wollten. ${ }^{6}$

\section{Regionale Unterschiede}

Neben den zeitlichen Schwankungen kann man außerdem auch noch viele andere Faktoren erkennen, die den Wechsel in ider Zustimmung für Krieg oder Frieden beeinflußten. Die entscheidendste Rolle spielte das Territorium, in dem der Schriftsteller wohnte und dessen Zensur er ausgesetzt war. Wie schon früher häufig festgestellt wurde, unterschied sich die Außenpolitik der deutschen Territorien, besonders die

6 Die Position dieser Gruppe der »militärischen Friedensverteidiger» ist sehr schwer zu bestimmen. Gewöhnlich fordert die gleiche Schrift einerseits einen Friedenschluß mit Frankreich und andererseits einen gemeinsamen Angriff im Bund mit Frankreich gegen Österreich und andere Koalitionsstaaten. Gleiche Probleme ergeben sich manchmal bei anderen Schriftsstellern, vgl. S. 167-168. 
der zwei Hauptmächte, sehr deutlich von einander. Dies spiegelt sich auch in der tagespolitischen Literatur dieser Gebiete. Wenn man eine grobe Teilung des Deutschen Reiches in drei Teile vornimmt, Preußen, Österreich und das 'dritte Deutschland', und in diesen dann die Entwicklung der Einstellungen zu Krieg oder Frieden in der Literatur vergleicht, wird der Unterschied sehr deutlich.

In Preußen war die für einen Frieden eintretende Literatur während des ganzen Zeitraums in der Mehrheit, wie die folgende Tabelle zeigt:

$\begin{array}{lrrrrrrr} & 1795 & 1796 & 1797 & 1798 & 1799 & 1800 & 1801 \\ \text { für Frieden } & 28 & 25 & 15 & 19 & 21 & 13 & 13 \\ \text { gegen Frieden } & 0 & 2 & 6 & 10 & 5 & 4 & 3 \\ \text { zusammen } & 18 & 27 & 21 & 29 & 26 & 17 & 16\end{array}$

In Österreich zeigt sich ein genau entgegengesetztes Bild, nur ist die Ablehnung des Friedens noch konsequenter und eindeutiger:

$\begin{array}{lccccccc} & 1795 & 1796 & 1797 & 1798 & 1799 & 1800 & 1801 \\ \text { für Frieden } & 2 & 0 & 0 & 0 & 1 & 0 & 4 \\ \text { gegen Frieden } & 12 & 21 & 14 & 11 & 10 & 5 & 1 \\ \text { zusammen } & 14 & 21 & 14 & 11 & 11 & 5 & 5\end{array}$

Im 'dritten Deutschland', das sich aus zahlreichen sehr unterschiedlichen Territorien zusammensetzte, weicht die Literatur von der in den beiden Großstaaten ab:

$\begin{array}{lccccccr} & 1795 & 1796 & 1797 & 1798 & 1799 & 1800 & 1801 \\ \text { für Frieden } & 43 & 73 & 30 & 18 & 20 & 23 & 27 \\ \text { gegen Frieden } & 28 & 27 & 34 & 44 & 36 & 28 & 8 \\ \text { zúsammen } & 71 & 100 & 64 & 62 & 56 & 51 & 35\end{array}$

Wenn man die Zensurbedingungen in den Gebieten der beiden Großmächte und andere Bindungen der Schriftsteller an die Politik ihrer Regierungen berücksichtigt, - die direkt bezahlten Schriftsteller, die Beamten, die Abhängigkeit von Hilfsgeldern — so ist die Entwicklung in den Stellungsnahmen natürlich. Was Österreich betrifft, so war die absolute Ablehnung fast einstimmig - der Wiener Jude Lazarus

7 Im allgemeinen ergaben sich keine Schwierigkeiten bei der Bestimmung des Wohnortes der Schriftssteller mit Hilfe der Allgemeinbiographien, die wichtigsten waren ADB, NDB, BLDG, Hamberger-Meusel und Wurzbach. Wenn der Wohnort eines Schriftsteller nicht bestimmt werden konnte, wurde er hier zu den Schriftstellern des 'dritten Deutschland' gerechnet. 
Bendavid, dessen Artikel in Biesters »Berlinische Monatsschrift» und »Neue Berlinische Monatsschrift» veröffentlicht wurden, verteidigte den Baseler Frieden und setzte sich später für den Frieden ein, außerdem hieß der Wiener Regierungsbeamte Kaspar Lehmann den Baseler Frieden gut, wobei er die Friedenshoffnung mehr grundsätzlich begründete und ausdrücklich seine Treue zum Kaiser betonte. ${ }^{8}$ In Preußen konnte die Regierung in größerem Maße kritisiert werden, wie schon früher gezeigt wurde. Die betreffenden Friedensgegner wurden oben schon vorgestellt. ${ }^{9}$ Wenn man jedoch sowohl die Literatur in Österreich als auch in Preußen als mehr oder weniger »programmgemäß» betrachtet, so bleibt noch idie freiere oder zumindest uneinheitlichere tagespolitische Literatur im 'dritten Deutschland'. Diese bestätigt im großen und ganzen die im vorangegangenen Kapitel vorgetragene Auffassung, daß die Zustimmung zu Krieg oder Frieden in ihrem Umfang schwankte. Der Baseler Frieden wurde von 28 preußischen Schriftstellern verteidigt und von 12 österreichischen Schriftstellern angegriffen. Wenn man diesen Umstand unberücksichtigt läßt, kann man feststellen, daß 1795 im 'dritten Deutschland' die Zahl der Friedensanhänger bedeutend größer war als die Zahl der Befürworter eines Krieges. Noch deutlicher geht das Übergewicht der Friedensanhänger aus den Zahlen des Jahres 1796 hervor. Die österreichischen Schriftsteller stellen über die Hälfte der Friedensgegner, die preußischen ungefähr ein Viertel der Friedensanhänger. In den folgenden Jahren folgt die Literatur des 'dritten Deutschland' ungefähr der Literatur im ganzen Reich, was sich einerseits aus der größeren Uneinheitlichkeit in der preußischen Literatur und andererseits aus der bedeutend geringeren Anzahl österreichischer Schriften erklärt.10 Wenn man die Auffassungen der Schriftsteller der beiden großen Staaten außer Betracht läßt, so ergibt sich für die Jahre 1799 und 1800, daß die Zustimmung zum Krieg sich für das Jahr 1799 zu einer deutlichen zahlenmäßigen Mehrheit verstärkt hat und 1800 noch besteht. Es wird deutlich, daß das Gesamtbild des 'dritten Deutschland' für das Jahr 1800 der

8 Berl. Mon. 1795: 6 S. 516-529 und 1795:5 S. 369-383, N. Berl. Mon. 1799 II: 11 S. 27-29. Lehmann (1795) Vorerinnerung.

9 Vgl. S. $192-199$.

10 Alles im allem ist der Anteil der österreichischen Literatur bedeutend geringer als der der preußischen Literatur. Teilweise rührt dies daher, daß die preußischen Zeitschriften leichter zugänglich waren, aber auch daher, daß die öffentlichte Diskussion in Preußen und im 'dritten Deutschland' viel reger war als in Österreich. Das Zurückgehen der österreichischen Stimmen ist darauf zurückzufuhren, daß die einzige zur Verfügung stehende Zeitschrift dieser Art, das »Magazin der Kunst und Literatur», mit Ende des Jahres 1796 ihr Erscheinen einstellte. Vgl. Tiainen (1971) S. 39-41 und Karte. 
wirklichen Situation im ganzen Reich näher kommt, weil es in diesem Jahr überhaupt keine österreichische Zeitschriftenliteratur als Gegengewicht zur verhältnismäßig zahllreichen preußischen Literatur gibt. Im Jahre 1801 untenstützt im 'dritten Deutsohland' eine klare Mehrheit einen Frieden, so wie es auch natürlich ist.

Eine Untersuchung der zahlenmäßigen Untenschiede zwischen den Territorien könnte matürlich in einer noch umfangreicheren Arbeit fortgesetzt werdon, wenn man z.B. die Literatur in don verschiedenen Territorien des 'dritten Deutschland' oder in verschiedenen Gruppen von Territorien untersuchen, oder neben der Bedeutung des Wohnorts der Schriftstelier auch die Bedeutung des Geburtsortes für ihre Auffassungen berücksichtigen würde. Außerdem könnte z.B. auch eine sozialhistorische Untersuchung nach den einzelnen Sozialgruppen, Religionsgruppen, Altersgruppen u.s.w. vorgenommen werden. ${ }^{11}$ Um aber das Material nicht zu sehr auszuweiten, blieben diese Gesichtspunkte unberücksichtigt.

\section{Ideelle Unterschiede}

Wie zu Beginn dieser Arbeit ausgeführt wurde, hat sie sich nicht nur die Aufgabe gestellt, die zahlenmäßigen und regionalen Unterschiede in der Zustimmung zu Krieg oder Frieden zu untersuchen, sondern sie will auch eine Antwort auf die Frage geben, warum man sich für Krieg oder Frieden einisetzte. Während die Erörterung der ersten beiden Punkt noch verhältnismäßig einfach und eine quantitative Schätzung möglich war, bringt eine Analyse der Begründungen natürlich wesentlich schwierigere und kompliziertere Probleme mit sich. Die äußerst große Uneinheitlichkeit des Quellenmaterials, die Widersprüchlichkeit der in ihm vorgetragenen Meinungen untereinander und die ungewöhnliche Vielfältigkeit der Begründungen machen eine Interpretation der Gründe für die Zustimmung von Krieg oder Frieden und eine quantitative Schätzung sehr schwer, wenn nicht direkt unmöglich. Trotzdem lassen sich einige Schlußfolgerungen ziehen.

11 Einige Versuche in dieser Richtung haben z.B. unternommen: Schultze, Johanna, Die Auseinandersetzung zwischen Adel und Bürgertum in den deutschen Zeitschriften der letzten drei Jahrzehnte des 18. Jahrhunderts (1773-1806), Berlin 1925/Nachdr. Vaduz 1965; Tiainen (1971) S. 208-214 und andere. Der Verfasser dieser Arbeit plant seine Untersuchungen in sozial-historischer Richtung an einem größeren Quellenmaterial und mit sozial-historischen Methoden fortzusetzen. AIRA KEMILÄINEN hat Methoden entwickelt in l'Affaire d'Avignon, (1789-1791), from the Viewpoint of Nationalism, Helsinki 1971, S. 173-181. 
Mit Ausgang des 18. Jahrhunderts und zu Beginn des 19. Jahrhunderts hatte die Tradition der Aufklärung noch einen verhältnismäßig großen Einfluß. Grundsätzlich war ja die Aufklärung für den Frieden und gegen Krieg, weil ein Krieg vom Standpunkt der Aufklärung aus die Menschheit vom Weg zum Glück abbringen würde. Die Aufklärer verurteilten den Krieg deshalb, weil er wirtschaftliche Verluste bringen und das Erwerbsleben behindern würde. So verteidigte man sehr häufig den Frieden mit wirtschaftlichen Argumenten. Die andere Leitidee der Aufklärung verbindet sich mit dem Begriff Humanismus. Ein Krieg würde unmenschliche Leiden verursachen und sei deshalb zu verurteilen. Besonders in den protestantischen Gebieten verbanden sich mit dieser an Verstand und Gefühl appellierenden Aufklärungstradition christliche Elemente. Auch mit dem aufklärerischen Ideal vom Kosmopolitismus verteidigte man einen Friedensschluß. Die Menschen seien gleich unabhängig von ihrer Nationalität und sie dürften sich nicht gegenseitig töten. Auch die zustimmende Haltung zu Reformen im Reich steht der Aufklärung nahe. Die Bewunderung Frankreichs war in Aufklärerkreisen in Deutschland Tradition. Nachdem die Französische Revolution eine Reihe großer Reformen gebracht hatte, die man im Sinne des Fortschritts hielt, wollte man diesem Beispiel folgen, wenn man auch nicht bereit war, aktiv am Kampf gegen das Reich für die Verwirklichung dieser Reformen teilzunehmen. Kurz vor der Jahrhundertwende konnte diese Tradition der Aufklärung auch kriegerische Züge annehmen, als man befürchtete, daß die Sonderfriedenspolitik Frankreichs in Deutschland alles beim alten lassen könne. Ausgehend von der Tradition der Aufklärung - zumindest in ihren Hauptzügen — gaben fast alle Deutschen grundsätzlich dem Frieden vor einem Krieg den Vorzug.

Mit dem Ende des 18. und dem Beginn des 19. Jahrhunderts setzte sich auch eine andere geistige Strömung durch. Die Romantik wurde in der Literatur Deutschlands bestimmend. Aber ihre Ideenwelt blieb nicht nur auf die Literatur beschränkt. Das erwachende Nationalgefühl entwickelte sich zu einem konsequenten Nationalismus und wurde leicht zu einem Mament in der Begründung der kriegerischen Einstellung. Die Betonung der germanischen Herkunft führte leicht zu einer Verherrlichung des Krieges. Damit verband sich häufig eine grundsätzlich konservative Haltung, die Reformen und besonders auch Umwälzungen ablehnite. Vom konservativen Standpunkt aus klammerte man sich gerne an das heilige Grundgesetz des Reiches, das unverändert bleiben müsse: weil ein Friedensschluß mit Frankreich zwangsläufig zu Veränderungen in der inneren Struktur des Reiches führen würde, blieb man in konservativen Kreisen dabei, einen Friedensschluß abzulehnen. Mit der konser- 
vativen Einstellung verband sich eng, daß man die Bedeutung von Kirche und Religion hervorhob. So war es besonders in den katholischen Teilen des Reiches. In Frankreich wurde die katholische Kirche schlimm behandelt, der Papst angegriffen und die Priester aus dem Lande vertrieben, was unter strenggläubigen Katholiken zu Haß gegenüber Frankreich führte. Auch die nördlicheren Lutherianer wandten sich scharf gegen die atheistische Revolution. Wie das Beispiel »Eudämonia»zeigt, konnle sich der christlich gefärble Kunservalismus nicht nur gegen die Revolution sondern auch gegen die Aufklärung als Ganzes wenden und äußerst agressive Züge annehmen. Der sich mit der Romantik verbindender religiös-nationaler Konservatismus hatte sich noch nicht $\mathrm{zu}$ der Weltanschauung entwickelt, wie sie für die Zeit nach 1815 - zwar größtenteils unter Aufgabe des Nationalismus - bestimmend war, aber er bildete doch ein bedeutendes Gleichgewicht zu der für den Frieden eintretenden Aufklärung.

Mit den gerade erwähnten Geistesrichtungen verband sich ein traditioneller Patriotismus und Untertanengeist. Patriotismus war in Deutschland um die Wende vom 18. zum 19. Jahrhundert ein sehr unbestimmter und vieldeutiger Begriff. Der religiös und nationalistisch gefärbte Patriotismus war häufig auf das alte Deutsche Reich und sein Oberhaupt den Kaiser gerichtet, um dann zu einem an die Politik Österreichs gebundenen gegen einen Frieden gerichteten Faktor $\mathrm{zu}$ werden. Aber Patriotismus konnte auch auf territorialer Ebene auftreten. So besonders in Preußen, wo man besonders »vaterländisch» Friedrich den Großen und die glänzende militärische Vergangenheit bewunderte und sich als Untertanen der Person des Königs betrachtete und ihm auch religiöse Verehrung zollte. Dieser Patriotismus verband sich oft mit Militarismus und Ablehnung der Aufklärung und auch der Revolution und deren Ürsprungsiand. Außerdem gab es eine völlig gewöhnliche Verehrung des Monarchen, die man auoh als Patriotismus bezeichnete. Diese die Traditionen eines aufgeklärten Absolutismus fortsetzende Denkweise unterwarf sich der Politik der Regierungen. Da die Herrscher Preußens und der meisten übrigen Territorien und die Regierungen Friedenspolitik betrieben, konnte mit einer patriotischen Einstellung ebenso der Frieden verteidigt werden, wie sie in Österreich und Süddeutschland $\mathrm{zu}$ einer Rechtfertigung des Krieges führen konnte. Der Begriff Patriotismus wird noch widersprüchlicher dadurch, daß sich auch die Anhänger der Revolution gerne in Anlehnung an ihre geistigen Brüder in Frankreich als Patrioten bezeichneten. Ihr Patriotismus bezog sich sowohl auf die kommende deutsche Republik (oder das Rheinland oder Süddeutschland o.ä.) als auch direkt auf Frankreich. 
Neben dem oben beschriebenen Patriotismus, für den der Gehorsam gegenüber den Herrschenden und der Politik der Regierungen typisch ist, wurde Krieg oder Frieden von pragmatisch-politischen Gesichtspunkten aus verteidigt. Nicht alle Schriftstellern legten Wert darauf, die Vorteile von Krieg oder Frieden ideell zu begründen, und ihre Motive scheinen überhaupt keinen Bezug zu der konkreten Situation zu haben, in der zu dem Friedensschluß Stellung zu beziehen war. Der Feind konnte für den stark patriotisch und national Gesinnten als übermächtig und die eigenen Kräfte als unzureichend erscheinen, weshalb man der Bewahrung des Friedens oder zumindest einem Friedensschluß den Vorzug gab. Andererseits konnten die grundsätzlich für den Vorzug des Friedens sprechenden wirtschaftlichen Argumente und vernunftsmäßigen Überlegungen dann abgewiesen werden, wenn eine Gelegenheit gekommen schien, den Erbfeind $\mathrm{zu}$ schlagen, das Gebiet des Vaterlandes zu vergrößern und die nationale Ehre wieder herzustellen.

Von keinem Schriftsteller wurden nur pragmatisch-politische Argumente vorgetragen, sondern man verwendete fast immer auch ideelle Motive. Andererseits wurden wiederum in ideell ausgerichteten Schriften fast immer Bezug auf die aktuelle militärisch-politische Situation genommen. Im folgenden Kapitel soll das quantitative Verhältnis von ideell und pragmatisch begründenden Schriften untersucht und eine vorsichtige Wertung nach der Vorrangigkeit der Ausgangspunkte vorgenommen werden.

\section{Idealismus oder Realpolitik}

Typisch für die politische Tagesliteratur zwischen 1795 und 1801 in Deutschland ist, daß die Zustimmung zur großen Revolution fortgesetzt geringer wurde. Während in den Anfangsphasen der Revolution, wie zu Beginn dieser Untersuchung festgestellt wurde, in den Kreisen der Gebildeten Deutschlands die Zustimmung zur Revolution sehr allgemein war, hatte diese Zustimmung schon während des Baseler Friedens deutlich abgenommen. Ein beträchtlicher Teil derjenigen, die für einen Frieden eintraten, nahm jedoch zur Französischen Revolution oder zumindest zum größten Teil ihrer Reformen eine positive Haltung ein. Dies war besonders im 'dritten Deutschland' der Fall, aber auch in Preußen gab es weiterhin reichlich Zustimmung zur Revolution bei denjenigen, die jetzt für den Frieden eintraten. In den folgenden Jahren wurden diese Sympathien schwächer sowohl in Preußen als auch im 'dritten Deutschland' - von Revolutionarismus in der öffentlichen Diskussion in Österreich kann man ja nicht direkt sprechen. Das Zurüikgehen der Zahl der Stim- 
men, die der Revolution zustimmten und die den Frieden befürworteten, ist lange eine parallele verlaufende Erscheinung. Beachtenswert ist, daß die Gunst der Leitideen der Revolution nicht einmal in den Jahren 18001801 größer wurde, als im Gegensatz dazu die Stimmen für den Frieden im Reich ein Ưbergewicht gegenüber den Stimmen für einen Krieg gewannen.

Während des ganzen untensuchten Zeitraums bewahrte man in den sich für einen Frieden einsetzenden Kreisen die Tradition der Aufklärung. Fast alle, die sich für einen Frieden öffentlich einsetzten, wiesen auf die durch den Krieg verursachten Leiden und auf die segensreichen Wirkungen des Friedens für den Fortschritt der Menschheit hin. Gewöhnlich berief man sich auch auf das Humanitätsideal der Aufklärung. Auch in Schriften, die für den Beginn eines Krieges oder die Fortsetzung des Krieges eintraten, finden sich an die Tradition der Aufklärung anknüpfende Argumente, allerdings in bedeutend geringerer Zahl. In diesen Schriften bevorzugte man bewußt die übrigen, vor allem pragmatisch-politischen, Argumente, die grundsätzlich für einen Frieden und seine segensreichen Wirkungen sprachen. Gewissermaßen eine Ausnahme stellt der eng zur Aufklärung gehörende Antiklerikalismus dar, der mit der Zeit immer stärker in den einen Frieden verteidigenden Kreisen wurde. Dies erklärt sich aus der heftigen Diskussion um die Säkularisation, der man in kirchlichen Kreisen zumindest in Süddeutschland allgemein stark ablehnend gegenüberstand, weshalb man sie als Feind des Friedens betrachtete.

Der Konservatismus, der in der Gegnerschaft zur Revolution und oft zur Aufklärung und $\mathrm{zu}$ allen Reformen deutlich wurde, verband sich von Anfang an mit den Argumenten der Kreise überall im Reich, die sich besonders konsequent für einen Krieg einsetzten. Dies war besonders in Österreich der Fall, dessen kriegerische Sohriften sich in der bekannten Weise auf eine Tradition, Grundgesetz und Revolution ablehnende Haltung stützten.

Der mit dem Konservatismus eng verbundene Nationalismus bewahrte ebenfalls seine Bedeutung und gewann sogar während des untersuchten Zeitraums an Einfluß. In Österreioh, einem in viele Nationen aufgesplitterten Staat, sollte man vermuten, daß der Nationalismus keine große Bedeutung hatte, trotzdem beriefen sich die sich zum Krieg bekennenden Schriftsteller in den verschiedenen Teilen des habsburgischen Machtbereiches und der verschiedenen Nationalitäten auf den Nationalismus. In der Verehrung des Kaisers und während des zweiten Koalitionskrieges besonders des Erzherzogs Karl verschmolzen die Österreicher den gegen die Revolution und die Aufklärung gerichteten Konservatismus mit dem Nationalismus. Eine noch größere Bedeutung bekam der Nationalismus 
in kriegsbereiten Kreisen im 'dritten Deutschland'. Schon von Anfang an war er bemerkbar, aber besondens zur Jahreswende von 1797 berief man sich ibewußt auf ihn. Die Aggression Frankreichs bezeichnete man als nationale Demütigung, und immer häufiger bezog man sich auf die kriegerischen Tugenden der Germanen und forderte alle Deutschen zum Kampf gegen den gemeinsamen nationalen Erbfeind auf. In Preußen, w.o sich weniger Stimmen offen für den Krieg aussprachen, verbanden sich die Argumente der kriegerischen Schriftsteller auch mit Konservativismus und Nationalismus.

Die Rolle der Religion schwankte in der Diskussion beträchtlich. In den Anfangsjahren, als Zustimmung zum Frieden den größten Teil der tagespolitischen Literatur beherrschte, gebrauchte man neben aufklärerischen Argumenten religiöse Argumente im Dienste der Friedenspropaganda. In protestantischen Kreisen hernschte zwar gewöhnlich ein offener Antiklerikalismus, der die katholische Kirche und ihre Besitzungen kritisierte, aber trotzdem forderte man einen Frieden im Namen des Christentums. In der Diskussion in Preußen und in den protestantischen Kreisen des 'dritten Deutschlands' spielte die Religion immer diese Rolle. Für den herrschenden Friedenszustand dankte man neben dem Kaiser auch Gott, und man versicherte, daß die Friedenspolitik der Regierung christ. lich sei. In Süddeutschland sahen die Verhältnisse von Anfang an anders aus. Dort bezog man sich gerne in gegen den Frieden eingestellten Kreisen auf den Atheismus der Revolutionsregierung und auf die Priesterverfolgungen in Frankreich. Die Anhänger der Revolution bezeichnete man als Ketzer, Freimaurer, Juden usw. Religiöse Argumente wurden mehr für den Krieg als für den Frieden verwendet. Besonders in Österreich, aber auch in den anderen katholischen Ländern verbanden sich religiöse Argumentationen mit konservativen, nationalen und regierungstreuen Erwägungen, um kriegerische Anstrengungen zu unterstützen. Auch die wenigen sich in Preußen für einen Krieg einsetzenden Schriftsteller verbanden sich mit der pietistisoh-christlichen Tradition ihres Landes.

Kriegsbegeisterung und Militarismus setzten sich immer mehr durch. Die kriegerischen Schriftsteller in Österreich und im 'dritten Deutschland' betonten gerne die traditionelle Tapferkeit und die Kriegstugenden der Deutschen. In Verbindung zum Nationalismus erklärte man die Deutschen als die den Franzosen überlegenen Soldaten. Beachtung verdient, daß auch in der für einen Frieden eintretenden Literatur nationalistische Argumente $\mathrm{zu}$ finden sind. Dies trifft vor allem für Preußen, aber auch für einige Territorien des 'dritten Deutschland' zu, die mit Frankreich Frieden geschlossen hatten. Obgleich man zumindest offiziell 
die Friedenspolitik befürwortete, betonte man fortgesetzt, wie tapfer die eigenen Truppen im vergangenen Krieg und schnn früher gewesen seien. Diese schriften nahmen dann leicht mit einer veränderten außenpolitischen Lage eine offen für den Krieg eintretende Haltug ein.

Besonders ausgeprägt ist in der Diskussion der Patriotismus in beiden Lagern. Es ist natürlich, daß sich Vaterlandsliebe, Verehrung und Bewunderung des Herrschers und Regentenhauses mit der Kriegspropaganda verband, und daß dies überall im Reich gesthah. Man forclerte die Fortsetzung des Krieges oder die Vergrößerung der Kriegsanstrengungen für Kaiser und Vaterland, aber auch für das Grundgesetz, den Altar und die nationale Ehre. Diese an die Vaterlandsliebe appellierende Literatur wurde mit der Zunahme an kriegerischer Literatur häufiger. Dies ist besonders in Preußen zu beobachten, wo die monarchistische Presse und Flugschriftenliteratur fortgesetzt gerade zur Treue gegenüber dem Herrscher und Vaterland aufrief und dabei zur unerschütterlichen Fortsetzung der Friedenspolitik aufforderte. Natürlich muß man an der Aufrichtigkeit dieser Argumentation zweifeln, aber jedenfalls pries man den König als Friedenserhalter allgemein in Preußen und teilweise auch in anderen Teilen des Landes, besonders in dänischen Gebieten. Bei der Rechtfertigung des Friedens berief man sich an erster Stelle auf die Tradition der Aufklärung und an zweiter Stelle auf den Patriotismus. In den Gebieten des 'dritten Deutschland' und besonders in Süddeutschland traten jene revolutionäre Stimmen hinzu, die einen Frieden mit Frankreich im Namen des eigenen 'Patriotismus' forderten.

Patriotismus und Regierungstreue verbanden sich nahtlos miteinander und schließlich mit dem Grundsatz, daß man Krieg oder Frieden deshalb zustimmen müsse, weil es für das Land von Nutzen sei. Betrachtet man die Entwicklung der öffentlichen Diskussion als Ganzes, so muß man den pragmatischpolitischen Argumenten die größte Bedeutung zuschreiben. Dies wird bis zum Ende des untersuchten Zeitraums immer deutlicher. Beachtenswert ist, daß man 1795 und 1798 sich für Krieg oder Frieden mit vollkommen gleichen Argumenten einsetzen konnte, um jedoch $z u$ gegensätzlichen Schlußfolgerungen $\mathrm{zu}$ kommen. Unbestreitbar ist, daß in der zweiten Hälfte der neunziger Jahre des 18. Jahrhunderts in Deutschland die auf den Traditionen der Aufklärung fußende grundsätzliche Zustimmung zum Frieden von einer starken Strömung abgelöst wurde, die mit der - konservativ-nationalistischen - Tradition der Romantik für den Krieg war. Dies wird an der um Krieg und Frieden geführten Diskussion deutlich sichtbar. Aber am meisten wurde das Gesamtbild dieser Diskussion von der Entwicklung der militärisch-politischen Situation bestimmt. In den Jahren 1795-96 und 1800-01, als Frankreich seine 
größten militärischen Erfolge errang, war auch die Zustimmung zum Frieden am größten, während andererseits die Kriegsbereitschaft ihren Höhepunkt erreichte, als die Koalitionsstaaten zu Beginn des zweiten Koalitionskrieges siegreich waren. Indem ein typischer Vertreter des Konservatismus, Friedrich Gentz, 1800 seine Sohrift »Ưiber den ewigen Frieden» verfaßte, wählte er fast die gleichen Angumente wie Immanuel Kant, vielleicht der bedeutendste Vertreter der pazifistischen Aufklärungstradition, in seiner 1795 enschienenen Schrift »Zum ewigen Frieden». Die unterschiedlichen Schlußfolgenungen der Sohriftsteller lassen sich mit den grundlegenden Veränderungen der politischen Situation in den vorangegangenen Jahren erklären. Nachdem der Friedensoptimismus der Aufklärung infolge der offenen Aggressionspolitik geschwunden war, begann man sich als Reaktion gegen Frankreich zu wenden. 


\section{QUELLEN UND DARSTELLUNGEN}

\section{A. QUELLEN}

\section{Periodische Schriften}

Annalen der Braunschweig-Lüneburgischen Churlande. Hannover 1795.

Europäische Annalen. Hrsg. v. D. Ernst Ludwig Posselt. Tübingen 1795-1801.

Göttingische Anzeigen von gelehrten Sachen unter den Aussicht der königl. Gesellschaft der Wissenschaften. Göttingen 1796.

Archiv für die Geschichte, Erdbeschreibung, Statskunde und Alterthümer der Deutschen Nieder-Rheinlande. Angelegt von Dr. August Christian Borheck. Elberfeld 1800.

Preußisches Archiv. Hrsg. und Sr. Majestät dem Könige gewidmet von der Königl. Deutschen Gesellschaft in Königsberg in Preußen. Königsberg 1795-98.

Athenaeum. Eine Zeitschrift von August Wilhelm Schlegel und Friedrich Schlegel. Berlin 1798-1800.

Neue allgemeine deutsche Bibliothek. Kiel 1795-96.

Das Rothe Blatt. Eine Dekadenschrift. Koblenz J. VI [1798].

Berlinische Blätter. Hrsg. v. Biester. Berlin 1797-98.

Dänische Blätter. Altona 1795-96.

Französische Blätter. Basel 1796.

Niederrheinische Blätter für Belehrung und Unterhaltung. Hrsg. W. Aschenberg. Dortmund 1801.

Schleswig-Holsteinische Blätter für Polizei und Kultur. Altona und Kiel 17991801.

Denkwürdigkeiten und Tagesgeschichte der Mark Brandenburg. Hrsg. v. J. W. A. Kosmann und Th. Heinsius. Berlin 1796-1801.

Deutschland. Berlin 1796.

Eudämonia oder deutsches Volksglück. Ein Journal für Freunde von Wahrheit und Recht. Bd. I Leipzig 1795, Bd. II-V Frankfurt am Main 1796-97, Bd. VI Nürnberg 1798.

Europa. In seinen politischen und Finanz-Verhältnissen. 1795.

Frankreich im Jahr 1795-1801. Aus den Briefen deutscher Männer in Paris. Altona 1795-1801.

Der Genius der Zeit. Ein Journal hrsg. von August Hennings. Altona 1795-96.

Geschichte und Politik. Eine Zeitschrift hrsg. von K. L. Woltmann. Berlin 18001801.

Hamburg und Altona. Eine Zeitschrift zur Geschichte der Zeit, der Sitten und des Geschmaks. Hamburg 1801.

Die Horen. Eine Monatschrift hrsg. v. Schiller. Tübingen 1795-97. 
Jahrbücher der preußischen Monarchie unter der Regierung Friedrich Wilhelms des Dritten. Berlin 1798-1801.

Historisches Journal. Hrsg. v. Friedrich Gentz. Berlin 1799-1800.

Klio. Eine Monatschrift für die französische Zeitgeschichte. Leipzig 1795-96.

Neue Klio. Eine Monatschrift für die französische Zeitgeschichte. Hrsg. von Ludwig Ferdinand Huber. Leipzig 1796-97. Ergänzungsheft 1798.

Der Kosmopolit. Eine Monatschrift zur Beförderung wahrer und allgemeiner Humanität. Halle 1797-98.

Europens politische Lage und Staats-Interesse. 1795-99.

Laterne bey Tag für die mittlere Volksklasse. Heft I-III Paris [Altona] 1797-98.

Allgemeine Literatur-Zeitung. Jena und Leipzig 1795-1801.

London und Paris. Zeitschrift. Weimar 1798-1801.

Magazin für die Geschichte der Menschenrechte. Leipzig 1797.

Magazin der neuesten und merkwürdigsten Kriegsbegebenheiten. Frankfurt 1795-96. Hrsg. v. August Wilhelm von Leipziger.

Magazin der Kunst und Literatur. Wien 1795-96.

Magazin der Europäischen Staatenverhältnisse. Frankfurt und Leipzig 1797.

Magazin für Westphalen. Der Geographie, Geschichte, Statistik und allem nützlichen Wissen gewidmet. Hrsg. von M. Weddigen und A. Mallingkrodt. Dortmund 1797-99.

Hanseatisches Magazin. Hrsg. v. J. Smidt, Prof. der Philos. in Bremen. Bremen 1799-1801.

Staatswissenschaftliches Magazin. Mainz und Leipzig [Hamburg] 1800.

Neues fortgesetztes Westphälisches Magazin zur Geographie, Historie und Statistik. Hrsg. von P. F. Weddigen. Wesel 1798.

Der Französische Merkur. Hrsg. von Julius Graf v. Soden. Dortmund 1800-1801.

Niedersächsischer Merkur als Einleitung zum neuen grauen Ungeheuer. Altona 1798 (N. graue Ungeheuer XII. Bagdad [Altona] 1798).

Neuer Teutscher Merkur. Hrsg. v. C. M. Wieland. Weimar und Leipzig 1795-1801.

Minerva. Ein Journal historischen und politischen Inhalts hrsg. v. J. W. von Archenholtz, vormals Hauptmann in Königl. Preußischen Dienste. Hamburg 1795-1801.

Miscellen zur Geschichte des Tages. Hrsg. von J. W. v. Arcenholtz. Bd. I. Hamburg 1795.

Berlinische Monatschrift. Hrsg. von Biester. Berlin/Dessau 1795-96.

Neue Berlinische Monatschrift. Hrsg. von Biester. Berlin und Stattin 1799-1801.

Musen-Almanach für das Jahr 1796-1801. Hrsg. von Schiller. Neustrelitz 1796, Tübingen 1797-1801.

National-Zeitung der Teutschen. Teutschland [Gotha] 1796.

Olla Potrida. Eine Vierteljahrsheft hrsg. von H. A. O. Reichardt. Berlin 179597.

Schleswig-Holsteinische Provinzialberichte. Altona und Kiel 1795-98.

Der deutsche Redakteur für das Jahr 1798. Nürnberg o.0. [1798].

Kaiserlich privilegirter Reichs-Anzeiger oder Allgemeines Intelligenz-Blatt zum Behuf der Justiz, der Polizey und der bürgerlichen Gewerbe im Teutschen Reiche wie auch zur öffentlichen Unterhaltung der Leser über gemeinnützige Gegenstände aller Art. 1797.

Revolutions-Almanach. Göttingen 1795-99.

Neueste Staats-Anzeigen. 1798-1800. 
Teutsches Staats-Magazin. Hrsg. von dem Professor von Berg zu Göttingen. Bd. I-III. Göttingen 1796-98, 1800.

Das neue graue Ungeheuer. Hrsg. von einem Freund der Menschheit. Bd. I-XVI. Altona 1795, Upsala [Altona] 1797-1800, Köln [Altona] 1799.

Gothaische gelehrte Zeitungen. Gotha 1795-1801.

Neue Kielische gelehrte Zeitung oder Annalen der neuesten Schleswig-Holsteinischen Literatur und der neuern Literärgeschichte der Universität zu Kiel. Hrsg. v. Johann Otto Thiess. Kiel 1797.

\section{Flugschriften und ähnliche Tagesliteratur}

Abdruck Kaiserlichen Handschreibens an die Herren Kurfürsten d.d. Wien, den 7 ten September, 1796. Die Königlich Preußischen Brandenburgischen Occupations-Vorschritte in Franken betreffend. 1797.

Die Abtretung des linken Rheinufers, und die Entschädigungen nach rechtlichen und politischen Grundsätzen erwogen. 1798.

Anekdote und Charakterzüge aus dem Einfalle der Neufranken in Altfranken im Jahre 1796. [Erlangen] 1797. [F. J. A. Muck].

Anekdoten, Karakterzüge und Reflexionen Beleuchtung merkwürdiger Personen und Begenbenheiten der neuesten Zeitgeschichte mit prüfenden Auswahl gesammelt von einem Unpartheyischen. Jena 1800.

Anmerkungen zu der preußischen Declaration an die Reichs-Mitstände. 1795. [K. G. Glave-Kolbielski].

Anmerkungen über die an die allgemeine Reichsversammlung gerichtete Königlich Preußische Erklärung, in Betreff des zu Basel den 5then April geschlossenen Friedens. [1795, J. v. Müller].

Anselmus Rabiosus der Jüngere, Wanderungen und Kreuzzüge durch einem Theil Deutschlands. Th. I-II., Altona 1796. [G. F. Rebmann].

Antifragmente. An Beziehung auf die königlich preußische Erklärung auf der allgemeinen Reichsversammlung in Betreff des zu Basel am 5ten April 1795 geschlossenen Friedens und die gegen die dawider erschienener Anmerkungen eines Ungenannten erschienene Fragmente. Im July 1795.

Antwort eines k.k. Offiziers auf das Gedicht von einem schweizerischen Jüngling J. B. Zürich 1799.

Antwort auf das Schreiben eines Wirtenbergers an seine Mitbürger wegen des Landaufgebothes. [Nürnberg] 1795. [G. W. Majer].

Antwort eines französischen Soldaten auf den Aufruf eines Deutschen. Aus dem Französischen übersetzt. 1799.

Antwortschreiben des Herzogs von $* * *$ an seinen Reichstags-Gesandten auf dessen Bericht der zwei Schriften: die Entschädigung der auf dem linken Rheinufer verlierenden Reichsstände betreffend. Julius 1798.

Apologie Dännemarks wider die Schrift Hamburgs bestes Glück nicht von Aussen. Von einem Holsteiner. Im Julius 1801. [N. Funk].

Appenzeller, J. C., Die Schweizer in Paris oder der 10te August 1972. Ein Traum aus dem letzten Dezennio unsers Jahrhunderts dem Bernerschen Heerführer Erlach zugeeignet. St Gallen 1798.

Der erste und wichtigste Artikel beim Reichsfriedenskongresse in Rastadt. 1797. [J. L. Klüber]. 
Der siebente Artikel des Friedens von Lüneville bedarf allerdings einer Auslegung. Ein Nachtrag zu dem Versuche einer doctrinellen Auslegung des siebenten Friedensartikels von Lüneville. Germanien 1801 [J. M. v. Seuffert].

Politische Aufklärungen der Geschichte und Verbindlichkeiten Europäischer Staaten gegen einander von einem Staatsmanne. Bd. I-II. Frankfurt und Leipzig 1799.

Auflösung der Frage Ob, wie, und von wem die auf dem linken Rheinufer verlierenden Reichsstände wieder entschädigt werden sollen? 1798.

Aufruf. [1796].

Aufruf an die Menschheit bei dem Antritt eines neuen Jahrhunderts. [Leipzig] 1801. [C. F. Michaelis].

Aufruf an die vorliegende Reichskreise nach der Befreyung von Maynz. Ende Oktober 1795.

Aufruf eines rechtschaffenen Schweizers an seine noch nicht befreyten Mitbürger. Im Juny 1799 [K. L. Haller].

Patriotischer Aufruf und herzliche Bitte um baldige Errichtung einer zweckmässigeren und höchstnotwendigen Gesinde-Polizei. Helmstädt 1798.

Aufschrift eines Denkmahls deutscher Dankbarkeit: für Franz den Zweyten. Wien 1797.

Aufstellung und Anwendung der französischen Brandschazungs-RepartitionsGrundsäze. Tübingen im September 1796. [C. L. Kraft].

Lord Aukland, Einige Anmerkungen über die scheinbaren Umstände des Kriegs in der vierten Woche des Oktobers 1795. Aus dem Englischen übersetzt. [Hamburg] 1796. [J. v. Schwarzkopf].

Auszüge vertrauten Briefe aus Rastadt. Lief. I-III. 1798.

Baiern nach den Bestimmungen des Friedens von Campo Formio. November 1800. [J. G. J. C. M. v. Aretin].

Barentin, Frankreichs monarchische Staats-Verfassung im Kampfe mit seiner Regierung. Hrsg. von J. G. Dyk. Leipzig 1798.

Basis des Rastädter Friedens, enthaltend die zu Campo Formido festgesetzten Friedensartikel, welche $\mathrm{zu}$ Rastadt ratifizirt werden sollen. Bremen [Hamburg] 1798. [Brehl].

Beantwortung der Frage: Ob die königl. preußische Demarkations- oder vielmehr Neutralitätslinie entweder in geographisch - oder politischem Betracht noch existire? Im Jenner 1796.

Bedarf der siebente Artikel des Friedens von Luneville einer Auslegung? Ein Gegenstück zu dem Versuch einer doctrinellen Auslegung des siebenten Friedensartikels von Luneville. Germanien 1801. [Bingel].

v. Beilstein, Apollonius, Zur kritischen Geschichte des Rastadter Friedens, von einem unpartheiischen Beobachter. Braunshorn VI [1798].

Ein Beitrag zur Beurtheilung der Schrift des Herrn Hofrath Häberlin über die Dienstentlassung des Chur-Hannöverschen Herrn Hofrichters und Landraths von Berlepsch. [G. A. W. v. Pape]. Hannover 1797.

Noch ein Beitrag zur Erörterung der Frage: wie kan die französische Brandschazung umgelegt werden? Stuttgart. [Moser].

Beiträge zur richtigen Beurtheilung der Kapitulation von Mannheim. 1796.

Fernere Beiträge zur Beleuchtung des Basler Friedenschlusses von dem Verfasser der Fragmente. 1795. [C. Kaufmann]. 
Bekanntmachung an die Bewohner Bayerns, Schwabens, Frankens, Tirols und Salzburgs, [München] Februar 1801.

Fernere Beleuchtung des zu Basel geschlossenen Friedens und der damit verbundenen Handlungen. Dem Verfasser der Anmerkungen über die kön. preuß. Erklärung durch Gegenschriften angenöthiget. 1795. [J. v. Müller].

Nähere Beleuchtung des Nichteinigungssystems. Ein Bruchstück für die Geschichte der Zukunft. An meine Mitstände. Vaterland 1798. [Graf zur Lippe-Weissenfeld, C.C.]

Bemerkungen über Ausgewanderte und ihre Rechte bey Gelegenheit ihrer Verbannung aus mehrern deutscher Provinzen. Hamburg 1796.

Bemerkungen eines französischen Bürgers und alten Soldatens über die Feldzüge in Champagne, an dem Rhein, der Saar, Blies und Mosel, und die Ursachen ihres bekannten Erfolgs in Briefen an seinen ausgewanderten Bruder. Aus der franzözischen Handschrift übersetzt und herausgegeben von einem Schweizer. Basel [Leipzig] 1796. [P. B. Horstmann].

Bemerkungen über den Charakter, die Sitten und Gewohnheiten der Venezianer nebst einer kurzen Geschichte der teutschen protestantischen Nazion in Venedig und einigen Bemerkungen über das an dessen Laguna angrenzende Landvolk in Briefen. Bd. I-II. Bayreuth 1800. J. J. F[ick].

Bemerkungen über Frankreich während der Feldzüge in den Jahren 1793-1795. 1797.

Bemerkungen über den Gang der Staatsumwälzung und Entwicklung der neuen Staatsumwälzung und Entwicklung der neuen Staatsverfassung von Frankreich. Vom Anfange bis zur gegenwärtigen Zeit. Von einem Augenzeugen. Ein interessanter Beitrag zu Girtanners und Anderer Schriften über die französische Revolution. 1796.

Bemerkungen über das schwäbische Kreiskorps und dessen Vertheidigung der Vestung Kehl. 1797.

Bemerkungen über das Schicksal der französischen Gesandten zu Rastadt. 1799. [Shilling].

Bemerkungen über die Umlegung der französischen Kontribution in Würtemberg. 1796. [Steinkopf].

Flüchtige Bemerkungen über das rechtliche Gutachten, die Uebergabe der Festung Mannheim an den Reichsfeind betreffend. Ebenfalls den Göttingischen Professoren Herrn geheimen Justizrath Pütter und Herrn Hofrath von Martens zu öffentlicher Prüfung gewidmet. Regensburg den 1 December 1795.

Freymüthige Bemerkungen über das jüngste kaiserliche Kommissionsdekret de diet 5 März in Beziehung auf die künftige Reichsverrathschlagung von einem Patrioten. Bopfingen [Regensburg] 1801.

Kurze Bemerkungen über den authentischen Bericht die Ermordung der Franz. Gesandtschaft vorwärts Rastadt betreffend.

Militairische und politische Bemerkungen über die Vertheidigung von Frankreich. Bd. I-IV. Frankfurt 1795-96.

Patriotische Bemerkungen über 1) die Diminution der zu der französischen Brandschazung einzuziehenden Vermögenssteuer 2) Die Einschränkung des ausländischen Adels 3) Die durch die Beamte zum Theil selbst, zum Theil durch die Landmiliz eingerissenen Unsittlichkeit, und denen Hebung 4) Die Ursachen, warum nicht aus jedem Magistrate ein Landtagsdeputirter gewählt werden könne. Sizilien 1796 [C. Hehl]. 
Patriotische, aber ehrfurchtsvolle Bemerkungen über die von Sr. Majest. dem Könige von Preußen, durch höchst dero Minister am Reichstage zu Regensburg gemachte Erklärung in Betreff des am 5ten April, 1795 mit der französischen Republik geschlossenen Friedenstraktates. 1795. [J. v. Müller].

Einige polizeymässige Bemerkungen über die staatsrechtlichen Bemerkungen eines deutschen Rechtsgelehrten über die Wahl der Reichsdeputirten zu dem künftigen Friedens-Congresse. Germanien 1796. [A. J. Hoffmann].

Staatsrechtliche Bemerkungen über die neueste fürstbischöfliche Consistorialverordnung wider die unenthaltsamen Kleriker des Regensburger Kirchsprengels, in Hinsicht auf die anmaßgeblichen Eingriffe in die höchst landesherrlichen Gerechtsamen Seiner Kurfürstlichen Durchlaut zu Pfalzbaiern. 1796.

Staatsrechtliche Bemerkungen eines deutschen Rechtsgelehrten über die Wahl der Reichsdeputirten. Germanien 1796. [J. P. Sattler].

Staatsrechtliche Bemerkungen über den vom Herrn Herzog zu Pfalzzweibrücken zur Reichstagsversammlung genommenen neuesten Rekurs, und einige Stellen der Druckschrift Ho! Ho! oder rechtliche Verwunderung. Im Monat Hornung 1796. [O. P. Gross von Trockau].

Noch einmal Bemerkungen über den weitern preußischen Vertrag mit der Frankenrepublik vom 17ten May, 1795 in Betreff der Demarkationslinie, und der Neutralität. 1795. [J. v. Müller?]

Nun auch patriotische Bemerkungen über das kaiserliche Hofdekret vom 19ten im May, 1795. Aus Veranlassung des bekannten preußischen Friedens mit der Frankenrepublik. 1795.

Preußens Benehmen nach seinem Separat-Frieden mit Frankreich verglichen mit dem kaiserlichen Hofdekret vom 29sten Julius 1795. Neueres Schreiben eines deutschen Comitialgesandten an das Ministerium seines Hofes. Germanien [Nürnberg] 1795.

Bergk, J. A., Briefe über Immanuel Kant's Metaphysische Anfangsgründe der Rechtslehre enthaltend Erläuterungen, Prüfung und Einwürfe. Leipzig und Gera 1797.

Bericht und Gutachten eines deutschen Reichstags-Gesandten an seinen Hof über das kaiserliche Hof-Dekret vom 9ten September 1795. In Betreff des von Hessen-Cassel mit Frankreich am 28. August zu Basel geschlossenen Friedens. Germanien [Heilbronn] Nov. 1795. [F. A. v. d. Becke].

Authentischer Bericht von dem an der französischen Friedensgesandschaft bei ihrer Rükreise von dem Congreß in der Nähe von Rastadt verübten Meuchelmord. 1799. [C. W. v. Dohm].

Des Herrn Heinrich Wilhelm von Bülow ämtliche Berichte über den FriedensKongreß zu Basel. Frankfurt und Leipzig 1796.

Ausführliche Beschreibung des Kriegsschauplatzes zwischen dem Rhein, der Nahe und der Mosel, nebst Betrachtungen über einige der merkwürdigsten Begebenheiten, welche sich auf diesem Kriegsschauplatze in den Jahren 1793 und 1794 ereignet haben. Bd. I-II. Berlin 1798-99. [C. C. A. L. v. Massenbach].

Auch eine Betrachtung durch den gemeineidgenössischen feierlichen Buss- und Danktag. 1796. [J. Tobler].

Betrachtungen über die Darstellung und die Wirkung des Rastadter-Vorfalls in Paris. May 1799.

Betrachtungen über die letzten Friedensunterhandlungen. Im Dezember 1800. 
Freymüthige Betrachtungen über den bisherigen Geschäftsgang beim hohen Friedenskongresse und über die allerneueste französische Antwort vom 22. Junius in Rastadt. Im Julius 1798.

Staatswissenschaftliche Betrachtungen über die Bezahlung feindlicher Kontributionen. Von einem Wirtemberger in Rüksicht auf sein Vaterland. St. 1-6. Stuttgart 1796. [C. B. Treffz].

Des Hof- $u$. Canzleyraths von Martens Betrachtungen über das Memoire vom 1sten Februar und den dazu gehörigen Nachtrag vom 19. März 1798, welche Herr Friedrich Ludwig von Berlepsch an den Congreß zu Rastadt gerichtet hat. Aus dem Französischen übersetzt. 1798.

Beytrag zur Reichsberathung über die Bewilligung neuer Römermonate. Nürnberg 1799 .

Ueber die Beyziehung der Besoldungen und Pensionen zu der französischen Kriegskontribution. Tübingen 12 September 1796. [J. W. Camerer].

Bitt-Psalm guter österreichischer und teutscher Bürger in dem gegenwärtigen Krieg, um den Göttlichen Segen über Se. Majestät den Kaiser Franz II., und Se. k. Hoheit, den Erzherzog Carl. Konstanz. Im Brachmonat 1799.

Ernsthafte Blicke auf die Moralität der fränkischen Regierung, den Charakter ihrer Agenten, und die ungeheuren Entwürfe ganz Deutschland republikanisiren. Mit einem freymüthigen Rückblick auf Italien, die Schweiz, Neapel, Spanien, Tosskana, Malta und Sardinien. Cairo [Nürnberg] 1799. [L. C. Wiessner].

Umbefangene Blicke in Frankreichs Zukunft. [Wien] 1796.

Botschaft des französischen Directoriums an den Rath der fünfhundert wegen des Kriegs gegen das Haus Oesterreich und den Großherzog von Toscana nebst einer höchstnöthigen Beylage zu dieser Bothschaft mit Anmerkungen. 1799.

de Bouillé, Marquis, Memoiren über die französische Revolution. Aus den Englischen. Hamburg 1798.

Briefe eines Abgeordneten bey dem Congresse zu Rastadt. Bd. I. 1798.

Briefe deutscher Bürger und Landleute über das Betragen der Französen in Deutschland in Sommer und Spätjahr 1796. Beiertheim 1796.

Briefe aus Italien. Ein Beitrag zur Geschichte und Charakteristik der österreichischen Armeen in den Feldzügen 1794, 95, 96, 97. [Tübingen] 1798.

Acht Briefe über einige Widersprüche und Inconsequenzen in Herrn Professor Kants neuesten Schriften. Nebst einem Postscripte betreffend von Herrn Kants und Herrn Fichtens mathematischen Kenntnissen. Berlin und Stettin 1799.

Neue Briefe eines preußischen Augenzeugen über die Feldzüge gegen die Neufranken. Altona 1796.

Republikanischer Bruderkuß im ersten Jahre deutscher Freiheit. [1800].

Brun (geb. Münter), Friederike, Gedichte, hrsg. durch Fridrich Matthison. Zürich 1798.

Buonaparte General der Neufrankenrepublik an den Hochansehnlichen FriedensCongreß zu Rastadt, über den Einfluß der unglücklichen Touloner Flotte auf Krieg und Frieden. Ein politisches Traumgeschicht. Cairo 5799 [1799].

Büsch, J. G., Die politische Wichtigkeit der Freiheit Hamburgs und ihrer Schwesterstädte Lübeck und Bremen für das ganze handelnde Europa in ein neues Licht. Hamburg 1797.

Cisrhenanien unter den Franken, besonders in Hinsicht auf die Pfalz, bis auf Bonaparte. 1801.

Der Congreß zu Bopfingen. Im November 1795. 
Der Congre $\beta$ in Rastadt vor dem Richterstuhle der Vernunft nebst Bemerkungen über den politischen Charakter der Teutschen. Rastadt und Großcairo [Jena] 1799. [J. A. Bergk].

An den Rastatter Congre $\beta$ bei seiner Auflösung. April 1799.

Danksagung der ländlichen Bewohner Deutschlands an die allgemeine Reichsversamlung wegen den neue bewilligten Römermonaten, und Bitte an die Reichsstände, daß das desfallige jüngere Reichsgutachten auch erfüller werden möge. Nürnberg 1799.

Danksagungsadresse von der bayerischen Nation an Max Joseph IV [München] 1800.

Actenmässige Darstellung der Sache des Herrn von Berlepsch; zur Berichtigung der Schrift des Herrn Hofrath Häberlin, über die Dienstentlassung des Herrn Hofrichters, auch Land- und Statsraths von Berlepsch. Hannover 1797. [A. W. Rehberg].

Getreue Darstellung des Auflaufs, welchen die französische Botschaft durch Aushängung einer dreyfärbigen Fahne den 13. April 1798 in Wien veranlasst hat. Von einem Augenzeugen. [C. G. Glave-Kolbielski].

Pragmatische Darstellung des Constitutionswidrigen Preußischen Separatfriedens in Bezug auf die Reichsstandschaft nebst einigen Betrachtungen über die bekannte Rüksprache. Frankfurt und Leipzig 1795.

Deutschland über alles wenn es nur will. Heft I-X. 1798. [P. Freiherr v. Gemmingen].

Deutschland und Pohlen. Eine Rhapsodie. 1795.

An Deutschland. Eine Beantwortung der kürzlich erschienenen Schrift: Preußens Neutralitäts-System dessen Ursachen und wahrscheinliche Folgen. Germanien [Altona] 1799.

Ueber das mittägige Deutschland. Zuschrift der süddeutschen Bürger an die französische Regierung. Nach dem französischen Original. 1801.

zu Dohna, Albrecht Burggraf, Der Feldzug der Preussen gegen die Franzosen in den Niederlanden im Jahr 1793. Bd. I-III. Berlin [Stendal] 1798.

Dümouriez, Ueber den Krieg. Im Aprill 1799.

v. Eiberg, Carl, Tyrols Vertheidigung gegen die Franzosen in dem Jahren 1796 und 1797 nach ihren Hauptepochen und Grundzügen aus Urkunden. Innsbruck 1798.

Ueber den Einflu $\beta$ des jetzigen Kriegs auf öffentliche Meinung. 1795.

Einladung von Konfuz an den Weltbürger Syrach zu seinen Vorlesungen über Europa. Auch nach dem Frieden noch immer zu lesen. Peking [Thal-Ehrenbreitstein] 1795.

Entwicklung der Grundsäze nach welchen ein dem Geist der Zeit und rechtlichen Principien angemessener Steuerfuß in Bezug auf die wirtembergische Kriegskontribution zu entwerfen wäre, nebst Abhandlung der besondern hieher gehörigen Gegenstände. Von L. M. Stuttgart 1796. [J. L. Müller].

Epistel an den jungen Mann, der an Teutschlands Reichsstände ein Wort zu seiner Zeit verfasset hat. Regensburg und Augsburg [Altona] 1795. [K. G. GlaveKolbielski].

Der Eremit Kaphta an die Bürger Würtembergs und Schwabens. Oder: Wie ist die Schaden, den die Neufranken in diesen Gauen verursachten, wieder in etwas gut zu machen? Germanien [Stuttgart] 1796. [F. Streim]. 
Erklärung der zur Herstellung ihres Vaterlandes vereinigten Schweizer bey ihrem Wiedereintritt in der Schweiz. Zürich 1799.

Erklärung der zur Herstellung ihres Vaterlandes vereinigten Schweizer bey ihrem Wiedereintritte in die Schweiz. May 1799. [C. L. v. Haller, hrsg. F. Steiger].

Erklärung Sr. Königl. Majestät von Preußen etc. an ihre Höchst- und hohen Reichs-Mitstände in Betreff des am 5ten April 1795 mit der Französischen Republik geschlossenen Friedens-Tractates. Berlin 1. Mai 1795.

Erklärung im Namen Seiner Königlichen Majestät von Preußen der allgemeinen Reichsversammlung mitgetheilt in Betref des zu Basel am 5 April geschlossenen Friedens, mit einigen Anmerkungen. 1795. [J. v. Müller].

Gemeinschaftliche Erklärung mehrerer ansehnlichen Gesandschaften zu Rastadt über die Ermordung der französischen Gesandten und die übrigen dabei vorgekommenen Umstände. 1799.

Erläuterungen und Zusäze zu dem politischen Handbuche, welches Junker David Wyss im Jahr 1796 zum Nuzen und Vergnügen der erwachsenen Jugend der Stadt und Landschaft Zürich im Druke herausgegeben hat. Straßburg 1797, 5. der fränkischen Republik.

Zwei staatsrechtliche Erläuterungen. 1797.

Ermordung der bevollmächtigten Minister der fränkischen Republik beim Rastadter Congreß durch die Ostreicher. Strasburg Jahr VII [1799].

Ernesti, Beyträge zur Geschichte der Deutschen. Bayreuth 1796.

Etwas über Krieg und Frieden an die Fürsten, Herren, Bürger und Bauern Deutschlands, mit Noten. Zum Anfange des März im Jahr 1800. Freistadt [1800].

Europa nach seinem politischen und militairischen Zustand im Januar 1800 von M. du P-n. Leipzig 1800. [J. Mallet du Pan].

v. Faber, Documentirte Beleuchtung der äußeren Verhältnisse der Festung Ehrenbreitstein. Im Brachmonat 1798.

v. Fabrice, August, Was hat das Haus Braunschweig-Lüneburg bey dem bevorstestehenden Reichsfrieden zu erwarten. Ein Brief von Carl Gustav von Dahlstiern vormaligem Capitain in Braunschweigischen Diensten. Hamburg 1799.

Buonaparte's ruhmvoller Feldzug in Italien in den Jahren 1796-1797. Altona [Frankreich].

Die Folgen der Säkularisationen. Germanien [Zürich] 1801. [J. H. K. v. Wessenberg].

Ueber die Folgen des Friedens in Bayern, Straßburg [München] im 9. Jahre der Republik [1801].

Die von der französischen Gesandschaft zu Rastadt in den Noten vom 24. Floreal, 4. Messidor und 1. Thermidor an das deutsche Reich gemahten Forderungen wegen Ueberlassung mehrerer festen Punkte auf dem rechten Rheinufer können und dürfen schlechterdings nie bewilligt werden. 1798.

Fortsetzung der patriotischen Bemerkungen über das kaiserliche Hofdekret vom 19ten im May 1795. 1795.

Ueber die Frage: Ist es Frankreichs Vortheil, seine Besitzungen bis an den Rhein auszudehnen und das linke Ufer dieses Flusses zu der künftigen Grenze der neuen Republik zu bestimmen? Frankfurt und Leipzig 1795.

Fünfzig politische Fragen über Krieg und Frieden. Den Publizisten des heil. röm. Reichs bei dem Eintritt des neunzehnten Jahrhunderts vergelegt von D.W.P.W. 1801. [D. W. P. Wollmer]. 
Unvorgreifliche Fragen dem Verfasser des im May bey J. Decker in Basel erschienenen neuen Entschädigungs-Plans zur näheren Prüfung vorgelegt von einem warmen Freunde seines deutschen Vaterlandes. Deutschland [Basel und Rastadt] 1798. [C. J. v. Bachem].

Fragmente. In Beziehung auf die Königlich Preußische Erklärung an die allgemeine Reichsversammlung, in Betreff des zu Basel am 3ten April 1795 geschlossenen Friedens; und die dawider erschienenen Anmerkungen eines Ungenannten. 1795. [C. Kaufmann].

Fragmente über Deutschlands Friede mit Frankreich. Aus dem Portefeuille eines nach Basel im November 1794 durch Frankreich reisenden Ministers verloren. Mit einigen Anmerkungen und einer Vorrede des Herausgebers. Frankfurt und Leipzig im September 1795.

Franzosen, packt in Deutschland ein, und geht nach London! Oder werdet Spartaner. Germanien [Hildburghausen] 1797. [E. A. C. Strasser].

Freiheit, Gleichheit, Bruderliebe. [1796, G. F. List].

Freiheits-Gedichte. Bd. I-II. Paris [Mannheim] 5 [1797].

Der Friede von Lüneville ist über alle Auslegung erhaben. Ein Nachtrag zu der Piece: Bedarf der Siebente Artikel des Friedens von Lüneville einer Auslegung. Germanien 1801. [Bingel].

Preußens Friede mit Frankreich. In Bezug auf seine Folgen für Oesterreich, Teutschland und ganz Europa. In Briefen welche die neue Postkommission zu Amsterdam im April 1795 erbrochen und weggeworfen hat. Basel 1795.

Ueber den Frieden zwischen der Frankenrepublik und Sr. Majestät dem König von Preußen. Aus dem Französischen übersaetzt. Frankfurt und Leipzig 1795.

Ueber den bevorstehenden Frieden des teutschen Reichs mit Frankreich. Unterthänigstes Gutachten eines geheimen Raths an seine Fürsten. Basel 1796.

Ueber Teutschlands Frieden mit Frankreich. Eine Unterredung zwischen Polemon und Irenophilus. Nebst einer Denkschrift an den Friedenscongress zu Rastadt. 1798.

Der FriedensTraktat von Lüneville. Französisch und Teutsch mit Reminiscenten. Wien und Paris 1801. [A. C. Wedekind].

Gedanken über die Mittel, zu einem gerechten und dauerhaften Reichsfrieden mit Frankreich zu gelangen. Germanien [Frankfurt] 1795.

Gedanken Ueber das Princip der Französischen Brandschazungs-Repartition. Am ersten September Stuttgart 1796. [W. A. F. Danz].

Freymüthige Gedanken eines teutschen Staatsbürgers über die Säcularisirung der geistlichen Wahlstaaten Teutschlands. Altona und Hamburg [Würzburg] 1798.

Unmaßgebliche Gedanken über die vielen Gebrechen einer Landmiliz und wie ein dauerhaftes, stehendes, den vaterländischen Einkünften angemessenes aus Landeskindern bestehendes Militär in Württemberg zu erzielen sein möchte? Zur Beherzigung der württembergischen Prälaten und Landschaft. Januar 1797.

Unvorgreifliche Gedanken eines patriotischen Wirtembergers. Stuttgart 1796. [Müller]

Die Gefahren der Zeit. Anfangs August 1796. [J.v. Müller].

Geheimnisse eines mehr als fünfzigjährigen württembergischen Staatsmannes. 1799. [J. G. Pahl]. 
Geist der herrschenden Franzosen, sichtbar in den Wahlen ihrer Directoren. 1799.

Der Geist des Zeitalters. Ein Denkmal des achtzehnten Jahrhunderts, zum Besten des neunzehnten errichtet von einem Freunde der Wahrheit. Zürich 1801. [J. H. K. v. Wessenberg].

Geist und Gang der letzten Pariser Revolution oder: Was ist von derselben für den Frieden zu hoffen oder zu fürchten? Deutschland [Schaffhausen] 1800. [K. L. v. Haller].

Gemälde aus der Relagerung von Mannheim im Jahr 1795. Mit PJan und Beilagen, nebst bei Gelegenheit gewechselten französischen und deutschen Originalschreiben. Mannheim 1796.

Gentz, Friedrich, Ueber die Ermordung der französischen Congreßgesandten. 1799.

- Ueber den Ursprung und Charakter des Krieges gegen die Französiche Revolution. Berlin 1801.

- Von dem politischen Zustande von Europa vor und nach der Französischen Revolution. Eine Prüfung des Buches: De l'état de la France à la fin de l'an VIII. Berlin 1801.

Germania im Jahr 1795. Aus dem Himmeln herabgesandt den 6 Nivose des Jahres 4 und ehrerbietigst gewidmet Seiner hochreichsfreiherrlichen Excellenz Herrn Christuph Albrecht Reichsfreiherrn von Seckendorf. Stuttgard [Augsburg] 1796. [K. G. Glave-Kolbielski].

Geschichte der menschlichen Ausartung und Verschlimmerung durch das gesellschaftliche Leben. Eine Schrift die ehedem durch den Henker zu Paris verbrannt jetzt allen Königen und Priestern zum Frommen herausgegeben worden. Vom Verfasser des Hierokles. Bd. I-II. Altona 1795-96. [C. L Paalzow].

Geschichte des K. K. militärischen Marie Theresie Ordens seit desselben Stiftung Regensburg und Mainz 1796.

Geschichte eines Teutschen der neuesten Zeit. Leipzig 1798. [F. M. Klinger].

Geschichte der Unterhandlungen zu Rastatt über die sogenannte Brüderischer Insel und den Wahlstrohm. Nebst zwey topographischen Karten. Basel 1799.

Zur Geschichte des Anfangs der Schweizerischen Revolution, oder Vertheidigung des ehemaligen General von Weiss gegen seine Verläumder. April 1799. Nürnberg 1799 .

Authentische Geschichte des französischen Revolutionskriegs in Italien, mit besonderer Hinsicht auf den Antheil Toskana's am demselben. Leipzig 1798.

Geheime Geschichte von Coblenz während der französischen Revolution. Aus den Urkunden der Cabinette des Churfürsten und der Prinzen Brüder Ludwigs des XVI. Frankfurt und Leipzig 1795.

Geheime Geschichte des Preußischen Separatfriedens; oder: Wolhberechnete Würkungen desselben am Schlusse des philosophischen Jahrhunderts. Germanien [Bamberg] 1798. [K. M. E. Fabritius].

Geheime Geschichte des Rastadter Friedensverhandlungen in Verbindung mit den Staatshändeln dieser Zeit. Von einem Schweizer. Th. I-VI. Germanien [Zürich] 1799. [C. U. D. Eggers].

Unpartheyische Geschichte des Aufenthalts der Fränkischen Bürger in Kurfürstentume Trier, vorzüglich in der Residenz-Stadt Coblenz. Heft I. Coblenz [1795]. 
Unpartheyische Geschichte der Reichsstadt Rothenburg und derselben Gebiet. Für Liebhaber der vaterländischen Geschichte. Rothenburg ob der Tauber 1798. [J. W. v. Winterbach].

Geschichte und Darstellung der polnischen Revolution in ihren nähern und entfernten Ursachen entwickelt von einem Vetter Hippolitus a Lapide. Germanien [Leipzig] 1796. [K. v. Woyda].

Des alten Vater Gerhards Gespräche über die politische Lage, worin sich das Menschengeschlecht überhaupt, und Deutschland insbesondere, durch die französische Revolution befindet. Mainz, VII [1799].

Deutschlands Gewinn und Verlust bei der Rastadter Friedens-Basis nebst Vorschlägen zu einem Entschädigungs-Plan und $\mathrm{zu}$ einer verbesserten ReichsVerfassung. April 1798.

Politisches Glaubensbekenntniss eines aufrichtigen Bayern über die Schicksale seines Vaterlandes. München den 1. Jänner 1801.

Ueber die Gleichgültigkeit der meisten Teutschen, gegen einen guten oder schlechten Frieden die geringe Wahrscheinlichkeit für den Ersten und die traurigen Folgen des Andern. Geschrieben in der Zeit nach der Aufkündigung des Waffenstillstandes von Seiten der Franzosen den 28. August 1800.

Görres, J., Resultate meiner Sendung nach Paris im Brumaire des achten Jahres. Koblenz im Floreal J. VIII [1800].

Gott regiert die Welt. Oder Critik über das Verhalten der Deutschen bei den gegenwärtigen Weltereignissen. 1796.

Häberlin, Sammlung einiger Actenstücke die Rechtssache des Herrn Hofrichters, Land- und Schatz-Raths von Berlepsch betreffend. Helmstädt und Leipzig 1797.

- Ueber das dem Freyherrn Moritz von Brabeck angeschuldigte Verbrechen der beligten Majestät. Braunschweig 1800.

Hartmann, Johann Georg, Gutächtliche Gedanken über die Umlage der neuerlichen Kriegs-Schäden in Würtemberg. Tübingen und Stuttgard 1797.

Heinzmann, Johann Georg, Meine Frühstunden in Paris. Basel 1800.

- Ueber die Pest der deutschen Literatur. Appel an meine Nation. Bern 1795.

v. Hess, J. L., Was darf und was darf nicht in Hamburg geschehen. Hamburg 1799.

Ho-! Ho-! oder rechtliche Verwunderung über einige Stellen einer Druckschrift die Uebergabe der Festung Mannheim an den Reichsfeind betreffend. Im Jenner 1796.

Hippolytos a Lapide der Jüngere, Gemälde von Europa. 1800. [J. W. v. Archenholtz].

Hoffmann, Leopold Alois, Aktenmässige Darstellung der Deutschen Union und ihrer Verbindung mit dem Illuminaten-Freimaurer- und Rosenkreutzer-Orden. Ein nöthiger Anhang $\mathrm{zu}$ den höchst wichtigen Erinnerungen zur rechten Zeit. Wien 1796.

- Höchst wichtige Erinnerungen zur rechten Zeit, über einige der allerernsthaftesten Angelegenheiten dieses Zeitalters. Als erster Nachtrag der W. Zeitschrift, den Leser und Gegnern derselben gewidmet. Heft I-II. Wien $1795-96$.

Holland vor und nach der Revolution in Beziehung mit der Statthalterwürde betrachtet. Frankfurt am Main 1795. [F. H. Hatzfeld]. 
Hoyer, Johann Gottfried, Geschichte der Kriegskunst seit der ersten Anwendung des Schießpulvers zu Kriegsgebrauch bis an das Ende des achtzehnten Jahrhunderts. Bd. I. Göttingen 1797.

Heteroklitische Ideen über die natürliche Begränzung der europäischen Staaten, als Grundlage zu einem ewigen Friede. Frankfurt und Leipzig [Mannheim] 1796. [C. T. Edler v. Traiteur].

Just, Carl Alexander Heinrich, Ueber Friedrich Wilhelm III. Nebst einigen freymuthigen Untersuchungen über das, was zeither durch ihn geschehen ist. Frankfurt und Leipzig 1798 .

v. Justin, K. F., Geschichte des, durch die Französische Revolution, zwischen dem größten Theile der Europäischen Mächte und der französischen Nation veranlaßten Krieges. Vierter Feldzug, sowohl die 1795sten Kriegsbegebenheiten der Armeen und Flotten der in der großen Coalition verbliebenen alliirten Mächte, als auch die mit Frankreich eingegangenen Friedensschlüße einiger von dem grossen Bunde abgegangenen Staaten enthaltend. Regensburg 1796.

- Geschichte des, durch die Französische Revolution, zwischen dem größten Theile der Europäischen Mächte und der französischen Nation, veranlaßten Krieges. Fünfter Feldzug, vom Jahre 1796. Regensburg 1797.

Ueber Kaisermacht, Friedenskongreß, und Reichsdeputation, bei dem allgemeinen Reichsfriedensschlusse mit der Neufrankenrepublik. 1797. [F. W. Rothammer].

Kant, Immanuel, Zwo Abhandlungen über moralische und politische Gegenstände. Frankfurt und Leipzig 1795.

- Ueber die Buchmacherey. Zwey Briefe an Herrn Friedrich Nicolai. Königsberg 1798.

- Zum ewigen Frieden. Ein philosophischer Entwurf. Königsberg 1795.

- Erneuerte Frage: Ob das menschliche Geschlecht im beständigen Fortschreiten zum Besseren sey? Immanuel Kant's vermischte Schriften III Bd., 8. Aufgabe. Halle 1799.

- Sämmtliche kleine Schriften. Nach der Zeitfolge geordnet. IV Bd., 1. Abt. Königsberg und Leipzig 1798.

- Verkündigung des nahen Abschlusses eines Traktats zum ewigen Frieden in der Philosophie. [hrsg. J. G. Heynig]. [Ulm] 1798.

Kennzeichen der Jakobiner. MDCCXCV (1795).

Klagen eines Rheinländers über das Betragen der Verkündiger der Freyheit und Gleichheit am rechten Rheinufer des Rheins in Briefen. 1796.

Können die Europäischen Mächte besonders England und Oesterreich ruhig zusehen? 1800.

Konstitution der Republik Frankreich vom Jahre 8 mit aufklärenden Noten. Basel [München] 1800.

Ueber Krieg, Subsidientraktate und Volkszutrauen, Gedanken Machiavellis und Friedrichs des Großen mit Anmerkungen des baierischen Herausgebers. 1800.

Kriegs-Lied für die tapfern Schweizer die für Religion, und Vaterland kämpfen. [Zürich, 1799].

Die allerneueste Kriegszucht der Franzosen während ihrer Aufenthalt an der Lahn im Junius und Julius, August und September 1796. In Briefen an einen Freund. I-II Lief. 1796-97. [P. B. Horstmann].

Kritik des Jahres 1797. Ein Taschenbuch für 1798. Altona.

Neue Kronik der kais. Kön. V. Oester Stadt Konstanz am Bodensee. Konstanz 1798. 
Krug, Wilhelm Traugott, Über das Verhältniß der kritischen Philosophie zur moralischen, politischen und religiösen Kultur des Menschen. Jena 1798.

Politische Lage und Staatsinteresse des Königreichs Preußen. Von einem Staatsbürger desselben. 1795. [A. Riem].

Ueber die politische Lage und das Staatsinteresse Preußens nach der neuesten Holländischen Revolution von dem preußischen Bürger Bauchwitz. May 1795. [K. G. Glave-Kolbielski].

Landungsgeschichte der Engländer und Russen in Holland, im Herbst 1799. Nebst Anekdoten oder die Anführer. Verf. v. einem Officier im Gefolge des Generals Brüne mit einer Vorrede und Anmerkungen vom deutschen Herausgeber. Hamburg 1800.

Lauber, Joseph, Denkmahl der Vaterlandsliebe und Fürstentreue. Wien 1797.

Lavater, Johann Caspar, Christliche Belehrungen und Erweckungen, den gegenwärtigen Zeitumständen angemessen, Oder Predigt über die Frage: Was sollen wir thun? Lucä III: 10 Gehalten in der Sankt Peterskriche zu Zürich, Sonntags den 18. Augustmonat 1799. Zürich 1799.

- An das Directorium der französischen Republik. Nebst einer Litanei, fürs ganze Leben brauchbar. Schweiz 1798. [Leipzig]

Leben Charette's. Mit den wichtigsten Anecdoten aus derselben, und den vorzüglichsten Details über den Vendeekrieg. Aus dem Französischen übersetzt. 1796.

Lehmann, Kaspar, Versuch einer Geschichte östreichischer Regenten in ihren Verhältnissen gegen das deutsche Reich. Nebst einem Anhänge über die östreichische Gerechtsame auf die bayerische Verlassenschaft 1778. Frankfurt und Leipzig 1795.

Das neue Licht oder Rastatter Friedens-Congress-Aussichten. Rastatt [Nürnberg] 1798. [J. L. Klüber].

Neue lustige Lieder. [1799].

Zwey schöne alte Lieder, mit neuen Abänderungen. 1799.

de Luca, Ignaz, Practische Staatskunde von Europa. Wien 1796.

Majer, Johann Christian, Ueber das Princip der Französischen BrandschazungsRepertition. Tübingen im August 1796.

- Recension der sämtlichen Schriften über das Princip der Französischen Brandschazungs-Repartition. Tübingen im September 1796.

Majer, Johann Christoph, Teutsche Staatskonstitution. Hamburg 1800.

Mallet du Pan, J., Zerstörung des Schweitzer-Bundes und der Schweitzer-Freyheit; ein historischer Versuch. Aus dem Französischen mit einigen erläuternden Anmerkungen. Bd. I-II. Leipzig 1799.

Materialien zur Erörterung der Frage: Wie kann die Französische Contribution umgelegt werden? Stuttgart 1796. [J. W. Kapff].

Materialien zu einem künftigen Landtage in Bayern, hrsg. von V. W., einem bayerschen Landstande. Regensburg [München] 1800. [J. Utschneider].

Medicus, W. L., Ueber das Beywürkungsrecht der einzelnen Reichsstände zu Reichsfriedenshandlungen. Frankfurt 1795.

Merkwürdigkeiten des achtzehnten Jahrhunderts. Eine Art Denkbuch. Wien 1799. Die Preußische Mitverwendung für den Reichsfrieden. Ulm 1795. [J. v. Müller]. Müller, geb. Maisch, Wilhelmine, Gedichte an Se. Königliche Hoheit den Erzherzog Carl von Oestreich. Zürich im Jully 1799. 
Aechte Nachricht von dem Krieg der teutschen Bauern gegen die Franzosen. 1796.

Nähere Nachricht über das traurige endliche Schicksal der französischen FriedensGesandten in Rastadt. [Regensburg] May 1799.

Gute Nacht Republik! Die Emigrirten stehen auf! oder meine Meinung von dem Gebrauche der bewaffneten Emigrirten in den Kaiserlich-Königlichen Heeren, die vielleicht Prüfung und Beherzigung verdient. Deutschland [Frankfurt] 1796. [P. B. Horstmann].

Nachtrag zum französischen Soldaten an den deutschen Bauersmann vom deutschen Patrioten. 1800.

Nachtrag zu der Schrift: Preußens Neutralitäts-System, dessen Ursachen und wahrscheinliche Folgen. Von dem Verfasser derselben. Deutschland [Hamburg] 1799. [H. M. Marcard].

Bayerische Nationallieder am Ende des achtzehnten Jahrhunderts und im letzten Jahre der Sklaverei. [München 1800].

Natur, Ursachen und Resultate der französischen Revolution. Eine Fortsetzung des Werkes: Frankreichs monarchische Staatsverfassung im Kampfe mit seiner Regierung. Hrsg. v. J. G. Dyk. Leipzig 1798.

Die Neufrankenrepublik Alles und das teutsche Reich Nichts in den neuesten Friedensprätensionen, Noten und Antworten oder Zusäze zu der östreichischen und kursächsischen Abstimmung in Rastadt. Im Junius 1798.

Preußens Neutralitits-System dessen Ursachen und wahrscheinliche Folgen. Deutschland [Hamburg] 1799. [H. M. Marcard].

Von der Nothwendigkeit eines zu versammelnden Landständischen Kongresses in Oberschwaben und dessen nüzliche Folgen. Strassburg [?] 1798.

Ueber die Nothwendigkeit einer allgemeinen Secularisation der deutschen Erzbisthümer, Bisthümer, Prälaturen und Klöster. Mit Hinsicht aud Deutschlands gegenwärtige Verfassung. Germanien [Straßburg] 1798.

Die Occupation der Stadt und Festung Mainz durch die Truppen der französischen Republik am 30sten December 1797, in Verbindung mit den darüber gepflogenen Verhandlungen der Reichsfriedens-Deputation zu Rastadt. Germanien [Strassburg] 1798.

Ohanny, A. R., Exjesuit, Anmerkungen gegen die staatsrechtlichen Bemerkungen über die regensburgische Verordnung wider die unenthaltsamen Kleriker. 1796.

Oesterreich im Jahre 1799. 1799.

Ueber die Pacification und Indemnisation oder Plan zur Entschädigung der Reichsstände deren Länder und Besizungen zu Erlangung des Friedens vom Reiche zum Opfer gebracht werden. Von einem Teutschen. 1798.

Pahl, Johann Gottfried, Materialien zur Geschichte des Kriegs in Schwaben im Jahre 1796. Lief. I-III. Nördlingen 1797-98.

Ueber das Petitionsrecht der Wirtembergischen Landstände; für alle und zu allen Zeiten lesbar. [Stuttgart] 1797. [C. F. Baz].

Pfaff, Friderich Burkhard, Vorschläge zu einem Steuer-System, zur Repartition der französischen Contribution, und der weitern Kriegs-Schäden von Anno 1796 und 1797. Tübingen und Stuttgard 1797.

Phileleutheros Orthodoxos, N. Bonaparte als Mensch, Bürger, Krieger und Regent geschildert. Nebst Bemerkungen über die neueste Verfassung der französischen Republik. Strassburg [Gera] 1801. [J. A. Bergk].

Der Prediger in der Wüsten. Deutschland [Reutlingen] 1798. 
Ueber den französischen Priester-Eid und der dadurch veranlaßten Auswanderung der französischen Geistlichkeit. Von F. -X. -Chr. -Pf. zu I. Deutschland [Ulm] 1795. [F. X. Christmann].

Die Privilegien des Adels in Bayern vor dem Richterstuhl der gesunden Vernunft. [München] 1800.

v. Promnitz, Charlotte Friederike, Vertheidigung der Vernunft und Religion wider die Kritik des Herrn Kant. Berlin 1798.

Prüfung der Schrift: Preußens Neutralitäts-System usw., 1799. [A. Hennings].

Unpartheyische Prüfung der staatsrechtlichen Bemerkungen über die neueste fürstbischöfliche Konsistorialverordnung wider die unenthaltsamen Kleriker des regensburger Kirchensprengels etc., verfaßt von einem Laien. 1796.

Rambach, Friedrich, Hochverrath, oder: der Emigrant. Ein Schauspiel in fünf Aufzügen. Grätz 1798.

Rebmann, Georg Friedrich, Satyrisches Hand-Wörterbuch für jede Gattung von Leser nach Alphabetischer Ordnung. I-II Lief. Paris [Altona] 1797.

- Holland und Frankreich, in Briefen geschrieben auf einer Reise von der Niederelbe nach Paris im Jahr 1796 und dem fünften der französischen Republik. I-II. Paris und Kölln [Hamburg] 1796.

- Die fünf Männer. Lebensgeschichte der fünf jetzt in Frankreich regierenden Direktoren, Geschichte ihrer Regierung und Entwickelung ihres Systems. Paris [Hamburg] im 5ten Jahr der Republik [1797].

Rechtfertigung des Versuchs einer doctrinellen Auslegung des siebenten Friedensartikels von Lüneville. Gegen den Versuch einer natürlichen Erklärung des besagten Friedensartikels. Germanien [Bamberg] 1801.

Reflexionen über die Art der Entrichtung der von Würtemberg an die Franzosen zu bezahlenden Contribution. Tübingen 1796. [W. G. Ploucquet].

Reflexionen über die Verschiedenheit des Begriffs der Raison de guerre bey deutschen Reichskriegen. 1796.

Das allgemein außerordentliche Kaiserliche und Reichsgericht zur Untersuchung des bekannten Vorfalls bey Rastadt, oder: meine Betrachtungen über das jüngste Kaiserliche allerhöchste Hofdekret an die allgemeine Reichsversammlung ddo 6ten dictato 11ten Juny 1799. Juny 1799.

An Deutschlands Reichsstände. Germanien im August 1795.

An Teutschlands Reichsstände. Ein Wort zu seiner Zeit. 1795. [L. v. Seckendorff].

Rescript des Herrn Herzogs von ... an seinen Comitialgesandten in Regensburg dessen beyde Berichte d.d. den ... May und ... August betreffend. Den 4ten November 1795.

Resultat der Reichsfriedens-Unterhandlungen zu Rastadt in Verbindungen mit dem neueren Frieden von Luneville. Offenbach 1801.

Die Revolution in der Schweiz, im Jahre 1798 von einem Augenzeugen. Zürich und London [Hannover] 1798.

Rückblick auf das achtzehnte und Aussichten in das neunzehnte Jahrhundert. Leipzig 1800.

Rückblicke auf den, wenn Gott will, für Teutschland nun bald geendigten Krieg. Nebst einigen Erläuterungen, die Propaganda, Jacobiner und Illuminaten betreffend. Coppenhagen [Bremen] 1795. [A. v. Knigge].

Ruhm-Gesang der Kaiserl. Königlichen Armee unter höchst beglückten Commando Sr. Königl. Hocheit Erzherzogen Karls. [1799]. 
Eine Sammlung von deutschen Biedersinn zur Stärkung der Schwachen. Wahrburg im Junius 1799.

v. Sartori, Jos., Memoiren über die wichtigsten Staats-Materien unserer Zeit. Bd. I-II. Germanien [Zürich] 1795-97.

- Zur Geschichte Baierischer Landschaft und Steuern bearbeitete Urkunden und Beilagen. München 1800.

Schlachtgesang für die hier in Zürich stehenden Helden-Heere Im Herbstmonath 1799. Zürich 1799.

Schlenkert, Friedrich, Kcin Faustrecht mehr. Fin reichsstädtisches Schauspiel in vier Aufzügen. Grätz 1797.

Schmeisser, G. Beyträge zur näheren Kenntniß des gegenwärtigen Zustandes. der Wissenschaften in Frankreich. Th. I., Hamburg 1797.

Schreiben eines Deutschen an der General Buonaparte. [Neustrelitz] 1798. [H. v. Graeffe].

Schreiben eines reisenden preußischen Patrioten an das Französische Directorium. Germanien [Erlangen] 1798. [K. D. H. Bensen].

Schwab, Johann Christoph, Vergleichung des Kantischen Moralprincips mit dem Leibnitzisch-Wolffischen. Berlin und Stettin 1800.

Die zwo Schwestern $\mathrm{P}^{* * *}$ und $\mathrm{W}^{* * *}$ oder neuentdecktes Freymaurer- und Revolutionssystem. Ganz Deutschland besonders aber Oesterreich aus Originalmaurerschriften vorgelegt. [Ausburg] 1796. [L. A. Hoffmann].

v. Seida und Landensberg, Franz Eugen Freyherr, Politisch-Militairische Geschichte des merkwürdigen Feldzuges vom Jahre 1799. Ulm 1801.

Merkwürdiges Sendschreiben an den Kardinal-Erzbischoff Migazzi in Wien. Frankfurt und Leipzig 1798.

Sieyes, Emmanuel, Politische Schriften, vollständig gesammelt von dem deutschen Uebersetzer nebst zwei Vorreden über Sieyes Lebensgeschichte, seine politische Rolle, seinen Charakter, seine Sitten etc. Bd. I-II. 1796.

Weltbürger Sirach der Sohn an Deutschlands Reichsversammlung. Aus dem Französischen. Sarmatien 1795. [S. de Piattoli].

Skizzen zu einem Gemälde von Hamburg. Von dem Verfasser der Darstellungen aus Italien. Hamburg 1801. [F. J. L. Meyer]

Der Französische Soldat an den deutschen Bauersmann. Straussburg 1800.

v. Solemel, Riphelius, Auch ein Entschädigungsplan an den Friedenskongress zu Rastadt. 1798. [J. v. Ullheimer].

Ueber die geistlichen Staaten in Deutschland und die vorgebliche Nothwendigkeit ihrer Säcularisation. Deutschland [Würzburg] 1798.

Die preußischen Staaten vor und seit dem 16 ten November 1797. I Heft. Paris [?] 1798.

Wichtige Staatsfrage: Möchte die Säkularisation der Klöster und Stifter nicht etwa durch die itzigen besondern Konjunkturen gerechtfertiget, und gedachte Stifter etc. den verlierenden weltlichen Erbfürsten gar wohl an Entschädigungsstatt überlassen werden können. 1801.

Ueber das Staatsnothrecht als Grund des Rechts zu säcularisiren. Vom Verfasser der Unrechtmässigkeit der Säcularisirungen. Philalethopolis [Würzburg] 1800. [F. Berg].

Staatsproblem: War es rathsam, dass das deutsche Reich den Französen den Frieden antrug? [1795]. 
Staatsveränderungen ohne revolutionnären Sinn im Herzogthum Neuburg. Mannheim 1800. [A. Friedrich].

Stimme eines Arktikers über Fichte und sein Verfahren gegen die Kantianer von D. K. 1799. [G. B. Jäsche].

Stimme eines Einzelnen über die Art der Beywürkung des Reichs zu dem gewünschten Frieden mit Frankreich. Im Juny 1795.

Die Stimme Europas, im letzten Jahre des achtzehnten Jahrhunderts. Von einem freyen Bürger Teutschlands. Merseburg 1800. [K. L. A. v. Münchhausen].

Die Stimme eines Kosmopoliten an die deutsche Nation und an den Kongress zu Rastadt! Leipzig 1798.

Die Stimme der öffentlichen Meinung über Max Joseph, Kurfürsten von Bayern. Eine Skizze, 1800.

v. Strengschwerd, Karl Graf (1), Beurtheilung der Note, welche der Kurbrandenburgische Komitial Gesandte Herr Graf von Goerz, den 5ten September 1795 dem Reichstage zu Regensburg übergeben hat. Regensburg den 30 Sept. 1795. [K. G. Glave-Kolbielski].

- (2) Kommentar und Beurtheilung der Erklärung welche Se. Majestät der König von Preußen den 2 October 1795 dem Fränkischen Kreise hat machen lassen. Regensburg 24 Oct. 1794 [1795]. [K. G. Glave-Kolbielski].

- (3) Beurtheilung des Schreibens, welches der regierende Herr Herzog von Braunschweig Lüneburg den 30 September 1795 an den Herrn Grafen von Westphal zu Fürstenberg kaiserlichen Gesandten beim niederrheinischen Kreise erlassen hat. Regensburg den 14 November 1795. [K. G. Glave-Kolbielski].

- Rectliches Gutachten die Uebergabe der Festung Mannheim an den Reichsfeind betreffend. Den Göttingischen Professoren Herrn Geheimen Justizrath Pütter und Herrn Hofrath von Martens zu öffentlichen Prüfung gewidmeet. Regensburg [Leipzig] den 21. October 1795. [J. A. v. Hügel].

Suchbein, Alexander, Scenen und Züege aus dem Benehmen der französischen Republikaner in den Gegenden des Oberrheins. Mit Anmerkungen des Nachtwächters von Neuenheim. Leipzig [Carlsruhe] 1797. [J. v. Müller].

Ueber Süddeutschland. Von einem süddeutschen Bürger im Monat Oktober 1798 dem französischen Gouvernement zur Beherzigung vorgelegt [Nürnberg] 1799. [J. v. Hazzi].

Syrach der Enkel, oder: Ein Wort der Wahrheit über die Frage: Haben die fränkischen Direktoren oder der Kaiser den Frieden Deutschlands gehindert? Deutschland [Kempten] 1799. [J. M. Weissegger].

Tagebuch von den Theil des Feldzuges der Königl. Preuß. Truppen an dem Nieder-Rhein im Jahr 1793 in welchem der Herzog von Braunschweig-Oels das Commando über dieselben führte, nebst denen dazu erforderlichen Belägen. Von einem Königl. Preuß. Officier der diesen Feldzug mitgemacht hat. Breslau 1796. [Friedrich August Herzog zu Braunschweig-Lüneburg-Wolfenbüttel].

Taschenbuch von J. G. Jacobi und seinen Freuden für 1798. Basel 1798.

Taschenbuch für 1801. Hrsg. von Friedrich Gentz, Jean Paul und Johann Heinrich Voss. Braunschweig.

Teller, Wilhelm Abraham, Die Zeichen der Zeit angewandet auf öffentliche christliche Religionslehrer bey dem Wechsel des Jahrhunderts. Jena 1799.

Wohlverdientes Todesurtheil des Joseph N. Vulgo Patriot ... [München 1800]. Wahrer Ueberblick der Geschichte der bayerischen Nation. 1800.

Die Uibereilungen. 1795. [J. v. Müller]. 
Ueber die Umlegung feindlicher Kriegsschazung, Entschädigung der Geplünderten und derer die durch Heereszüge an Häusern und Gütern Schaden erlitten haben, auch über die Besteuerung geflüchteter Güter. 2. Aufl. Stuttgart 1796. [J. F. Zeller].

Umschlag oder Appendix zu allen gegenwärtigen und künftigen Präliminarien, bittlichen Vorstellungen, Bundbriefen und bayerischen Landtagschriften, nebst ihren Erläuterungen, Beilagen, Prüfungen, Briefen und Gesprächen darüber etc., etc., [München] 1800.

Die Unrechtmässigkeit der Säcularisirungen. Philalethopolis [Würzburg] 1799. [F. Berg].

Rechtliche Untersuchung der Frage: Sind die Landesherren zu Abwendung ihren Ländern drohenden feindlichen Gefahr berechtigt - besonders in den gegenwärtigen Kriegszeiten - ihre Unterthanen zum allgemeinen Landsturm aufzufordern, und im Fall der Widersetzlichkeit gegen die Gewalt zu gebrauchen. [Hadamar] 1800. [A. A. Kleber].

Untersuchungen und Vorschläge über die Umlegung der französischen Kontribution an Wirtemberg. Von dem Verfasser der Gedanken über die Wahl der Abgeordneten zum Wirtembergischen Landtage. 1796. [J. F. Maerklin]. 1800.

Utzschneider, J., Unterthänigst gehorsamster Antrag über einen Landtag in Bayern 1800.

Ueber Deutschlands Verlust und das dabei eintretende Entschädigungssystem, in Bezug auf das Intresse des gesamten Reichs und der übrigen Mächte Europens. Der hohen Reichsversammlung in Regensburg gewidmet. Zweite stark vermehrte Auflage. 1801.

Versuch einer doctrinellen Auslegung des siebenten Friedensartikels von Lüneville. Germanien [Bamberg] 1801. [J. M. v. Seuffert].

Versuch einer natürlichen Erklärung des siebenten Friedensartikels von Luneville. Germanien 1801. [A. F. Batz].

Versuche zu sehen. Iliaros intra muros peccatur et extra. Bd. I-II. Hamburg 1797-1800. [J. L. v. Hess].

Drey Volks-Lieder über die Geschichte unserer Täge. 1799.

Dringende und gründliche Vorstellung an das teutsche Reich über die konstitutionellen Pflichten bei den nunmehrigen Siegsvorschritten der kaiserl. Armeen. Germanien 1796.

Votum eines Kanzleiverwandten über die Contributions-Umlage. Stutgart 1796. [J. C. F. Weisser].

Was ist bei Vertheilung der französischen Brandschazung und anderer Kriegsschäden den Rechten und der Klugheit gemäss. Tübingen 1796. [C. G. Gmelin].

Was haben die Mächte von Bonaparte zu erwarten. Basel [Bremen] 1801. [H. M. Marcard].

Was ist besser Krieg oder Frieden mit den Franzosen. Nebst einigen Betrachtungen über die letzten vermuthlichen Friedens-Präliminarien. [Nürnberg] 1800. [C. L. v. Haller].

Was sind eigentlich unsere Teutschen Domkapitel? Germanien 1800.

Weiller, Zum Andenken an unsern unvergeßlichen Mutschelle. München [1800].

Ueber die gerechteste, und geschwindeste Weise, den Frieden Lüneville im deutschen Reiche auszuführen. Von einem Freunde des Friedens und der Gerechtigkeit. Deutschland [Landshut] 1801. 
Weisser, Johann Friderich Christoph, Gutachten über die Umlegung der französischen Contribution und anderer Kriegsschäden in Wirtemberg. Tübingen und Stuttgard 1797.

Des Freiherrn Knigge Welt- und Menschenkenntniss. 1796.

v. Wessenberg, Ignaz Heinrich, Ueber den Verfall der Sitten in Teutschland. Eine poetische Epistel. 1799.

Westenrieder, L., Abriß der deutschen Geschichte. Eine Lese- und Lehrbuch. München 1798.

- Historischer Kalender für 1795-1801. München 1795-1801.

Ueber die Wichtigkeit der Besitznahme der Schweiz in politischer und militairischer Hinsicht. Als eine kurze Einleitung zu einer vollständigen Ausführung, welche in kurzer Zeit erscheinen wird. 1799.

Widerlegung der Druckschrift: Neueste, fürstbischöfliche Konsistorialverordnung wider die unenthaltsamen Kleriker des regensburger Kirchensprengels sammt dem Gutachten darüber von Seite drey Universitäten, Ingolstadt, Würzburg und Göttingen. Im Jahre 1796.

Wiebeking, Der Übergang der Franzosen über den Rhein am 6. Sept. 1795. Frankfurt a.M. 1796.

Wieland, C. M., Ubber den fränkischen Staatseid, Hass dem Königthum. Weimar 1799.

An Wien über Hatschka. 29. Januar 1796.

Wird Krieg oder Friede? Freymuthig untersucht und beantwortet von einem Staatsmanne. 1801.

Ueber Wirtemberg an die Wirtemberger [Hohe Asperg]. Im Monat Oktober 1800.

Der patriotische Wirtemberger von Umgegung der Französischen Kriegssteuer. Billig und willig. Stuttgart 1796. [F. A. H. Weckherlin].

Ein Wort unter guten Freunden an den Gränzen des Bodensees über die wirkliche Kriegslasten von einem ehrlichen Seehaase. 1800.

Ein Wort für das Vereinigungsfest der zwoen entzweiten Schwestern der politischen und der Moralischen Freyheit. Baden 1800.

Noch ein Wort über das Säkularisationswesen. Von einem Freunde der Menschheit und der guten Sache. Teutschland [Nürnberg] 1801.

Noch ein Wort an Teutschland. Im Februar 1800.

Wörterbuch der französischen Revolutionssprache. 1799.

Wührer, Joseph, Rede am feyerlichen Gedächtnißtage des freywilligen Aufgebothes, gehalten den 17ten April 1799. Wien [1799],

Patriotische Wünsche für Teutschland bei dem bevorstehenden Definitiv-ReichsFrieden. Nebst Verlusts- und Entschädigungs-Tabellen. Frankfurt a.M. 1801.

Zacharia, Karl Salomo, Geist der deutschen Territorial-Verfassung. Leipzig 1800.

Zauner, Judas Thaddäus, Beyträge zur Geschichte des Aufenthalts der Franzosen im Salzburgischen und in den angränzenden Gegenden. I Bd. Salzburg 1801.

Die Zeichen der Zeit oder die letzten Zuckungen des Adels und der Pfaffen in Bayern. Köln [München] Jahr IX [1800].

Neue Zeitblätter. Deutschland und Göttingen 1795. Heft 1-3.

Zimmermann, E. A. W., Ernste Hinsicht auf sein Vaterland bei Annäherung des Friedens von einem biedern Deutschen. Allen Edlen und Grossen Germaniens gewidmet. Leipzig 1795. 
Zschocke, Heinrich, Freie Bündner, verlaßt die braven Schweizer nicht! Nothwendiger und letzter Zuruf an biedere nachdenkende Vaterlandsfreunde. Chur 1798.

- Rede im Namen der verfolgten Patrioten Bündtens, gehalten vor dem großen Rathe der helvetischen einen und untheilbaren Republik, am 24ten Weinmonats 1798. Luzern [1798].

- Soll Bünden sich an die vereinte Schweiz schließen? Soll Bünden ein eigner Staat bleiben? Ein vaterländisches Wort an das freie Bündnervolk und dessen Regierung. Chur 1798.

- Zuschrift des Herrn Doktor Heinrich Zschokke, an sen Hohlöblichen Landtag der Republik Graubünden, in Chur versammelt. Chur 1798.

\section{B. DARSTELLUNGEN}

Andreas, Willy, Carl August von Weimar in und nach der Kampagne gegen Frankreich. Diss. München 1955.

Arnold, Robert F., (bearb). Fremdherrschaft und Befreiung 1795-1815. Deutsche Literatur, Reihe: Politische Dichtung 2. Bd. Leipzig 1932.

v. Arx, Oskar, Lavaters Schweizerlieder. Diss. Zürich 1897.

Bußrs, Kurt, Friedrich Buchhollz. Ein preußischer Publizist. 1768-1845. Berlin 1907/Nachdr. Vaduz 1965.

Benedey, Jakob, Die deutsche Republikaner unter der französischen Republik. Leipzig 1870.

Berger, Karl, Vom Weltbürgertum zum Nationalgedanken. München 1918.

Berger, Martin, Görres als politischer Publizist. Bonn und Leipzig 1921.

Bettex, Albert, Der Kampf um das klassische Weimar 1788-1798. Antklassische Strömungen in der deutschen Literatur vor dem Beginn der Romantik. Basler Beiträge zur deutschen Literatur- und Geistesgeschichte I. Zürich und Leipzig 1935.

Boas, Eduard, Schiller und Goethe im Xenienkampf I. Stuttgart und Tübingen 1851.

Bobeth, Johannes, Die Zeitschriften der Romantik. Leipzig 1911.

Burg, Peter, Kant und die französische Revolution. Berlin 1974.

Borries, Kurt, Kant als Politiker. Zur Staats- und Gesellschaftslehre des Kritisismus. Leipzig 1928.

Böttiger, Theodor, Hamburgs Patrioten 1800-1814. Berlin-Leipzig 1926.

Brandt, Gustav-Adolf, Herder und Görres 1798-1807. Ein Beitrag zur Frage Herder und die Romantik. Diss. Berlin 1937.

Bruford, W. H., Die gesellschaftlichen Grundlagen der Goethezeit. Weimar 1936.

Buhr, Manfred, Revolution und Philosophie. Die ursprüngliche Philosophie Johann Gottlieb Fichtes und die französische Revolution. Berlin 1965.

Bulling, Karl, Johann Babtist von Alxinger. Diss. Leipzig 1914.

Czygan, Paul, Zur Geschichte der Tagesliteratur während der Freiheitskriege Bd. I-II. Leipzig 1910-11.

Dalgren, Lars, Sverige och Pommern 1792-1806. Upsala 1914.

Dempf, Alois, Görres spricht zu unserer Zeit. Freiburg im Br. 1933.

Droz, Jacques, Deutschland und die Französische Revolution. Institut für europäische Geschichte Mainz. Vorträge. Wiesbaden 1955. 
Ebbinghaus, Julius, Kants Lehre vom ewigen Frieden und die Kriegsschuldfrage. Tübingen 1929.

Eder, Karl, Der Liberalismus in Altösterreich. Wiener historische Studien 3. Wien-München 1955.

Eisner, Kurt, Das Ende des Reichs. Deutschland und Preußen im Zeitalter der grossen Revolution. 2. Aufl. Berlin 1907.

Epstein, Klaus, The Genesis of German Conservatism. Princeton N. J. 1966.

Fahrner, Rudolf, Arndt. Stuttgart 1937.

Fambach, Oscar, Goethe und seine Kritiker. Düsseldorf 1953.

Franz, Günther, Geschichte des deutschen Bauernstandes vom früher Mittelalter bis zum 19. Jahrhundert. Deutsche Agrargeschichte IV. Stuttgart 1970.

Friedell, Egon, Uudenajan kulttuurihistoria. II. Porvoo 1955.

Friess, Herrmann, Theaterzensur, Theaterpolizei und Kampf um das Volksspiel in Bayern zur Zeit der Aufklärung. Diss. München 1934.

Fritz, Curt, Goethes Stellung zum Kriege. Diss. Marburg 1931.

Fürst, Friederike, August Ludwig von Schlözer, ein deutscher Aufklärer im 18. Jarhundert. Heidelberger Abh. zur mittleren und neueren Geschichte Heft. 56. Heidelberg 1928.

Gaxotte, Pierre, Geschichte Deutschlands und der Deutschen Bd. 2. Freiburg im Br. 1967.

v. Gleichen-Russwurm, Alexander, Die Klassiker und die Politik. Baden-Baden 1947.

v. Göckingk, L. F. G., Friedrich Nicolai's Leben und literarischer Nachlass. Berlin 1820.

Görland, Ingtraud, Die Kantkritik des jungen Hegel. Philosophische Abh. Bd. 28. Frankfurt a.M. 1966.

Gollwitzer, Heinz, Europabild und Europagedanke. Beiträge zur deutschen Geistesgeschichte des 18. und 19. Jahrhunderts. München 1914.

Gooch, G. P., Germany and the French Revolution. London 1927. - Studies in German History. London (New York, Toronto) 1948.

Görland, Albert, Kant als Friedensfreund. Kultur- und Zeitfragen Heft 13. Leipzig 1924.

Georg Joachim Göschen. Sein Verlag 1785-1935 und die Sammlung Göschen. Berlin und Leipzig 1935.

Gratthoff, Ernst, Deutsche Bauern- und Dorfzeitungen des 18. Jahrhunderts. Diss. Heidelberg/Würzburg 1937.

v. Grauert, Hermann, Zur Geschichte des Weltfriedens, des Völkerrechts und der Idee einer Liga der Nationen. HJb. 39, München 1919.

Groth, Otto, Die Geschichte der deutschen Zeitungswissenschaft. München 1948.

Haacke, Wilmont, Handbuch des Feuilletons. Bd. I. Emsdetten/Westf. 1951.

- Die Zeitschrift - Schrift der Zeit. Essen 1961.

— Die politische Zeitschrift 1665-1965. Bd. I. Stuttgart 1969.

Haasbauer, Adolphine, Die historischen Schriften Karl Ludwig von Hallers. Diss. Basel 1949.

Habermas, Jürgen, Strukturwandel der Öffentlichkeit. Politica Bd. IV. Neuwied 1962.

Hausherr, Hans, Hardenberg. Eine politische Biographie I: 1750-1800. Köln 1963.

v. Heinemann, Albrecht, Friedrich Johann Justin Bertuch. Ein Weimarischer Buchhändler der Goethezeit. Bad Münster am Stein 1950. 
Heinl, Otto, Heereswesen und Volksbewaffnung in Vorderösterreich im Zeitalter Josefs II. und der Revolutionskriege. Diss. Freiburg i.Br. 1941.

Hemleben, Sylvester John, Plans for World Peace through Six Centuries. Chigaco 1943.

Herse, Wilhelm, Die Goethezeit in Deutschland. Hannover 1949.

Hild, Joachim, August Hennings ein schleswig-holsteinischer Publizist um die Wende des 18. Jahrhunderts. Erlanger Abh. zur neueren und mittl. Gesch. Bd. 9. Erlangen 1932.

Hirzel, Ludwig, Wielands Beziehungen zu den deutschen Romantikern. Diss. Bern 1904.

Hokkanen, Kari, Pohjoismaiden ulkopolitiikka Saksan päivänpoliittisessa kirjallisuudessa 1795-1801. Historica III, Studia Historica Jyväskyläensia IX, Vammala 1972.

Holborn, Hajo, Deutsche Geschichte in der Neuzeit II. München-Wien 1970.

Holm, Edvard, Danmarks-Norges udenrigske historie under den franske revolution of Napoleons krige fra 1791 til 1907. I. Kjøbenhavn 1875.

Hölschner, Eberhard, Gleim und Voss in ihren persönlichen und literarischen Beziehungen. Auszug aus der Diss. Kiel 1921, Berlin 1921.

Huber, Ernst Rudolf, Deutsche Verfassungsgeschichte seit 1789. I. Stuttgart 1957.

Hüffer, Hermann, Der Rastatter Congress und die zweite Coalition I-II. Bonn 1878.

- Die Kabinetsregierung in Preussen und Johann Wilhelm Lombard. Leipzig 1891.

- Der Krieg des jahres 1799 und die zweite Koalition. I-II. Gotha 1904-05.

Joachimsen, Paul, Vom deutschen Volk zum deutschen Staat. 3. Aufl. Göttingen 1956.

Julku, Kyösti, Die revolutionäre Bewegung im Rheinland am Ende des achtzehnten Jahrhunderts II. Helsinki 1969.

Keil, Robert, Wiener Freunde 1784-1808. Wien 1883.

Kemiläinen, Aira, Auffassungen über die Sendung des deutschen Volkes um die Wende des 18. und 19. Jahrhunderts. Diss. Helsinki 1956.

Körte, Wilhelm, Johann Wilhelm Ludewig Gleims Leben. Halberstadt 1811.

Krüger, Gustav, Die Eudämonisten. HZ 143, 1931.

Kummer, Paul, Sippen um Rudolph Zacharias Becker. Görlitz 1938.

Lange, Chr. L. - Schou, August, Histoire de l'internationalisme II. Oslo 1954.

Lange, Gerhard, Gerhard Anton von Halem (1792-1819), Leipzig 1928.

Leitzmann, Albert, Wilhelm Heinse in Zeugnissen einer Zeitgenossen. Jena 1938.

Löhde, Walter, Friedrich Schiller im politischen Geschehen seiner Zeit. Pähl (Obb.) 1959.

Mann, Thomas, Goethe und die Demokratie. Uppsala 1951.

Meinecke, Friedrich, Goethe und die Geschichte. München 1949.

Meisner, Heinrich, Ernst Moritz Arndts Leben und Schaffen. Lepzig 1909.

Merkle, Sebastian, Die katholische Beurtheilung des Aufklärungszeitalters. Berlin 1909.

Meyer, Friedrich, Schillers Horen als Verlagswerk betrachtet. Ein bibliographischer Bericht. Leipzig 1941.

Milch, Werner, Christoph Kaufmann. Leipzig 1932.

Mommsen, Wilhelm, Geschichte des Abendlandes von französischen Revolution bis zur Gegenwart 1789-1945. 2. Aufl. München 1960. 
Müller, Franz, Deutsche Größe. Ein wiedererstandener Hymnusentwurf Schillers. Demmin 1905.

Müller, Heinrich, Der letzte Kampf der Reichsritterschaft um ihre Selbstständigkeit (1790-1815) Berlin 1910/nachd. Vaduz 1965.

Müsebeck, Ernst, Ernst Moritz Arndt. I. Gotha 1914.

Natorp, Paul, Kant über Krieg und Frieden. Ein geschichtphilosophischer Essay. Erlangen 1924.

Ost, Günther, Friedrich Nicolais Allgemeine Deutsche Bibliothek. Berlin 1928.

Pertz, G. H., Das Leben des Ministers Freiherrn vom Stein. I. (1759-1807). 2. Aufl. Berlin 1850.

Pribram, Alfred Francis - Fischer, Erich, Ein politischer Abenteurer (Karl Glave-Kolbielski, 1752-1831). Wien und Leipzig 1937.

$v$. Ranke, Leopold, Dekwürdigkeiten des Staatskanzlers Fürsten von Hardenberg bis zum Jahre 1806 Bd. I. Leipzig 1877.

v. Raumer, Kurt, Ewiger Friede. Friedensrufe und Friedenspläne seit der Renaissance. München/Freiburg im Br. 1953.

Reininger, Robert, Kant, seine Anhänger und seine Gegner. München 1923.

Reisse, Roman, Die weltanschauliche Entwicklung des jungen Joseph Goerres (1776-1806) Breslau 1926.

Rieber, Horst, Liberaler Gedanke und französische Revolution im Spiegel der Publizität der Reichsstädte Augsburg und Ulm. Diss. München 1969.

Röhrdanz, Günther, Die Stellung Kants in und zu der Presse seiner Zeit. Zeitung und Leben Bd. 29., München 1936.

Rössler, Hellmuth, Zwischen Revolution und Reaktion. Ein Lebensbild des Reichsfreiherrn Hans Christoph von Gagern 1766-1852. Göttingen (Berlin, Frankfurt) 1958.

Ruof, Wilhelm, Johann Wilhelm von Archenholtz. Berlin 1915.

Russel, Bertrand, History of Western Philosophy. London 1947.

Ruth, Paul, Hermann, Arndt und die Geschichte. München und Berlin 1930.

Saitschick, Robert, Joseph Görres und die abendländische Kultur. Olten und Freiburg im Br. 1953.

Salomon, Ludwig, Geschichte des Deutschen Zeitungswesens von den ersten Anfängen bis zur Wiederaufrichtung des Deutschen Reichs II (1792-1814). Oldenburg-Leipzig 1902.

Scheel, Heinrich (eingeleitet und herausgegeben) Jakobinische Flugschriften aus dem deutschen Süden Ende des 18. Jahrhunderts. Berlin 1965.

- Deutsche Jakobiner. ZfG 9/1969.

- Süddeutsche Jakobiner. Berlin 1962.

Schubert, Eduard, Der Ideengehalt von Görres' Schriften »Teutschland und die Revolution» und »Europa und die Revolution». Köln 1922.

Schulz, Günter, Schillers Horen. Politik und Erziehıng. Heidelberg 1960.

Sengle, Friedrich, Wieland. Stuttgart 1949.

Seyffert, Wolfgang, Schillers Musenalmanache, Palaestra 80. Berlin 1913.

Spengler, Karl, Die publizistische Tätigkeit des Freiherrn Adolf von Knigge während der französischen Revolution. Diss. Bonn 1931.

Staehlin, Ernst, Johann Caspar Lavaters Deportation nach Basel im Jahre 1799. Sonderabdruck aus dem Basler Jahrbuch 1945.

Stern, Alfred, Der Einfluß der französischen Revolution auf das deutsche Geistesleben. Stuttgart und Berlin 1928. 
Streisand, Joachim, Deutschland von 1789 bis 1815. 2. Aufl., Berlin 1961.

Struck, Joachim Lorenz, Die Kgl. Regierungsbuchdruckerei, die Stralsundische Zeitung und ihre Beziehungen zu Schweden. Stralsund 1928.

Stuckmann, Werner, Zur Geschichte der Stralsundischen Zeitung. 175 Jahre Zeitungsverlag Struck 1753 21. März 1928. Stralsund 1928.

Ter Meulen, Jacob, Der Gedanke der internationalen Organisation 1300-1800. 1917.

Tiainen, Jorma, Napoleon und das napoleonische Frankreich in der öffentlichen Diskussion des 'dritten Deutschland' 1797-1806. Diss Jyväskylä/Kuopio 1971.

- Saksalaiset lentokirjaset julkisen keskustelun väylänä uskonpuhdistuksen ajasta vuoden 1800 tienoille. Historica III, Studia Historica Jyväskyläensia IX Vammala 1972.

- Schillerin ja Goethen suhde Napoleoniin 'porvarillisen julkisuuden' käsitteen valossa. Jyväskylän yliopiston historian laitos. Yleisen historian tutkimuksia 1. Jyväskylä 1972 .

Tschirch, Otto, Geschichte der öffentlichen Meinung in Preußen von Baseler Frieden bis zum Zusammenbruch des Staates (1795-1806) I-II. Weimar 1933 -34 .

Valentin, Veit, Deutsche Geschichte Bd. I München/Zürich 1965.

Valjavec, Fritz, Die Entstehung der politischen Strömungen in Deutschland 1770 -1815. München 1951.

Voegt, Hedwig, Die deutsche jakobinische Literatur und Publizistik 1789-1800. Berlin 1955.

Vorländer, Karl, Kant, Schiller, Goethe. Leipzig 1907.

Wahl, Adalbert, Uber die Nachwirkungen der Französischen Revolution vornehmlich in Deutschland. Stuttgart 1939.

Wahl, Hans, Geschichte des Deutschen Merkur. Palaestra 77. Berlin 1914.

Wendland, Wilhelm, Versuche einer allgemeinen Volksbewaffnung in Süddeutschland während der Jahre 1791, bis 1794. Berlin 1901/nachd. Vaduz 1965.

Wiegand, Julius, Deutsche Geistesgeschichte im Grundriss. Frankfurt a.M. 1932.

Wieneke, Ernst, Patriotismus und Religion in Friedrich Sohlegels Gedichten. Diss. München/Dresden 1913.

v. Wrasky, Nadeschda, A. G. F. Rebmann. Diss. Heidelberg 1907.

Zickendraht, K., Kants Gedanken über Krieg und Frieden. Tübingen 1922.

\section{Biographien und andere Nachschlagwerke}

Allgemeine deutsche Biographie (ADB) Bd. 1-45. Leipzig 1875-1912.

Neue deutsche Biographie (NDB) Bd. 1-9. Berlin 1951-72.

Hamberger, Georg Christoph - Meusel, Johann Georg, Das gelehrte Teutschland oder Lexikon der jetzt lebenden Teutschen Schriftssteller 1796-1831. Leipzig.

Holzmann, Michael - Bohatta, Hanns, Deutsches Anonymenlexikon 1501-1850. Bd. 1-7. Weimar 1902-1928.

- Deutsches Pseudonymen-Lexikon. Hildesheim 1961.

Kirchner, Joachim, Bibliographie der Zeitschriften des deutschen Sprachgebiets bis 1900, Band I, Stuttgart 1969. 
Kosch, Wilhelm, Biographisches Staatshandbuch Bd. 1-2, Bern und München 1963.

Kosch, Wilhelm, Das katholische Deutschland. Biographisch-Bibliographisches Lexikon Bd. 1-2. Augsburg 1933-35.

Krollmann, Chistian, Altpreussische Biographie Bd. I-II. Königsberg (Pr) 1941, 1967.

v. Krücken, Oskar - Parlagi, Imre, Das geistige Ungarn. Biographisches Lexikon Bd. 1-2. Wien und Leipzig 1923-52.

Biographisches Lexikon zur Deutschen Geschichte (BLDG). Hrsg. v. Karl Obermann, Heinrich Scheel, Helmut Stocker, Bernhard Töpfer, Gerhard Zschäbitz. Berlin 1967.

Dansk biografisk leksikon. København 1933-44.

Meusel, Johann Georg, Leitfaden zur Geschichte der Lehrsamkeit. I. Leipzig 1799 .

Meusel, Johann Georg, Lexicon der vom Jahr 1750 bis 1800 verstorbenen deutschen Schriftsteller Bd. 1-15. Leipzig 1802-16.

Putzger's Historischer Schulatlas. Bielefeld und Leipzig 1939.

Schlichtengroll, Friedrich, Nekrolog auf das Jahr 1796-1801. Enthaltend den von dem Leben merkwürdiger in diesem Jahre verstorbenen Personen. Gotha $1796-1801$.

Schröder, J., Lexikon der Hamburgischen Schriftssteller. Hamburg 1851-83.

v. Selle, Götz, Ostdeutsche Biographien. Würzburg 1955.

Westermann's Grosser Atlas zur Weltgeschichte. Braunschweig 1969.

v. Wurzbach, Constant, Biographisches Lexikon des Kaiserthums Österreich, enthaltend die Lebensskizzen der denkwürdigen Personen, welche 1750 bis 1850 in seinen Kronländern gelebt haben. Bd. 1-60. Wien 1856-1890. 


\section{PERSONENREGISTER}

Die Namen, die mit* versehen sind, kommen in Fußnoten vor.

Agricola, R. 34

Alberoni, Kardinal 28

v. Albini, F. J. 78

Alexander d. Grosse 197

v. Alxinger, J. B. 110

v. Archenholtz, J. W. 9, $56 *, 60-62$, $92,100,123,136-138,184,185,187$, $188,192-193,200-203,228,232$, $212,215^{*}$

Arndt, E. M. 232, 233, 242

Augereau, General 181

Augustin 26

Augustus 26

Aukland, Lord 121 *

v. Baczko, L. 188

de Barentin, C. L. F. 208

Barras, Direktor 33, 144, 176

Barrere 169

Barthélemy, Direktor 75, 144, 181, 198, 202, 211

Batsányi, J. 111

Batz, A. F. 241

Baumgarten-Crusius, G. A. 114

Beck 127

Becker, R. Z. 10, 111, 137, 149, 185

Bendavid, L. 40, 216 *, 248-249

Beneken, G. W. F. 131

Bentham, J. 29

v. Bentzel-Sternau, C. E. 53, 54

Berg, F. 161-162

v. Berg, J. H. 139,140

Bergk, J. A. 141-142, 240

v. Berlepsch, E. 208

Bernadotte, J. B. 153,158

Bernstorff, A. P. 12, 19, 134, 203

Bertuch, F. J. 202, 203, 228

Biergan, F. T. 168

Biester, J. E. 40, 86, 107, $112 *, 127$, 215-216, 227, 239, 249

Bingel 242

v. Birkenstock, J. M. 112 *

Bischoffswerder, Minister 21

Blau, F. A. $112 *, 185$
Bode 112

Bodin, J. 27

Böhmer, G. W. $80,100,101 *, 112$ *

de Bouillé, Marquis 208 *

Bonaparte, Napoléon 61, 95, 96, 100, $121,138,139,143,144,145,146,147$, $158,175,176,180,181,187,189,194$, 196, 197, 201, 202, 203, 205, 206, 212, $213,217,220,222,223,225,226,227$, $228,229,230,231,232,234,239,240$, 242,243

v. Boyen, L. 127

v. Brabeck, F. M. 135 *

v. Braunschweig, Herzog 191

Brun, F. 56 *

v. Bülow, H. W. 121 *

Burke, E. 64, 130, 139, 196, 208

Camerer, J. W. 104

Campe 112*

Carnot, Direktor 24, 33, 47, 95, 96, $181,198,211,213$

Christmann, F. X. 84

Clerfayt, Graf 71, 132

Cloots, A. 29, 80, 112 *

v. Coburg, Prinz 118, 132

Constant, B. 49

v. Cobenzl, Graf 21

Cramer, J. F. 112 *

Cramer, K. F. 36, $112 *, 126,186$

Cranz, A. F. 80

Custine, General 22

v. Dalberg $56 *$

Dassdorf, K. W. 202

Decius 41

Denis, M. $111 *, 112 *$

v. Dohm, C. W. 46

zu Dohna, A. 165

Dorsch, A. J. $80,100,101 *, 112 *, 168$, $184,186,200$

Dumouriez, General 23, 208, 209

Dyk, J. G. 208, 209 
Eberhard 80

v. Eckhel, J. H. 112 *

v. Eggers, C. U. D. 203

Ehlers 112 *

Ehrmann, T. F. 46, 229, 230

v. Eiberg, K. 150 *

Eikmeyer $112 *$

Embser, V. 30

Emerich, J. F. 240

Empedokles 25

Engel 56 *

Erasmus von Rotterdam 27

Erhardt, J. B. 56 *

Erskine, T. 99 *

v. Erthal, K. F. 12

Eschafferiaux $98 *, 99 *$

v. Faber, Oberst $150 *$

Falbe, G. S. 192

Falk, J. D. 64, 138

v. Fersen, A. 145

Fichte, J. G. $20,56 *, 80,92,131,162$, 163,235

Fischer, F. C. J. 112 *

Fischer, H. L. 117

Fitzwilliam, Lord 169

Focke 80

Fölsch, J. B. 107

Forster, G. 8, 22, 24, 61, $112 *, 208$

Franz II. 67, 84, 109, 151, 156

Freudentheil, W. IM. 52

Friedrich II. d. Grosse 42, 43, 71, 121, 129, 192, 193, 194, 202, 204, 227, 252

Friedrich Wilhelm II. 11, 21, 24, 41, 128, 129, 188, 204

Friedrich Wilhelm III. 11, 14, 15, 146, 191, 196, 199, 207, 209, 227

Fröhlich 25

From, L. 277 *

Funk, J. D. $39,56 *, 128$

v. Gagern, H. C. E. 60,165

Garve, C. 56 *

Gedike, F. 34, 40, 86, 107, $112 *$, 127, $227 *$

v. Gemmingen, P. 164, 165

Gentz, F. 14, 15, 20, $56^{*}, 61,93,130$, $153 *, 169,193,196-199,201,210$, $214,232-238,245 *, 257$

Georg III. 227

Gerber, A. S. $39,40,128$

v. Gerning, J. I. 52

Girtanner, C. 82, 92, 130, 233

Glave-Kolbielski, K. G. G. 10, 74$78,92,113,131,148,153,245^{*}$

Gleim, J. W. L. 51, 56 *, 61-63, 129, $130,138,182,188,192-195,199$, $209,216 *, 232,245 *$

v. Göchausen, E. A. W. 78, 79, 182

Goethe, J. W. 14, 56 *, 58, 59, 92, 123, $127,131,219,245$ *
Görres，J. 14，168-177，182，183， 243

Göschen 56

Gramberg, G. A. 227 *, 239 *

Grenville, T. 207

Gries, J. D. 56 *

v. Grollmann, L. A. C. 182

Gross v. Trockau, O. P. 56 *

Grotius 28, 89

Gustav III. 30

Häberlin, K. F. 124, 134, 135

v. Halem, G. A. 52, 112 *, 214

v. Haller, C. L. 224,225

v. Hammer-Purgstall, J. $112 *, 149$

v. Hardenberg, K. A. 75, 76, 136, 183

La Harpe, J. F. 121 *

Hartmann, J. G. 105 *

Haschka, L. L. 69, 109-114, 118, 121, $133,149,223$

Hatry, General 176

Hehl, C. 104

Heinrich IV. (König v. Frankreich) 30

Heinse 92

Heinsius, T. 129

Heinzmann, J. G. 85, 130

v. Held, H. H. L. 34, 191, 232

Hennig, A. E. 38,128

Hennig, G. E. S. 38,39

Hennings, A. 50, 51, 110, $112 *, 124$, $133,134,182,193,198,205 *, 214$, 239,243

Hensler, K. F. $112 *$

Herakleitos 25

Herder, J. G. 19, 52, $56^{*}$, 58, 59, 63, 170,210

Herrmann (Arminius) 64, 80, 81, 143, 149, 167, 195, 204, 239

v. Hertzberg, Graf 21

v. Hess, J. L. 210

Hetzrodt 168

Heynig, J. G. 210

v. Hinsberg, J. 64

Hinze $112^{*}$

Hirt $56 *$

Hoche, General 95, 96

v. Hoff, K. E. A. 240 *

Hoffmann, A. J. 22, 48, 186

Hoffmann, J. F. 187

Hoffmann, L. A. 70, 111, 114, 127, 133, $182,207,223$

Hofstätter, F. F. 68, 69, 114, 133, 223

Horstmann, P. B. 119

Huber, L. F. 49, 50, 80, 110, 112 *, 132, $133,182,208$

Hufeland, G. 56 *

v. Hügel, J. A. 74, 77, 102, 113

v. Humboldt, A. 56 *

v. Humboldt, W. $56^{*}$

v. Hutten, U. 195, 218

d'Ivernois 201 
Jacobi, F. H. 56 *, 63, 92, 143

Jacobi, J. G. $156^{*}$

Jacobsen, F. J. 203

Jahn, F. L. 233

Jenisch, D. 92, 232

John, G. F. 187

Joseph II. 16, 67, 73, 111

Joubert, General 176

Jourdan, General 95, 132, 147

Jung, J. H. 115

v. Justin, K. F. 113, 114 *

Kaatzky 128,188

Kämmerer 112 *

Kant, I. 10，11，13，20，29，30，34，52, $56-58,63,66,70,80,85-94,115$, $123,127,131,133,141-143,160$ $162,163,169,170-173,182,188$, $193,195,207-210,215,234,237$, $240,245 *, 257$

Karl, Erzherzog 95, 108, 109, 111, 119, $147,155,156,204,221,223,232$, 254

Karl der Grosse 26, 67

Karl XII. 30

Karl, Herzog v. Mecklenburg-Strelitz 40

Karl August, Herzog v. Weimar 12

Karl Theodor, Kurfürst v. PfalzBayern 121

Karl Wilhelm, Herzog v. Braunschweig-Lüneburg 76

Kästner, A. G. 216 *

Katarina II. 21, 77

Kaufmann, C. 42, 43, 72, 113

Kellner, J. C. 240 *

Kerner, J. G. 36

Kleber, A. A. 166

v. Klingsporn, Domherr 128, 188

Klipfel 129

Klopstock, F. G. 19, 52, 112 *

Klüber, J. L. 166, 167

v. Knigge, A. $24,79,80,107,112 *, 115$ $121 *, 124$

Knoblauch 112 *

Kob, J. A. 108

Köhler, O. F. 34

v. Köpke, F. 41

Kosciusko, T. 24

Kosmann, J. W. A. 129, 189

Köster 127

Kraus, A. F. 92

Kronemann 112 *

Krug, W. T. 207, 234

Lamprecht, W. C. A. 52

Lassailx, F. 168

Lauber, J. 122

Laukhard, F. C. 24

Lavater, J. C. 156 *

Lehmann, K. 84, 249 v. Leipziger, A. W. 43, 44, 193

Lenz, C. 14

v. Leon, G. $111 *$

Leopold Friedrich Franz v. AnhaltDessau 12

Letourneur, Direktor 33

Lezay, A. 208

Likemeyer 80

v.d. Lippe-Weissenfeld, C. C. 165

List, G. F. 186

Louise, Königin v. Preussen 191

Löw 100

de Luca, I. $114 *$

Ludwig XIV. 27, 33, 73

Machiavelli 103

Majer, J. C. $103,104,105 *$

Mallet du Pan, J. 49, 208 *

Marat 49

Marcus Aurelius 153

Marcard, H. M. 204-207, 214, 233, 242

Maria Theresia 15, 73

Marie Antoinette 67

Martinovics, I. J. 80

Masséna, General 221

Matthisson, F. 56 *

Mauvillon 24, 112 *

Maximilian, I. 16

Meissner, A. G. 149

Messerschmid 56*

Metternich $112 *$

Michaelis, C. F. 240

Miranda, General 37, 48, 49, 135

Montesquieu 28

More, T. 27

Moreau, General 103, 132

Müchler, K. 34

Muck, F. J. A. 119

v. Müller, J. 20, 42, 43, 71-74, 113, $114,123,124,131,149,163,184$, $195,224,245$ *

Müller, W. 225 *

Münch 112 *

Nelson, Admiral 147, 194, 205

Nicolai, C. F. 6-8, 11, 63, 80, 85, 107 , $112^{*}, 115,130,131,209,210,216$ *

Niemann, A. C. H. 214, 227, 239

Novalis 233

Oelsner 61, 186

Ohanny, A. R. 120 *

v. Ompteda, D. H. L. 65,113

Paalzow, C. L. 65, 66

v. Pahl, J. G. 119, 199

v. Palthen, A. 28

v. Pape, G. A. W. 112 *

Paul I., Zar 207, 221

Pfaff, F. B. 105 * 
Pfeffel, G. K. 56 *

de Piattoli, S. 84

Pichegru, General 174

Pitt, W. 12, 23, 37, 48, 62, 98, 99 *, $108,135,136,171,175,180,227$

Pius VI. 99

Ploucquet, W. G. 104

Posselt, E. L. 46-50, 98-100, 124, 196, $211-214,228,229,239,245 *$

v. Promnitz, C. F. 209

Pufendorff 89

Ragg, J. 107

Raicevich, S. I. 107

Ralle, M. 128

Rambach, F. E. 124, 189, 191, 193, 227, 239

Ratschky, J. F. $111 *$

Rautenstrauch, J. 223

Rebmann, A. G. F. 24, 36, 52, 53, 80, $101,107,115,142,168,177-184$, 200

Rehberg, A. W. 64, 138, 182

Reichardt, J. F. 11, 13, 35, 52, 58, 123125,215

Reichardt, H. A. O. 78, 81, 109, 116$118,121,130,182,185,199$

Reichert, I. A. 145

Reimarus, J. A. H. 25

Reinhard, F. 46, 61

Reinhard, P. C. 168

v. Retzer, J. F. $111 *, 112 *$

La Revelliére-Lépeaux, Direktor 33, 144

Rewbell, Direktor 33, 47, 144

Richer-Serizi, 80, 201

Riem, A. 11, 52, 53, 77, 135, 136, 183185,200

Robespierre 49, 124

v. Rochow, F. E. 191

Röderer 49

Rothammer, F. W. 122

Rousseau, J. J. 28, 29, 30, 170

Saintard 28

Salzmann 112 *

v. Sartori, J. 84, 149

Sattler, J. P. 102

v. Scheel, H. J. 129, 194

Schiller, F. 9, 19, 37, 56-58, 63, 92, $112 *, 123,127,131,163,219$

v. Schirach, G. B. $80,182,226$

Schlegel, A. W. 233

Schlegel, F. $56 *, 92,233$

Schlözer, A. 7, 8, 12, 15, 20, 60

Schmalz, T. A. H. 140

Schmeisser, J. G. 142

Schmid, J. C. 277 *

Schmidt, F. W. A. $227 * 239 *$

Schneider, E. 80,112 *
Schubart, L. A. 37, 127

Schütz, C. G. 56 *

Schulz, J. C. F. 56 *

Schwab, J. C. 210

v. Schwarzkopf, J. 80

v. Seckendorff, K. L. 75, 113

v. Seida und Landensberg, F. E. J. 232

v. Seuffert, J. M. 241

v. Sickingen, F. 164,218

Sieyés 102, 158

Smidt, J. 215, 228, 239

Smith, A. 237

v. Soden, J. 76, 229

Sömmering 92

v. Sonnenfels, J. 107, $112 *, 149$

Stamm 112 *

Stäudlin, G. F. 52

v. Stolberg, F. L. 80,114

St. Pierre, Abbé 27, 28, 30, 93, 141, 169,236

Streim, F. 105

Suworow, General 77, 138, 147, 155, $156,205,221,225$

Swift, J. 28

Teller, W. A. $216 *$

Theremin, C. 37

v. Thugut, Minister 196

Tiedemann, F. 138

Tieftrunk 127

Tissot 127

Toze, E. 30

v. Traiteur, K. T. 93, 94

Trajanus 41

Trapp 112

Treffz, C. B. 105

Tuiskon 165, 167, 226

Vattel 89

Vischer $103 *$

Vollmer 208

Voltaire 28

Voss, C. D. 127

Voss, J. H. 52, 56 *

Weckherlin, F. A. H. 178

Wedekind, A. C. $112 *$

Weiss $161 *$

Weshaupt, A. 80, 107, 112 *

Weissegger, J. M. 108, 153-154

Werner, G. F. 138 *

v. Wessenberg, I. H. K. 158, 241

v. Wiebeking, K. F. 101

Wieland, C. M. 8, 9, 14, 15, 19, 52, 60, $62-64,86,92,110,111,135,138-$ $139,175,193,195,196,200,202$, $216-219,245^{*}$

Wiesser, L. C. 157

Wilhelm IX. Landgraf v. HessenKassel 176 
Wolff, C. 210

Woltmann, K. L. 37, 52, 56 *, 123, 227, 239

v. Wreden 116

Wührer, J. 153
Zech $112 *$

v. Zimmermann, E. A. W. $80,82,83$, 127,182

Zschocke, H. 138 